1994

\title{
Modelling air pollution near arterial roads and highways
}

Deloor Abdel Shaheed Shenouda

University of Wollongong

\section{Recommended Citation}

Shenouda, Deloor Abdel Shaheed, Modelling air pollution near arterial roads and highways, Doctor of Philosophy thesis, Department of Civil and Mining Engineering, University of Wollongong, 1994. http://ro.uow.edu.au/theses/1251 


\section{NOTE}

This online version of the thesis may have different page formatting and pagination from the paper copy held in the University of Wollongong Library.

\section{UNIVERSITY OF WOLLONGONG}

\section{COPYRIGHT WARNING}

You may print or download ONE copy of this document for the purpose of your own research or study. The University does not authorise you to copy, communicate or otherwise make available electronically to any other person any copyright material contained on this site. You are reminded of the following:

Copyright owners are entitled to take legal action against persons who infringe their copyright. A reproduction of material that is protected by copyright may be a copyright infringement. A court may impose penalties and award damages in relation to offences and infringements relating to copyright material. Higher penalties may apply, and higher damages may be awarded, for offences and infringements involving the conversion of material into digital or electronic form. 


\section{MODELLING AIR POLLUTION NEAR ARTERIAL ROADS AND HIGHWAYS}

A thesis submitted in partial fulfilment of the requirements for award of the degree of

\section{Doctor of Philosophy}

from

\section{UNIVERSITY OF WOLLONGONG}

by

DELOOR ABDEL SHAHEED SHENOUDA

(M SC., Ilinois Institute of Technology, Illinois, USA) 


\section{ACKNOWLEDGMENTS}

The author would like to acknowledge the support of both the Department of Civil and Mining Engineering, Wollongong University and the Division of Coal and Energy Technology, Commonwealth Industrial Research Organisation (CSIRO) for offering the valuable experimental facilities and for the research collaborative fund offered.

The author would like to express his gratitude to his supervisor Professor L.C. Schmidt, Professor of Civil Engineering in the Department, for his great support and guidance, and for offering the tutorship.

The author is indebted to his co-supervisor Mr D.J. Williams, Senior Principal Research Scientist and Manager of Urban Emissions, CSIRO-DCET, for the close supervision, fruitful discussions, invaluable suggestions and generous help throughout the period of study, and also for offering the author the opportunity to be one of the CSIRO research team related to the CSIRO/RTA (Road and Traffic Authority) air quality assessment project.

The help and suggestions provided by Dr. J.N. Carras, Senior Research Scientist and Manager of Plume Rise Studies, CSIRO-DCET, is gratefully acknowledged.

Acknowledgment is also made to all of the technical staff of the air quality research group in the Division of Coal and Energy Technology, CSIRO, in particular to Mr. M. Drummond and Mr T. Lang. Also, the author would like to thank Dr. Y. Ashaari, lecturer, Department of Civil and Mining Engineering, Wollongong University, for her help to establish the link between Wollongong University and the Division of Coal and Energy Technology, CSIRO.

Finally the author wishes to thank his wife Nahed and his sons John and Maged for their encouragement and forbearance and understanding during such a long period of time in which he placed this study above his responsibilities to them. 


\section{ABSTRACT}

In this study emissions of carbon dioxide $\left(\mathrm{CO}_{2}\right)$, carbon monoxide $(\mathrm{CO})$, hydrocarbons (HC) and nitrogen oxides $\left(\mathrm{NO}_{\mathrm{x}}\right)$ from vehicles are modelled by considering the instantaneous power generated by each vehicle and modifying the expressions developed by Post et al, (1981). The emissions from both spark ignition (SI) and diesel vehicles have been included.

The model was used to estimate fuel consumption and emissions over a standard driving cycle. When used for spark ignition vehicles over a driving cycle, the influence of cold starts was quantified and allowance was made, in the case of equipped vehicles, for catalyst warm-up and for variations in catalyst efficiency.

The model was validated against fuel consumption and emissions data obtained using ADR27 and ADR37 tests, and also against detailed, high time resolution analysis of ADR27 tests carried out by the Victorian EPA.

The emissions model was used in conjunction with two pollution dispersion models viz: HIWAY and CALINE to compare predicted concentrations with an experimental dataset consisting of measurements of the pollutants of $\mathrm{CO}_{2}, \mathrm{CO}, \mathrm{HC}$, and $\mathrm{NO}_{\mathrm{x}}$, and were made under a variety of traffic and meteorological conditions. The measurements were made at locations up to 60 metres downwind from the roadside and to heights of $10 \mathrm{~m}$ above the ground. A video camera was used to record the traffic flow, speed and type (classified simply as domestic, light or heavy commercial).

The emission rates of $\mathrm{CO}, \mathrm{HC}$, and $\mathrm{NO}_{\mathrm{x}}\left(\right.$ at slope $0^{\circ}$ ) for spark ignition and diesel vehicles produced by the power-based emissions model were found to be similar to those produced by the California EPA, EMFAC7, emissions model. 


\section{TABLE OF CONTENTS}

\begin{tabular}{|c|c|}
\hline & Page \\
\hline TITLE PAGE ...................... & $\mathrm{i}$ \\
\hline 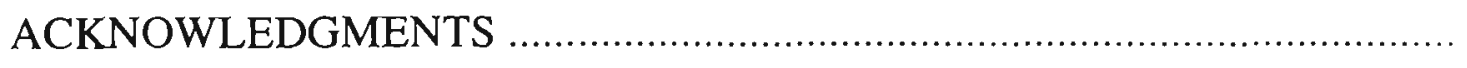 & ii \\
\hline ABSTRACT & iii \\
\hline 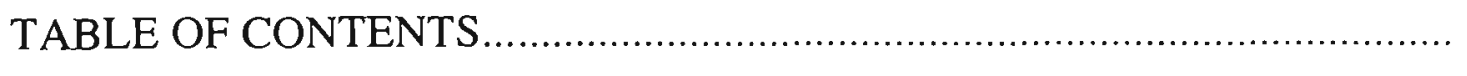 & iv \\
\hline LIST OF FIGURES ....... & viii \\
\hline LIST OF TABLES ....................................... & xviii \\
\hline NOMENCLATURE . & $\mathrm{xxii}$ \\
\hline LIST OF PUBLICATIONS DURING Ph D STUDY .. & xxvi \\
\hline
\end{tabular}

CHAPTER 1 : INTRODUCTION

CHAPTER 2 : LITERATURE REVIEW ….................................. 5

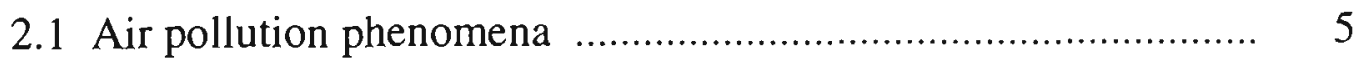

2.2 Road vehicles as the major source of air pollution $\ldots \ldots \ldots \ldots \ldots \ldots . . . . . . .6$

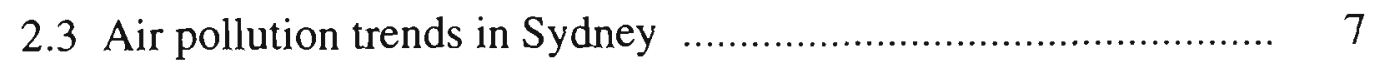

2.4 The requirements to control vehicle exhaust emissions ............ 9

2.5 Why pollutants are generated in the internal combustion engines 11

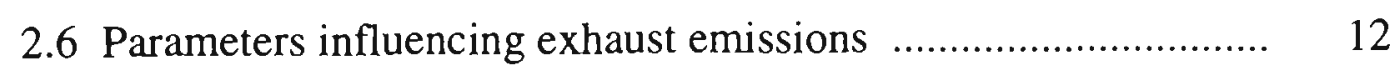

2.6.1 Spark ignition engines .......................................... 12

2.6.1.1 Engine-design measures ............................... 13

2.6.1.2 Exhaust gas after treatment .......................... 17

2.6.2 Diesel vehicles .................................................... 18

2.6.2.1 Engine conditions .................................... 20

2.6.2.2 Fuel specification ...................................... 21

2.6.2.3 Malfunction ............................................... 22

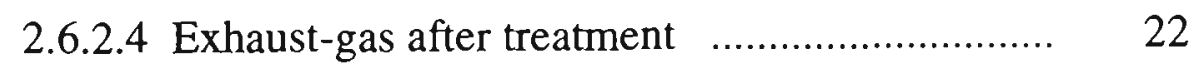

2.6.3 Exhaust emissions testing ....................................... 23

2.7 Pollutant concentrations: a combination of source intensity and

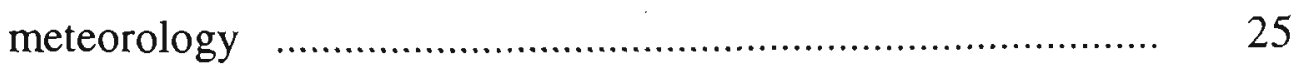

2.8 Source models and dispersion models f............................. 29 
2.9 Previous field studies utilised to assess dispersion models ...... 30

2.9.1 General Motors Sulfate Dispersion Experiment ........... 35

2.9.2 Study of Pollutant Dispersion Near Highways ............. 40

2.9.3 Line-Source Model of CO Concentrations in Sydney .... 46

2.9.4 Turbulent Diffusion Behind Vehicles ....................... 48

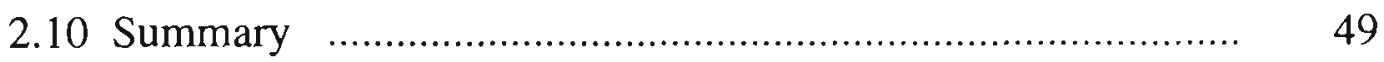

CHAPTER 3 : MODELLING MOTOR VEHICLE EMISSIONS .......... 53

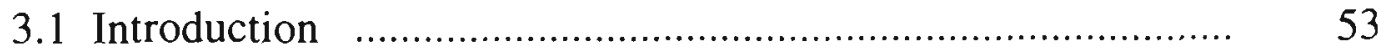

3.2 Power-Based Emissions Model ..................................... 54

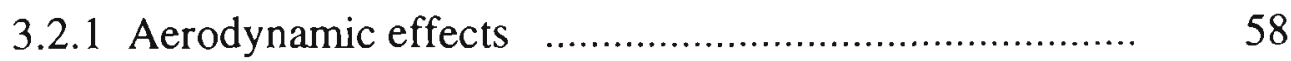

3.3 Car Exhaust Deterioration Factors …............................. 59

3.4 Running Losses .................................................... 61

3.5 The characteristics of the Power-Based Emissions Model .... 61

3.6 The comparison of the Power-Based Emissions Model

with US-EPA EMFAC7F ......................................... 70

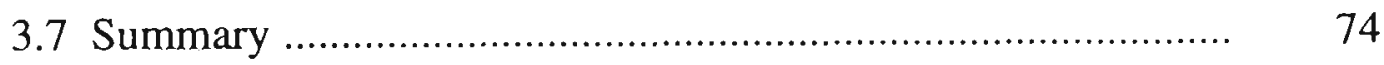

CHAPTER 4 : POLLUTANTS DISPERSION MODELLING ............. 75

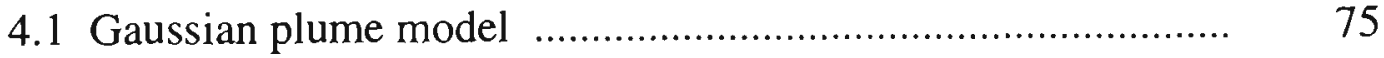

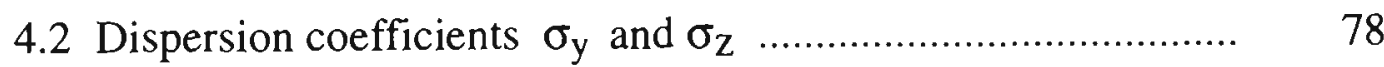

4.3 Model Description ..................................................... 83

4.3.1 HIWAY-2 ..................................................... 83

4.3.2 CALINE-4 ................................................... 85

4.4 Model Limitations ...................................................... 88

CHAPTER 5 : VALIDATION OF THE POWER-BASED EMISSIONS MODEL ............................................................. 90

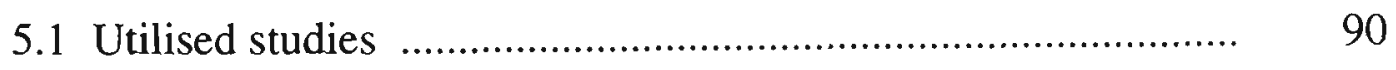

5.1.1 Particulate emissions from 'in use' motor

vehicles-spark ignition and diesel vehicles $\quad . . . . . . . . . . . . . . \quad 90$

5.1.2 Air Emissions Inventory - Port Phillip Control

Region: Planning for the future ................................ 94

5.1.3 Motor Vehicle Emission Test Results (SPCC, 1989) .... 99 
5.2 Validation results and discussion ….................................. 101

5.2.1 Fuel Consumption ................................................ 102

5.2.1.1 Over ADR 37A driving cycle ..................... 102

5.2.1.2 On-road driving pattem .............................. 105

5.2.2 Gaseous Emissions ............................................. 111

CHAPTER 6 : DISPERSION VALIDATION …............................. 123

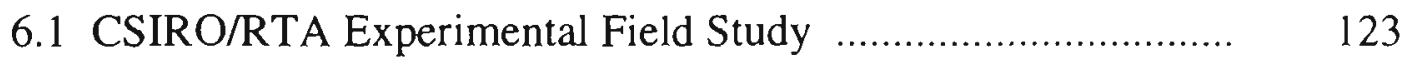

6.1 .1 Methodology ................................................. 123

6.1.2 The deployed instruments .................................. 125

6.1.2.1 Rosemount BINOS 100 Micro-Processor

Controlled NDIR Gas Analyser

6.1.2.2 Monitor Labs Nitrogen Oxides Analyser

Model 8840

6.1.2.3 Horiba Ambient HC Monitor ( APHA-350E)

6.1.2.4 Model 27005 GILL UVW Anemometer ........ 131

6.1.3 The experimental data .......................................... 135

6.2 Dispersion validation results and discussion ....................... 144

\section{APPENDICES}

A. GREENHOUSE GASES

B. AIR QUALITY CRITERIA ....................................... 197

B.1 Carbon monoxide .................................................... 197

B.2 Hydrocarbons ......................................................... 199

B.3 Oxides of nitrogen ................................................ 200

B.4 Lead in air .......................................................... 202

B.5 Particulate matters ................................................... 202

C. TESTING EXHAUST AND EVAPORATIVE EMISSIONS OF THE INTERNAL COMBUSTION ENGINE ..................... 204

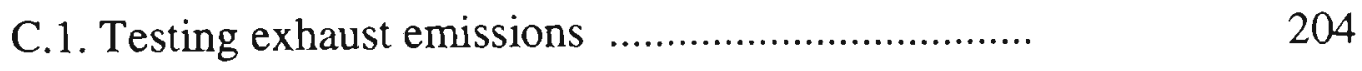


C.1.1 Test Program ……………..................................... 204

C.1.2 Chassis dynamometer ............................................ 204

C.1.3 Test samples and dilution procedures (CVS Method) 205

C.1.3 Test cycles ………………................................... 206

C. 2 Determination evaporative emissions from fuel system ..... 209

D. THE EFFECTS OF ROAD GRADIENT, ACCELERATIONDECELERATION MANOEUVRES, AND THE AERODYNAMIC DRAG ON THE POWER REQUIREMENTS, FUEL CONSUMPTION AND EMISSIONS LEVELS 


\section{LIST OF FIGURES}

Figure No.

Title

Page No.

2.1 The influence of excess-air factor $\lambda$ and ignition timing on $\mathrm{CO}$ emissions for spark-ignition vehicles

2.2 The influence of excess-air factor $\lambda$ and ignition timing on $\mathrm{NO}_{\mathrm{X}}$ emissions for spark-ignition vehicles

2.3 The influence of excess-air factor $\lambda$ and ignition timing on $\mathrm{HC}$ emissions for spark-ignition vehicles

2.4 The influence of excess-air factor $\lambda$ and ignition timing on specific fuel consumption $\left(F_{C}\right)$ for spark-ignition vehicles

2.5 The influence of excess-air factor $\lambda$ and ignition timing on the Torque for spark-ignition vehicles

2.6 The efficiency of the catalytic-converter as a function of Excess-air factor $\lambda$

2.7 The effect of exhaust gas recycling on exhaust emissions from a light-duty indirect injection diesel engine at part load

2.8 $\sigma_{\mathrm{Z}}$ as a function of downwind distance. The solid lines were estimated from the measurements of the measurements data of the General Motors Sulfate Dispersion Experiment and the dotted lines are used by the HIWAY model. The stability classes are indicated

2.9 Comparison of the new dispersion curves (solid lines) to Pasquill-Gifford curves (dashed lines) used in original HIWAY model. The upper bound of the new dispersion curves represents the values used for zero cross-wind speed situations while the lower bound represents the values used for cross-wind speed greater than $3.92 \mathrm{~m} / \mathrm{s}$ 
3.2 The increase in the power demands versus vehicle speed and as a function of road gradient for a petrol vehicle with all-up mass of $1430 \mathrm{~kg}$. (calculations for a two-way road)

3.3 The increase in the fuel consumption versus vehicle speed and as a function of road gradient for a petrol vehicle with all-up mass of $1430 \mathrm{~kg}$. (calculations for a two-way road)

3.4 The increase in the power demands versus vehicle speed and as a function of road gradient for a heavy-duty diesel vehicle with all-up mass of $10000 \mathrm{~kg}$. (calculations for a two-way road)

3.5 The increase in the fuel consumption versus vehicle speed and as a function of road gradient for a heavy-duty diesel vehicle with all-up mass of $10000 \mathrm{~kg}$. (calculations for a two-way road)

3.6 The increase in carbon monoxide emission levels versus vehicle speed and as a function of road gradient for a spark ignition (leaded) vehicle with all-up mass of $1430 \mathrm{~kg}$. (calculations for a two-way road) .......

3.7 The increase in hydrocarbon emission levels versus vehicle speed and as a function of road gradient for a spark ignition (leaded) vehicle with all-up mass of $1430 \mathrm{~kg}$. (calculations for a two-way road)

3.8 The increase in oxides of nitrogen emission levels versus vehicle speed and as a function of road gradient for a spark ignition (leaded) vehicle with all-up mass of $1430 \mathrm{~kg}$. (calculations for a two-way road) ..........

3.9 The increase in carbon monoxide emission levels versus vehicle speed and as a function of road gradient for a heavy-duty diesel vehicle with all-up mass of $10000 \mathrm{~kg}$. (calculations for a two-way road)

3.10 The increase in hydrocarbon emission levels versus vehicle speed and as a function of road gradient for a heavy-duty diesel vehicle with all-up mass of $10000 \mathrm{~kg}$. (calculations for a two-way road)

3.11 The increase in oxides of nitrogen emission levels versus vehicle speed and as a function of road gradient for a heavy-duty diesel vehicle with all-up mass of $10000 \mathrm{~kg}$. (calculations for a two-way road) 
3.12 The percentage change in power demands versus wind-road angle for an articulated truck with mass of 30 tons travelling at $80 \mathrm{~km} / \mathrm{h}$ through wind of $15 \mathrm{~km} / \mathrm{h}$.(Calculations based on the power-based emissions model for a car with dimensions of $2.5 \mathrm{~m}$ width, $4.3 \mathrm{~m}$ height, and 7 m length.)

3.13 The percentage change in fuel consumption versus wind-road angle for an articulated truck with mass of 30 tons travelling at $80 \mathrm{~km} / \mathrm{h}$ through wind of $15 \mathrm{~km} / \mathrm{h}$.(Calculations based on the power-based emissions model for a car with dimensions of $2.5 \mathrm{~m}$ width, $4.3 \mathrm{~m}$ height, and $7 \mathrm{~m}$ length.)

3.14 The comparison of $\mathrm{CO}$ emission rates for spark ignition (leaded) vehicles with all-up mass of $1430 \mathrm{~kg}$ estimated using US-EPA EMFAC7F model with those estimated using the Power-Based Emissions Model.

3.15 The comparison of $\mathrm{HC}$ emission rates for spark ignition (leaded) vehicles with all-up mass of $1430 \mathrm{~kg}$ estimated using US-EPA EMFAC7F model with those estimated using the Power-Based Emissions Model.

3.16 The comparison of $\mathrm{NO}_{\mathrm{X}}$ emission rates for spark ignition (leaded) vehicles with all-up mass of $1430 \mathrm{~kg}$ estimated using US-EPA EMFAC7F model with those estimated using the Power-Based Emissions Model.

3.17 The comparison of $\mathrm{CO}$ emission rates for heavy-duty diesel vehicles with all-up mass of $10000 \mathrm{~kg}$ estimated using US-EPA EMFAC7F model with those estimated using the Power-Based Emissions Model

3.18 The comparison of $\mathrm{HC}$ emission rates for heavy-duty diesel vehicles with all-up mass of $10000 \mathrm{~kg}$ estimated using US-EPA EMFAC7F model with those estimated using the Power-Based Emissions Model

3.19 The comparison of $\mathrm{NO}_{\mathrm{X}}$ emission rates for heavy-duty diesel vehicles with all-up mass of $10000 \mathrm{~kg}$ estimated using US-EPA EMFAC7F model with those estimated using the Power-Based Emissions Model 
4.1 Diagram of typical plume, illustrating concepts important in the Gaussian plume formula. Symbols: $u$ is the wind speed; $h$ is the effective source height; $\sigma_{\mathrm{y}}$ and $\sigma_{\mathrm{z}}$ are standard deviations of crosswind concentration distribution.

4.2 Curves of the standard deviation of the vertical dispersion, $\sigma_{\mathrm{Z}}$, for turbulence types based on Pasquill-Gifford (low source) and Briggs for elevated source $(>100 \mathrm{~m})$

4.3 Curves of the standard deviation of the horizontal dispersion, $\sigma_{\mathrm{Z}}$, for turbulence types based on Pasquill-Gifford (low source) and Briggs for elevated source ( $>100 \mathrm{~m}$ )

4.4 CALINE equivalent finite line sources

4.5 CALINE mixing zone

5.1 Test cycle employed to determine compliance with ADR 27A and ADR 37 exhaust emissions

5.2 Average Vehicle Kilometre Travelled (VKT) by cars and Station Wagons according to age, NSW (1988)

5.3 Relative VKT versus age by for cars and Station Wagons according to age, NSW (1988).

5.4 Comparison of predicted and measured ADR 37 fuel economy for pre-1986 spark ignition vehicle.

5.5 Comparison of predicted and measured ADR 37 fuel economy for post-1986 spark ignition vehicle.

5.6 Comparison of predicted and measured ADR 37 fuel economy for light-duty diesel vehicles.

5.7 The ratio of the predicted fuel consumption estimated taking into account the road gradient and the fuel consumption estimated for plain road as a function of both the distance and the altitude for the trip from Eastern Creek highway to the Blue Mountain in Sydney 
5.8 The ratio of the predicted fuel consumption estimated taking into account the road gradient and the fuel consumption estimated for plain road as a function of the road slope for the trip from Eastern Creek highway to the Blue Mountain in Sydney

5.9 Comparison of predicted and measured ADR 37 carbon monoxide emissions for pre-1986 spark ignition vehicle.

5.10 Comparison of predicted and measured ADR 37 carbon monoxide emissions for post-1986 spark ignition vehicle.

5.11 Comparison of predicted and measured ADR 37 hydrocarbon emissions for pre-1986 spark ignition vehicle.

5.12 Comparison of predicted and measured ADR 37 hydrocarbon emissions for post-1986 spark ignition vehicle.

5.13 Comparison of predicted and measured ADR 37 oxides of nitrogen emissions for pre-1986 spark ignition vehicle.

5.14 Comparison of predicted and measured ADR 37 oxides of nitrogen emissions for post-1986 spark ignition vehicle.

5.15 Comparison of predicted and measured ADR 37 carbon monoxide for light-duty diesel vehicles.

5.16 Comparison of predicted and measured ADR 37 hydrocarbon for light-duty diesel vehicles.

5.17 Comparison of predicted and measured ADR 37 oxides of nitrogen for light-duty diesel vehicles.

6.1 Schematic showing method of deploying CSIRO instrumented vehicle alongside an arterial road.

6.2 An overview for CSIRO instrumented vehicle with the anemometers and the two sampling lines (the fixed sampling line and the movable one). 
6.3 The interior of the CSIRO instrumented vehicle with the measuring instruments, the data logger, and the chart recorder.

6.4 Overview for BINOS 100 NDIR-Gas-Analyser

6.5 An overlook for the Nitrogen Oxides Analyser.

6.6 Overview for Model APHA-350E Horiba Ambient HC Monitor.

6.7 Comparison of predicted $\mathrm{CO}_{2}$ concentrations from CALINE4 for slope $=0.0^{\circ}$ with measured values.

6.8 Comparison of predicted $\mathrm{CO}_{2}$ concentrations from HIWAY-2 for slope $=0.0^{\circ}$ with measured values.

6.9 Comparison of predicted $\mathrm{CO}_{2}$ concentrations from CALINE4 for slope $=0.5^{\circ}$ with measured values.

6.10 Comparison of predicted $\mathrm{CO}_{2}$ concentrations from HIWAY-2 for slope $=0.5^{\circ}$ with measured values.

6.11 Comparison of predicted $\mathrm{CO}_{2}$ concentrations from CALINE4 for slope $=1.0^{\circ}$ with measured values.

6.12 Comparison of predicted $\mathrm{CO}_{2}$ concentrations from HIWAY-2 for slope $=1.0^{\circ}$ with measured values.

6.13 Predicted versus measured $\mathrm{CO}_{2}$ concentrations for HIWAY -2 and CALINE4 : slope $0.0^{\circ}$. sampling height $=2.5 \mathrm{~m}$ and distance $=30 \mathrm{~m}$ from the roadside.

6.14 Predicted versus measured $\mathrm{CO}_{2}$ concentrations for HIWAY -2 and CALINE4 : slope $0.5^{\circ}$. sampling height $=2.5 \mathrm{~m}$ and distance $=30 \mathrm{~m}$ from the roadside.

6.15 Predicted versus measured $\mathrm{CO}_{2}$ concentrations for HIWAY -2 and CALINE4 : slope $1.0^{\circ}$. sampling height $=2.5 \mathrm{~m}$ and distance $=30 \mathrm{~m}$ from the roadside. 
6.16 Comparison of predicted $\mathrm{CO}_{2}$ concentrations from HIWAY -2 and CALINE4 ( for slope $0.0^{\circ}$, height $=2.5 \mathrm{~m}$, and distance $=30 \mathrm{~m}$ from roadside) with the measured values as a function of perpendicular wind.

6.17 Comparison of predicted $\mathrm{CO}_{2}$ concentrations from HIWAY -2 and CALINEA ( for slope $0.5^{\circ}$, height $=2.5 \mathrm{~m}$, and distance $=30 \mathrm{~m}$ from roadside) with the measured values as a function of perpendicular wind.

6.18 Comparison of predicted $\mathrm{CO}_{2}$ concentrations from HIWAY -2 and CALINE4 ( for slope $0.5^{\circ}$, height $=2.5 \mathrm{~m}$, and distance $=30 \mathrm{~m}$ from roadside) with the measured values as a function of perpendicular wind.

6.19 Predicted versus measured $\mathrm{CO}_{2}$ concentrations for HIWAY -2 and CALINE4 : slope $0.0^{\circ}$ for neutral stability condition.

6.20 Predicted versus measured $\mathrm{CO}_{2}$ concentrations for HIWAY -2 and CALINE4 : slope $0.5^{\circ}$ for neutral stability condition.

6.21 Predicted versus measured $\mathrm{CO}_{2}$ concentrations for HIWAY -2 and CALINE4 : slope $1.0^{\circ}$ for neutral stability condition.

6.22 Predicted versus measured $\mathrm{CO}_{2}$ concentrations for HIWAY -2 and CALINE4 : slope $0.0^{\circ}$ for slightly-unstable condition.

6.23 Predicted versus measured $\mathrm{CO}_{2}$ concentrations for HIWAY -2 and CALINE4 : slope $0.5^{\circ}$ for slightly-unstable condition.

6.24 Predicted versus measured $\mathrm{CO}_{2}$ concentrations for HIWAY -2 and CALINE4 : slope $1.0^{\circ}$ for slightly-unstable condition.

6.25 Comparison of predicted $\mathrm{CO}_{2}$ concentrations from CALINE4 model with measured values for slopes $=0.0^{\circ}, 0.5^{\circ}$, and $1.0^{\circ}$. (data for 6 April 1993. Homebush).

6.26 Comparison of predicted $\mathrm{CO}_{2}$ concentrations from CALINE4 model with measured values for slopes $=0.0^{\circ}, 0.5^{\circ}$, and $1.0^{\circ}$. 
6.27 Comparison of predicted $\mathrm{CO}_{2}$ concentrations from CALINE4 model with measured values for slopes $=0.0^{\circ}, 0.5^{\circ}$, and $1.0^{\circ}$.

(data for 22 September 1992 . James Ruse Drive Highway).

6.28 Comparison of predicted $\mathrm{CO}_{2}$ concentrations from CALINE4 model with measured values for slopes $=0.0^{\circ}, 0.5^{\circ}$, and $1.0^{\circ}$.

(data for 16 June 1992. James Ruse Drive Highway)

6.29 Comparison of predicted $\mathrm{CO}_{2}$ concentrations from CALINE4 model with measured values for slopes $=0.0^{\circ}, 0.5^{\circ}$, and $1.0^{\circ}$.

(data for 26 May 1992. James Ruse Drive Highway)

6.30 Comparison of predicted $\mathrm{CO}_{2}$ concentrations from CALINE4 mode] with measured values for slopes $=0.0^{\circ}, 0.5^{\circ}$, and $1.0^{\circ}$.

(data for 6 May 1992. Epping Highway)

6.31 Comparison of predicted $\mathrm{CO}_{2}$ concentrations from CALINE4 model with measured values for slopes $=0.0^{\circ}, 0.5^{\circ}$, and $1.0^{\circ}$.

(data for 5 May 1992. Epping Highway)

6.32 Comparison of predicted $\mathrm{CO}_{2}$ concentrations from CALINE4 model with measured values for slopes $=0.0^{\circ}, 0.5^{\circ}$, and $1.0^{\circ}$ (data for 5 March 1992 . Epping Highway)

6.33 Model performance $(\mu)$ versus wind-road angle for $\mathrm{CO}_{2}$. (calculations from CALINE4 for road slope $=0.0^{\circ}$ )

6.34 Model efficiency versus downwind distance for $\mathrm{CO}_{2}$ (based on calculations from CALINE4) for road slope $=0.0^{\circ}$.

6.35 Model performance versus wind speed for $\mathrm{CO}_{2}$ (based on calculations from CALINE4) for road slope $=0.0^{\circ}$.

6.36 Comparison of predicted CO concentrations CALINE4 (slope $\left.=1.0^{\circ}\right)$ with measured values. 
6.37 Comparison of predicted CO concentrations HIW AY-2 (slope $\left.=1.0^{\circ}\right)$ with measured values.

6.38 Comparison of predicted HC concentrations CALINE4 (slope $\left.=1.0^{\circ}\right)$ with measured values.

6.39 Comparison of predicted HC concentrations HIW AY-2 (slope $\left.=1.0^{\circ}\right)$ with measured values.

6.40 Comparison of predicted $\mathrm{NO}_{\mathrm{X}}$ concentrations CALINE4 (slope $\left.=1.0^{\circ}\right)$ with measured values.

6.41 Comparison of predicted $\mathrm{NO}_{\mathrm{X}}$ concentrations HIWAY-2 (slope $\left.=1.0^{\circ}\right)$ with measured values.

A.1 World primary energy consumption (BP, 1990; Verein Deutscher Kohlenimporteure, 1990; Smith, 1991)

A.2 Trends in global carbon dioxide emissions (Source: Boden and others, 1990; Smith, 1991)

B.1 Carbon monoxide levels in Sydney: Days Exceeding NHMRC Goal over the past decade for Sydney region.

B.2 Ozone yearly peak hour value for Sydney region.

B.3 Ozone: Days Exceeding NHMRC Goal over the past decade for Sydney region.

B.4 $\mathrm{NO}_{2}$ yearly peak hour value for Sydney region.

B.5 $\mathrm{NO}_{2}$ : Days Exceeding NHMRC Goal over the past decade for Sydney region.

C.1 Test layout for USA Federal Test Procedure. 
D.1 The instantaneous power demands for a spark ignition vehicle with all-up mass of $1430 \mathrm{~kg}$ as a function of road slope and vehicle speed.

D.2 The fuel consumption for a spark ignition vehicle with all-up mass of $1430 \mathrm{~kg}$ as a function of road slope and vehicle speed.

D.3 The instantaneous power demands for a heavy-duty diesel truck with all-up mass of $10000 \mathrm{~kg}$ as a function of road slope and speed.

D.4 The fuel consumption for a heavy-duty diesel truck with all-up mass of $10000 \mathrm{~kg}$ as a function of road slope and speed.

D.5 CO emission levels versus vehicle speed for a pre-1986 spark ignition vehicle with all-up mass of $1430 \mathrm{~kg}$ and as a function of road slope.

D.6 CO emission levels versus vehicle speed for a heavy-duty diesel vehicle with all-up mass of $10000 \mathrm{~kg}$ and as a function of road slope.

D.7 HC emission levels versus vehicle speed for a pre-1986 spark ignition vehicle with all-up mass of $1430 \mathrm{~kg}$ and as a function of road slope.

D.8 HC emission levels versus vehicle speed for a heavy-duty diesel vehicle with all-up mass of $10000 \mathrm{~kg}$ and as a function of road slope.

D.9 $\mathrm{NO}_{\mathrm{X}}$ emission levels versus vehicle speed for a pre-1986 spark ignition vehicle with all-up mass of $1430 \mathrm{~kg}$ and as a function of road slope.

D.10 $\mathrm{NO}_{\mathrm{x}}$ emission levels versus vehicle speed for a heavy-duty diesel vehicle with all-up mass of $10000 \mathrm{~kg}$ and as a function of road slope.

D.11 The power demands versus wind-road angle for an articulated truck with mass of 30 tons travelling at $80 \mathrm{~km} / \mathrm{h}$ through wind of $15 \mathrm{~km} / \mathrm{h}$. (Calculations based on the power-based emissions model for a car with dimensions of $2.5 \mathrm{~m}$ width, $4.3 \mathrm{~m}$ height, and $7 \mathrm{~m}$ length.) ......

D.12 The fuel consumption versus wind-road angle for an articulated truck with mass of 30 tons travelling at $80 \mathrm{~km} / \mathrm{h}$ through wind of $15 \mathrm{~km} / \mathrm{h}$. (Calculations based on the power-based emissions model for a car with dimensions of $2.5 \mathrm{~m}$ width, $4.3 \mathrm{~m}$ height, and $7 \mathrm{~m}$ length.) $\ldots . .$. 


\section{LIST OF TABLES}

Table No.

Title

Page No.

2.1 Consumption of petroleum products, 1985 to 1992

2.2 Sydney estimated levels of gaseous emissions and contributions from traffic

2.3 Estimated emissions of Greenhouse gases by Australian Transport, 1991 8

2.4 Typical exhaust gas constituents for petrol and diesel engines as a function of driving mode

2.5 Influence of diesel fuel quality on some exhaust components

2.6 Gaseous emission rates for ADR 37 test cycle for (post-1986) spark ignition vehicles used in SPCC, 1989 study

2.7 Values of surface roughness length $\left(\mathrm{z}_{\mathrm{O}}\right)$ for various types of surfaces 26

2.8 Meteorological Conditions Defining Pasquil Turbulence Types 28

2.9 Classification of atmospheric stability (data from DeMarrais, 1978; Best et al., 1986 ; and Hanna, 1989) 28

2.10 Irwin classification of the atmospheric stability 29

2.11 Comparison between measured and predicted sulfate and SF6 concentrations $\left(\mu \mathrm{g} / \mathrm{m}^{3}\right)$ for three runs from the GM sulfate Dispersion Experiment (model calculations from HIWAY)

2.12 Statistical results of linear regression between observed $\mathrm{SF}_{6}$ concentrations and predicted concentrations of all Guassian models for perpendicular, oblique, and parallel wind-road orientation angles 
2.13 Ratios of predicted to observed concentrations at the roadside receptor for each Guassian model as a function of wind-road orientation angle. Numbers greater than unity indicate overprediction by the model

3.1 The adopted exhaust deterioration rates $(\mathrm{g} / \mathrm{km} / 10000 \mathrm{~km}$ travel $)$ for the Australian fleet

4.1 Brookhaven National Laboratory Parameters Values in the Formulas 4.8 and 4.9

4.2 Values of the constants k1, k2, k3, and $\mathrm{k}_{4}$ in the Equations 4.10 and 4.11

4.3 The Briggs (1973) standard deviations functions $\left(\sigma_{y}\right.$ and $\sigma_{z}$ ) for urban and rural conditions.

5.1 The list of spark ignition vehicle parameters used in Williams et al. (1987) study.

5.2 The list of light-duty diesel vehicle parameters used in Williams et al. (1987) study.

5.3 Gaseous emission rates for ADR 37 test cycle for the spark ignition vehicles used in Williams et al. (1987) study.

5.4 Gaseous emission rates for ADR 37 test cycle for light-duty diesel vehicles used in Williams et al. (1987) study.

5.6 Comparison between the exhaust deterioration rates of US-EPA (1985), Pingelly (SPCC, 1989), and Collins, (1989) for ADR 27A and ADR 37.

5.7 The list of spark ignition vehicle parameters (model 1989) given in SPCC, 1989 report.

5.8 Gaseous emission rates for ADR 37 test cycle for (post-1986) spark ignition vehicles used in SPCC, 1989 study. 
5.9 Summary of the performance of the power-based emissions model with regard of the fuel consumption prediction of the CSIRO instrumented vehicle against eight experimental Trips carried out on the 6th, the 7th of July, and the 30th of September 1994

5.10 The comparison between the predicted emissions with the measured data of Carnovale et al, (1992).

6.1 Instruments deployed near major roadways during CSIRO/RTA experimental field study to quantify traffic generated pollution near arterial roads and highways in Sydney.

6.2 The summary of sites, dates and duration of the eight-day experimental data.

6.3 Data average values for April 6, 1993, Homebush 136

6.4 Data average values for January 13, 1993, Epping Highway

6.5 Data average values for September 22, 1992, James Ruse Drive Highway 138

6.6 Data average values for June 16, 1992, James Ruse Drive Highway

6.7 Data average values for May 26, 1992, James Ruse Drive Highway

6.8 Data average values for May 6, 1992, Epping Highway

6.9 Data average values for May 5, 1992, Epping Highway

6.10 Data average values for March 5, 1992, Epping Highway

6.11 Summary of the performance of CALINE4 dispersion model against the eight-day experimental data for slopes $0.0^{\circ}, 0.5^{\circ}$, and $1.0^{\circ}$.

6.12 Summary of the performance of CALINE4 and HIWAY-2 dispersion models against the eight-day experimental data itemised according to the stability class for slope of $1.0^{\circ}$. 
A.l A summary of greenhouse gases including principal source and the percentage contribution based on temperature rise potential

A.2 Estimated direct and indirect emissions of Australia's $\mathrm{CO}_{2}(\mathrm{Mt} / \mathrm{y})$ by end use sector and by fossil fuels - 1987/88

A.3 Energy transformation and final consumption in IEA countries for 1973 and 1987

B.1 Ambient air quality standards currently applied in nineteen nations for carbon monoxide, sulphur dioxide, nitrogen dioxide and ozone.

B.2 NSW selected air quality criteria with their agency.

C.1 Emissions limits under USA-FED (49-states) and California FTP 75 Test cycle.

C.2 Emissions limits for FTP 75 Test cycle in Australia, Austria, Brazil, Canada, Finland, Mexico, Norway, South Korea, Sweden, and Switzerland.

D.1 The instantaneous power demands for a spark ignition vehicle with all-up mass of $1430 \mathrm{~kg}$ as a function of road slope and vehicle speed.

D.2 The fuel consumption for a spark ignition vehicle with all-up mass of $1430 \mathrm{~kg}$ as a function of road slope and vehicle speed.

D.3 The instantaneous power demands for a heavy-duty diesel vehicle with all-up mass of $10000 \mathrm{~kg}$ as a function of road slope and vehicle speed.

D.4 The fuel consumption for a heavy-duty diesel vehicle with all-up mass of $10000 \mathrm{~kg}$ as a function of road slope and vehicle speed.

D.5 Carbon monoxide emission levels (CO) for a pre-1986 spark ignition vehicle with all-up mass of $1430 \mathrm{~kg}$ as a function of road slope and vehicle speed. 
D.6 Hydrocarbon emission levels (HC) for a pre-1986 spark ignition vehicle with all-up mass of $1430 \mathrm{~kg}$ as a function of road slope and vehicle speed.

D.7 Oxides of nitrogen emission levels $\left(\mathrm{NO}_{\mathrm{X}}\right)$ for a pre-1986 spark ignition vehicle with all-up mass of $1430 \mathrm{~kg}$ as a function of road slope and vehicle speed.

D.8 Carbon monoxide emission levels (CO) for a heavy-duty diesel vehicle with all-up mass of $10000 \mathrm{~kg}$ as a function of road slope and vehicle speed.

D.9 Hydrocarbon emission levels (HC) for a heavy-duty diesel vehicle with all-up mass of $10000 \mathrm{~kg}$ as a function of road slope and vehicle speed.

D.10 Oxides of nitrogen emission levels $\left(\mathrm{NO}_{\mathrm{X}}\right)$ for a heavy-duty diesel vehicle with all-up mass of $10000 \mathrm{~kg}$ as a function of road slope and vehicle speed. 


\section{NOMENCLATURE}

Abbreviation

Term

A

$\alpha$

ac

ADR

AIRPOLL-4

CALINE4

$\mathrm{Cd}_{\mathrm{d}}$

$\mathrm{CO}$

$\mathrm{CO}_{2}$

CVS

DI

DIST

EC

$\mathrm{E}_{\text {cat }}$

EMFAC7

EPA

$\phi$

$\mathrm{F}_{\mathrm{C}}$

FCF

$f_{\text {Cat }}$

$\mathrm{F}_{\mathrm{Cco}}$

$\mathrm{F}_{\text {chc }}$

$\mathrm{FC}_{\mathrm{n}}$

$\mathrm{f}_{\text {cold }}$

FTP

FWY1 (NFC)

FWY2 (SFC)
Frontal area

Fuel consumption rate at idle conditions

Acceleration of the vehicle

Australian Driving Rule

A Dispersion Model for Predicting Air Pollution Levels Near Highways.

Mode correction factor

The measure of the efficiency of power generation

Pollutant concentrations in $\mathrm{g} / \mathrm{m}^{3}$

A Dispersion Model for Predicting Air Pollution Levels Near Highways.

A Dispersion Model for Predicting Air Pollution Levels Near Highways.

Vehicle drag coefficient

Carbon monoxide emission rate

Carbon Dioxide emission rate

Constant Volume Sampling Method

Direct injection

Receptor down-wind distance

Engine capacity

Catalyst efficiency

California EPA Emissions Model

Environmental Protection Agency

Wind-road angle

Fuel consumption

Fuel correction factor

Catalyst-equipped factor

The parts of fuel consumption that end up as $\mathrm{CO}$

The parts of fuel consumption that end up as $\mathrm{HC}$

Normalised instantaneous fuel consumption at the

characteristic time $t(t=60 s)$

Engine warm up factor

American Federal Test Procedure

Way 1 (going north from the city business district)

Way 2 (going south from the city business district) 
GM A Dispersion Model for Predicting Air Pollution Levels Near Highways.

$\mathrm{H} \quad$ Vehicle height

$\mathrm{h} \quad$ Source effective height above the ground

$\mathrm{HC} \quad$ Hydrocarbons

HGT Height of the receptor

HIWAY-2 A Dispersion Model for Predicting Air Pollution Levels Near Highways.

IDI Indirect injection

L vehicle length

$\lambda \quad$ The excess-air factor

LML Lean misfire limit

LPG Liquid petroleum gas

M Mass of the vehicle

NMHC Non-methane hydrocarbon emission rate

NMVOCs Non-methane volatile organic compounds

NO Nitrogen oxide emission rate

$\mathrm{NO}_{2} \quad$ Nitrogen dioxide emission rate

$\mathrm{NO}_{\mathrm{X}} \quad$ Oxides of nitrogen emission rate

Q Point source emission rate

Q Line source emission rate

$\theta \quad$ Road slope angle

$\rho \quad$ Specific gravity of the fuel

$\mathrm{R}_{\mathrm{i}} \quad$ Bulk Richardson number

ROADWAY

A numerical model for Predicting Air Pollution Levels Near Highways.

$\begin{aligned} \text { ROG } & \text { Reactive organic gases } \\ \text { SCF } & \text { Speed correction factor } \\ \text { SF6 } & \text { Sulfur hexaflouride tracer gas } \\ \text { SF }_{\mathrm{n}} & \text { The fuel consumed (ml) since engine start normalised to } 2.51 \\ \mathrm{SI} & \text { Spark ignition } \\ \mathrm{SL} & \text { Surface layer } \\ \text { SPCC } & \text { State Pollution Control Commission } \\ \sigma_{\theta} & \text { The standard deviation of the horizontal wind fluctuations. } \\ \sigma_{\omega} & \text { The standard deviation of the vertical wind speed } \\ & \text { fluctuations. } \\ \sigma_{\mathrm{y}} & \text { The horizontal dispersion standard deviation } \\ \sigma_{\mathrm{Z}} & \text { The vertical dispersion standard deviation } \\ \mathrm{TCF} & \text { Tempreture correction factor }\end{aligned}$




$\begin{aligned} \text { TOT } & \text { total density of the traffic in time slot } \\ \mathrm{u} & \text { Wind speed } \\ \text { ULP } & \text { Unleaded petrol } \\ \text { UVW } & \text { Wind speed components in } \mathrm{x}, \mathrm{y} \text {, and } \mathrm{z} \text { directions, respectively } \\ \mathrm{V} & \text { Vehicle speed } \\ \mathrm{VEPA} & \text { Victoria EPA } \\ \mathrm{VKT} & \text { Vehicle kilometres travelled } \\ \mathrm{V}_{\mathrm{r}} & \text { Relative car-wind speed } \\ \mathrm{W} & \text { Vehicle width } \\ (\mathrm{x}, \mathrm{y}, \mathrm{z}) & \text { Coordinate system (wind direction, cross-wind direction, and } \\ & \text { vertical direction) } \\ \mathrm{z} & \text { Receptor height in metres } \\ \mathrm{Z}_{\mathrm{a}} & \text { Power required to overcome aerodynamic drag } \\ \mathrm{Z}_{\mathrm{d}} & \text { Power required to overcome the vehicle drive-train resistance } \\ \mathrm{Z}_{\mathrm{e}} & \text { Power required to overcome the vehicle inertial and } \\ \mathrm{Z}_{\mathrm{i}} & \text { gravitational resistance } \\ \mathrm{z}_{\mathrm{O}} & \text { Top of the boundary layer } \\ \mathrm{Z}_{\mathrm{r}} & \text { Roughness layer } \\ \mathrm{Z}_{\mathrm{H}} & \text { Power required to overcome the tyre rolling resistance } \\ & \text { Total instantaneous power } \\ & \text { percentage heavy-duty diesel vehicles } \\ & \end{aligned}$




\section{LIST OF PUBLICATIONS DURING Ph D STUDY}

- Williams D.J., Shenouda D.A., and Carras J.N. , "Modelling Air Toxic Emissions from Motor Vehicles" 1994 Air Toxics Conference Co-sponsored by Clean Air of Australia and New Zealand and CSIRO Centre for Pollution Assessment and Control, 10 -11 August 1994.

- Williams D.J. , Carras J.N. , and Shenouda D.A., "Traffic Generated Pollution Near Arterial Roads and Highways, Model and Measurements" Fourth CRC OnRoad Vehicle Emission Workshop, San Diego. California, March 14-16, 1994.

- Williams D.J., Carras J.N. , and Shenouda D.A., Drummond M.S., and Lang A.L., "Final Report to the RTA on Traffic Generated Pollution Near Roads and Highways" Investigation Report CET/ IR238 CSIRO, Division of Coal and Energy Technology, North Ryde Laboratory, March 1994. 


\section{CHAPTER 1}

\section{INTRODUCTION}

Industrial development and the establishment of large urban areas with high densities of motor vehicles have resulted in increased emissions of pollutants to the atmosphere. Air pollution modelling is one of the most widely used techniques which have been used to assess future road and building configurations against the National Air Quality Criteria (see Appendix B). According to Seinfeld, (1975), air quality models are considered a unique tool for :

(a) establishing emission control legislation; ie., determining the maximum allowable emission rates that will meet fixed air quality standards

(b) evaluating proposed emission control techniques and strategies ie., evaluating the impacts of future control .

(c) selecting locations of future sources of pollutants, in order to minimise their environmental impacts.

(d) assessing responsibility for existing air pollution levels; ie., evaluating present sourcereceptor relationships.

Conceptually, there are three components to modelling the concentrations of traffic generated pollution near arterial roads. These are (Williams et al., 1994):

(a) estimation of pollution source strength. This is a function of, inter alia, traffic speed, density and flow, vehicle type and road gradient.

(b) simulation of the road link, including the number and width of the lanes, width of the median strip, road gradient and orientation.

(c) modelling the dispersion of the pollution, which is a function of, inter alia, the wind speed and direction, atmospheric stability, vehicle wake turbulence and local terrain.

Whilst the road link can be modelled with reasonable precision, it will be shown that there are significant inherent uncertainties associated with items (a) and (c) (Williams et al., 1993).

The major thrust of this study is to investigate in detail the estimation of pollution source strength because it is a major factor affecting the accuracy of the prediction of dispersion models.

One commonly-used approach for modelling motor vehicle emissions is to adjust emissions data produced by subjecting vehicles to a standard driving cycle (the standard Federal Test Procedure, FTP) and adjust them to match the highway speed by means of a speed correction factor (the average vehicle speed is used as the sole descriptor for 
pollutants emission levels). Allowance has to be made for both exhaust and evaporative emissions from different vehicle technology groups and their population, effects of vehicle age, ambient temperature ect.

The above approach is used by California Resources Board (USA) who have developed the EMFAC7 methodology (1993) which develops emission factors for both exhaust and evaporative emissions for different vehicle technology groups, and weights them according to vehicle population and annual distance travelled.

In Australia, the EPA (Victoria) used the same above procedure to develop emissions factors based on splitting the Australian Federal Test Procedure (ADR 27) into segments representing three driving modes. These driving modes are freeway. arterial, and congested roads (Carnovale et al., 1991).

Cadle et al. (1991) reported that the US model does not, currently, provide reliable estimates of on-road pollutant emissions. Analysis of air quality in well defined situations such as tunnels shows that $\mathrm{CO}$ and $\mathrm{HC}$ concentrations are about twice those anticipated from traffic type and density (Robinson et al., 1993), although $\mathrm{NO}_{\mathrm{X}}$ levels are only 50\% higher. Guensler et al. (1993) measured the emissions from over 500 vehicles using five driving cycles with different average speeds and found that actual emissions were much higher than predicted concentrations using the speed correction factor and the Federal Test Procedure (FTP) data. One of the reasons that the FTP procedure does not provide reliable estimates concerns open loop operation of catalyst-equipped vehicles when uncontrolled exhaust emissions occur to avoid overheating the catalyst.

The EPA (USA) approach and the EPA (Victoria) procedure which employ the average vehicle speed as the sole descriptor for pollutants emission levels is more suitable to estimate emissions for an airshed or over a number of links rather than at a specific location. This limitation occurs because airshed or multi-link modelling involves a range of driving conditions better approximated by the standard driving cycle (FTP) related data. The limitation is particularly evident when attempting to model pollution near significant inclines. A power (or load) model has the potential for overcoming some of these problems (Kent et al., 1982).

It was required as objectives of this study to:

(1) Develop an estimation for the pollution source strength based on the total instantaneous power required to propel the vehicle along the road is taken as a basis for estimating the fuel consumption and emission rates at that instant. The model must be 
capable of simulating the driving cycle emissions and its performance when tested against emission data obtained from FTP cycle testing.

(2) Validate the power-based emissions model by (i), comparing the modelled emissions of the city driving cycle with the experimental data of several workers such as Williams: et al., 1987, Carnovale et al., 1991, and SPCC, 1989, and (ii), using the model in conjunction with dispersion models such as CALINE4 (Benson, 1984), and HIWAY-2 (Petersen, 1980), and comparing the predicted emissions with the experimental data basc of the CSIRO/RTA project which was conducted at 1992-1993 to quantify air born pollutants due to traffic near arterial roads in Sydney (Williams et al., 1993).

(3) Compare the performance of the developed emissions model with that of the USA EMFAC7 model (California EPA, 1993).

In this study two traffic pollution models have been employed to simulate the atmospheric dispersion at locations up to $60 \mathrm{~m}$ downwind from the roadside and to heights of $10 \mathrm{~m}$ above the ground. The models are CALINE4 (Benson, 1984) and HIWAY-2 (Petersen, 1980).

These particular models were chosen for two reasons. First, HIWAY-2, and CALINE4 are commonly used models in the USA for regulatory purposes. Second, those models are Gaussian plume models (Hanna et al., 1982) which model the emissions source and dispersion separately.

As each of these models requires, as input, estimates of the pollutant source strength for each lane of the highway, the emissions module will be described in Chapter 3 , and the employed mathematical models in Chapter 4.

Three studies are deployed in this study to validate the power-based emissions model. These studies are Williams et al., (1989), Carnovale et al., 1991, SPCC, 1989. Validation results and discussion are presented in Chapter 5.

The results of recent CSIRO/RTA field study (Williams et al., 1994) were utilised to assess the predictions of two dispersion models used in conjunction with the powerbased emissions model. The predicted emissions of CALINE4 (Benson, 1984) and HIWAY-2 (Petersen, 1980) using a new vehicle emissions module were compared with eight days of the experimental data collected at three sites.

The experimental data base of the CSIRO/RTA project, which was conducted at 1992-1993 to quantify air born pollutants due to traffic near arterial roads in Sydney, 
consisted of measurements of the pollutants $\mathrm{CO}, \mathrm{CO}_{2}$, total hydrocarbons ( $\mathrm{HC}$ ), and NOx. The measurements were made under a variety of traffic and meteorological conditions. Measurements were made at locations up to $60 \mathrm{~m}$ downwind from the roadside and to heights of $10 \mathrm{~m}$ above the ground. A video camera was used to record the traffic flow, speed and type (classified simply as domestic, light or heavy commercial). The experimental method and dispersion validation are presented in Chapter 6 .

The summary and final conclusions are presented in Chapter 7 . 


\section{CHAPTER 2}

\section{LITERATURE REVIEW}

The change in the composition of the ambient air over earth has been underway for the last 200 years. Anthropogenic activities have provided a clear perturbation of the earth's environmental balance. In the atmosphere, these anthropogenic pollutants have often generated locally unhealthy air quality and, sometimes, lethal air pollution concentrations, as during the London episode of December 1952 and New York episode of November 1966. In 1945, it was recognised that the combustion of the petroleum products are responsible for a new type of smog, a photochemical smog, first discovered in the Los Angles area (Zannetti, 1991).

Two global issues have been recently become a major concern: 1) the green house effect, which could cause an increase of the earth's average temperature as a consequence of increasing concentrations of carbon dioxide $\left(\mathrm{CO}_{2}\right)$, a species whose huge emissions have never been controlled; and 2) the possible depletion of the stratosphere ozone layer, a natural protective layer from harmful solar radiation, by certain species emitted by anthropogenic activities.

Several studies point out that $\mathrm{CO}_{2}$ strongly adsorb electromagnetic radiation at a wavelength of about $15 \mu \mathrm{m}$, which corresponds to the maximum intensity of earth radiation (the atmosphere and the $\mathrm{CO}_{2}$ are transparent to sun's radiation, which heats the earth's surface, but about $30 \%$ of the sun's radiation is reflected to space). Therefore, an increase of $\mathrm{CO}_{2}$ in the global atmosphere can trigger a general increase of earth temperature, an effect that has been called the greenhouse effect (Zannetti, 1990).

\subsection{Air pollution phenomena}

Air pollutants in the atmosphere are found in the form of

a) primary gaseous pollutants such as $\mathrm{CO}, \mathrm{HC}, \mathrm{NO}_{\mathrm{X}}, \mathrm{SO}_{2}$, and particulate matter such as fine dust. These pollutants are injected to the atmosphere from either natural resources (volcanoes, ocean spray, and pollen) and/or anthropogenic sources (industrial, commercial, agriculture, and transportation activities. These pollutants may have adverse health effect. Also through complex chemical interaction in the atmosphere (photochemical smog), $\mathrm{CO}, \mathrm{HC}$, and $\mathrm{NO}_{\mathbf{X}}$ play an indirect role in the greenhouse effect by influencing the levels of greenhouse gases. 
b) greenhouse gases include carbon dioxide $\left(\mathrm{CO}_{2}\right)$, methane $\left(\mathrm{CH}_{4}\right)$, ozone $\left(\mathrm{O}_{3}\right)$. nitrogen oxide $\left(\mathrm{N}_{2} \mathrm{O}\right.$ ), and the chlorofluorocarbons (CFC). These greenhouse gases are responsible for the possible future global climate change including increases in surface air temperature and see level (see Appendix A).

As discussed in Appendix A, It is expected that world primary energy requirements are expected to grow 54 percent in the next 15 years from about 7654 Mtoe (megatons oil equivalent) in 1987 to 118820 Mtoe in 2005 (Allen et al., 1990). Also It is expected that the energy requirements for transport sector trend likely to increase resulting in increasing the transport both the share of global $\mathrm{CO}_{2}$ emissions and the emissions of $\mathrm{CO}, \mathrm{HC}$, and $\mathrm{NO}_{\mathbf{X}}$

As mentioned in Chapter 1, the major thrust of this study to deal with the primary gaseous pollutants such as $\mathrm{CO}, \mathrm{HC}, \mathrm{NO}_{\mathrm{X}}$ mentioned in (a).

\subsection{Road vehicles as the major source of air pollution}

The exhaust emissions from spark-ignition and diesel vehicles resulting from the combustion of petrol and diesel fuels are the main source of air pollution in urban areas. Leaded petrol is one of the commonly used fuel for private passenger vehicles (Table 2.1). Its use leads to emissions of the pollutants carbon monoxide ( $\mathrm{CO}$ ), hydrocarbons $(\mathrm{HC})$, nitrogen oxides $\left(\mathrm{NO}_{\mathrm{x}}\right)$, and particulate lead $(\mathrm{Pb})$, besides emissions of water vapour and carbon dioxide.

Table 2.1 Consumption of petroleum products, 1985 to 1992 (Source: Australian Bureau of Transport and Communications Economics, 1993).

(million litres)

\begin{tabular}{|l|r|r|r|r|r|r|r|r|}
\hline \multicolumn{1}{|c|}{ Fuel type } & \multicolumn{1}{c|}{1985} & \multicolumn{1}{c|}{1986} & 1987 & \multicolumn{1}{c|}{1988} & 1989 & 1990 & 1991 & 1992 \\
\hline Petrol-leaded & 15479 & 15091 & 14318 & 13830 & 13098 & 11930 & 10858 & 10234 \\
\hline Petrol-unleaded & 274 & 912 & 1897 & 2944 & 4141 & 5218 & 6022 & 6836 \\
\hline Diesel-automotive & 8242 & 8558 & 8864 & 9365 & 9994 & 10022 & 9784 & 10054 \\
\hline Diesel-industrial /marine & 307 & 221 & 231 & 189 & 172 & 138 & 123 & 133 \\
\hline Aviation gasoline & 111 & 108 & 113 & 121 & 126 & 118 & 98 & 101 \\
\hline Aviation turbine fuel & 2371 & 2499 & 2612 & 2931 & 2801 & 3139 & 3370 & 3551 \\
\hline Fuel oil & 2813 & 2498 & 2228 & 2331 & 2450 & 2206 & 2084 & 1624 \\
\hline Others products & 4133 & 4174 & 4536 & 4786 & 5272 & 6071 & 5290 & 5635 \\
\hline Total & 34730 & 34061 & 34806 & 36497 & 38054 & 38842 & 37629 & 38167 \\
\hline
\end{tabular}

* Includes lighting and power kerosene, heating oil. lubricants, and LPG. 
Unleaded petrol (ULP) is the other major liquid fuel in common use in the post-1986 vehicles designed with catalytic converter systems in vehicle exhausts to minimise the emissions of the gaseous pollutant of $\mathrm{CO}, \mathrm{HC}$, and $\mathrm{NO}_{\mathrm{x}}$ (Table 2.1). This fuel has been chosen because lead poisons the rare metal catalysts, platinum or palladium, used in the conversion of gases to harmless emissions (Taylor and Young, 1988).

An increasing number of vehicle fleets in Australia have been adapted to run on the liquid petroleum gas (LPG) because it offers a cheap alternative to petrol. It was estimated that LPG replaced about $12 \%$ of gasoline in 1991 (ABS, 1991). Gaseous emissions from (LPG) are less than those from petrol (for $\mathrm{CO}, \mathrm{HC}$, and $\mathrm{NO}_{\mathrm{x}}$ ) with an absence of particulate lead, but fuel consumption in volumetric terms is $25 \%$ worse than that of petrol (Taylor and Anderson, 1982).

Diesel fuel is widely used for large vehicles, and occasionally by passengers cars (Table 2.1). Diesel fuels offer greater fuel efficiency (more kilometres per litre) and significant reduction in emissions of carbon monoxide $(\mathrm{CO})$ and hydrocarbons $(\mathrm{HC})$ (Williams et al., 1987; Braddock et al., 1986), but they may produce more sulphur oxides compared with the petrol because diesel fuel contains roughly ten times as much sulphur as does petrol (Watkins, 1991).

It was estimated that the road vehicles in Australia consumed about 26660 million litres of fuel in 1991 ( $71 \%$ of the total national petroleum products). This fuel accounted for the production of 3.389 million tones of carbon monoxide emissions, 0.386 million tones of oxides of nitrogen emissions, and 0.485 million tones of hydrocarbon emissions (see Table 2.3).

\subsection{Air pollution trends in Sydney}

Forrest, 1990 represented the estimates of the quantities of pollutants discharged annually into Sydney metropolitan area atmosphere for 1976 and 1990 as well as the predicted quantities for the year 2011. These estimates, prepared by The New South Wales EPA (see Table 2.2), have been based on both the original study done 1976 and the current understanding about anticipated changes in emissions from motor vehicles and industry resulting from technology improvements and the implementation of emission control legislation. 
Table 2.2 Sydney estimated levels of gaseous emissions and contributions from traffic (Forrest, 1990)

\begin{tabular}{|c|c|c|c|c|c|c|}
\hline \multirow{2}{*}{ Emission } & \multicolumn{2}{|c|}{1976} & \multicolumn{2}{c|}{1990} & \multicolumn{2}{c|}{2011} \\
\cline { 2 - 7 } & $\begin{array}{c}\text { Total } \\
\text { emission } \\
\text { in } \\
\text { tonne p.a. }\end{array}$ & $\begin{array}{c}\text { Percentage } \\
\text { from road } \\
\text { transport } \\
\text { percent }\end{array}$ & $\begin{array}{c}\text { Total } \\
\text { emission } \\
\text { in } \\
\text { tonne p.a. }\end{array}$ & $\begin{array}{c}\text { Percentage } \\
\text { from road } \\
\text { transport } \\
\text { percent }\end{array}$ & $\begin{array}{c}\text { Total } \\
\text { emission } \\
\text { in } \\
\text { tonne p.a. }\end{array}$ & $\begin{array}{c}\text { Percentage } \\
\text { from road } \\
\text { transport } \\
\text { percent }\end{array}$ \\
\hline Carbon monoxide & 750000 & 90 & 650000 & 90 & 800000 & 80 \\
\hline Hydrocarbon & 200000 & 50 & 155000 & 48 & 195000 & 40 \\
\hline Nitrogen oxides & 60000 & 80 & 66000 & 80 & 90000 & 70 \\
\hline
\end{tabular}

On the national scale, the Bureau of Transport and Communications Economics have developed an emission inventory for the greenhouse gases emitted by Australian transport for 1991. In this inventory, the greenhouse gases emitted by various transport modes in Australia and its contribution to the national emissions were estimated ( see Table 2.3).

Table 2.3 Estimated emissions of Greenhouse gases by Australian Transport, 1991 (Source: Bureau of Transport and Communications Economics estimates).

\begin{tabular}{|c|c|c|c|c|c|c|}
\hline \multirow[b]{2}{*}{ Trace gas } & \multicolumn{5}{|c|}{ Transport Mode } & \multirow{2}{*}{$\begin{array}{c}\text { Contribution to } \\
\text { national emissions } \\
\text { percent }\end{array}$} \\
\hline & $\begin{array}{l}\text { Road } \\
(\mathrm{Kt})\end{array}$ & $\begin{array}{l}\text { Rail } \\
(\mathrm{Kt})\end{array}$ & $\begin{array}{l}\text { Air } \\
(\mathrm{Kt}) \\
\end{array}$ & $\begin{array}{l}\text { Sea } \\
(\mathrm{Kt}) \\
\end{array}$ & $\begin{array}{c}\text { Total } \\
\text { transport } \\
(\mathrm{Kt}) \\
\end{array}$ & \\
\hline Carbon dioxide & 52354 & 3207 & 8268 & 3995 & 68049 & 24 \\
\hline Methane & 20.9 & 0.2 & 0.4 & 0.4 & 21.8 & 1 \\
\hline Nitrous oxides & 4.0 & 0.0 & 0.1 & 0.1 & 4.2 & 2 \\
\hline Nitrogen oxides & 386.1 & 41.9 & 32.9 & 89.5 & 550.6 & 45 \\
\hline Carbon monoxide & 3388.9 & 14.2 & 93.9 & 46.2 & 3543.0 & $26 *$ \\
\hline NMVOCs & 484.9 & 3.0 & 3.8 & 9.5 & 501.2 & 49 \\
\hline
\end{tabular}

* Transport contribution to energy-related $\mathrm{CO}$ emissions is estimated at 90 per cent. The bulk of Australian CO emissions are due to grassland burning. NMVOCs is nonmethane volatile organic compounds. $\mathrm{Kt}$ is kilotons.

The progressive introduction of legislated emission controls on passenger cars (the introduction of the unleaded petrol with the petrol vehicles equipped with catalytic converters in 1986) has brought about a decline in the estimated carbon monoxide and hydrocarbons annual emissions in Sydney, despite the growth in vehicle usage (see Table 2.2). It was estimated that about $90 \%$ of all carbon monoxide emissions, $48 \%$ of 
all hydrocarbons emissions, and $80 \%$ of all oxides of nitrogen emissions in the Sydney region were emitted by road transport in 1990 (Forrest, 1990).

On the national scale, about 23 per cent of the national emissions of $\mathrm{CO}$ and about 48 per cent of the national emissions of the non-methane volatile organic compounds, NMVOCs, were emitted by road transport in Australia in 1991 (Table 2.3 ).

Unlike hydrocarbons and carbon monoxide, oxides of nitrogen emissions for Sydney have increased over the time frame considered as given in Table 2.2. Motor vehicles accounted for $80 \%$ of all oxides of nitrogen emissions in Sydney in 1991. On the national scale, about 32 per cent of the national emissions of $\mathrm{NO}_{\mathrm{X}}$ were emitted by road transport in Australia for 1991 (Table 2.3 ).

Oxides of nitrogen were incorporated for the first and only time in emission control legislation applying to passengers cars in 1976 and this resulted in a levelling off in mass emissions for a couple of years before increasing again. Whilst oxides of nitrogen were not controlled any further in 1986, most manufacturers now employ three-way catalyst technology to reduce that pollutant from new cars by $50 \%$ on average. As a result mass emissions of oxides of nitrogen from motor vehicles has remained constant over the past five years (Forrest, 1990).

\subsection{The requirements to control vehicle exhaust emissions}

Substantial evidence has accumulated that air pollution affects the health of the human beings and animals, damages vegetation, soil and deteriorates materials, affects the climate, reduces visibility and solar radiation.

The carbon monoxide in atmosphere originates to a large extent from motor vehicles and is almost completely due to them in the vicinity of streets (see Tables 2.2, and 2.3). It can be assumed that the daily average of $30 \mathrm{ppm}$ apply for an individual travelling by a car in town and exceptionally of $80 \mathrm{ppm}$ for someone standing at a heavily polluted point.

The toxic properties of carbon monoxide are due to its ability to react with the haemoglobin in the blood to produce carboxy-haemoglobin $\left(\mathrm{COH}_{b}\right)$. Carbon monoxides affinity for haemoglobin is more than 200 times greater than that of oxygen. When inhaled, it is taken up by the blood and reduces the capacity of blood to transport oxygen. The degree of absorption depends on the concentration of carbon monoxide in the air, the periods of exposure and the activity of the individual (Cafe et al., 1993). 
Symptoms of carbon monoxide intoxication are lassitude and headaches, usually nol reported until the concentration of carboxyhaemoglobin in the blood are in excess of $10 \%$ of saturation. This percentage is approximately the equilibrium value achieved with an ambient atmospheric concentration of $58 \mathrm{ppm}$ for a person engaged in light activity. There is evidence, however, that there is a risk for individuals with cardiovascular disease when the carboxyhaemoglobin concentration reaches $4 \%$ of saturation.

Nitrogen oxides $\left(\mathrm{NO}_{\mathrm{X}}\right)$, emitted by motor vehicles are nitrogen oxide, NO (approximately 95\%), and nitrogen dioxide, $\mathrm{NO}_{2}$ (approximately $5 \%$ ). NO is the less harmful at the concentrations normally found in urban air. $\mathrm{NO}_{2}$ is known to irritate the alveoli, leading to symptoms resembling emphysema upon long term exposure to concentrations of the order of $1 \mathrm{ppm}$ (Seinfeld, 1986).

Hydrocarbons alone do not generally pose a problem in the urban environment at the concentrations commonly experienced. Some hydrocarbons such as benzene are known to have an adverse effect on human health, but the effects are thought to occur at concentrations much higher than the level of exposure found at roadsides.

Hydrocarbons do play a significant role in photochemical smog formation which is characterised by the presence of excessive concentrations of ozone (O3), nitrogen dioxide ( $\mathrm{NO}_{2}$ ), peroxyacetyl nitrate (PAN). The $\mathrm{O}_{3}, \mathrm{NO}_{2}$, and PAN are highly active oxidising chemicals. The fine particulate matter, which consists mainly of nitrates and sulphates, interferes with visibility.

It was reported that ozone at levels of $1 \mathrm{ppm}$ produces a narrowing of airways deep in the lung, resulting an increased airway resistance (Seinfeld, 1986). Many people, even healthy young children, suffered adverse effects from exposure to ozone at quite low levels (less than $0.05 \mathrm{ppm}$ ) including eye irritation, coughs, chest discomfort, headaches, respiratory illness, increased asthma attacks, and reduced pulmonary functions (Watkins, 1991).

There remain serious concerns concerning the effect of lead from car emissions in the atmosphere, and its possible effects on unborn and young children. Lead additives have been used in Australia for many years, to raise the octane rating of motor vehicle fuels. Changes in engine design allowed the introduction of unleaded fuel from 1986, but more than $50 \%$ of current vehicles still operate on leaded fuel (Table 2.1).

Air lead levels have been reduced since the introduction of unleaded petrol, and are expected to fall further as a result of a reduction in the number of cars using leaded 
petrol, and planned reduction in the quantity of lead in leaded petrol. It is expected that production of leaded petrol will cease around the year 2003. There was new scientific evidence that suggests prolonged lead exposure can have a detrimental effect on the intellectual development of children. (Cafe et al., 1993).

The presence of particulate matter in the air can have an adverse effect on health and amenity. Particles lodged in the lungs can affect the respiratory system. especially if they contain adsorbed acid gases such as sulfur dioxide.

\subsection{Why pollutants are generated in the internal combustion engines}

Actual engine operation involves a very rapid batch-burning process. After ignition, the flame progresses in the combustion chamber until it cools and stops burning or is quenched as it nears the chamber wall. This process leaves a layer of unburnt hydrocarbon next to the wall, a portion of which subsequently mixes with the bumt charge and escapes with exhaust. In actual operation, the air/fuel ratio entering the engine is not usually the optimum theoretical mixture. Furthermore, the flow is such that no two cylinders or cycles get exactly the same mixture homogeneously distributed throughout the combustion chamber. Thus, combustion is not complete, particularly when mixture is fuel rich. As a result of these and other factors a complex mixture of exhaust products is emitted from the tailpipe (Perkins, 1974).

The by-products of the complete combustion of petrol and diesel fuels in the internal combustion engines are carbon dioxides, nitrous oxides, lead oxides, lead halogenides, sulfurous oxides, and water. The additional by-products of the incomplete combustion include paraffins, olefines, aromatic hydrocarbons, aldehydes, ketones, carboxylic acids, carbon monoxide, acetylene, ethylene, hydrogen, soot, and polycyclic hydrocarbons. The emissions of carbon dioxide, a major by-product of the combustion process, are being subjected to increasing interest due to their contribution to the "greenhouse effect". (Taylor et al, 1988).

Carbon monoxide ( $\mathrm{CO}$ ) arises primarily from incomplete combustion of carbonaceous materials. The concentration of carbon monoxide increases as the ratio between the quantity of intake air and the theoretical air requirements $(\lambda)$ decreases, so the concentration of carbon monoxide is at a maximum during idling and deceleration of vehicles. High-power requirements, such as maximum acceleration, also produce higher carbon monoxide concentration than moderate-power cruising where carbon monoxide emission levels are at a minimum . Table 2.4 gives typical exhaust gas constituents from petrol and diesel engines as a function of driving mode (Watkins, 1991). 
Oxides of nitrogen $\left(\mathrm{NO}_{\mathrm{X}}\right)$ are nitric oxide $(\mathrm{NO})$ and nitrogen dioxide $\left(\mathrm{NO}_{2}\right)$. Nitric oxide is generated through combustion and is considered a precursor of photochemical oxidants. Nitrogen dioxide may be considered as belonging to two different classes of pollutants, as a primary pollutant generated primarily through the combustion processes of conventional fuels (Table 2.4) and as a secondary pollutant produced through the oxidation of nitric oxide .

Table 2.4 Typical exhaust gas constituents for petrol and diesel engines as a function of driving mode (Watkins, 1991).

\begin{tabular}{|c|l|c|c|c|c|}
\hline Engine & \multicolumn{1}{|c|}{ Pollutant } & $\begin{array}{c}\text { Idling } \\
\mathrm{ppm}\end{array}$ & $\begin{array}{c}\text { Acceleration } \\
\mathrm{ppm}\end{array}$ & $\begin{array}{c}\text { Cruising } \\
\mathrm{ppm}\end{array}$ & $\begin{array}{c}\text { Deceleration } \\
\mathrm{ppm}\end{array}$ \\
\hline \multirow{4}{*}{ Petrol engines } & Carbon monoxide & 69000 & 29000 & 27000 & 39000 \\
\cline { 2 - 6 } & hydrocarbon & 5300 & 1600 & 1000 & 10000 \\
\cline { 2 - 6 } & Oxides of nitrogen & 30 & 1020 & 650 & 20 \\
\cline { 2 - 6 } & Aldehydes & 30 & 20 & 10 & 290 \\
\hline \multirow{3}{*}{ Diesel engines } & Carbon monoxide & Trace & 1000 & Trace & Trace \\
\cline { 2 - 6 } & hydrocarbon & 400 & 200 & 100 & 300 \\
\cline { 2 - 6 } & Oxides of nitrogen & 60 & 350 & 240 & 30 \\
\cline { 2 - 6 } & Aldehydes & 10 & 20 & 10 & 30 \\
\hline
\end{tabular}

Hydrocarbons are present in exhaust gases in a variety of forms. When exposed to the sunlight in the presence of the oxides of nitrogen they react to form Photochemical oxidants such as ozone, organic peroxides, and peroxy-acetylnitrates (Kelly, 1992).

\subsection{Parameters influencing exhaust emissions}

In the following part, the parameters influencing both the spark ignition and diesel exhaust emissions and the methods used to control the composition of the exhaust gases are discussed.

\subsubsection{Spark ignition engines}

The methods used to alter the composition of the exhaust gases from spark ignition engines are divided into two basic categories: engine design measures and exhaust-gas treatment. 


\subsubsection{Engine-design measures}

The two main factors controlling the formation of pollutants within the petrol engine are the composition of the air and fuel mixture and the timing of its ignition.

The air/fuel ratio has a great effect on the formation of pollutants (air/fuel ratio is also defined in the terms of unit "lambda" $(\lambda)$ which is the ratio between the quantity of intake air and the theoretical air requirements). $\lambda$ has a value of 1.0 at the stoichiometric ratio of 14.7:1. Values higher than 1.0 represent weak mixtures and those less than 1.0 represent rich mixtures. The combustion of rich mixtures $(\lambda<1.0)$ which have too little oxygen is incomplete resulting in the production of high levels of carbon monoxide and hydrocarbons and low levels of nitrogen oxides. Unfortunately increasing the excess-air factor $(\lambda)$ to reduce carbon monoxide and hydrocarbons emission levels increases the production of oxides of nitrogen emissions which reaches a maximum at about the same excess-air factor $(\lambda)$ that minimises $\mathrm{HC}$ and $\mathrm{CO}$ emissions (Figure 2.1, 2.2, 2.3). A further increase in the excess-air factor $(\lambda)$, providing an excess of air, reduces the cylinder temperature and production of oxides of nitrogen falls. Excess-air factors of $\lambda$ $=0.9 \ldots 1.05$ are selected for idle. An excessively lean mixtures $(\lambda>1.1)$ result in the engine's lean misfire limit (LML) being reached or exceeded, and as the mixture is progressively leaned out, misfiring causes a rapid increase in $\mathrm{HC}$ emissions (Figure 2.1, 2.2 , and 2.3).

In spark-ignition vehicles, the engine produces its maximum torque at approximately $\lambda=$ 0.9 ; thus this ratio is generally programmed for full load operation (Figure 2.5). Optimum fuel economy is achieved with mixtures in the range of $\lambda=1$. This coincides with the setting for low $\mathrm{CO}$ and $\mathrm{HC}$, emissions; oxides of nitrogen $\left(\mathrm{NO}_{\mathbf{X}}\right)$ however, are at a maximum at this ratio (see Figures 2.1, 2.2, 2.3, and 2.4). (Bosch Automotive Handbook, 1993; Watkins, 1991).

The ignition timing exerts a direct effect on both exhaust emissions and fuel economy by varying the cylinder temperature profile. Retarded ignition results in lower peak temperatures and higher exhaust temperatures than advanced timing. Using the firing point for optimum fuel economy as a baseline, the timing is retarded to a point at which the exhaust valve opens before the combustion process is completed, including a thermal reaction in the exhaust system. Although this method achieves reduction in $\mathrm{NO}_{\mathrm{X}}$ and unburnt hydrocarbons, this is at the price of increased fuel consumption (see Figures $2.1,2.2,2.3$, and 2.4). At the same time, fuel consumption, nitrous oxides and hydrocarbons all increase when the ignition timing is advanced beyond the optimum (Watkins, 1991; Bosch Automobile Handbook, 1993). 


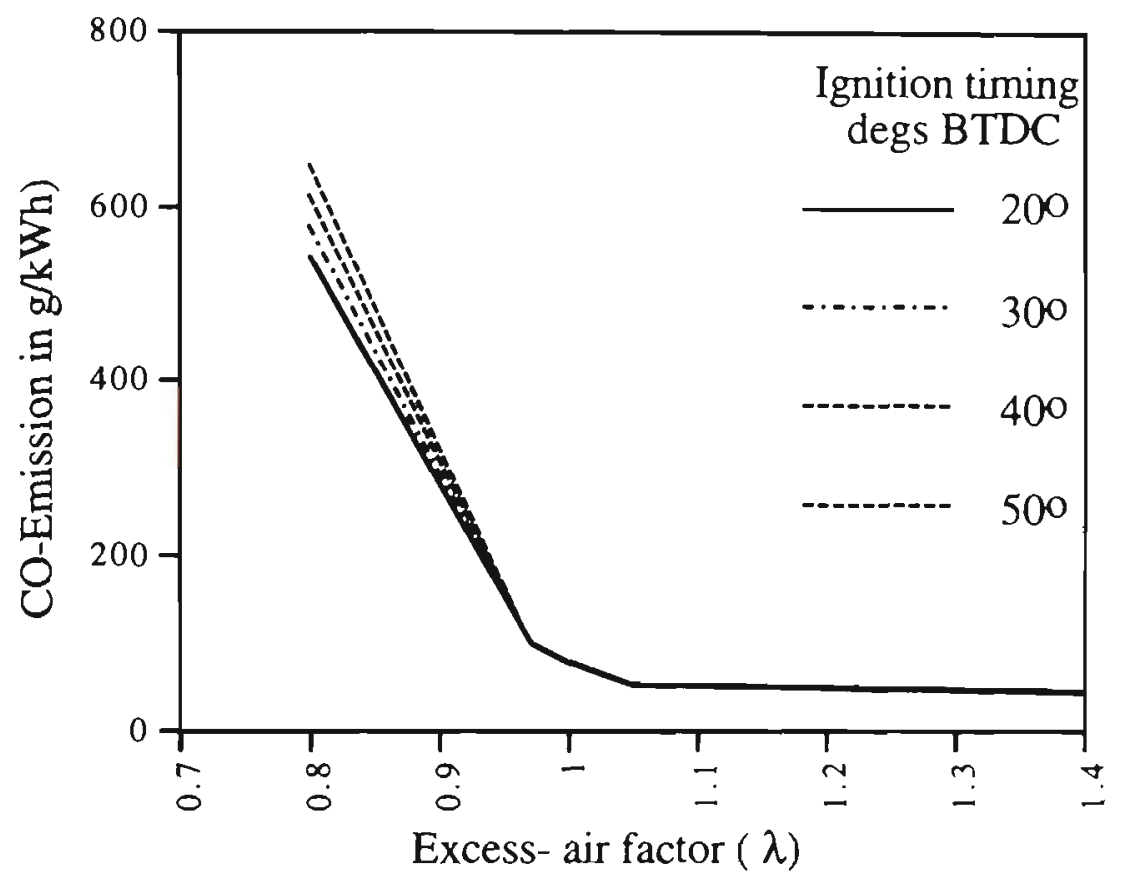

Figure 2.1 The influence of excess-air factor $\lambda$ and ignition timing on CO emissions for spark-ignition vehicles. (Source; Watkins,1991).

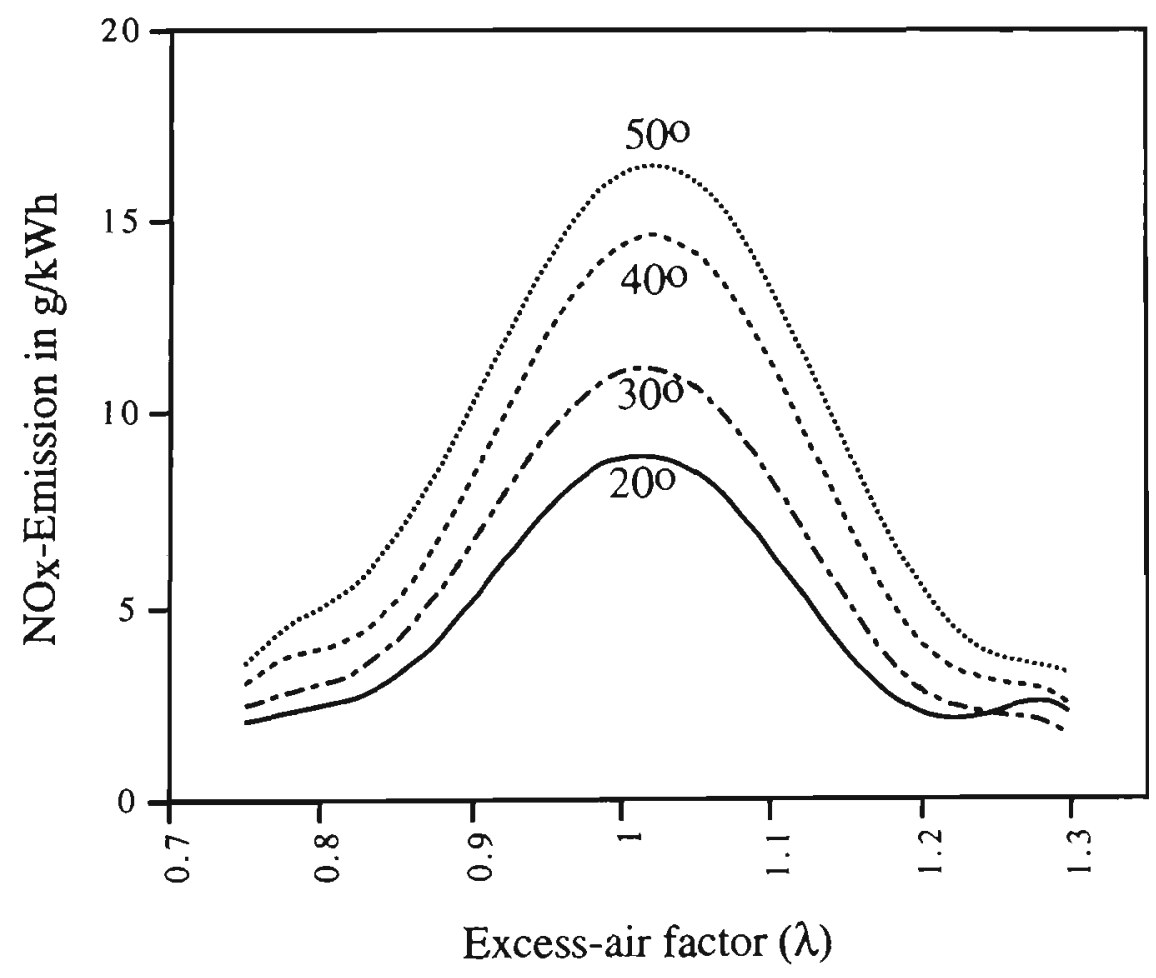

Figure 2.2 The influence of excess-air factor $\lambda$ and ignition timing on $\mathrm{NO}_{\mathbf{x}}$ emissions for spark-ignition vehicles.

(Source; Watkins, 1991). 


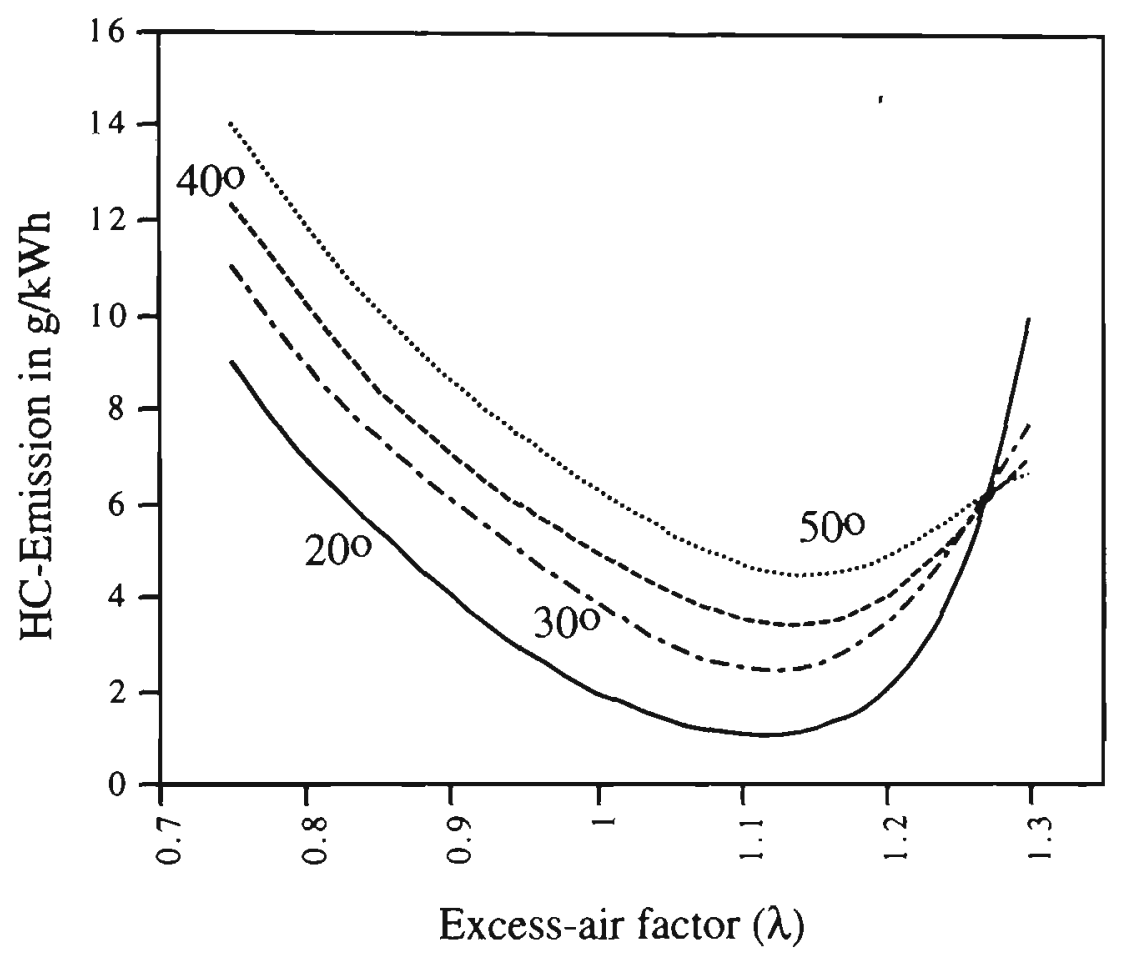

Figure 2.3 The influence of excess-air factor $\lambda$ and ignition timing on HC emissions for spark-ignition vehicles.

(Source; Watkins, 1991).

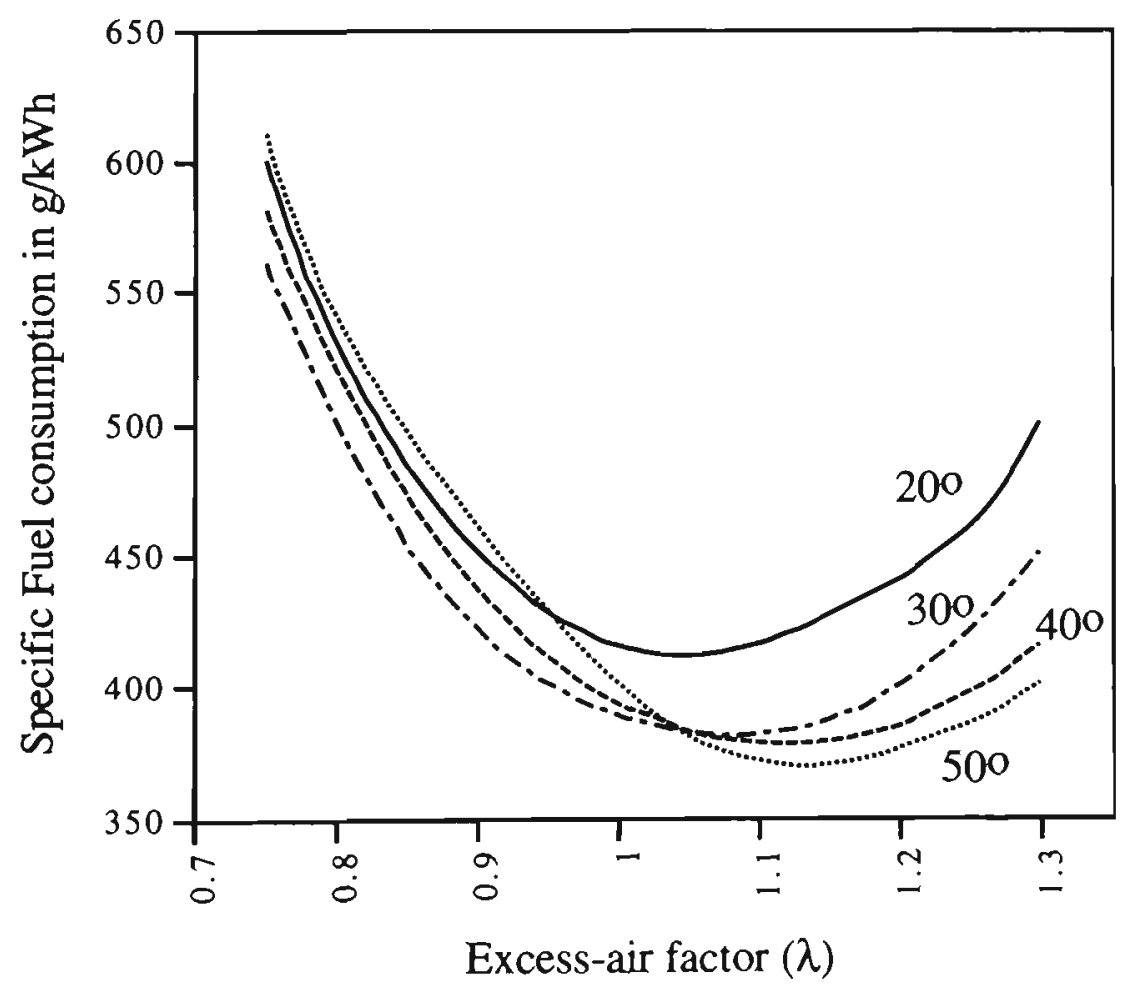

Figure 2.4 The influence of excess-air factor $\lambda$ and ignition timing on specific fuel consumption $\left(F_{c}\right)$ for spark-ignition vehicles. (Source; Watkins, 1991). 


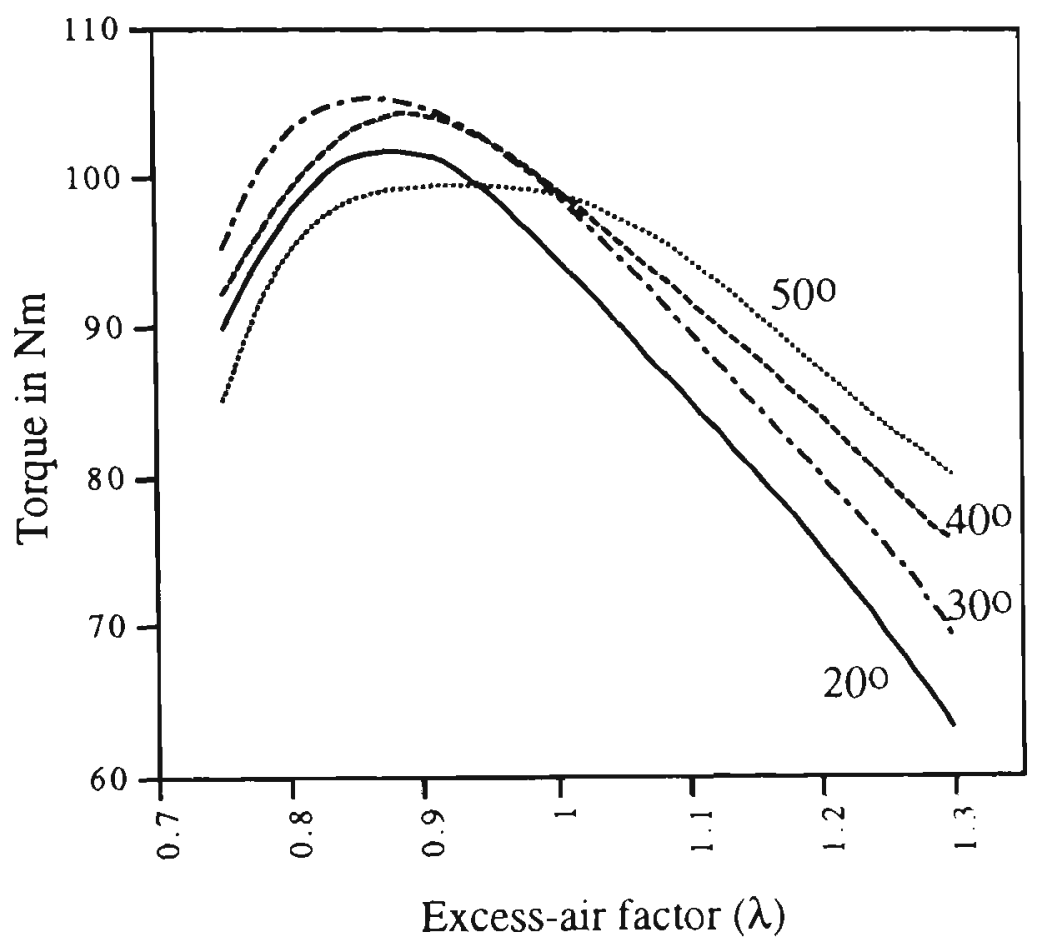

Figure 2.5 The influence of excess-air factor $\lambda$ and ignition timing on the Torque for spark-ignition vehicles.

(Source; Bosch Automotive Handbook, 1993)

The other factors controlling the formation of pollutants within the petrol engine include fuel metering, mixture formation, uniform distribution, exhaust gas recirculation, compression ratio, combustion-chamber design, ignition system, and crankcase ventilation (blowby). The optimisation of the processes of air and fuel metering, mixing and ignition is an important step in production of low-emission engines. Also the advances in the engine design such as the inlet manifold design, the size, number and geometry of the valves, and the shape and configuration of the cylinder head are essential in determining the efficiency of the fuel mixing and combustion. The internal cylinder design, cervices and surface retain fuel and oil that escape burning, strongly influence hydrocarbons emissions. The concentration of hydrocarbons in the crankcase can be many times that found in the engine's exhaust gases. Control systems conduct these gases to a suitable point in the engine's intake tract, from where they are drawn into the combustion chamber for burning. Originally these gases were allowed to escape untreated directly into the atmosphere (Perkins, 1974). Also the design and materials used for the cylinder head determine the thermal properties (Aluminium engines operate at lower combustion temperatures and produce less oxides of nitrogen) (Watkins, 1991).

Exhaust-gas recirculation (EGR) is another common means of reducing the formation of oxides of nitrogen. The addition of a proportion of inert exhaust gas to the air/fuel 
charge is an effective way of reducing the peak cylinder temperature by increasing the mass of gas to be heated by a given mass of petrol.

The main sources of hydrocarbon emissions are the fuel system (fuel tank and carburettor) and crankcase ( crankcase emissions are the HC blowby which goes past the piston ring into the crankcase). The concentration of hydrocarbons in the crankcase can be many times that found in the engine's exhaust gases. Control systems conduct the gases from the fuel system and crankcase to a suitable point in engine's intake tract, from where they are drawn into the combustion chamber for burning. Originally these gases were allowed to escape untreated directly into the atmosphere (Perkins, 1974).

\subsubsection{Exhaust-gas after treatment}

Before the recent catalytic treatment of exhaust emissions became standard, initial attempts to reduce emissions utilised thermal afterburning. This method employs a specific residence time at high temperatures for burning the exhaust-gas components which failed to combust during normal combustion in the engine. In the rich range $(\lambda$ $=0.9$ to 1.0 ), the process must be supported with supplementary air injection. In the lean range $(\lambda=1.1$ to 1.2$)$, the residual oxygen in the exhaust gas is sufficient for afterburning. Today thermal afterburning is considered to have limited potential, as it is of no value in meeting low $\mathrm{NO}_{\mathrm{X}}$ limits. However, thermal afterburning with air injection can be used to reduce emissions of $\mathrm{HC}$ and $\mathrm{CO}$ in the warm-up phase, before the catalytic converter reaches operating temperature.

The catalytic converter is composed of a carrier substrate, which serves as a base for the catalytic material, mounted within a housing using vibration -proof, heat insulated supports. Granulate and ceramic or metallic monolith structure are employed as substrate materials. The monolith structure provides the following advantages: maximum utilisation of catalytic surface, durability combined with physical strength, low thermal retention and limited exhaust back pressure. The active catalytic layer consists of small quantities of noble metals ( $\mathrm{Pt}, \mathrm{Rh}, \mathrm{Pd}$ ), and is sensitive to lead. For this reason, it is essential that engines with catalytic converters be run on unleaded fuel exclusively, as lead destroys the effectiveness of the active layer. The unit's conversion rate is largely a function of operating temperature; no meaningful treatment of pollutants takes place until the converter has reached an operating temperature of approximately $250^{\circ} \mathrm{C}$. Operating temperatures of approximately 400 to $800^{\circ} \mathrm{C}$ provide ideal conditions for maximum efficiency and extended service life. Installing the catalytic converter directly adjacent to the engine provides benefits in the form of high exhaust-gas temperature, resulting in optimum efficiency, but with the disadvantage of high thermal stresses. As the maximum permissible operating temperature is reached just slightly above $1000^{\circ} \mathrm{C}$, the units are 
generally installed at a less critical location under the floor of the vehicle. Engine malfunctions, such as ignition miss, can cause the temperature in the catalytic converter to increase to the point where the substrate melts, resulting in destruction of the unit. Reliable, maintenance-free ignition systems must be used to prevent this form happening (Bosch Automotive Handbook, 1993).

Oxidation catalytic converters oxidise $\mathrm{CO}$ and $\mathrm{HC}$ either by utilising the excess air supplied by lean engine mixtures or by relying on secondary air injection while reduction catalytic converters operate with an air deficiency, and thus without air injection, to reduce $\mathrm{NO}_{\mathbf{X}}$ levels.

The reduction and oxidation converters can also be combined in series to produce a dualbed catalytic converter, a device whose capabilities extend beyond the control of the $\mathrm{NO}_{\mathrm{x}}$ emissions when supported with secondary air injection, it also limits $\mathrm{HC}$ and CO levels. The disadvantages of the dual-bed catalytic converter include design complication (two converters, air injection) and the necessity of operating the engine in the highconsumption range $(\lambda=0.9)$.

The three-way or selective catalytic converters with lambda closed-loop control have proven to be an effective concept for exhaust-gas after treatment. They are able to oxidise carbon monoxide and hydrocarbons and, at the same time, reduce oxides of nitrogen provided the engine is operated with a stoichiometric mixture. The "window" for treatment of the three components is narrow (see Figure 2.6); this means that a conventional open-loop fuel-metering system is not sufficiently precise for application with this concept (Watkins, 1991).

Lambda closed-loop control is a closed-loop control system represents the only means of controlling air-fuel mixture composition with the necessary precision. In such a system, the exhaust gasses are constantly monitored to provide the information required for instantaneous adjustments to the fuel-metering system. The composition of the exhaust gases is monitored with an exhaust-gas oxygen sensor (Lambda sensor) which reflects a stoichiometric mixture $(\lambda=1)$ by generating a voltage switch high-low. Thus indicating whether the mixture is richer or leaner than $\lambda=1$ (Bosch Automotive Handbook, 1993).

\subsubsection{Diesel vehicles}

Diesel engines operate at air/fuel ratios far higher than petrol engines and because of the availability of excess oxygen, diesel engines produce less carbon monoxide and hydrocarbons but because of the inhomogenity of the fuel spray, incomplete mixing, cooling, and deposition on relatively cold surfaces such as cylinder walls, some fuel is 


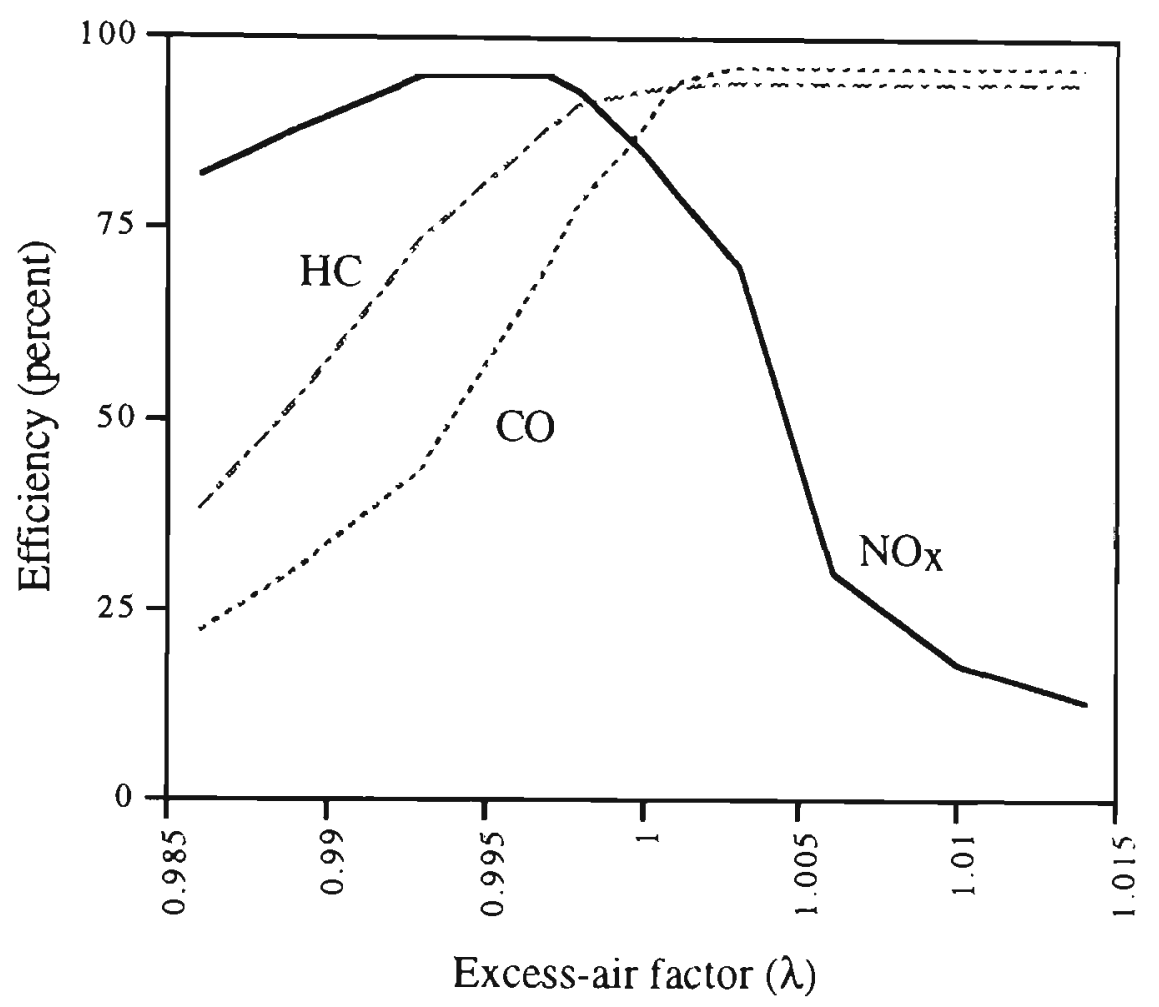

\section{Figure 2.6 The efficiency of the catalytic-converter as a function of Excess-air factor $\lambda$ (Watkins, 1991).}

not burnt and is emitted in the exhaust. The formation of oxides of nitrogen depends on the temperature, pressure, and the availability of oxygen during the combustion cycle (Watkins, 1991).

At lower air/fuel ratios smoke increases heavily (OECD, 1993). To avoid over-rich mixtures and to improve the air/fuel mixing process, wall wetting and delay of fuel injection are used (Concawe, 1986). In naturally aspirated engines the amount of air in the cylinder is independent of the power output. For these engines, maximum power output is limited by the amount of fuel which can be injected with smoke formation. In turbocharged engines however, increasing the amount of fuel injected increases the energy in the exhaust gas and leads the turbocharger to pump more air into the combustion chamber. For this reason, power output of turbocharged engines is not smoke limited. Low air to fuel ratios can only occur during transient accelerations. Most turbocharged engines are further equipped with a cooling system for the compressed air to reduce adverse thermal effects (intercooler). In both types of engines, fuel injection is carried out either directly into the combustion chamber (Direct Injection, DN) or indirectly into a separate pre-chamber where it is mixed and partly burned before getting into the main combustion chamber (Indirect Injection, IDI) (OECD, 1993). According to Scheepers \& Bos (1992a), DI is mainly used for heavy-duty vehicles while IDI is used for light-duty vehicles. Concawe (1986) reported in their study with different light and 
heavy-duty diesel vehicles that the adjustment of the engine plays a major role in diesel emission levels.

The parameters influencing diesel exhaust emissions include the engine conditions. the fuel specifications, malfunction, and exhaust aftertreatment.

\subsubsection{Engine conditions}

Efficient combustion, with low emissions of hydrocarbons and smoke, is achieved by more homogeneous mixing of air and fuel. Important design considerations are the shapes of cylinders, pistons, and induction ports, which determine the level of swirl and turbulence of the air/fuel mixture in the cylinder, and the fuel injection systems. A tine fuel mist promotes thorough mixture of the air and fuel, thereby contributing to reductions in emissions of soot (particulate) and hydrocarbons. This kind of line mist is achieved with high injection pressures and optimum discharge-orifice geometry. The maximum fuel flow for a given quantity of intake air must be limited in order to prevent the engine from producing soot emissions. Deficiencies of the fuel injection equipment increase the levels of hydrocarbons. Secondary injections of fuel can occur if pressure pulses in the high pressure fuel lines are high enough to reopen the injectors. Because these injections occur late in the cycle, the fuel is not burnt efficiently resulting in increasing the hydrocarbons emissions.

Engines featuring a divided combustion chamber (prechamber, swirl chamber) produce fewer nitrogen oxides than engines with direct injection. On the other hand, directinjection engines provide better fuel economy. The swirl pattern of the air in the combustion chamber and the fuel-discharge pattern can be matched for maximum mutual compatibility and effectiveness, resulting in a more homogeneous air-fuel mixture and more complete combustion. The combustion temperature must be high enough to ensure reliable ignition. To prevent this happening, the fuel volume between the injection nozzle's seat and the end of its discharge orifice is held to a minimum. It is also essential that the dribble and post-injection be avoided (Bosch Automotive Handbook, 1993).

Retarding the injection timing in diesel engines is the most effective way of reducing oxides of nitrogen emissions because it reduces peak temperatures and pressures during combustion but on the other hand, injection retard increases fuel consumption, smoke, and hydrocarbons emissions. Excessive delay in injection timing results in higher levels of oxides of nitrogen and hydrocarbons emissions in the exhaust (Perkins, 1974; Watkins, 1991). 
Higher intake-air temperatures are accompanied by higher combustion temperatures, with a commensurate increase in $\mathrm{NO}_{\mathrm{X}}$ emissions. On turbocharged engines, cooling the compressed intake air (intercooling) represents an effective means of inhibiting the formation of $\mathrm{NO}_{\mathbf{X}}$ (Bosch Automotive Handbook, 1993).

The exhaust gases from diesel engines can be rerouted into the intake air in order to reduce the amount of oxygen in the fresh intake charge while increasing its specific heat. Both factors engender lower combustion temperatures (thus limiting $\mathrm{NO}_{\mathrm{X}}$ production) and reduce exhaust emissions. Excessive recirculation of exhaust gases results in higher emissions of soot, $\mathrm{CO}$, and $\mathrm{HC}$, all due to insufficient air (see Figure 2.7).

A significant proportion of hydrocarbons and particulate emissions is derived from lubricating oil that can enter the engine via the piston rings, valve guide of turbocharger. Unburnt oil can contribute 30 or 40 percent of particulate mass emissions from engines operated over the US Heavy Duty Transient Cycle (Watkins, 1991). Hollis (1984) found that hydrocarbon levels fell by about $50 \%$ after fitting valve stem seals.

\subsubsection{Fuel specification}

Many of the properties of diesel fuel significantly influence exhaust emission rates. Table 2.5 shows the influence of diesel fuel quality on some exhaust components.

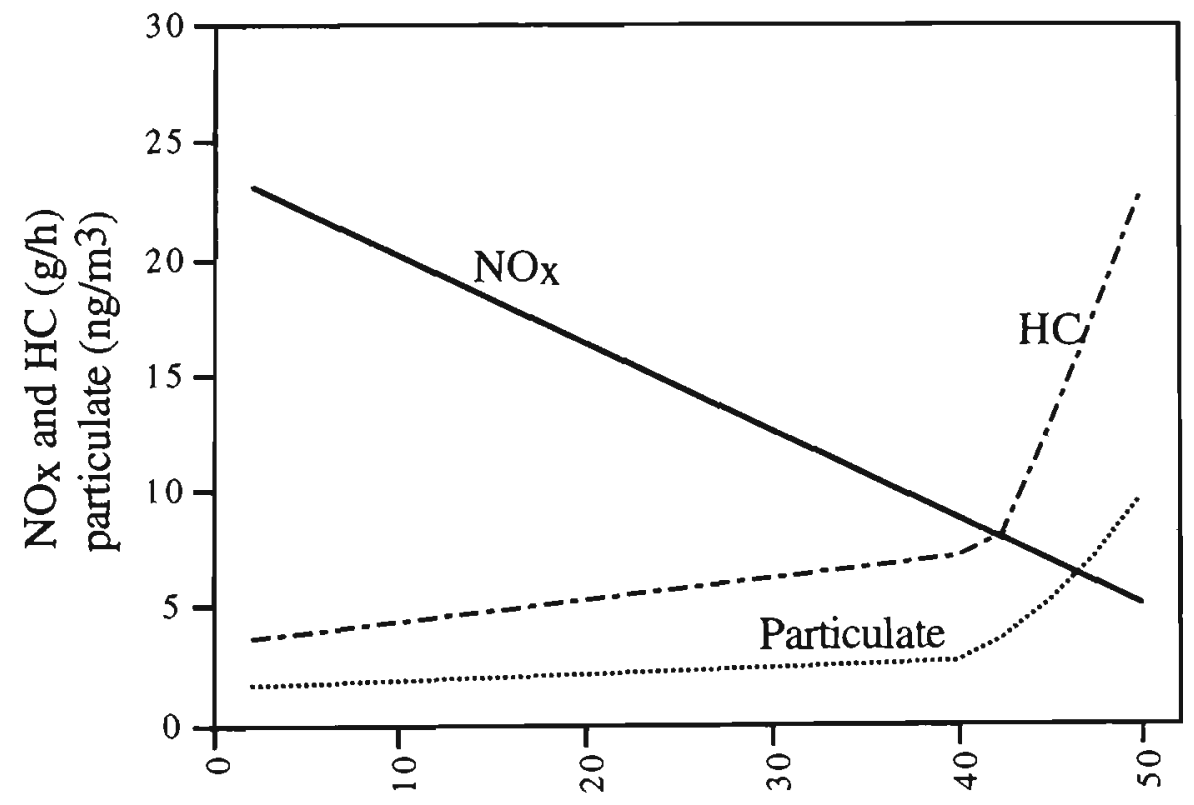

Exhaust gas recycling (percent)

Figure 2.7 The effect of exhaust gas recycling on exhaust emissions from a light-duty indirect injection diesel engine at part load. (Source: Hollis, 1984; Watkins, 1991). 
Diesel fuels contain substantial amounts of sulphur (typically 0.15 to 0.5 percent by weight (Watkins, 1991)). On combustion, the sulphur yields sulphur dioxide, particulate sulphates, and a small proportion of sulphur trioxide. Most of these sulphur particulate are emitted to the atmosphere and contribute to its burden of acid species and some of these particulate is retained in the engine and exhaust system where its corrosive nature accelerates wear. The sulphate content of diesel particulate matter is typically 10-15 percent and reductions would assist significantly in reducing total particulate emissions (Watkins, 1991).

Table 2.5 Influence of diesel fuel quality on some exhaust components (Source: Weidmann et al., 1988; Watkins, 1991)

\begin{tabular}{|c|c|c|c|c|c|}
\hline Rise in: & $\mathrm{HC}$ & $\mathrm{CO}$ & $\mathrm{NO}_{\mathrm{X}}$ & PAHs & Aldehydes \\
\hline Cetane number & -- & -- & $+/ 0$ & - & - \\
\hline Aromatic content & + & + & 0 & + & ++ \\
\hline Density & ++ & ++ & + & ++ & + \\
\hline Volatility : Initial boiling point & 0 & $0 /-$ & + & ++ & $+/-$ \\
\hline Volatility : 90\% boiling point & 0 & - & + & + & $0 /-$ \\
\hline
\end{tabular}

-- much lower; - lower; 0 neutral; + more, ++ much more

\subsubsection{Malfunction}

Malfunctions of defective components of the engine/exhaust gas system may lead to considerable higher emissions as compared to those of properly maintained engine. Volkswagen AG (1989) founded significant increases in emissions of $\mathrm{CO}, \mathrm{HC}$, and particulate matter when they tested a diesel passenger car with defective injection nozzles in different driving cycles. The release of nitrogen oxides were barely affected while the emitted amounts of benzene and the polycyclic aromatic hydrocarbons (PAHs) were slightly increased. Williams et al., (1989) achieved comparable results when testing several light-duty diesel vehicles equipped with defective injectors.

\subsubsection{Exhaust-gas after treatment}

Diesel exhaust emissions can be reduced by exhaust-gas after treatment equipment such as particle traps (trap-oxidisers) and catalytic converters. Particulate traps remove both the soot and the soluble organics adsorbed while catalytic converters reduce mainly carbon monoxide and gaseous hydrocarbons. Hydrocarbon emissions are reduced with 
noble-metal catalytic converters in exhaust system. In these, a portion of the gaseous hydrocarbons, including those attached to particulate (carbon), is bumed using oxygen contained in exhaust gas. The use of catalytic converters requires low fuel sulfur contents as sulfur poisons the active centres of the catalyst.

As discussed earlier in this chapter, the catalytic converters employed to reduce $\mathrm{NO}_{\mathrm{X}}$ emissions in gasoline engine operate with either an oxygen deficiency or stoichiometric mixtures. Those conventional catalytic converters are not suitable for limiting $\mathrm{NO}_{\mathrm{X}}$ emissions in diesel engines because they can only run on excess-air mixture $(\lambda>1)$.

\subsubsection{Exhaust emissions testing}

Some kind of testing is required in order to determine accurately whether emissions standards are being met. To determine a vehicle's emission levels precisely, then the vehicle must be tested in the emissions test cell under standardised conditions which provide an accurate reflection of actual driving conditions. These test conditions are the only means of ensuring that the individual emissions tests remain mutually comparable.

The vehicle to be tested is parked with the drive wheels on special rollers whose rotating resistance can be adjusted to simulate friction losses and aerodynamic resistance using a chassis dynamometer, while inertial mass can be added to simulate the vehicle's weight. The required cooling is provided by a fan mounted a short distance from the vehicle. The measurements of emissions levels is based on a simulated driving pattern which progresses through a precise driving cycle incorporating various vehicle speeds. The testing is based on a standardised driving cycle in which gearshifts, braking, idle phases, and standstill periods have all been selected to provide a high level of correspondence with the velocities and acceleration that characterise typical driving in normal traffic. Usually, a driver sits in the vehicle to maintain the speed at levels indicated on a display screen .

The exhaust gasses produced in the course of this procedure are collected for subsequent analysis of pollutant mass. The manner in which exhaust gasses are collected and the procedures for determining emissions have largely been standardised in various countries, but the driving cycles have not. In some countries including Australia, regulations on exhaust emissions are supplemented by limits on evaporative-emissions losses from the fuel system (see Bosch Automotive Handbook, 1993). 
The spark ignition and light-duty diesel vehicles were tested over standard driving cycles used for the evaluation of gaseous emissions, under the Australian Design Rules ADR 27C and 37 which purport to replicate urban driving patterns. Two driving cycles are used in testing exhaust emissions. These cycles are CVS-C and CVS-CH driving cycles.

The driving cycle (CVS-C) is a 23-minute dynamometer-simulated city/urban driving schedule from a cold start (a cold transient segment lasting $505 \mathrm{~s}$. and the cold stabilised segment lasting $867 \mathrm{~s}$ ). The CVS-C cycle is specified in NSW Clean Air Regulations 26 (3) and is the same as that specified in Australian Design Rule ADR $27 \mathrm{~A} / \mathrm{B} / \mathrm{C}$, and the United States 1972 - Federal Test Procedure (FTP).

The CVS-CH cycle is a 23-minute dynamometer-simulated city/urban driving schedulc from a cold start followed by a 10-minute hot soak, a hot start and a repetition of the first 8.5 minutes of the driving schedule. The CVS-Ch cycle is specified in NSW Clean Air Regulations 26 (4) for application to cars manufactured on or after the first of January 1986, and is the same as that specified in Australian Design Rule ADR 37, and the United States 1975 - Federal Test Procedure (FTP).

Table 2.6 shows atypical ADR 37 test results for a number of unleaded spark ignition vehicles tested by the New South Wales State Pollution Control Commission in 1989.

Table 2.6 Gaseous emission rates for ADR 37 test cycle for (post1986) spark ignition vehicles used in SPCC, 1989 study.

\begin{tabular}{|c|c|c|c|c|c|}
\hline \multirow{2}{*}{ Make } & \multirow{2}{*}{ Model } & Capacity & $\mathrm{CO}$ & $\mathrm{NMHC}$ & $\mathrm{NO}$ \\
\cline { 3 - 6 } & & $($ litres $)$ & $\mathrm{g} / \mathrm{km}$ & $\mathrm{g} / \mathrm{km}$ & $\mathrm{g} / \mathrm{km}$ \\
\hline Ford & Falcon & 3.9 & 4.9 & 0.28 & 0.65 \\
\hline Ford & Fairlane & 3.9 & 3.50 & 0.41 & 0.59 \\
\hline Ford & Laser & 1.6 & 2.6 & 0.17 & 1.02 \\
\hline Holden & Commodore SE & 5.0 & 5.2 & 0.78 & 0.61 \\
\hline Holden & Astina & 1.8 & 4.5 & 0.30 & 0.48 \\
\hline Mitsubishi & Magna & 2.6 & 7.6 & 0.23 & 0.65 \\
\hline Mitsubishi & Lancer & 1.5 & 5.0 & 0.39 & 0.91 \\
\hline Mitsubishi & Colt & 1.6 & 2.9 & 0.17 & 1.03 \\
\hline Toyota & Corolla & 1.6 & 5.8 & 0.29 & 0.85 \\
\hline Toyota & Camry & 2.5 & 1.0 & 0.24 & 0.31 \\
\hline Nissan & Pintarta & 2.0 & 1.20 & 0.14 & 0.37 \\
\hline Hyundai & Sonata & 2.4 & 1.90 & 0.34 & 0.37 \\
\hline
\end{tabular}




\subsection{Pollutant concentrations: a combination of source intensity and meteorology}

Meteorology strongly influences the fate of a puff or plume of pollutant from the time it is emitted to the time it is detected at some other location. The motion of the air causes a dilution of air pollutant concentrations. The calculation of the resulting concentrations downwind of a given known source requires some knowledge of the elements of meteorology (Perkins, 1974).

If we consider a source of polluted gas having the same density as air at the ground or from a stack. Such source may emit for short times in "puffs" of pollution or may emit for large times as a plume. As the plume moves downwind, it grows through the action of the turbulent eddies and the concentration of a pollutant at a particular location under the plume depends on the sampling time. The rate at which the plume spreads is not only dependent on the intensity of the turbulence and the distribution of eddy sizes but also on dimension of the plume which depend on the travel time from the source. Scorer (1968) suggests, as a rule of thumb, that the appropriate sampling time is equal to about the time for the wind to carry the plume from the source to the point of observation. This point is important since the diffusion coefficients are tabulated for a particular averaging time.

According to the conservation principle, if the polluted gas is not absorbed in the atmosphere or at the ground, the mean volume of mass flow rate of the polluted gas is constant at all planes downwind placed normal to the mean flow. If the average concentration over the plume area, $S$, is $C_{a v}$ and the mean wind velocity parallel to the mean streamline is $\mathrm{u}$, the volume flow rate is, $\mathrm{Q}$, at a distance $\mathrm{x}$ from the source can be estimated as follows

$$
\mathrm{Q}=\mathrm{C}_{\mathrm{av}} \mathrm{u} \mathrm{S}
$$

$\mathrm{S}$ and $\mathrm{C}_{\mathrm{av}}$ can be precisely defined if the plume shape is known. As discussed earlier, the cross-wind area covered by a plume depends on the length of time that we observe the plume behaviour. For over short times the plume has a narrow, sinuous shape but over longer times the effects of eddies in the atmosphere is to broaden out the plume. It is assumed that the Gaussian model give a mathematical representation of the above physical behaviour. 
Assuming that the pollutant emitted at a height $\mathrm{h}$ and the plume shape is Gaussian shape (see Chapter 4) with dimensions $\sigma_{y}$ (the horizonal dispersion standard deviation) and $\sigma_{Z}$ (the vertical dispersion standard deviation) in the two direction normal to the mean streamline and assuming that the vertical diffusion becomes restricted by the ground and the pollutant is reflected back into the atmosphere. This leads to the following expression for the ground level concentration of the pollutant (Pasquill, 1974)

$$
C(x, y, z)=\frac{Q}{2 \pi \sigma_{y} \sigma_{z} u} \exp \left(\frac{-y^{2}}{2 \sigma_{y}^{2}}\right) \exp \left(\frac{-(z-h)^{2}}{2 \sigma_{z}^{2}}+\frac{-(z+h)^{2}}{2 \sigma_{z}^{2}}\right)
$$

The thickness of the plume expressed by $\sigma_{y}$ and $\sigma_{Z}$ increases with the downwind distance $x$, the rate of increase $\sigma_{y}$ and $\sigma_{z}$ is depending mainly on the stability of the atmosphere. In the case of low wind, the roughness of the ground (Table 2.7) affects the values of $\sigma_{y}$ and $\sigma_{z}$.

Table 2.7 Values of surface roughness length $\left(z_{0}\right)$ for various types of surfaces (from Zannetti, 1990).

\begin{tabular}{|l|c|}
\hline \multicolumn{1}{|c|}{ Type of surface } & $\mathrm{z}_{\mathrm{O}}(\mathrm{cm})$ \\
\hline Sand & $0.01-0.1$ \\
\hline Sea Surface & $0.0003 \mathrm{a}-0.5 \mathrm{~b}$ \\
\hline Snow Surface & $0.1-0.6$ \\
\hline Mown Grass (@ 0.01 m) & $0.1-1.0$ \\
\hline Low Grass, Steppe & $1.0-4.0$ \\
\hline Fallow Field & $2.0-3.0$ \\
\hline High Grass & $4.0-10.0$ \\
\hline Palmetto & $10.0-30.0$ \\
\hline Pine Forest (Mean height of trees: $15 \mathrm{~m}$; one tree per $\left.10 \mathrm{~m}^{2}\right)$ & $90.0-100.0$ \\
\hline Outskirts of Towns, Suburbs & $20-40$ \\
\hline Centres of Towns & $35-45$ \\
\hline Centres of Large Cities & $60-80$ \\
\hline
\end{tabular}

a: Wind speed at $10 \mathrm{~m}$ above surface $=1.5 \mathrm{~m} / \mathrm{sec}$.

$\mathrm{b}$ : Wind speed at $10 \mathrm{~m}$ above surface $>15 \mathrm{~m} / \mathrm{sec}$. 
Values of $\sigma_{\mathrm{y}}$ and $\sigma_{\mathrm{Z}}$ in (2.2) are traditionally obtained from curves of dispersion coefficient versus distance from the stack as a function of atmospheric stability. Thesc were first presented by Pasquill (1961) and modified by Turner (1970). Later versions of these curves have been presented by Smith (1972) and Pasquill (1974).

The three most common means of estimating the stability of the atmosphere are

1) wind speed and isolation (see Table 2.8),

2) the value of The standard deviation of the he horizontal wind direction fluctuations, $\sigma_{\theta}$ (see Table 2.9 and 2.10), and

3 ) the value of the vertical temperature gradient (see Table 2.9).

In this study we compare the predictions of ground level concentration from two Gaussian plume models (HIWAY-2 and CALINE4). HIWAY-2 uses values of $\sigma_{\mathrm{y}}$ and $\sigma_{\mathrm{Z}}$ from Pasquill-Gifford curves (1976) for downwind distance greater than 100 meters. For downwind distance less than 100 meters, Rao and Keenen (1980) modified the values of $\sigma_{\mathrm{y}}$ and $\sigma_{\mathrm{Z}}$ derived from Pasquill-Gifford curves (1976) by considering the effect of vehicle generated turbulence.

CALINE4 uses the vertical dispersion standard deviation, $\sigma_{\mathrm{Z}}$, from Pasquill-Smith vertical dispersion curves (Pasquill, 1974) after modifying it to incorporate the effects of both the vehicle-induced thermal turbulence and vehicle generated turbulence. The horizontal dispersion standard deviation, $\sigma_{\mathrm{y}}$, is obtained directly from the formulation due to Draxler (1976) in which

$$
\sigma_{y}=\sigma_{\theta} \times f\left(T / t_{L}\right)
$$

where $\sigma_{\theta}$ is the standard deviation of the horizontal wind direction fluctuations, $\mathrm{x}$ is the downwind distance, $\mathrm{T}$ is the travel time and $\mathrm{t}_{\mathrm{L}}$ is the Lagrangian time scale (The time interval between a step change in concentration input and the first observable corresponding change in response). CALINE4 uses Draxler's (1976) parameterization of $\mathrm{tL}_{\mathrm{L}}$ and his suggestion for the effect of wind shear on $\sigma_{\mathrm{Z}}$ at greater distances. Values for $\mathrm{t} L$ may be obtained by direct measurements or estimated by various methods (Hanna, 1983; Yamartino, 1984). 
Table 2.8 Meteorological Conditions Defining Pasquil Turbulence Types (from Zannetti, 1990).
A: Extremely unstable conditions
B: Moderately unstable conditions
C: Slightly unstable conditions
D: Neutral conditions
E: Slightly stable conditions
F: Moderately stable conditions

\begin{tabular}{|c|c|c|c|c|c|}
\hline \multirow{2}{*}{$\begin{array}{c}\text { Surface wind speed } \\
\mathrm{m} / \mathrm{sec}\end{array}$} & \multicolumn{3}{|c|}{ Day time insolation* } & \multicolumn{2}{c|}{ Night time conditions $^{* *}$} \\
\cline { 2 - 6 } & Strong & Moderate & Slight & $\begin{array}{c}\text { Thin overcast } \\
\text { or }>4 / 8 \\
\text { low cloud }\end{array}$ & $\leq 3 / 8$ \\
\hline$<2$ & A & A - B & B & & \\
\hline $2-3$ & A - B & B & C & E & F \\
\hline $3-4$ & B & B - C & C & D & E \\
\hline $4-6$ & C & C - D & D & D & D \\
\hline$>6$ & C & D & D & D & D \\
\hline
\end{tabular}

* Strong insolation corresponds to a solar elevation angle of $60^{\circ}$ or more above the horizon. Slight insolation corresponds to a solar elevation angle of $15^{\circ}$ to $35^{\circ}$.

** Pollutants emitted under clear night-time skies with winds less than $2.0 \mathrm{~m} / \mathrm{s}$, more recently defined to be class $G$, may be subject to unsteady meandering which renders the prediction of concentrations at downwind locations unreliable.

Table 2.9 Classification of atmospheric stability (data from DeMarrais, 1978; Best et al., 1986 ; and Hanna, 1989)

\begin{tabular}{|l|c|c|c|c|c|}
\hline $\begin{array}{c}\text { Stability } \\
\text { classification }\end{array}$ & $\begin{array}{c}\text { Pasquill } \\
\text { categories }\end{array}$ & $\begin{array}{c}\sigma_{\theta} \\
\text { (degrees) }\end{array}$ & $\begin{array}{c}\text { temperature } \\
\text { change with } \\
\text { height } \\
\left({ }^{\circ} \mathrm{C} 10^{-2} / \mathrm{m}\right)\end{array}$ & $\begin{array}{c}\text { gradient } \\
\text { Richardson } \\
\text { number } \\
\text { at } 2 \mathrm{~m}\end{array}$ & $\sigma_{\omega} / \overline{\mathrm{u}}$ \\
\hline Extremely unstable & $\mathrm{A}$ & 25.0 & $<-1.9$ & -0.9 & $>0.15$ \\
\hline Moderately unstable & $\mathrm{B}$ & 20.0 & -1.9 to -1.7 & -0.5 & $0.1-0.15$ \\
\hline Slightly unstable & $\mathrm{C}$ & 15.0 & -1.7 to -1.5 & -0.15 & $0.1-0.15$ \\
\hline Neutral & $\mathrm{D}$ & 10.0 & -1.5 to -0.5 & 0 & $0.05-0.1$ \\
\hline Slightly stable & $\mathrm{E}$ & 5.0 & -0.5 to 1.5 & 0.4 & $0.0-0.05$ \\
\hline Moderately stable & $\mathrm{F}$ & 2.5 & 1.5 to 4.0 & 0.8 & $0.0-0.05$ \\
\hline Extremely stable & $\mathrm{G}$ & 1.7 & $>4.0$ & 0.8 & $0.0-0.05$ \\
\hline
\end{tabular}

$\sigma \theta$ is the standard deviation of the horizontal wind direction fluctuations.

$\sigma_{\omega}$ is the standard deviation of the vertical wind speed fluctuations.

$\overline{\mathrm{u}}$ is the average downwind speed. 
Table 2.10 Classification of the atmospheric stability

( from U. S. EPA, 1986, adapted from Irwin, 1980 and Zannetti, 1990 )

\begin{tabular}{|c|c|c|}
\hline $\begin{array}{c}\text { Pasquil stability } \\
\text { categories }\end{array}$ & $\begin{array}{c}\text { Standard deviation of the } \\
\text { horizontal wind direction } \\
\text { fluctuations } \\
\sigma_{\theta} \text { (degrees) }\end{array}$ & $\begin{array}{c}\text { Standard deviation of the } \\
\text { vertical wind direction } \\
\text { fluctuations } \\
\sigma_{\mathcal{E}} \text { (degrees) }\end{array}$ \\
\hline A & Greater than 22.5 & Greater than 11.5 \\
\hline B & 17.5 to 22.5 & 10.0 to 11.5 \\
\hline C & 12.5 to 17.5 & 7.8 to 10.0 \\
\hline D & 7.5 to 12.5 & 5.0 to 7.8 \\
\hline E & 3.8 to 7.5 & 2.4 to 5.0 \\
\hline F & Less than 3.8 & Less than 2.4 \\
\hline
\end{tabular}

1. These criteria are appropriate for steady-state conditions, a measurements height of 10 $\mathrm{m}$, for level terrain, and an aerodynamic surface roughness length of $15 \mathrm{~cm}$.

2.A surface roughness factor of $\left(z_{0} / 15 \mathrm{~cm}\right)^{0.2}$, where $z_{0}$ is the average surface roughness in centimetres within a radius of $1-3 \mathrm{~km}$ of the source, may be applied to the Table values (Zannetti. 1990).

\subsection{Source models and dispersion models}

Source models are used to estimate pollution source strength which is a function of traffic speed, density, and flow, road gradient and orientation.

The most commonly-used approach for modelling motor vehicle emissions is to adjust emission data produced by subjecting vehicles to a standard driving cycle ( the standard Federal Test Procedure, FTP) and to adjust them to match the highway speed by means of a speed correction factor (the average vehicle speed is used as the sole descriptor for pollution levels). EMFAC7 methodology, developed by California Resources Board (1993), is the most widely used model based on the above mentioned approach. EMFAC7 methodology is discussed in more detail in Chapter 4.

In this study, a more realistic procedure based on the work of Kent et al., 1981 has been adopted here. In this approach, the total instantaneous power required to propel the vehicle along the road is taken as a basis for estimating the fuel consumption and emission rates at that instant. This approach has been modified and extended to include diesel vehicles as well as catalyst-equipped spark ignition vehicles (see Chapter 3). 
Dispersion models are used to: (1) simulate the road link which is a function of the number and width of the lanes, width of the median strip, road gradient and orientation: (2) modelling the dispersion of the pollution which is a function of the wind speed and direction, atmospheric stability, vehicle wake and local terrain. Because dispersion models require an estimation for the source strength, they are always used in conjunction with source emissions models. Models such as GM (Chock, 1977), HIWAY-2 (Petersen, 1980), CALINE3 (Benson, 1984), and ROADWAY (Eskridge, 1987) include aspects specific to roadways, such as enhanced mixing due to traffic movement, elevated roadways and intersections. Although these models perform adequately in open areas, the basic assumptions underlying the dispersion equations are not strictly applicable to complex urban terrains.

Dispersion models such as HIWAY (Zimmerman and Thompson, 1975), HIWAY-2 (Petersen, 1980), GM (Chock, 1977), CALINE2 (Ward et al., 1975), CALINE3 (Benson, 1980), CALINE4 (Benson, 1984), and ROADWAY (Eskridge, 1987) are discussed in detail in the following section (2.9).

\subsection{Previous field studies utilised to assess dispersion models}

In the last two decades, a large variety of computerised procedures for air quality assessment have been formulated. These procedures are the most widely adopted techniques which have been used to assess future road and building configurations against the National Air Quality Criteria (see Appendix B). Physical models, for example, are based on the physical principle of conservation of mass applied to the turbulent layer of air near the surface of the earth. They allow for chemical transportation of pollutants and for microscale time changes in meteorological conditions. Chemical sub-models of the boundary layer classes have been refined in the laboratory studies but little has been done to validate such schemes in the real atmosphere because of the numerous complexities involved (Taylor et al., 1988).

Statistical models take advantage of the information contained in existing data sets involving emissions and concentrations with or without meteorological factors. However, these models are unable to handle substantial changes in the amount or geographical distribution of pollutant emissions from the situation that prevailed during the data collection.

Mathematical models simulate traffic emissions as a series of line sources with subsequent dispersion of pollutants through turbulent atmospheric processes. 
Although numerous models which predict concentrations of vehicle-emitted pollutants along roadways may be used, the confidence held in the model predictions is limited by the extent to which their performances have been verified in real-world situations. Comparative field studies are an important tool to validate such models. One of the reasons for the lack of comparative field studies is the inability to determine the sources of errors which affect the comparison of observed and predicted concentrations of air pollutants. These sources of error may be measurement errors, inappropriate input data found in the field situation where control is difficult, and errors in the model itself.

Of these comparative field studies, one was conducted in September and October of 1975 in Milford, Michigan by General Motors (Cadle et al., 1976). The major objective of the General Motors Sulfate Dispersion Experiment was to investigate the validity of the Environmental Protection Agency's HIWAY dispersion model . Later, this experiment was used to investigate the validity of the California Department of Transport's CALINE dispersion model (Benson, 1992). Another field study was carried out in New York by the State Department of Environmental Construction (Sistla et al., 1979). The experimental data were used to assess numbers of Gaussian dispersion models such as HIWAY, GM, and CALINE-2. Watson, 1983, carried out a field study in Sydney to evaluate the ability of line source models to predict road-side concentrations of carbon monoxide at four different locations during the morning rush hours and neutral to stable meteorological conditions. Watson's field study was used to assess the performance of the GM Gaussian dispersion model . Gronskei, 1988, conducted a field study to evaluate the influence of car speed on the vertical dispersion of exhaust gases and to assess the performance of a Gaussian dispersion model (HWWAY-2). Gronskei's experiments were carried out using two gas tracers applied over a relatively flat snowcovered plain. Tracers were emitted from two moving vehicles in stable and near neutral conditions. Vertical distributions of tracer gases were obtained at 10,30 , and $70 \mathrm{~m}$ downwind of the road using 5 and $10 \mathrm{~m}$ towers.

A number of Gaussian dispersion models were assessed in the above mentioned field studies. These models are HIWAY (Zimmerman and Thompson, 1975), HIWAY-2 (Petersen, 1980), GM (Chock, 1977), CALINE2 (Ward et al., 1975), CALINE3 (Benson, 1980), CALINE4 (Benson, 1984), and ROADWAY (Eskridge, 1987).

HIWAY model (Zimmerman and Thompson, 1975) is basically a Gaussian dispersion model, designed for estimation of dispersion in a stationary atmosphere. For a continuous line source, such as a roadway, the model assumes that the concentration at a point is the summation of contributions from an infinite number of point sources which make up the line source. For such a continuous point source located at $(0,0, \mathrm{~h})$ with the 
emission rate of $\mathrm{Q}$, the concentration $\mathrm{C}(\mathrm{x}, \mathrm{y}, \mathrm{z})$ at coordinate $(\mathrm{x}, \mathrm{y}, \mathrm{z})$ is given by equation (2.2). In equation (2.2), the wind speed is $u$, the wind direction is along the $x$ axis (perpendicular wind), and $\sigma_{y}$ and $\sigma_{z}$ are, respectively, the horizontal crosswind and vertical dispersion parameters.

The HIWAY model uses the dispersion parameters of Pasquill-Gifford (Turner, 1970) and extrapolates the values at $100 \mathrm{~m}$ back to the emission source. These dispersion parameters are a function of stability and downwind distance. Initial values of $3 \mathrm{~m}$ and $1.5 \mathrm{~m}$ are assigned for $\sigma_{y}$ and $\sigma_{Z}$, respectively, for all stability classes to account for the initial mixing due to the traffic wake.

Although HIWAY model maintains conservation of mass, it does not take proper account of ambient wind shear generated turbulence in traffic wake and the buoyancy effects due to the heat generated by the traffic. The model also assumes that the traffic in the downwind lanes does not affect the dispersion from the traffic in the upwind lanes. Since the concentration is inversely related to wind speed (Equation 2.2), the concentration is predicted to go to infinity as wind speed goes to zero, which suggests that the model will not be applicable at low wind speed.

Previous investigations by Chock, 1977), Noll et al., 1978, Sistla et al., 1979, and Rao, et al., 1980 indicated that the HIWAY model significantly overestimates the pollutant concentrations adjacent to the highway, especially under stable atmospheric conditions and for parallel wind-road orientation angles with low wind speed. This overestimation is due to the fact that the model's dispersion parameters do not properly account for the traffic induced turbulence near roadways. Also, the overestimation may be attributed to either the low wind speed or the orientation of the wind-road angle (parallel wind) or to the both. Rao,et al., 1979 and Eskridge et al., 1979 demonstrated that the dispersion in the near-field is completely dictated by the locally generated turbulence, and that the ambient atmospheric stability pays an insignificant role in dispersing pollutants in the immediate vicinity of the roadway.

Rao et al., 1980 addressed two possible ways to modify the line source dispersion equation used in the HIWAY model to account for the enhanced dispersion due to traffic flow by the application of an aerodynamic drag factor and the application of a new set of dispersion curves that properly reflect the turbulence characteristics adjacent to the roadway. HIWAY-2 (Petersen, 1980), the developed version of the original HIWAY, replaces Pasquill-Gifford curves (Turner, 1970) with new dispersion curves applicable for pollutant dispersion estimation near roadways based on the data collected in the General Motors study (Chock et al., 1976) and in the New York State Study (Sistla et 
al., 1978). Downwind diffusion is a function of initial diffusion and stability class (three stability regimes are utilised to characterise downwind diffusion). Further, the initial spread has incorporated in it a vehicle-induced drag factor that accounts for the initial dilution of the pollutant over the roadway, and allows the model to make reasonable estimates of concentrations when the wind speed is low and the wind direction is parallel to the roadway (see Chapter 4 ).

The GM model (Chock, 1978) is a Guassian simple line-source model developed to estimate emissions concentrations downwind of a roadway once total emissions. wind orientation with respect to the roadway, wind speed and atmospheric stability are known. Pollutant concentrations are computed from the expression,

$$
C(x, z)=\frac{Q}{\sqrt{2} u \sigma_{z}}\left\{\exp \left[-\frac{1}{2}\left(\frac{\underline{z}+\underline{h}}{\sigma_{z}}\right)^{2}\right]+\exp \left[-\frac{1}{2}\left(\frac{z-h}{\sigma_{z}}\right)^{2}\right]\right\}
$$

and

$$
h_{p}=\left[\frac{R g\left(\rho_{o}-\rho\right)}{\alpha \rho_{o} u^{2}}\right]^{0.5} x
$$

where $\mathrm{Q}$ is the emission rate per unit length, $\mathrm{u}$ is the effective crosswind speed plus a correction factor determined according to the stability, and $\mathrm{h}$ is the plume-centre height ( $h$ is the sum of the height of emission and the plume rise, $h_{p}$ ), $\rho$ and $\rho_{o}$ are densities of the plume and ambient air respectively, $\alpha$ is an entrainment coefficient, and $R$ is the plume width. The vertical dispersion is given by

$$
\sigma_{Z}=(A+B f(\theta) x)^{C}
$$

where

$$
f(\theta)=1+\beta\left|\frac{\theta-90^{o}}{90^{\circ}}\right|^{\gamma}
$$

$\theta$ is the wind angle relative to the road, $A, B, c, \alpha, \beta$, and $\gamma$ are empirically-derived parameters, and $\mathrm{x}$ is the distance between the lane centre and where the concentration is desired to be known. The parameters $A, B, C, \beta$, and $\gamma$ are determined according to stable $\left(R_{i}>0.07\right)$, neutral $\left(0.07>R_{i} \geq-0.1\right)$, and unstable $\left(R_{i} \leq-0.1\right)$ conditions (where $\mathrm{R}_{\mathrm{i}}$ is the Richardson number) (see Chock, 1978). 
Chock, 1978 suggests that the advantages of GM model over the similar models such as HIW AY model are that the predicted concentration does not become infinite as the wind speed approaches zero. It allows for the plume rise due to the heated exhaust, which can be important at a very low crossroad wind, and it utilises a new set of vertical dispersion parameters which reflect the influence of traffic-induced turbulence.

The first version of the California Line Source Dispersion Model series, CALINE, was published by Beaton et al., 1972. It consisted of a series of tables and nomographs that enabled the user to predict $\mathrm{CO}$ concentrations near roadways based on estimated meteorology and traffic. The transport and dispersion element of the model was a modified form of the Gaussian point source plume dispersion model.

Ward et al., 1975 replaced the original model with a FORTRAN version, CALINE2. The new model was able to compute concentrations for depressed sections and for winds parallel to the roadway. However studies indicated that CALINE2 overpredicted concentrations for stable, parallel wind conditions (Noll et al., 1978; Bensen et al., 1979). CALINE2 neglected to adjust its modified Pasaquill-Gifford horizontal dispersion curves for average time. The model also was unable to handle multiple line sources and to modify dispersion parameters for surface roughness.

Benson, 1980 developed the third version of the model, CALINE3, that retained the basic Gaussian dispersion methodology, but used new vertical and horizontal dispersion curves modified for the effects of the surface roughness, averaging time, and vehicleinduced turbulence. Benson also replaced the virtual point source representation used in CALINE2 with an equivalent finite line source, and added multiple link capabilities to the model format.

CALINE4 is the most recent version of the CALINE series (Benson, 1984). It represents a refinement and extension of the capabilities contained in CALINE3. Concentrations of $\mathrm{CO}, \mathrm{NO}_{2}$, and aerosols can be predicted by the model. An option for modelling intersections has been added. The model employs a modified Gaussian plume approach similar to the one used in CALINE3, but with new provisions for lateral plume spread and vehicle-induced turbulence. Sub-models for $\mathrm{CO}$ model emissions and reactive plume chemistry are included (see Chapter 4 ).

The ROADWAY model (Eskridge, 1987) is a numerical model which solves a conservation of species equation to predict pollutant concentrations within two hundred meters of a highway. It uses surface layer similarity theory to predict ambient wind and 
eddy diffusion profiles. A unique feature of the model is its use of vehicle wake theory. In the model, it is assumed that the vehicle wake effects are additive to the ambient wind and turbulence fields with wake intensity a function of vehicle speed, downwind distance, and distance from the wake centre. Because the ROADWAY model incorporates the vehicle wake theory, it is capable of assessing the impact of different vehicle speeds on ambient air quality.

In Gaussian type highways models such as HIWAY-2 and CALINE3, the predicted turbulence fields are not dependent on vehicle speed. The aerodynamic drag factor incorporated in HIWAY-2 allows the model to make reasonable estimates under low wind speed conditions. However, the empirical constant used in the aerodynamic drag factor was developed for moderate to high traffic speeds.

Eskridge et al., 1991 found that pollutant concentrations predicted by the ROADWAY model near highways were a function of vehicle speed and in agreement with the experimental results of the Norwegian Field Experiments carried out by Gronskei, 1988. The effect of vehicle speed was more significant during stable atmospheric conditions. On the other hand, Eskridge et al., 1991 compared the predicted concentrations with the experimental data of the New York State Study (Sistla et al., 1978) and found that the ROADWAY model predicted a smaller effect of vehicle speed on the concentration pattern when the atmosphere was neutral or unstable. The New York State Study did not provide sufficient data to assess the model predictions of the traffic speed effect during stable conditions. When the atmosphere is neutral or unstable, It was demonstrated that the Gaussian dispersion models such as HWAY-2 and CALINE3 should be sufficiently accurate. However, when the atmosphere is extremely stable, the traffic-induced turbulence will dominate the near field diffusion.

\subsubsection{General Motors Sulfate Dispersion Experiment}

In the General Motors Sulfate Dispersion Experiment, a fleet of 352 catalyst equipped automobiles were driven on a north-south track of $10 \mathrm{~km}$ length for 17 days during the morning hours. The cars ran for two hours at a speed of $80 \mathrm{~km} / \mathrm{h}$, which is equivalent to traffic density of 5500 vehicles per hour on a four lane highway. The gasoline used by the cars was unleaded and was blended to contain 0.03 sulfur by weight (See Cadle et al., (1976), for a complete description of the experiment and analysis procedure).

Meteorological instruments and chemical samplers were located on six towers and two stands $2.4 \mathrm{~km}$ north of the south end of the test track. Wind speeds from 20 Gill VUW anemometers were recorded once per second. The wind instruments were located on the 
towers approximately 1. 5, 4.4 and $10.44 \mathrm{~m}$ above the surface and the syringe samplers used to sample sulfur hexafluoride gas $\left(\mathrm{SF}_{6}\right)$ were located at $0.5,3.5$ and $9.5 \mathrm{~m}$ above the surface. Temperature data were recorded from towers 1 and 6 every 5 seconds using Rosemount Model single element, platinum-resistance thermometers mounted in Model 43404 Gill aspirated temperature shields. The temperature instruments were located approximately at the same heights as the VUW instruments.

Convoys of 22 cars were spaced $300 \mathrm{~m}$ apart with the lead car travelling $80 \mathrm{~km} / \mathrm{h}$. Uniformly distributed through the 16 convoys were seven or eight pickup trucks that released sulfur hexaflouride tracer gas $\left(\mathrm{SF}_{6}\right)$. Sampling began approximately five minutes after the vehicles started around the track. Four sequential samples, each taken over a 30 min period, were analysed for $\mathrm{SF}_{6}$ at each observation point. Sampling of sulfur hexafluoride gas $\left(\mathrm{SF}_{6}\right)$ was accomplished using a modified Developmental Science syringe sampler which collected a $30 \mathrm{~cm}^{3}$ sample in a $30 \mathrm{~min}$ period. The samples were analysed using an automatic dual-column gas chromatography equipped with electron capture detectors.

The mass flow rate of catalyst-generated particulate sulfur across a plane $15 \mathrm{~m}$ from the edge of the road was measured. The fine particulate sulfur concentration was determined at five heights above the ground at a distance of $15 \mathrm{~m}$ from the road. One sampler was located $30 \mathrm{~m}$ west of the roadway at a height of $1 \mathrm{~m}$ and five samplers were located $15 \mathrm{~m}$ east the roadway at height of $1.0,1.9,3.9,5.6$, and $8.2 \mathrm{~m}$. One to four additional samplers were operated at various height and distances from the roadway. The details of methodology for determining background sulfate, sulfate emissions, and SF6 emission rate were given in Cadle et al., 1976.

The major objective of the General Motors Sulfate Dispersion Experiment was to investigate the validity of the HIWAY dispersion model (see 2.8).

The parameters required for using HIWAY model to make prediction for the GM sulfate Dispersion Experiment were the values of atmospheric stability, wind speed, and wind direction. These parameters were chosen for each experimental run as follows

The stability classes were classified according to Golder, 1972 who suggested a procedure to determine the stability classification directly from the roughness length and Monin-Obukhov length, L', which can be estimated from the measurements. The roughness length at the test site (determined under near neutral conditions, assuming a homogeneous surface layer) is about $3 \mathrm{~m}$. The Monin-Obukhov length, L', can be 
estimated from measurements of gradients of temperature and wind speed and friction velocity, $\mathrm{u}^{*}$ as follows

$$
\mathrm{L}^{\prime}=\frac{\mathrm{u}^{*} \frac{\partial \overline{\mathrm{u}}}{\partial \mathrm{z}}}{\frac{\mathrm{g}}{\mathrm{T}} \frac{\partial \overline{\mathrm{T}}}{\partial \mathrm{z}}}
$$

where $u^{*}$ is the friction velocity $\left(u^{*}\right.$ is a function of wind speed and stability. According to Panofsky and Prasad, 1964, $\mathrm{u}^{*}$ was estimated using the wind measurement at $1.5 \mathrm{~m}$ near the ground under neutral conditions ), $\partial \overline{\mathrm{u}} / \partial z$ and $\partial \overline{\mathrm{T}} / \partial z$ are, respectively, the vertical gradients of mean wind and temperature, and $g$ is the acceleration of gravity. Golder, 1972 used the reciprocal of the Monin-Obukhov length, L', in his stability classification.

Although the wind speed in the atmospheric surface layer increases with height, Turner, 1970 suggested using the mean wind speed within $2 \sigma_{Z}$ of downwind distance. For transport distances between 0.1 and $1 \mathrm{~km}$, the wind speed at a height of $10 \mathrm{~m}$ is generally used (Pasquill, 1974). No suggestions were made for distances less than $100 \mathrm{~m}$. Since wind measurements were made at heights of $1.5,4.5$, and $10.5 \mathrm{~m}$ in the GM sulfate Dispersion Experiment, the wind speed and direction at $4.5 \mathrm{~m}$ were chosen to represent the ambient surface wind.

Comparison of HIWAY predictions for the sulfate with measured values of both the sulfate and $\mathrm{SF}_{6}$ indicated that under unstable conditions, the model predictions were fairly accurate, except for a general tendency of overpredictions at low wind speeds. Under neutral and stable conditions, not only did the above tendency persist, but the model also overpredicted at the bottom level $(0.5 \mathrm{~m})$ and underpredicted at the top level $(9.5 \mathrm{~m})$ as shown in Table $2.11(\mathrm{a}, \mathrm{b}$, and $\mathrm{c})$.

The comparison of the predicted and measured values of run 2960805 (Table 2.11(b)) showed that the Guassian model predicted very high roadside concentrations when the wind is almost parallel to the roadway. In this case, the wind direction was $181.4^{\circ}$ or $1.4^{\circ}$ with upwind traffic, and the stability was class F. During run 2950809 (Table $2.11(\mathrm{c}))$ there was a strong temperature inversion and very low wind speed. There were substantial overpredictions at the two lower levels downwind. For the bottom level of tower 1 , the overprediction was by a factor more than 50 . The measured concentrations increased with increasing height on this tower, while the HIWAY model assumes no 
Table 2.11 Comparison between measured and predicted sulfate and SF6 concentrations $\left(\mu \mathrm{g} / \mathrm{m}^{3}\right)$ for three runs from the GM sulfate Dispersion Experiment (model calculations from HIWAY) (Source: Chock, 1977).

(a) Run 2790809

\begin{tabular}{|c|c|c|c|c|c|c|c|c|}
\hline $\begin{array}{l}\mathrm{Ht} \\
(\mathrm{m})\end{array}$ & Site (1) & $\begin{array}{l}\text { Site (2) } \\
\text { Roadway }\end{array}$ & $\begin{array}{l}\text { Site (3) } \\
\text { Roadway }\end{array}$ & Site (4) & Site (5) & Site (6) & \multirow{2}{*}{\multicolumn{2}{|c|}{$\begin{array}{l}\text { wind: } 1.00 \mathrm{~m} / \mathrm{s}, 251.1^{\circ} \\
\text { Stability: Class } \mathrm{F} \\
\text { Emis. rate: } 6.65 \\
\mu \mathrm{g} / \mathrm{m} / \mathrm{s} \\
\text { m. sulfate }\left(\mathrm{m} . \mathrm{SF}_{6}\right)\end{array}$}} \\
\hline 9.5 & $\frac{0.1(0)}{0}$ & $\frac{2.4(0)}{0}$ & $\frac{0(0)}{0}$ & $\frac{2.6(0.4)}{0}$ & $\frac{0(1.0)}{0}$ & $\frac{1.1(1.2)}{0}$ & & \\
\hline 3.5 & $\frac{1.0(0)}{0}$ & $\frac{1.0(0.2)}{0}$ & $\frac{2.4(2.7)}{0.9}$ & $\frac{2.2(3.8)}{2.2}$ & $\frac{1.3(3.8)}{2.7}$ & $\frac{2.0(3.2)}{3.3}$ & Predict & d sulfate \\
\hline 0.5 & $\frac{0(0)}{0}$ & $\frac{2.0(4.2)}{0}$ & $\frac{5.6(4.1)}{6.1}$ & $\frac{5.6(4.1)}{11.4}$ & $\frac{6.9(4.8)}{10.3}$ & $\frac{3.4(3.6)}{9.1}$ & $\frac{2.3(2.8)}{8.0}$ & $\frac{2.3(2.8)}{6.1}$ \\
\hline
\end{tabular}

(b) Run 2960805

\begin{tabular}{|c|c|c|c|c|c|c|c|}
\hline $\begin{array}{l}\mathrm{Ht} \\
(\mathrm{m})\end{array}$ & & $\begin{array}{l}\text { Site (2) } \\
\text { Roadway }\end{array}$ & $\begin{array}{l}\text { Site (3) } \\
\text { Roadway }\end{array}$ & Site (4) & Site (5) & Site (6) & \multirow{2}{*}{$\begin{array}{l}\text { wind: } 2.92 \mathrm{~m} / \mathrm{s}, 181.4^{\circ} \\
\text { Stability: Class F } \\
\text { Emis. rate: } 6.69 \mu \mathrm{g} / \mathrm{m} / \mathrm{s} \\
\text { m. sulfate }\left(\mathrm{m} . \mathrm{SF}_{6}\right) \\
\end{array}$} \\
\hline 9.5 & $\frac{0.1(0.7)}{1.2}$ & $\frac{3.3(1.6)}{4.6}$ & $\frac{0.4(2.4)}{7.2}$ & $\frac{3.6(2.2)}{8.1}$ & $\frac{1.1(2.3)}{7.0}$ & $\frac{1.8(1.4)}{4.1}$ & \\
\hline 3.5 & $\frac{2.0(0.6)}{1.5}$ & $\frac{1.8(2.5)}{10.4}$ & $\frac{4.8(4.3)}{16.5}$ & $\frac{2.8(4.1)}{17.2}$ & $\frac{1.3(3.3)}{10.9}$ & $\frac{0.9(1.9)}{6.6}$ & Predicted sulfate \\
\hline 0.5 & $\frac{0.4(0.6)}{1.5}$ & $\frac{3.6(4.8)}{15.3}$ & $\frac{8.1(5.1)}{21.4}$ & $\frac{5.6(4.1)}{22.6}$ & $\frac{5.6(3.5)}{12.0}$ & $\frac{2.5(1.8)}{7.0}$ & $\frac{1.0(1.0)}{3.9}$ \\
\hline
\end{tabular}

(c) Run 2950809

\begin{tabular}{|c|c|c|c|c|c|c|c|}
\hline $\begin{array}{l}\mathrm{Ht} \\
(\mathrm{m})\end{array}$ & Site (1) & $\begin{array}{l}\text { Site (2) } \\
\text { Roadway }\end{array}$ & $\begin{array}{l}\text { Site (3) } \\
\text { Roadway }\end{array}$ & Site (4) & Site (5) & Site (6) & \multirow{2}{*}{$\begin{array}{l}\text { wind: } 0.45 \mathrm{~m} / \mathrm{s}, 51.4^{\circ} \\
\text { Stability: Class F } \\
\text { Emis. rate: } 7.42 \mu \mathrm{g} / \mathrm{m} / \mathrm{s} \\
\text { m. sulfate }\left(\mathrm{m} . \mathrm{SF}_{6}\right)\end{array}$} \\
\hline 9.5 & $\frac{4.2(4.5)}{0.1}$ & $\frac{3.1(3.0)}{0}$ & $\frac{1.7(1.2)}{0 .}$ & $\frac{2.1(0.1)}{0}$ & $\frac{0.3(0)}{0}$ & $\frac{0.3(0)}{0}$ & \\
\hline 3.5 & $\frac{4.3(3.6)}{10.4}$ & $\frac{4.8(5.6)}{6.7}$ & $\frac{1.9(3.5)}{2.9}$ & $\frac{1.5(1.1)}{0}$ & $\frac{0(0)}{0}$ & $\frac{0(0)}{0}$ & Predicted sulfate \\
\hline 0.5 & $\frac{0(0.5)}{25.5}$ & $\frac{8.7(8.6)}{33.7}$ & $\frac{6.3(4.8)}{17.9}$ & $\frac{2.4(2.4)}{0.02}$ & $\frac{0(0)}{0}$ & $\frac{0(0)}{0}$ & $\frac{0.1(0)}{0}$ \\
\hline
\end{tabular}


rising of the plume. The temperature data (Cadle et al., 1976) indicated that this plume rise was induced by the heated exhaust. It was noted that at the bottom level of the downwind roadside tower, the Guassian model tended to underpredict for class B and overpredict for classes $\mathrm{E}$ and $\mathrm{F}$, which indicated that the vertical dispersion parameter, $\sigma_{\mathrm{Z}}$, was too large for class $\mathrm{B}$ and too small for classes $\mathrm{E}$ and $\mathrm{F}$. When the wind was less that $20^{\circ}$ or greater than $140^{\circ}$ relative to the upwind traffic direction, the model overpredicted by at least a factor of two for classes D, E, and F, and by at least $20 \%$ for classes B and C. Wind less than $2 \mathrm{~m} / \mathrm{s}$ also resulted in overprediction while higher wind speeds resulted in underprediction. On moving away from the roadway at the height 0.5 $\mathrm{m}$, the tendency of the model to overestimate was not serious for classes $\mathrm{B}$ and $\mathrm{C}$, but got worse for class $F$ (for class $F$, the overestimates at $30 \mathrm{~m}$ downwind from the road were 1.5 to 2 times worse than those at $0.5 \mathrm{~mm}$ level at the roadside tower). At higher levels near the roadway, the HIWAY model severely underpredicted the concentrations for classes $\mathrm{D}, \mathrm{E}$, and $\mathrm{F}$ due to the overrestrictive $\sigma_{\mathrm{Z}}$. Further downwind, the crossover point between overprediction and underprediction increased in height (Chock, 1977).

As a conclusion of the analysis of the General Motors Sulfate Dispersion Experiment, Chock, 1970 addressed many limitations in the applicability of the HIWAY model. In particular, under the worst meteorological conditions (conditions of extreme stability and very low wind speed), variable wind at different levels, and plume rise from the heated exhaust render that the model completely useless in estimating dispersion. Under adverse meteorological conditions with nonparallel wind relative to the road, the model overpredicted the downwind lower level concentrations and the degree of overprediction worsened as the distance from the roadway increased. At higher levels $(\geq 4.5 \mathrm{~m})$, the model underpredicted the concentrations near the roadway and overpredicted further downwind. When the wind was essentially parallel to the road, overpredictions resulted at all sampling sites. It was obvious that the dispersion parameters are overrestrictive for adverse meteorological conditions.

Chock, 1970 developed a new vertical dispersion parameters for stable, neutral, and unstable conditions. Figure 2.8 shows a comparison between the newly developed vertical dispersion parameters for stable, neutral, and unstable conditions with those used in the HIWAY model .

It was noted that the initial dispersion parameters in Figure 2.8 were all comparable, whereas at $100 \mathrm{~m}$ the values derived from the experiment fell between those for class $B$ and class $\mathrm{C}$ (unstable conditions) of the HIWAY model. For the first $50 \mathrm{~m}$ there is little distinction among different stabilities because of the fact that downwind from the road, 


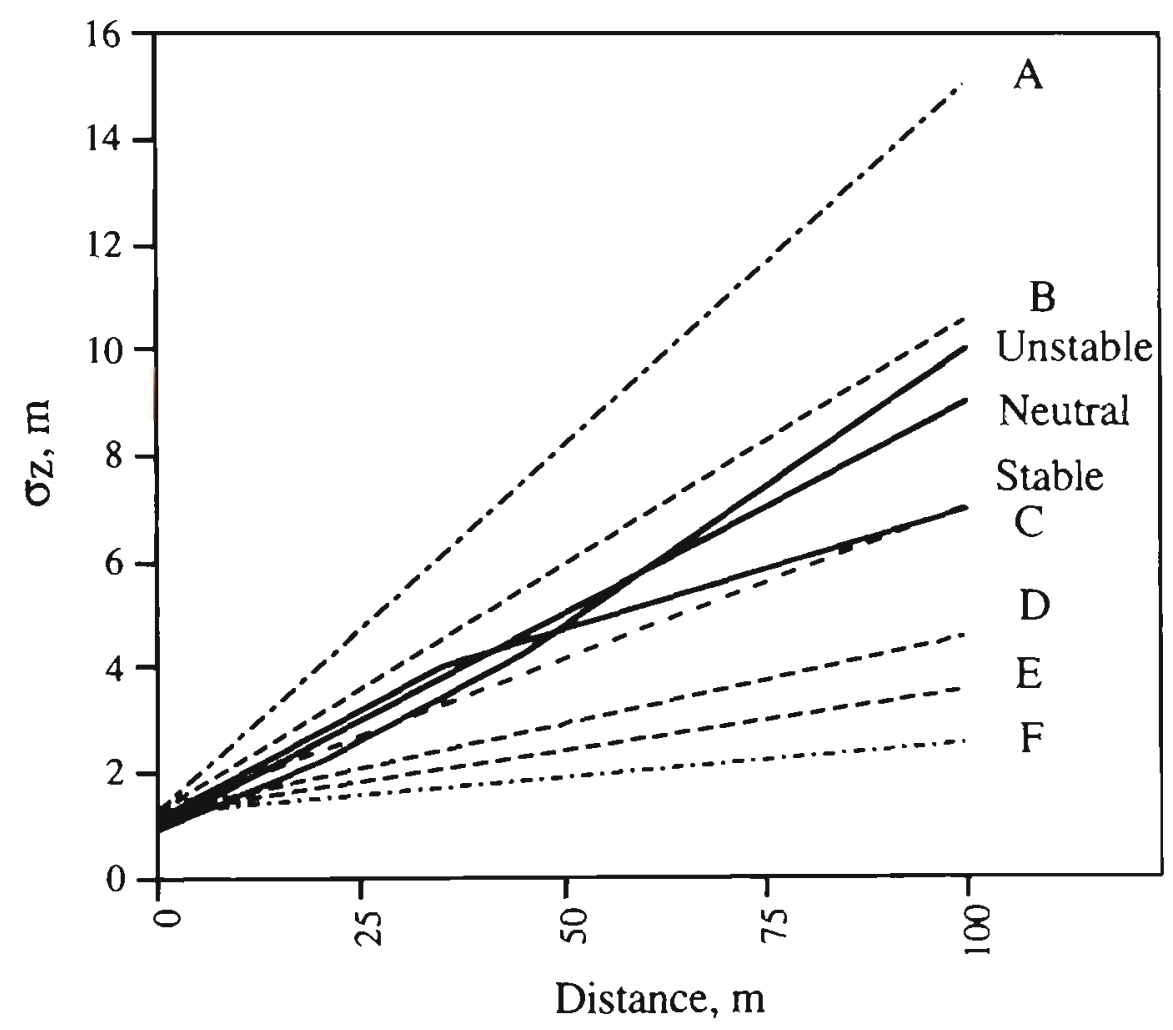

Figure 2.8 $\sigma_{Z}$ as a function of downwind distance. The solid lines were estimated from the measurements of the measurements data of the General Motors Sulfate Dispersion Experiment and the dotted lines are used by the HIWAY model. The stability classes are indicated (Chock, 1977).

and mechanical mixing dominates the mixing induced by the stability considerations. The fact that the values derived from the experiment fall between those for class $B$ and class $C$ rather than close to class $D$ could be due to the initial mixing which effectively simulates a vertically extended source.

The outcome of the analysis of the General Motors Sulfate Dispersion Experiment led to the development of GM model (Chock, 1978).

\subsubsection{Study of Pollutant Dispersion Near Highways}

As a part of a major roadway dispersion project undertaken by the New York State Department of Environmental Conservation (Sistla et al., 1979), several tracer release experiments were conducted along the Long Island Expressway near New York. Sufficiently detailed pollutant, traffic and meteorological data were collected. Wind flow characteristics adjacent to the road way were analysed to identify how traffic modifies the 
flow due to turbulent eddy generation and changes in effective roughness. The tracer gas concentrations observed downwind of the line source were compared with those predicted by four Gaussian models, HIWAY, GM, AIR POL-4, CALINE-2. The simulation capability of each model was discussed. The dispersion parameters in two of the Gaussian models (HIWAY and GM) were compared with those obtained by solving the Gaussian equation for known source strength, meteorological conditions and measured concentrations of tracer gas.

The section of the selected roadway had three lanes in each direction separated by a wide median strip and had an annual average daily traffic volume in excess of 100,000 vehicles. The surrounding terrain was relatively flat in the vicinity of the sampling plan. A comprehensive sampling network was employed to monitor wind speed and direction, air quality, traffic and temperature structure (Sistla et al., 1979).

Measurements of source strength were made using sulphur hexafluoride gas, $\mathrm{SF}_{6}$, as a tracer gas on the expressway. The simulation of the line source was achieved by releasing the gas at a constant rate near the tail pipes of six station wagons which were driven in the middle lane at $88 \mathrm{~km} / \mathrm{h}$ in both directions. A total of 23 tracer runs were made over a period of three weeks. The runs reflect a wide range of wind speeds and directions (Rao et al., 1978b).

Four Gaussian models, HIWAY, GM, CALINE-2, and AIR POL-4 were used in this study. The first thee Gaussian models, HIWAY, GM, and CALINE-2, were discussed above, the fourth model, AIR POL-4 (Carpenter and Clemena, 1975), is based on a Gaussian formulation (see Chapter 4). The model uses two Euclidean coordinate systems, namely the roadway and receptor coordinate system. The model can predict pollutant levels for all wind speeds $(\geq 0)$, for any sampling interval, and for all traffic speeds $(\geq 0)$. The dispersion parameters $\sigma_{y}$ and $\sigma_{z}$ are incorporated in the model following the procedure used in HIWAY (Zimmerman and Thompson, 1975).

Pasquill-Turner stabilities were determined for the periods of interest from the routine cloud cover and wind speed measurements taken at the Islip Airport located about $25 \mathrm{~km}$ from the experimental site. Stability estimates indicated most runs to be in neutral stability while stability parameters, such as the Bulk Richardson number, wind angle fluctuations and vertical temperature gradients based on data observed at the site, indicated most run periods to be under unstable conditions. This would seem that local generated turbulence modifies the ambient conditions and tend to decrease the atmospheric stability adjacent to the highway. All the models were run for both neutral and unstable stability conditions (stabilities D and B, respectively, according to the Pasquill-Tumer classification). 
The SF6 runs were divided into three sets, perpendicular (winds $60-900$ from the axis of the highway), oblique ( $30-60^{\circ}$ from the axis), and parallel (0-30 from the axis). For each set of wind-road orientations, linear regression analysis was performed between the measured concentrations and those predicted by each model. The results of these regressions for Gaussian models are listed in Table 2.12.

Table 2.12 Statistical results of linear regression between observed $\mathrm{SF}_{6}$ concentrations and predicted concentrations of all Guassian models for perpendicular, oblique, and parallel wind-road orientation angles. (Source: Sistla et al., 1978)

\begin{tabular}{|c|c|c|c|c|c|c|c|c|c|}
\hline \multirow[t]{2}{*}{ WRA } & \multirow[t]{2}{*}{ SP } & \multicolumn{2}{|c|}{ HIW AY } & \multicolumn{2}{|c|}{ GM } & \multicolumn{2}{|c|}{ CALINE-2 } & \multicolumn{2}{|c|}{ AIRPOL-4 } \\
\hline & & Neutral & Unstable & Neutral & Unstable & Neutral & Unstable & Neutral & Unstable \\
\hline \multirow{4}{*}{$\begin{array}{c}60^{\circ} \\
\text { to } \\
90^{\circ}\end{array}$} & $\mathrm{r}^{2}$ & 0.73 & 0.87 & 0.88 & 0.86 & 0.74 & 0.66 & 0.61 & 0.70 \\
\hline & b & 0.45 & 0.71 & 0.91 & 1.01 & 1.07 & 1.16 & 1.09 & 1.93 \\
\hline & $\mathrm{a}$ & 0.95 & 0.61 & 0.43 & 0.44 & 0.03 & 0.31 & 0.38 & -0.28 \\
\hline & $\mathrm{s}_{\mathrm{O}} / \mathrm{p}$ & 1.09 & 0.76 & 0.73 & 0.78 & 1.07 & 1.23 & 0.34 & 1.18 \\
\hline \multirow{4}{*}{$\begin{array}{c}30^{\circ} \\
\text { to } \\
60^{\circ}\end{array}$} & $\mathrm{r}^{2}$ & 0.55 & 0.74 & 0.75 & 0.76 & 0.51 & 0.52 & 0.66 & 0.78 \\
\hline & $\mathrm{b}$ & 0.42 & 0.76 & 0.88 & 1.01 & 0.54 & 1.49 & 0.90 & 2.22 \\
\hline & $\mathrm{a}$ & 0.70 & 0.32 & 0.24 & 0.26 & 0.25 & -0.03 & 0.05 & -0.72 \\
\hline & $\mathrm{s}_{\mathrm{O}} / \mathrm{p}$ & 1.15 & 0.88 & 0.85 & 0.84 & 1.20 & 1.19 & 1.00 & 0.81 \\
\hline \multirow{4}{*}{$\begin{array}{c}0^{\circ} \\
\text { to } \\
30^{\circ}\end{array}$} & $\mathrm{r}^{2}$ & 0.50 & 0.67 & 0.89 & 0.92 & 0.49 & 0.45 & 0.72 & 0.69 \\
\hline & $\mathrm{b}$ & 0.14 & 0.40 & 0.71 & 0.91 & 0.29 & 0.83 & 0.65 & 1.68 \\
\hline & $\mathrm{a}$ & 1.92 & 1.33 & 0.32 & 0.45 & 1.21 & 1.11 & 0.56 & 0.42 \\
\hline & $s_{0} / p$ & 1.65 & 1.34 & 0.76 & 0.64 & 1.68 & 1.74 & 1.24 & 1.31 \\
\hline \multirow{4}{*}{ All } & $r^{2}$ & 0.45 & 0.70 & 0.83 & 0.86 & 0.41 & 0.54 & 0.62 & 0.72 \\
\hline & $\mathrm{b}$ & 0.19 & 0.52 & 0.76 & 0.96 & 0.34 & 1.03 & 0.73 & 1.91 \\
\hline & $\mathrm{a}$ & 1.67 & 0.97 & 0.48 & 0.39 & 1.25 & 0.61 & 0.62 & -0.19 \\
\hline & $\mathrm{s}_{\mathrm{O}} / \mathrm{p}$ & 1.53 & 1.13 & 0.86 & 0.77 & 1.58 & 1.40 & 1.29 & 1.10 \\
\hline
\end{tabular}

$\mathrm{SP}$ is the statistical parameter, WRA is the wind-road angle, $\mathrm{P}$ is the predicted concentration, and $\mathrm{O}$ is the observed concentration.

Table 2.12 shows that the GM model performed best for these sets of data, especially, for all cases when unstable stability was used. Also, all Guassian models predicted the best results for the perpendicular wind case where the magnitude of diffusion terms become less important. The comparison of parallel wind cases indicated that the GM model predictions are markedly better than the predictions from other models. 
The ratios of predicted to observed concentration for the nearest roadside receptor for the four models are listed in Table 2.13.

Table 2.13 Ratios of predicted to observed concentrations at the roadside receptor for each Guassian model as a function of wind-road orientation angle. Numbers greater than unity indicate overprediction by the model. (Source: Sistla et al., 1978)

\begin{tabular}{|c|c|c|c|c|c|c|c|c|c|}
\hline \multirow{2}{*}{ WRA } & \multirow{2}{*}{ P/O } & \multicolumn{2}{|c|}{ HIWAY } & \multicolumn{2}{c|}{ GM } & \multicolumn{2}{c|}{ CALINE-2 } & \multicolumn{2}{c|}{ AIRPOL-4 } \\
\cline { 3 - 10 } & & Neutral & Unstable & Neutral & Unstable & Neutral & Unstable & Neutral & Unstable \\
\hline \multirow{2}{*}{$\begin{array}{c}60^{\circ} \\
\text { to } \\
90^{\circ}\end{array}$} & Max. & 1.97 & 1.59 & 1.15 & 1.06 & 0.94 & 0.82 & 0.78 & 0.64 \\
\cline { 2 - 11 } & Min. & 0.84 & 0.68 & 0.68 & 0.68 & 0.53 & 0.34 & 0.62 & 0.42 \\
\hline \multirow{2}{*}{$\begin{array}{c}30^{\circ} \\
\text { to }\end{array}$} & Max. & 1.36 & 1.11 & 0.95 & 0.88 & 0.68 & 0.56 & 0.65 & 0.48 \\
\cline { 2 - 11 } $60^{\circ}$ & Min. & 0.89 & 0.63 & 0.66 & 0.63 & 0.64 & 0.25 & 0.64 & 0.32 \\
\cline { 2 - 11 } & Avr. & 1.55 & 1.16 & 1.03 & 0.95 & 1.13 & 0.44 & 0.92 & 0.49 \\
\hline \multirow{2}{*}{$\begin{array}{c}0^{\circ} \\
\text { to } \\
30^{\circ}\end{array}$} & Max. & 6.63 & 2.79 & 1.69 & 1.27 & 2.76 & 0.91 & 1.42 & 0.49 \\
\cline { 2 - 10 } & Min. & 1.02 & 0.80 & 1.06 & 0.80 & 0.96 & 0.40 & 0.59 & 0.23 \\
\cline { 2 - 10 } & Avr. & 2.84 & 1.42 & 1.25 & 0.99 & 1.48 & 0.50 & 1.05 & 0.40 \\
\hline
\end{tabular}

WRA is the wind-road angle, $\mathrm{P}$ is the predicted concentration, and $\mathrm{O}$ is the observed concentration.

Since the nearest downwind roadside receptor had the highest concentration, the minimum and maximum ratios in Table 2.13 provide a range of under to over prediction for each model. In particular, in the cases of HIWAY, CALINE2, and AIR POL-4, for neutral stability, the ranges between the maximum and minimum values (for parallel wind with respect to the roadway) were $6,3,2.4$, respectively which indicated that GM model handled initial dispersion more realistically than the other three models.

It was noted that none of the models tested (HIWAY, GM, CALINE-2, and AIR POL4), except GM model, incorporate any induced turbulence near the roadway. In the case of GM model, the effective source height is obtained by treating the plume rise from a line source. This could account for the good correlation obtained between the observed and GM model predicted concentrations. Because of the fact that the observed upward vertical motions over the roadway, in the case of parallel wind, were due to the mechanical turbulence generated by the moving vehicles, Sistla et al., 1978 suggested that vehicle-induced turbulence fluxes of momentum should be taken in account in model formulation. 
As the classical Pasquill-Turner type stability classification did not properly represent the stability conditions near the roadways, Sistla et al., 1978 suggested that the stability adjacent to the roadways might be determined through the Richardson number (or bulk Richardson number) or through wind fluctuation data obtained at the site.

It was found that the vertical dispersion parameter, $\sigma_{Z}$, obtained from the standard deviation of the elevated angle $\left(\sigma_{\phi}\right)$ is in a good agreement with the standard deviations used by GM and HIWAY (unstable) models, as well as the values calculated from the observed concentrations. Hence, it was suggested that for roadway dispersion problems with a typical sampling period of $1 \mathrm{~h}$, wind fluctuation data should be collected with the averaging times in the range of 1-25 $s$ to provide the necessary dispersion parameters.

Based on the data collected in the General Motors Sulfate Dispersion Experiment (Cadle et al., 1976) and in New York State Study (Sistla et al., 1978), Rao and Keenan, 1980 developed a new set of dispersion curves applicable for pollutant dispersion taking into the account the nature of the traffic induced turbulence and its influence on the pollutant dispersion in the near-field. Also they developed an aerodynamic drag factor to handle dispersion under low wind speeds. To modify the original HIWAY model (HIWAY-2), Rao and Keenan, 1980 suggested to replace Pasquill-Gifford curves with the new set of dispersion curves (Figure 2.9) and the aerodynamic factor, which accounts for the change in the mean wind field due to the moving vehicles.

In the recent CSIRO/RTA study (Williams et al., 1993)., The comparison between the experimental data (stability classes were Neutral to unstable) with the predictions of four traffic pollution models (HIWAY-2, CALINE4, Chock (alias GM), and ROADWAY) showed that HIWAY-2, CALINE4 performed fairly well, while Chock and ROADWAY showed poor performances. It was believed that the good agreement between CALINE4 predictions and the experimental data is attributed to CALINE4's use of $\sigma_{\theta}$, the standard deviation of the horizontal wind direction fluctuations, to estimate horizontal dispersion and the addition of the vehicle-induced heat flux algorithm.

The good agreement between HIWAY-2 predictions and the experimental data were attributed to HIWAY's use of new dispersion curves, given in Figure 2.9. These curves account for the nature of the traffic induced turbulence and its influence on the pollutant dispersion in the near-field, instead of Pasquill-Gifford stability categories (Turner, 1970) and the use of the aerodynamic drag factor which was developed by Rao and Keenan (1980) to handle dispersion under low wind speeds. 

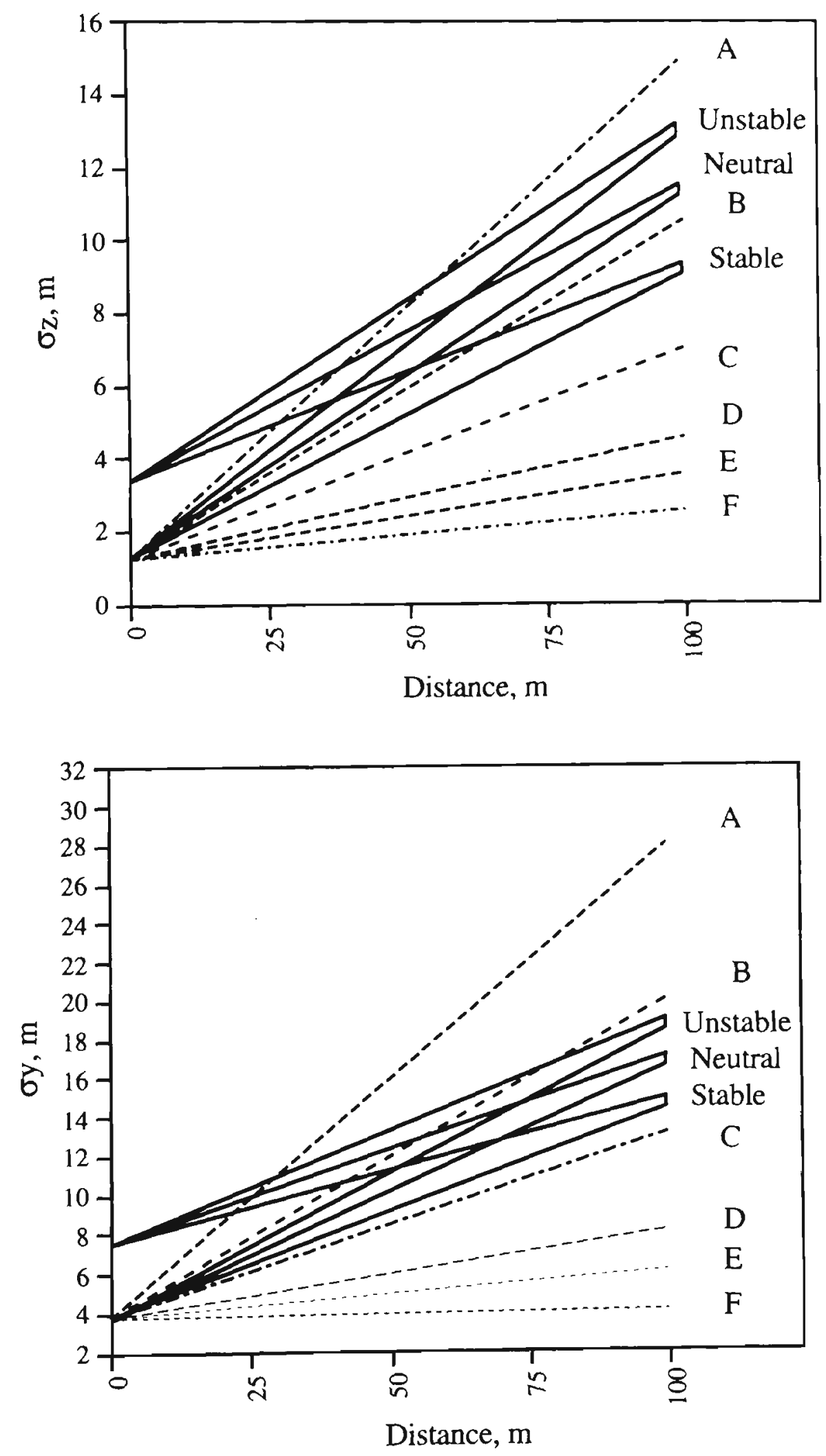

Figure 2.9 Comparison of the new dispersion curves (solid lines) to Pasquill-Gifford curves (dashed lines) used in original HIWAY model. The upper bound of the new dispersion curves represents the values used for zero cross-wind speed situations while the lower bound represents the values used for cross-wind speed greater than $3.92 \mathrm{~m} / \mathrm{s}$.

(Source Rao and Keenan, 1980) 
It was believed that the poor performance of the Chock model is attributed to the poor treatment of the vertical dispersion. In the case of ROADWAY, whilst vehicle wake is included, subsequent vertical dispersion seems to be very small. It may be that ROADWAY is better suited to stable conditions.

\subsubsection{Line-Source Model of Carbon Monoxide Concentrations in Sydney}

This field study, which had been carried out in Sydney (Watson, 1983), was used to verify the ability of a dispersion model to predict concentrations of carbon monoxide (CO) along Sydney roadsides. The GM model ( Chock, 1978) was employed in this study (GM was discussed in more detail in the above section). Its advantages over similar models are that the predicted concentration does not become infinite as the wind speed approaches zero; plume rise due to heated exhaust is accounted for, and the choice of vertical dispersion parameters allows for the effects of traffic-induced turbulence. The GM model does not account for the effects of topography, nor does it make allowance for the dispersion of emissions with cut-sections, roadway intersections, as it was intended for use along at-grade roadways . Hourly average $\mathrm{CO}$ levels were measured on 24 occasions during morning peak traffic flow along four routes which feed traffic towards the Sydney commercial business district. At these locations the necessary traffic and meteorological information was obtained for input to a dispersion model which then furnished estimates of road-edge concentrations of $\mathrm{CO}$. The comparison of measured and predicted $\mathrm{CO}$ concentrations permits an evaluation of the usefulness of the dispersion model.

The effect of lateral and vertical dispersion on the distribution of concentration is incorporated by specifying $\sigma_{z}$ as a function of both downwind distance and wind-road orientation angle. The stability categorisation was determined according to stable $\left(R_{i}>\right.$ 0.07), neutral $\left(0.07>R_{i} \geq-0.1\right)$, and unstable $\left(R_{i} \leq-0.1\right)$ where $R_{i}$ is the bulk Richardson number.

Observations were made at four locations, Site 1 was a relatively free-flowing, four-lane at-grade roadway with no median strip and is bounded on both sides by residential development. For the purpose of modelling exercise, Site 1 was considered to be threelane roadway because parked cars precluded use of one lane during the morning. Data were collected for six hours of peak traffic on three different days. Site 2 was located on a major route to the Sydney CBD where the highest traffic volume was carried during peak periods and where there was an incline and occasional queuing at the traffic lights. The roadway at this site was six lanes and a median strip was $0.9 \mathrm{~m}$ wide. Data were collected for six hours of peak traffic on three different days. Site 3 also was located on a major access route but closer to the Sydney CBD. The roadway at this site was six 
lanes and a median strip was $1.2 \mathrm{~m}$ wide. Data were collected for six hours of peak traffic on three different days. Site 4 was located on the southern alternative to the major access route. The roadway at this site was two lanes without a median strip bounded on both sides by houses and multistorey apartments. Data were collected for six hours of peak traffic on three different days.

Concentrations of $\mathrm{CO}$ were measured at a height of $1.5 \mathrm{~m}$ along the road-edges with an Ecolyser 2000 portable monitoring instrument. Output from the device was connected to a chart recorder and the chart later digitised to give one-hour average concentrations of $\mathrm{CO}$. The instrument was calibrated prior to each measurement period using calibration gas at a certified concentration of $50 \mathrm{ppm}$.

An anemometer was used to provide a continuous record of wind direction and hourly average wind speed for each two-hours of measurement. The anemometer was placed on top of a demountable two-meter mast located within three meters of the road-edge at each side. Wind data were averaged to fulfil the model's need for hourly average wind speed and cross-road, wind-angle terms.

Because measurements of the atmospheric stability were not possible because of the built-up nature of the sites, stabilities were determined during study periods from wind speed, and by observing the stratification or otherwise of visible exhaust emissions and the presence or absence of fog.

Average hourly mass emissions of $\mathrm{CO}$ in $\mathrm{g} / \mathrm{km} /$ vehicle were estimated for light vehicles at $662 \mathrm{~V}^{-0.85}$ and for heavy vehicles at $1220 \mathrm{~V}-0.85$. The two equations were based on experience in Australia and United States conditions (Johnson, 1980) on the basis of vehicle speeds $(\mathrm{V})$ in $\mathrm{km} / \mathrm{h}$. The latter expression was chosen because it provided for higher emission rates of heavy vehicles which at one of the sites, comprised nearly ten percent of all vehicles.

The numbers of vehicles using specified routes were monitored, and were totalled each hour during each of the study periods. Separate totals were made for light vehicles (four wheel), medium-sized vehicles (six wheels). These categories were also divided into either light vehicles or heavy vehicles.

Vehicle speeds were measured by two methods. The first was a 'tagged-car' technique using two observers, each equipped with two way radio and stop-watch, to time the travel of a car over a measured distance (about $100 \mathrm{~m}$ ). This technique provided average vehicle speeds from a sample of 100 vehicles per hour for the both two directions of the road. The second way was to use a radar gun which increased the sampling rate to 200 vehicle per hour. The disadvantage of the radar gun technique was that the heavy traffic 
in one direction often would obscure the traffic in the opposite direction. The data concerning the number of lanes, width of lanes, and width of the median stripes and road shoulders for each site were collected to be used as input data for the model.

It was found from the evaluation of the performance of the model that the predicted and measured concentrations of carbon monoxide at Site 1 were in close agreement. The mean ratio $(\mathrm{k})$ of the predicted to measured concentrations is 0.99 , with a mean underprediction error of 1 percent. At Site 2 and 3, good agreement was obtained with the mean ratio $(\mathrm{k})$ of the predicted to measured concentrations, which were 0.92 and 0.82 , respectively, with a mean underprediction error of 8 and 18 percent, respectively. At Site 4, the mean ratio ( $\mathrm{k}$ ) of the predicted to measured concentrations is 0.55 , with a mean underprediction error of 45 percent. The reason for this poor performance was a combination of stable atmospheric conditions, low wind speed and the nature of the site. Site 4 is the narrowest and is the most enclosed by buildings of the four sites. It approximates a cut-section within which vehicle emissions are trapped and recirculated. This trapping effect is exacerbated under stable atmospheric conditions. Because the GM model used in this study does not take this effect under consideration, it underpredicts the concentrations.

Also Watsons's work was carried out only at one area (Sydney commercial business district, at a limited period of the year (12 mornings), and covering only two stability classes (stable and neutral).

\subsubsection{Turbulent Diffusion Behind Vehicles}

A Norwegian field study was carried out (Gronskei, 1988) to evaluate the influence of car speed on the dispersion of exhaust gases. The experiments were carried out over a flat snow covered plain and the tracer gases were emitted from two moving cars. The vertical tracer distributions were determined at 10,30 and $70 \mathrm{~m}$ from the road using 5-10 $\mathrm{m}$ high masts. To understand the interaction between the car wakes and the atmospheric surface layer, tracer experiments were carried out with different car velocities using two cars emitting different tracer components $\left(\mathrm{SF}_{6}\right.$ and $\left.\mathrm{CBrF}_{3}\right)$ driven one after the other with different speeds. The samples of the tracer gases were taken downwind of the road. By changing the driving procedure, the dispersion effect of parameters describing the wake development (the speed of the cars) was evaluated. Gaussian distributions were found to fit the vertical profiles of the tracer concentrations.

Three models (HIWAY-2 model (Petersen, 1980), GM (Chock, 1978), and Nordic model for concentration calculations in street canyons (Larssen, 1984)) were used to provide information on pollutant concentrations close to the roads with high traffic. 
The atmospheric stability was classified according to observation of wind and temperature stratification (the stability classes were Neutral to Stable).

The calculated values of the vertical dispersion parameter, $\sigma z$, from the HIWAY-2 appear to be larger than the observed values. Gronskei attributed the reason for the discrepancy to the fact that HIWAY-2 was developed for fast running traffic at a highway with two lanes for each but the test road in Norway was smaller with adjacent flat snow covered ground.

Gronskei's results showed that the vertical dispersion increased as a result of increased driving speed of the cars. The car speed influenced the development of the wake, which in turn affected the diffusion. The faster the car speed the faster the growth of the wake. Also when the atmospheric wind was perpendicular to the road (five experiments), the vertical dispersion parameter $\sigma_{z}$ for the tracer material was linearly dependent on an estimated scale of the wake in each experiment. Also when the wind shear is small and car speed is small, the effect of the car wake is minimised over a flat surface.

Gronskei's empirical formula, developed for the vertical dispersion parameter, $\sigma_{Z}$, is applicable only when the scales of turbulence in the atmospheric surface layer are smaller than the scale of the wake. When houses and trees are present close to the road, the wakes of the cars are not believed to be important except in the immediate neighbourhood. The influence of the dispersion of the automobile exhaust and the conditions for interaction are changed.

Gronskei's results were the only field data which clearly show the speed effect upon vertical dispersion.

\subsection{Summary}

This Chapter consists of eight parts. The first part is concerned with the road vehicles as the major source of air pollution. It covers different road transport fuels used in Australia and the nature of pollutants emitted resulting from its combustion.

The second part of this Chapter is concerned with Sydney emissions inventory prepared by the NSW State Pollution Control Commissions (1976-2011) and the national emission inventory prepared by the Bureau of Transport and Communications Economics for Australia (1991). 
The third part of this chapter is about the requirements to control exhaust emissions. It covers the adverse health effects of air pollution on human beings. In the fourth part, the reasons for generating pollutants in vehicles are discussed.

The parameters influencing vehicles exhaust emissions and the methods used to control the composition of the exhaust gases from spark ignition and diesel engines are discussed in the fifth part. These methods are divided into two basic categories: engine design measures and exhaust-gas treatment. In this part, the exhaust emissions testing is also discussed in brief, and a typical test results for ADR 37 is presented.

The sixth part of this chapter is a discussion about the pollutant concentrations as a combination of source intensity and meteorology. It covers the major meteorological factors that affect the dispersion of air pollutants.

The seventh part is about include brief descriptions and discussions of some of the available source and dispersion models.

Dispersion models such as HIWAY (Zimmerman and Thompson, 1975), HIWAY-2 (Petersen, 1980), GM (Chock, 1977), CALINE2 (Ward et al., 1975), CALINE3 (Benson, 1980), CALINE4 (Benson, 1984), and ROADWAY (Eskridge, 1987) are discussed in detail in the eighth part which includes also the previous comparative field studies used to verify some of the dispersion models. This part covers four comparative field studies. The first comparative field study was The General Motors Sulfate Dispersion Experiment that was conducted in September and October of 1975 at the GM proving grounds in Milford, Michigan. This field study was used to investigate the validity of the Environmental Protection Agency's HIWAY dispersion model. Chock, 1977 addressed the many limitations and deficiencies in the model. These include: (1) inadequate dispersion parameters; (2) no treatment for the plume rise; (3) tendency towards severe overprediction when the wind is parallel to the roadway; (4) applicability not extended to low wind speeds; and (5) inadequate treatment of dispersion upwind of the road.

The outcome of the analysis of the General Motors Sulfate Dispersion Experiment was the development of the GM model (Chock, 1978). The model advantages include: (1) the predicted concentrations do not diverge as the wind speed approaches zero; (2) it allows for the plume rise due to the heated exhaust, which can be important at a very crossroad wind speed; and (3) it is utilise a new set of vertical dispersion parameters which reflects the influence of traffic-induced turbulence (Figure 2.8). 
The second comparative field study that was carried out in New York by the State Department of Environmental Construction (Sistla et al, 1979) to assess four Gaussian dispersion models (HIWAY, GM, CALINE-2, AIRPOLL-4).

It was noted that none of the models tested (HIWAY, GM, CALINE-2, and AIR POL4), except GM model, incorporate any induced turbulence near the roadway. In the case of GM model, the effective source height is obtained by treating the plume rise from a line source. This could account for the good correlation obtained between the observed and GM model predicted concentrations. Because of the fact that the observed upward vertical motions over the roadway in case of parallel wind were due to the mechanical turbulence generated by the moving vehicles, Sistla et al., 1978 suggested that vehicleinduced turbulence fluxes of momentum should be taken in account in model formulation. Also, the stability adjacent to the roadways might be determined through the Richardson number (or bulk Richardson number), or from wind fluctuation data obtained at the site.

It was found that the vertical dispersion parameter, $\sigma_{z}$, obtained from the standard deviation of the elevated angle $\left(\sigma_{\phi}\right)$ is in a good agreement with the standard deviations used by GM and HIWAY (unstable) models, as well as the values calculated from the observed concentrations. Hence, it was suggested that for roadway dispersion problems with a typical sampling period of $1 \mathrm{~h}$, wind fluctuation data should be collected with the averaging times in the range of 1-25 s to provide the necessary dispersion parameters.

Based on the data collected in the General Motors Sulfate Dispersion Experiment (Cadle et al., 1976) and in New York State Study (Sistla et al., 1978), Rao and Keenan, 1980 developed a new set of dispersion curves applicable for pollutant dispersion taking into the account the nature of the traffic induced turbulence and its influence on the pollutant dispersion in the near-field. Also they developed an aerodynamic drag factor to handle dispersion under low wind speeds. To modify the original HIWAY model (HIWAY-2), Rao and Keenan, 1980 suggested to replace Pasquill-Gifford curves with the new set of dispersion curves (Figure 2.9) and the aerodynamic factor, which accounts for the change in the mean wind field due to the moving vehicles.

The third comparative field study was carried out by Watson (1983), to evaluate the ability of line source models to predict road-side concentrations of carbon monoxide at four different locations during the morning rush hours and neutral to stable meteorological conditions in Sydney. The performance of the GM Gaussian dispersion model was judged to be good when the model predictions were compared with the experimental data. 
The fourth comparative field study was the Norwegian field study that was carried out by Gronskei, (1988) to evaluate the influence of car speed on the vertical dispersion of exhaust gases. The field study showed that the vertical diffusion of exhaust gasses tends to be larger from car driving with high speed than from cars driving with lower speed. When the atmospheric wind was perpendicular to the road, the vertical dispersion parameter, $\sigma z$, was linearly dependent on the estimated scale of the wake. The coefficients of linearity varied with the state of the atmospheric surface layer as indicated by wind measurements and stability classification.

However, all of these comparative field studies were carried out only at one location and at one period of the year. 


\section{CHAPTER 3}

\section{MODELLING MOTOR VEHICLE EMISSIONS}

\subsection{Introduction}

One commonly-used approach for modelling motor vehicle emissions is to adjust emissions data produced by subjecting vehicles to a standard driving cycle (the standard Federal Test Procedure, FTP) and adjust them to match the highway speed by means of a speed correction factor (the average vehicle speed is used as the sole descriptor for pollutants emission levels). Allowance has to be made for both exhaust and evaporative emissions from different vehicle technology groups and their population, effects of vehicle age, ambient temperature ect.

The above approach is used by California EPA (Air Resources Board), USA who have developed the EMFAC7 methodology (California EPA, 1993) which develops emission factors for both exhaust and evaporative emissions for different vehicle technology groups, and weighs them according to vehicle population and annual distance travelled. Emissions from cold and hot starts are taken into account as well as those from stabilised running. These data produced by subjecting vehicles to the American standard Federal Test Procedure (FTP) which uses an urban drive cycle equivalent to that used in Australia (ADR27 and ADR37) are adjusted for use in the given situation by four correction factors. These correction factors are mode correction factor (BCF), a speed correction factor (SCF), a temperature correction factor (TCF), and a fuel correction factor (FCF). The various correction factors, particularly the BCF and SCF are specified for a given model year to take vehicle deterioration into account. The vehicle groups are identified as light duty automobiles, light, medium and heavy duty trucks. These vehicles are then classified as catalyst or non-catalyst equipped gasoline fuelled vehicles or diesel vehicles.

Another interesting approach has been developed by the Victorian EPA (Carnovale et al., 1991). In this procedure, the ADR27 test cycle was split into segments representing three driving modes. These driving modes are freeway, arterial and congested roads. The exhaust emissions from over 1500 vehicles, from different technology classes, were analysed on this split mode basis. Deterioration factors (gram $/ \mathrm{km}$ ) were developed for $\mathrm{CO}, \mathrm{HC}$, and $\mathrm{NO}_{\mathrm{X}}$ emissions for each $10,000 \mathrm{~km}$ travelled.

A limitation of methodologies such as EMFAC7 and that developed by the Victorian EPA which employs the average vehicle speed as the sole descriptor for pollutants emission levels is that these methodologies are more suitable to estimate emissions for an airshed or 
over a number of links rather than at a specific locations. This limitation exists because airshed or multi-link modelling involves a range of driving conditions better approximated by the FTP related data.

However, it has been established that, despite the efforts and detail that has gone into the US models, they do not, currently, provide reliable estimates of on-road pollutant emissions (Cadle et al., 1991). Analysis of air quality in well defined situations such as tunnels shows that $\mathrm{CO}$ and $\mathrm{HC}$ concentrations are about twice those anticipated from traffic type and density (Robinson et al., 1993), although $\mathrm{NO}_{\mathrm{x}}$ levels are only 50\% higher. Guensler et al., (1993) measured the emissions from over 500 vehicles using five driving cycles with different average speeds and found that actual emissions were so much higher than predicted concentrations using the US model. Although the reasons why actual emissions were so much higher than predicted were unclear, one of the factors undoubtedly concerns so-called open loop operation of catalyst-equipped vehicles when uncontrolled exhaust emissions occur to avoid overheating the catalyst. A power (or load) model has the potential for overcoming some of these problems.

For the experimental database, which has data relating to fuel consumption, a more realistic procedure based on the work of Kent et al., 1981 has been adopted here. In this approach, the total instantaneous power required to propel the vehicle along the road is taken as a basis for estimating the fuel consumption and emission rates of hydrocarbons, carbon monoxide, and the oxides of nitrogen and at that instant. The model must be capable of simulating the driving cycle emissions and its performance when tested against emission data obtained from the Federal Test Procedure, FTP, cycle testing.

\subsection{Power-Based Exhaust Emissions Model}

The total instantaneous power $Z_{t}$ required to propel the vehicle along the road is taken as the basis for estimating the fuel consumption and emission rates at that instant. $Z_{t}$ is given by

$$
\mathrm{Z}_{\mathrm{t}}=\mathrm{Z}_{\mathrm{d}}+\mathrm{Z}_{\mathrm{r}}+\mathrm{Z}_{\mathrm{a}}+\mathrm{Z}_{\mathrm{e}}
$$

where $Z_{d}$ is the power required to overcome the vehicle drive-train resistance, $Z_{T}$ is the tyre rolling resistance, $Z_{a}$ is the aerodynamic drag and $Z_{e}$ is the inertial and gravitational resistance where $Z_{t}, Z_{d}, Z_{r}, Z_{a}$, and $Z_{e}$ are in $K w$. The various terms are functions of vehicle mass, speed and aerodynamic characteristics; the appropriate equations can be found in Richardson (1982). These equations are 


$$
\begin{aligned}
& Z_{d}=2.36 \times 10^{-7} \mathrm{~V}^{2} \mathrm{M} \\
& \mathrm{Z}_{\mathrm{r}}=3.72 \times 10^{-5} \mathrm{VM}+3.09 \times 10^{-8} \mathrm{~V}^{2} \mathrm{M} \\
& \left.\mathrm{Z}_{\mathrm{e}}=(\mathrm{M} / 1000)(\mathrm{V} / 3.6)((\mathrm{ac} / 3.6)+\mathrm{g} \sin \theta)\right)
\end{aligned}
$$

Where $M$ is the mass in kilograms, $V$ is the vehicle speed in $\mathrm{km} / \mathrm{h}$, ac is the vehicle acceleration in $\mathrm{km} / \mathrm{hr} . \mathrm{s}, \mathrm{g}$ is the gravity acceleration $\left(9.81 \mathrm{~ms}^{2}\right), \theta$ is the slope angle in radians. The term $g \sin \theta$ is the effective acceleration due to gravity whilst going up a hill of slope $\theta$.

The power required to overcome aerodynamic drag is a function of the vehicle speed, $\mathrm{V}$, and the frontal area, A, vehicle drag coefficient, wind speed, $u$, and wind-road angle (Richardson (1982), Close et al., (1981). The power required to overcome aerodynamic is given in the following section (3.2.1).

For spark ignition vehicles, Kent et al., (1981) showed that the fuel consumption rate, $\mathrm{F}_{\mathrm{C}}$, is related to the total instantaneous power of the vehicle by the linear relation

$$
\mathrm{F}_{\mathrm{c}}=\alpha+\beta * \mathrm{Z}_{\mathrm{t}}
$$

where $\alpha$ is the fuel consumption rate at idle conditions in $\mathrm{ml} / \mathrm{min}$ and $\beta$ is the measure of the efficiency of power generation (in $\mathrm{ml} / \mathrm{min} . \mathrm{kW}$ ), and $\mathrm{F}_{\mathrm{c}}$ is the fuel consumption in $\mathrm{ml} / \mathrm{min}$. Also, Post et al., (1981) found that the idle fuel flow rate a was a function of engine capacity, EC, such that

$$
\alpha=9.9 * \mathrm{EC}
$$

where $\alpha$ is in $\mathrm{ml} / \mathrm{min}$ and $\mathrm{EC}$ is in litres

These workers also found that $\alpha$ and $\beta$ for a given vehicle would vary somewhat with the state of tuning and vehicle conditions.

For spark-ignition engines, $\mathrm{CO}$ is thought to result from thermal equilibrium in the combustion process frozen as the temperature drops from $2500-3000 \mathrm{~K}$ during the expansion part of the cycle. The actual proportion of the fuel carbon that ends up as $\mathrm{CO}$ is dependent on the excess-air factor $\lambda$ (CO emissions increase with decreasing the excess-air factor , $\lambda<1$ ), fuel's homogeneity, its stratification patterns, its temperature, and valve timing. $\mathrm{HC}$ in the exhaust is thought to be due largely to unburnt fuel, which had dissolved in the cylinder oil film or been preserved in crevices. $\mathrm{NO}_{\mathrm{X}}$ is unavoidable product of high temperature combustion in air, increasing with combustion temperature 
and favoured by fuel lean conditions. These considerations lead to the expectation that $\mathrm{CO}, \mathrm{HC}$, and $\mathrm{NO}_{\mathrm{x}}$ emissions would be proportional in some way to fuel consumption with $\mathrm{CO}$ and $\mathrm{HC}$ showing more inter vehicle variation .

Similar considerations apply with respect to $\mathrm{CO}$ and $\mathrm{NO}_{\mathrm{X}}$ emissions from compressionignition (diesel) engines, except that combustion temperatures are not so high and the fuel is less well mixed with the air as burning fuel droplets are involved. With regard to $\mathrm{HC}$ emissions, any unburnt fuel is generally too involatile to be monitored resulting much less $\mathrm{HC}$ emissions. Also, the diesel engine does not control air intake and hence, as there is excess air often present, this would favour $\mathrm{NO}_{\mathrm{X}}$ formation.

Post et al., (1981) and Kent et al., (1982) modelled the exhaust emissions for pre-1986 spark ignition (SI) vehicles as follows:

$$
\begin{aligned}
& \mathrm{CO}=10.0+0.7 \mathrm{Z}_{\mathrm{t}} \\
& \mathrm{HC}=0.7+0.07 \mathrm{Z}_{\mathrm{t}} \\
& \mathrm{NO}_{\mathrm{X}}=29.0 \mathrm{Zt}
\end{aligned}
$$

The units for the emissions in equations 7,8 , and 9 are $\mathrm{g} / \mathrm{min}$ with $\mathrm{Z}_{\mathrm{t}}$ power in kilowatts. In equations $1,5,7,8$, and 9 , if the acceleration term is such that $Z_{t}$ is negative, then $Z_{t}$ is set to zero.

Equations similar to that for fuel consumption were developed by Post et al., (1981) and Kent et al., (1982) for SI exhaust emissions. This approach has been modified and extended to include diesel vehicles as well as catalyst-equipped spark ignition vehicles. These equations which have been matched to the experimental data of Williams et al., (1987), Carnovale et al., (1991), and SPCC, (1989) are:

For pre-1986 spark-ignition (SI) vehicles emissions (no catalyst)

$$
\begin{aligned}
& \mathrm{FC}=9.90 \mathrm{EC}+9.00 \mathrm{Z}_{\mathrm{t}} \\
& \mathrm{CO}=1.65 \mathrm{EC}+0.08 \mathrm{Z}_{\mathrm{t}} \\
& \mathrm{HC}=0.165 \mathrm{EC}+0.008 \mathrm{Zt} \\
& \mathrm{NO}_{\mathrm{X}}=0.045 \mathrm{EC}+0.12 \mathrm{Zt}
\end{aligned}
$$

For light-duty diesel

$$
\begin{aligned}
& \mathrm{FC}=6.0 \mathrm{EC}+6.00 \mathrm{Z}_{\mathrm{t}} \\
& \mathrm{CO}=0.165 \mathrm{EC}+0.01 \mathrm{Z}_{\mathrm{t}}
\end{aligned}
$$




$$
\begin{aligned}
& \mathrm{HC}=0.080 \mathrm{EC}+0.008 \mathrm{Zt} \\
& \mathrm{NO}_{\mathrm{X}}=0.045 \mathrm{EC}+0.12 \mathrm{Zt}
\end{aligned}
$$

For heavy-duty diesel

$$
\begin{aligned}
& \mathrm{FC}=6.0 \mathrm{EC}+6.00 \mathrm{Z}_{\mathrm{t}} \\
& \mathrm{CO}=0.136 \mathrm{EC}+0.01 \mathrm{Z}_{\mathrm{t}} \\
& \mathrm{HC}=0.080 \mathrm{EC}+0.008 \mathrm{Zt} \\
& \mathrm{NO}_{\mathrm{X}}=0.045 \mathrm{EC}+0.20 \mathrm{Zt}
\end{aligned}
$$

Also, the cold start operation for SI vehicles have been modelled to compare the model performance with the test driving cycle emission data. Engine warm-up has been

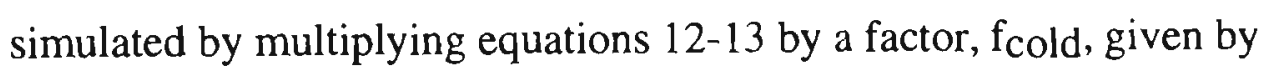

$$
\mathrm{f}_{\text {cold }}=7-6\left(1-\mathrm{e}^{-\left(S F_{\mathrm{n}} / \mathrm{t}\right)}\right)
$$

where $\mathrm{SF}_{\mathrm{n}}$ is the fuel consumed since engine start $(\mathrm{ml})$ normalised to $2.5 \mathrm{I}$ engine capacity, and $t$ is the characteristic warm-up time constant ( $t$ is chosen to be $120 \mathrm{~s}$ ) assuming that small cars are engineered such that they warm up at the same rate as large cars.

For catalyst-equipped vehicles another factor, $\mathrm{f}_{\mathrm{cat}}$, is applied to equations 11-13. $\mathrm{f}_{\mathrm{c}}$ at combines catalyst performance, $\mathrm{E}_{\mathrm{cat}}$, and warm-up from cold start. So, fuel consumption and exhaust emissions equations for post-1986 catalyst-equipped vehicles will be as follows

$$
\begin{aligned}
& \mathrm{FC}=9.70 \mathrm{EC}+8.80 \mathrm{Z}_{\mathrm{t}} \\
& \mathrm{CO}=\mathrm{f}_{\text {cat }}\left(1.65 \mathrm{EC}+0.08 \mathrm{Z}_{\mathrm{t}}\right) \\
& \mathrm{HC}=\mathrm{f}_{\text {cat }}(0.165 \mathrm{EC}+0.008 \mathrm{Zt}) \\
& \mathrm{NO}_{\mathrm{x}}=\mathrm{f}_{\text {cat }}(0.045+0.12 \mathrm{Zt})
\end{aligned}
$$

$\mathrm{f}_{\text {cat }}$ has been set at the same value for both $\mathrm{CO}$ and $\mathrm{HC}$ emissions, with the catalyst efficiency, $\mathrm{E}_{\text {cat }}$, given empirically by:

$$
\mathrm{E}_{\mathrm{cat}}=0.5\left(1-\exp \left(-\mathrm{FC}_{\mathrm{n}} / 120\right)\right)
$$

$\mathrm{f}_{\mathrm{cat}}$ (the factor which combines the catalyst performance, $E_{c a t}$, and warm-up from cold start )will be 


$$
f_{\text {cat }}=1 /\left(1+E_{\text {cat }}\right) e^{-S F_{n} / t}+E_{\text {cat }}
$$

where $\mathrm{FC}_{\mathrm{n}}$ is the normalised instantaneous fuel consumption and the characteristic time, $\mathrm{t}$, is $60 \mathrm{~s}$, as the catalyst warms up more rapidly than the engine and coolant system.

For $\mathrm{NO}_{\mathrm{x}}$ emissions:

$$
\begin{aligned}
& E_{\text {cat }}=0.3 \text { for 3-way catalyst } \\
& E_{\text {cat }}=0.7 \text { for oxidation catalyst }
\end{aligned}
$$

The form of $\mathrm{E}_{\mathrm{cat}}$ for $\mathrm{CO}$ and $\mathrm{HC}$ emissions in equation (3.27) was designed to reduce catalyst efficiency as the exhaust flow rate increases and hence as the residence time decreases. This form was based on the data of Carnovale et al., (1991) together with that derived from the following discussion.

One of the limitations of the Federal Test Procedure, FTP, and related test cycles is the absence of any high acceleration. This limitation is particularly important in respect of catalyst equipped cars as, under these conditions, the engine management system goes into 'open loop' operation during which fuel rich conditions are allowed to prevail to prevent over heating of the catalyst. This open loop operation can be simulated in the model by putting $E_{c a t}=1$ and multiplying, if necessary, by an enrichment factor when $Z_{t}$ exceeds a certain value.

Through the CSIRO major study of the pollution generated near arterial roads by motor vehicles (Williams et al., 1994), the excess atmospheric $\mathrm{CO}_{2}$ generated by the traffic has been measured. The measured $\mathrm{CO}_{2}$ can be directly related to fuel consumption. As nearly all the carbon in transport fuel is oxidised to $\mathrm{CO}_{2}$ these emissions can be estimated directly from the fuel consumption:

$$
\mathrm{CO}_{2}=\mathrm{M} \rho\left(\mathrm{F}_{\mathrm{C}}-\mathrm{F}_{\mathrm{CCO}}-\mathrm{F}_{\mathrm{chc}}\right)
$$

where $\mathrm{M}$ is the ratio of the molecular weight of $\mathrm{CO}_{2}$ relative to the molecular weight of the hydrocarbon fuel expressed per atom of $C, \rho$ is the specific gravity of the fuel, and $F_{c c o}$ and $F_{c h c}$ are the parts of the fuel consumption that end up as $\mathrm{CO}$ or $\mathrm{HC}$.

\subsubsection{Aerodynamic effects}

Strong winds can have a significant effect on fuel consumption, particularly heavy vehicles which have poor coefficients of drag. According to Bosch Automotive Handbook (1993), the instantaneous power required to overcome the aerodynamic drag 
in the case of a front wind or a tail wind ( $u$ should be negative) is given as $Z_{a}=1.29 x$ $10^{-5} C_{d} A_{f} V(V+u)$, where $V$ is the vehicle speed, $u$ is the wind speed, $C_{d}$ is the aerodynamic drag coefficient, and $A_{f}$ is the frontal area. In the case of inclined wind (wind-road angle $=\psi$ ), the instantaneous power required to overcome the aerodynamic drag can be estimated as follows:

$$
\mathrm{Z}_{\mathrm{a}}=1.29 \times 10^{-5} \mathrm{C}_{\mathrm{d}} \mathrm{A} \mathrm{V} \mathrm{\textrm {V } ^ { 2 }} \cos \phi
$$

and

$$
V_{r}=\left(V^{2}+u^{2}+2 u V \cos \psi\right)^{-0.5}
$$

Where $V_{r}$ is the relative car-wind speed in $\mathrm{km} / \mathrm{h}, \phi$ is the angle between $\mathrm{V}_{\mathrm{r}}$ and $\mathrm{V}(\phi=$ $\sin ^{-1}\left(\mathrm{u} \sin \psi / \mathrm{V}_{\mathrm{r}}\right)$ ), $\psi$ is the wind-road angle in radians, and $\mathrm{A}$ is the projected area of the vehicle normal to wind direction in $\mathrm{m}^{2}$. A can be estimated as follows:

$$
A=H(L \sin \phi+W \cos \phi)
$$

where $\mathrm{H}, \mathrm{W}$, and $\mathrm{L}$ are the height, width, and length of the vehicle, respectively, in meters.

\subsection{Car Exhaust Deterioration Factors}

Car exhaust deterioration factors are the rates at which emissions are modelled to increase with increasing vehicles distance travelled. The deterioration rates applies per 100,000 kilometres. Exhaust deterioration factors can be used to account for the loss of combustion efficiency, tampering with pollution control equipment or deterioration of catalytic converter with vehicle distance travelled. Exhaust deterioration factors are seen to dramatically increase emissions over new car values (see Chapter 5 - Victoria EPA study, 1991).

According to Carnovale et al. (1991) and Carnovale et al. (1993), The following deterioration factors for the Australian fleet in gram $/ \mathrm{km} / 10,000 \mathrm{~km}$, presented in Table 3.1, have been adopted here. These deterioration factors are for pre-1986 vehicles, post1986 two-way-equipped catalyst vehicles, and post-1986 three-way-equipped catalyst vehicles, respectively.

Carnovale et al., (1993) reported that the vehicle use (ie. annual distance travelled) varies significantly with vehicle age. A passenger vehicle in first year of use in New South Wales averaged approximately $21,000 \mathrm{~km}$, while a ten year old vehicle averaged only $15,000 \mathrm{~km}$. The accumulated vehicle travel distance is presented in Figure 3.1. 
Table 3.1 The adopted exhaust deterioration rates $(\mathrm{g} / \mathrm{km} / 10,00 \mathrm{~km}$ travel) for the Australian fleet (Source: Carnovale et al.,1993)

\begin{tabular}{|c|c|c|c|}
\hline \multirow{2}{*}{ Travel } & \multicolumn{3}{|c|}{ Deterioration rate $(\mathrm{g} / \mathrm{km} / 10,00 \mathrm{~km}$ travel $)$} \\
\cline { 2 - 4 } & $\begin{array}{c}\text { pre-86 } \\
\text { vehicles }\end{array}$ & $\begin{array}{c}\text { post-86 two-way-equipped } \\
\text { catalyst vehicles }\end{array}$ & $\begin{array}{c}\text { post-86 three-way equipped } \\
\text { catalyst vehicles }\end{array}$ \\
\hline $\mathrm{CO}$ & 1.27 & 1.57 & 0.782 \\
\hline $\mathrm{HC}$ & 0.079 & 0.093 & 0.052 \\
\hline $\mathrm{NO}_{\mathrm{X}}$ & 0.064 & 0.078 & 0.089 \\
\hline
\end{tabular}

Carnovale et al., (1993) also reported that the passengers vehicles up to 8 years of age contribute approximately 50\% of vehicle kilometres travelled (by passenger vehicles), VKT, ie. the effective mean age of the passenger vehicle fleet in NSW was 8 years (see Chapter 5 - Victoria EPA study, 1991). From Figure 3.1, the travelled VKT for passengers vehicles can be estimated according to the following formula

$$
\operatorname{VKT}(\mathrm{km})=22799 \text { y } 0.86
$$

where $\mathrm{y}$ is the vehicle age in years and VKT is the total kilometres travelled.

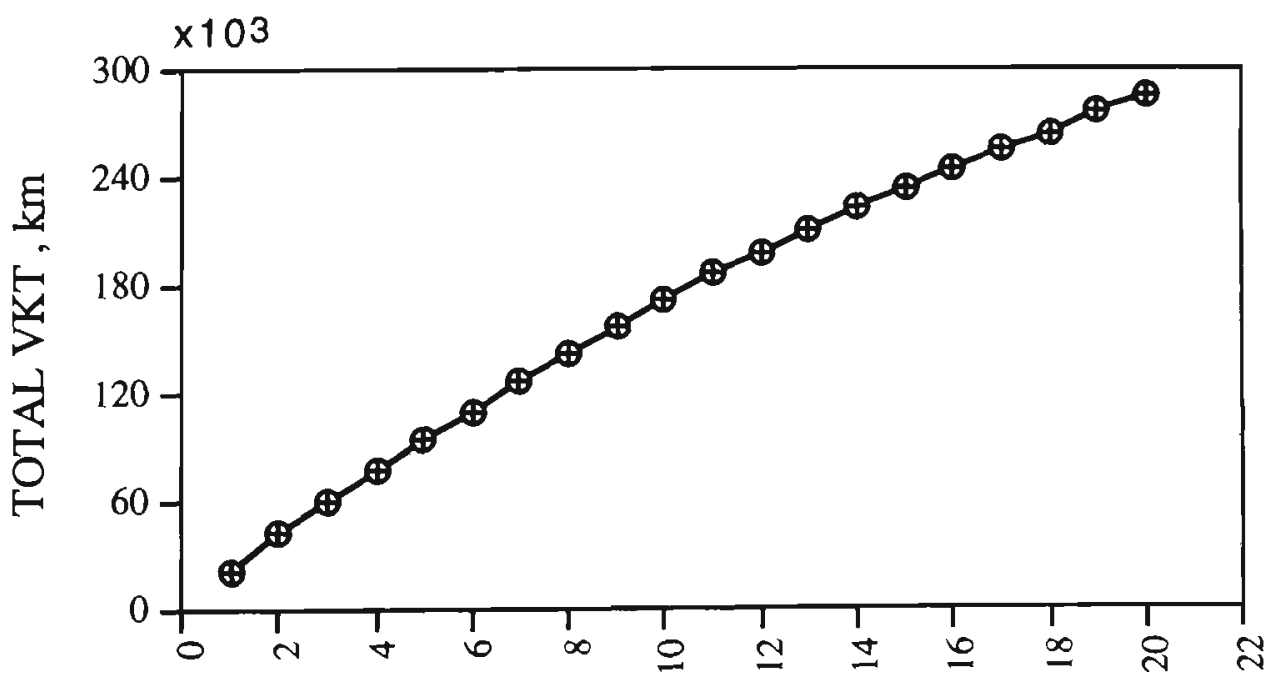

VEHICLE AGE, year

Figure 3.1 Total VKT for NSW passengers vehicles (1988) according to age (Source: Carnovale et al.,1993) . 


\subsection{Running Losses}

It is assumed that the evaporative emissions are either crankcase, diumal, or hot soak. " running losses" are the evaporative emissions (also referred to as HC (hydrocarbons) or reactive organic gases (ROG) which occur during vehicle operation.

Gasoline volatility is a primary factor in evaporative losses. The measure of the fuel volatility is the empirically determined "Reid Vapour Pressure", which is a composite value reflecting the cumulative effect of individual vapour pressures of different gasoline constituents. Reid Vapour Pressure (RVP) provides both a measure of how readily a fuel can vaporise to provide a combustible mixture at low temperatures and is an indicator of the tendency of the fuel to vaporise.

With evaporative emission control systems, which are designed to pass the petrol generated during this period directly into the "running" engine to be bumed, the fuel with a RVP of $62 \mathrm{kPa}$ (vapour pressure of fuel for testing regulatory compliance) were believed to have nearly zero evaporative running losses (EPA (Victoria), 1991). However, recent tests results show that running loss emissions from light-duty petrol driven vehicles and trucks are a non linear function of ambient temperature, fuel volatility and average vehicle speed. Running loss emissions are higher at higher temperature and higher fuel volatility. In addition, running losses have been found to be very low under freeway conditions regardless of temperature or fuel volatility, however at lower speed, running losses can be significant (EPA (Victoria), 1991, and EPA (USA), 1993).

According to EPA (Victoria), 1991, running losses from motor vehicles may be affected by the engine design (in particular pre and post 1986), ambient temperature and driving conditions (eg. speed and acceleration), consequently, losses for Australian vehicles driven under local conditions need not necessarily be similar to those of US vehicles.

For the study herein, US-EPA running losses, as modelled using the latest California Emissions Model (EMFAC7) are adopted because of the lack of data for Australian vehicles.

\subsection{The characteristics of the Power-Based Exhaust Emissions Model}

The developed power - based emissions model provide estimates for fuel consumption and exhaust emission rates of $\mathrm{CO}, \mathrm{HC}, \mathrm{NO}_{\mathbf{x}}$, and $\mathrm{CO}_{2}$ from spark ignition (both leaded and unleaded) and heavy-duty diesel vehicles. 
One of the characteristics of the new model is the capability of the model to estimate the excess atmospheric $\mathrm{CO}_{2}$ emissions generated by traffic. Emissions of $\mathrm{CO}_{2}$ are essentially a measure of fuel consumption.

The second characteristics of the power -based emissions model is the capability of the model to account for the effect of both the road gradients and acceleration-deceleration manoeuvres on power demands, fuel consumption, and gaseous emissions estimates. This is given and discussed in detail in Appendix D. It is noted from this study that the increase of the required instantaneous power demands and fuel consumption estimated for a vehicle going up a two-way hilly road with slope $\leq 30$ is not equal to the decrease in the required instantaneous power demands and fuel consumption when a vehicle is going down the two-way hilly road. This results in an increase in overall power demands and fuel consumption by substantial amounts compared with those power requirements and fuel consumption estimated for flat roads. This is given in details in Figures 3.2 - 3.5 for spark ignition (leaded or unleaded) vehicles with average mass of $1430 \mathrm{~kg}$ and for heavyduty diesel vehicles with average mass of $10000 \mathrm{~kg}$.

It is noted from Figures 3.2 - 3.5 that the increase in both the power demands and fuel consumption is a function of both the vehicle speed and road gradient. For example a petrol vehicle with average mass of $1430 \mathrm{~kg}$ running at a speed of $60 \mathrm{~km} / \mathrm{h}$ needs $75 \%$ net increase in the fuel consumption to account for both directions of a hilly road with a slope of $3^{\circ}$, while a heavy-truck diesel vehicle of average mass of $10000 \mathrm{~kg}$ running at a speed of $60 \mathrm{~km} / \mathrm{h}$ needs $100 \%$ net increase in the fuel consumption to account for both directions of a hilly road with a slope of $3^{\circ}$.

Also, Figures 3.6 - 3.11 show the impact of both the vehicle speed and the road gradient on the increase of the emission levels of $\mathrm{CO}, \mathrm{HC}$, and $\mathrm{NOx}$ emission levels for both the spark ignition (leaded or unleaded) vehicles with average mass of $1430 \mathrm{~kg}$ and for heavyduty diesel vehicles with average mass of $10000 \mathrm{~kg}$. It can be seen from these Figures that the effect of road gradient on $\mathrm{NO}_{\mathbf{X}}$ emissions is higher than the effect of road gradient on both $\mathrm{CO}$ and $\mathrm{HC}$ emissions.

The power -based emissions model can account for acceleration-deceleration manoeuvres. It is estimated that the effect of acceleration-deceleration manoeuvres of $0.62 \mathrm{~km} / \mathrm{h} / \mathrm{s}$ on the power demands, fuel consumption, and pollutant emissions is equal to the effect of the road slope of $\pm 1^{\circ}$ on the power demands, fuel consumption, and pollutant emissions, as discussed in more detail in Appendix D. This characteristic is essential when dealing with estimating traffic pollution in urban areas because the driving pattern in these areas includes great parts of acceleration and deceleration manoeuvres. This agrees with the conclusions of Lyons et al., 1990 who reported in their study of motor vehicle 
emissions inventory for the Perth airshed that the integration of driving characteristics and vehicle emissions based on speed and acceleration illustrated a marked variation in emission factors from the city business district to the outer suburbs.

Another interesting characteristic of the power-based exhaust emissions model is that the model accounts for the effects of wind speed and wind-road angle on power demands, fuel consumption and the gaseous emissions of $\mathrm{CO}_{2}, \mathrm{CO}, \mathrm{HC}$, and $\mathrm{NO}_{\mathrm{x}}$. This is discussed in detail in Appendix D. Figures $3.12-3.13$ show the effect of the cross winds on both of the power requirements and fuel consumption compared with the power requirements and fuel consumption for the front wind (wind-road angle = $\left.0^{\circ}\right)$.

It is clear from Figures 3.12 that if the cross-wind is such as the wind-road angle is less than $60^{\circ}$ the percentage of the power required increases from $0.0 \%$ at parallel wind to 5 $\%$ at wind-road angle 60 degrees, and the percentage of the power required decreases from $5 \%$ at wind-road angle 60 to $0 \%$ at the perpendicular wind.

TOTAL POWER $(\mathrm{Zt})$

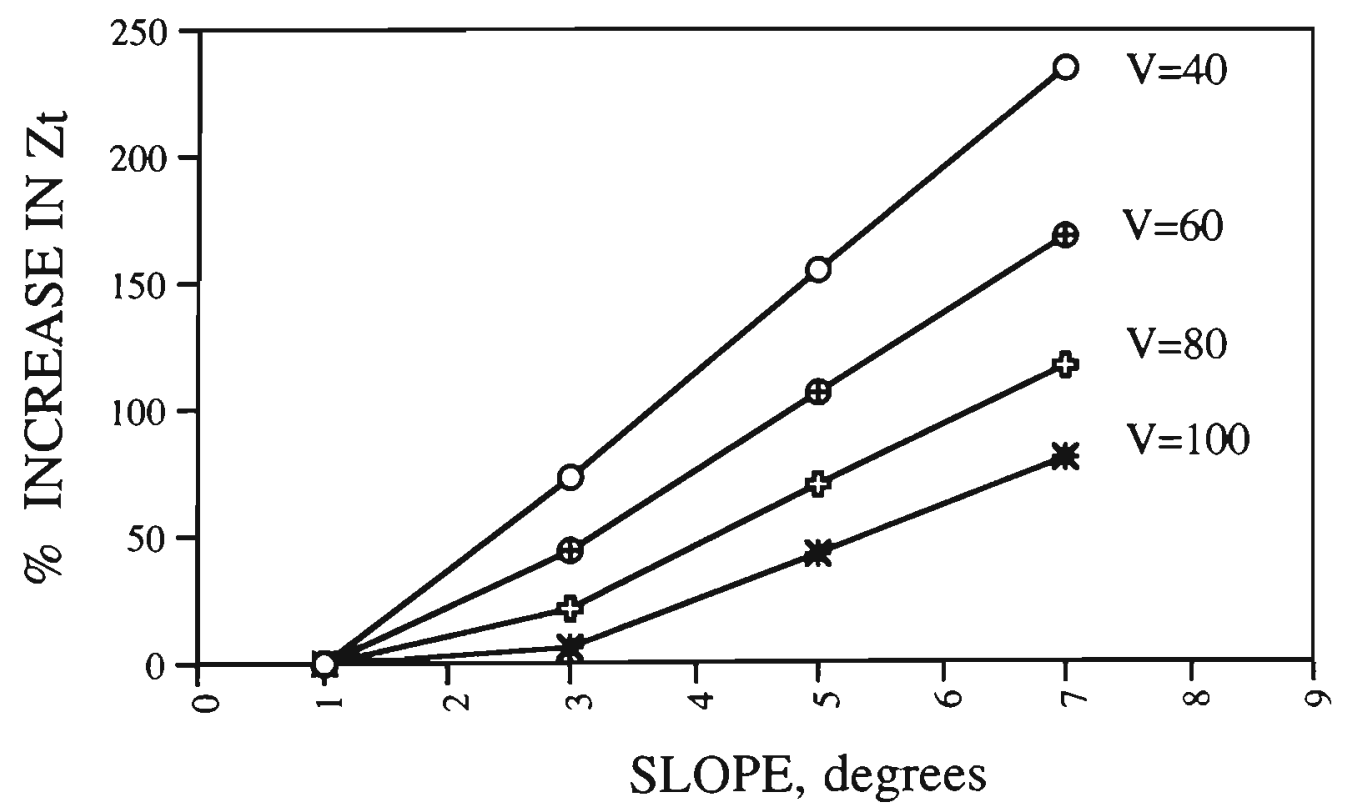

Figure 3.2 The increase in the power demands versus vehicle speed and as a function of road gradient for a petrol vehicle with all-up mass of $1430 \mathrm{~kg}$. (calculations for a two-way road). 


\section{FUEL CONSUMPTION $\left(\mathrm{F}_{\mathrm{C}}\right)$}

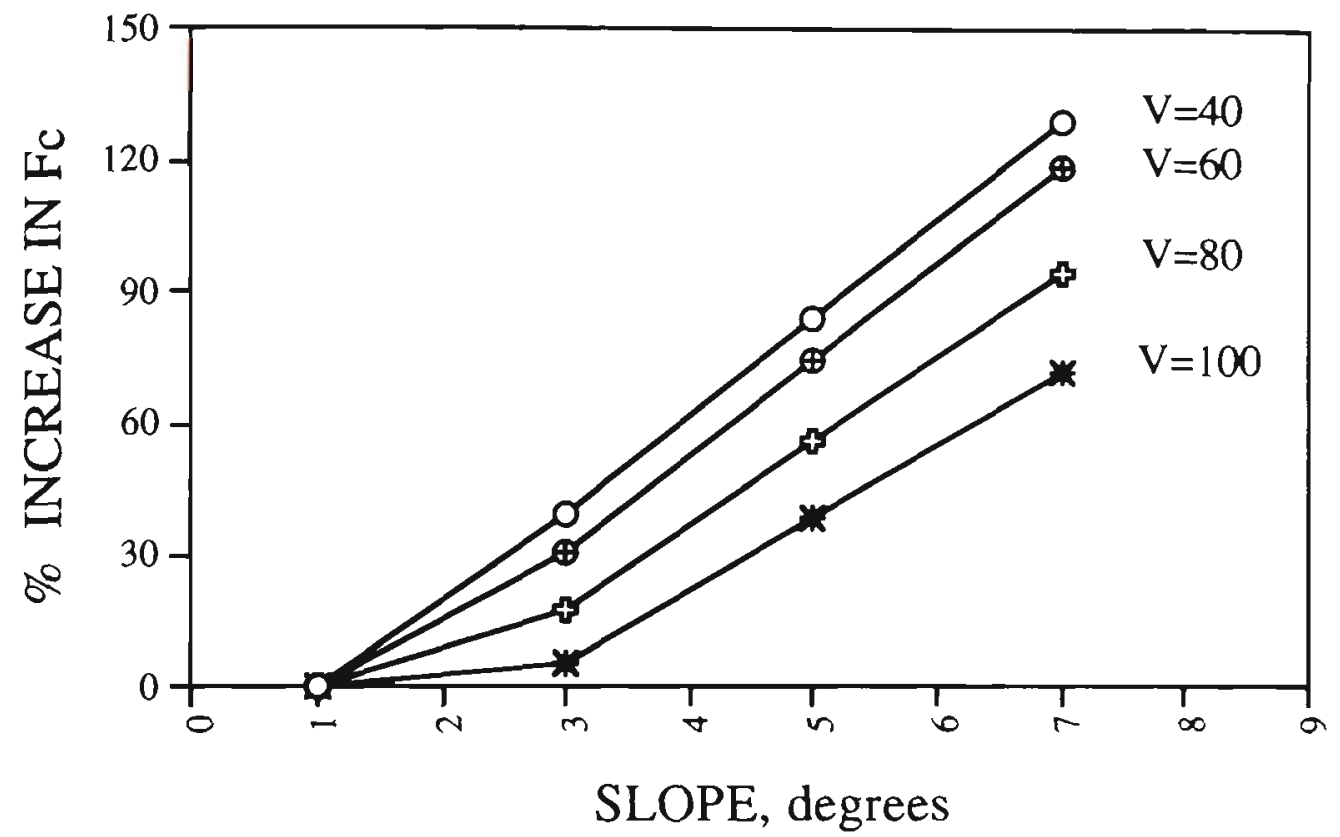

Figure 3.3 The increase in the fuel consumption versus vehicle speed and as a function of road gradient for a petrol vehicle with all-up mass of $1430 \mathrm{~kg}$. (calculations for a two-way road).

TOTAL POWER $\left(\mathrm{Z}_{\mathrm{t}}\right)$

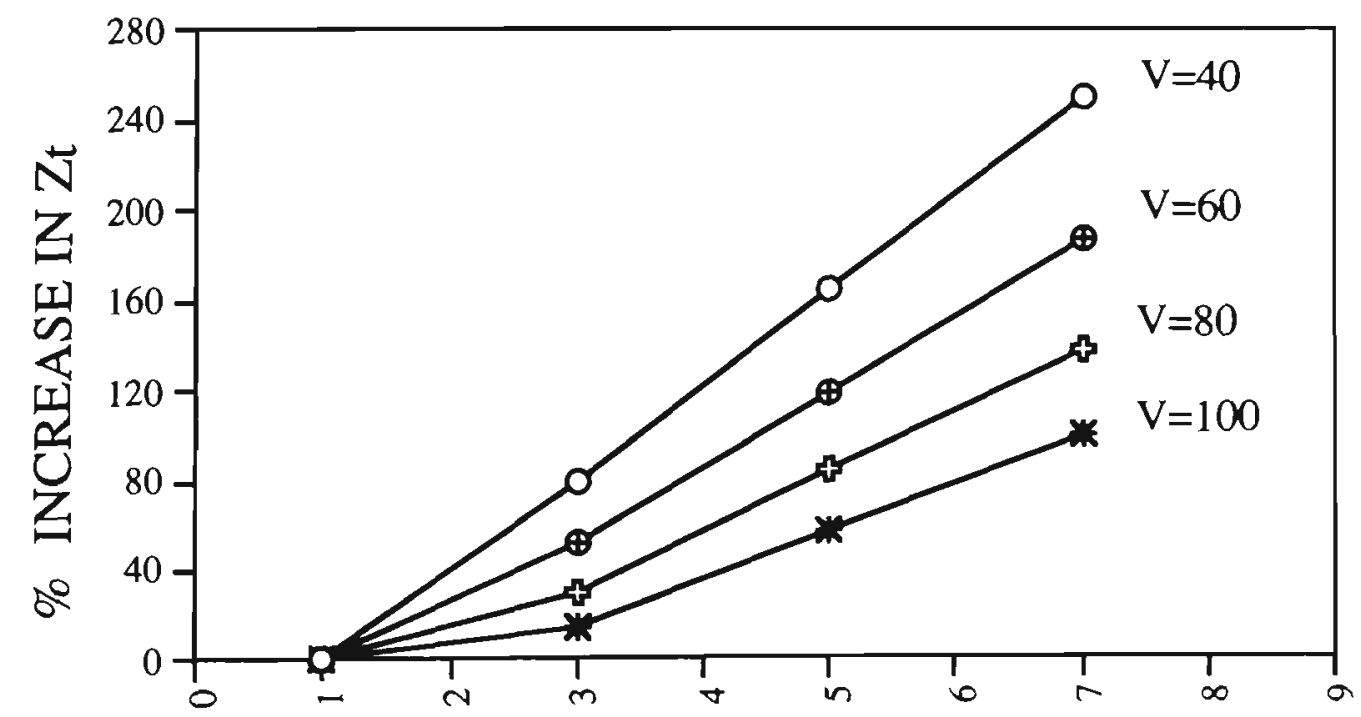

SLOPE, degrees

Figure 3.4 The increase in the power demands versus vehicle speed and as a function of road gradient for a heavy-duty vehicle with all-up mass of $10000 \mathrm{~kg}$.(calculations for a two-way road). 


\section{FUEL CONSUMPTION $\left(\mathrm{Fc}_{\mathrm{c}}\right)$}

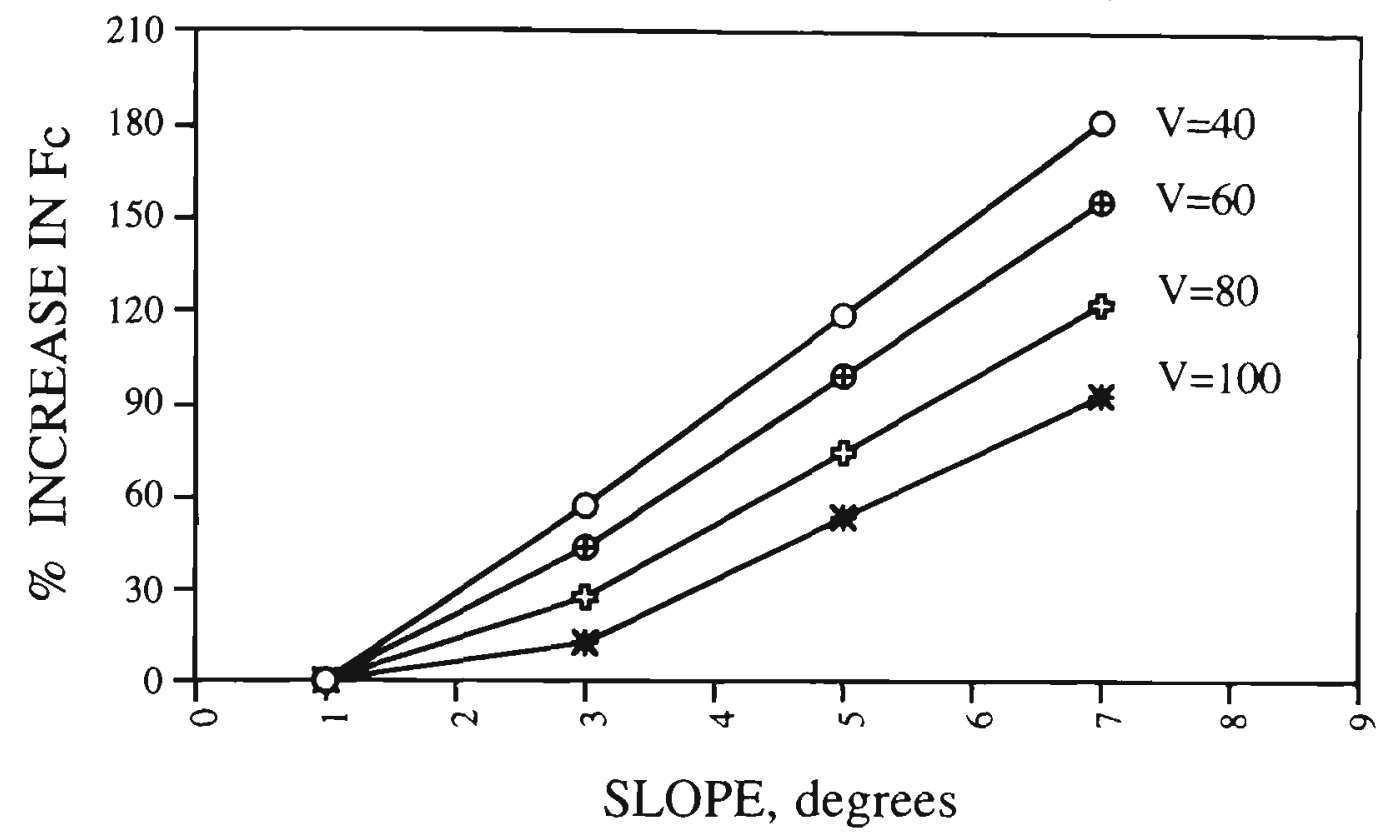

Figure 3.5 The increase in the fuel consumption versus vehicle speed and as a function of road gradient for a heavy-duty vehicle with all-up mass of $10000 \mathrm{~kg}$. (calculations for a two-way road).

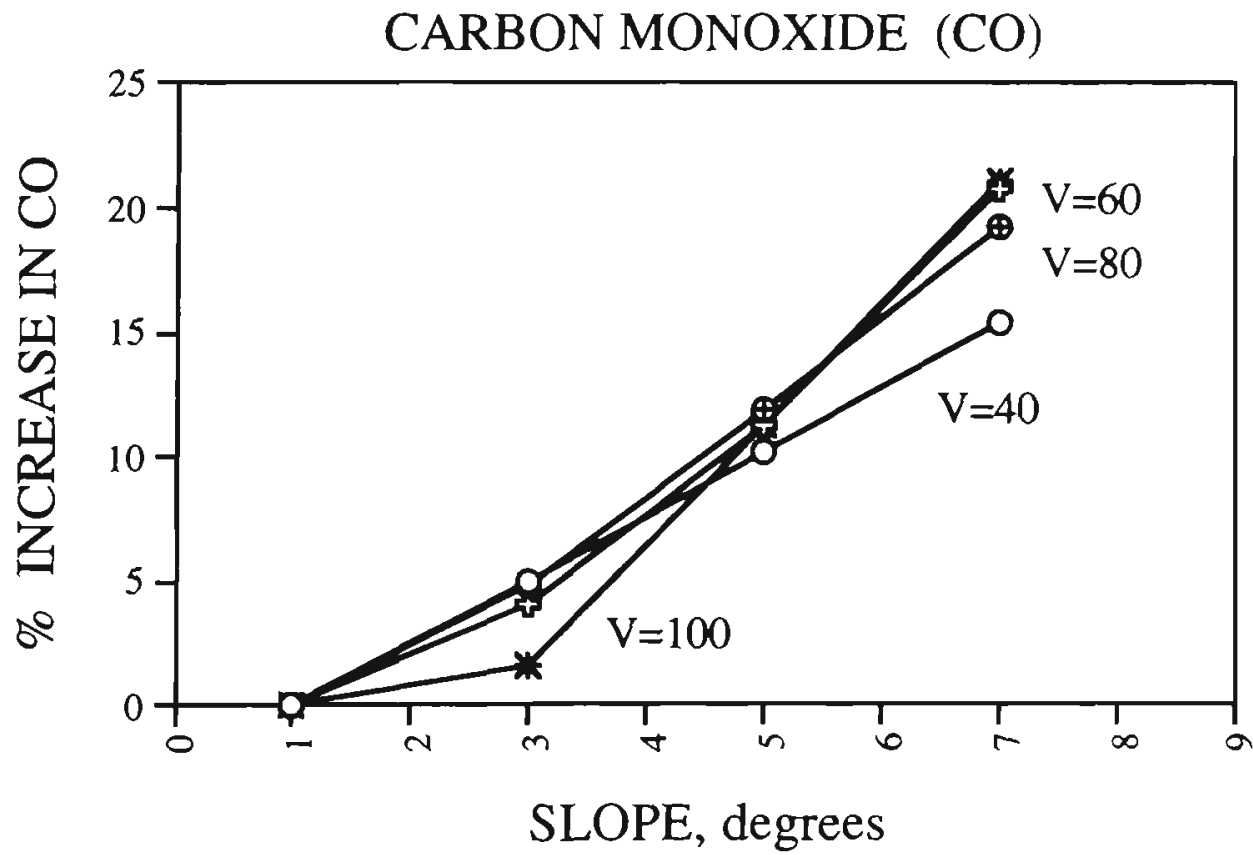

Figure 3.6 The increase in carbon monoxide emission levels versus road gradient and as a function of vehicle speed for a spark ignition (leaded) vehicle with all-up mass of $1430 \mathrm{~kg}$. (calculations for a two-way road). 


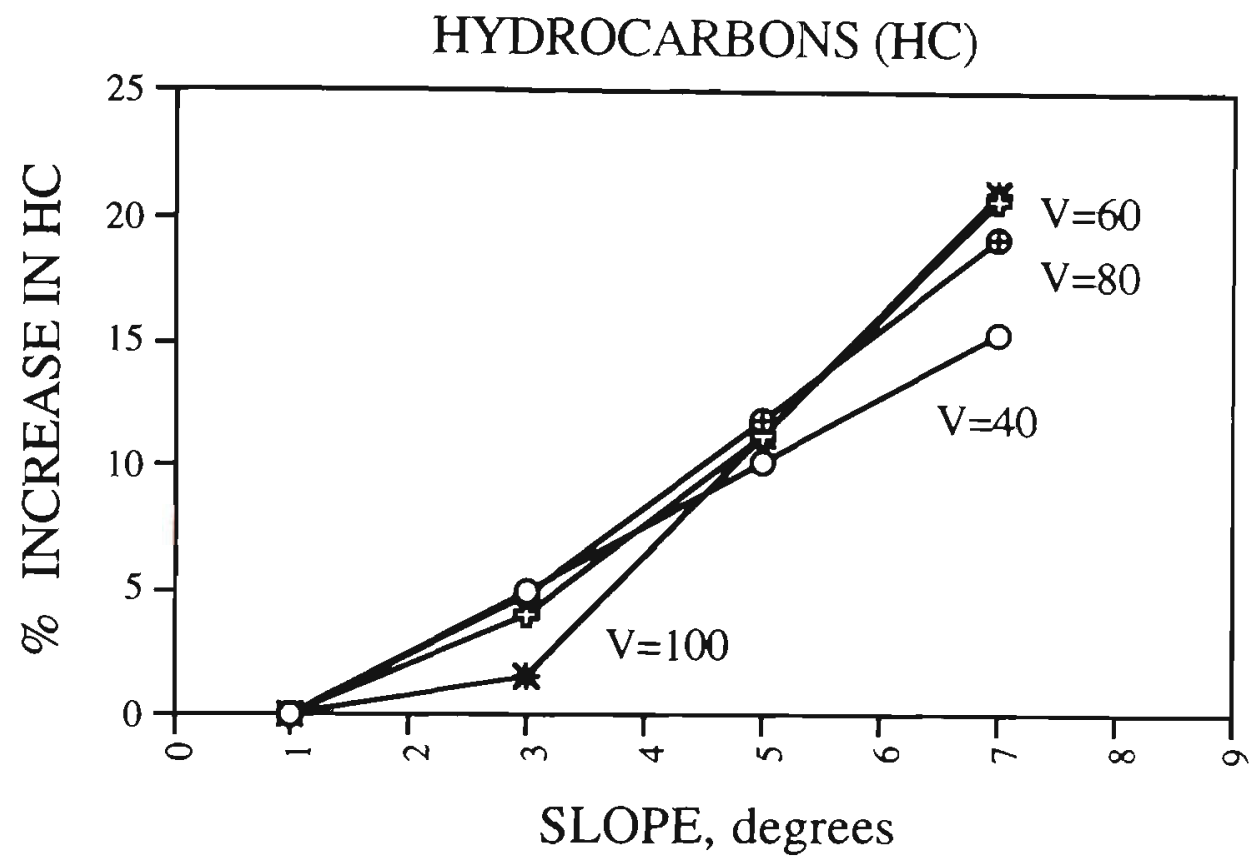

Figure 3.7 The increase in hydrocarbon emission levels versus road gradient and as a function of vehicle speed for a spark ignition (leaded) vehicle with all-up mass of $1430 \mathrm{~kg}$. (calculations for a two-way road).

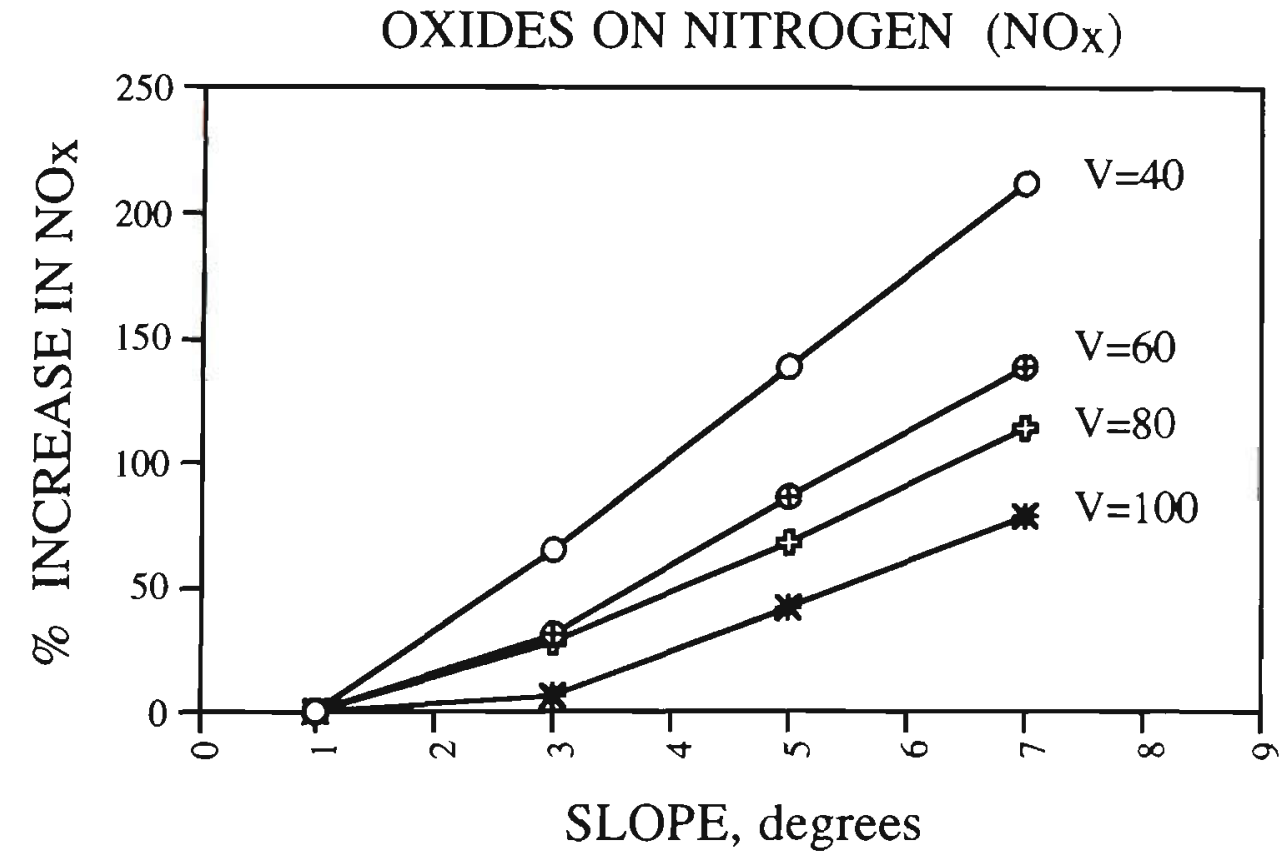

Figure 3.8 The increase in oxides of nitrogen emission levels versus road gradient and as a function of vehicle speed for a spark ignition (leaded) vehicle with all-up mass of $1430 \mathrm{~kg}$. (calculations for a two-way road). 


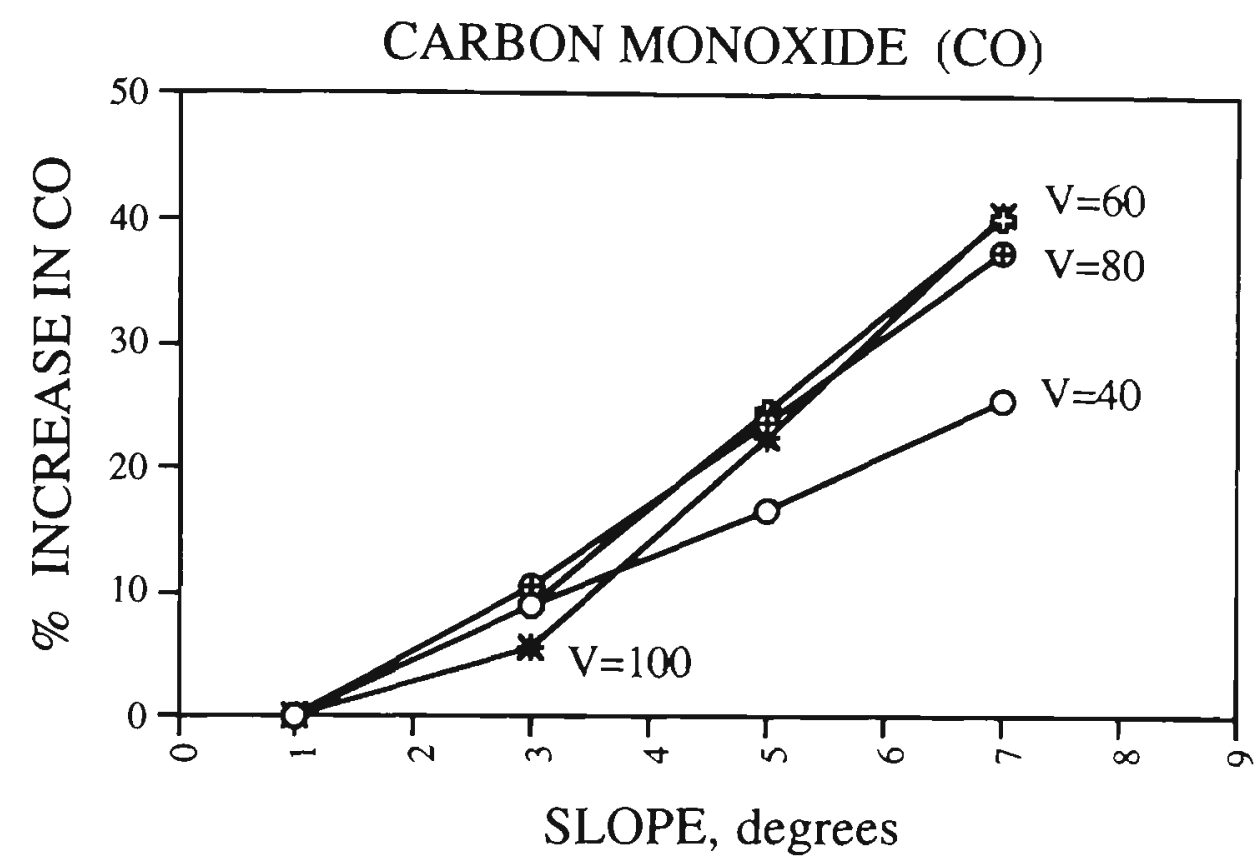

Figure 3.9 The increase in carbon monoxide emission levels versus road gradient and as a function of vehicle speed for a heavy-duty diesel vehicle with all-up mass of $10000 \mathrm{~kg}$. (calculations for a two-way road).

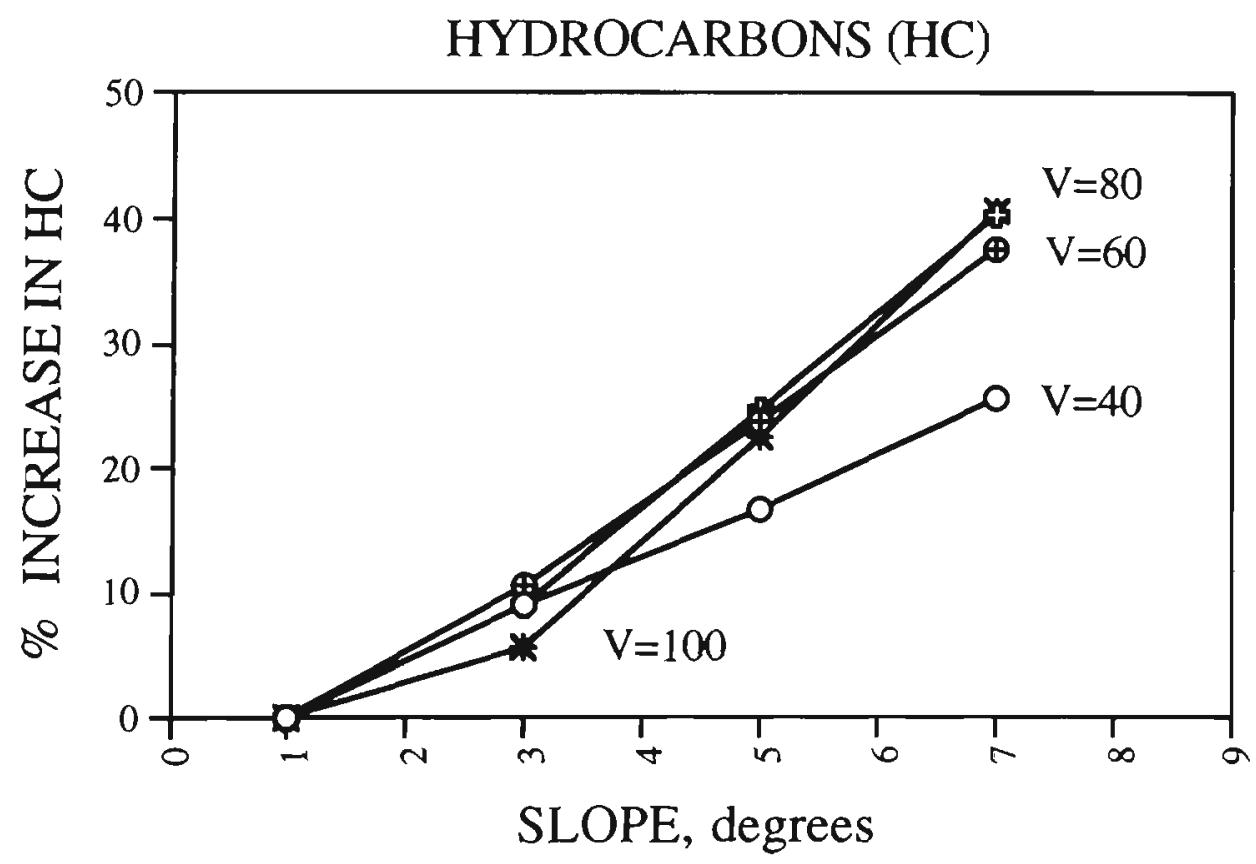

Figure 3.10 The increase in hydrocarbon emission levels versus road gradient and as a function of vehicle speed for a heavy-duty diesel vehicle with all-up mass of $10000 \mathrm{~kg}$. (calculations for a two-way road). 


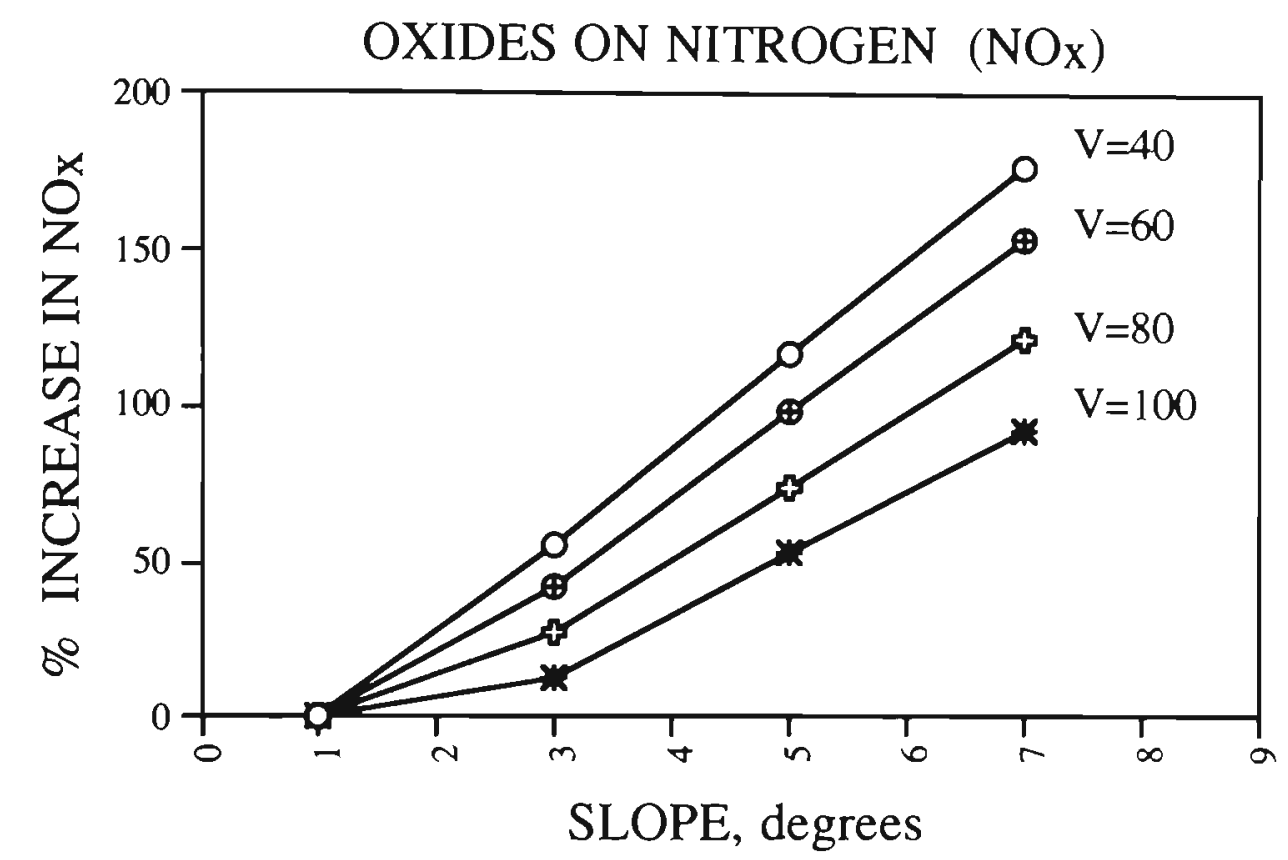

Figure 3.11 The increase in oxides of nitrogen emission levels versus road gradient and as a function of vehicle speed for a heavyduty diesel vehicle with all-up mass of $10000 \mathrm{~kg}$. (calculations for a two-way road).

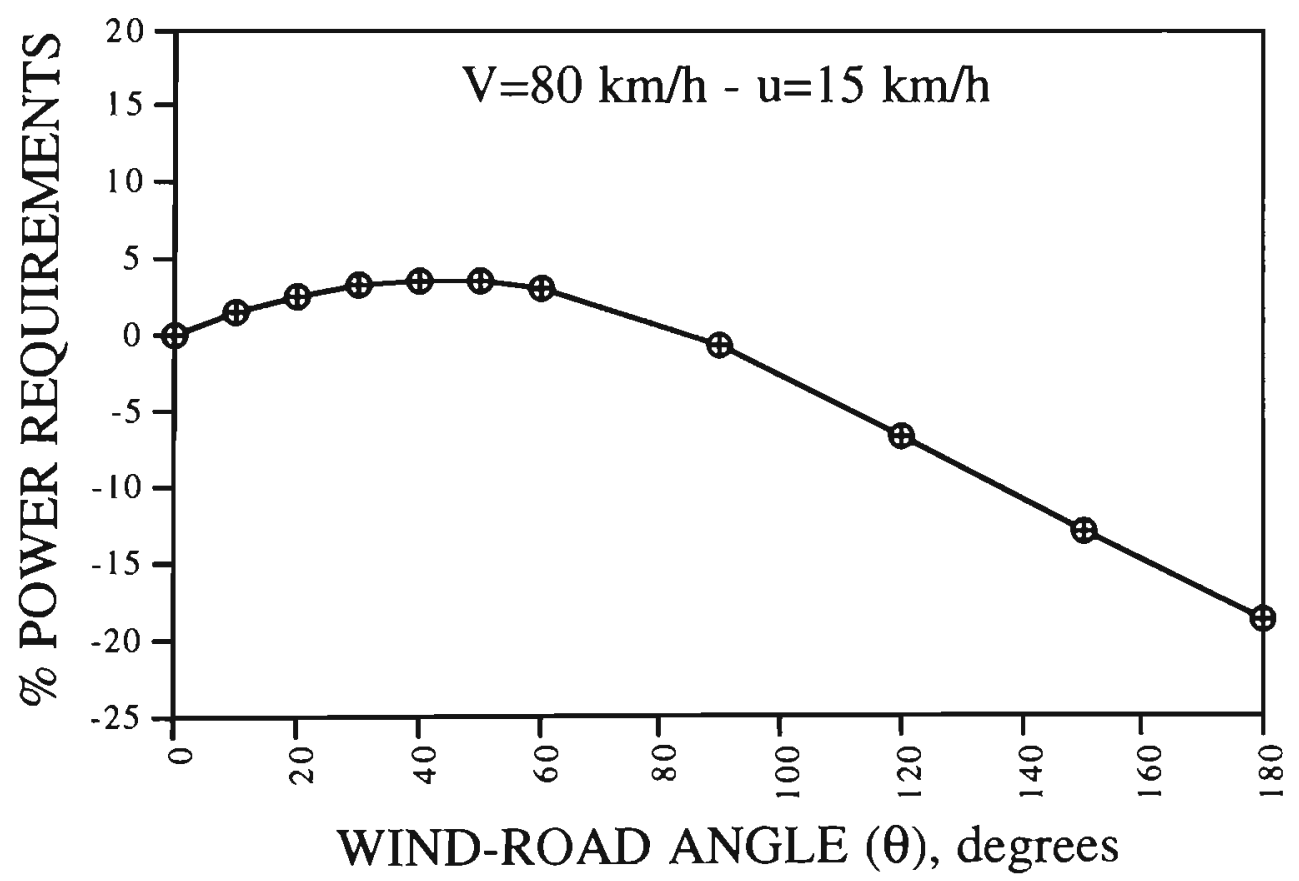

Figure 3.12 The percentage change in power demands versus wind-road angle for an articulated truck with mass of 30 tons travelling at $80 \mathrm{~km} / \mathrm{h}$ through wind of $15 \mathrm{~km} / \mathrm{h}$. (Calculations based on the power-based emissions model for a car with dimensions of $2.5 \mathrm{~m}$ width, $4.3 \mathrm{~m}$ height, and $7 \mathrm{~m}$ length.) 


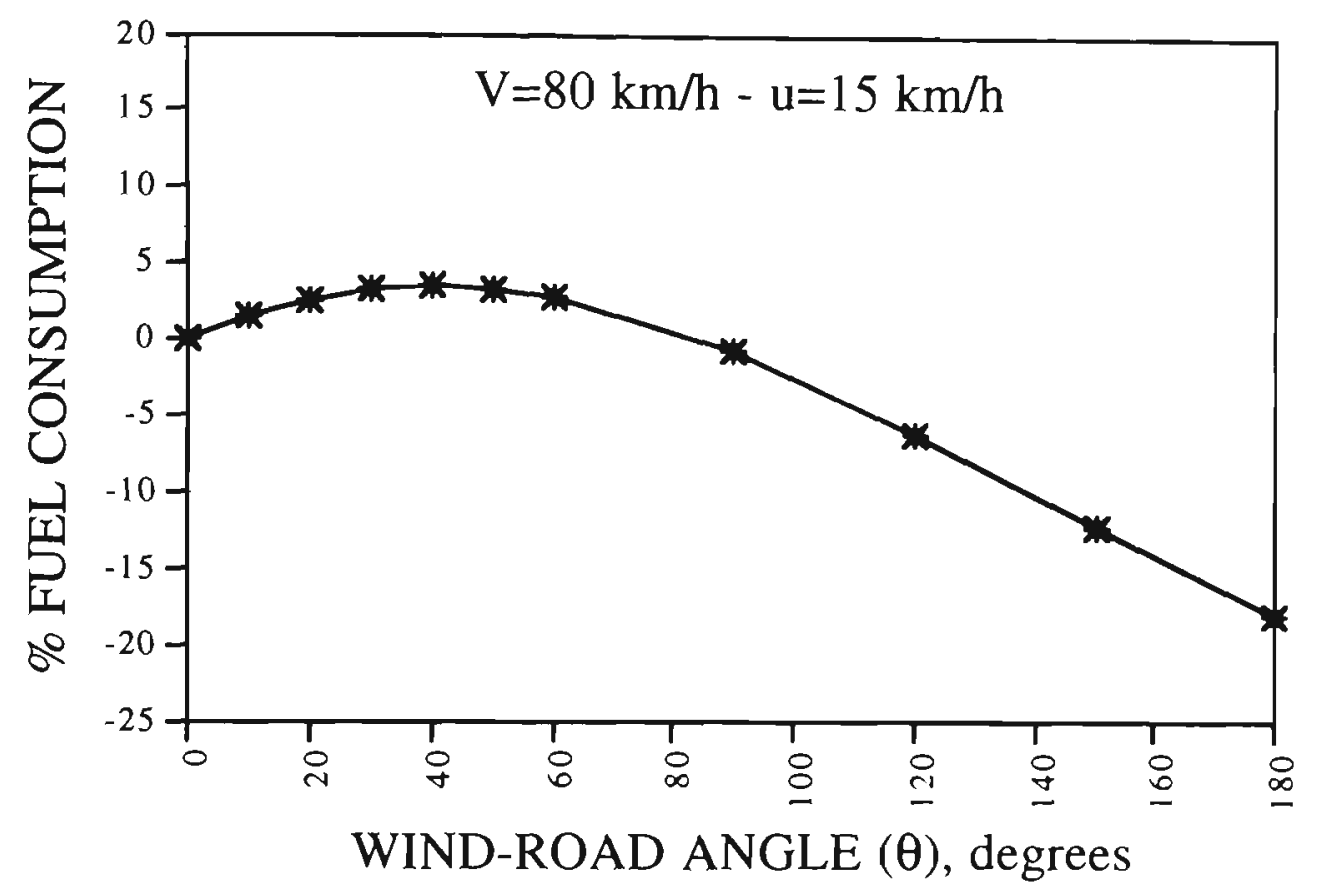

Figure 3.13 The percentage change in fuel consumption versus wind-road angle for an articulated truck with mass of $\mathbf{3 0}$ tons travelling at $80 \mathrm{~km} / \mathrm{h}$ through wind of $15 \mathrm{~km} / \mathrm{h}$. (Calculations based on the power-based emissions model for a car with dimensions of $2.5 \mathrm{~m}$ width, $4.3 \mathrm{~m}$ height, and $7 \mathrm{~m}$ length.)

However, if a cross-wind is such that $\left(90^{\circ}<\right.$ the wind-road angle $\left.\leq 180^{\circ}\right)$, the percentage power saving increases until it reaches $18 \%$ for a wind-road angle $=180^{\circ}$. This power saving occurs because the wind helps by blowing from the rear of the vehicle and gives the bluff vehicle a boost of wind power. Figure 3.13 shows the corresponding fuel consumption.

Also, it is demonstrated that the effect of wind-road on both $\mathrm{CO}_{2}$ and $\mathrm{NO}_{\mathrm{X}}$ emissions are higher than $\mathrm{CO}$ and $\mathrm{HC}$ emissions because $\mathrm{CO}_{2}$ and $\mathrm{NO}_{\mathrm{x}}$ are power-dependent pollutants.

The above effects of the wind speed and wind-road angle on power demands, fuel consumption and the gaseous emissions agree with Close et al., 1981, who discussed in detail the effect of truck specifications on fuel consumption. Close et al., 1981 reported that the aerodynamically inefficient shapes of trucks and buses require a great deal of

power to push the truck or bus through the air. The power required to overcome air drag increases directly in proportion with the frontal area of the vehicle. The increase in power demands will result in increasing both the fuel consumption and gaseous emissions. 


\subsection{The comparison of the Power-Based Emissions Model with US EPA EMFAC7F}

In this part the emission source strengths estimated, based on the power-based emissions model, are compared with US estimates for the 1990 SI vehicle fleet based on FTP data with SCF using EMFAC7F methodology of the California Air Resources Board. In estimating emission source strengths using the power-based emissions model, it has been assumed that unleaded vehicles made up to $55 \%$ of the passengers/light-duty vehicle fleet, which in turn had an average engine capacity of $3.5 \mathrm{~L}$, an average mass of $1430 \mathrm{~kg}$, and an aerodynamic factor, $\mathrm{C}_{\mathrm{d}} \mathrm{A}$, having a value of $0.73 \mathrm{~m}^{2}$. The corresponding values for heavy goods vehicles were $5 \mathrm{~L}, 10,000 \mathrm{~kg}$, and $3.6 \mathrm{~m}^{2}$. As EMFAC data are for a fleet average, extra CO, HC, and NOx have been added due to vehicle deterioration according to US EPA recommendations given in Carnovale et al., $1991(0.78 \mathrm{~g} / \mathrm{km} / 10,00 \mathrm{~km}$ for $\mathrm{CO}, 0.047 \mathrm{~g} / \mathrm{km} / 10,000 \mathrm{~km}$ for $\mathrm{HC}$, and $0.035 \mathrm{~g}$ $/ \mathrm{km} / 10,000 \mathrm{~km}$ for $\mathrm{NO}_{\mathrm{X}}$ ) and assuming $60,000 \mathrm{~km}$ as the average odometer reading. For the purposes of comparison the road slope and vehicle acceleration were assumed to be zero.

The results of $\mathrm{CO}, \mathrm{HC}$, and $\mathrm{NO}_{\mathrm{x}}$ for petrol leaded vehicles with all-up mass of $1430 \mathrm{~kg}$ are shown in Figures 3.14, 3.15, and 3.16 whilst the results of $\mathrm{CO}, \mathrm{HC}$, and NOx for heavy-duty diesel vehicles with all-up mass of $10,000 \mathrm{~kg}$ are shown in Figures 3.17, 3.18, and 3.19. It can be seen that the power-based emissions model produces curves which are similar in shape to EMFAC produced curves, but for road slope and acceleration equal zero.

In addition, the advantages of the power-based emissions model methodology include the capabilities of the model to account for both the road slope and the accelerationdeceleration manoeuvres, as well as wind-road angle which has a clear effect on source strengths estimates, as described in detail in Appendix D.

Another advantage of the power-based emissions model against US EMFAC methodology is the capability of the model to estimate the excess atmospheric $\mathrm{CO}_{2}$ emissions generated by traffic. This capability is important because emissions of $\mathrm{CO}_{2}$ are being subjected to increasing interest due to their contribution to the "greenhouse effect". 


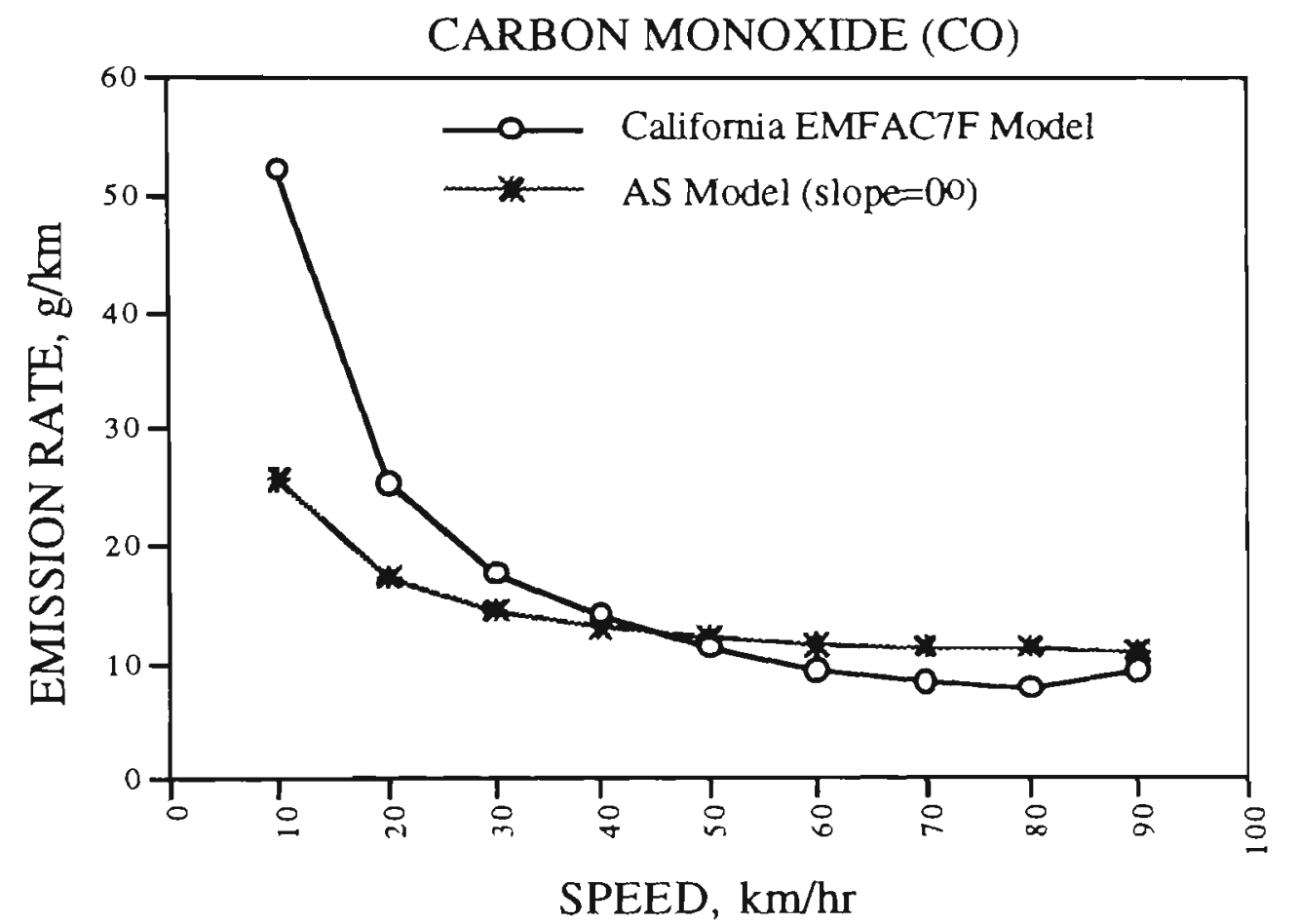

Figure 3.14 The comparison of $\mathrm{CO}$ emission rates for SI vehicles (leaded) with all-up mass of $1430 \mathrm{~kg}$ estimated using California EMFAC7F model with those estimated using the new Emissions Model .

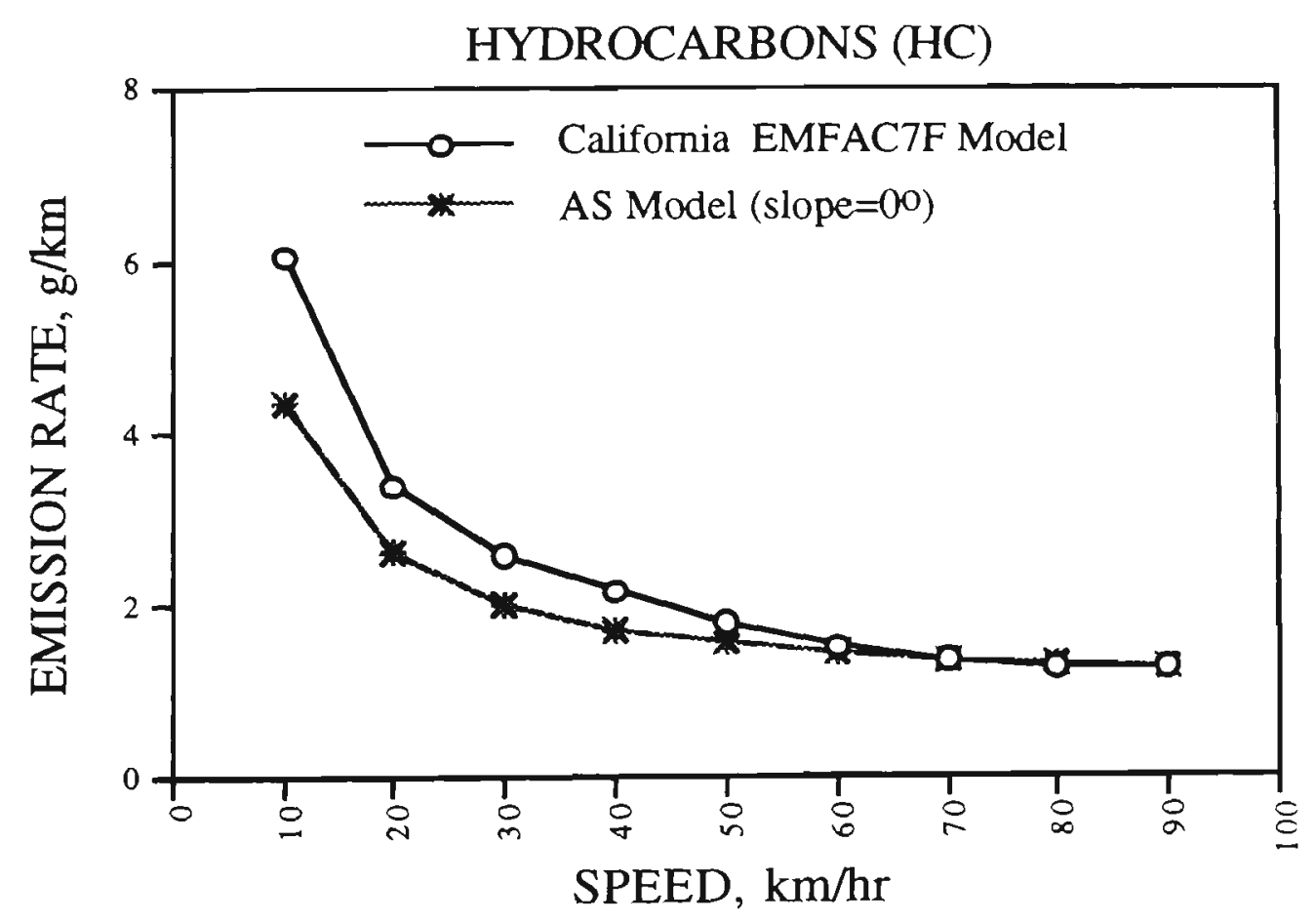

Figure 3.15 The comparison of $\mathrm{HC}$ emission rates for SI vehicles (leaded) with all-up mass of $1430 \mathrm{~kg}$ estimated using California EMFAC7F model with those estimated using the new Emissions Model . 


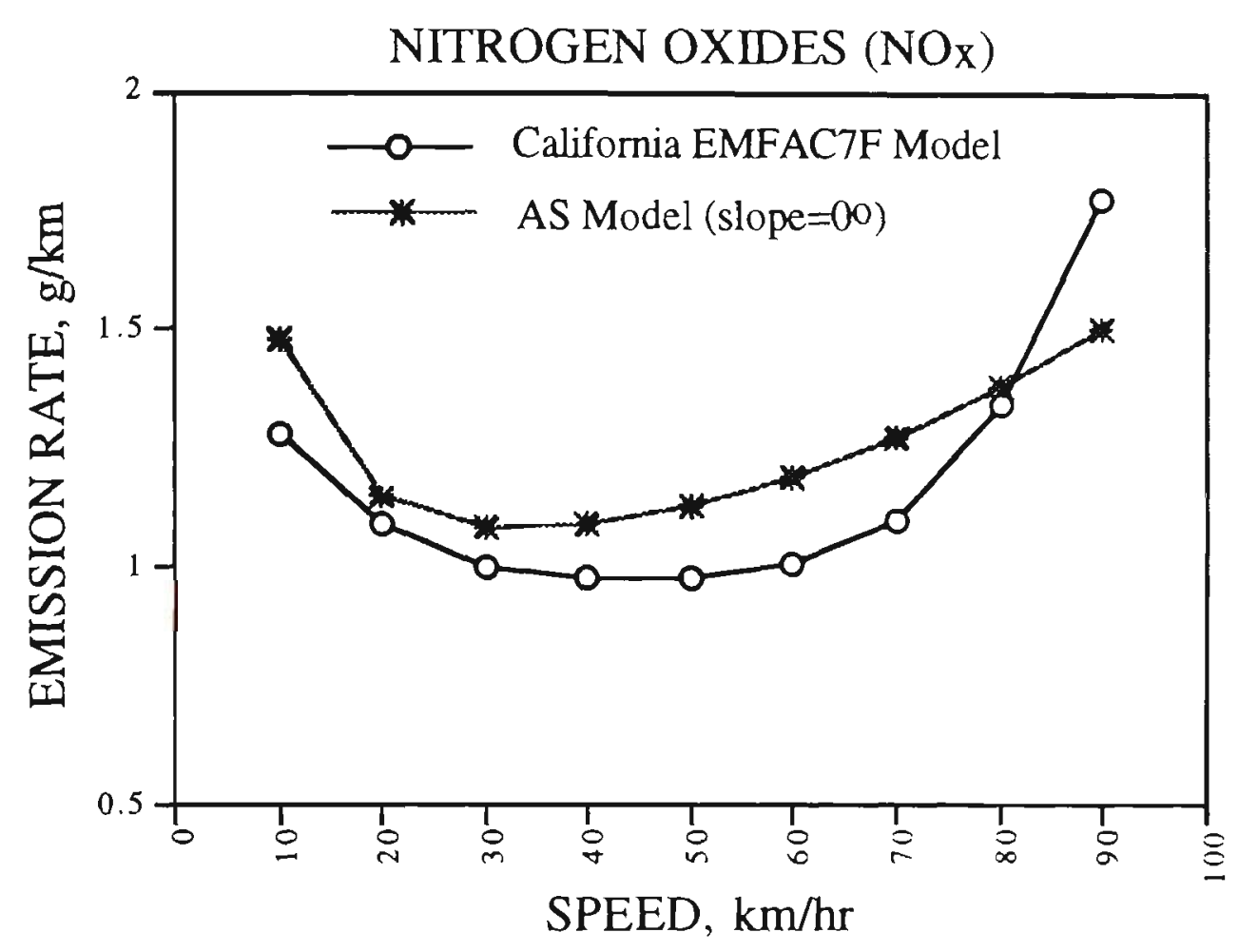

Figure 3.16 The comparison of $\mathrm{NO}_{\mathbf{x}}$ emission rates for SI vehicles (leaded) with all-up mass of $1430 \mathrm{~kg}$ estimated using California EMFAC7F model with those estimated using the new Emissions Model.

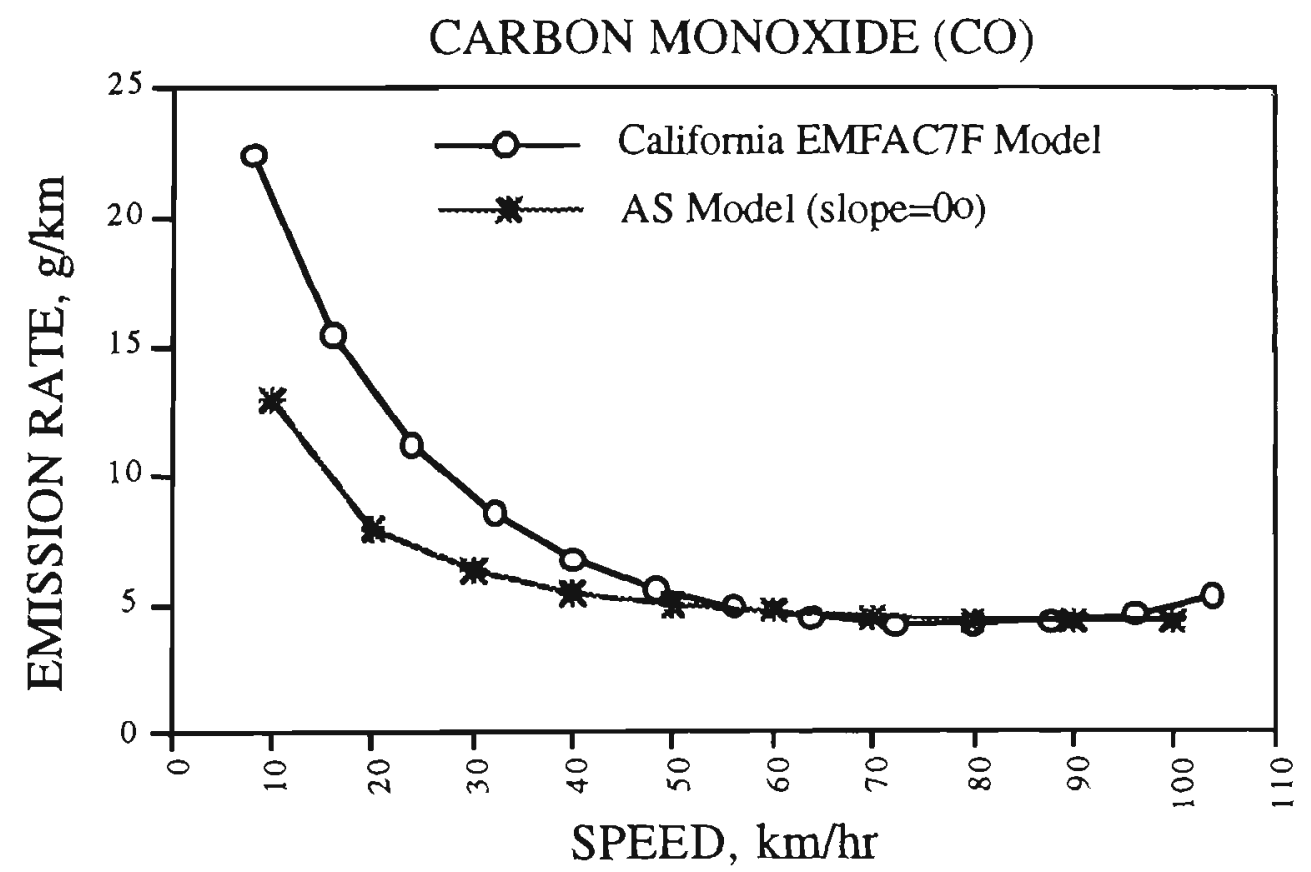

Figure 3.17 The comparison of $\mathrm{CO}$ emission rates for heavy-duty diesel vehicles with all-up mass of $10000 \mathrm{~kg}$ estimated using California EMFAC7F model with those estimated using the new Emissions Model . 


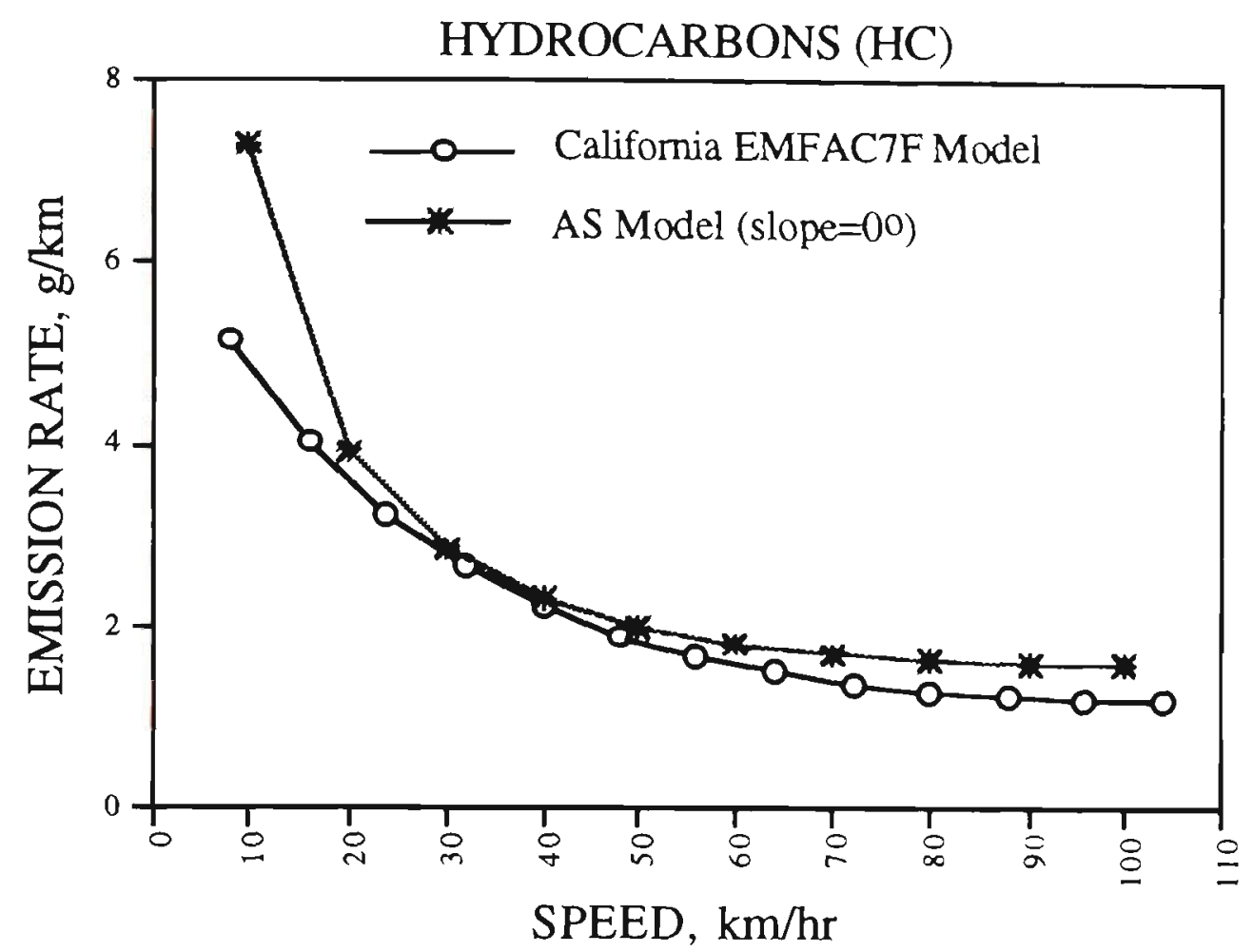

Figure 3.18 The comparison of $\mathrm{HC}$ emission rates for heavy-duty diesel vehicles with all-up mass of $10000 \mathrm{~kg}$ estimated using California EMFAC7F model with those estimated using the new Emissions Model.

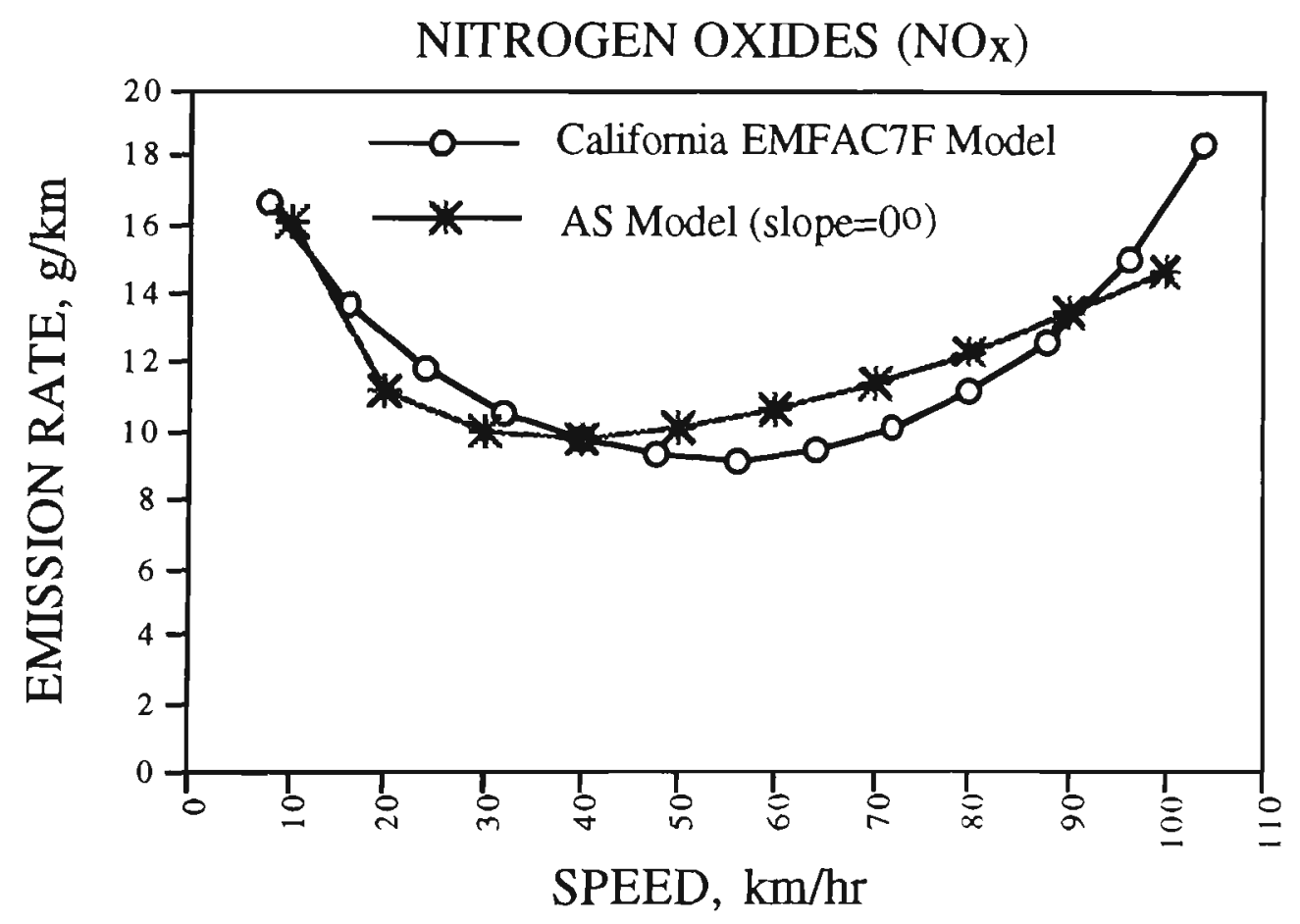

Figure 3.19 The comparison of $\mathrm{NO}_{\mathrm{x}}$ emission rates for heavy-duty diesel vehicles with all-up mass of $10000 \mathrm{~kg}$ estimated using California EMFAC7F model with those estimated using the new Emissions Model. 


\subsection{Summary}

Emissions of carbon $\left(\mathrm{CO}_{2}\right)$, carbon monoxide ( $\mathrm{CO}$ ), hydrocarbons ( $\left.\mathrm{HC}\right)$, and oxides of nitrogen $\left(\mathrm{NO}_{\mathbf{X}}\right)$ from both spark ignition vehicles $(\mathrm{SI})$ and diesel vehicles have been modelled by considering the instantaneous power requirements for a given situation using the approach developed by Post et al., (1981).and Kent et al., (1982). This approach have been modified to include diesel vehicles as well as catalyst-equipped spark ignition vehicles.

The model estimates the power required for a vehicle of specified mass to overcome rolling and drive-train resistance, aerodynamic resistance, and gravity. The power required for a vehicle for a given situation leads to estimates of fuel consumption and emissions. When the model for spark ignition is used over a drive cycle, the influence of cold starts is quantified and allowance is made. In the case of catalyst equipped vehicles, allowance is made for catalyst warm-up and for variations in catalyst efficiency.

The new model is capable of estimating the excess atmospheric $\mathrm{CO}_{2}$ emissions generated by traffic. Emissions of $\mathrm{CO}_{2}$ - essentially a factor of fuel consumption - are being subjected to increasing interest due to their contribution to the "greenhouse effect".

The power-based exhaust emissions model estimates the effects of both the road gradient and acceleration-deceleration manoeuvres on power demands, fuel consumption, and gaseous emissions levels.

The power-based exhaust emissions model also estimates the effects of wind speed and wind-road angle on power demands, fuel consumption and the gaseous emissions of $\mathrm{CO}_{2}, \mathrm{CO}, \mathrm{HC}$, and $\mathrm{NO}_{\mathbf{X}}$.

The power-based emissions model produces curves for $\mathrm{CO}, \mathrm{HC}$, and $\mathrm{NO}_{\mathrm{X}}$ similar in shape to those produced by US-EMFAC model (for both petrol and diesel vehicles), but for road slope and acceleration equal zero. 


\section{CHAPTER 4}

\section{POLLUTANTS DISPERSION MODELLING}

\subsection{Gaussian plume model}

The most widely used models in plume modelling are those based on assumptions connected with the Gaussian distribution and commonly known as Gaussian models. The origin of the Gaussian models is found in work by Sutton (1932), Pasquill (1961, 1974), and Gifford (1961, 1968). Most practical diffusion formulas are based on Gaussian concentration profiles and a tabulated or graphical representation of the horizontal and vertical standard deviations of cross-wind concentration distribution with distance downwind and stability.

The major assumptions of simple Gaussian models have been described by Carras et al. (1989) and are summarised here for reference. They are:

i) the model describes plume behaviour over an averaging time which is long compared to the natural time-scales of the dispersion processes.

ii) the cross-wind horizontal and vertical distributions of plume material are well described by the Gaussian distribution function with reflection of the plume by the ground;

iii) the plume travels in a straight line and the wind speed and direction of the plume are those defined at the source;

iv) diffusion in the along-wind direction is neglected;

v) the concentrations predicted by the model represent ensemble average values.

While more complicated applications for Gaussian models have been developed using algorithms to describe topography, building effects, plume penetration etc, the basic assumptions are as described above.

For a point source of emission rate $Q$ (in micrograms per second) and at an effective height $h$ (in meters) above the ground (the prescribed no-flux condition at the surface may be accommodated with the use of an image source as described in Figure 4.1, the concentration $\mathrm{C}(\mathrm{x}, \mathrm{y}, \mathrm{z})$ (in micrograms per cubic meter) is then given by the formula:

$$
C(x, y, z)=\frac{Q}{2 \pi \sigma_{y} \sigma_{z} u} \exp \left(\frac{-y^{2}}{2 \sigma_{y}^{2}}\right) \exp \left(\frac{-(z-h)^{2}}{2 \sigma_{z}^{2}}+\frac{-(z+h)^{2}}{2 \sigma_{z}^{2}}\right)
$$



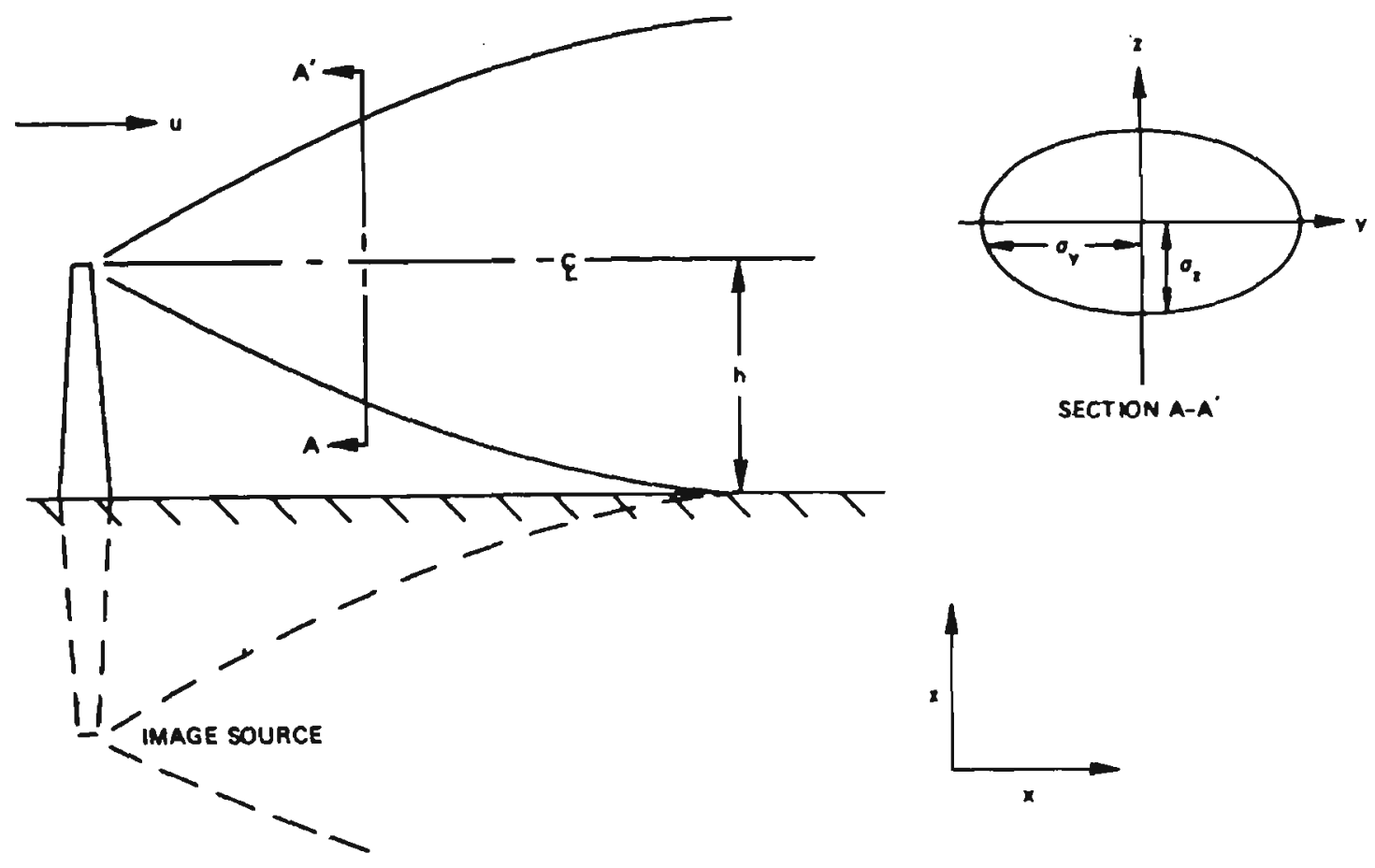

Figure 4.1 Diagram of typical plume, illustrating concepts important in the Gaussian plume formula. Symbols: $u$ is the wind speed; $h$ is the effective source height; $\sigma_{y}$ and $\sigma_{z}$ are standard deviations of crosswind concentration distribution (Hanna, 1982).

where $C(x, y, z)$ is the ground-level concentration, $Q$ is the source strength, $\sigma_{y}$ and $\sigma_{z}$ are the horizontal and vertical dispersion standards deviations, respectively, $u$ is the horizontal wind speed and $y$ is the lateral displacement from the plume centre-line. The resulting ground level $(z=0)$ concentration is

$$
C(x, y, z)=\frac{Q}{2 \pi \sigma_{y} \sigma_{z} u} \exp \left(\frac{-y^{2}}{2 \sigma_{y}^{2}}\right) \exp \left(\frac{-(z-h)^{2}}{2 \sigma_{z}^{2}}+\frac{-(z+h)^{2}}{2 \sigma_{z}^{2}}\right)
$$

Along the plume centre-line:

$$
C(x, 0,0)=\frac{Q}{\pi \sigma_{y} \sigma_{z} u} \exp \left(\frac{-h^{2}}{2 \sigma_{z}^{2}}\right)
$$


And for a ground level source $(h=0)$ :

$$
C(x, 0,0)=\frac{Q}{\pi \sigma_{y} \sigma_{z} u}
$$

The corresponding equations for the line source of emission rate $\mathrm{Q}$ (in micrograms per second per meter ) normal to the mean flow are:

$$
\begin{aligned}
& C(x, 0, z)=\frac{Q}{\sqrt{2} \pi \sigma_{y} \sigma_{z} u} \exp \left(\frac{-(z-h)^{2}}{2 \sigma_{z}^{2}}+\frac{-(z+h)^{2}}{2 \sigma_{z}^{2}}\right) \\
& C(x, 0,0)=\frac{2 Q}{\sqrt{2} \pi \sigma_{y} \sigma_{z} u} \exp \left(\frac{-h^{2}}{2 \sigma_{z}^{2}}\right)
\end{aligned}
$$

And for a ground level source $(h=0)$ :

$$
\mathrm{C}(\mathrm{x}, 0,0)=\frac{2 \dot{\mathrm{Q}}}{\sqrt{2} \pi \sigma_{\mathrm{y}} \sigma_{\mathrm{z}} \mathrm{u}}
$$

Concentrations computed using equations (4.1-4.7) depend strongly upon a correct calculation of $\sigma_{\mathrm{y}}$ and $\sigma_{\mathrm{z}}$, which is a major challenge for all Gaussian model applications.

Gaussian dispersion models require a number of inputs for their routine application. These can be summarised as follows:

i) values of the vertical and horizontal dispersion coefficients $\sigma_{y}$ and $\sigma_{z}$. A number of workers (e.g. Gifford 1968, Briggs 1973, Smith 1972 and Irwin 1979) have used a combination of experimental data and theoretical considerations to create 'recommended' values for these variables. The values of $\sigma_{y}$ and $\sigma_{z}$ are expressed as functions of atmospheric stability and distance or travel time from the source.

ii) wind speed and direction at the height of the plume. These are rarely available and measurements from $10 \mathrm{~m}$ anemometers are normally scaled to plume height. Although the wind speed in the atmospheric surface layer increases with height, Turner, 1970 suggested using the mean wind speed within $2 \sigma_{\mathrm{Z}}$ of downwind distance. For transport distances between 0.1 and $1 \mathrm{~km}$, the wind speed at a height of $10 \mathrm{~m}$ is generally used (Pasquill, 1974). No suggestions were made for distances less than $100 \mathrm{~m}$. 
The output from Gaussian plume models is the concentration of pollutant as a function of downwind and cross-wind distance. The concentrations are interpreted as ensemble averages for the particular averaging time appropriate to the $\sigma_{y}$ and $\sigma_{z}$ and wind input data.

\subsection{Dispersion coefficients $\sigma_{\mathrm{y}}$ and $\sigma_{\mathrm{Z}}$}

Values of the the horizontal and vertical dispersion standards deviations $\left(\sigma_{y}\right.$ and $\left.\sigma_{z}\right)$ in the Gaussian models have often obtained in the past from curves of dispersion coefficient versus distance from the emission source as a function of atmospheric stability. These curves are based on a few carefully performed diffusion experiments . Pasquill's (1961) curves, which were adapated by Gifford $(1961,1968,1976)$ into the forms shown in Figures 4.2 and 4.3, are based on Project Prairie Grass diffusion experimemnt (Haugen, 1959). The terrain was uniform, releases were from near the ground level, and the concentration measurements were at downwind distances less than $1 \mathrm{~km}$ (Hanna, 1982).

Because computers are presently in widespread use, most people would rather have a formula than a graph or a table. Several researchers have worked out analytical power low formulas for $\sigma y$ and $\sigma z$. Smith (1968) developed the Brookhaven National Laboratory analytical power-law formulas based on hourly average measurements out to about $10 \mathrm{~km}$ of diffusion of a non buoyant plume released from a height of $108 \mathrm{~m}$ as follows :

$$
\begin{aligned}
& \sigma_{y}=a_{x}^{b} \\
& \sigma_{z}=c_{x}^{d}
\end{aligned}
$$

where $\mathrm{x}$ is the downwind distance in meters and $\mathrm{a}, \mathrm{b}, \mathrm{c}$ and $\mathrm{d}$ are parameters (Table 4.1).

Table 4.1 Brookhaven National Laboratory (BNL) Parameters Values in the Formulas 4.8 and 4.9 (Data from Zannetti, 1990).

\begin{tabular}{|c|c|c|c|c|c|}
\hline Stability class & Gustiness category & $\mathrm{a}$ & $\mathrm{b}$ & $\mathrm{c}$ & $\mathrm{d}$ \\
\hline $\mathrm{A}$ & $\mathrm{B} 2$ & 0.4 & 0.91 & 0.41 & 0.91 \\
\hline $\mathrm{B} / \mathrm{C}$ & $\mathrm{B} 1$ & 0.36 & 0.86 & 0.33 & 0.86 \\
\hline $\mathrm{D}$ & $\mathrm{C}$ & 0.32 & 0.78 & 0.22 & 0.78 \\
\hline F & $\mathrm{D}$ & 0.31 & 0.71 & 0.06 & 0.71 \\
\hline
\end{tabular}


Pasquill-Gifford standard deviations also have been represented analytically by Green et al., (1980) as:

$$
\begin{aligned}
& \sigma_{y}=k_{1} x\left(1+\left(x / k_{2}\right)\right)^{-k_{3}} \\
& \sigma_{z}=k_{4} \times\left(1+\left(x / k_{2}\right)\right)^{-k_{5}}
\end{aligned}
$$

where $\mathrm{x}$ is the down-wind distance in meters and $\mathrm{k}_{1}, \mathrm{k}_{2}, \mathrm{k}_{3}, \mathrm{k}_{4}$ and $\mathrm{k}_{5}$ are constants given in Table 4.2

Table 4.2 Values of the constants in the Equations 4.10 and 4.11 (Data from Zannetti, 1990).

\begin{tabular}{|c|c|c|c|c|c|}
\hline Stability class & $\mathrm{k}_{1}$ & $\mathrm{k}_{2}$ & $\mathrm{k} 3$ & $\mathrm{k} 4$ & $\mathrm{k} 5$ \\
\hline $\mathrm{A}$ & 0.25 & 927 & 0.189 & 0.102 & -1.918 \\
\hline $\mathrm{B}$ & 0.202 & 370 & 0.162 & 0.0962 & -0.101 \\
\hline C & 0.134 & 283 & 0.134 & 0.0722 & 0.102 \\
\hline D & 0.0787 & 707 & 0.135 & 0.0475 & 0.465 \\
\hline E & 0.0566 & 1070 & 0.137 & 0.0335 & 0.624 \\
\hline F & 0.0370 & 1170 & 0.134 & 0.0220 & 0.700 \\
\hline
\end{tabular}

The values of $\sigma_{\mathrm{y}}$ and $\sigma_{\mathrm{Z}}$ computed from equations 4.10 and 4.11 and presented in Figures 4.2 and 4.3), are those most used for U.S. EPA regulatory modelling applications, These values of $\sigma_{\mathrm{y}}$ and $\sigma_{\mathrm{z}}$ were derived primarily from diffusion experiments in a flat terrain $\left(z_{0} @ 0.03 \mathrm{~m}\right.$ ) in which a non buoyant tracer gas was released near the surface and measured (three-minute averages) downwind up to a distance of $800 \mathrm{~m}$ from the source (Gifford, 1976).

Briggs (1973) combined the Pasquill and Brookhaven National Laboratory curves to produce the widely used set of formulas for urban and rural conditions given in Table 4.3 and presented in Figures 4.2 and 4.3. Initial plume spread at all stabilities is proportional to the downwind distance, $x$, the proportionality factor being $\sigma_{\theta}$ (in radians). At large distances, $\sigma_{y}$ is proportional to $x^{0.5}$. Values of $\sigma_{y}$ and $\sigma_{z}$ are independent of release height and roughness. Briggs's formulas were based on McElory and Pooler's (1968) diffusion experiment. 
Table 4.3 Formulas Recommended by Briggs (1973) for $\sigma_{y}(x)$ and $\sigma_{z}(x)\left(10^{2}<x<10^{4} \mathrm{~m}\right.$ ) (from Zannetti, 1990)

Open-Country Conditions

\begin{tabular}{|c|c|c|}
\hline Pasquill type & $\sigma_{\mathrm{y}}$ (meters) & $\sigma_{\mathrm{Z}}$ (meters) \\
\hline A & $0.22 \times(1+0.0001 \mathrm{x})-0.5$ & $0.20 \mathrm{x}$ \\
$\mathrm{B}$ & $0.16 \times(1+0.0001 \mathrm{x})-0.5$ & $0.12 \mathrm{x}$ \\
C & $0.11 \times(1+0.0001 \mathrm{x})-0.5$ & $0.08 \times(1+0.0002 \mathrm{x})-0.5$ \\
D & $0.08 \times(1+0.0001 \mathrm{x})-0.5$ & $0.06 \times(1+0.0015 \mathrm{x})-0.5$ \\
E & $0.06 \times(1+0.0001 \mathrm{x})-0.5$ & $0.030 \times(1+0.0003 \mathrm{x})-1$ \\
F & $0.04 \times(1+0.0001 \mathrm{x})-0.5$ & $0.016 \times(1+0.0003 \mathrm{x})-1$ \\
\hline
\end{tabular}

Urban Conditions

\begin{tabular}{|c|c|c|}
\hline Pasquill type & $\sigma_{y}$ (meters) & $\sigma_{z}$ (meters) \\
\hline A - B & $0.32 \times(1+0.0004 x)-0.5$ & $0.22 \times(1+0.0001 x)-0.5$ \\
C & $0.22 \times(1+0.0004 x)-0.5$ & $0.22 \times(1+0.0001 x)-0.5$ \\
D & $0.16 x(1+0.0004 x)-0.5$ & $0.22 \times(1+0.0001 x)-0.5$ \\
E - F & $0.11 \times(1+0.0004 x)-0.5$ & $0.22 \times(1+0.0001 x)-0.5$ \\
\hline
\end{tabular}

The comparison between Pasquill-Gifford and Briggs curves (see Figures 4.2 and 4.3) show that the standard deviation values, $\sigma_{y}$ and $\sigma_{z}$, computed using Briggs formulas agree with those computed using Pasquill-Gifford curves in the downwind direction in the range from $100 \mathrm{~m}$ to $10 \mathrm{~km}$, except that $\sigma_{Z}$ values for Pasquill A stability curve which approximate the $B_{2}$ Brookhaven curve (Table 4.1). It is believed that $\sigma_{Z}$ values for Pasquill A stability curve for downwind distance greater than $0.5 \mathrm{~km}$ are unrealistic.

Regarding the comparison between the surface release and the elevated release, Smith (1972) and Pasquill (1975) have found that $\sigma_{Z}$ varies as $z_{0} p$ where $z_{0}$ is the roughness length and $\mathrm{p}$ lies in the range 0.10 to 0.25 . The larger the values of the exponent $\mathrm{p}$ are applicable to shorter distances and rougher surfaces. Over rough urban surfaces, especially under the influence of the nighttime urban heat island, the increased roughness should be taken in account (Hanna, 1982). 


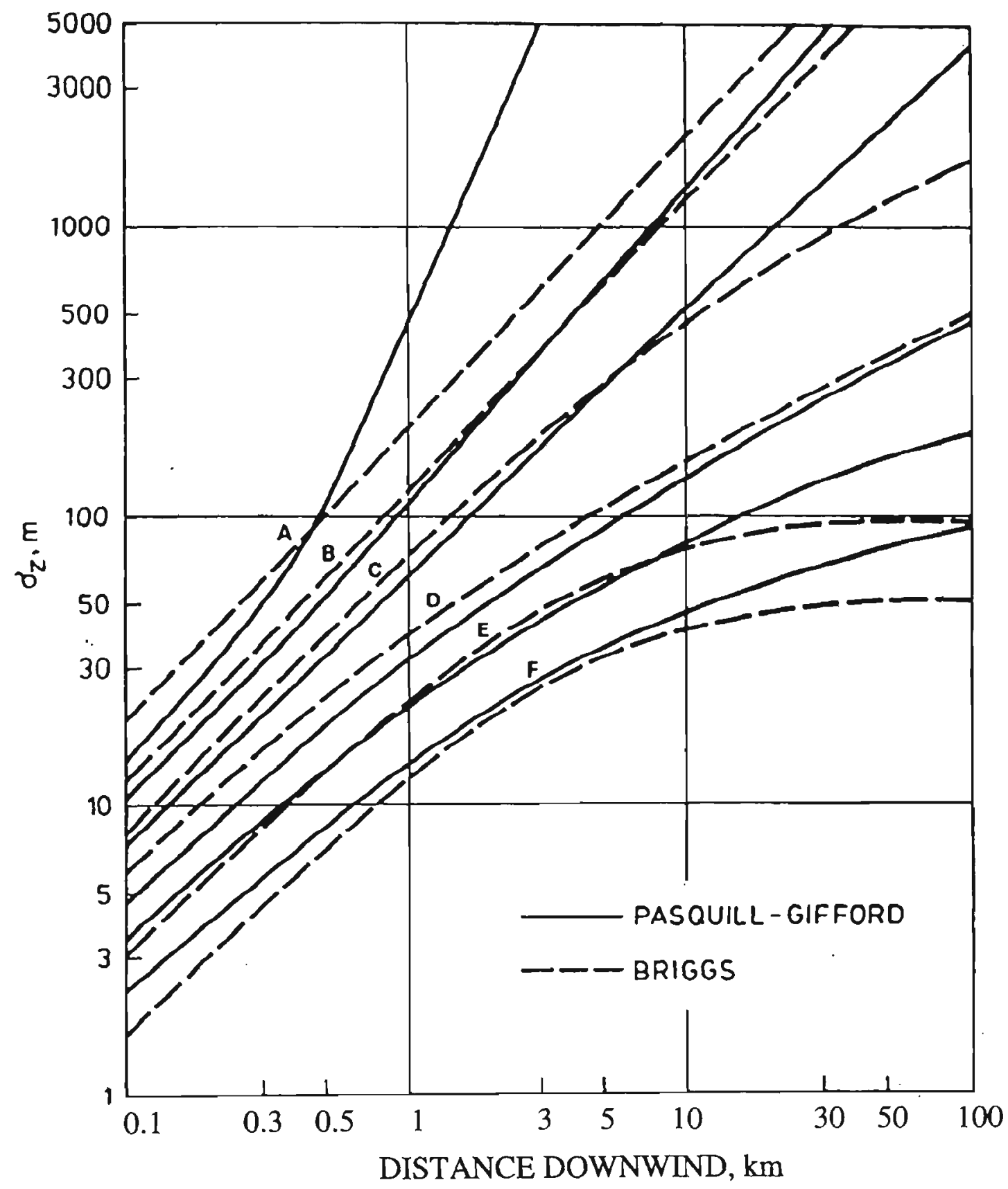

Figure 4.2 Curves of the standard deviation of the vertical dispersion, $\sigma_{\mathrm{Z}}$, for turbulence types based on Pasquill-Gifford (low source) and Briggs for elevated source $(>100 \mathrm{~m})$.

(Source: Pasquill, 1976 and Briggs, 1973) 


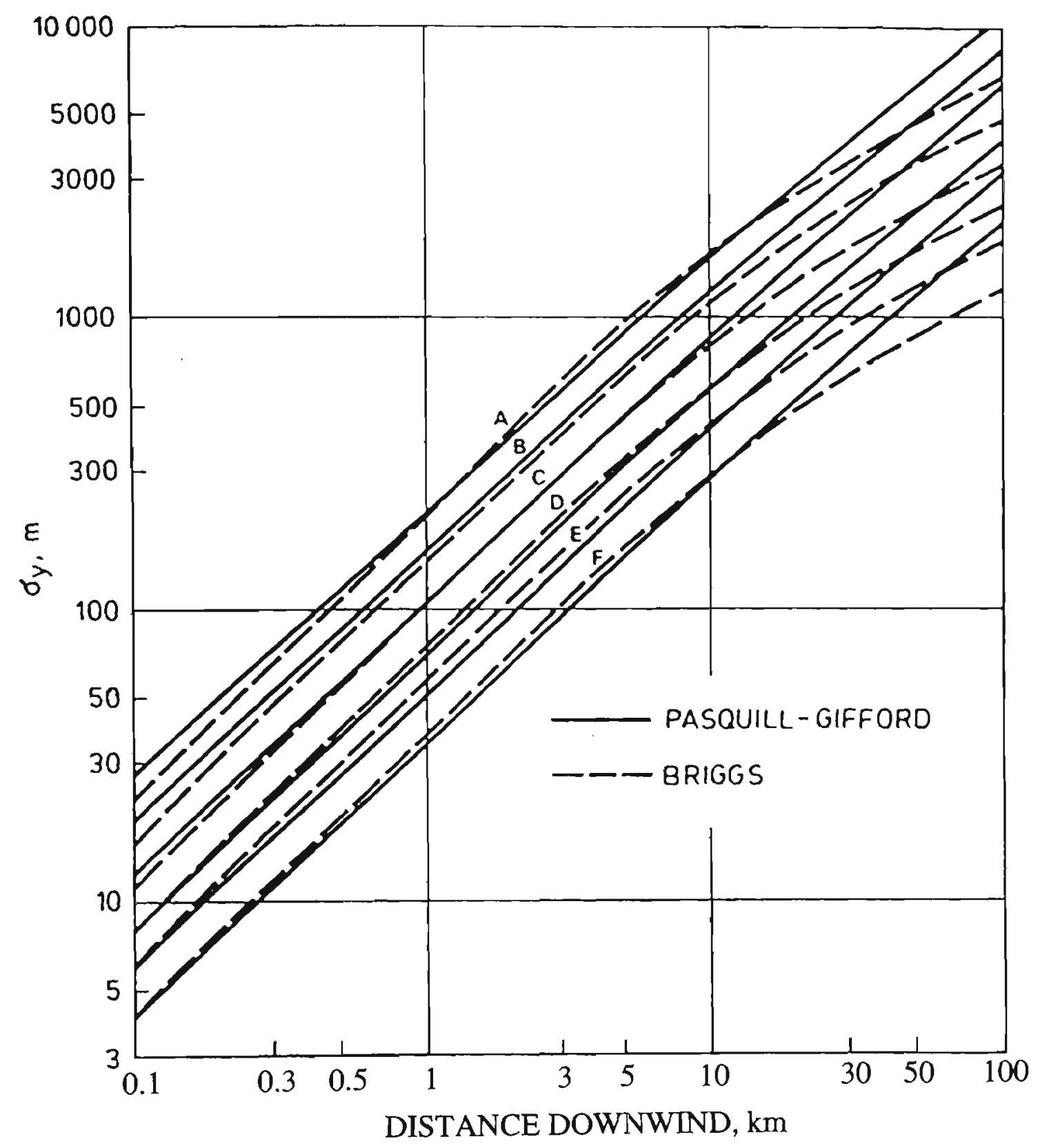

Figure 4.3 Curves of the standard deviation of the horizontal dispersion, $\sigma_{y}$, for turbulence types based on Pasquill-Gifford (low source) and Briggs for elevated source ( $>100 \mathrm{~m}$ ). (Source: Pasquill, 1976 and Briggs, 1973) 


\subsection{Model Description}

The two models analysed in this work, HTWAY-2 and CALINE-4, are Gaussian type models. These models separate out the advection from the cross-wind dispersion and use parameterization of the cross-wind diffusion to calculate concentrations from a Gaussian assumption. While each model performs its calculation in a unique manner the Gaussian assumption is central to its formulation. In the following sections these differences between the model formulations will be explicitly noted.

\subsubsection{HIWAY-2}

HIWAY-2 (Peterson, 1980) is a steady-state Gaussian model which can be applied to determine air pollution concentrations at receptor locations downwind of "at-grade" and "cut-section" highways located in relatively uncomplicated terrain. For an at-grade highway, each lane of traffic is modelled as a continuous line source which is simulated by a series of point sources with the total contribution of sources integrated at the receptor. For the cut-section, the top of the cut is considered an area source. The area source is simulated by using ten line sources of equal source strength. The total source strength equals the total emissions from the lanes in the cut. Each lane of traffic is modelled as though it were a straight, continuous, finite line source with uniform emission rate. The air pollution concentration representative of hourly average times at a downwind receptor location is found by a numerical integration along the length of each lane and a summing of the concentrations from each lane. The model cannot consider complex terrain or large obstructions to the flow such as buildings or large trees. No pollution emissions module is included in this version of the model. A value of the line-source strength for each lane of traffic must be obtained from a separate computation. Line-source strength is generally a function of traffic rate, average vehicle speed, and traffic mix (fraction of heavy-duty vehicles, fraction of late models with emission control devices).

HIWAY-2 assumes that the vertical dispersion of the pollution from a roadway is given by a Gaussian distribution. As in all Gaussian modelling the effects of atmospheric turbulence are contained implicitly in the dispersion coefficients $\sigma_{y}$ and $\sigma_{z}$, which are functions of atmospheric stability. As pointed out by Rao and Keenan ( 1980) the original formulation of HIWAY-2 did not include the effects on the dispersion coefficients of vehicle generated turbulence. Rao and Keenan (1980) addressed this 
limitation by re-evaluating the vertical dispersion coefficient and substituting this for the Pasquill-Gifford curves which had been used previously. They included the effects of wake generated turbulence on the dispersion coefficient by simply adding it to the dispersion due to ambient turbulence, i.e.

(i) For the vertical direction

$$
\sigma_{\mathrm{z}}^{2}=\sigma_{\mathrm{zw}}{ }^{2}+\sigma_{\mathrm{za}}{ }^{2}
$$

where $\sigma_{\mathrm{zw}}{ }^{2}$ is the variance due to wake effects and $\sigma_{\mathrm{za}}{ }^{2}$ the variance due to atmospheric turbulence. Rao and Keenan (1980) derived an empirical relation for the wake generated dispersion and used this in HIWAY-2 as follows

$$
\sigma_{\mathrm{ZW}}=3.57-0.53 \mathrm{U}_{\mathrm{cW}}
$$

where $\mathrm{U}_{\mathrm{cw}}$ is the cross-road wind speed in $\mathrm{m} / \mathrm{s}$. For all cross-road wind speeds greater than $3.91, \sigma_{\mathrm{ZW}}$ is held as constant at $1.5 \mathrm{~m}$.

The ambient atmospheric stability, $\sigma_{\mathrm{za}}$, was defined in terms of three stability classes, namely, unstable, neutral and stable. The contribution of the ambient stability to the dispersion was specified for the unstable stability class as

$$
\sigma_{\mathrm{za}}=110.62 \times 0.93198
$$

for the neutral stability class as

$$
\sigma_{\mathrm{za}}=86.49 \times 0.92332
$$

for stable stability class as

$$
\sigma_{\mathrm{Za}}=61.141 \times 0.91465
$$

(ii) for the cross-wind direction

$$
\begin{aligned}
& \sigma_{\mathrm{y}}^{2}=\sigma_{\mathrm{yw}}{ }^{2+} \sigma_{\mathrm{ya}}{ }^{2} \\
& \sigma_{\mathrm{yw}}=2 \sigma_{\mathrm{zw}}
\end{aligned}
$$




$$
\sigma_{\mathrm{ya}}=1000 \times \sin \theta /(2.15 \cos \zeta)
$$

where $\sigma_{\mathrm{z}}$ and $\sigma_{\mathrm{y}}$ are the dispersion parameters, in meters, in the vertical and crosswind direction, respectively, $\mathrm{x}$ is the downwind distance from the source in kilometers and $\zeta$ is specified for the unstable stability class as follows

$$
\zeta=(18.333-1.8096 \ln x) / 57.2958
$$

for the neutral stability class as

$$
\zeta=(14.333-1.7706 \ln x) / 57.2958
$$

for the stable stability class as

$$
\zeta=(12.500-1.0857 \ln x) / 57.2958
$$

These authors show that HIWAY-2, with the improved dispersion curves performed better than the earlier forms of dispersion coefficient used in the model.

The HIWAY-2 model provides a much simpler and more empirical formulation of the pollution from roadsides than does ROADWAY (Eskridge et al., 1987). It suffers a major draw-back common to all Gaussian model formulations. This draw-back is due to the inverse dependence of concentration on the average wind speed, which means that for stalled meteorological conditions (ie $\mathrm{u}<1 \mathrm{~m} / \mathrm{s}$ ), which frequently occur and give rise to the largest concentrations of pollutant, the model does not strictly apply.

\subsubsection{CALINE-4}

CALINE4 is the most recent version of the CALINE series (Benson, 1984). It is a line source model developed by the California Department of Transport. It represents a refinement and extension of the capabilities contained in CALINE3. Concentrations of $\mathrm{CO}, \mathrm{NO}_{2}$ and aerosols can be predicted by the model. An option for modelling intersections has been added. The model employs a modified Gaussian plume approach similar to the one used in CALINE3, but with new provisions for lateral plume spread and vehicle induced thermal turbulence. Sub-models for $\mathrm{CO}$ modal emissions and reactive plume chemistry have been added. 
CALINE4 divides the highway being considered into a series of elements auth representing a section of the road. The concentration at the receptor from all retivant upwind elements are added and the total concentration calculated. Effectively the modet replaces the highway by a series of equivalen linite line sources (see Figure 4.4).

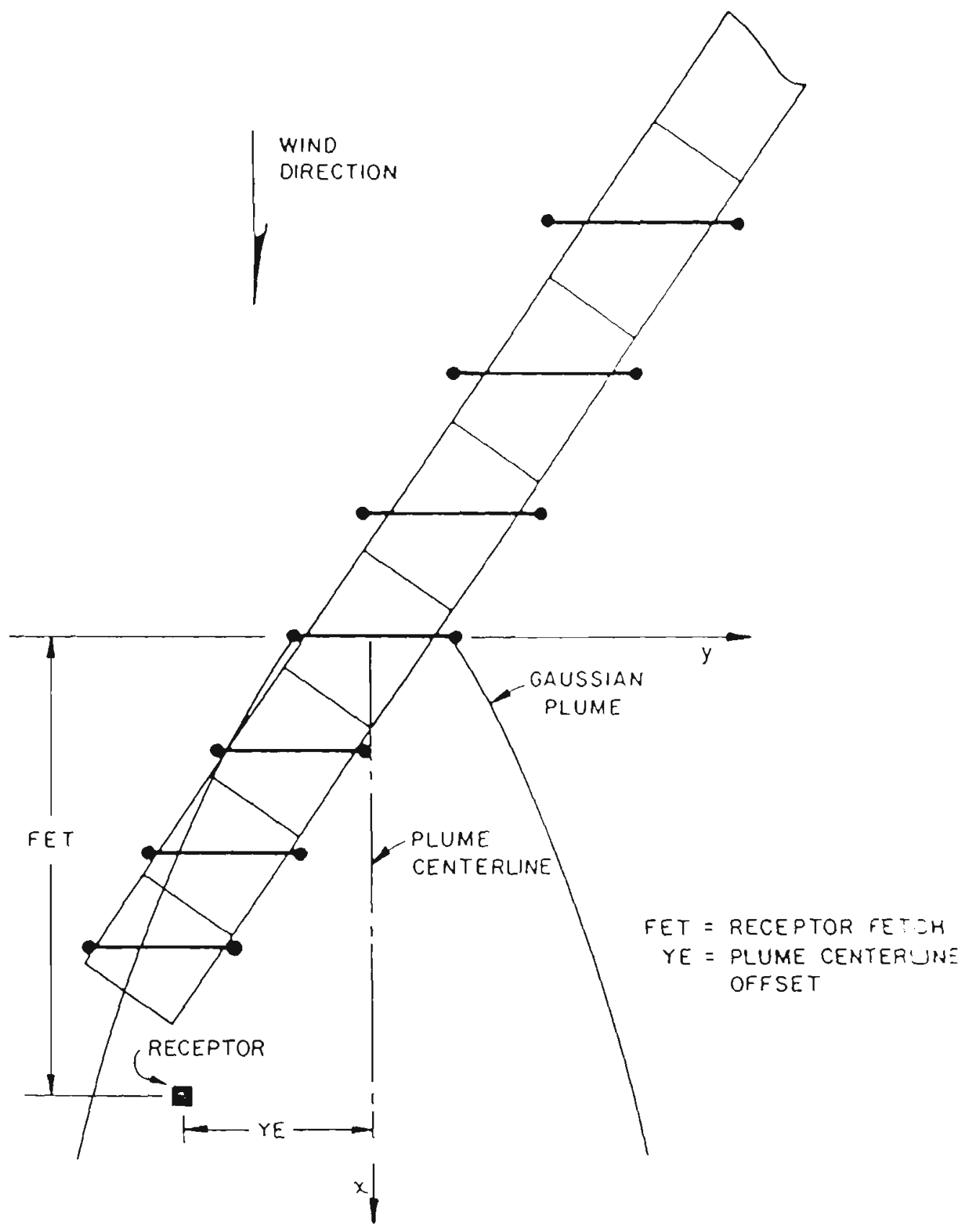

Figure 4.4 CALINE equivalent finite line sources (Benson, 1984). 
As shown in Figure 4.4, each element is modelled as an "equivalent" finite line source (FLS) positioned normal to the wind direction and centred at the element midpoint. Element size increases with the distance from the receptor to improve computational efficiency. Incremental downwind concentrations are computed using the cross-wind Gaussian formulation for a line source of finite length:

$$
C(x, y)=\frac{Q}{\pi \sigma_{z} u} \int_{y_{1}-y}^{y_{2}-y} \exp \left(\frac{-y^{2}}{2 \sigma_{y}^{2}}\right) d y
$$

where $Q$ is the lineal source strength, $u$ is the wind speed, $\sigma_{Z}$ and $\sigma_{y}$ are the vertical and horizontal Gaussian dispersion parameters, and $y_{1}$ and $y_{2}$ are the FLS endpoint $y$ coordinates. Each element is divided into three sub-elements: a central sub-element and two peripheral sub-elements. The geometry of the sub-elenents is a lunction ol element size and roadway-wind angle. A lineal source strengh is computed assuming uniform emissions throughout the element. Emissions for the peripheral sub-elements are modelled as decreasing linearly to zero at the ends of the FLS.

CALINE treats the region direculy ahove the highway as a zone of unilorm emissions and turbulence (see Figure 4.5).

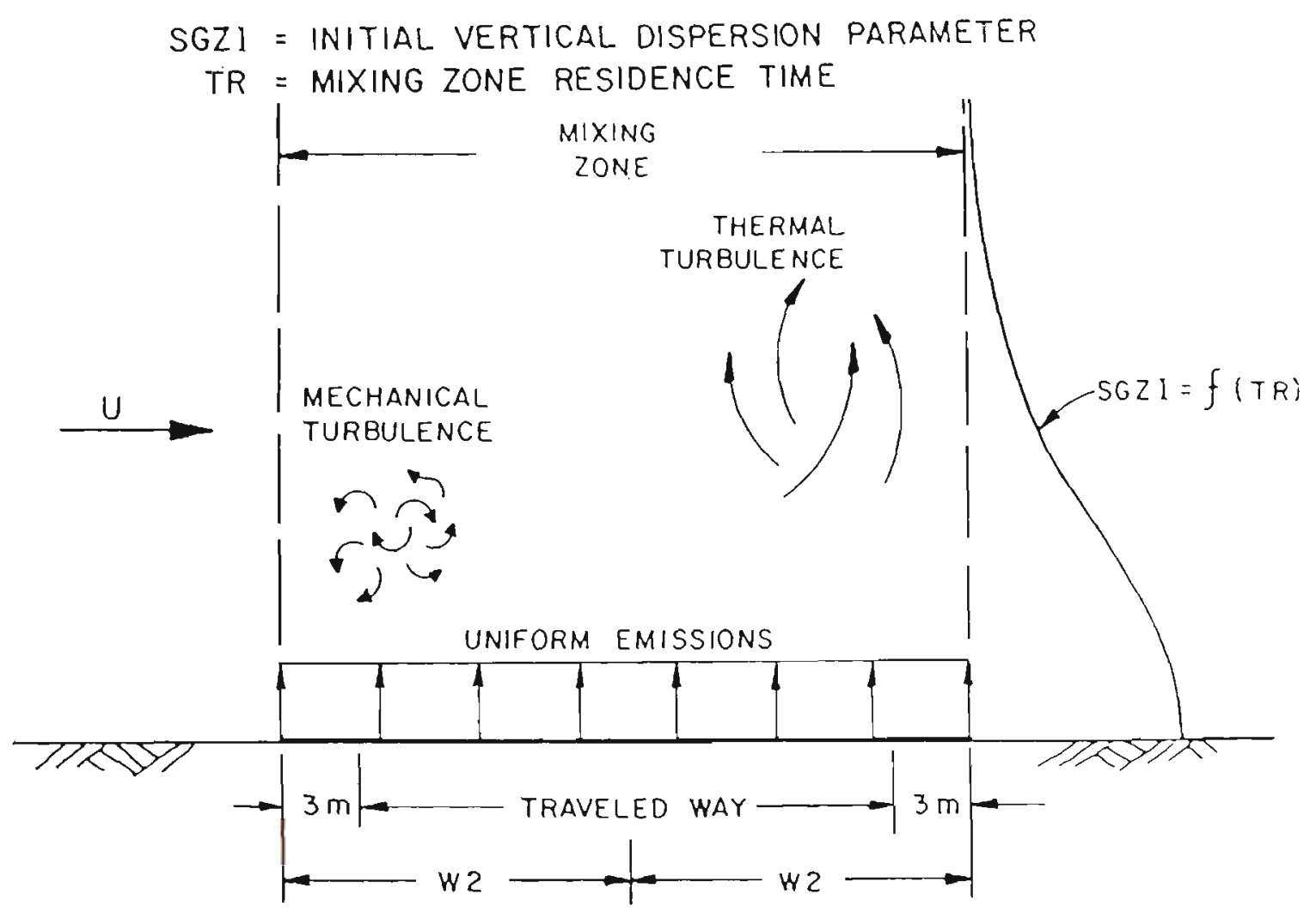

Figure 4.5 CALINE mixing zone (Benson, 1984). 
The "mixing zone" is defined as the region over the travelled way plus $3 \mathrm{~m}$ on either side. The additional width accounts for the initial horizontal dispersion imparted to pollutants by the vehicle wake. Within the mixing zone, the mechanical turbulence created by the moving vehicles and the thermal turbulence created by hot vehicle exhaust are treated as significant dispersive mechanisms (Benson, 1984). This procedure is adopted in order to approximate better the nature of the emissions which are dispersed by wake turbulence as well as the buoyancy of the hot exhaust.

The initial vertical dispersion at the edge of the mixing zone is modelled as a function of residence time within the initial turbulence region. ie

$$
\sigma_{\mathrm{Zi}}=1.5+0.1 \mathrm{tr}_{\mathrm{r}}
$$

where $\sigma_{Z}$ in meters and $t_{r}$ is the residence time in seconds; $t_{r}$ is a simple function of the wind speed and highway width.

The Pasquill-Smith vertical dispersion curves (Pasquill, 1974) are modified by CALINE4 to incorporate the effects of vehicle-induced thermal turbulence. A composite heat release rate of $24.6 \mathrm{~J} \mathrm{~cm}^{-1}$ per vehicle (based on an assumed average fuel economy of $8.5 \mathrm{~km} \mathrm{l}^{-1}$, 0.6 heat loss factor and specific energy of $3.48 \times 10^{7} \mathrm{~J} \mathrm{~J}^{-1}$ ) is used in conjunction with the stability nomograph to predict a modified stabilty class over the mixing zone. The rate of vertical plume spread is assumed to follow the modified stability curve until more than $50 \%$ of the plume mass fall outside of the mixing zone. From that point on, the modified vertical dispersion curve follows a trend back to the Pasquil- Gifford curve values at $10 \mathrm{~km}$ downwind.

The effects of roadway turbulence and heat flux on the spreading are assumed to operate for part of the distance downwind leading to enhanced dispersion. The horizontal dispersion coefficient is obtained directly from the formulation due to Draxler (1976) (see equation 2.3, Chapter 2).

\subsection{Model Limitations}

Models of plume behaviour represent a highly simplified picture of the atmospheric processes responsible for the transport and dispersion of pollution. In modelling dispersion from tall stacks, perhaps the most developed area of pollution modelling, it has long been recognised that this is the case. Considerable research has gone into attempting to reconcile the nature of model predictions and field measurements whilst 
recognizing the inherent variability associated with turbulent processes (see eg Fox, 1984, Weil et al., 1992).

Whilst for traffic pollution modelling, this type of uncertainty is reduced because the pollutant comes from a line source rather than a point source. Also it is a surface release and the receptor are close. However other difficulties arise. One has already been discussed, namely the uncertainty in the emission strength. Another is due to the motion of the vehicle and the location of the exhaust. Vehicles moving at any significant speed create a turbulent wake into which the exhaust is emitted. The wake may serve to dilute the exhaust plume rapidly to dimensions approximately double those of the vehicle cross section (Gronskei, 1987). For large trucks with vertical stacks the exhaust may or may not be entrained by the wake. Further, the extent to which the exhaust is affected by the wake depends on the speed of the vehicle and the wind speed and direction. These phenomena mean that the dispersion characteristics of vehicle emissions are governed by the interaction of, a) the inherent exhaust turbulence, b) the wake generated turbulence, and c) atmospheric turbulence, resulting in modelling those emissions very approximately. 


\section{CHAPTER 5}

\section{VALIDATION OF THE POWER-BASED EMISSIONS MODEL}

The developed power -based emissions model provide estimates for fuel consumption and exhaust emission rates of $\mathrm{CO}, \mathrm{HC}, \mathrm{NO}_{\mathrm{X}}$, and $\mathrm{CO}_{2}$ from spark ignition (both leaded and unleaded) and diesel vehicles (see Chapter 3). Emissions of carbon ( $\left.\mathrm{CO}_{2}\right)$, carbon monoxide $(\mathrm{CO})$, hydrocarbons $(\mathrm{HC})$, and oxides of nitrogen $\left(\mathrm{NO}_{\mathrm{X}}\right)$ from both spark ignition vehicles (SI) and diesel vehicles have been modelled by considering the instantaneous power requirements for a given situation using the approach developed by Post et al., (1981).and Kent et al., (1982). This approach has been modified to include diesel vehicles as well as catalyst-equipped spark ignition vehicles.

The model estimates the power required for a vehicle of specified mass to overcome rolling and drive-train resistance, aerodynamic resistance, and gravity. The power required for a vehicle for a given situation leads to estimates of fuel consumption and emissions. When the model for spark ignition is used over a drive cycle, the influence of cold starts is quantified and allowance is made. In the case of catalyst equipped vehicles, allowance is made for catalyst warm-up and for variations in catalyst efficiency.

The power-based exhaust emissions model estimates the effects of both the road gradient and acceleration-deceleration manoeuvres, and the aerodynamic drag, which is a function of both wind speed and wind-road angle, on power demands, fuel consumption, and gaseous emissions of $\mathrm{CO}_{2}, \mathrm{CO}, \mathrm{HC}$, and $\mathrm{NO}_{\mathbf{X}}$.

\subsection{Utilised studies}

Data from three studies were utilised in this study to validate the power-based emissions model. These studies are Williams et al., 1987, Carnovale et al., 1991, SPCC, 1989. These three studies are presented in the next section. In addition, the results of a CSIRO/RTA field study (Williams et al., 1994) were utilised to assess the predictions of two dispersion models used in conjunction with the power-based emissions model (see Chapter 6).

\subsubsection{Particulate emissions from 'in use' spark ignition and diesel vehicles (Williams et al., 1987).}

A detailed study was undertaken of the gaseous emissions and particulate matter (EPM) emitted by 22 spark ignition (SI), 19 light-duty diesel, and 13 heavy-duty diesel vehicles. 
The spark ignition and light-duty diesel vehicles were tested under a standard city drive cycle on a chassis dynamometer used for the evaluation of the gaseous under the Australian Design Rules (Australian Standard 2077-1982), whist the heavy-duty diesel vehicles were subjected to a multi-mode test cycle on a power dynamometer. The details of the spark ignition and light-duty diesel vehicles used in this study are given in Table 5.1 and Table 5.2, respectively. The details of the test and results were given in Williams et al., 1987, and are summarised here.

Table 5.1 The list of spark ignition vehicle parameters used in Williams et al., 1987 study.

\begin{tabular}{|c|c|c|c|c|c|c|}
\hline First reg. & Make & Model & Cylinders & $\begin{array}{c}\text { Capacity } \\
\text { (litres) } \\
\end{array}$ & $\begin{array}{c}\text { Weight } \\
(\mathrm{kg})\end{array}$ & $\begin{array}{c}\text { Odometer } \\
(\mathrm{km})\end{array}$ \\
\hline $74 / 07$ & Ford & XC Falcon & 8 & 4.9 & 1307 & 22045 \\
\hline $80 / 05$ & Holden & Gemini TE & 4 & 1.6 & 1134 & 14757 \\
\hline $83 / 03$ & Datsun & Bluebird & 4 & 2.0 & 1247 & 955 \\
\hline $83 / 05$ & Holden & Commodore SE & 8 & 4.2 & 1588 & 6644 \\
\hline $83 / 06$ & Holden & VH Commodore & 6 & 3.3 & 1361 & 4870 \\
\hline $83 / 08$ & Ford & XE Falcon & 6 & 4.1 & 1588 & 25 \\
\hline $70 / 09$ & Hilman & Hustler & 4 & 1.7 & 1134 & 166372 \\
\hline $83 / 07$ & Holden & Camira & 4 & 1.6 & 1247 & 8118 \\
\hline $71 / 10$ & Ford & XY Falcon & 6 & 4.1 & 1588 & 122997 \\
\hline $74 / 06$ & Datsun & $120 Y$ & 4 & 1.2 & 907 & 169115 \\
\hline $74 / 08$ & Leyland & Marina & 4 & 1.7 & 1134 & 135000 \\
\hline $81 / 07$ & Mitsubishi & Sigma** & 4 & 2.0 & 1247 & 7924 \\
\hline $81 / 11$ & Mitsubishi & Sigma (a) ${ }^{\mathrm{S}}$ & 4 & 2.0 & 1247 & 50228 \\
\hline $81 / 11$ & Mitsubishi & Sigma $(b)^{S}$ & 4 & 2.0 & 1247 & 76735 \\
\hline $76 / 07$ & Toyota & Celica & 4 & 2.0 & 1134 & 115388 \\
\hline $65 / 06$ & Chrysler & Valiant Sedan & 6 & 3.6 & 1588 & 105239 \\
\hline $76 / 05$ & Nissan & Datsun $240 \mathrm{~K}$ & 6 & 2.4 & 1361 & 192717 \\
\hline $82 / 02$ & Holden & Commodore & 6 & 3.3 & 1361 & 50940 \\
\hline $78 / 09$ & Ford & Cortina Sedan & 6 & 3.3 & 1361 & 93113 \\
\hline $82 / 11$ & Toyota & Landcruiser & 6 & 4.2 & 2041 & 11498 \\
\hline $76 / 08$ & Ford & F100 Custom & 8 & 4.9 & 2268 & 75321 \\
\hline $78 / 02$ & Toyota & Corolla & 4 & 1.3 & 1020 & 93329 \\
\hline
\end{tabular}

** Used only unleaded fuel but not equipped with catalyst.

$s$ The same vehicle 
Table 5.2 The list of light-duty diesel vehicle parameters used in Williams et al., 1987 study

\begin{tabular}{|c|c|c|c|c|c|c|}
\hline First reg. & Make & Model & Cylinders & $\begin{array}{c}\text { Capacity } \\
(\text { litres })\end{array}$ & $\begin{array}{c}\text { Weight } \\
(\mathrm{kg})\end{array}$ & $\begin{array}{c}\text { Odometer } \\
(\mathrm{km})\end{array}$ \\
\hline \multicolumn{7}{|c|}{ Passengers cars } \\
\hline $78 / 11$ & V-Wagen & Golf Gld & 4 & 1.5 & 1020 & 70172 \\
\hline $80 / 01$ & Mercedes & 300D & 5 & 3.0 & 1588 & 22955 \\
\hline $82 / 01$ & Holden & Gemini TE & 4 & 1.5 & 1247 & 11843 \\
\hline $79 / 03$ & V-Wagen & Golf 174D & 4 & 1.5 & 1020 & 69246 \\
\hline Commercial vehicles & & & & \\
\hline $81 / 12$ & Ford & Econovan & 4 & 2.0 & 1361 & 33112 \\
\hline $82 / 03$ & Ford & Courier & 4 & 2.0 & 1361 & 70172 \\
\hline $82 / 01$ & Toyota & Hilux & 4 & 2.0 & 1361 & 28180 \\
\hline $80 / 10$ & Daihatsu & V22 Truck & 4 & 3.0 & 2268 & 5572 \\
\hline $81 / 02$ & Daihatsu & V22 Truck & 4 & 2.5 & 2268 & 48017 \\
\hline $80 / 10$ & Daihatsu & V24 Truck & 4 & 2.5 & 2041 & 52639 \\
\hline $80 / 10$ & Daihatsu & Delta & 4 & 1.8 & 1588 & 55635 \\
\hline $83 / 12$ & Toyota & Dyna & 4 & 2.0 & 1588 & 6053 \\
\hline $83 / 12$ & Toyota & Dyna & 4 & 2.0 & 2495 & 3379 \\
\hline $84 / 03$ & Toyota & Dyna & 4 & 2.0 & 2495 & 3465 \\
\hline $84 / 04$ & Toyota & Hilux & 4 & 2.4 & 1814 & 22839 \\
\hline $84 / 06$ & Toyota & Dyna & 4 & 2.0 & 2495 & 3802 \\
\hline $84 / 05$ & Toyota & Dyna & 4 & 2.3 & 2495 & 7450 \\
\hline $83 / 08$ & Toyota & Hilux & 4 & 2.4 & 1814 & 18201 \\
\hline
\end{tabular}

The spark ignition and light-duty diesel vehicles were tested over standard driving cycles used for the evaluation of gaseous emissions, under the Australian Design Rules ADR $27 \mathrm{C}$ and 37 which purport to replicate urban driving patterns. The ADR 37 test consists of a cold transient segment lasting $505 \mathrm{~s}$. The next $867 \mathrm{~s}$ constitute the cold stabilised segment and, after 10-min soak, there is a 505-s segment called the hot transient. The test is equivalent to the 1975 US Federal Test Procedure (FTP). The details of the chassis dynamometer test and the 1975 US Federal Test Procedure (FTP) are presented in Appendix C . 
The ADR 27 test is the same as the ADR 37 without the hot soak and the final 505-s segment and is equivalent to the 1972 US FTP. A hot start ADR 27 test (ADR 27H) consists of a hot transient 505-s and a hot stabilised $867 \mathrm{~s}$.

The vehicles were all tested at their reference inertial mass as defined in the ADR 37 procedure. The petrol used was commercial super-grade fuel containing $0.4 \mathrm{~g}$ /litre $\mathrm{Pb}$ with a density of $0.74 \mathrm{~g} / \mathrm{ml}$. The standard diesel fuel used in the tests had boiling range of $219-335^{\circ}$ and a density of $0.825 \mathrm{~g} / \mathrm{ml}$. The gaseous emissions for SI vehicles are given in Table 5.3 whilst those of the light-duty diesel vehicles are given in Table 5.4.

Table 5.3 Gaseous emission rates for ADR 37 test cycle for the spark ignition vehicles used in Williams et al., 1987 study

\begin{tabular}{|c|c|c|c|c|c|c|c|}
\hline \multirow[t]{2}{*}{ First reg. } & \multirow[t]{2}{*}{ Make } & \multicolumn{2}{|c|}{$\mathrm{CO}$} & \multicolumn{2}{|c|}{ NMHC } & \multicolumn{2}{|c|}{$\mathrm{NO}_{\mathrm{X}}$} \\
\hline & & $\mathrm{g} / \mathrm{km}$ & $\mathrm{g} / \mathrm{kgf}$ & $\mathrm{g} / \mathrm{km}$ & $\mathrm{g} / \mathrm{kgf}$ & $\mathrm{g} / \mathrm{km}$ & $\mathrm{g} / \mathrm{kgf}$ \\
\hline $74 / 07$ & Ford & 42.98 & 285.6 & 2.63 & 17.5 & 0.75 & 5.0 \\
\hline $80 / 05$ & Holden & 14.77 & 171.1 & 1.52 & 17.6 & 1.30 & 15.1 \\
\hline $83 / 05$ & Holden & 18.74 & 157.8 & 1.61 & 13.6 & 1.31 & 11.1 \\
\hline $83 / 06$ & Holden & 12.68 & 120.7 & 1.64 & 15.6 & 1.29 & 12.3 \\
\hline $83 / 08$ & Ford & 19.24 & 137.8 & 1.98 & 14.2 & 1.23 & 8.8 \\
\hline $70 / 09$ & Hilman & 21.77 & 317.3 & 2.75 & 40.1 & 1.73 & 25.2 \\
\hline $83 / 07$ & Holden & 8.74 & 114.9 & 1.27 & 16.7 & 2.09 & 27.5 \\
\hline $71 / 10$ & Ford & 10.80 & 116.5 & 1.89 & 20.4 & 4.27 & 46.1 \\
\hline $74 / 08$ & Leyland & 30.49 & 369.1 & 5.5 & 66.6 & 1.88 & 22.8 \\
\hline $81 / 07$ & Mitsubishi & 5.11 & 64.5 & 1.26 & 15.9 & 1.57 & 19.8 \\
\hline $81 / 11$ & Mitsubishi (a) & 10.29 & 130.8 & 1.64 & 20.8 & 2.10 & 26.7 \\
\hline $81 / 11$ & Mitsubishi (b) & 10.39 & 142.0 & 1.36 & 18.6 & 1.70 & 23.2 \\
\hline $76 / 07$ & Toyota & 22.42 & 287.3 & 0.0 & 7.6 & 2.86 & 36.7 \\
\hline $65 / 06$ & Chrysler & 40.06 & 381.1 & 5.19 & 49.4 & 1.67 & 15.9 \\
\hline $76 / 05$ & Nissan & 29.6 & 346.1 & 2.77 & 32.4 & 5.72 & 66.9 \\
\hline $82 / 02$ & Holden & 20.44 & 214.7 & 2.066 & 21.6 & 2.30 & 24.2 \\
\hline $78 / 09$ & Ford & 22.95 & 253.9 & 3.15 & 34.8 & 2.05 & 22.7 \\
\hline $82 / 11$ & Toyota & 24.4 & 146.5 & 2.22 & 13.4 & 6.29 & 37.8 \\
\hline $76 / 08$ & Ford & 58.75 & 307.4 & 6.71 & 35.1 & 4.56 & 23.9 \\
\hline $78 / 02$ & Toyota & 7.39 & 119.3 & 2.95 & 47.6 & 1.36 & 22.0 \\
\hline
\end{tabular}


Table 5.4 Gaseous emission rates for ADR 37 test cycle for diesel vehicles used in Williams et al., 1989 study.

\begin{tabular}{|c|c|c|c|c|c|c|c|c|}
\hline \multirow{2}{*}{ First reg. } & \multirow{2}{*}{ Make } & Model & \multicolumn{2}{|c}{$\mathrm{CO}$} & \multicolumn{2}{c|}{ NMHC } & \multicolumn{2}{c|}{ NO } \\
\cline { 3 - 9 } & & & $\mathrm{g} / \mathrm{km}$ & $\mathrm{g} / \mathrm{kgf}$ & $\mathrm{g} / \mathrm{km}$ & $\mathrm{g} / \mathrm{kgf}$ & $\mathrm{g} / \mathrm{km}$ & $\mathrm{g} / \mathrm{kgf}$ \\
\hline $78 / 11$ & V-Wagen & Golf Gld & 0.786 & 12.838 & 0.162 & 2.646 & 0.576 & 9.508 \\
\hline $80 / 01$ & Mercedes & $300 \mathrm{D}$ & 0.460 & 6.148 & 0.038 & 0.508 & 0.914 & 12.217 \\
\hline $82 / 01$ & Holden & Gemini TE & 0.610 & 8.802 & 0.059 & 0.851 & 0.862 & 12439 \\
\hline $79 / 03$ & V-Wagen & Golf 174D & 0.620 & 11.679 & 0.071 & 1.337 & 0.797 & 15.013 \\
\hline $82 / 03$ & Ford & Courier & 1.007 & 10.086 & 0.104 & 1.042 & 1.172 & 11.738 \\
\hline $82 / 01$ & Toyota & Hilux & 0.846 & 8.825 & 0.115 & 1.200 & 0.893 & 9.315 \\
\hline $80 / 10$ & Daihatsu & V22 Truck & 1.320 & 11.683 & 0.326 & 2.885 & 1.541 & 13.639 \\
\hline $81 / 02$ & Daihatsu & V22 Truck & 3.020 & 21.366 & 0.712 & 5.037 & 1.904 & 13.471 \\
\hline $80 / 10$ & Daihatsu & V24 Truck & 1.100 & 11.941 & 0.233 & 2.529 & 1.340 & 14.546 \\
\hline $80 / 10$ & Daihatsu & Delta & 1.980 & 23.084 & 0.553 & 6.447 & 1.619 & 18.875 \\
\hline $83 / 12$ & Toyota & Dyna & 1.520 & 12.852 & 0.422 & 3.568 & 1.869 & 15.803 \\
\hline $83 / 12$ & Toyota & Dyna & 1.780 & 12.593 & 0.500 & 3.537 & 2.270 & 16.060 \\
\hline $84 / 03$ & Toyota & Dyna & 1.850 & 14.046 & 0.463 & 3.515 & 2.286 & 17.356 \\
\hline $84 / 04$ & Toyota & Hilux & 0.750 & 10.029 & 0.108 & 1.444 & 0.956 & 12.784 \\
\hline $84 / 06$ & Toyota & Dyna & 1.240 & 12.914 & 0.400 & 4.166 & 1.980 & 20.620 \\
\hline $84 / 05$ & Toyota & Dyna & 1.690 & 12.644 & 0.420 & 3.142 & 2.140 & 16.011 \\
\hline $83 / 08$ & Toyota & Hilux & 0.590 & 7.242 & 0.090 & 1.105 & 0.910 & 11.17 \\
\hline
\end{tabular}

\subsubsection{Air Emissions Inventory - Port Phillip Control Region: Planning} for the Future, SRS 91/1001, Victoria EPA (Carnovale et al., 1991).

As a part of a detailed study to prepare an Air Emissions Inventory for Port Phillip Control Region, Victoria in the year 1990, Carnovale et al. estimated the gaseous emissions of volatile organic compounds (VOC, excluding methane), oxides of nitrogen $\left(\mathrm{NO}_{\mathrm{X}}\right)$, carbon monoxide $(\mathrm{CO})$, sulfur dioxide $\left(\mathrm{SO}_{2}\right)$, and air born particulate for both cars manufactured pre-1986 (leaded) and post-1986 (catalyst-equipped). The study also included an estimation for vehicle deterioration factors as well as the vehicle kilometres travelled (VKT). The details of the study can be found in Carnovale et al., 1991.

In Victoria EPA procedure, the ADR 27 test cycle was split into segments representing freeway, arterial, and congested driving modes ( see Figure 5.1) and the emissions from 


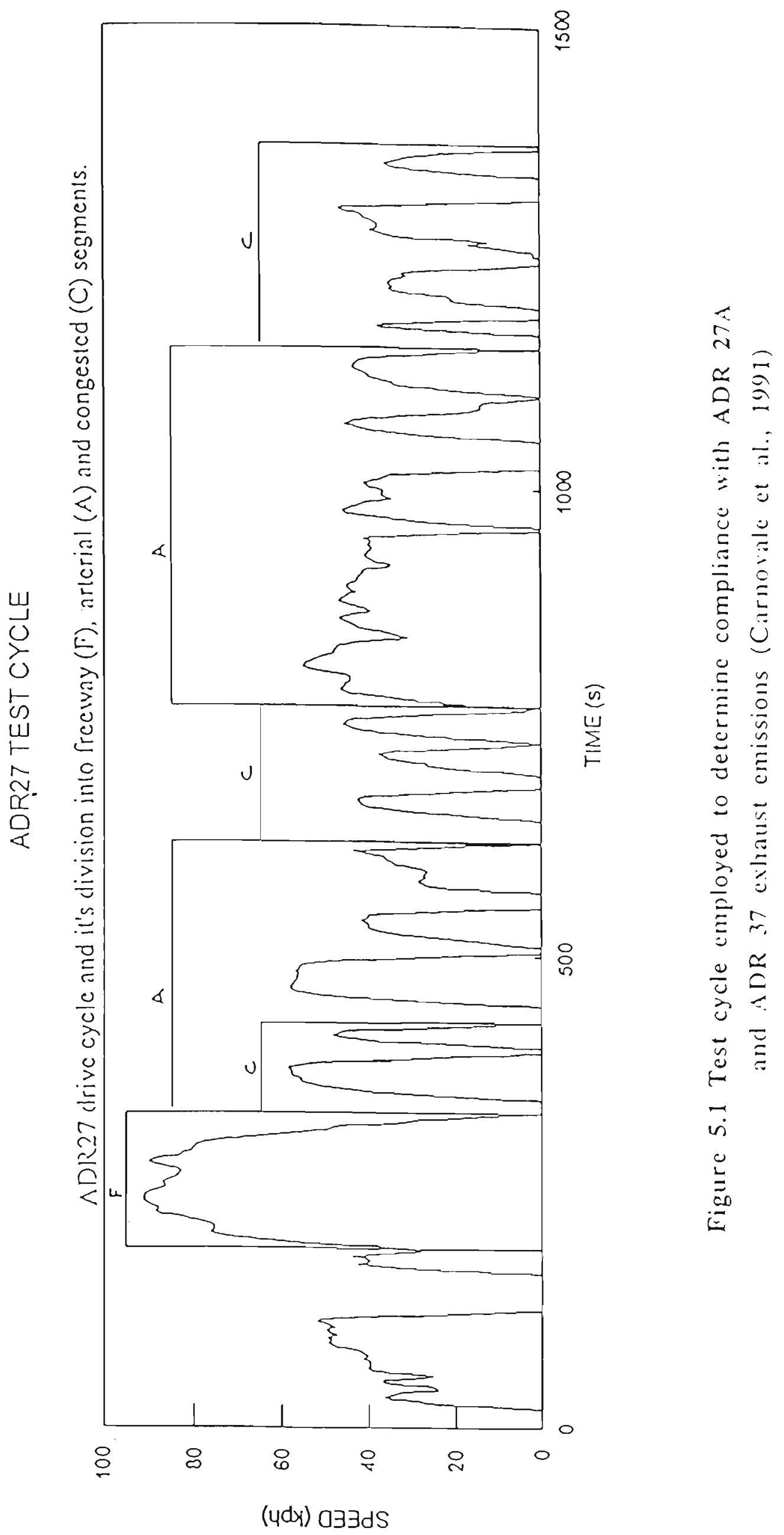


over 1500 vehicles, from different technology classes, were analysed on this split mode basis. Deterioration factors $(\mathrm{g} / \mathrm{km})$ were developed for $\mathrm{CO}, \mathrm{HC}$, and $\mathrm{NO}_{\mathrm{X}}$ emissions for each $10000 \mathrm{~km}$ travelled.

Carnovale et al. analysed in excess of 1200 exhaust emission test results on motor cars manufactured between from 1976 to 1985 and 123 test results for "in service" cars manufactured after 1985 (catalyst-equipped vehicles). From ADR27 cycle emissions of $\mathrm{CO}, \mathrm{HC}$, and $\mathrm{NO}_{\mathrm{X}}$, Carnovale et al. calculated the fractional emissions for freeway, arterial, and congested flow. The results are given in Table 5.5.

Table 5.5 EPA (Victoria) car exhaust emission rates (Source: Carnovale et al., 1991).

\begin{tabular}{|c|l|c|c|c|c|}
\hline \multirow{2}{*}{ Pollutant } & \multirow{2}{*}{ ADR 27A fraction } & \multicolumn{4}{|c|}{ Exhaust emission rates $(\mathrm{g} / \mathrm{km})$} \\
\cline { 2 - 6 } & & Pre-1976 & $1976-1980$ & $1981-1985$ & Post-1985 \\
\hline \multirow{3}{*}{$\mathrm{CO}$} & Freeway & 37.84 & 9.69 & 8.73 & 2.87 \\
\cline { 2 - 6 } & Arterial & 37.84 & 14.48 & 13.04 & 2.35 \\
\cline { 2 - 6 } & Congested & 37.84 & 21.83 & 19.58 & 3.38 \\
\cline { 2 - 6 } & ADR 27A & 37.84 & 21.43 & 19.30 & 6.56 \\
\hline \multirow{3}{*}{$\mathrm{HC}$} & Freeway & 3.41 & 1.14 & 1.08 & 0.25 \\
\cline { 2 - 6 } & Arterial & 3.41 & 1.45 & 1.37 & 0.20 \\
\cline { 2 - 6 } & Congested & 3.41 & 2.22 & 2.09 & 0.32 \\
\cline { 2 - 6 } & ADR 27A & 3.41 & 1.86 & 1.76 & 0.51 \\
\hline \multirow{2}{*}{$\mathrm{NO}_{\mathrm{X}}$} & Freeway & 2.15 & 2.25 & 2.16 & 1.60 \\
\cline { 2 - 6 } & Arterial & 2.15 & 1.25 & 1.20 & 0.87 \\
\cline { 2 - 6 } & Congested & 2.15 & 1.71 & 1.64 & 1.10 \\
\cline { 2 - 6 } & ADR 27A & 2.15 & 1.61 & 1.54 & 1.17 \\
\hline
\end{tabular}

To account for the exhaust emissions deterioration due to vehicle aging (total vehicle kilometres travelled), Exhaust deterioration factors can be used to account for the loss of combustion efficiency, tampering with pollution control equipment or deterioration of the catalytic converter with vehicle distance travelled. Exhaust deterioration factors are the rates at which emissions are modelled to increase with increasing vehicles distance travelled. These factors apply per 100,000 kilometres. Exhaust deterioration factors are seen to dramatically increase emissions over new car values (US EPA, 1993). 
Carnovale et al., 1991 reported that until 1989, the deterioration factors recommended by US EPA (1985) were employed in estimating car exhaust emissions in Australia because of the lack of the experimental data required to estimate the deterioration factors for the Australian fleet. But in 1989, Two major studies were conducted by both the State Pollution Control Commission of New South Wales (SPCC, 1989) and the Advisory Committee on Vehicle Emissions and Noise, ACVEN, (Collins, 1989) to estimate the exhaust deterioration factors for Australian cars (VEPA, 1991).

The SPCC study considered a significant proportion of vehicles which had accumulated distances in excess of 60,000 kilometres. In the case of $\mathrm{HC}$, values ranging from 0.04 0.17 gram $/ 10,000 \mathrm{~km}$ travel were found of two popular six cylinder models. NO deterioration factors for the same two vehicle models averaged 0.05-0.06 gram/10,000 $\mathrm{km}$ travel with $\mathrm{CO}$ averaging $0.4-2.3$ gram $/ 10,000 \mathrm{~km}$ travel. Whilst average-fleet exhaust deterioration factors were well above those of US EPA, US values fell within the range found for individual popular Australian vehicle models (VEPA, 1991).

In the Advisory Committee on Vehicle Emissions and Noise (ACVEN) study, Collins (1989) reported exhaust deterioration factors for post 1976 Australian cars. For ADR 27A and ADR 37 vehicles, Collins estimated average deterioration factors significantly higher than those recommended by US EPA (1985) as presented in Table 5.6

Table 5.6 Comparison between the exhaust deterioration rates of US EPA (1985), Pengilley (SPCC, 1989), and Collins, (1989) for ADR 27A and ADR 37. (Source: EPA (Victoria), 1991)

\begin{tabular}{|c|c|c|c|c|}
\hline \multicolumn{2}{|c|}{ Travel } & \multicolumn{3}{c|}{ Deterioration rate $(\mathrm{g} / \mathrm{km} / 10,00 \mathrm{~km}$ travel) } \\
\cline { 3 - 5 } \multicolumn{2}{|c|}{} & US EPA & SPCC $(\text { Range })^{\mathrm{a}}$ & Collins (Range) $^{\mathrm{b}}$ \\
\hline \multirow{3}{*}{ ADR 27A } & $\mathrm{CO}$ & 0.953 & 1.67 & $1.39(0.72-2.27)$ \\
\cline { 2 - 5 } & $\mathrm{HC}$ & 0.066 & 0.10 & $0.10(0.07-0.12)$ \\
\cline { 2 - 5 } & $\mathrm{NO}_{\mathrm{X}}$ & 0.016 & 0.10 & $0.05(0.02-0.07$ \\
\hline \multirow{2}{*}{ ADR 37 } & $\mathrm{CO}$ & 0.781 & $1.60(0.36-2.30)$ & $1.37(0.18-2.67)$ \\
\cline { 2 - 5 } & $\mathrm{HC}$ & 0.047 & $0.10(0.04-0.17)$ & $0.12(0.03-0.20)$ \\
\cline { 2 - 5 } & $\mathrm{NO}_{\mathrm{X}}$ & 0.035 & $0.07(0.05-0.06)$ & $0.25(0.17-0.33)$ \\
\hline
\end{tabular}

a The range of average deterioration factors for two most popular Australian car models (1986-1988).

b Weighted average of six and four-cylinder fleet results and range of minimum and maximum error bound for cars speed. 
Carnovale et al., 1993 found that vehicle use (ie. annual distance travelled) varies significantly with vehicle age.

From a survey of motor vehicle use in 1985, ABS (1986) reported that a car in its first year of use averaged approximately $22000 \mathrm{~km}$ whilst ten year old cars average only $15000 \mathrm{~km}$ (see Figure 5.2).

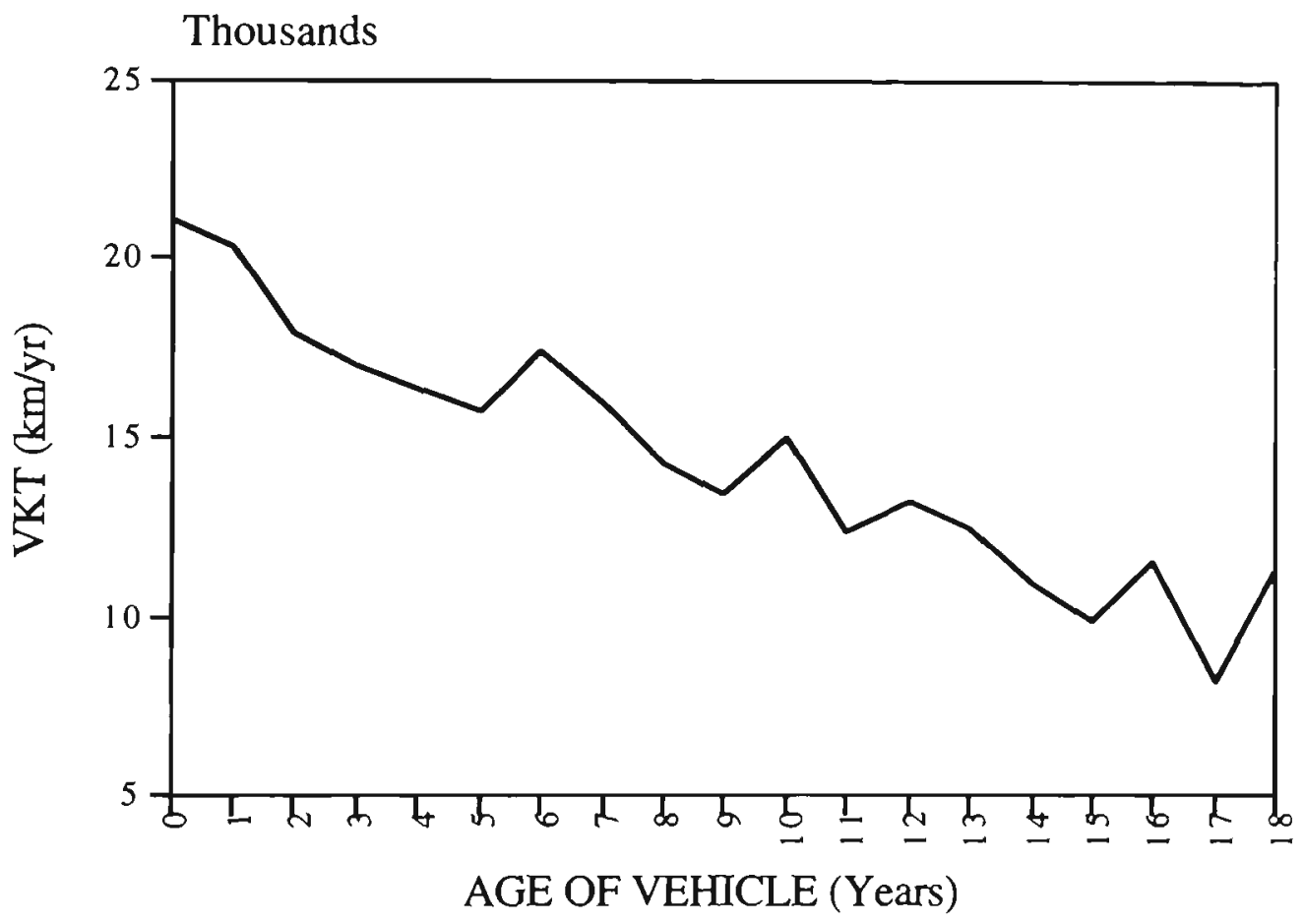

\section{Figure 5.2 Average Vehicle Kilometre Travelled (VKT) by cars and Station Wagons according to age, NSW (1988). (Data from Carnovale et al., 1993).}

Carnovale et al., (1993) also reported that passengers vehicles up to 8 years of age contribute approximately $50 \%$ of VKT (by passenger vehicles), ie. the effective mean age of the passenger vehicle fleet in NSW was 8 years.

In order to account accurately for the pollution contributed by vehicles of varying vintage, Carnovale et al., 1993 estimated the relative vehicle kilometres travelled by weighing the number of cars registrations (by year of manufacture) by the average distance travelled (by age). As an example, cars manufactured between 1986 and 1988 inclusive, constitute approximately $17 \%$ of total car registrations (September 1988). However, they contribute $22 \%$ of all car VKT in New South Wales (see Figure 5.3). 


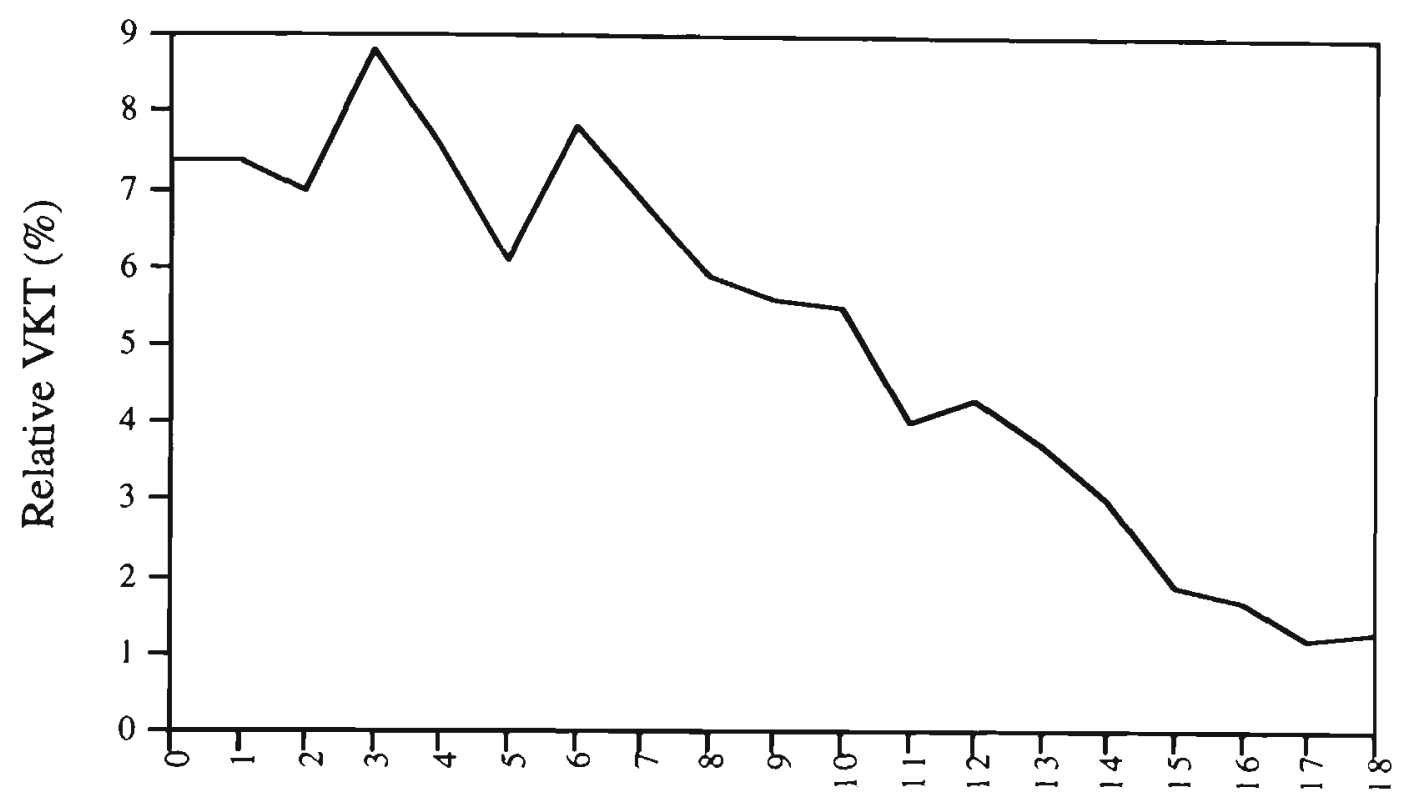

AGE OF VEHICLE (Years)

\section{Figure 5.3 Relative VKT versus age by for cars and Station Wagons according to age, NSW (1988). (Data from Carnovale et al., 1993).}

\subsubsection{Motor Vehicle Emission Test Results (SPCC, 1989)}

In the State Pollution Control Commission report of 1989, the results of light-duty motor vehicle emissions for the vehicle tested between July 1987 and August 1989 in the Motor Vehicle Testing Laboratory at Lidcombe, N.S.W. The first five volumes covered the vehicle tested between March 1980 and July 1986. The testing was carried out in accordance with NSW Clean Air Regulations 26 (2), 26 (3), 26 (4), and 27 . The testing employed CVS-C or CVS-CH driving cycles.

The driving cycle (CVS-C) is a 23-minute dynamometer-simulated city/urban driving schedule from a cold start. The CVS-C cycle is specified in NSW Clean Air Regulations 26 (3) and is the same as that specified in Australian Design Rule ADR 27A/B/C, and the United States 1972 - Federal Test Procedure (FTP) whilst the CVS-CH cycle is a 23minute dynamometer-simulated city/urban driving schedule from a cold start followed by a 10-minute hot soak, a hot start and a repetition of the first 8.5 minutes of the driving schedule. The CVS-CH cycle is specified in NSW Clean Air Regulations 26 (4) for application to cars manufactured on or after 1st January 1986, and is the same as that specified in Australian Design Rule ADR 37, and the United States 1975 - Federal Test Procedure (FTP). The testing procedure is given in Appendix C . 
The details of selected new spark ignition vehicles which were tested in 1989 are given in Table 5.7 which includes the vehicle make, vehicle model, the number of cylinders, engine capacity in litres, vehicle test weight, employed exhaust system (3-way catalytic converter or oxidation catalytic converter), and the odometer reading at the beginning of the test.

Table 5.7 The list of spark ignition vehicle parameters (model 1989) given in SPCC, 1989 report.

\begin{tabular}{|c|c|c|c|c|c|c|}
\hline Make & Model & Cylinders & $\begin{array}{c}\text { Capacity } \\
(\text { litres })\end{array}$ & $\begin{array}{c}\text { Weight } \\
(\mathrm{kg})\end{array}$ & $\begin{array}{c}\text { Exhaust } \\
\text { system }\end{array}$ & $\begin{array}{c}\text { Odometer } \\
(\mathrm{km})\end{array}$ \\
\hline Ford & Falcon & 6 & 3.9 & 1588 & $3 \mathrm{w}$ & 42 \\
\hline Ford & Fairlane & 6 & 3.9 & 1588 & $3 \mathrm{w}$ & 115 \\
\hline Ford & Falcon & 6 & 3.9 & 1644 & $3 \mathrm{w}$ & 72 \\
\hline Ford & Laser & 4 & 1.6 & 1077 & ox & 32 \\
\hline Ford & Telstar & 4 & 2.2 & 1304 & $3 \mathrm{w}$ & 33 \\
\hline Holden & Commodore SE & 6 & 3.8 & 1474 & $3 \mathrm{w}$ & 42 \\
\hline Holden & Commodore SE & 6 & 3.8 & 1531 & $3 \mathrm{w}$ & 75 \\
\hline Holden & Commodore SE & 8 & 5.0 & 1644 & $3 \mathrm{w}$ & 182 \\
\hline Holden & Astina & 4 & 1.8 & 1134 & $3 \mathrm{w}$ & 45 \\
\hline Mitsubishi & Magna WGN & 4 & 2.6 & 1474 & ox & 27 \\
\hline Mitsubishi & Lancer & 4 & 1.5 & 1191 & ox & 100 \\
\hline Mitsubishi & Colt & 4 & 1.6 & 1077 & ox & 31 \\
\hline Toyota & Corolla & 4 & 1.6 & 1134 & ox & 260 \\
\hline Toyota & Camry & 6 & 2.5 & 1531 & $3 \mathrm{w}$ & 117 \\
\hline Toyota & Camry & 4 & 2.0 & 1417 & $3 \mathrm{w}$ & 65 \\
\hline Nissan & Pintarta & 4 & 2.0 & 1361 & $3 \mathrm{w}$ & 38 \\
\hline Hyundi & Sonata & 4 & 2.4 & 1814 & $3 \mathrm{w}$ & 35 \\
\hline
\end{tabular}

$3 w$ : vehicles equipped with 3 -way catalytic converters

ox: vehicles equipped with oxidation catalytic converters

The gaseous emission levels for (post-1986) spark ignition vehicles used in SPCC, 1989 study are given in Table 5.8 . 
Table 5.8 Gaseous emission rates for ADR 37 test cycle for (post-1986) spark ignition vehicles used in SPCC, 1989 study.

\begin{tabular}{|c|c|c|c|c|c|}
\hline \multirow{2}{*}{ Make } & \multirow{2}{*}{ Model } & Capacity & $\mathrm{CO}$ & $\mathrm{NMHC}$ & $\mathrm{NO}$ \\
\cline { 3 - 6 } & & $($ litres $)$ & $\mathrm{g} / \mathrm{km}$ & $\mathrm{g} / \mathrm{km}$ & $\mathrm{g} / \mathrm{km}$ \\
\hline Ford & Falcon & 3.9 & 4.9 & 0.28 & 0.65 \\
\hline Ford & Fairlane & 3.9 & 3.50 & $0.4 \mathrm{l}$ & 0.59 \\
\hline Ford & Falcon & 3.9 & 3.80 & 0.29 & 0.65 \\
\hline Ford & Laser & 1.6 & 2.6 & 0.17 & 1.02 \\
\hline Ford & Telstar & 2.2 & 2.5 & 0.18 & 0.42 \\
\hline Holden & Commodore SE & 3.8 & 3.3 & 0.28 & 0.94 \\
\hline Holden & Commodore SE & 3.8 & 3.9 & 0.32 & 0.55 \\
\hline Holden & Commodore SE & 5.0 & 5.2 & 0.78 & 0.61 \\
\hline Holden & Astina & 1.8 & 4.5 & 0.30 & 0.48 \\
\hline Mitsubishi & Magna & 2.6 & 7.6 & 0.23 & 0.65 \\
\hline Mitsubishi & Lancer & 1.5 & 5.0 & 0.39 & 0.91 \\
\hline Mitsubishi & Colt & 1.6 & 2.9 & 0.17 & 1.03 \\
\hline Toyota & Corolla & 1.6 & 5.8 & 0.29 & 0.85 \\
\hline Toyota & Camry & 2.5 & 1.0 & 0.24 & 0.31 \\
\hline Toyota & Camry & 2.0 & 3.1 & 0.57 & 1.27 \\
\hline Nissan & Pintarta & 2.0 & 1.20 & 0.14 & 0.37 \\
\hline Hyundi & Sonata & 2.4 & 1.90 & 0.34 & 0.37 \\
\hline
\end{tabular}

\subsection{Validation results and discussion}

The measured carbon monoxide, hydrocarbon, and oxides on nitrogen emissions data of the ADR 37 city cycle from Williams et al., 1987, Carnovale et al., 1991, and SPCC, 1989 testing studies were compared with the modelled emissions to validate the powerbased exhaust emissions model regarding pre-1986 spark ignition (leaded), post-1986 spark ignition (unleaded), and light-duty diesel vehicles.

Two sources of experimental data were utilised to validate the model predictions of the fuel consumption. These experimental data were the measured fuel consumption data of the ADR 37 city cycle from Williams et al., 1987 and SPCC, 1989 testing studies, and data from on-road driving measurements. These type of data obtained for the application of the power-based emissions model to predicting fuel consumption in-traffic. The predicted and measured fuel consumption of seven experimental trips carried out in 
Sydney using CSIRO instrumented vehicle were compared. The vehicle speed, the altitude of the road, wind speed and direction, and the fuel consumption were monitored every second over the trip duration. The predicted fuel consumption were estimated over the duration of every trip taking into account the acceleration-deceleration manoeuvres, the road gradient, the effect of the aerodynamic drag over the period of the trips.

The results of the multi-mode test cycle used for heavy-duty diesel vehicles are not suitable for direct validation due to the lack of a precise speed-time profile available from ADR 37 test cycle.

The experimental data of the recent CSIRO/RTA field study (Williams et al., 1994) is compared with the predicted emissions of two dispersion models (CALINE4 (Benson, 1984) and HIWAY-2 (Petersen, 1980)) used in conjunction with the power-based emissions model (see Chapter 6).

It should be noted that, in the following discussion, the term ADR27A test cycle is identical to the FTP test cycle of duration $1372 \mathrm{~s}$, whilst the ADR37A cycle is the $1372 \mathrm{~s}$ cycle plus the initial $505 \mathrm{~s}$ segment (after a 10-minute hot soak). Catalyst-equipped SI vehicles became mandatory in Australia after 1985.

The nature of the model that the fuel consumption is the primary parameter evaluated and emphasis, therefore, must be placed on how well the model performs in this respect, although the main thrust of the model is to predict $\mathrm{CO}, \mathrm{HC}$ and $\mathrm{NO}_{\mathrm{X}}$.

\subsubsection{Fuel Consumption}

\subsubsection{Over ADR 37A driving cycle}

Equations 3.1, 3.10, and 3.23 have been integrated on a second by second basis over the $\mathrm{ADR} 37 \mathrm{~A}$ driving cycle to estimate fuel consumption rates and the exhaust emissions of $\mathrm{CO}, \mathrm{HC}$ and $\mathrm{NO}_{\mathrm{X}}$ for a number of in-use pre-1986 vehicles that were the subject of particle emission testing (Williams et al., 1987) and also a number of new post-1986 vehicles (SPCC, 1989). The fuel consumption results are compared with actual measurements in Figures 5.4 and 5.5. It should be noted that for post-1986 cars, a value for $C_{d}$ of 0.35 was chosen as opposed to 0.4 for the older vehicles.

It can be seen that the model provides a reasonable estimate of fuel consumption for both the pre-1986 in-use vehicles and post-1986 new vehicles. In Figure 5.4, It can be seen that the model underpredicts the fuel consumption for the pre-1986 in-use vehicles (the 


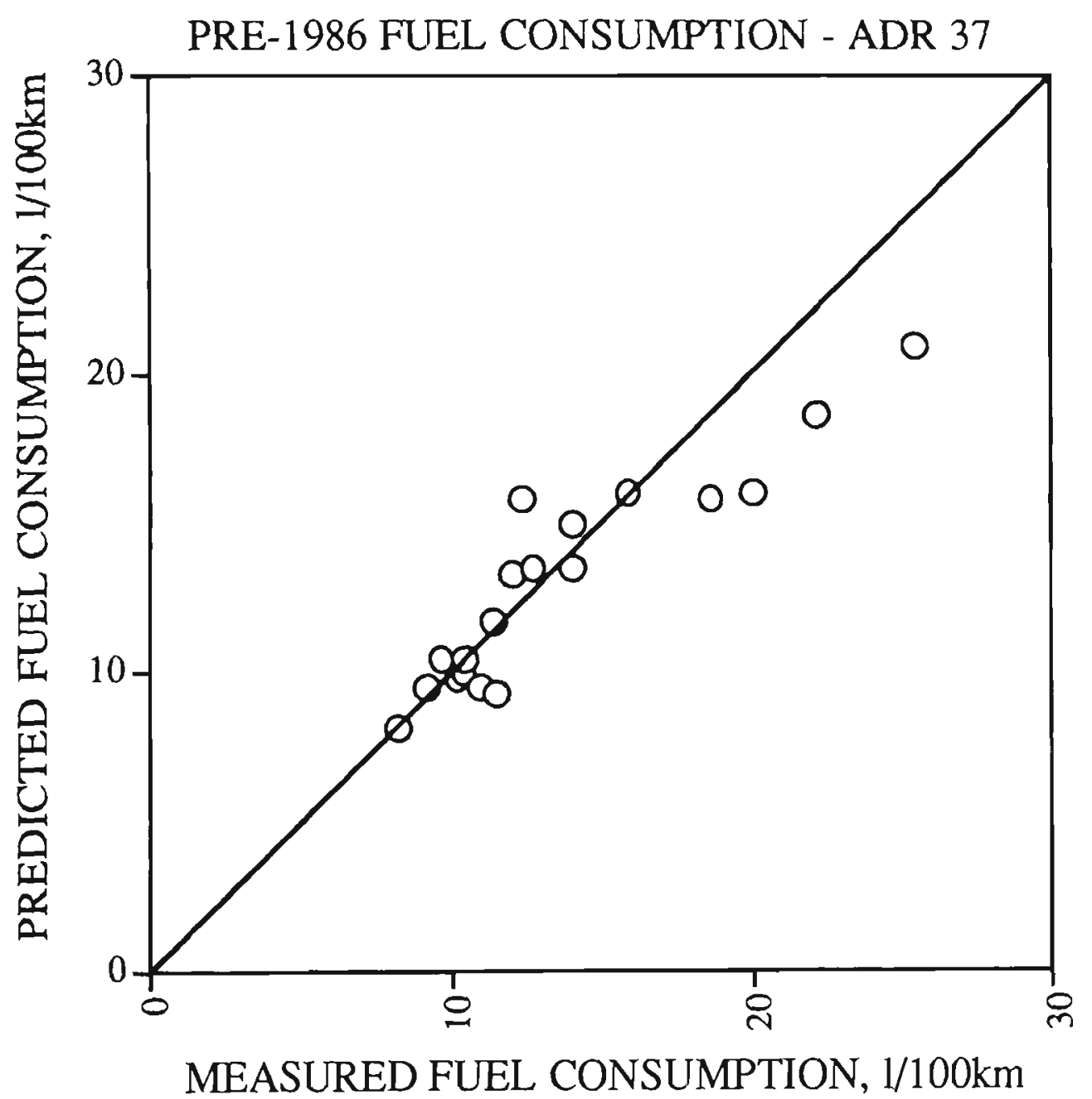

Figure 5.4 Comparison of predicted and measured ADR 37 fuel consumption for pre-1986 spark ignition vehicle (regression $\mathbf{r}^{2}=\mathbf{0 . 8 4 4 )}$. 


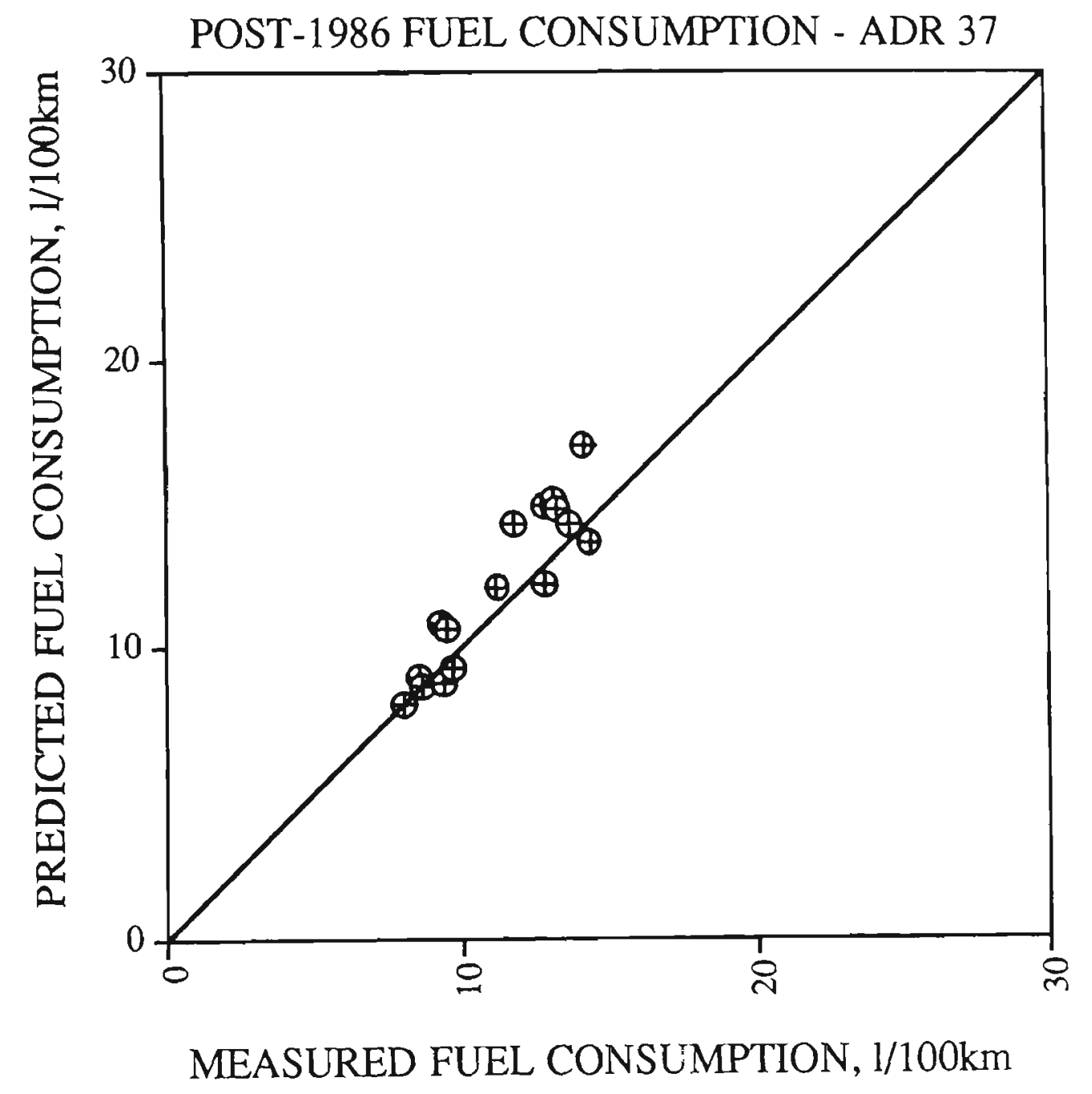

Figure 5.5 Comparison of predicted and measured ADR 37 fuel consumption for post-1986 spark ignition vehicle (regression $\mathrm{r}^{2}=0.852$ ). 
ratio between the predicted and measured fuel economy varies from 0.807 to 1.283 with average value of 0.915 ). The reason for this trend is that the estimation of the fue] consumption using equation (3.10) is for new vehicles, and all the cars tested in Williams et a1., 1987 study were "in use" old cars with different travelled distances. In the same time, Figure 5.5 shows that the fuel consumption predictions of post-1986 new spark ignition vehicles are quite fair (the ratio between the predicted and measured fuel economy varies from 1.05 to 1.17 with average value of 1.083 ).

It is also noted that although the used experimental data were limited (19 pre-1986 (Williams et al., 1987) and 18 post-1986 (SPCC, 1989) spark ignition vehicles), the regression lines in Figures 5.4 and 5.5 show good consistencies (variance $r^{2}=0.844$ and 0.852 , respectively).

Diesel vehicles are a significant traffic component but for which there is much less information on which to base an emission model. However, the general approach of estimating engine power demand should be equally applicable. The diesel engine is substantially more efficient than a petrol engine, so the value of $\beta$ is likely to be around 5 - 6 when estimating fuel consumption.

The predicted fuel consumption from some in-use light-duty diesel vehicles (estimated by the integration of equation 3.18) are compared with the data of Williams et al., (1987) in Figure 5.6. There is more scatter than for the SI vehicles, but the agreement is still fair (the ratio of predicted fuel economy to the measured fuel economy varies from 0.63 to 1.2 with average value of 0.7 ). The variance $r^{2}$ is 0.465 which reflects reasonable consistency. It is suggested that more data are required to better evaluate $\alpha$ and $\beta$.

\subsubsection{On-road driving pattern}

An additional type of data obtained for the application of the power-based emissions model to predicting fuel consumption in-traffic and to validate the effect of wind and altitude. Table 5.9 shows the comparison of the predicted and measured fuel consumption of seven experimental trips carried out using CSIRO instrumented vehicle.

For the first four trips, the vehicle speed and the fuel consumption were monitored every second over the trip duration while for trip $5,6,7$, and 8 , the altitude of the road was measured besides the vehicle speed, wind speed, wind direction and fuel consumption. 


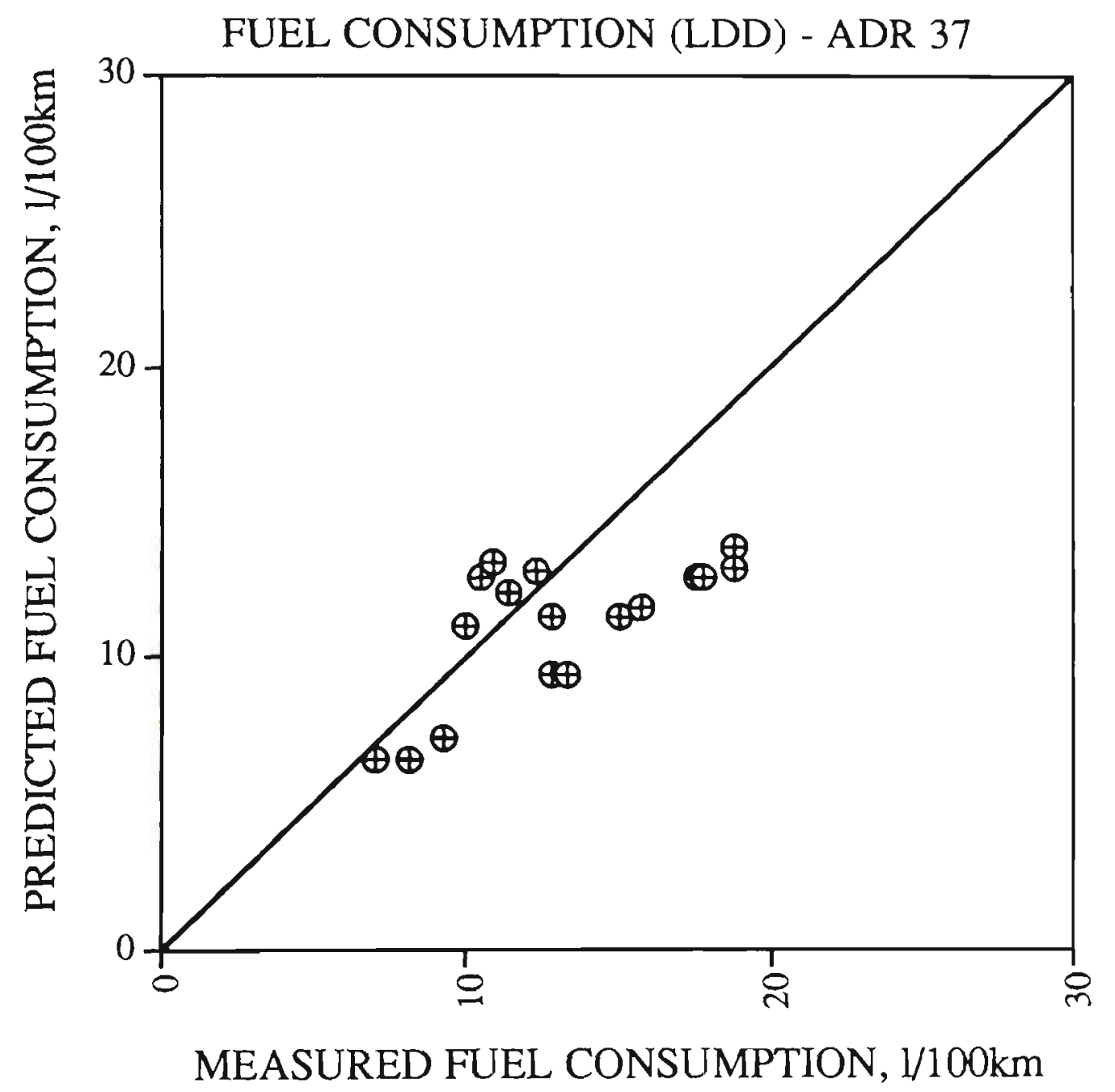

Figure 5.6 Comparison of predicted and measured ADR 37 fuel consumption for light-duty diesel vehicles (regression $r^{2}=0.465$ ). 
Table 5.9 Summary of the performance of the power-based emissions model with regard of the fuel consumption prediction of the CSIRO instrumented vehicle $(\mathrm{EC}=5.8$ litres, $\mathrm{M}=3300 \mathrm{~kg}, \mathrm{~L}=5.15 \mathrm{~m}, \mathrm{~W}=1.8$ $\mathrm{m}, \quad \mathrm{H}=\mathbf{2 . 8} \mathrm{m}$, and $\mathrm{C}_{\mathrm{d}}=\mathbf{0 . 4 5}$ ) against eight experimental Trips carried out on the 6th, the 7th of July, and the 30th of September 1994.

\begin{tabular}{|c|c|c|c|c|c|c|}
\hline No. & Trip & Date & $\begin{array}{c}\text { Duration } \\
\text { seconds }\end{array}$ & $\begin{array}{c}\text { Predicted Fuel } \\
\text { cons.(litres) }\end{array}$ & $\begin{array}{c}\text { Measured Fuel } \\
\text { cons.(litres) }\end{array}$ & $\mu$ \\
\hline $1^{*}$ & $\begin{array}{c}\text { From Concord via } \\
\text { GWH to Parramatta }\end{array}$ & $7 / 7 / 94$ & 918 & 4.680 & 4.67 & 1.00 \\
\hline $2^{*}$ & $\begin{array}{c}\text { From Parramatta } \\
\text { via M4 Freeway } \\
\text { to Concord }\end{array}$ & $7 / 7 / 94$ & 983 & 3.957 & 4.40 & 0.90 \\
\hline $3^{*}$ & $\begin{array}{c}\text { From Concord } \\
\text { via M4 Freeway } \\
\text { to Parramatta }\end{array}$ & $7 / 7 / 94$ & 570 & 3.745 & 3.75 & 1.00 \\
\hline $4^{*}$ & $\begin{array}{c}\text { From Parramatta via } \\
\text { GWH to Concord }\end{array}$ & $7 / 7 / 94$ & 568 & 3.642 & 4.09 & 0.89 \\
\hline $5^{* *}$ & $\begin{array}{c}\text { From N. Ryde } \\
\text { via Epping HWY } \\
\text { to Balmain }\end{array}$ & $6 / 7 / 94$ & 1342 & 5.990 & 5.89 & 1.02 \\
\hline $6^{* *}$ & $\begin{array}{c}\text { From N. Ryde via } \\
\text { Epping HWY } \\
\text { to Balmain }\end{array}$ & $6 / 7 / 94$ & 2650 & 11.400 & 10.90 & 1.05 \\
\hline $7^{* *}$ & $\begin{array}{c}\text { From Eastern Creek } \\
\text { HWY via M4 Freeway } \\
\text { to Blue Mountain }\end{array}$ & $30 / 9 / 94$ & 2160 & 19.700 & 20.30 & 0.97 \\
\hline $8^{* *}$ & $\begin{array}{c}\text { From Eastern Creek } \\
\text { HWY via M4 Freeway } \\
\text { to Penrith }\end{array}$ & $30 / 9 / 94$ & 640 & 6.391 & 6.286 & 1.02 \\
& & $4.600)$ & $0.73^{+}$ \\
\hline
\end{tabular}

$\mu$ is the model performance (ratio of predicted to measured concentrations, GWH is the Great Western Highway

* The predicted fuel consumption was estimated taking into the account the accelerationdeceleration manoeuvre over the period of the trip.

** The predicted fuel consumption was estimated taking into the account both the acceleration-deceleration manoeuvre and the road gradient over the period of the trip The value in brackets is the predicted fuel consumption at zero wind speed. + The (ratio of predicted(for zero wind speed) to measured concentrations. 
The predicted fuel consumption for trip 1, 2, 3, and 4 were estimated by integrating equation 3.23 (Chapter 3 ) over the duration of every trip taking into account the acceleration-deceleration manoeuvres while the predicted fuel consumption for trip 5,6 , 7 , and 8 were estimated taking into account the acceleration-deceleration manoeurres and the road gradient over the period of the trips.

Table 5.9 shows good agreement between the predicted and measured fuel consumption for the eight trips. For the first four trips, It is obvious that the predicted fuel consumption for (Trip 2, and 4) were less than measured fuel consumption reflecting the effect of the increase of the idle periods. The results of the first four trips agree with the investigations of Kent et al. (1982) who investigated over two thousands traffic links and more than $1000 \mathrm{~km}$ of road instantaneous velocity, acceleration and gradient data and found that the instantaneous power model generates aggregate fuel estimates that agree withe the actual usage determined by fuel flow measurements.

Figures 5.7 and 5.8 show the effect of the road gradient on the fuel consumption for the trip from Eastern Creek highway to the Blue Mountain. The altitude in Eastern Creek highway was around $50 \mathrm{~m}$ above the see level while the altitude in the Blue Mountain was $500 \mathrm{~m}$ above the see level. It is obvious that ratio of the predicted fuel consumption estimated taking into account the road gradient and the fuel consumption estimated for plain road is a function of the road slope. Blue mountains experiment indicate better the experimental set for vehicle speed, fuel consumption and altitude.

Penrith trip (trip 8) indicate better the effect of the aerodynamic drag. This trip was from Eastern Creek to Penrith with duration of $640 \mathrm{~s}$. The wind was front wind with speed of $7 \mathrm{~m} / \mathrm{s}(25.2 \mathrm{~km} / \mathrm{h})$. The predicted total fuel consumption estimated taking in account the effect of the aerodynamic drag was 6.391 litres and the corresponding model performance was 1.02 while the predicted total fuel consumption estimated without taking the effect of the aerodynamic drag $(\mathrm{u}=0)$ in account was 4.600 litres and the corresponding model performance was 0.73 .

The range of the model performance (the ratio between the predicted to measured fuel consumption) of the first four trips were from 0.89 to 1.00 with average value of 0.95 while the range of the model performance of trip 5, 6, 7, and 8 is 0.97 to 1.05 , respectively, with average value of 1.02 showing improvement of the model performance due to taking into account both the acceleration-deceleration manoeuvres and the road gradient when estimating predicted fuel consumption. 


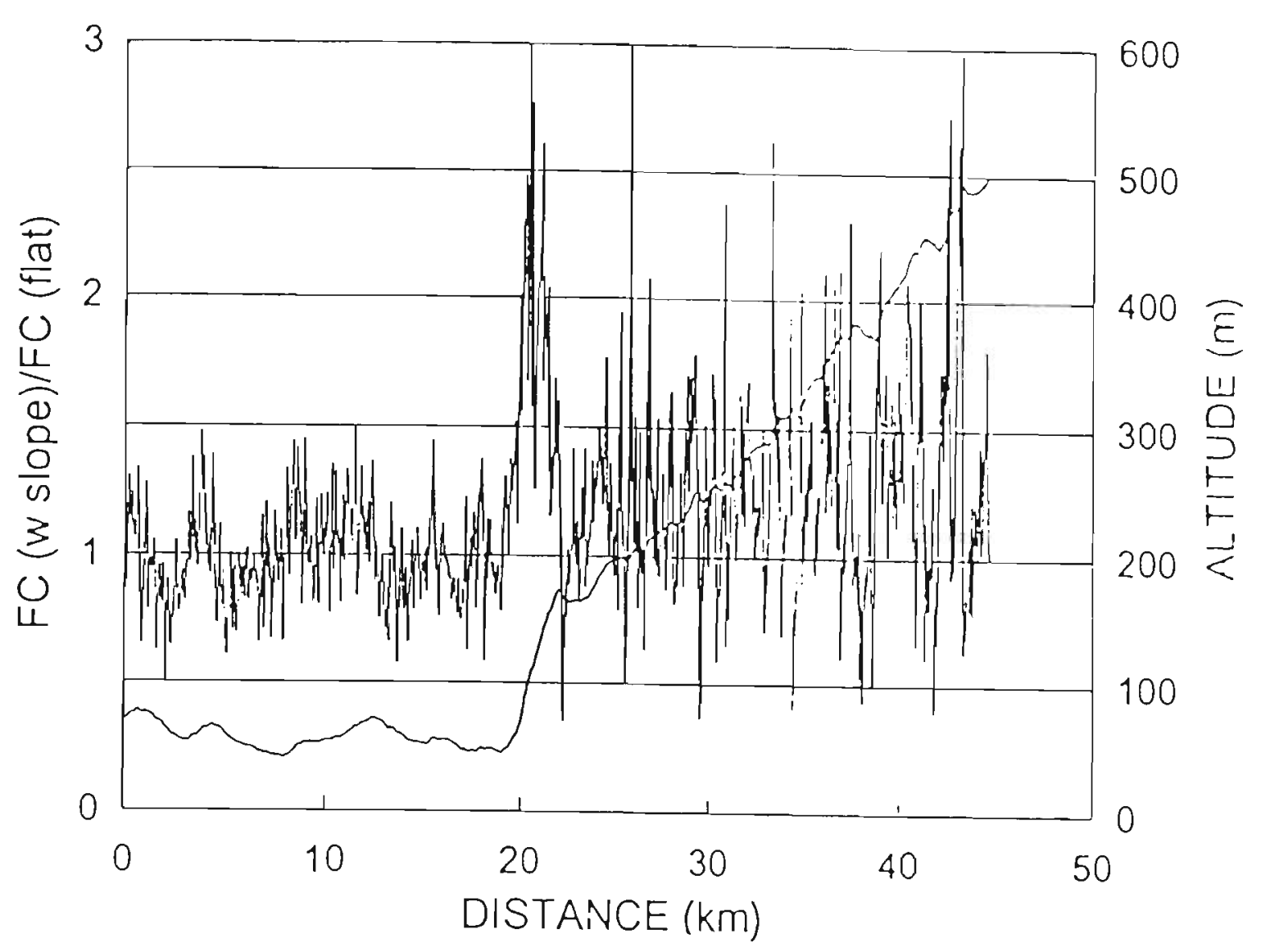

Figure 5.7 The ratio of the predicted fuel consumption estimated taking into account the road gradient and the fuel consumption estimated for plain road as a function of both the distance and the altitude for the trip from Eastern Creek highway 10 the Blue Mountain in Sydney. 


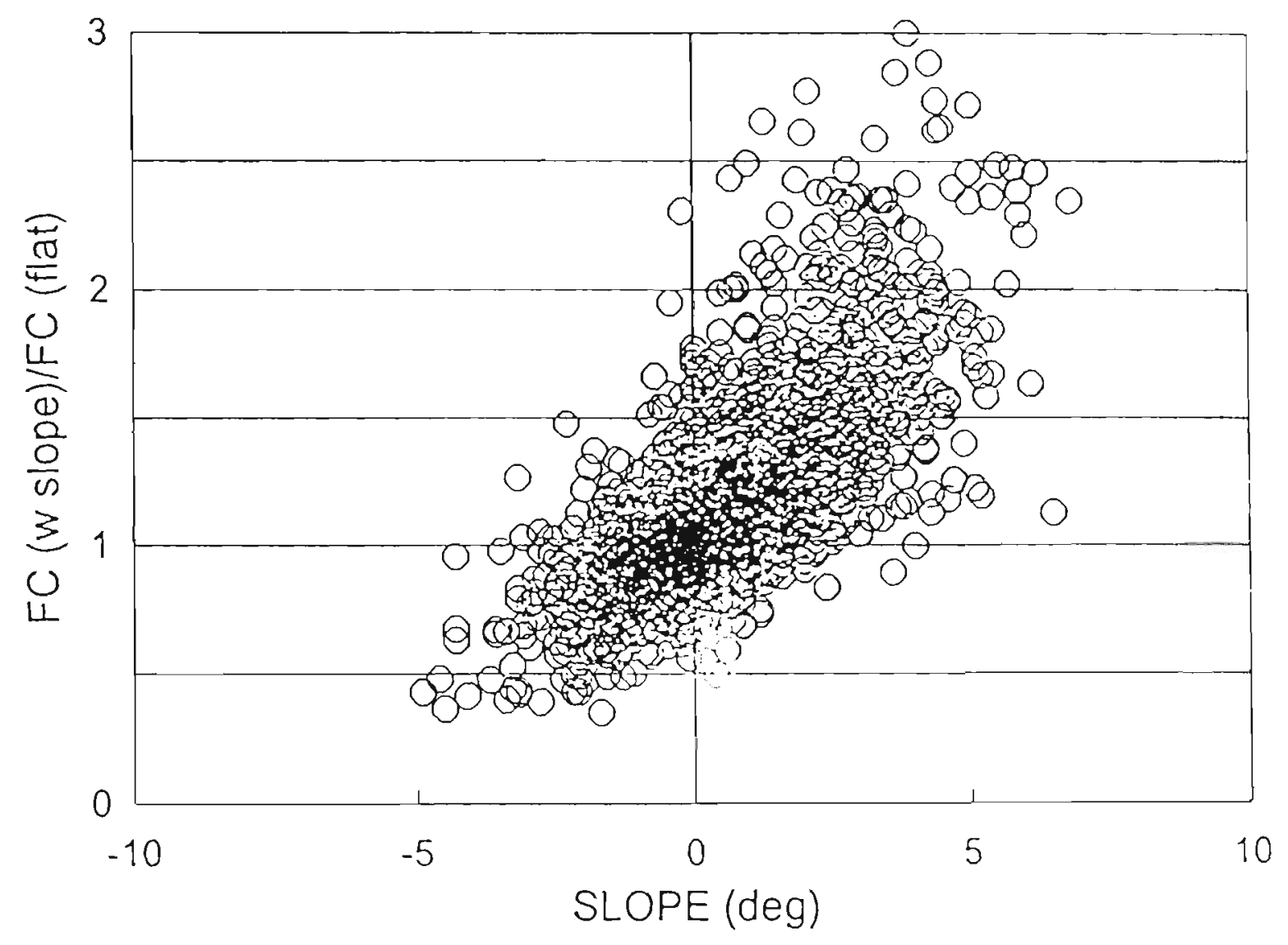

Figure 5.8 The ratio of the predicted fuel consumption estimated taking into account the road gradient and the fuel consumption estimated for plain road as a function of the road slope for the trip from Eastern Creek highway to the Blue Mountain in Sydney. 


\subsubsection{Gaseous Emissions}

Equations $3.1,3.11$ to 3.13 , and 3.24 to 3.26 have been integrated on a second by second basis over the ADR37A driving cycle to estimate fuel consumption rates and the exhaust emissions of $\mathrm{CO}, \mathrm{HC}$ and $\mathrm{NO}_{\mathrm{X}}$ for a number of in-use pre-1986 vehicles that were the subject of particle emission testing (Williams et al., 1987) and also a number of new post-1986 vehicles (SPCC, 1989).

The predicted $\mathrm{CO}, \mathrm{HC}$ and $\mathrm{NO}_{\mathrm{X}}$ emissions for the pre-1986 SI vehicles are compared with the test data in Figures 5.9, 5.11, and 5.13, respectively, and those for the catalystequipped vehicles in Figures 5.10, 5.12, and 5.14.

In Figure 5.9 the ratio between the predicted to measured CO emissions for pre-1986 spark ignition "in use" vehicles varies from 0.5 to 1.3 with average value of 0.63 with reasonable standard deviation of 0.583 . The reason for the reasonable values of $\mathrm{CO}$ emissions for pre-1986 spark ignition vehicles is that car deterioration factors based on the Victorian EPA recommendation for the Australian fleet (Canovale et al., 1991) were taken into account when estimating the predicted emissions. Also, Figure 5.10 shows that the ratio between the predicted to measured CO emissions for post-1986 new spark ignition vehicles varies from 0.5 to 1.2 with an average value of 0.74 with a reasonable regression of 0.70 .

With regard to $\mathrm{HC}$, Figure 5.11 and 5.12 show that the ratio between the predicted to measured $\mathrm{HC}$ emissions for pre-1986 spark ignition "in use" vehicles varies from 0.3 to 1.1 with an average value of 0.60 , and the ratio between the predicted to measured $\mathrm{HC}$ emissions for post- 1986 new vehicles varies from 0.35 to 1.8 with an average value of 0.71 . The variance for Figures 5.5 and 5.6 are 0.283 and 0.258 , respectively.

With regard to $\mathrm{NO}_{\mathrm{X}}$, Figures 5.13 and 5.14 show that the ratio between the predicted to measured $\mathrm{NO}_{\mathrm{X}}$ emissions for pre-1986 spark ignition "in use" vehicles varies from 0.35 to 1.8 with an average value of 0.56 , and the ratio between the predicted to measured $\mathrm{NO}_{\mathrm{X}}$ emissions for post-1986 new vehicles varies from 0.48 to 1.41 with an average value of 0.66 . The variance for Figures 5.10 and 5.11 are 0.687 and 0.324 , respectively.

It can be seen that there is a large scatter in the predicted versus experimental emissions of $\mathrm{CO}$ and $\mathrm{HC}$ in the data leading to the above equations. This scatter is common to all such databases as the minor exhaust components depend to a great extent on condition and tune of the vehicle than does fuel consumption. However, overall, the predicted values were in the "ballpark". 


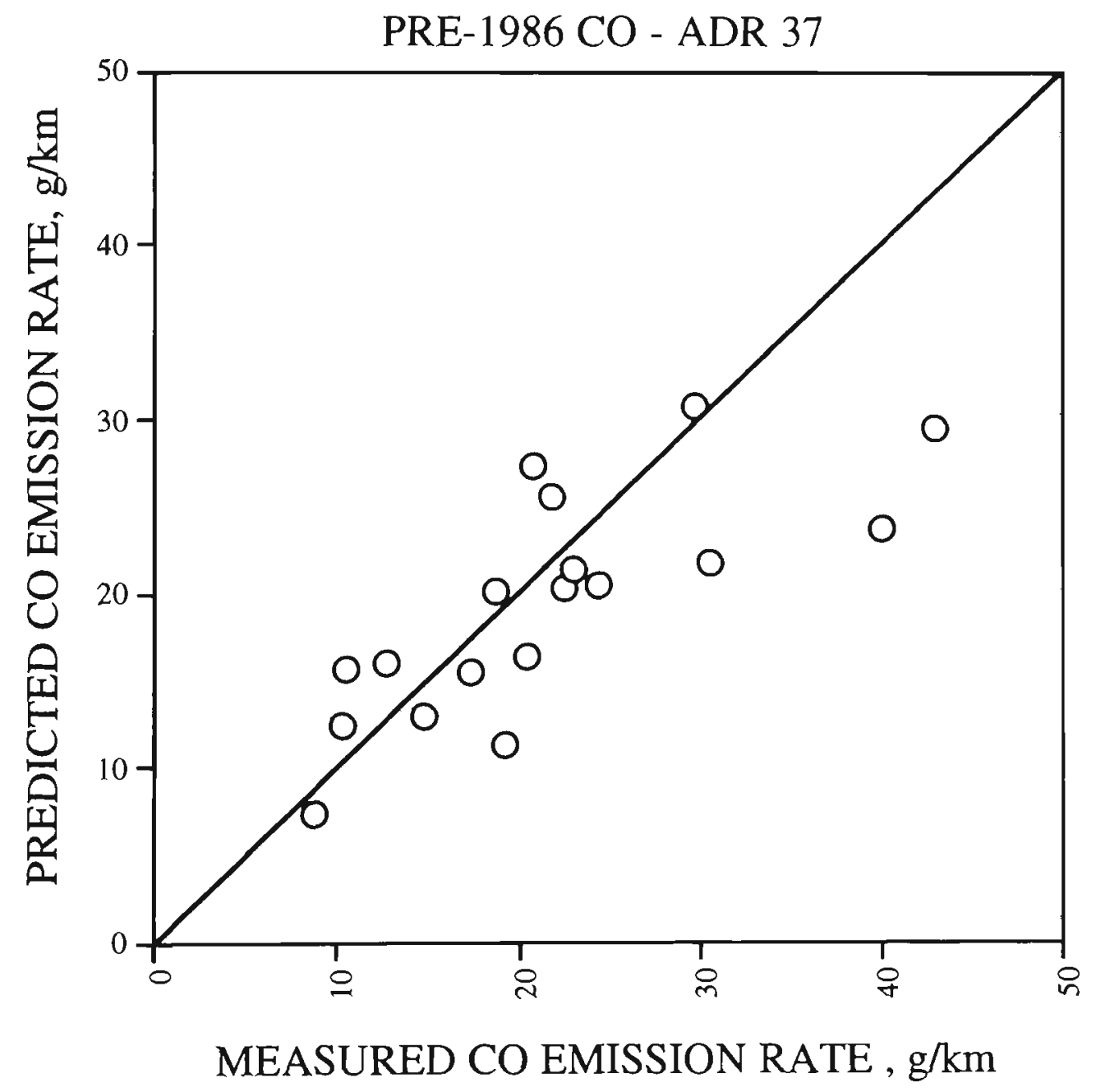

Figure 5.9 Comparison of predicted and measured ADR 37 carbon monoxide emissions for pre-1986 spark ignition vehicle (regression $\mathbf{r}^{2}=\mathbf{0 . 5 8 2}$ ). 


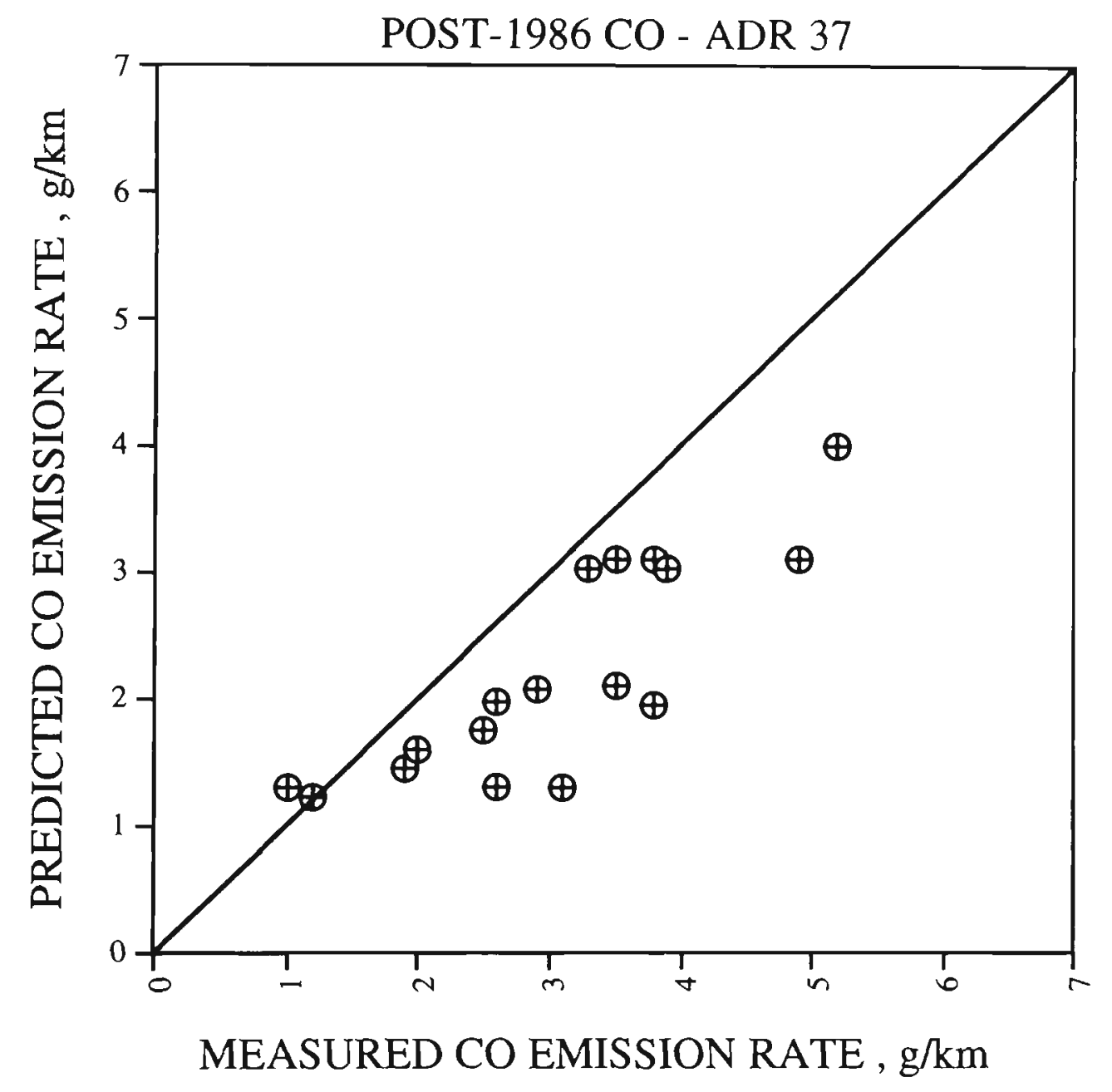

Figure 5.10 Comparison of predicted and measured ADR 37 carbon monoxide emissions for post-1986 spark ignition vehicle (regression $\mathrm{r}^{2}=0.7$ ). 


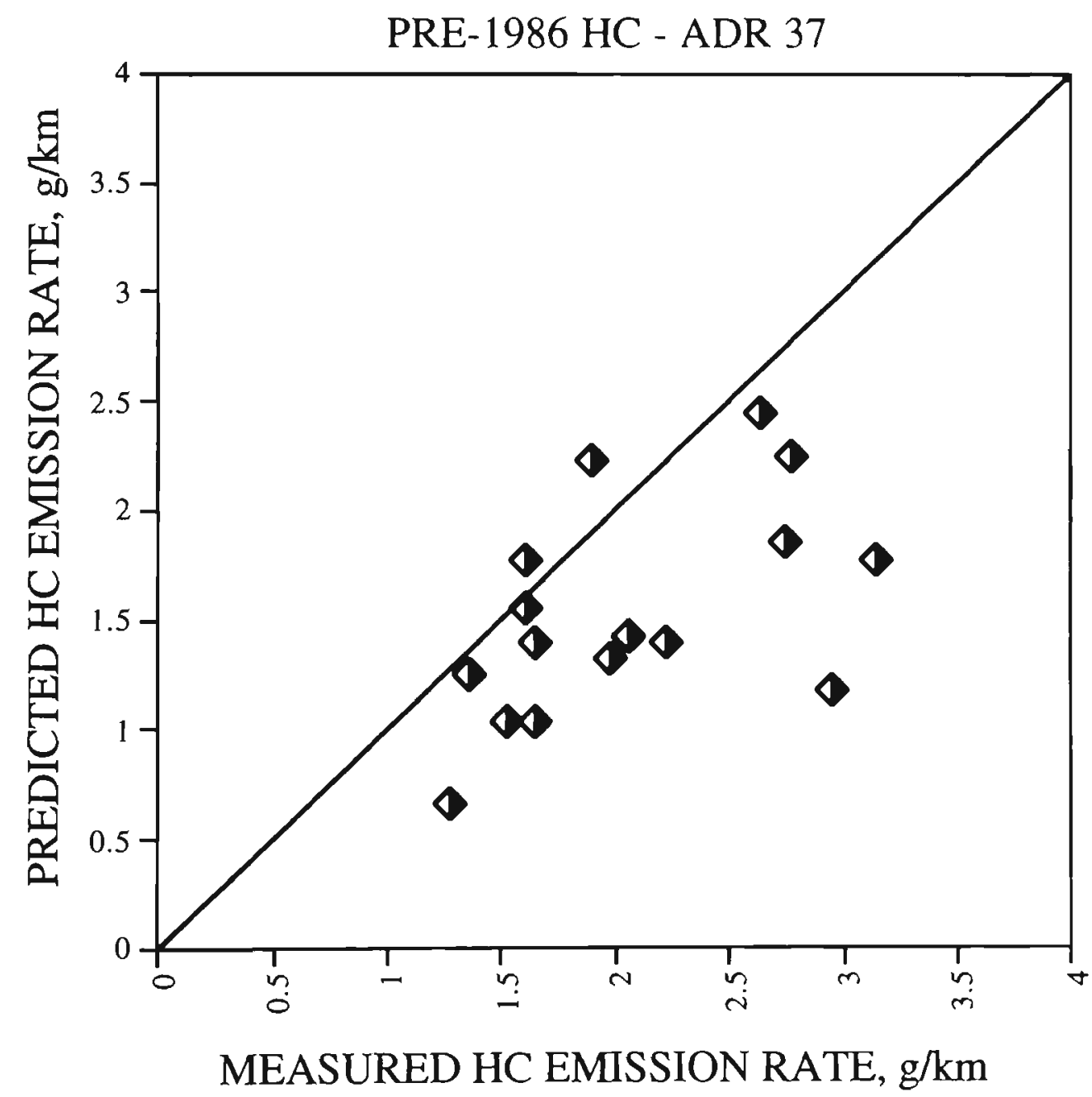

Figure 5.11 Comparison of predicted and measured ADR 37 hydrocarbons emissions for pre-1986 spark ignition vehicle (regression $r^{2}=0.283$ ). 


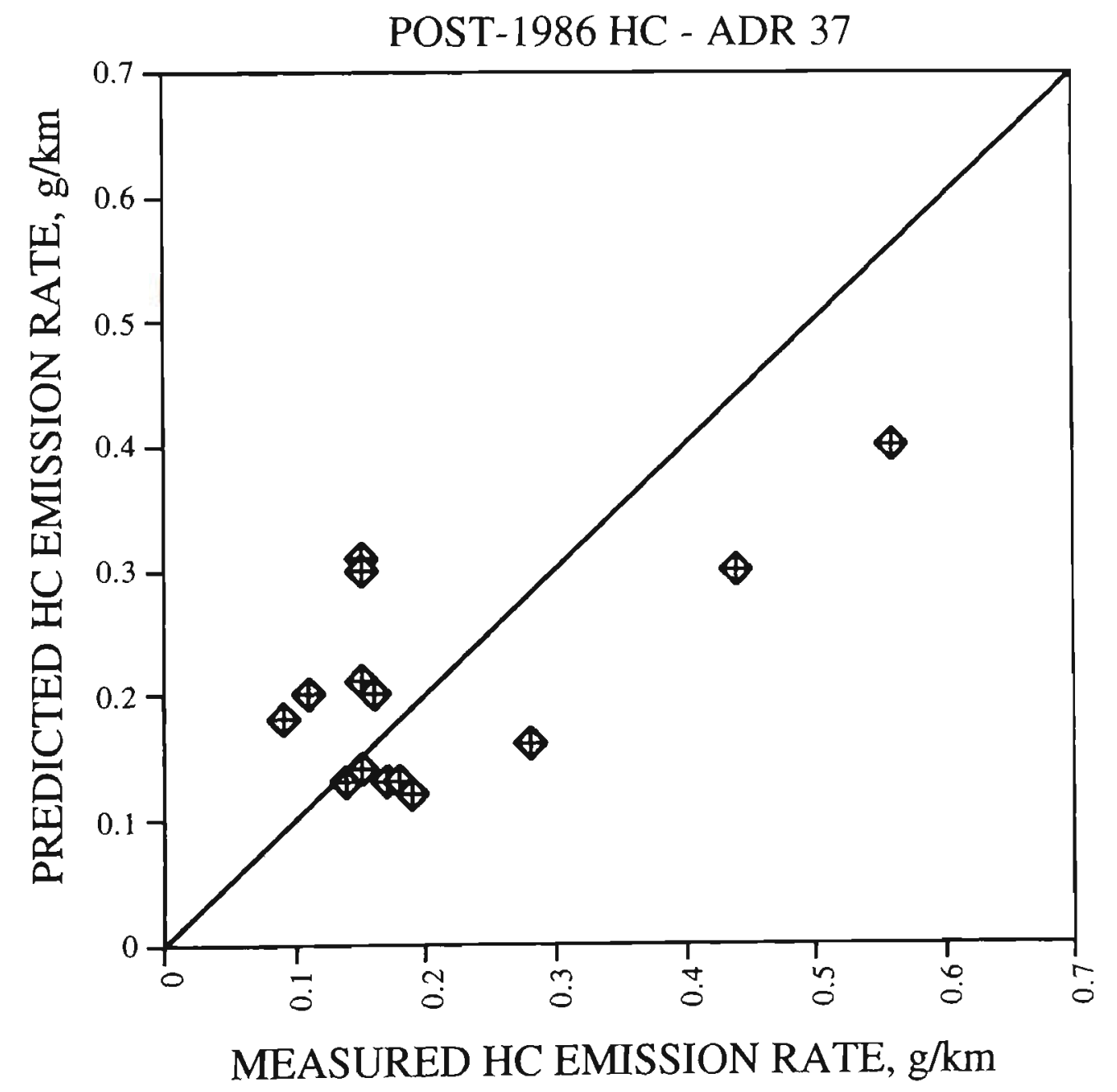

Figure 5.12 Comparison of predicted and measured ADR 37 hydrocarbons emissions for post-1986 spark ignition vehicle (regression $\mathbf{r}^{2}=0.258$ ). 


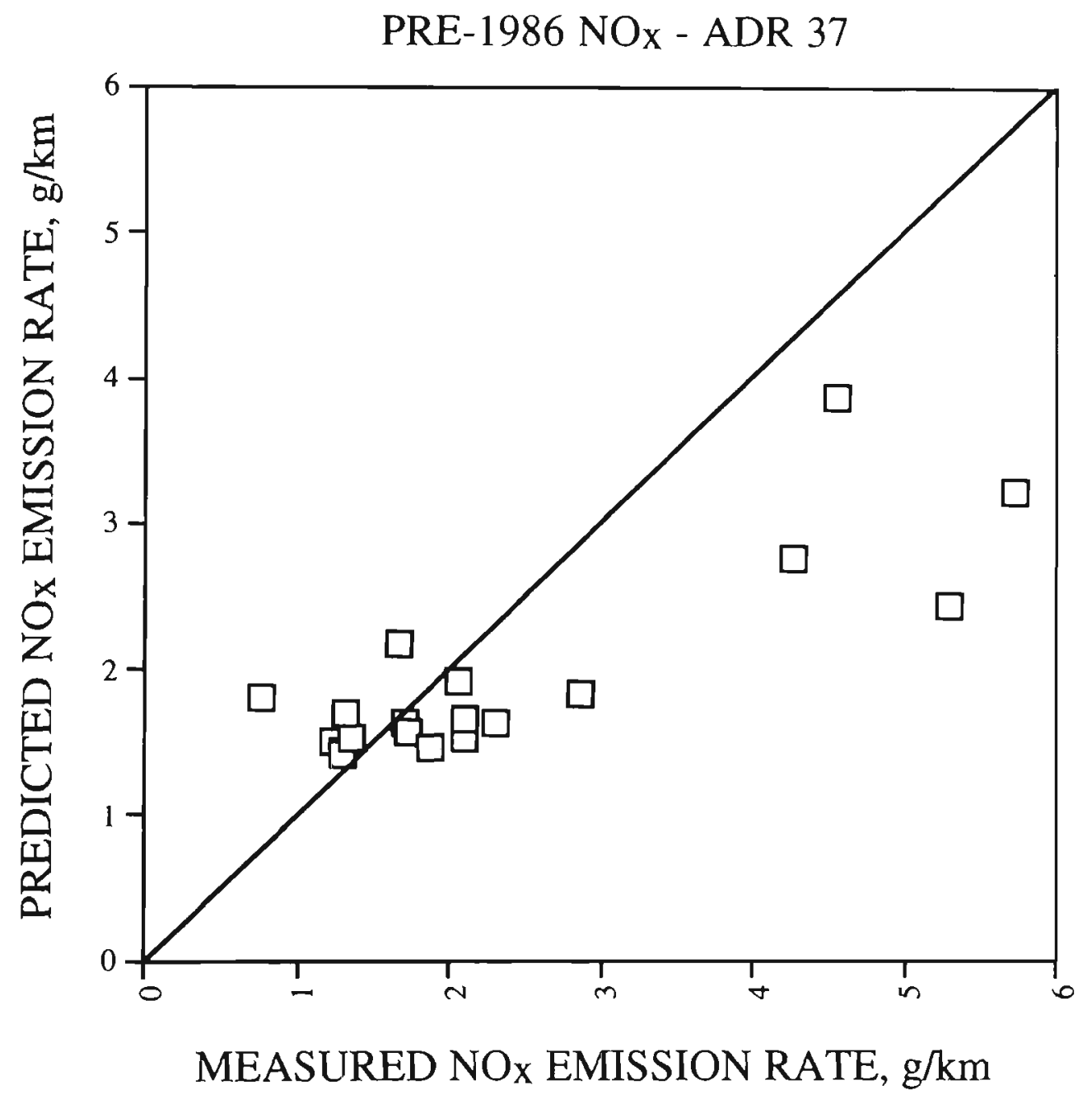

Figure 5.13 Comparison of predicted and measured ADR 37 oxides of nitrogen emissions for pre-1986 spark ignition vehicle (regression $\left.\mathbf{r}^{2}=0.687\right)$. 


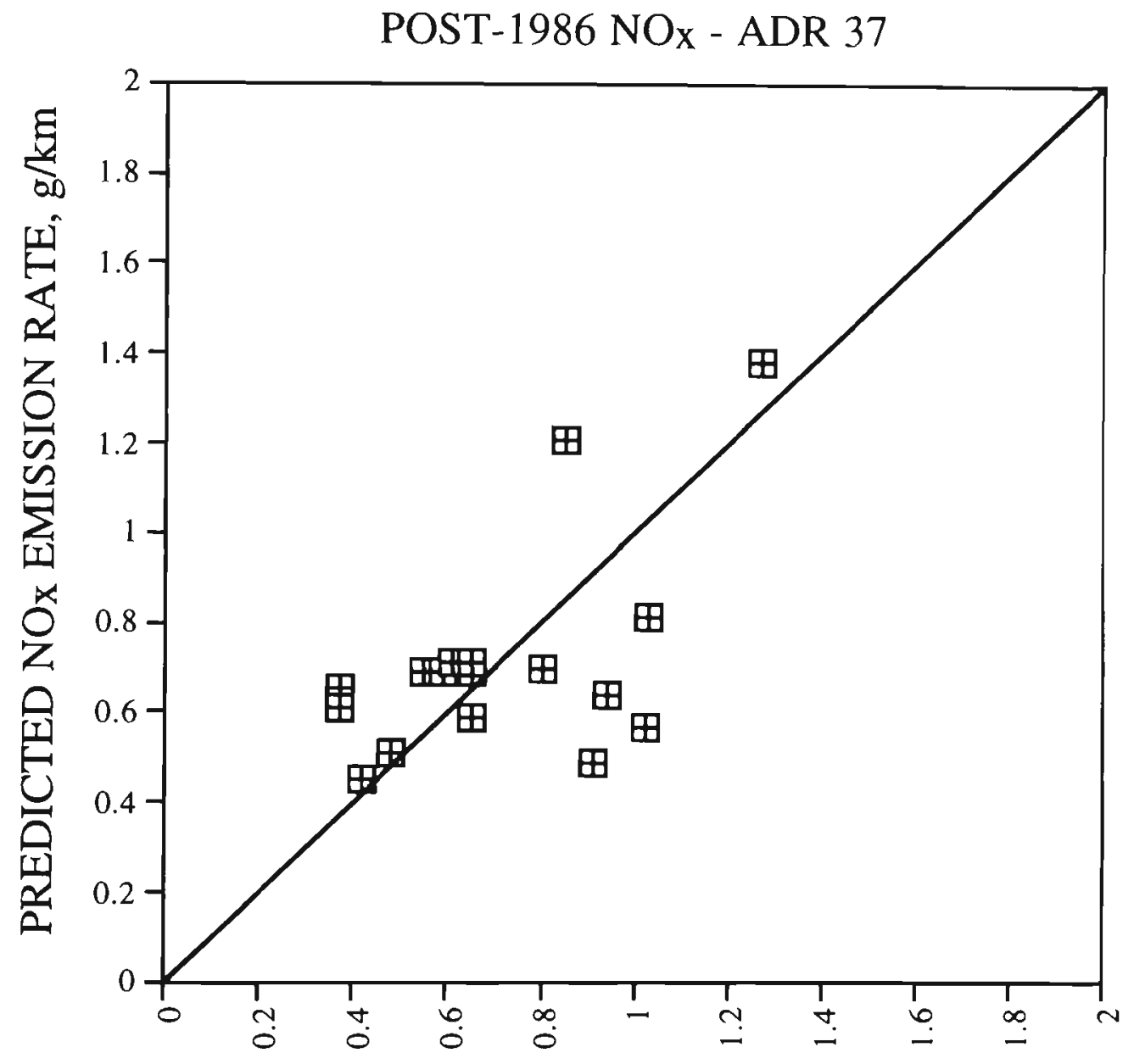

MEASURED NOx EMISSION RATE, $\mathrm{g} / \mathrm{km}$

Figure 5.14 Comparison of predicted and measured ADR 37 oxides of nitrogen emissions for post-1986 spark ignition vehicle (regression $\mathrm{r}^{2}=\mathbf{0 . 3 2 4}$ ). 
For the vehicles in the study of Williams et al., (1987), the predicted specific CO emissions (ie for unit ( $\mathrm{kg}$ ) fuel consumption) were in the range $100-250 \mathrm{~g}$, while the measured values were $200-400 \mathrm{~g}$, the corresponding ranges for HC were $12-30 \mathrm{~g}$ versus $5-70$ and for $\mathrm{NO}_{\mathrm{X}}, 15-30 \mathrm{~g}$ versus $5-70 \mathrm{~g}$.

In the Victorian EPA study (Carnovale et al., 1991), emissions were measured from over 1500 vehicles on a second by second basis over the ADR27A test cycle. The test cycle was split into three modes consisting of freeway, arterial and congested segments and the exhaust emissions were binned accordingly. The power-based exhaust emissions model have been integrated over these segments as well as the complete ADR27A test for a range of vehicles, and a fleet average emission rate have been derived comparable in vehicle make up to their emission rate. The results are compared with their test data in Table 5.10.

Table 5.10 The comparison between the predicted emissions with the measured data of Carnovale et al, (1992).

\begin{tabular}{|c|c|c|c|c|c|}
\hline \multirow{2}{*}{ Pollutant } & \multirow{3}{*}{ Road category } & \multicolumn{4}{|c|}{ Emission rates (g/km) } \\
\cline { 3 - 6 } & & \multicolumn{2}{|c|}{ Pre - 1986 } & \multicolumn{2}{c|}{ Post - 1986 } \\
\cline { 3 - 6 } & & Model & Measured & Model & Measured \\
\cline { 3 - 6 } $\mathrm{CO}$ & Freeway & 9.76 & 8.73 & 2.29 & 2.87 \\
& Arterial & 12.89 & 13.04 & 2.16 & 2.35 \\
& Congested & 18.78 & 19.58 & 3.00 & 3.38 \\
& ADR27A & 20.30 & 19.30 & 5.36 & 6.56 \\
\hline \multirow{2}{*}{$\mathrm{HC}$} & Freeway & 0.98 & 1.08 & 0.23 & 0.25 \\
& Arterial & 1.29 & 1.37 & 0.21 & 0.20 \\
& Congested & 1.88 & 2.09 & 0.30 & 0.32 \\
& ADR27A & 2.03 & 1.76 & 0.53 & 0.31 \\
\hline \multirow{2}{*}{$\mathrm{NO}_{\mathrm{X}}$} & Freeway & 1.95 & 2.16 & 1.08 & 1.60 \\
& Arterial & 1.77 & 1.20 & 1.05 & 0.87 \\
& Congested & 2.17 & 1.64 & 1.31 & 1.10 \\
& ADR27A & 2.04 & 1.54 & 1.20 & 1.17 \\
\hline
\end{tabular}

It is noted that the differences in the trend of emission rates for $\mathrm{CO}$ and $\mathrm{HC}$ between the different technology groups are due to the differences of road categories. For pre-1986 vehicles $\mathrm{CO}$ and $\mathrm{HC}$ emissions increase from freeway to congested conditions reflecting the increasing proportions of idle time, whereas this is not the case for catalyst-equipped 
cars. It is this aspect that suggests that catalyst efficiency increases as vehicle speed decreases, (ie lower exhaust flow rate) that has led to equation 3.27 .

Also the comparison of predicted levels of $\mathrm{CO}, \mathrm{HC}$, and $\mathrm{NO}_{\mathrm{X}}$ emissions ((estimated by the integration of equations 3.19, 3.20, and 3.21) from some in-use light-duty diesel vehicles with measured data of Williams et al., (1987) are shown in Figures 5.15, 5.16 and 5.17 respectively. As discussed in the case of spark ignition vehicles, the large scatter in Figures 5.15, 5.16 and 5.17 is common because the minor exhaust components depend to a large extend on condition of tune up of the vehicle.

As was the case for spark ignition vehicles, emissions of $\mathrm{CO}, \mathrm{HC}$, and $\mathrm{NO}_{\mathrm{X}}$ are vehicle dependent. The predicted specific CO emissions (ie for unit $(\mathrm{kg})$ fuel consumption) were in the range of 15-35 $\mathrm{g}$ whilst the measured values (Williams et al., 1987) were 10-55 $\mathrm{g}$, the corresponding ranges for $\mathrm{Hc}$ emissions were 4-10 $\mathrm{g}$ versus $1-9 \mathrm{~g}$ and for $\mathrm{NO}_{\mathrm{X}}$ emissions $15-40 \mathrm{~g}$ versus $12-40 \mathrm{~g}$. 


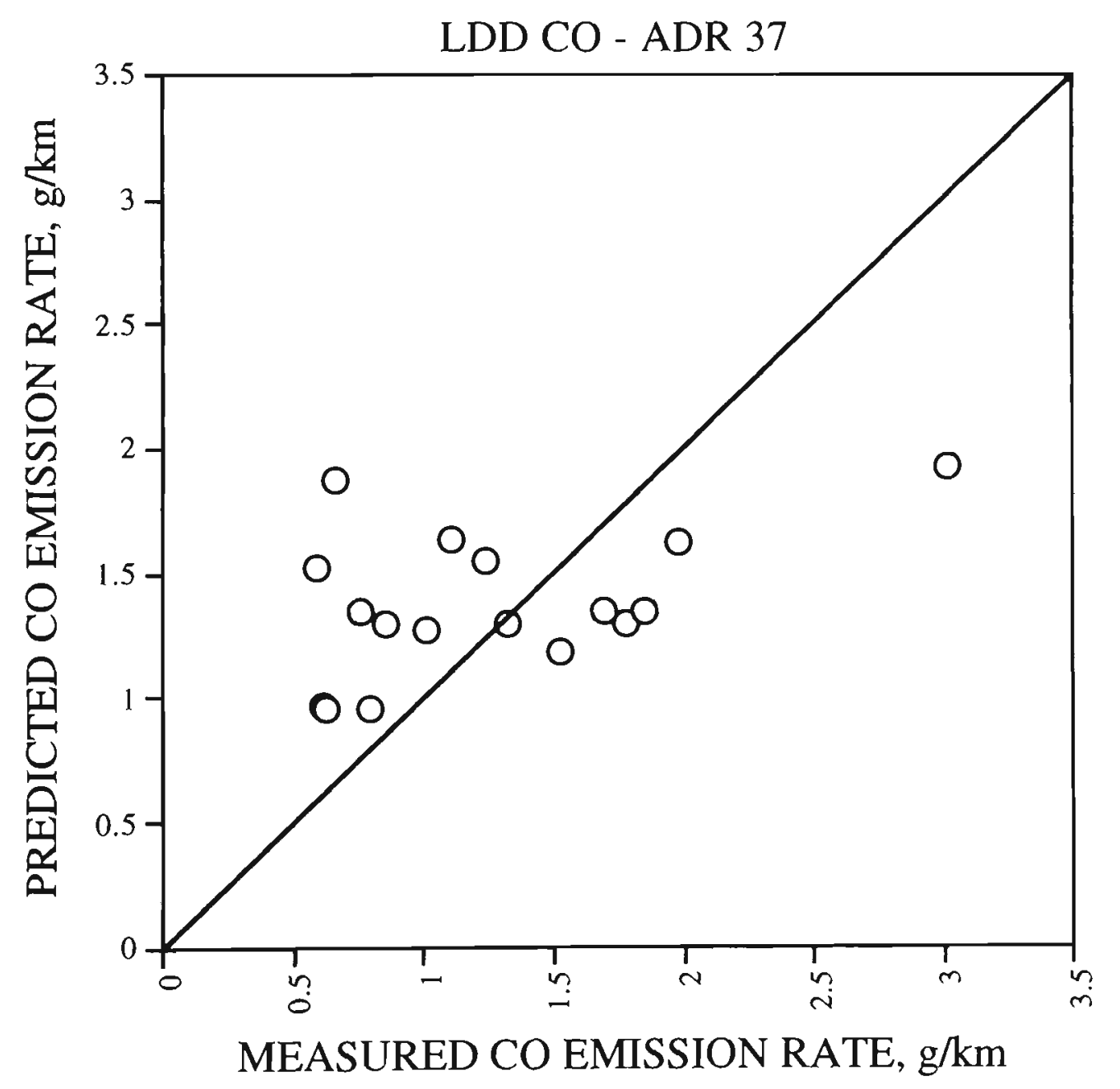

Figure 5.15 Comparison of predicted and measured ADR 37 carbon monoxide emissions for light-duty diesel vehicles (regression $\mathbf{r}^{2}=0.21$ ). 


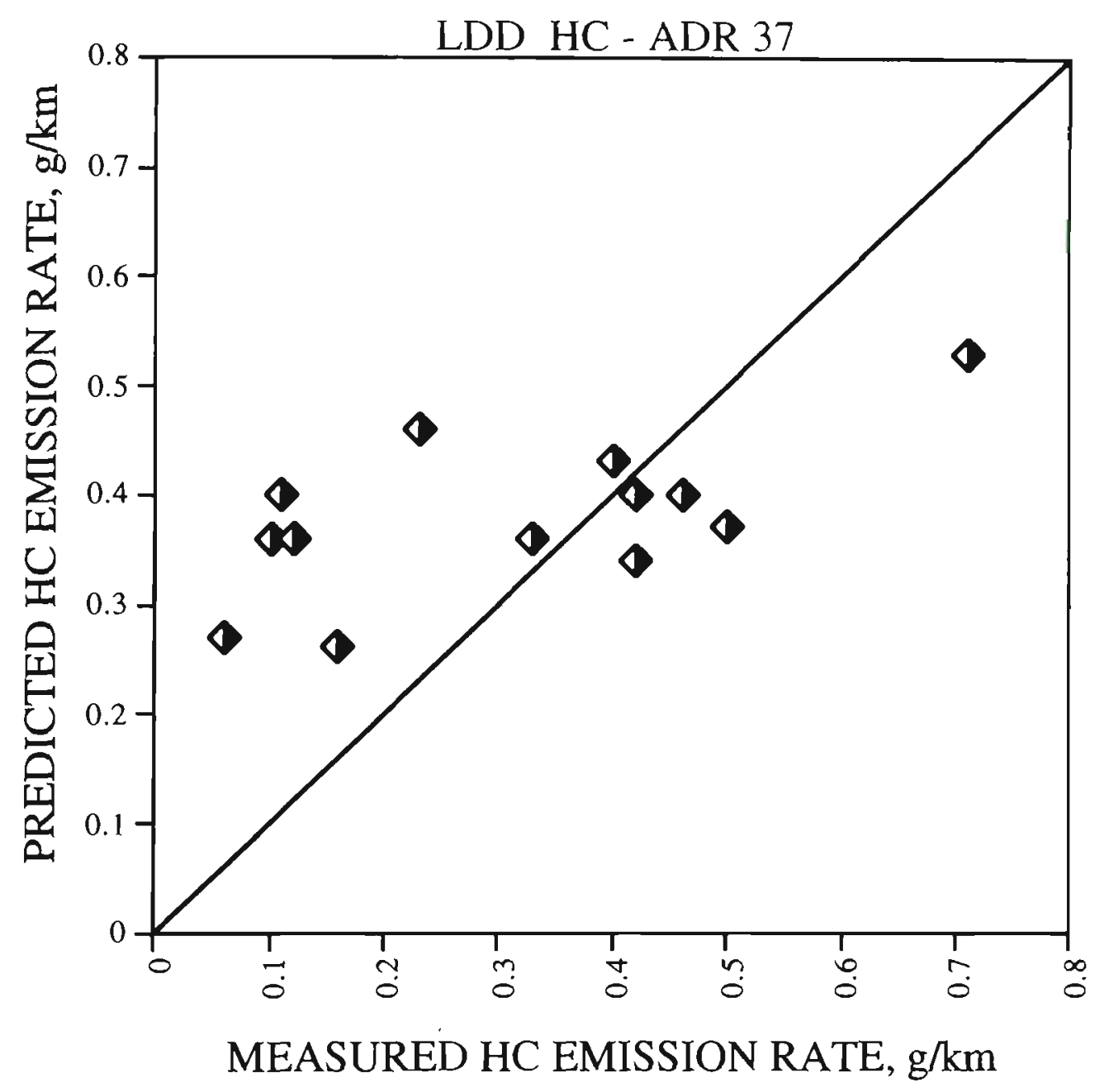

Figure 5.16 Comparison of predicted and measured ADR 37 hydrocarbon emissions for light-duty diesel vehicles (regression $\mathrm{r}^{2}=0.39$ ). 


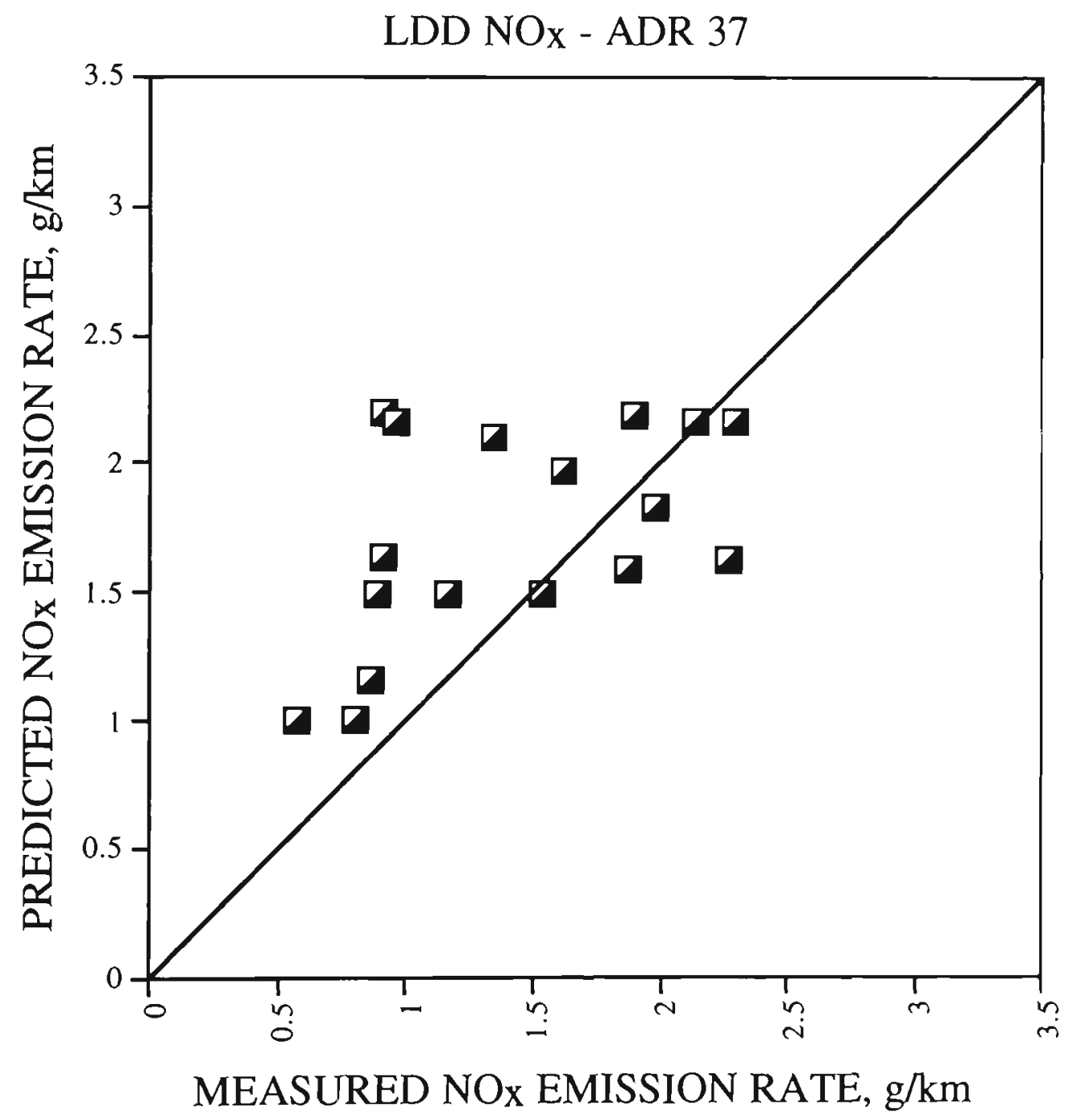

Figure 5.17 Comparison of predicted and measured ADR 37 oxides of nitrogen emissions for light-duty diesel vehicles (regression $\mathrm{r}^{2}=0.26$ ). 


\section{CHAPTER 6}

\section{DISPERSION VALIDATION}

The power-based emissions model was used in conjunction with two dispersion models (HIWAY-2 and CALINE4) to predict concentrations of vehicle-generated pollution near arterial roads. The predictions were compared with the eight-day experimental data from the recent road field study designed by the Commonwealth Scientific Industrial Research Organisation - Division of Coal and Energy Technology (CSIRO - DCET) and carried out on behalf of the Roads and Traffic Authority of New South Wales (RTA) to quantify air pollution near major roads and highways in Sydney (Williams et al., 1994).

\subsection{CSIRO/RTA Experimental Field Study}

The CSIRO Division of Coal and Energy Technology in collaboration with the University of Wollongong and on behalf of the Roads and Traffic Authority of New South Wales has carried out a major study of the pollution generated near arterial roads by motor vehicles in Sydney during the period from January 1992 to March 1994 . The author has been one of the research team in this project.

The objectives of this study included determining the concentrations of the airborne pollutants generated by motor vehicles on arterial roads $\left(\mathrm{CO}, \mathrm{HC}, \mathrm{NO}_{\mathrm{X}}\right.$, and $\left.\mathrm{CO}_{2}\right)$ for a range of traffic conditions, relating these measurements to the flow and type of traffic and to the meteorology prevailing at times of measurements.

The measurements were carried out during the period from January, 1992, to December, 1993 and covered all seasons of the two years. Three sites in Sydney were chosen for the measurements. These sites were close to Epping Highway, James Ruse Drive Highway, and F4 Freeway (Homebush).

The choice of the measurement sites covered different traffic speed, density, flow, vehicle type, and road gradients.

The study was published and given in Williams et al., 1993 and Williams et al., 1994. 


\subsubsection{Methodology}

The experimental methodology employed to quantify traffic generated pollution near arterial roads and highways in Sydney consisted of an instrumented vehicle equipped for measuring the gaseous pollutants carbon monoxide $(\mathrm{CO})$, non-methane hydrocarbons $(\mathrm{HC})$ and nitrogen oxides $\left(\mathrm{NO}_{\mathrm{X}}\right)$ as well as fine visibility-degrading particles as measured by a nephelometer (Williams et al., 1993) .

In addition, as carbon dioxide $\left(\mathrm{CO}_{2}\right)$ produced by traffic is directly related to fuel consumption rate, this species was also measured. Two simultaneous sampling positions were used. One was sited at the research vehicle, which was normally located about $30 \mathrm{~m}$ from the edge of the road under study, either on a side street or on a vacant lot. A large flexible sample line was used to position the second sampling point within $\pm 30 \mathrm{~m}$ of the research vehicle. This allowed concentrations to be measured up to $60 \mathrm{~m}$ from the edge of the road. Both sample lines could also be deployed up to $10 \mathrm{~m}$ above the ground to assess the vertical extent of pollution. Figure 6.1 shows a schematic of the overall layout.

Meteorological data were measured using two Gill UVW anemometers. These instruments provided the mean wind and direction as well as turbulence statistics at two heights. The lower height was fixed at $2.5 \mathrm{~m}$, whilst the upper one was variable up to $10 \mathrm{~m}$.

The data obtained from the instruments were recorded on a chart recorder and logged every second on a computer. Due to the number of inputs and the logging rate each hour of experiment resulted in about $1 \mathrm{M}$ byte of data.

A video camera was also located strategically to record the traffic flow in both directions. The video-taped information was subsequently analysed to provide data on vehicle flow and type.

Data from each instrument were used to construct 2 to 30 minute averages of $\mathrm{CO}_{2}, \mathrm{CO}$, $\mathrm{HC}$ and $\mathrm{NO}_{\mathrm{X}}$ concentrations as well as wind speed and direction.

The video data were examined and a manual count made of the vehicle flow, in both directions. The vehicles were classified by their appearance as domestic, light commercial or heavy commercial. 
It should be noted that all of the instruments were calibrated prior to the day of measurement using calibration gas.

Figure 6.2 shows an overview of the CSIRO instrumented vehicle with the anemometers and the two sampling lines (the fixed sampling line and the movable one), while Figure 6.3 shows the interior of the CSIRO instrumented vehicle with the measuring instruments, the data logger, and the chart recorder.

\subsubsection{The deployed instruments}

Table 6.1 shows a description of the instruments used in the study, their response times and the pollutant each instrument measured. Brief technical information has been presented here. Detailed technical information can be found in the manuals of these instruments which include the detailed technical description and the principle of operation.

Table 6.1 Instruments deployed near major roadways during CSIRO/RTA experimental field study to quantify traffic generated pollution near arterial roads and highways in Sydney (Williams et al., 1993).

\begin{tabular}{|l|c|c|}
\hline \multicolumn{1}{|c|}{ Instrument } & Species & $\begin{array}{c}\text { Response } \\
\text { Time }\end{array}$ \\
\hline $\begin{array}{l}\text { Monitor Labs Nitrogen Oxides Analyser Model } \\
8840 \\
\left.\text { (NB NO2 is obtained from NO2 }=\mathrm{NO}_{\mathrm{X}}-\mathrm{NO}\right)\end{array}$ & $\mathrm{NO}_{\mathrm{X}}, \mathrm{NO}$ & $1 \mathrm{~s}$ \\
\hline $\begin{array}{l}\text { Rosemount Micro-Processor Controlled NDIR Gas } \\
\text { Analyser Model BINOS 100 }\end{array}$ & $\mathrm{CO}, \mathrm{CO} 2$ & $5 \mathrm{~s}$ \\
\hline $\begin{array}{l}\text { Horiba Ambient Total Hydrocarbons Monitor } \\
\text { Model APHA-350E (NB NMHC }=\text { Total HC - } \\
\text { CH4) }\end{array}$ & $\begin{array}{c}\text { CH4, NMHC, } \\
\text { and Total HC }\end{array}$ & $60 \mathrm{~s}$ \\
\hline $\begin{array}{l}\text { Nephelometer } \\
\text { Model 27005 GILL UVW Anemometer }\end{array}$ & $\begin{array}{c}\text { visibility degrading } \\
\text { aerosol }\end{array}$ & $1 \mathrm{~s}$ \\
\hline
\end{tabular}




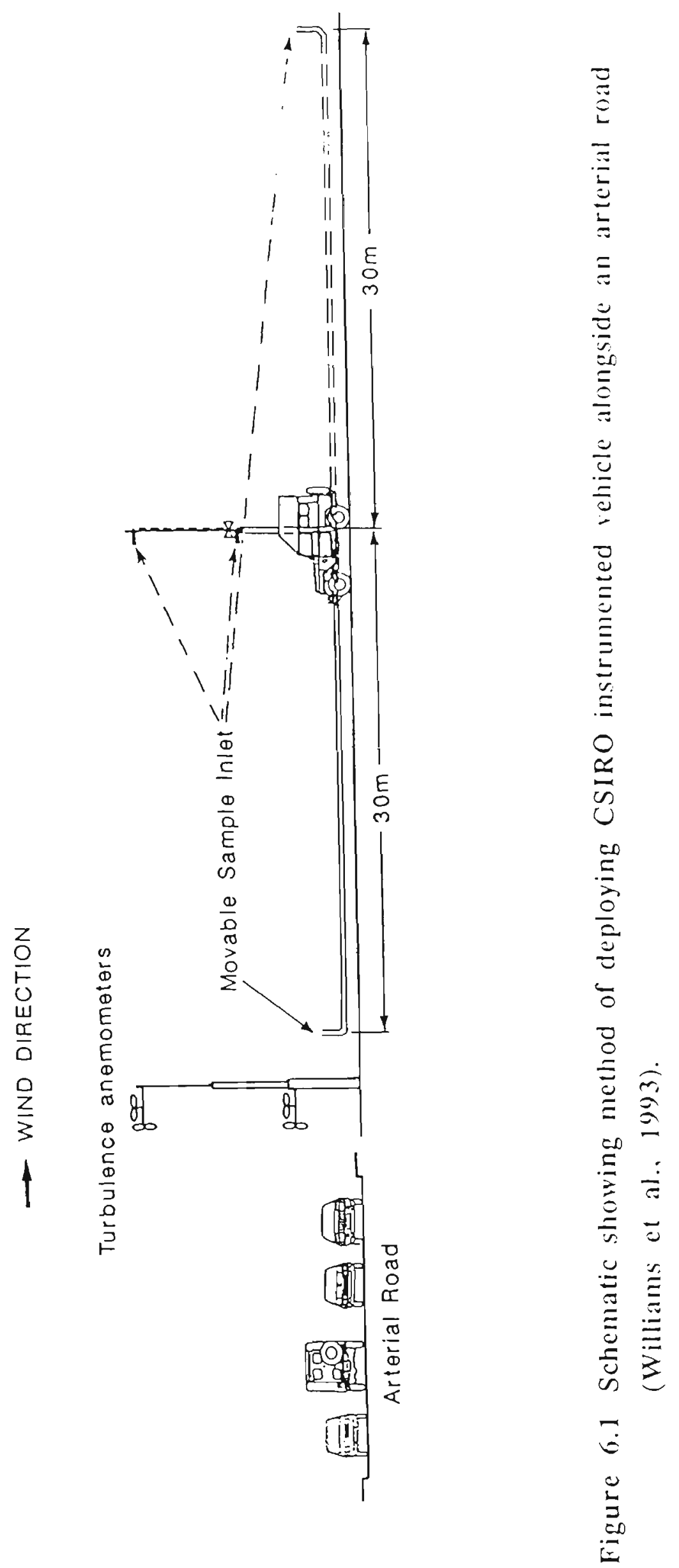




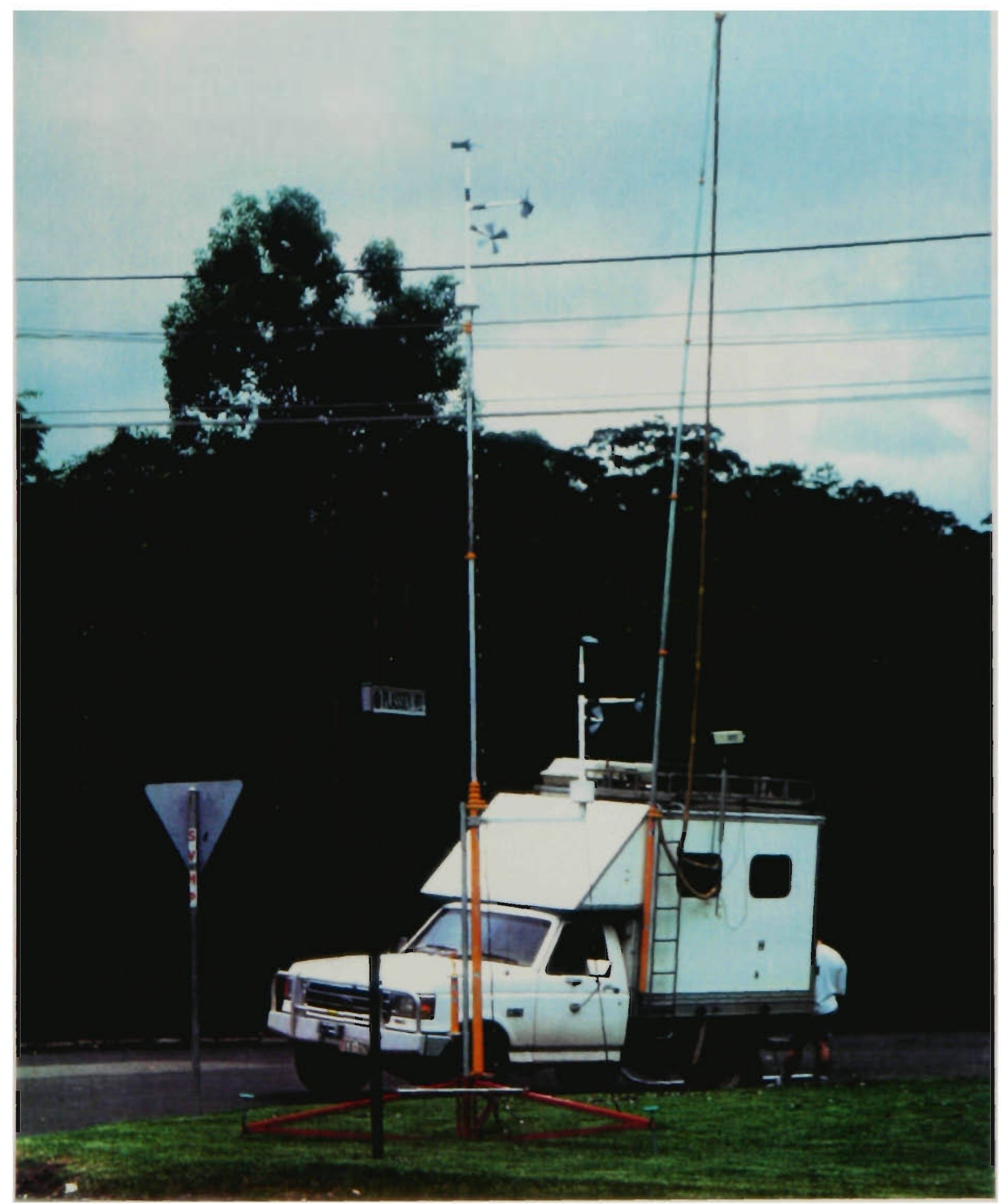

Figure 6.2 An overview for CSIRO instrumented vehicle with the anemometers and the two sampling lines (the fixed sampling line and the movable one). 


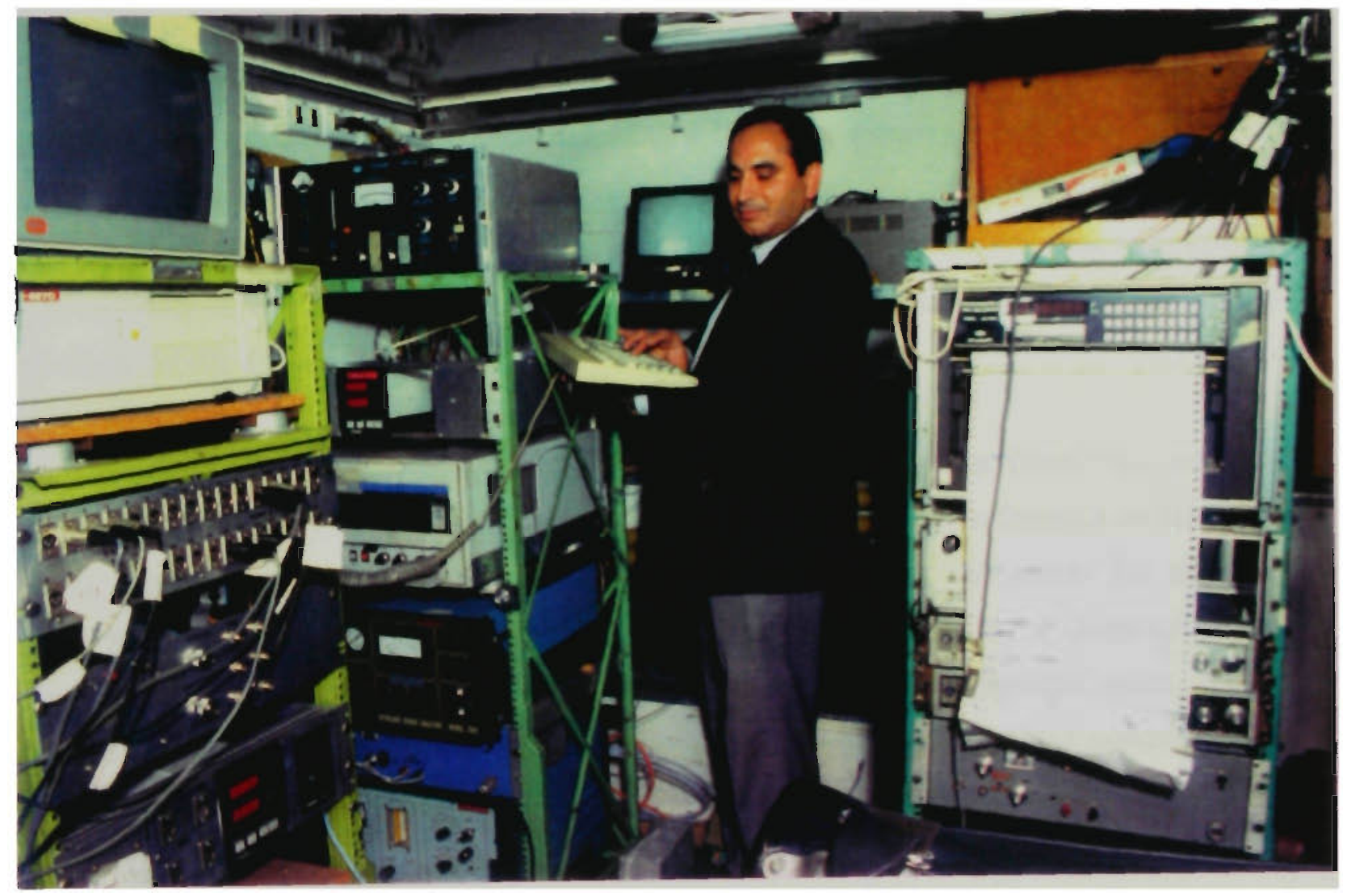

Figure 6.3 The interior of the CSIRO instrumented vehicle with the measuring instruments, the data logger, and the chart recorder. 


\subsubsection{Rosemount BINOS 100 Micro-Processor Controlled NDIR Gas Analyser}

The BINOS 100 analyser is non-dispersive infrared photometers (NDIR). It utilises a comparison of the transmitted intensities in two differing wavelength bands for its operation. Each analysis cell is alternatively illuminated with filtered light concerned in one of two spectrally separated wavelength bands. One of these bands is chosen to coincide with an absorption band of the gas constituent whose concentration is to be measured, and other is chosen such as that none of the gas constituents expected to be encountered in practice absorbs anywhere within the band.

The detector signal amplitude thus alternates between concentration-dependent and concentration-independent values. The difference between the two is a reliable measure of the concentration of the absorbing gas constituent. This operating system is known as "filter correlation". Figure 6.4 shows an overview for BINOS 100 Microprocessorcontrolled NDIR-Gas-Analyser

With regard to the theory of operation, the broadband emission from two infrared radiation sources (light sources) passes through the sample and reference cells to the rotating chopper blade, then through combinations of filters, and enters the analysis cell. The light transmitted through these cell is focussed on to a detector. The preamplified detector output signal is sent to micro processor separate units, which converts the analytical signals to results expressed directly in physical concentration units (ppm), and transmits them to the displays and to the signal terminals.

\subsubsection{Monitor Labs Nitrogen Oxides Analyser Model 8840}

The Monitor Labs Nitrogen Oxides Analyser Model 8840 is a gas-phase chemiluminescence-detection device which performs a continuous dry analysis of nitric Oxide (NO), total nitric oxides $\left(\mathrm{NO}_{\mathrm{X}}\right)$, and nitrogen dioxide $\left(\mathrm{NO}_{2}\right)$. Its operation is based on the chemiluminescence of an activated $\mathrm{NO}_{2}$ species $\left(\mathrm{NO}_{2}{ }^{*}\right)$ produced by chemical reaction between ozone and NO in an evacuated chamber. Figure 6.5 shows an overview for the instrument.

The Model 8840 dual channel chemiluminescence analysis system has two complete detection systems comprised of reaction cell with Isoflo, PMT, preamp, and phasesensitive amplifier. The reaction cell has four sub-systems. They are Isoflo rate control, Concentric ozone and sample nozzles, Reaction chamber, and exhaust ports. Air 
containing the nitric oxide enters through the outer concentric nozzle. The centre nozzle brings the ozone to the reaction chamber. One wall of the reaction chamber is an optical filter through which the photomultiplier tube measures the chemiluminescence emission intensity and converts it to an equivalent electrical current. The NO molecules react with ozone to form the activated $\mathrm{NO}_{2} *$ species. As the activated species $\left(\mathrm{NO}_{2}{ }^{*}\right)$ reverts to a lower energy state, it emits broad-band radiation. The chemiluminescence emission intensity is linearly proportional to the NO concentration in the sample. The photomultiplier tube current is then directly proportional to the chemiluminescence intensity.

Because of this feature that the chemiluminescence reaction is between $\mathrm{O}_{3}$ and $\mathrm{NO}$ only, an analysis for $\mathrm{NO}_{2}$ is only accomplished after the $\mathrm{NO}_{2}$ in the sample is reduced chemically to NO prior to its entry to the NO reaction cell. This processing is accomplished by a catalytic converter, called MOLYCON. The sample stream entering the Model 8840 is split immediately into an $\mathrm{NO}$ and $\mathrm{NO}_{\mathrm{x}}$ stream. The only difference between the $\mathrm{NO}$ and $\mathrm{NO}_{\mathrm{X}}$ stream is that the $\mathrm{NO}_{\mathrm{X}}$ stream encounters MOLYCON which converts the $\mathrm{NO}_{2}$ to $\mathrm{NO}$. Thus, the $\mathrm{NO}_{X}$ channel measures the $\mathrm{NO}+\mathrm{NO}_{2}$ carried by the sample while the NO stream measures only the NO. $\mathrm{NO}_{2}$ concentration level is derived by electronically subtracting the NO signal from the NO signal. The Nitrogen Oxides Analyser does not use any reagent gas other than the ozone manufactured from dry air by the integral ozone generator.

\subsubsection{Horiba Ambient HC Monitor ( APHA-350E)}

The APHA-350E Ambient HC Monitor employs the principle of flame ionisation detection to measure continuously the concentration of hydrocarbons in the ambient air. Utilising the FIC system in combination with a catalytic hydrocarbon cutter, it provides measurement results for total hydrocarbons (THC) and methane $\left(\mathrm{CH}_{4}\right)$.

Features include an integral ambient air purifier to generate hydrocarbon-free air for the detector. Hydrogen fuel for the detector may also be provided by a hydrogen generator. The APHA-350E employs a dual cross-flow modulation system. Inside the analyser, the reference gas passes first through a purifier and then into two separate lines. The sample gas is also divided into two lines, one of which leads the gas through an HC cutter which burns heavier hydrocarbons and leave methane unburnt. The sample passes through the other as is. Two rotary valves introduce reference gas and sample gas 
alternately into a single detector to permit continuous analysis of both $\mathrm{THC}$ and $\mathrm{CH}_{4}$. The electronic circuit then subtracts one from the other for presentation of the concentration of non-methane hydrocarbons (NMHC). Electrical signals are output continuously for THC, $\mathrm{CH}_{4}$ and NMHC. There are also three types of alarm displayflow, flame and cutter. The flame alarm flashes if the hydrogen flame is extinguished for maximum safety. Figure 6.6 shows the overlook of Model APHA-350E Horiba Ambient HC Monitor.

\subsubsection{Model 27005 GILL UVW Anemometer}

The Gill Anemometer is a three component wind instrument for direct measurement of $\mathrm{U}, \mathrm{V}$ and $\mathrm{W}$ orthogonal wind vectors. It consists of three identical propeller anemometer are mounted at right angles to each other on a common mast with spacing to minimise wake effects. The individual anemometer are low threshold precision air speed measuring sensors using fast response helicoid propellers.

In each anemometer a tachometer-generator coupled to the propeller shaft converts propeller rotation to a DC voltage which is linearly proportional to wind velocity. The two horizontal $\mathrm{U}$ and $\mathrm{V}$ anemometers produce a positive output voltage with wind flow from front the sensor (counter-clockwise propeller rotation) and a negative voltage with wind flow from behind. The socket for the vertical $W$ anemometer is wired so the output is negative for down drafts, positive for updraughts. The anemometer sensors are identical and may be installed at any position on the mast.

The propeller responds only to that component of the wind which is parallel to its axis of rotation so off axis response closely approximates a cosine curve. The propeller does not rotate when the wind flow is perpendicular to its axis. 


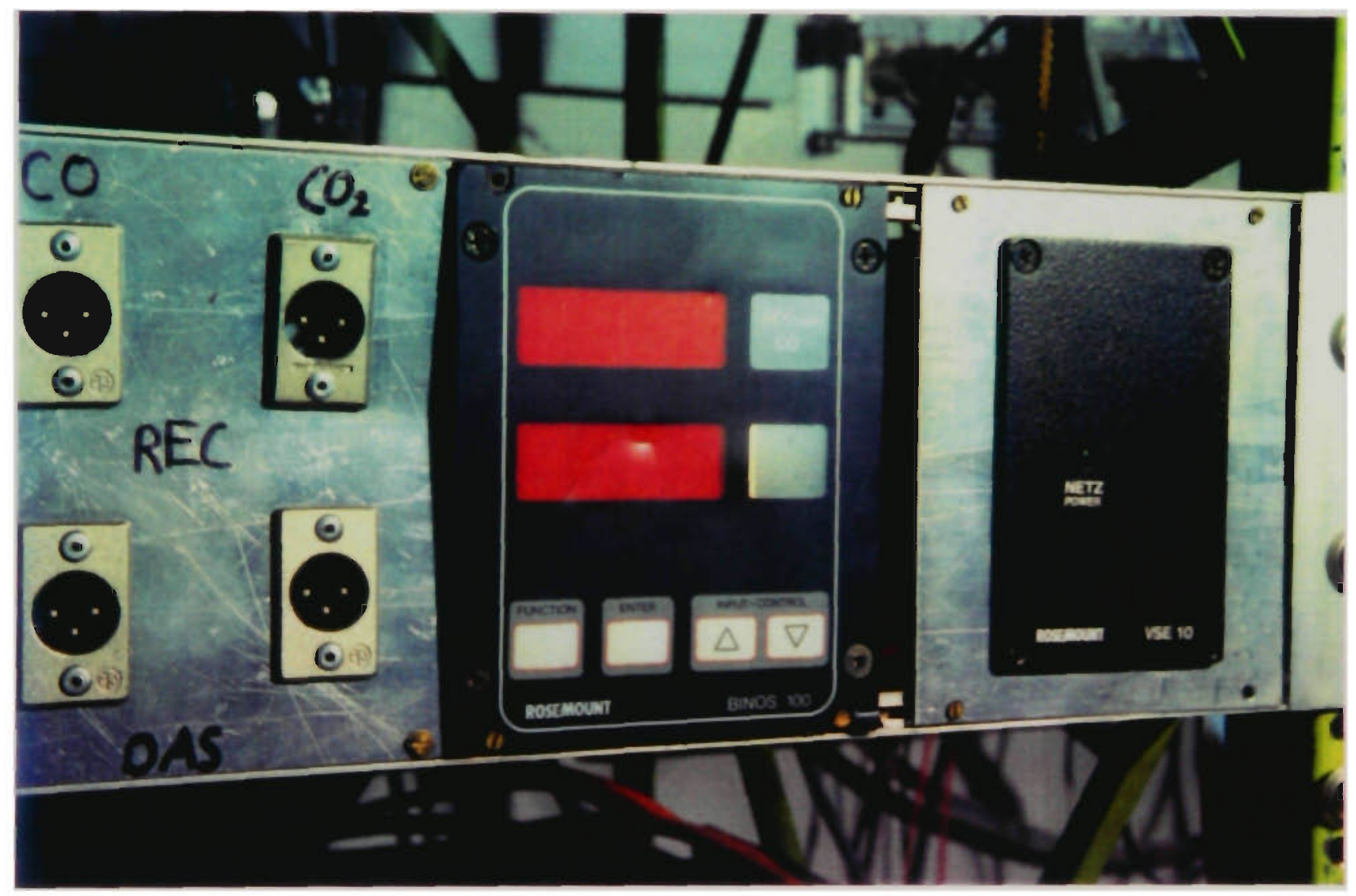

Figure 6.4 overview for BINOS 100 NDIR-Gas-Analyser 


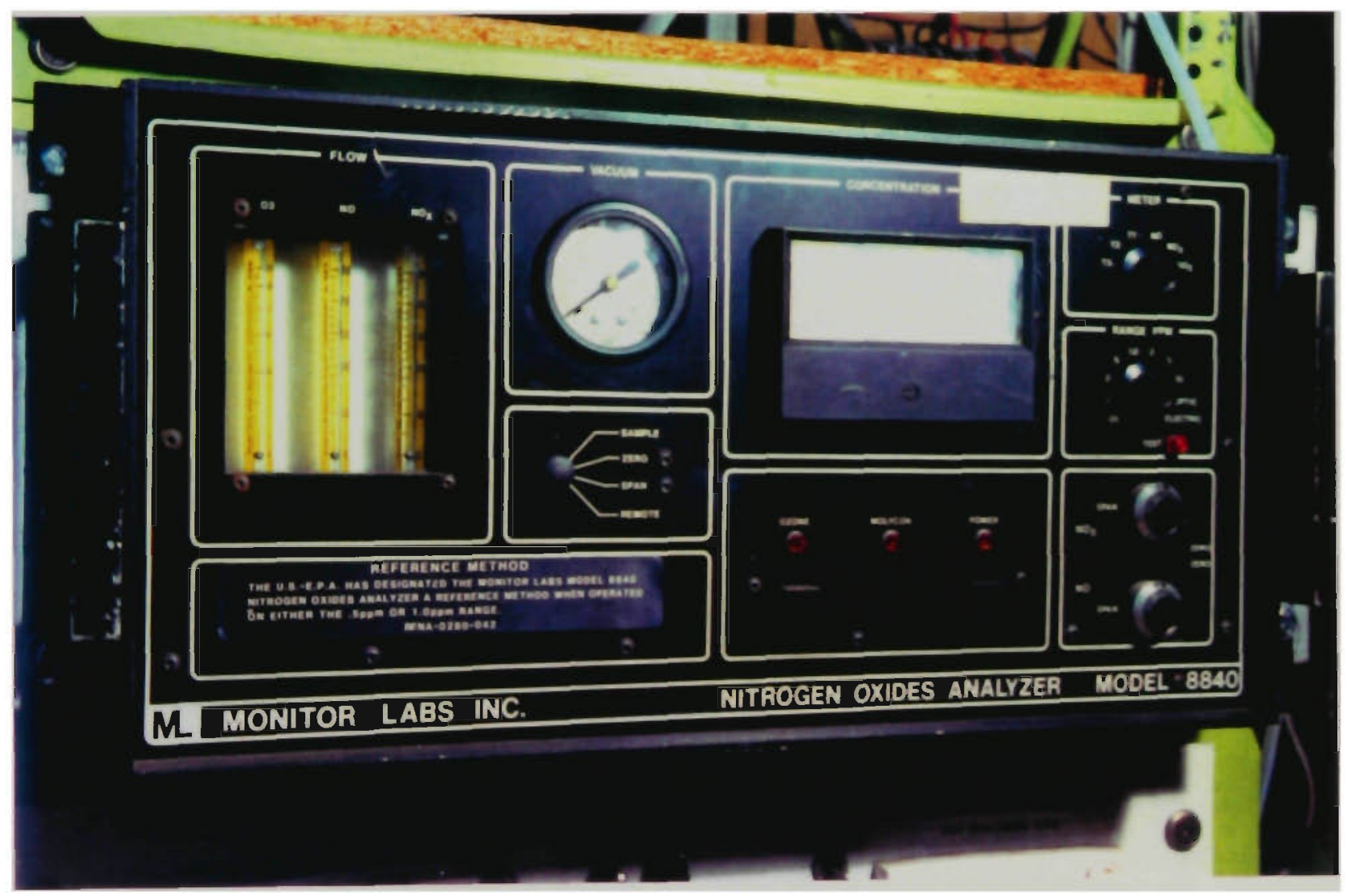

Figure 6.5 An overview for the Monitor Labs Nitrogen Oxides A nalyser (Model 8840). 


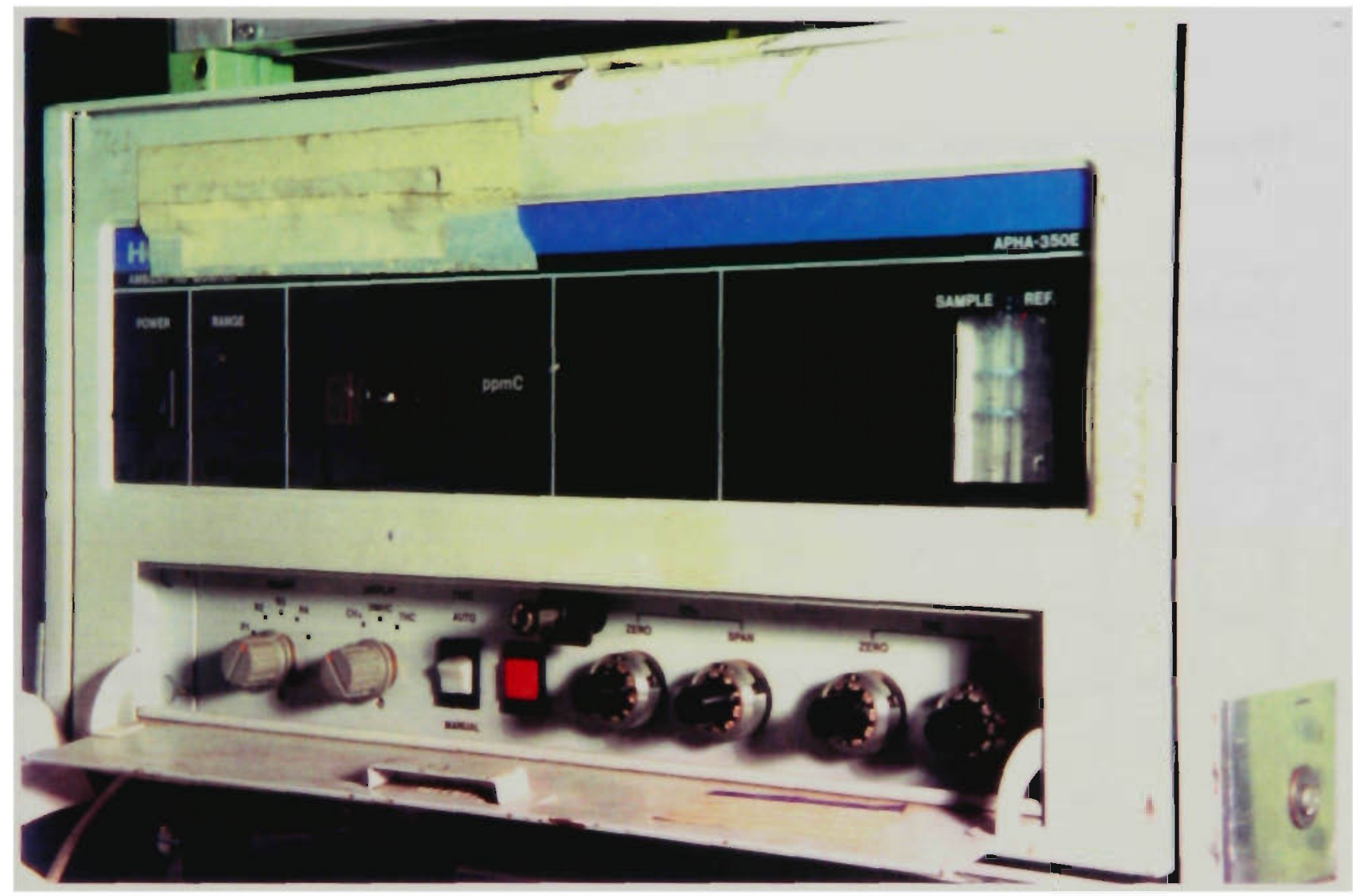

Figure 6.6 An overview for Model APHA-350E Horiba Ambient HC Monitor. 


\subsubsection{The experimental data}

Table 6.2 shows the summary of sites, dates and duration of the eight-day experimental data. The summary of the experimental data collected in eight days at three measuring sites and covering neutral and slightly unstable stability classes is given are given in Tables 6.3 to 6.10 .

Table 6.2 The summary of sites, dates and duration of the eight-day experimental data. (Data from Williams et al., 1994).

\begin{tabular}{|c|c|c|c|}
\hline Date & Location & Monitoring time & $\begin{array}{c}\text { Duration } \\
\text { (min.) }\end{array}$ \\
\hline 5 March 1992 & Epping Highway & $16: 00-18: 30$ & 120 \\
\hline 5 May 1992 & Epping Highway & $14: 10-17: 10$ & 120 \\
\hline 6 May 1992 & Epping Highway & $16: 20-17: 50$ & 90 \\
\hline 26 May 1992 & James Ruse Drive & $8: 00-10: 10$ & 130 \\
\hline 16 June 1992 & James Ruse Drive & $8: 00-10: 40$ & 160 \\
\hline 22 September 1992 & James Ruse Drive & $8: 00-10: 40$ & 160 \\
\hline 13 January 1993 & Epping Highway & $13: 56-17: 20$ & 204 \\
\hline 6 April 1993 & Homebush Highway & $8: 36-11: 36$ & 180 \\
\hline
\end{tabular}




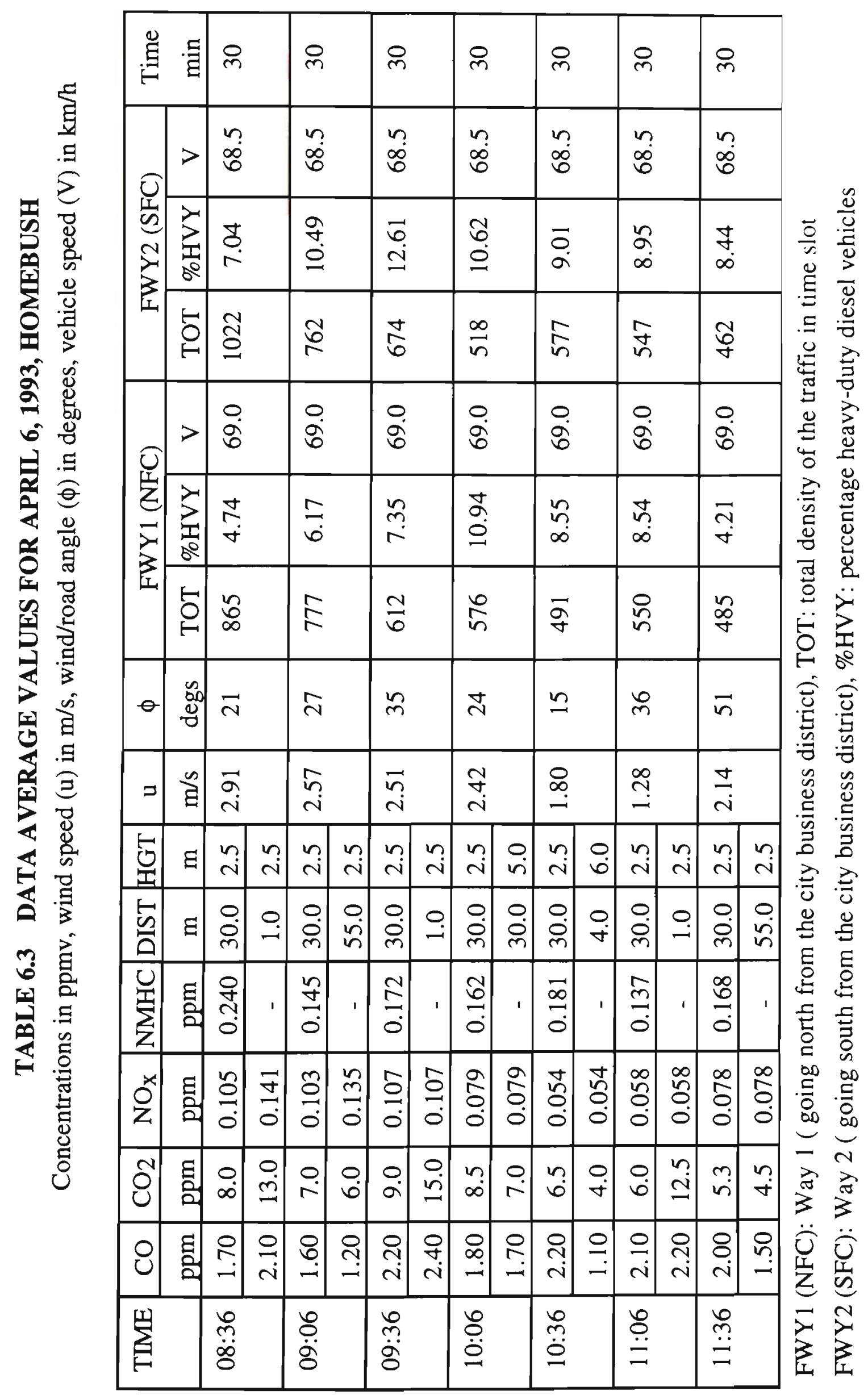




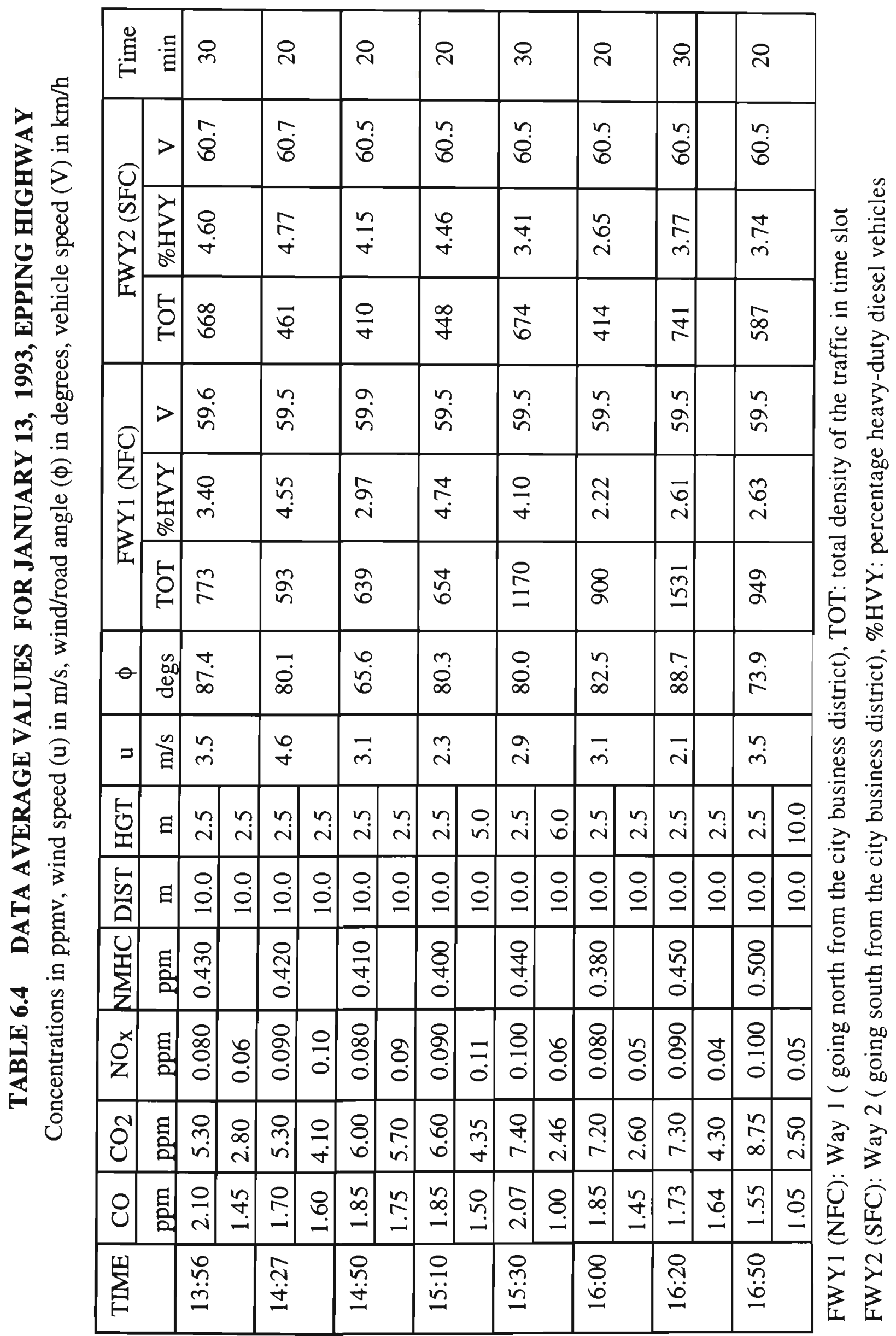




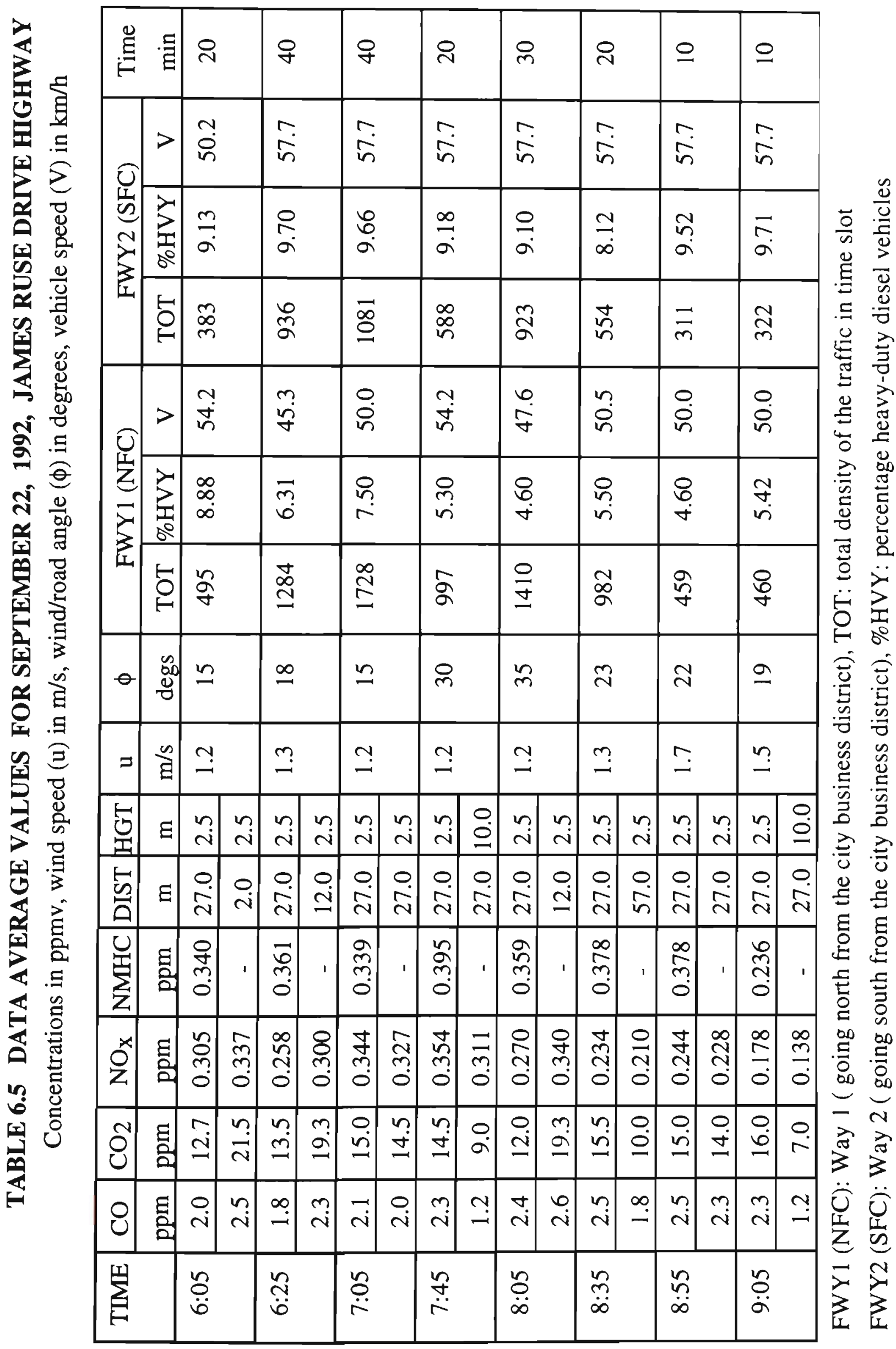




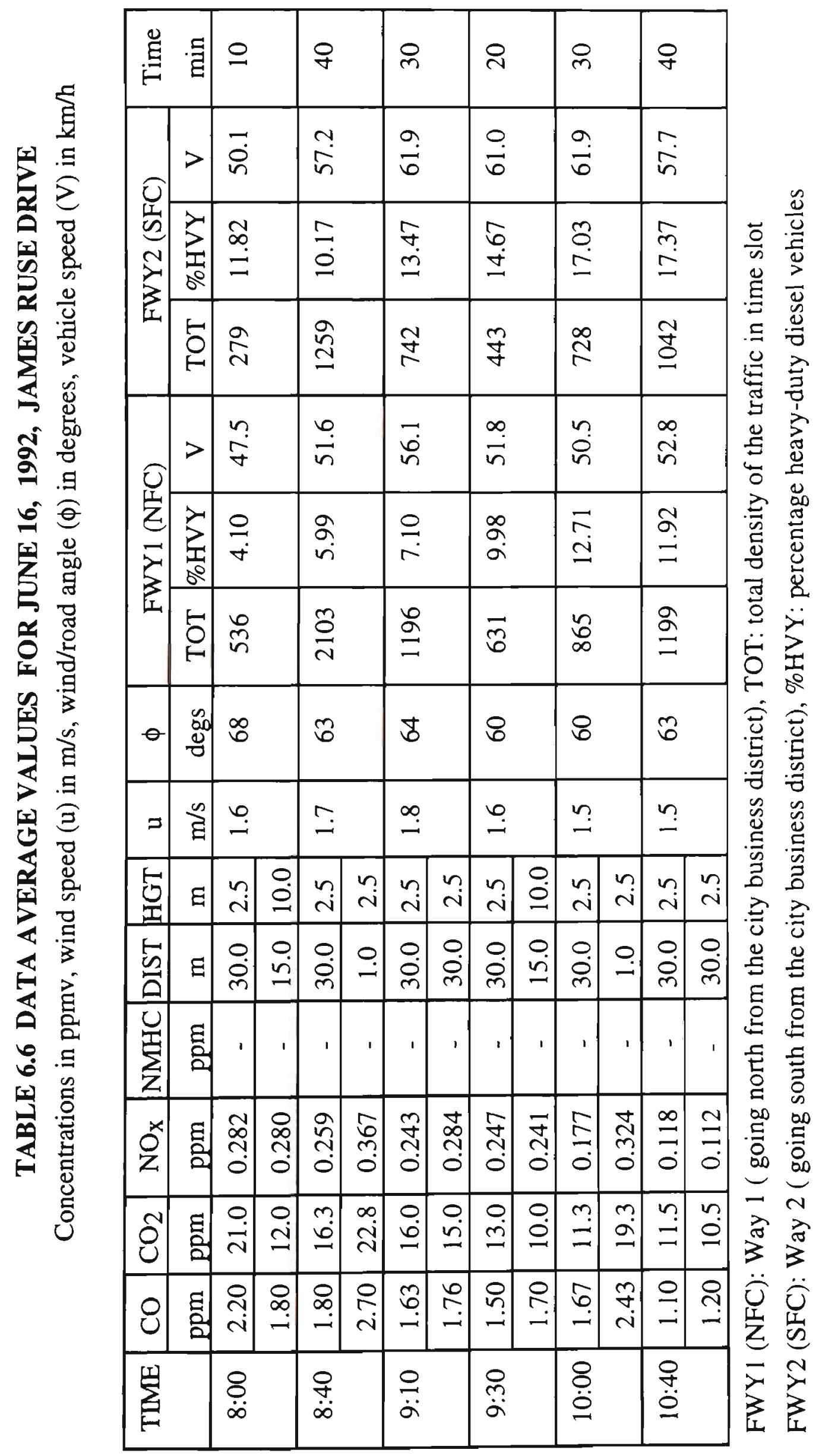




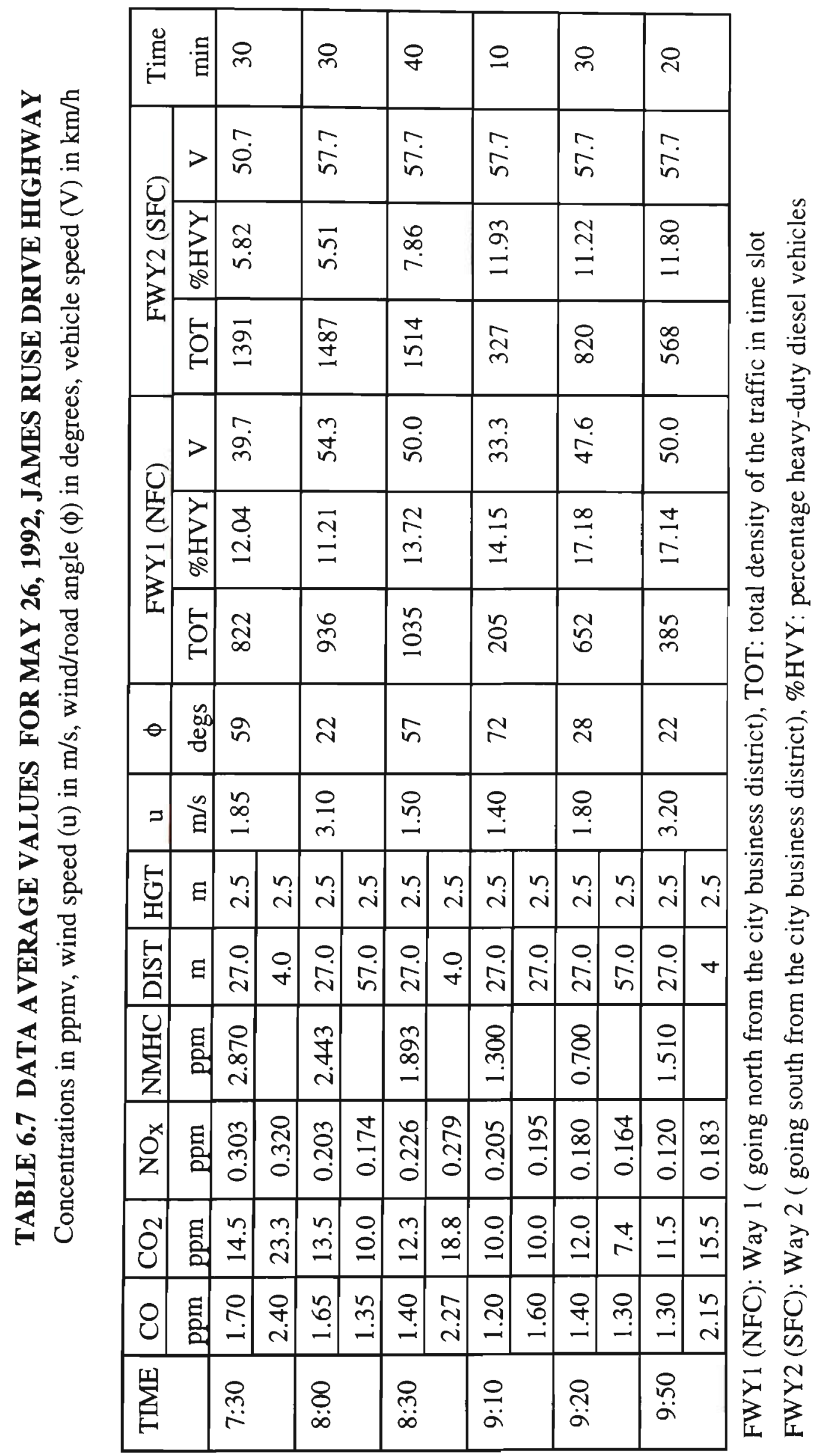




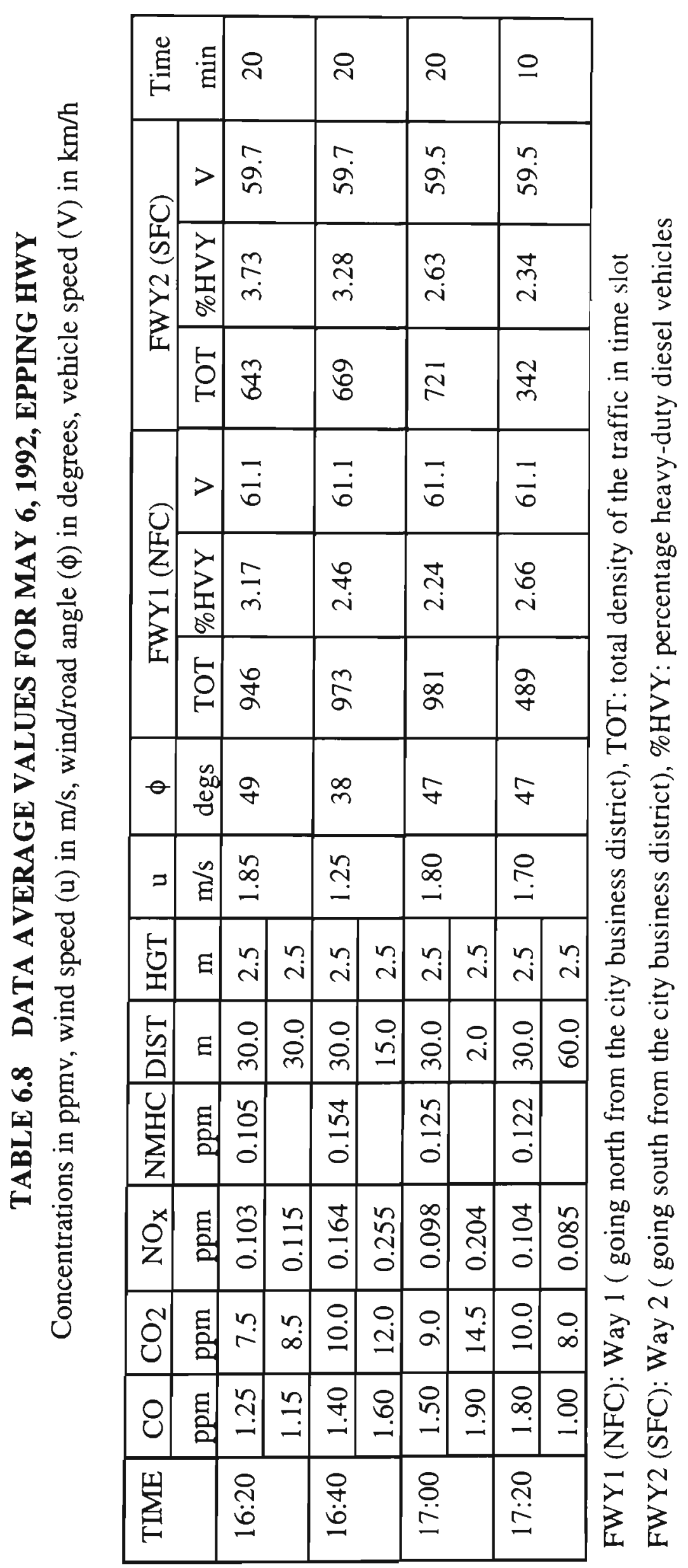




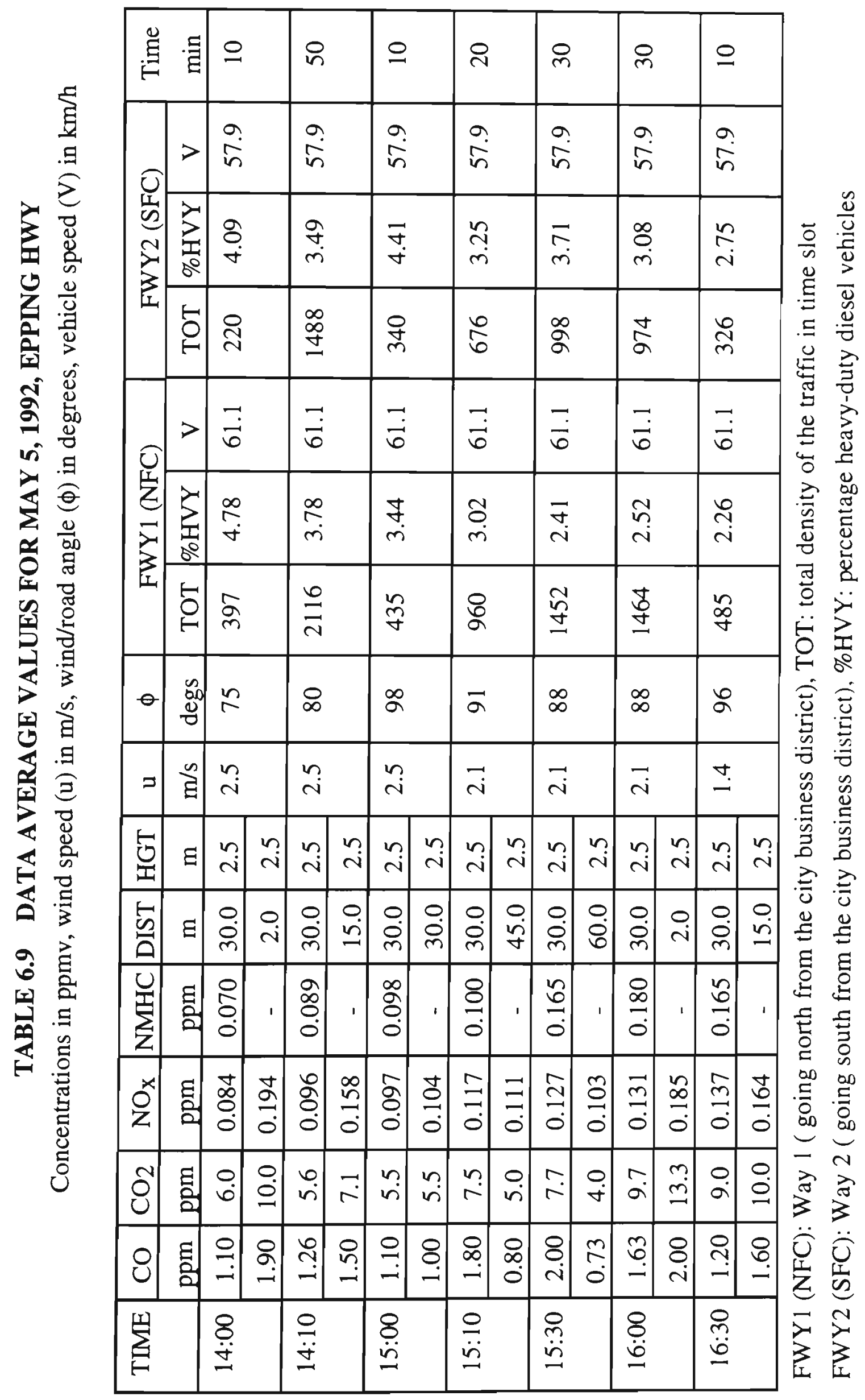




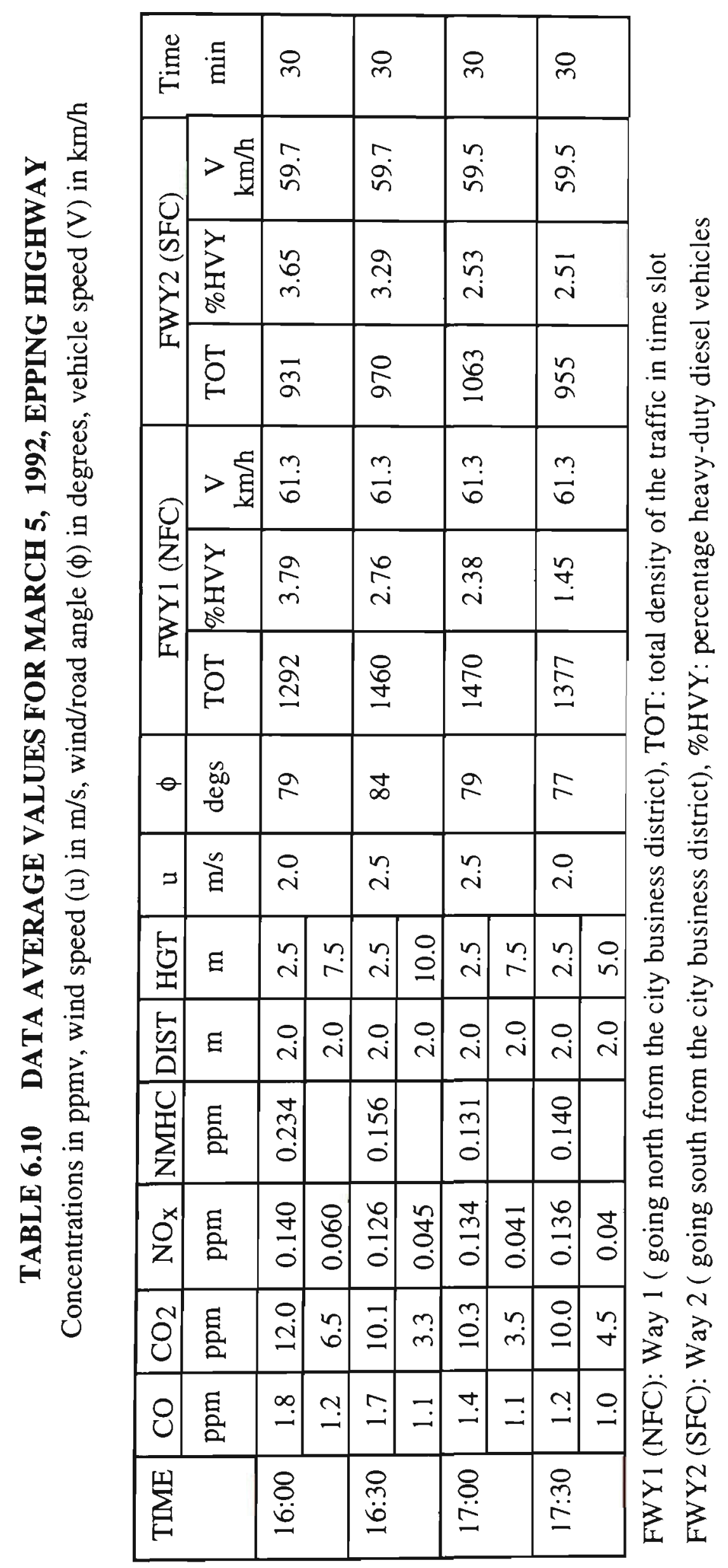




\subsection{Dispersion validation results and discussion}

A feature of the field study was the measurement of $\mathrm{CO}_{2}$ concentrations. As the emissions model provides a better estimate of fuel consumption than $\mathrm{CO}, \mathrm{HC}$ or $\mathrm{NO}_{\mathrm{x}}$ emission rates, (due to much less inter-vehicle variability), emphasis has been put on how well $\mathrm{CO}_{2}$ concentrations are predicted.

In estimating emission source strengths, It was assumed that unleaded vehicles made up $55 \%$ of the passenger / light duty vehicle fleet and that $40 \%$ of catalysts were of the three-way type. Other parameters were average engine capacity of 2.5 litre, an average mass of $1430 \mathrm{~kg}$ and an aerodynamic factor, $\mathrm{C}_{\mathrm{d}} \mathrm{A}$, having a value of $0.73 \mathrm{~m}^{2}$. The corresponding values for heavy good vehicles (HGV) were $5 \mathrm{~L}, 10,000 \mathrm{~kg}$ and $3.6 \mathrm{~m}^{2}$.

Deterioration factors for $\mathrm{CO}$ and $\mathrm{HC}$ for petrol-fuelled vehicles were based on a combination of US and Australian recommendations outlined in Carnovale et al., (1992), with the higher SPCC values used for pre-1986 and the U.S. EPA values for later vehicles. The deterioration factors used for $\mathrm{NO}_{\mathrm{X}}$ emissions selected were lower than those in Carnovale et al., (1992). It is believed that car aging may affect the efficiency of the combustion process resulting in increasing the amount of unburnt hydrocarbons and decreasing the final temperature which is one of the main parameters for forming $\mathrm{NO}_{\mathbf{X}}$ emissions. Running loss $\mathrm{HC}$ emissions were also added to the exhaust $\mathrm{HC}$ emissions according to U.S. EPA recommendations.

The stability classes chosen to best represent the meteorology at any instant varied from Pasquill-Gifford category B (slightly unstable) to D (slightly stable).

Although each of the field locations was substantially flat, the effect of the slopes of up to $1.0^{\circ}$ imposed on each way was investigated, in order to account for a combination of non-zero slope and random vehicle acceleration manoeuvres. It should be noted that the effect of slope is dramatic, increasing the vehicle's requirement for power, resulting in increased $\mathrm{CO}_{2}$ and $\mathrm{NO}_{\mathbf{x}}$ emission rates but with a smaller influence on $\mathrm{CO}$ and $\mathrm{HC}$ emission rates, as these pollutants are less power-sensitive (see Chapter 3 ).

Figures $6.7,6.9$, and 6.11 present the comparison between measured and predicted $\mathrm{CO}_{2}$ concentrations for all the data points for slopes of $0^{\circ}, 0.5^{\circ}$ and $1.0^{\circ}$ respectively using the CALINE4 dispersion model, while Figures 6.8, 6.10, and 6.12 present the comparison between measured and predicted $\mathrm{CO}_{2}$ concentrations for all the data points 


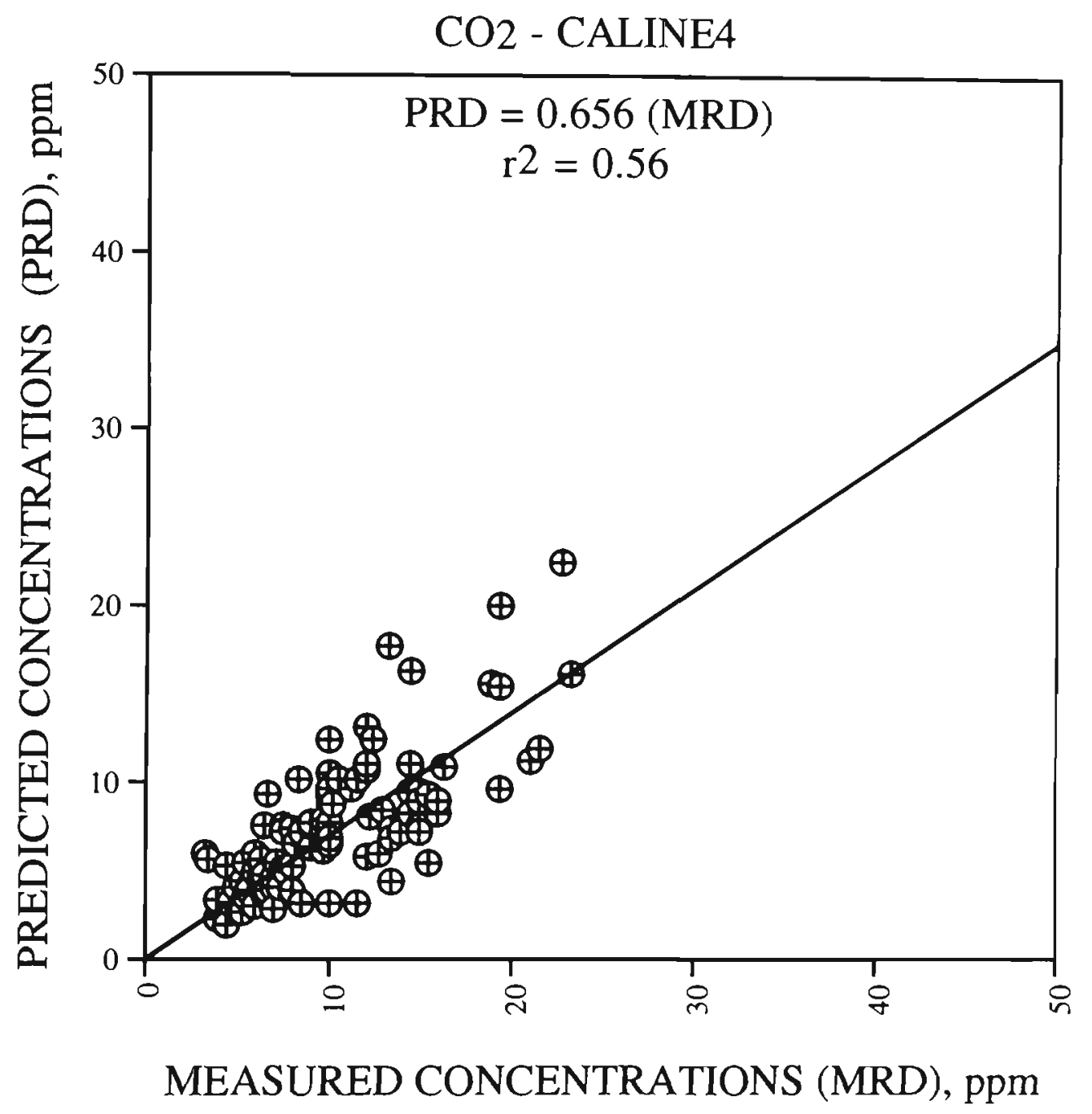

Figure 6.7 Comparison of predicted $\mathrm{CO}_{2}$ concentrations from CALINE4 for slope $=0.0^{\circ}$ with measured values (regression $r^{2}=0.562$ ). 


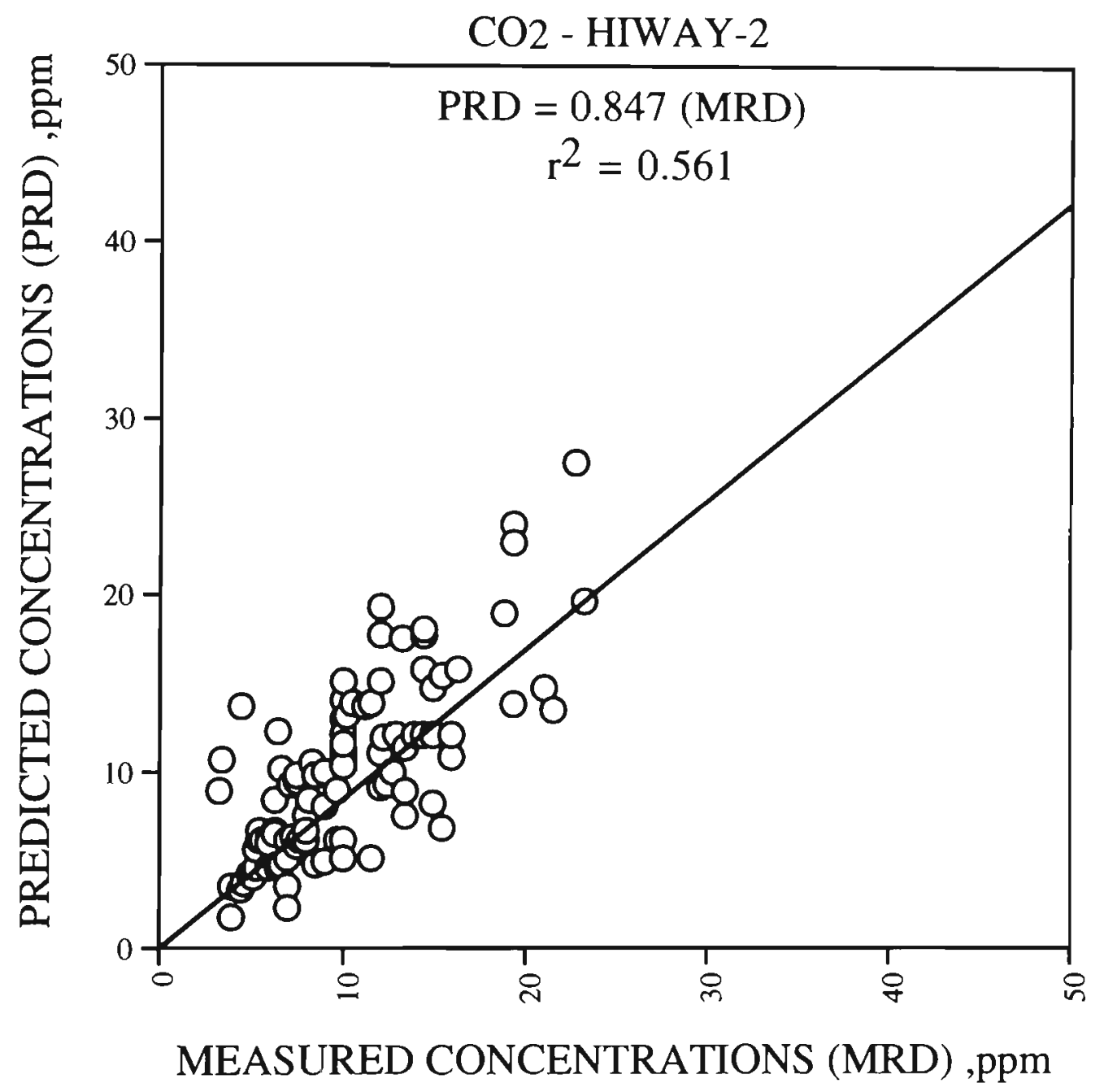

Figure 6.8 Comparison of predicted $\mathrm{CO}_{2}$ concentrations from HIWAY-2 for slope $=0.0^{\circ}$ with measured values (regression $r^{2}=0.561$ ). 


\section{CO2 - CALINE4}

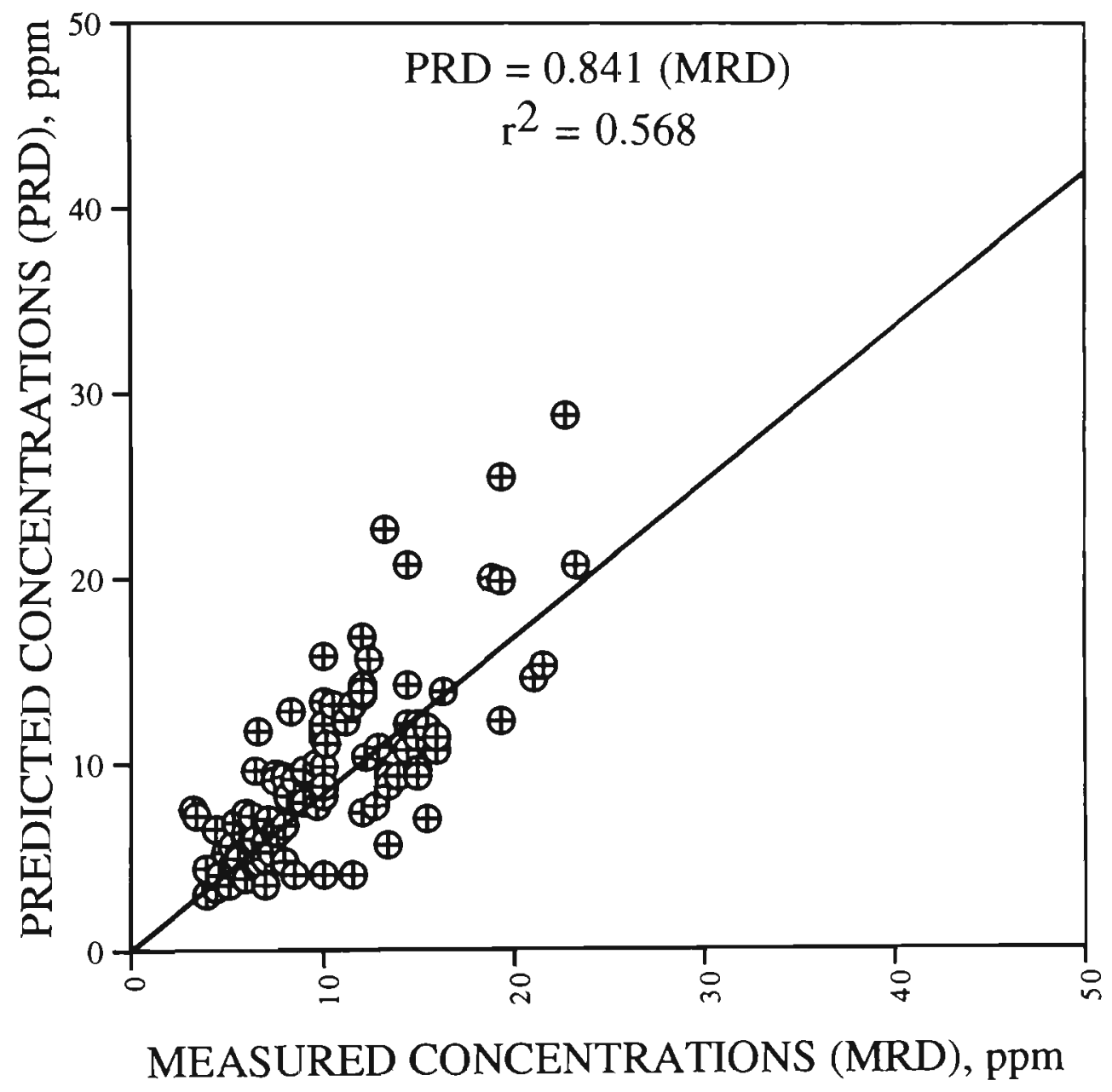

Figure 6.9 Comparison of predicted $\mathrm{CO}_{2}$ concentrations from CALINE4 for slope $=0.5^{\circ}$ with measured values (regression $\left.r^{2}=0.568\right)$. 


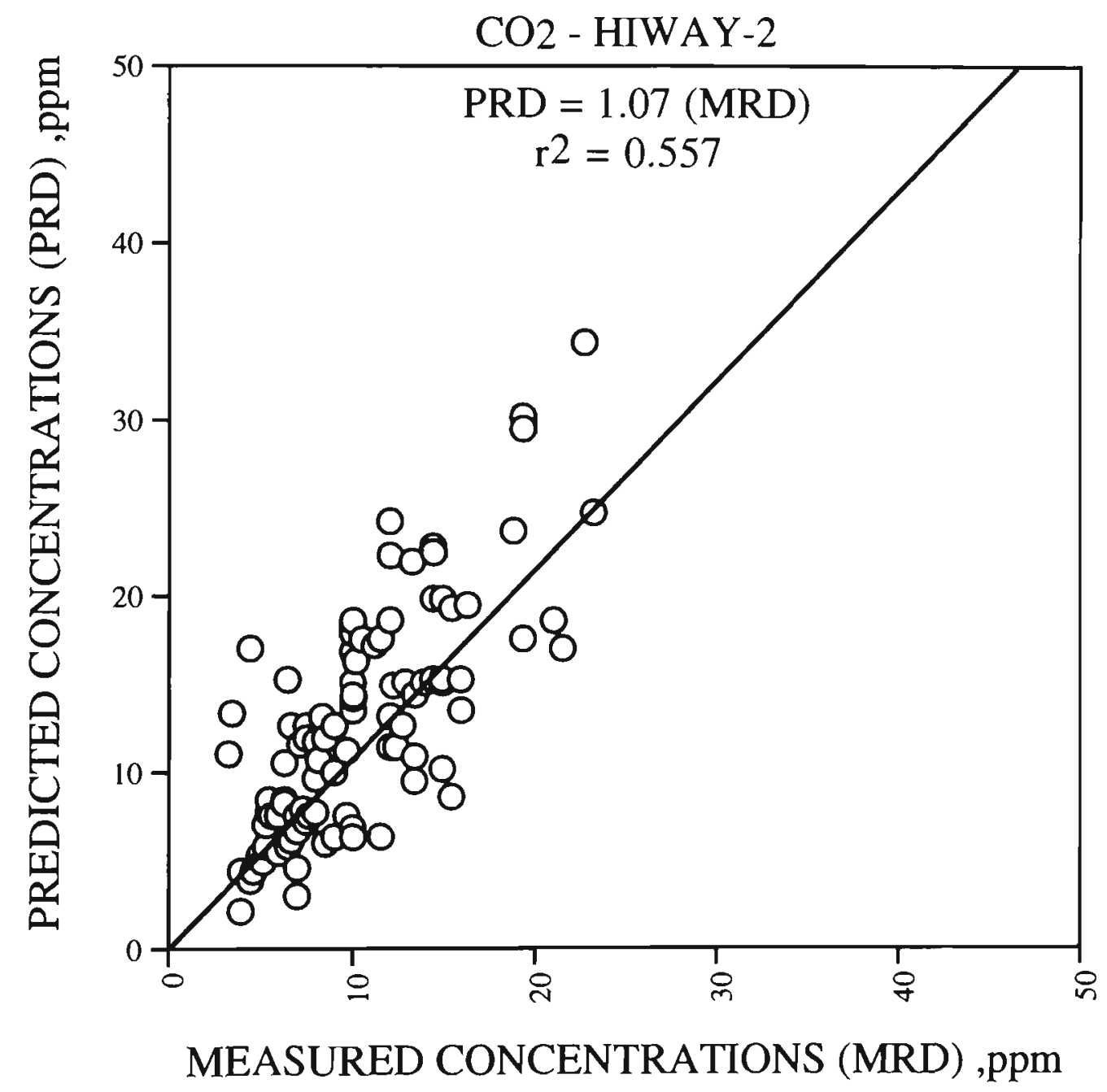

Figure 6.10 Comparison of predicted $\mathrm{CO}_{2}$ concentrations from HIWAY-2 for slope $=0.5^{\circ}$ with measured values (regression $r^{2}=0.557$ ). 


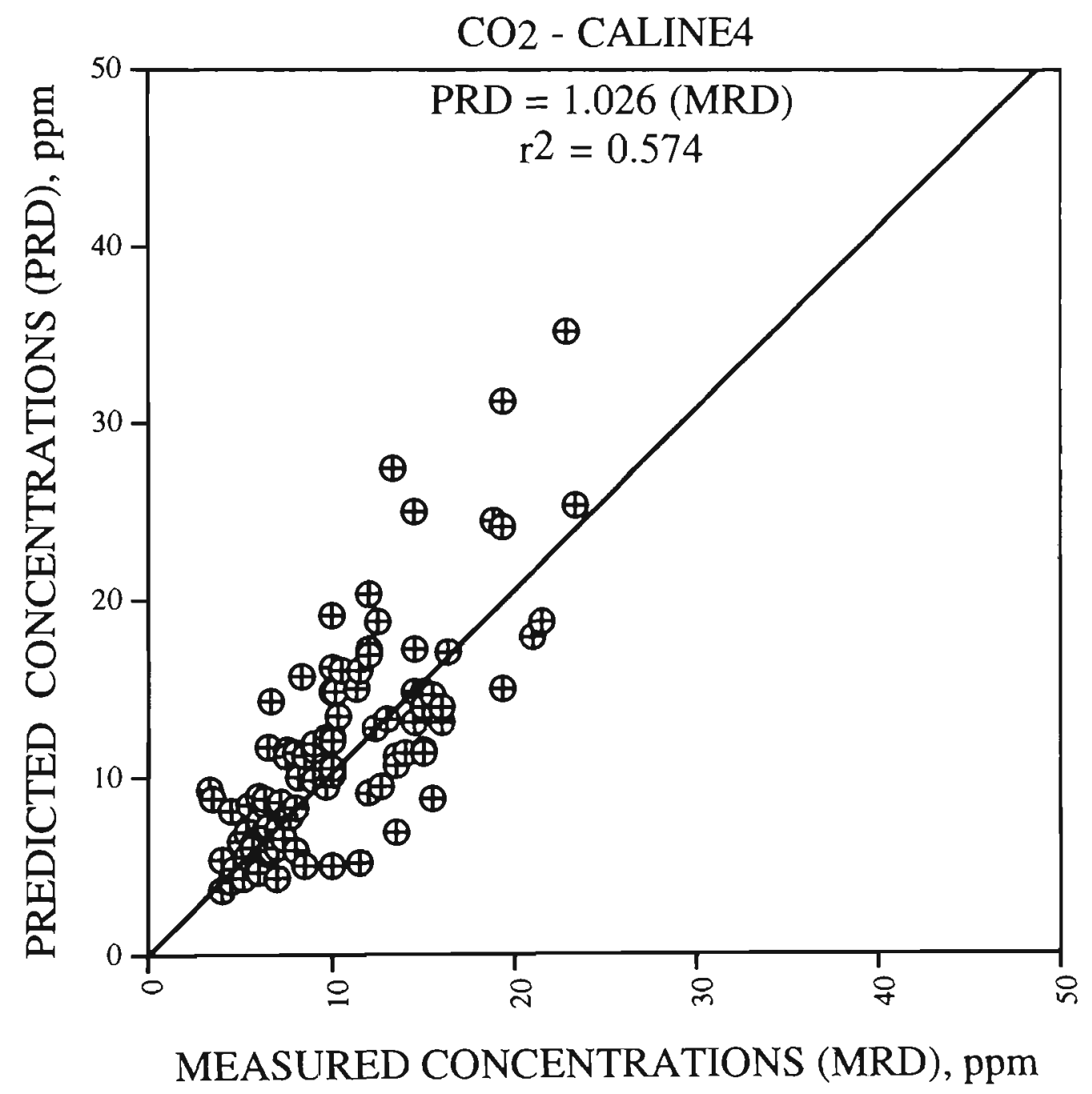

Figure 6.11 Comparison of predicted $\mathrm{CO}_{2}$ concentrations from CALINE4 for slope $=1.0^{\circ}$ with measured values (regression $\left.r^{2}=0.574\right)$. 


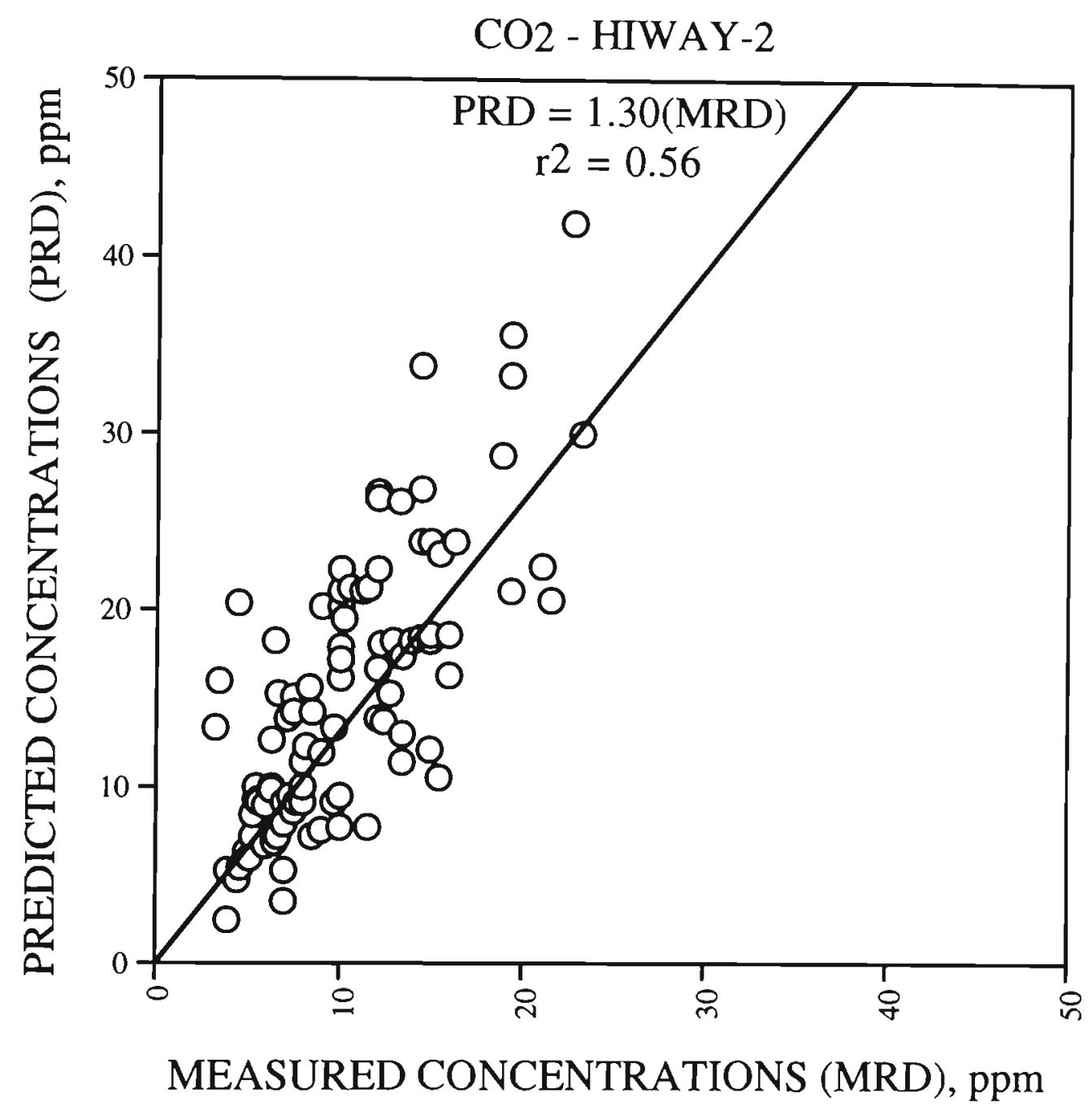

Figure 6.12 Comparison of predicted $\mathrm{CO}_{2}$ concentrations from HIWAY-2 and HIWAY-2 (slope $\left.=1.0^{\circ}\right)$ with measured values $\left(\right.$ regression $\left.r^{2}=0.563\right)$. 
for slopes of $0^{\circ}, 0.5^{\circ}$ and $1.0^{\circ}$, respectively, using the HIWAY-2 dispersion model. It should be noted that the effect of the slopes up to 30 is negligible on the emission source because the upgrade effect is cancelled by the downgrade effect (Appendix D), unless there is a significant traffic balance, which is our case (Tables 6.3-6.10).

As expected, the levels of predicted $\mathrm{CO}_{2}$ concentrations using HIWAY-2 dispersion model (Figures 6.8, 6.10, and 6.12) are higher than those levels of predicted $\mathrm{CO}_{2}$ concentrations using CALINE4 (Figures 6.7, 6.9, and 6.11) for slopes of $00,0.5^{\circ}$ and $1.0^{\circ}$, respectively. The reason for this is that the vertical dispersion parameter $\sigma_{Z}$ deployed in CALINE4 is larger than that deployed in HIWAY-2 (see Chapter 4). CALINE4 treats the region directly above the highway as a zone of uniform emissions and turbulence to get a better approximation of the nature of the emissions which are dispersed by wake turbulence and the buoyancy of the hot exhaust. The effects of roadway turbulence and heat flux on spreading are assumed to operate for par of distance down-wind leading to enhanced dispersion (see Chapter 4).

The data in Figures 6.7 - 6.12 have been obtained at different heights and distances from the roadside and over a range of wind speeds, road-wind angles and atmospheric stability. The agreement between measured and predicted concentrations is remarkably good for atmospheric pollution studies.

In the following part, a restricted experimental data set obtained at one receptor height $(2.5 \mathrm{~m})$ and at one downwind distance $(30 \mathrm{~m})$ was examined in detail.

Figures 6.13 to 6.15 show the comparison of the predicted $\mathrm{CO}_{2}$ concentrations from both HIWAY-2 and CALINE4 for slopes $0.0^{\circ}, 0.5^{\circ}$, and $1.0^{\circ}$, respectively, with the measured $\mathrm{CO}_{2}$ emissions obtained at one height $(2.5 \mathrm{~m})$ and at one distance $(30 \mathrm{~m})$. It is noted, by comparing those Figures with Figures 6.7 to 6.12 , that the scatter is reduced.

Figures 6.16 to 6.18 show the comparison of the predicted $\mathrm{CO}_{2}$ concentrations from both HIWAY-2 and CALINE4 for slopes $0.0^{\circ}, 0.5^{\circ}$, and $1.0^{\circ}$, respectively, with the measured $\mathrm{CO}_{2}$ concentrations obtained at one height $(2.5 \mathrm{~m})$ and at one distance $(30 \mathrm{~m})$ and as a function of the perpendicular wind speed.

The data have been examined in more detail by plotting the experimental and modelled results from HIWAY-2 and CALINE4 as a function of the atmospheric stability. 


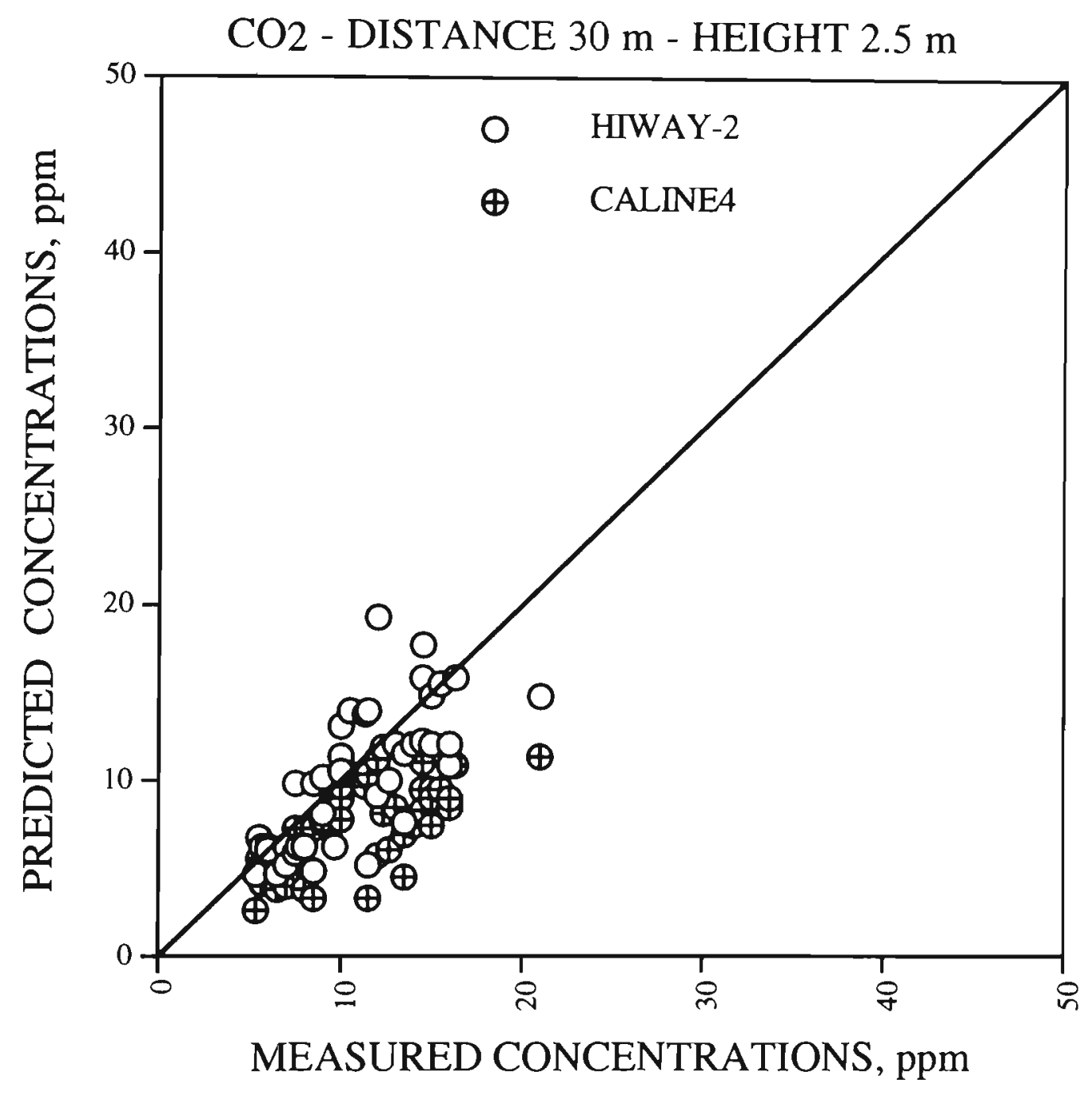

Figure 6.13 Predicted versus measured $\mathrm{CO}_{2}$ concentrations for $\mathrm{HWAY}-2$ and CALINE4 : slope $0.0^{\circ}$. sampling height $=2.5 \mathrm{~m}$ and distance $=30 \mathrm{~m}$ from the roadside. 


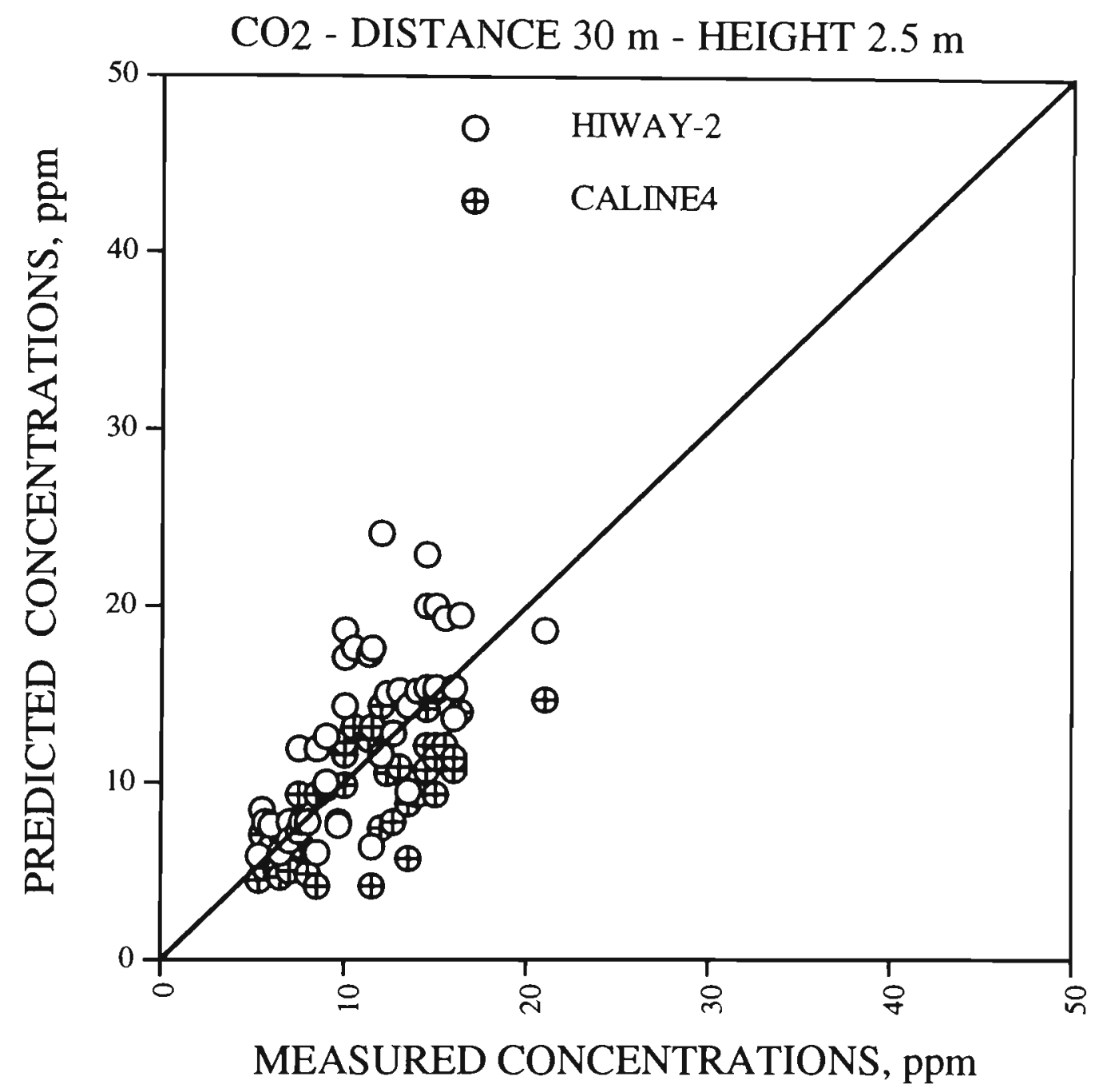

Figure 6.14 Predicted versus measured $\mathrm{CO}_{2}$ concentrations for HIWAY -2 and CALINE4 : slope $0.5^{\circ}$. sampling height $=2.5 \mathrm{~m}$ and distance $=30 \mathrm{~m}$ from the roadside. 


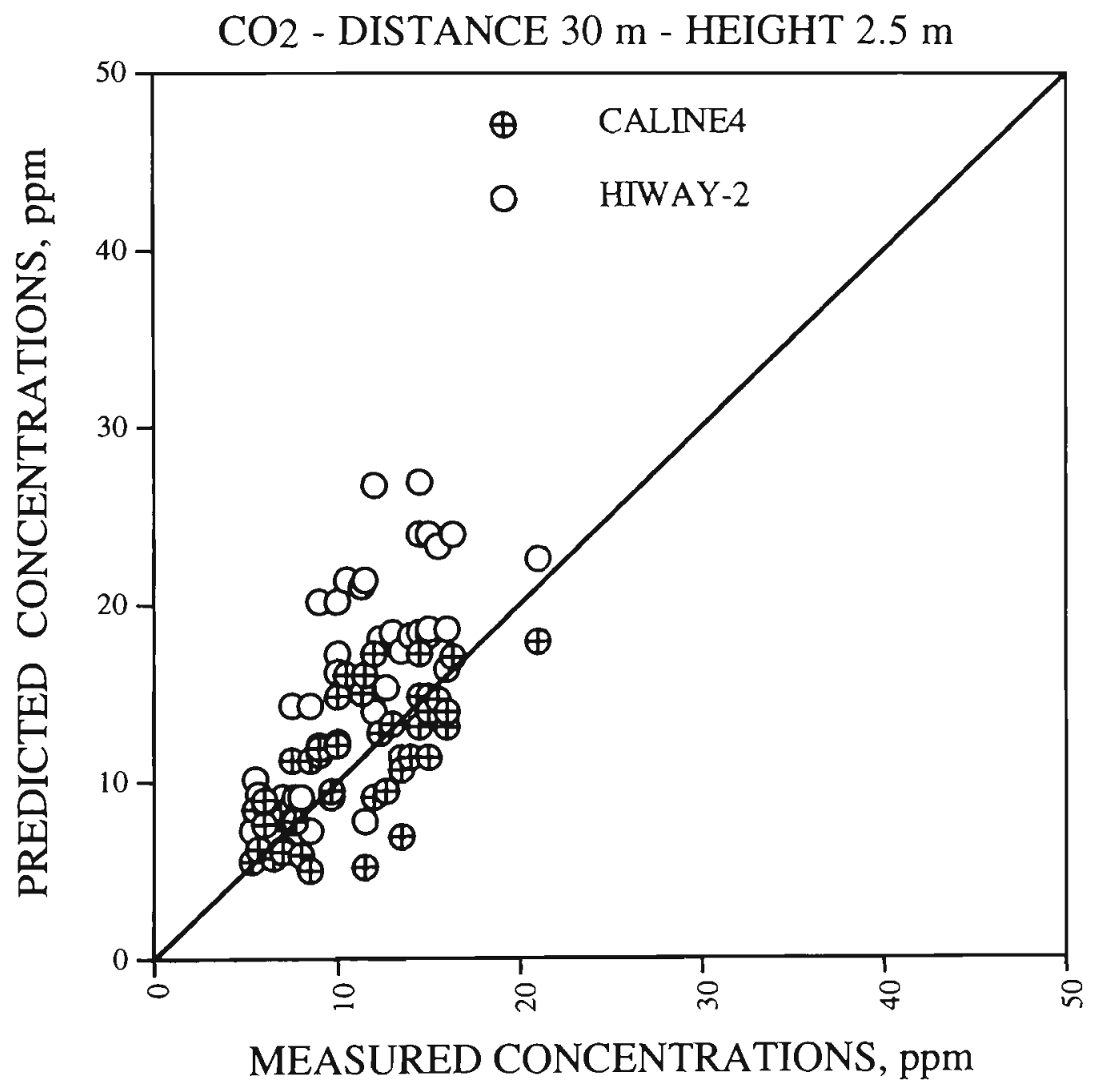

Figure 6.15 Predicted versus measured $\mathrm{CO}_{2}$ concentrations for HIWAY -2 and CALINE4 : slope $1^{0}$. sampling height $=2.5 \mathrm{~m}$ and distance $=30 \mathrm{~m}$ from the roadside. 


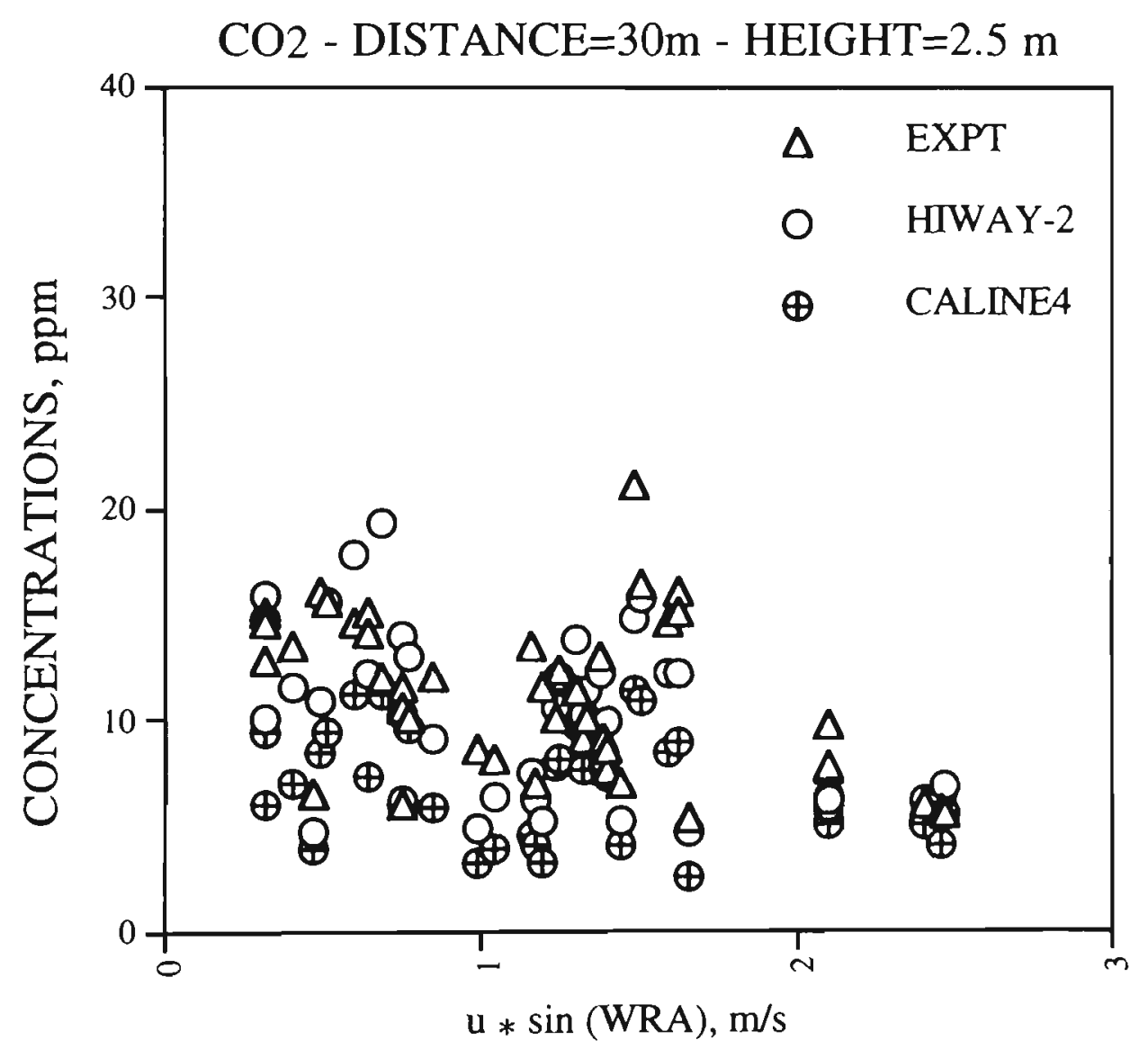

Figure 6.16 Comparison of predicted $\mathrm{CO}_{2}$ concentrations from HIWAY -2 and CALINE4 ( for slope $0.0^{\circ}$, height $=2.5 \mathrm{~m}$, and distance $=30 \mathrm{~m}$ from roadside) with the measured values as a function of perpendicular wind. 


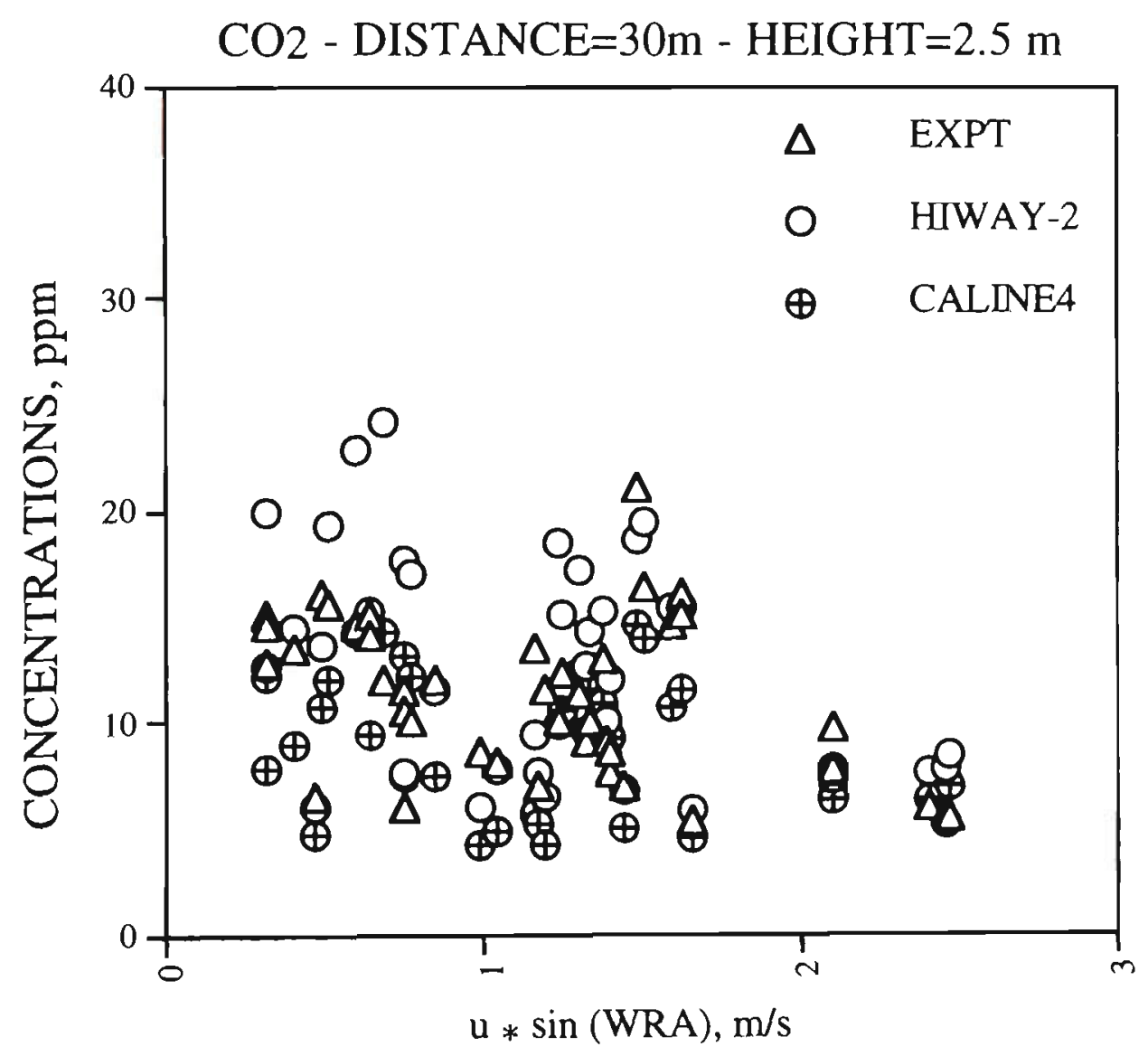

Figure 6.17 Comparison of predicted $\mathrm{CO}_{2}$ concentrations from HIWAY -2 and CALINE4 ( for slope $0.5^{\circ}$, height $=2.5 \mathrm{~m}$, and distance $=30 \mathrm{~m}$ from roadside) with the measured values as a function of perpendicular wind . 


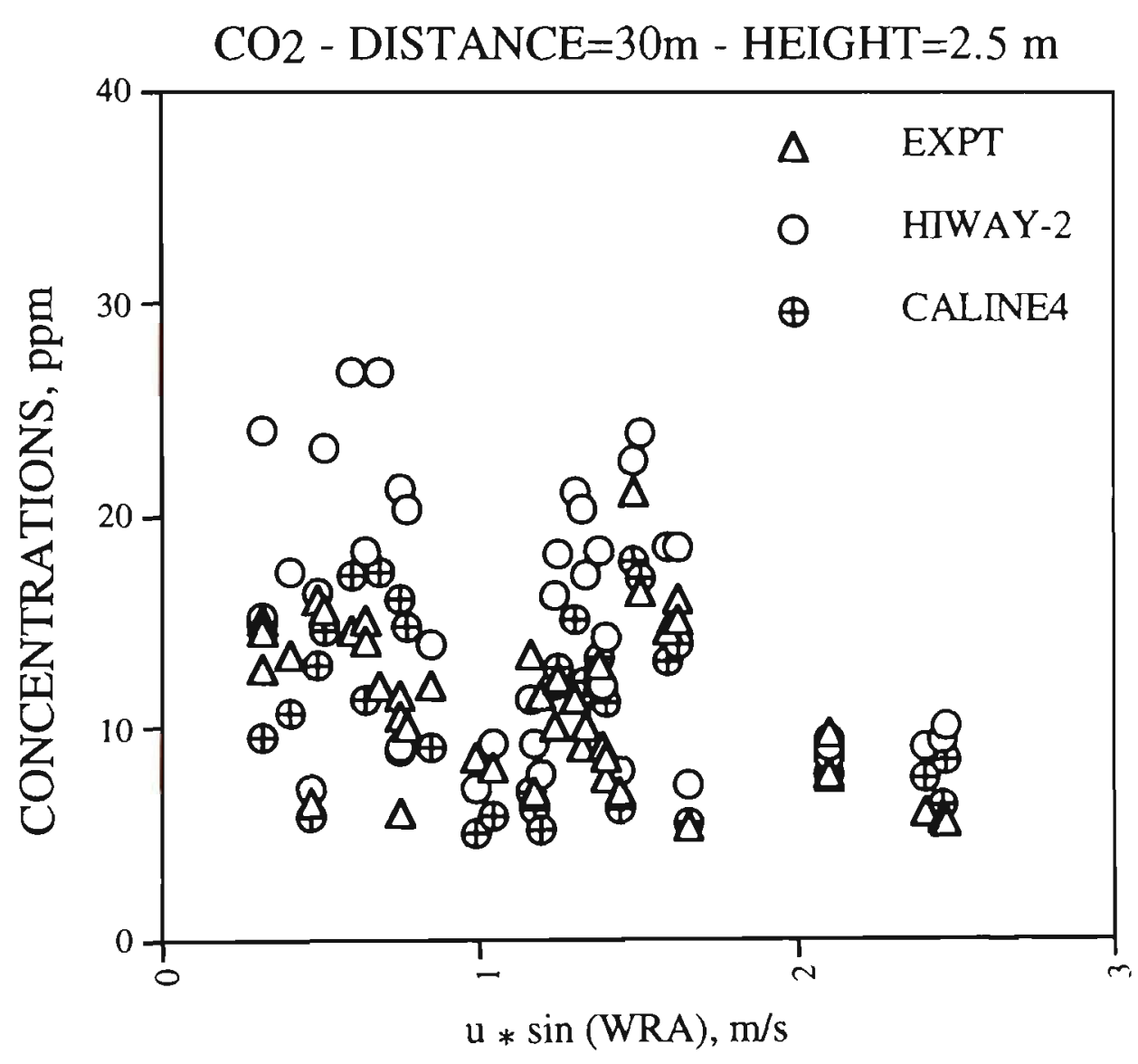

Figure 6.18 Comparison of predicted $\mathrm{CO}_{2}$ concentrations from HWWY -2 and CALINE4 ( for slope $1^{0}$, height $=2.5 \mathrm{~m}$, and distance $=30 \mathrm{~m}$ from roadside) with the measured values as a function of perpendicular wind . 


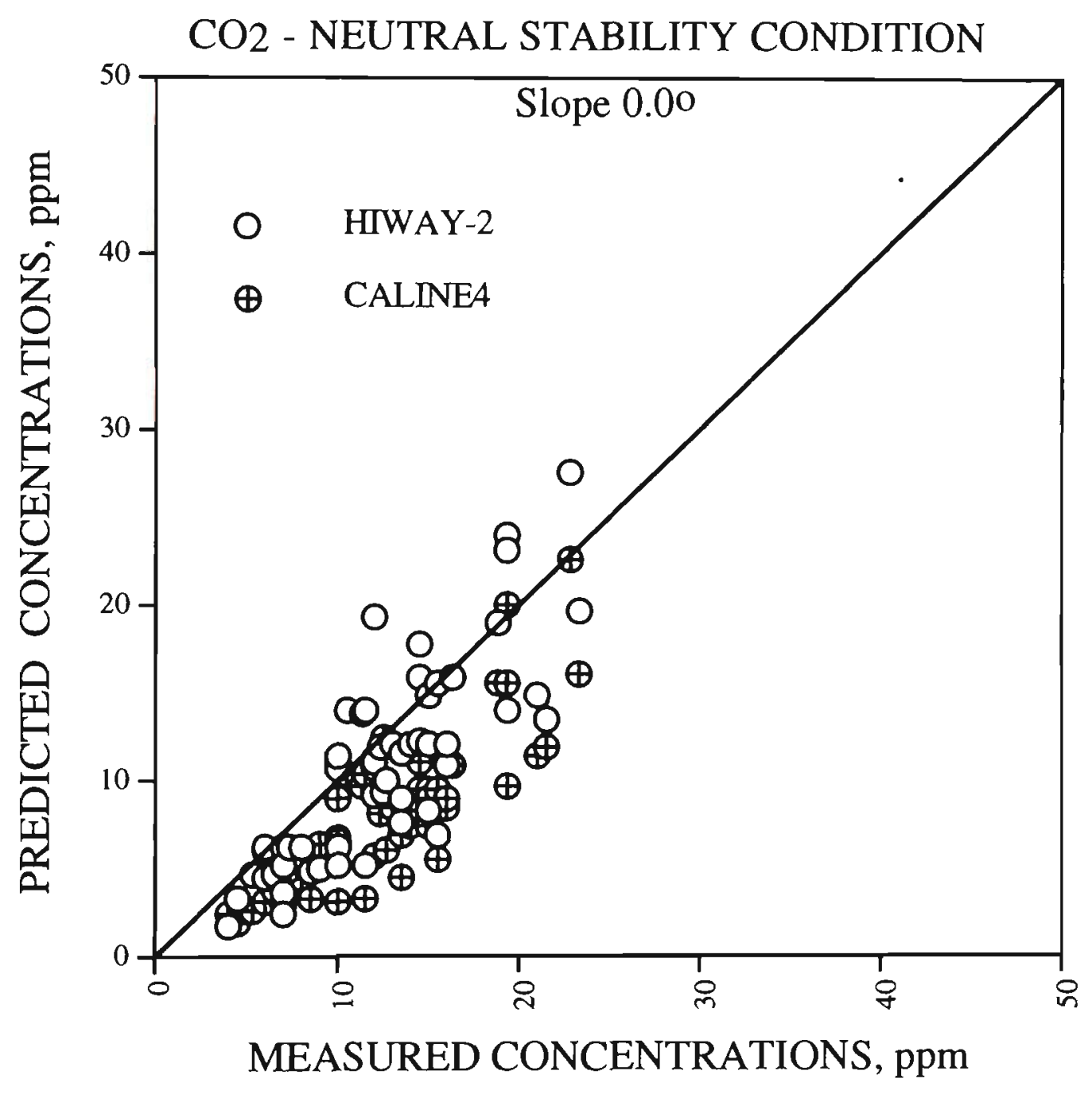

Figure 6.19 Predicted versus measured $\mathrm{CO}_{2}$ concentrations for HIWAY -2 and CALINE4 : slope $0.0^{\circ}$ for neutral stability condition. 


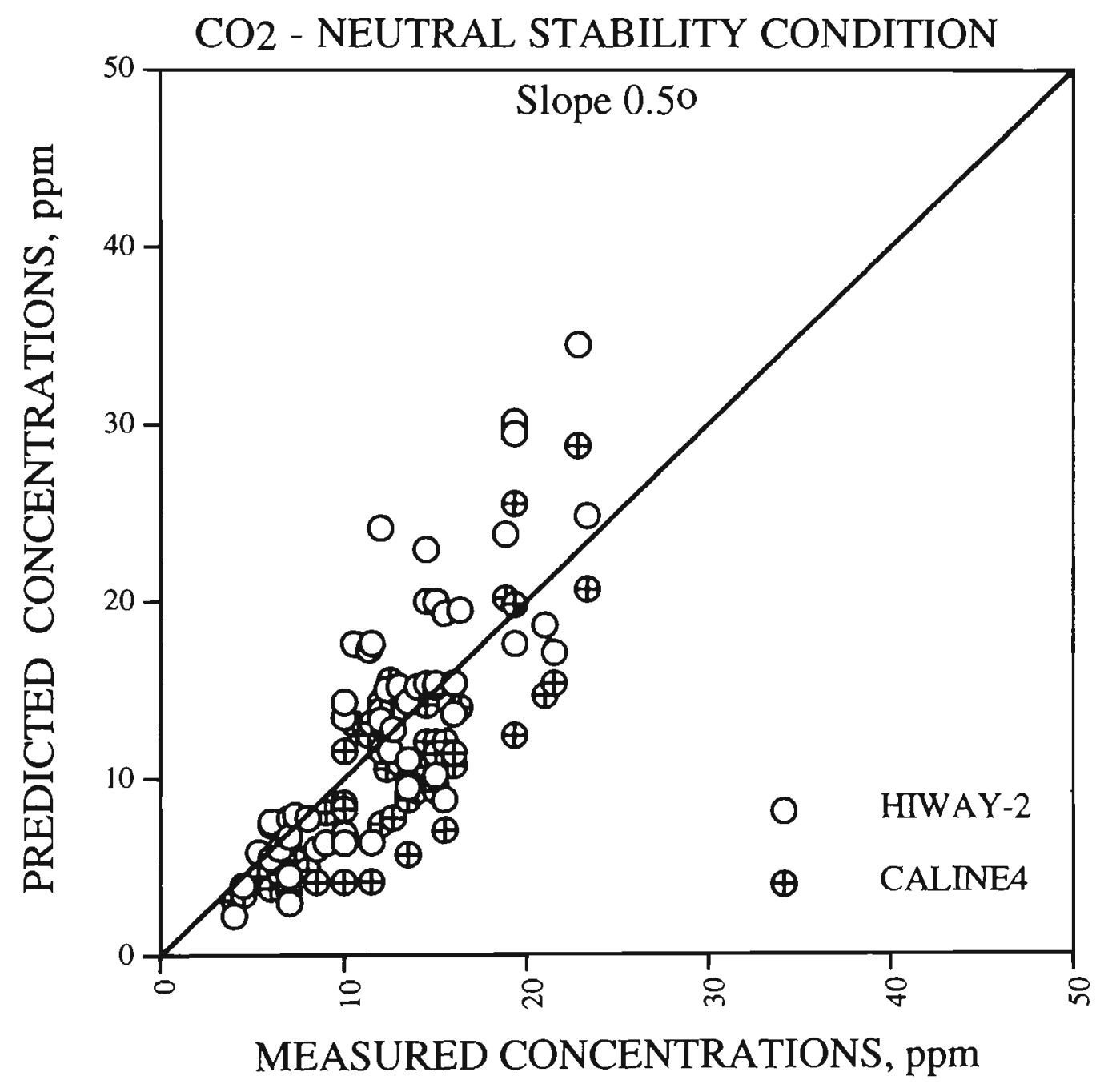

Figure 6.20 Predicted versus measured $\mathrm{CO}_{2}$ concentrations for HIWAY -2 and CALINE4 : slope $0.5^{\circ}$ for neutral stability condition. 


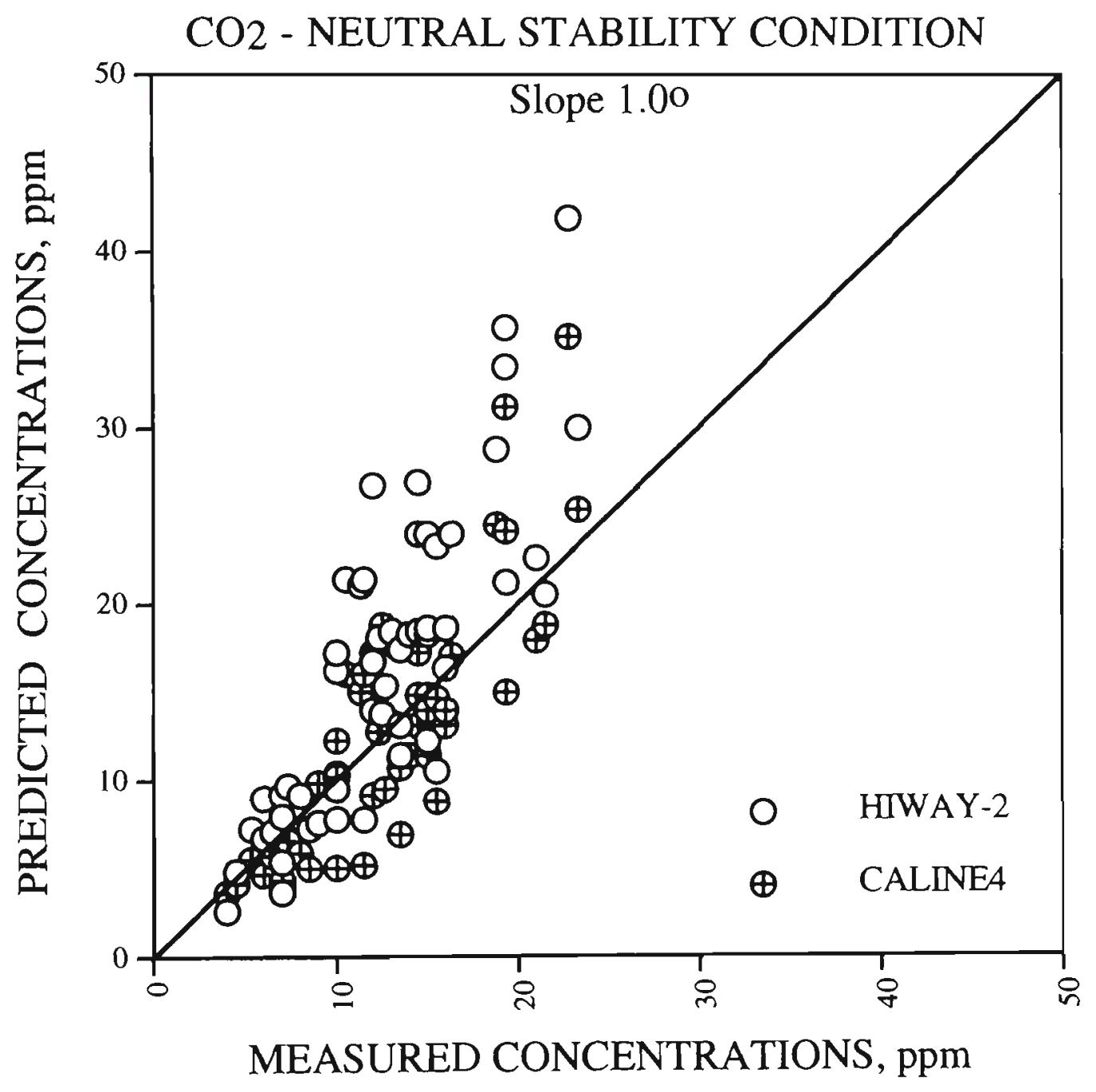

Figure 6.21 Predicted versus measured $\mathrm{CO}_{2}$ concentrations for HIWAY -2 and CALINE4 : slope $1.0^{\circ}$ for neutral stability condition. 


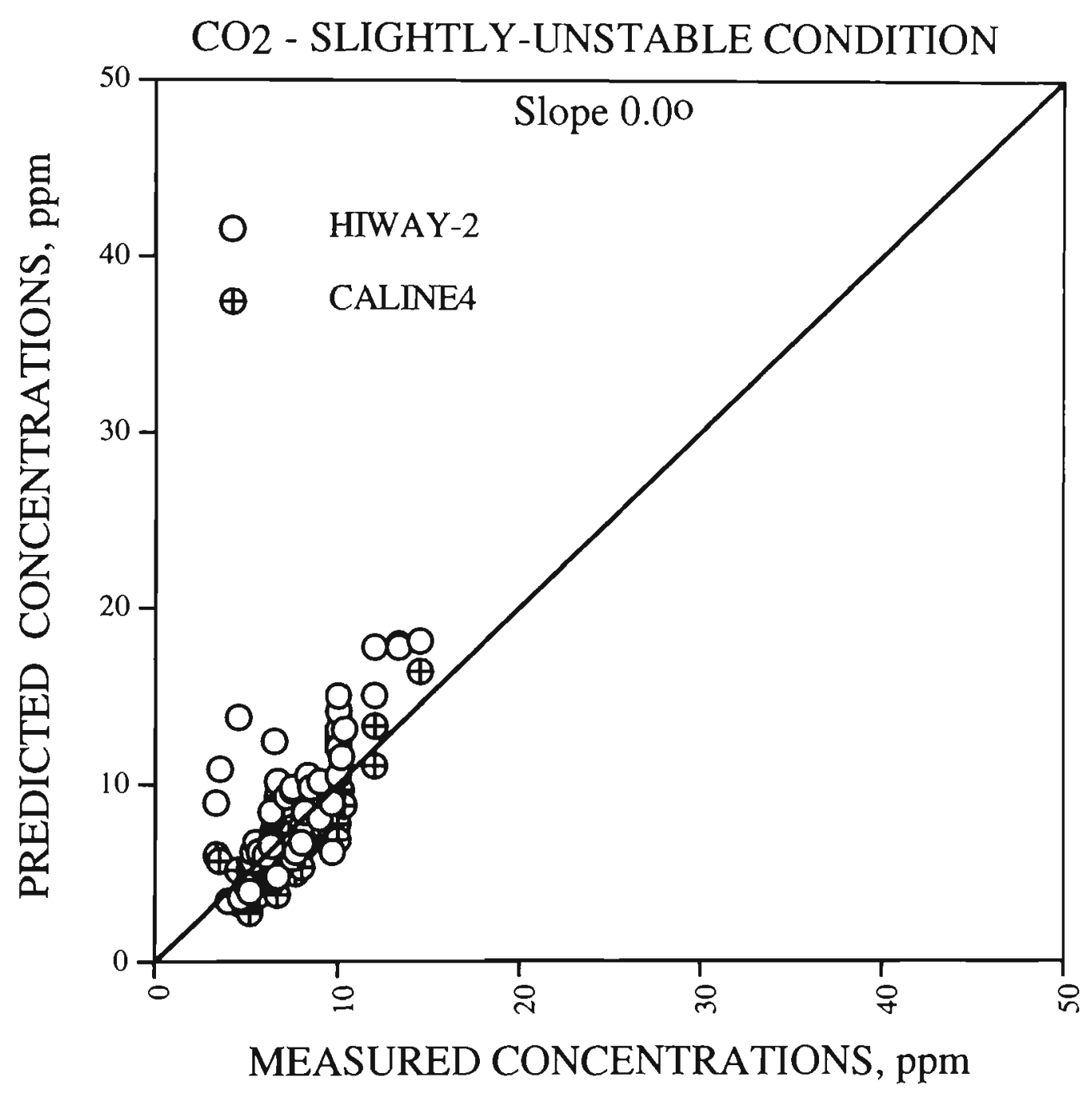

Figure 6.22 Predicted versus measured $\mathrm{CO}_{2}$ concentrations for $\mathrm{HIWAY}-2$ and CALINE4 : slope $0.0^{\circ}$ for slightly-unstable condition. 


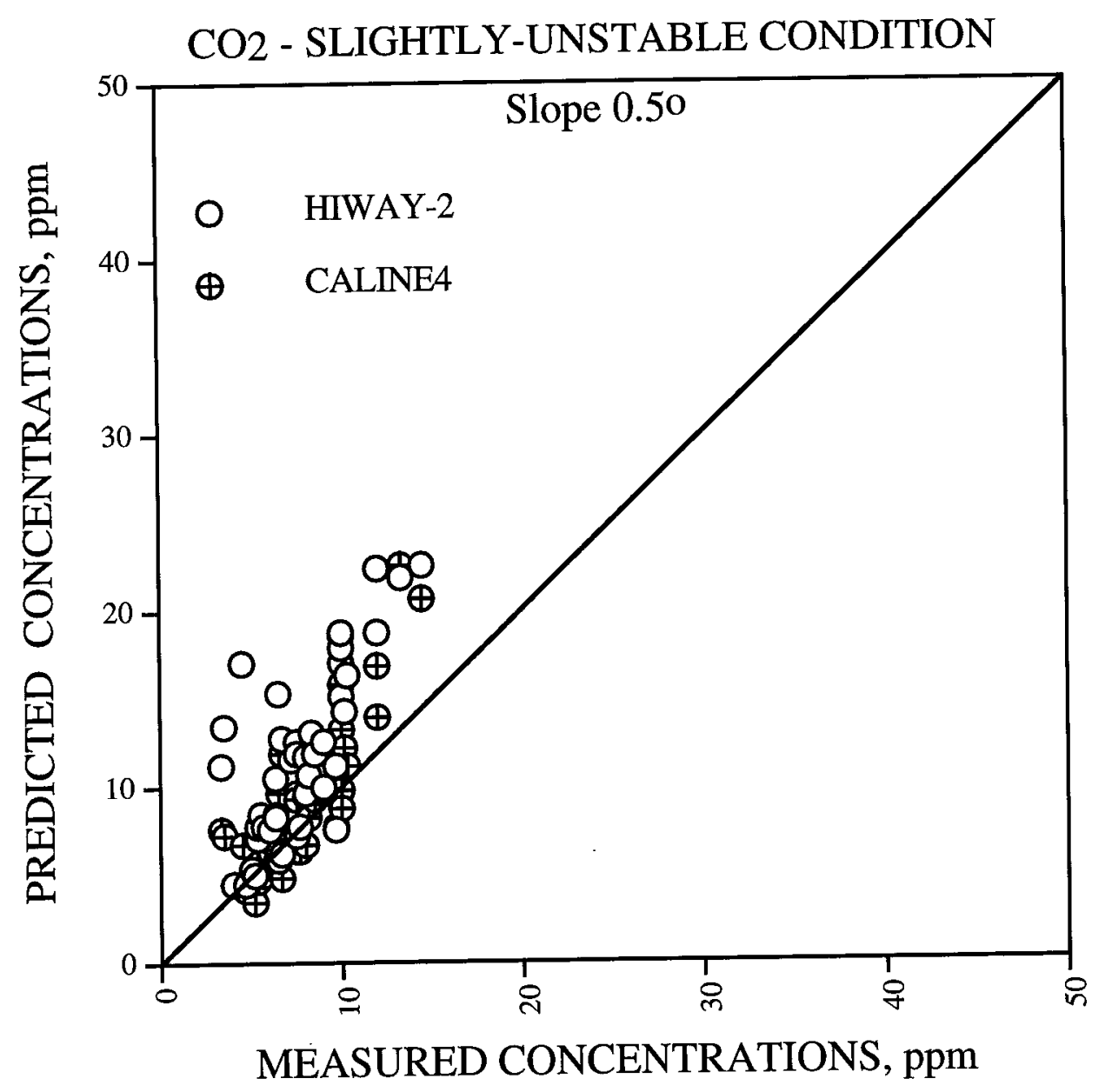

Figure 6.23 Predicted versus measured $\mathrm{CO}_{2}$ concentrations for HIWAY -2 and CALINE4 : slope $0.5^{\circ}$ for slightly-unstable condition. 


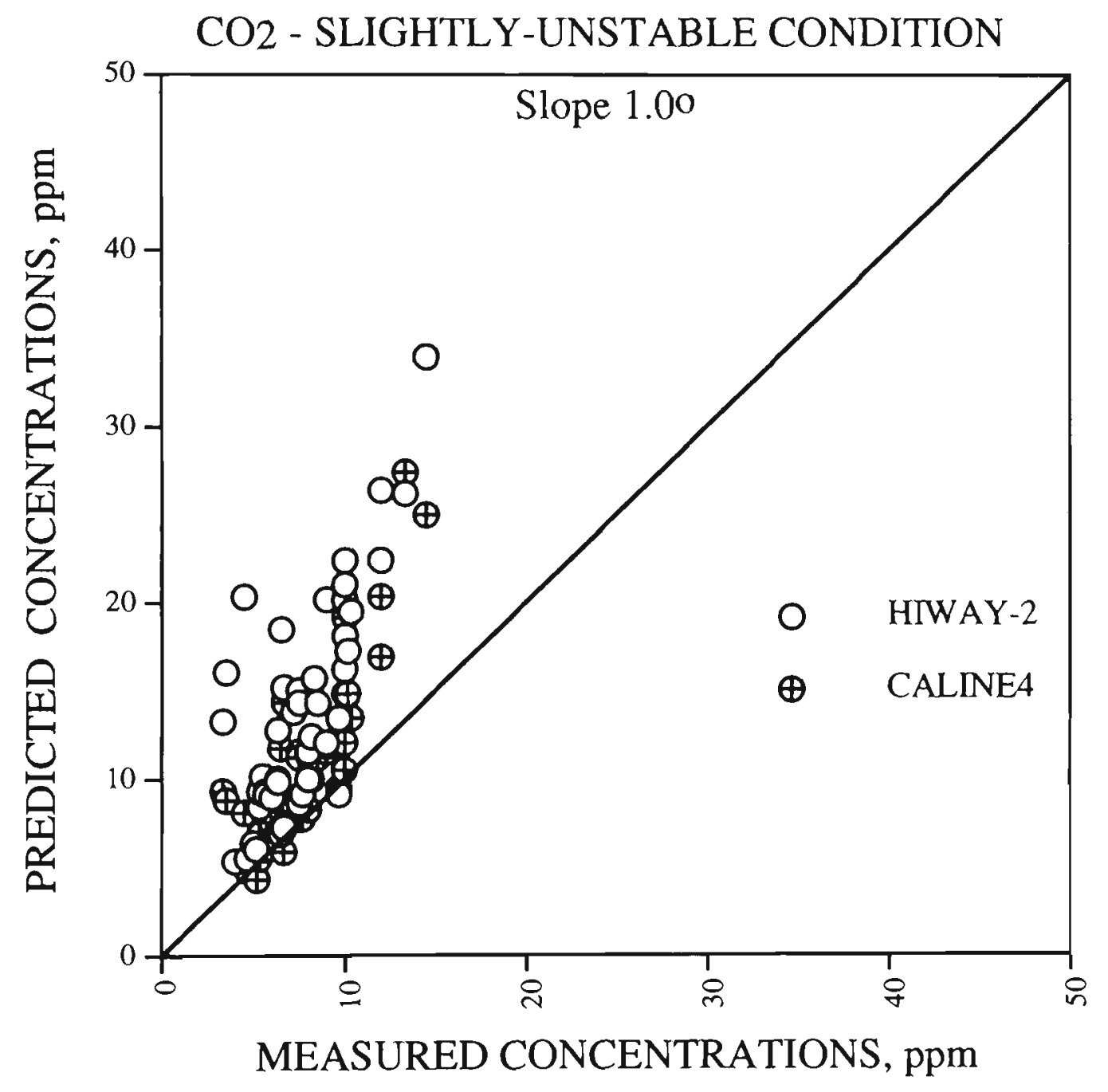

Figure 6.24 Predicted versus measured $\mathrm{CO}_{2}$ concentrations for HIWAY -2 and CALINE4 : slope $1 .^{\circ}$ for slightly-unstable condition. 
Figures $6.19,6.20$, and 6.21 show the comparison of the measured $\mathrm{CO}_{2}$ concentrations with the modelled $\mathrm{CO}_{2}$ concentrations from both HIWAY-2 and CALINE4 for a neutral stability condition ( for slopes $0.0^{\circ}, 0.5^{\circ}$, and $1.0^{\circ}$, respectively), while Figures 6.22 , 6.23 , and 6.24 show the comparison of the measured $\mathrm{CO}_{2}$ concentrations with the modelled $\mathrm{CO}_{2}$ concentrations from both HIWAY-2 and CALINE4 for slightly-unstable condition (for slopes $0.0^{\circ}, 0.5^{\circ}$, and $1.0^{\circ}$, respectively).

It is believed, on the basis of these data, that CALINE4, using a slope of $1.0^{\circ}$, performs slightly better than CALINE4, using a slope of $0.5^{\circ}$ for neutral stability conditions whilst CALINE4, using a slope of $0.5^{\circ}$, performs slightly better than CALINE4, using either a slope of $0.0^{\circ}$ or $1.0^{\circ}$ for a slightly-unstable condition. At the same time, HTWAY-2, using a slope of $0.5^{\circ}$, performs slightly better than HIWAY-2. using either a slope of $0.0^{\circ}$ or a slope of $1.0^{\circ}$ for neutral stability conditions, while HIW AY-2, using a slope of $0.0^{\circ}$, performs slightly better than HWAY-2, using either a slope of $0.5^{\circ}$ or a slope of $1.0^{\circ}$ for a slightly-unstable condition .

Also in the following part, the data have been examined individually (for each experiment day) and in more detail. The eight-day experimental data were gathered along routes which access the Sydney Commercial Business District CBD. Two measurements sites (Homebush and James Ruse Drive sites) were located along major western access routes. The third measurement site (Epping) was located along a major northern route.

James Ruse Drive site is located on the major route to the Sydney CBD where the highest traffic volume is carried during the peak periods with a relatively high percentage of heavy-duty diesel vehicles (up to 17\%), and where there is an incline and occasional queuing at traffic lights. The road way in this site has six lanes and a median strip $1.0 \mathrm{~m}$ wide. Data from nineteen measurements periods (half an hour) over three different mornings (22 September, 16 June, and 26 May 1992) are given in Tables 6.5, 6.6, and 6.7.

The Homebush site is located near a major highway (F4) which access to the Sydney $\mathrm{CBD}$ where the traffic is free-flowing and the highest traffic volume is carried during the peak periods with an average percentage of heavy-duty diesel vehicles of $9 \%$. The road way in this site has six lanes and a median strip $0.4 \mathrm{~m}$ wide. Data from seven measurements periods (half an hour) over the one morning (6 April 1993) is given in Table 6.3. 


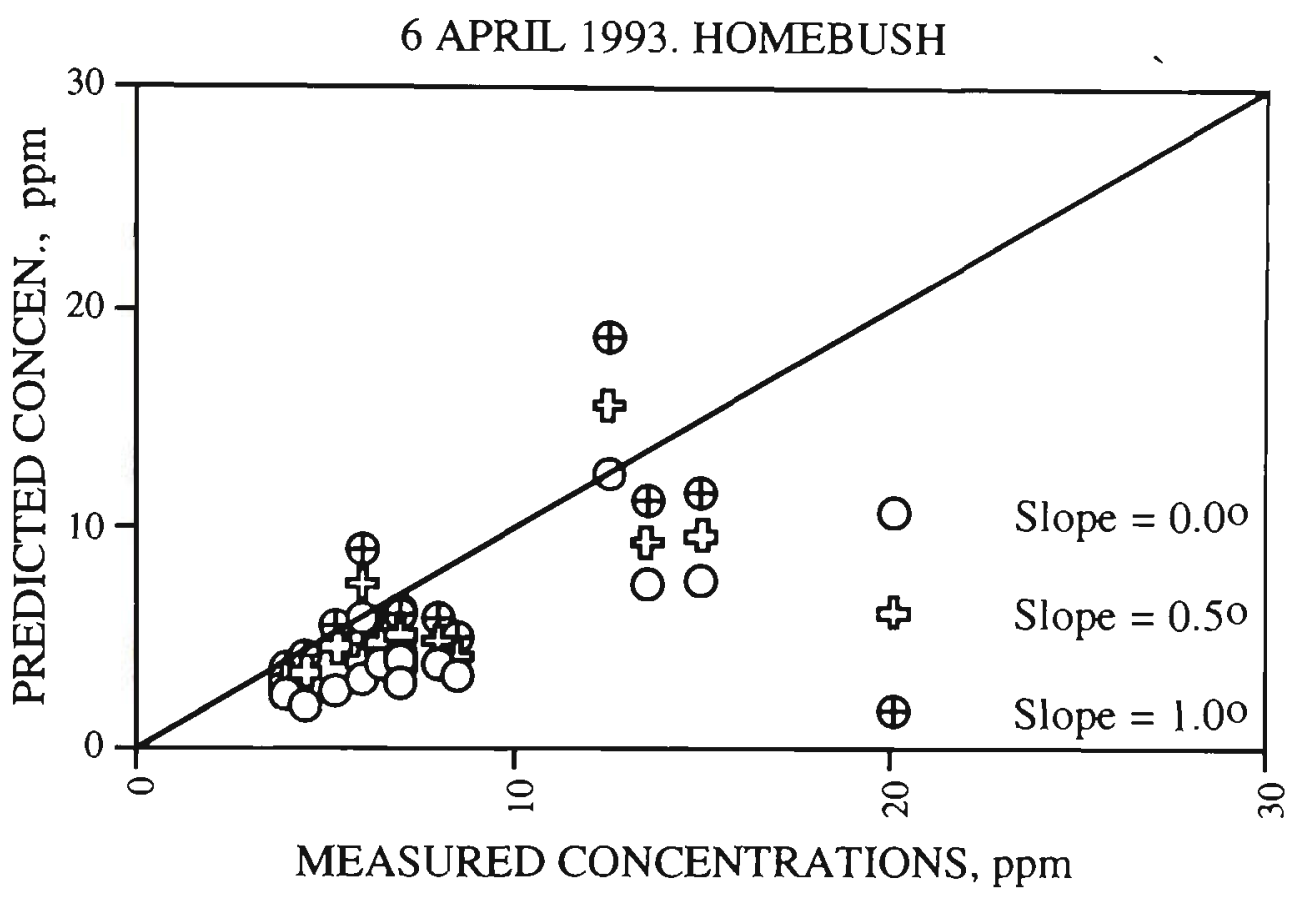

Figure 6.25 Comparison of predicted $\mathrm{CO}_{2}$ concentrations from CALINE4 model with measured values for slopes $=0.0^{\circ}, 0.5^{\circ}$, and $1.0^{\circ}$ (data for 6 April 1993. Homebush).

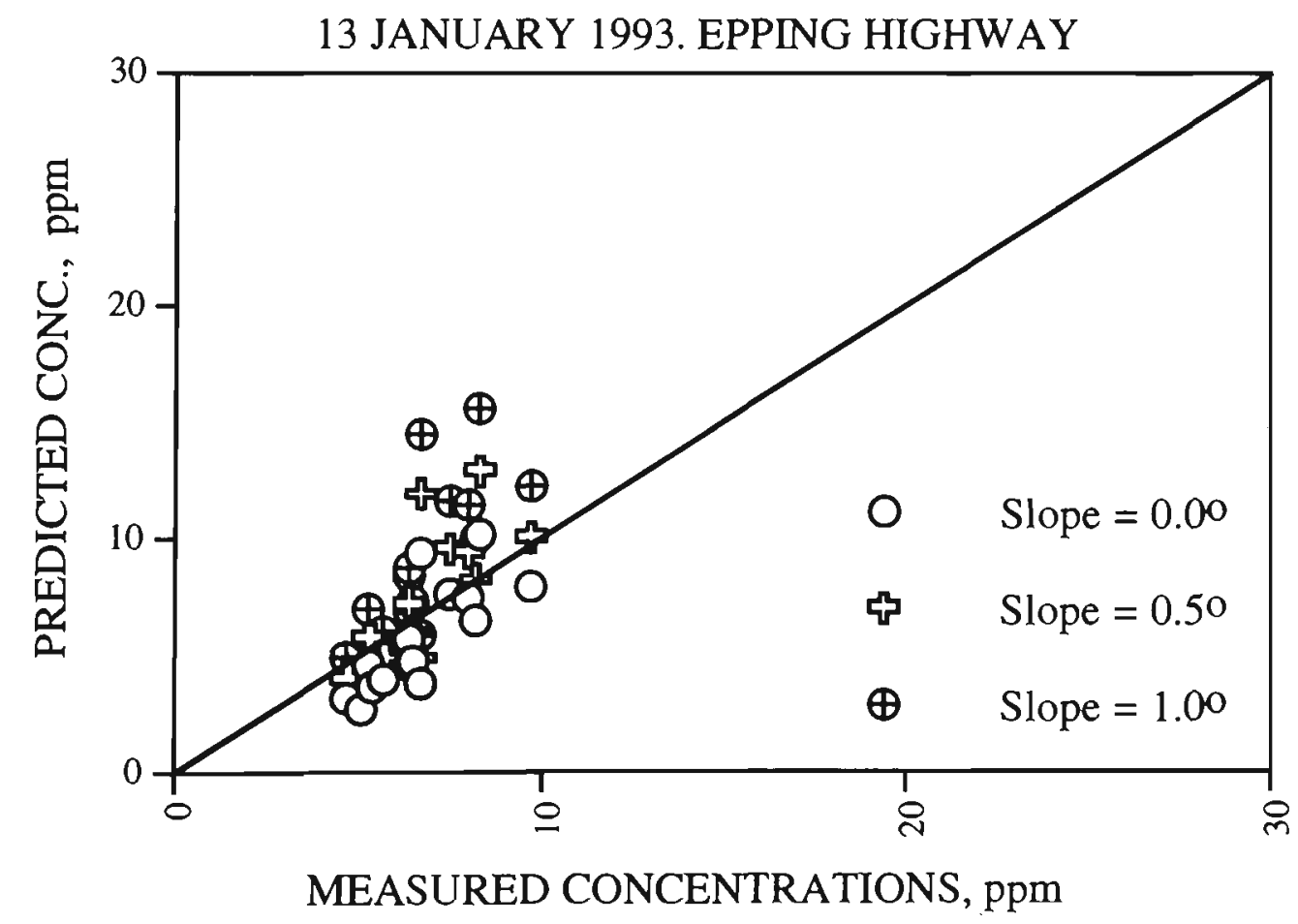

Figure 6.26 Comparison of predicted $\mathrm{CO}_{2}$ concentrations from CALINE4 model with measured values for slopes $=0.0^{\circ}, 0.5^{\circ}$, and $1.0^{\circ}($ data for 13 January 1993 . Epping Highway.). 


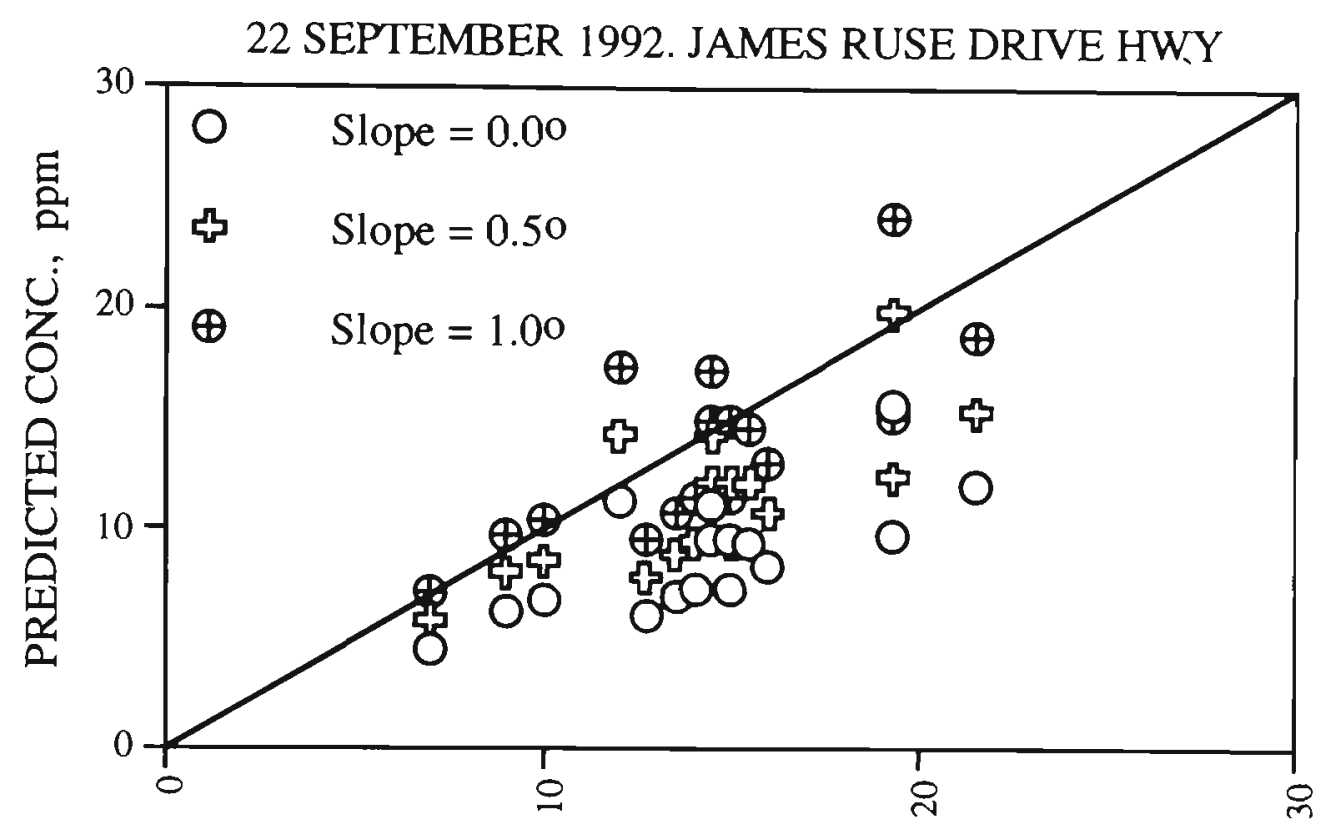

MEASURED CONCENTRATIONS, ppm

Figure 6.27 Comparison of predicted $\mathrm{CO}_{2}$ concentrations from CALINE4 model with measured values for slopes $=0.0^{\circ}, 0.5^{\circ}$, and $1.0^{\circ}$ (data for 22 September 1992 . James Ruse Drive Highway).

16 JUNE 1992. JAMES RUSE DRIVE HWY

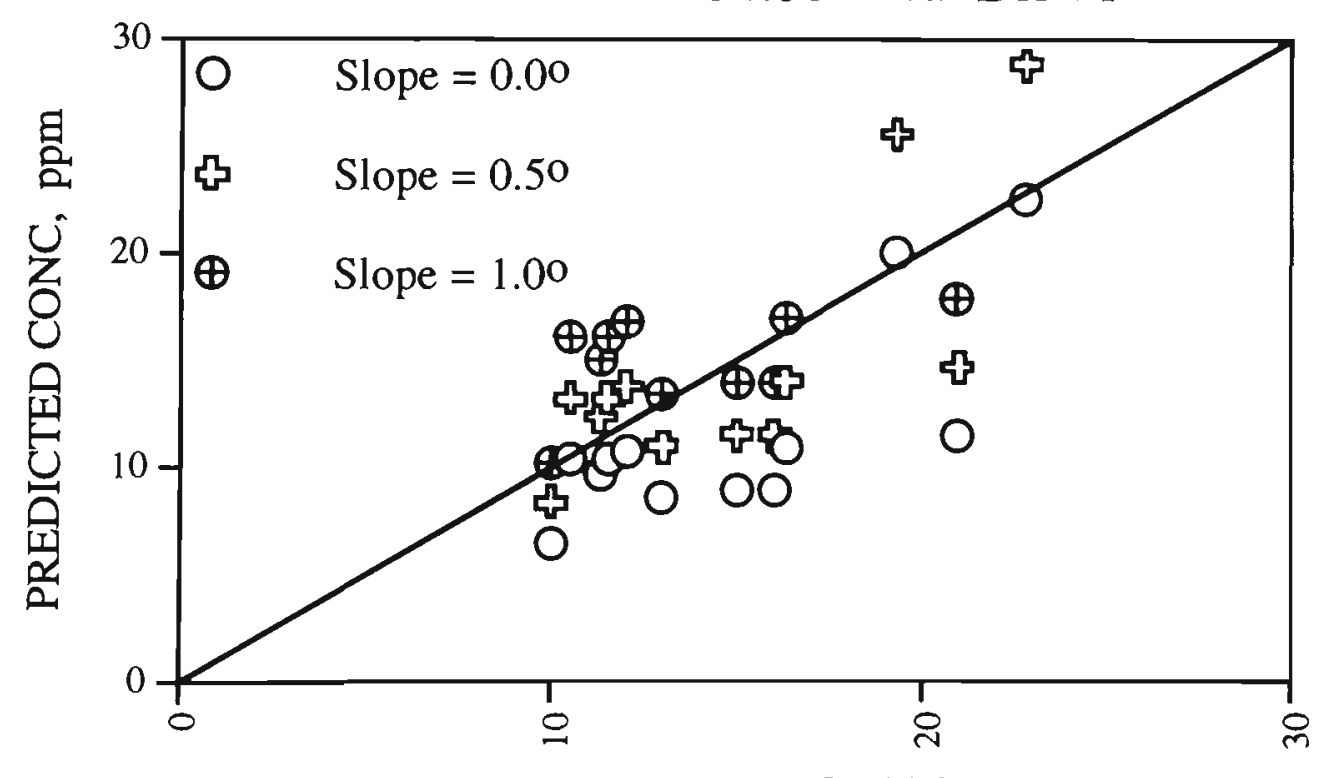

MEASURED CONCENTRATIONS, ppm

Figure 6.28 Comparison of predicted $\mathrm{CO}_{2}$ concentrations from CALINE4 model with measured values for slopes $=0.0^{\circ}, 0.5^{\circ}$, and $1.0^{\circ}$ (data for 16 June 1992. James Ruse Drive Highway). 


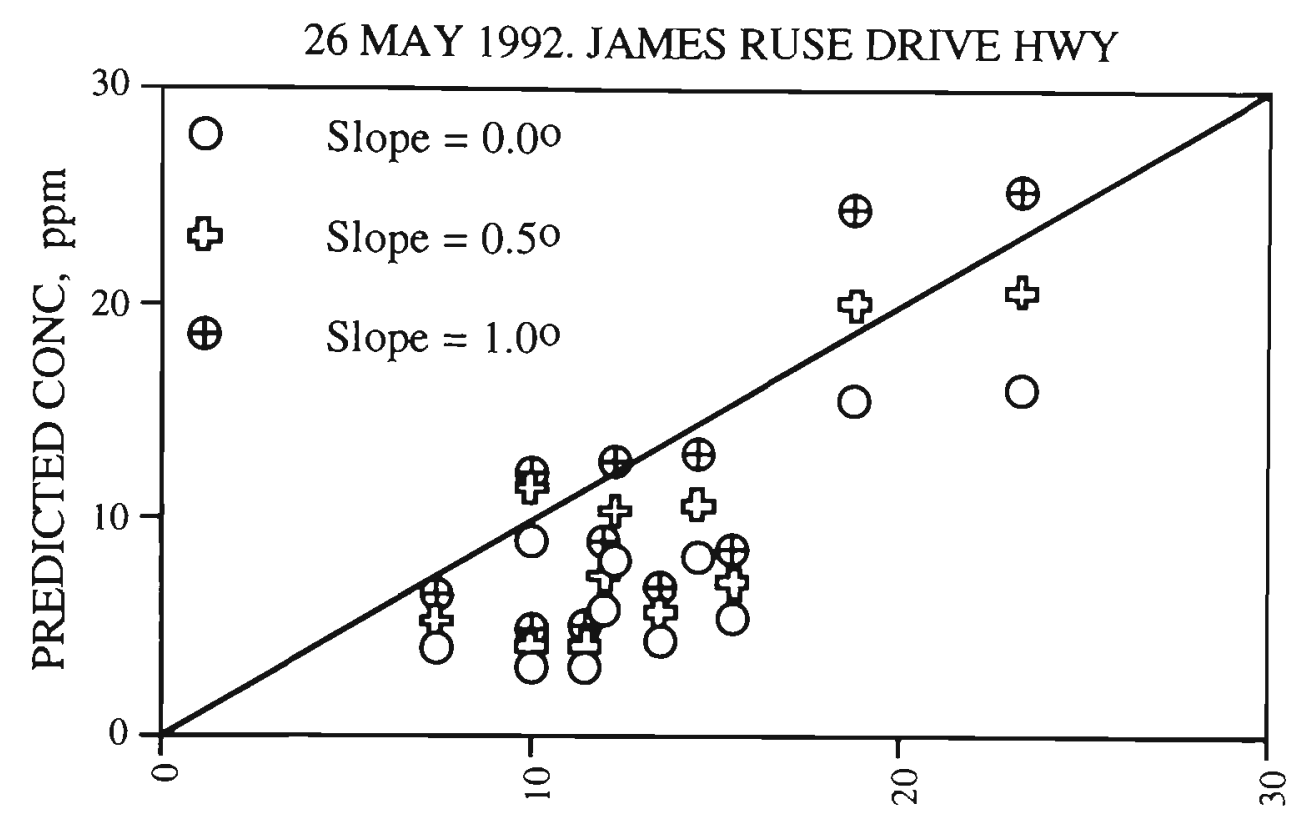

MEASURED CONCENTRATIONS, ppm

Figure 6.29 Comparison of predicted $\mathrm{CO}_{2}$ concentrations from CALINE4 model with measured values for slopes $=0.0^{\circ}, 0.5^{\circ}$, and $1.0^{\circ}$ (data for 26 May 1992. James Ruse Drive Highway).

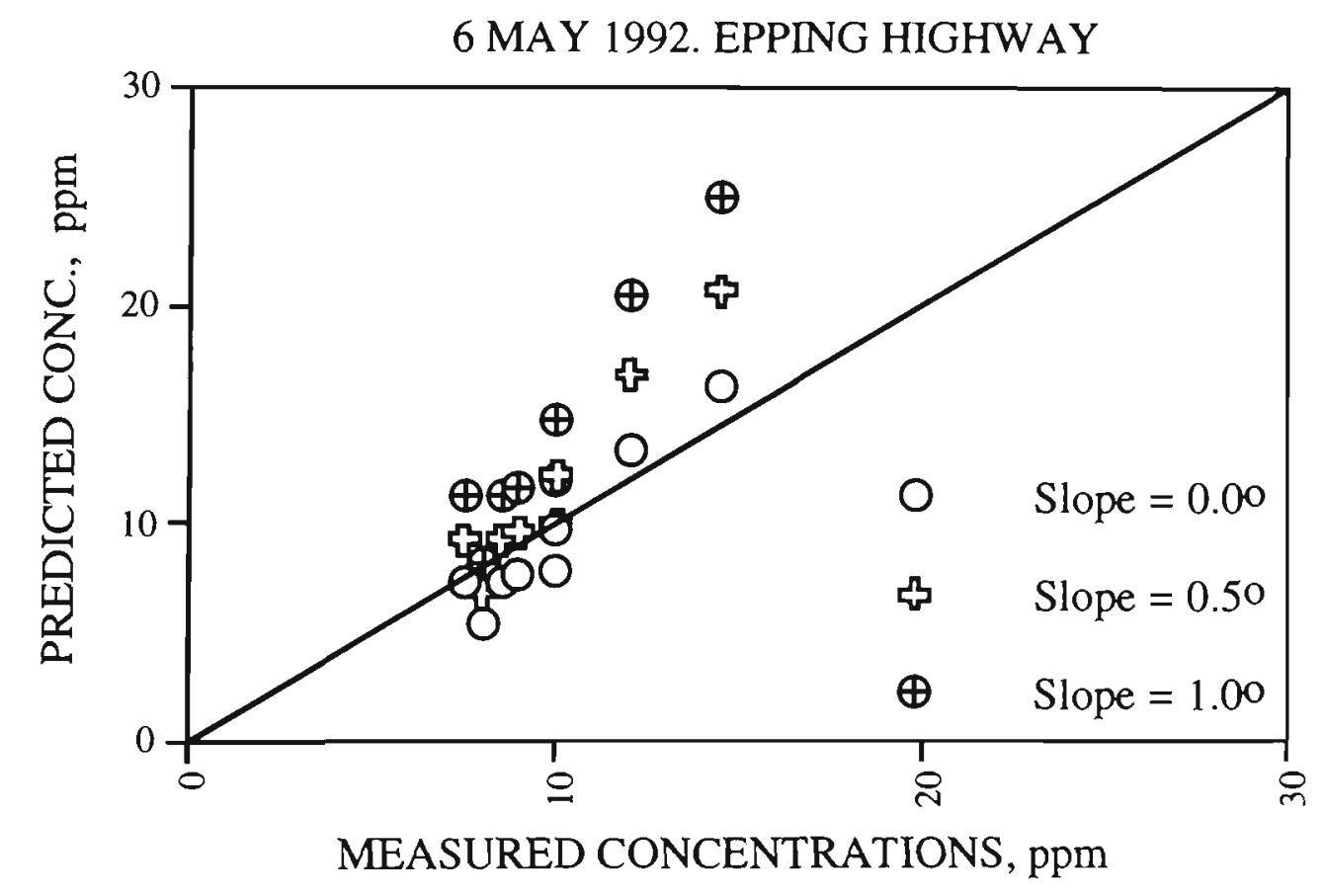

Figure 6.30 Comparison of predicted $\mathrm{CO}_{2}$ concentrations from CALINE4 model with measured values for slopes $=0.0^{\circ}, 0.5^{\circ}$, and $1.0^{\circ}$ (data for 6 May 1992. Epping Highway). 


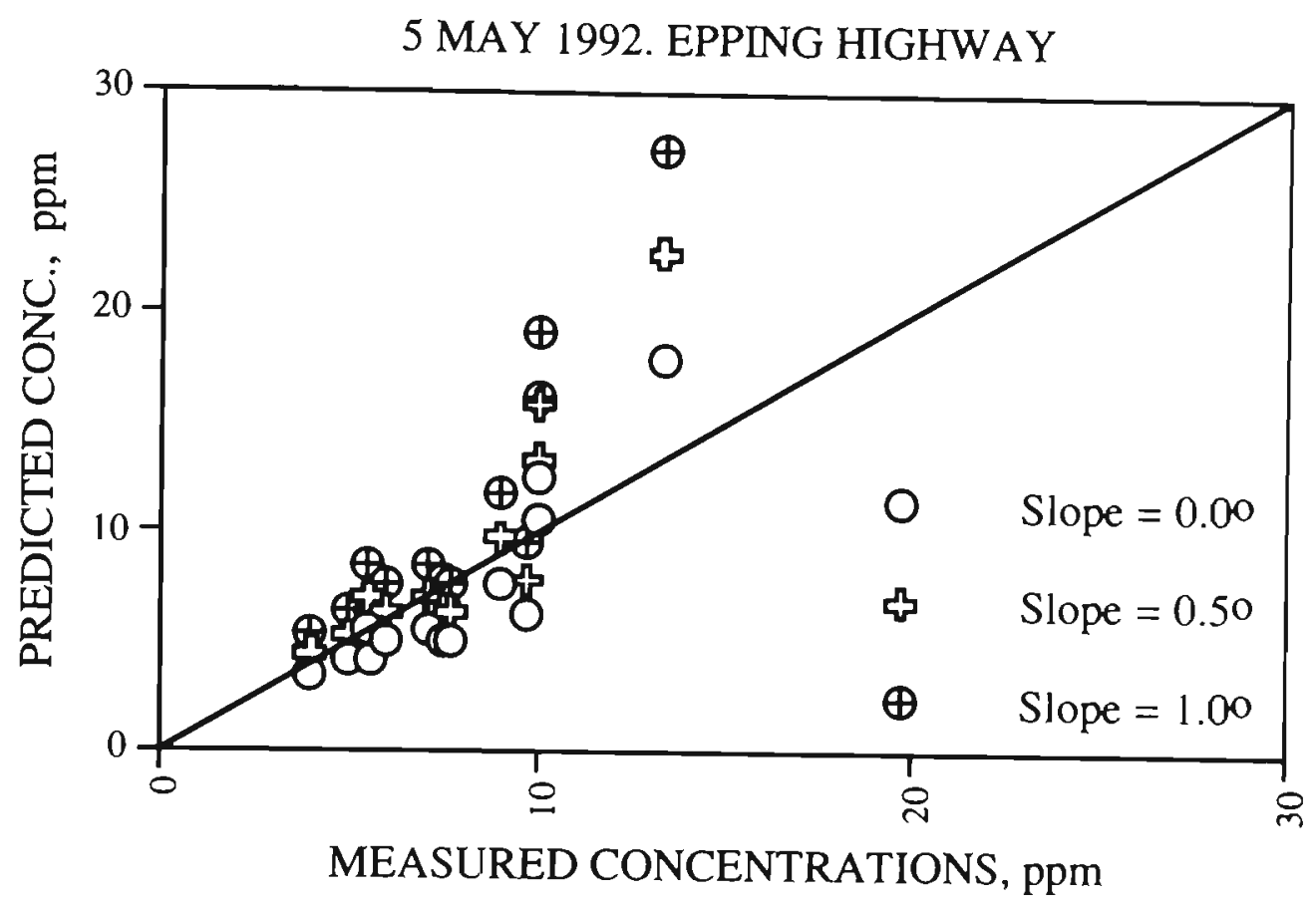

Figure 6.31 Comparison of predicted $\mathrm{CO}_{2}$ concentrations from CALINE4 model with measured values for slopes $=0.0^{\circ}, 0.5^{\circ}$, and $1.0^{\circ}$ (data for 5 May 1992. Epping Highway.

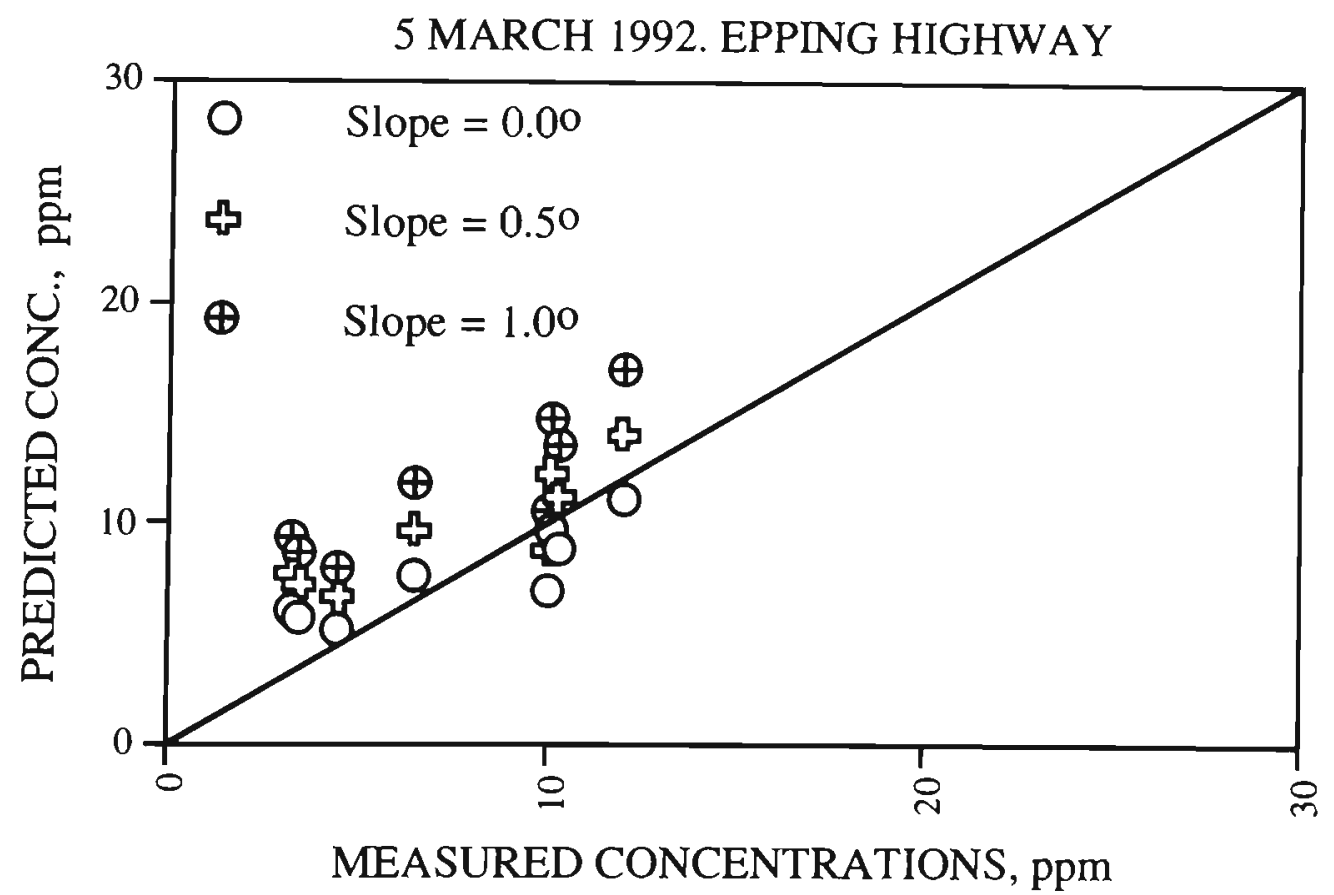

Figure 6.32 Comparison of predicted $\mathrm{CO}_{2}$ concentrations from CALINE4 model with measured values for slopes $=0.0^{\circ}, 0.5^{\circ}$, and $1.0^{\circ}$ (data for 5 March 1992 . Epping Highway. 
The Epping site is located on a major northern route where the traffic is relatively freeflowing with an incline and occasional queuing at traffic lights. The highest traffic volume is carried during the peak periods with an average percentage of heavy-duty diesel vehicles of $4 \%$. The road way in this site has six lanes and a median strip $0.8 \mathrm{~m}$ wide. Data from twenty three measurements periods (half an hour) over the four mornings (6 April 1993) are given in Tables 6.4, 6.8, 6.9, and 6.10. The experimental results for each day were compared with the modelled results from CALINE4 ( for slope $0.0^{\circ}, 0.5^{\circ}$, and $1.0^{\circ}$ ). These comparisons are given in Figures 6.25, 6.26, 6.27, $6.28,6.29,6.30,6.31$, and 6.32 .

As a number of statistical procedures have been proposed for evaluating the success or otherwise of the dispersion model predictions (Mertinez et al., 1980), the performance of the model, which may be expressed as the ratio $(\mu)$ of predicted to measured concentrations, will be used in this study. Table 6.11 show how CALINE4 performs against the previous eight-day experimental data for slopes $0.0^{\circ}, 0.5^{\circ}$, and $1^{\circ}$.

By investigating Figures 6.25-6.32 and Table 6.11, it is obvious that :

(1) the average CALINE4 performances $(\mu$ ) for Epping site (slightly-unstable conditions) varies from 0.85 to 1.00 for slope $0.0^{\circ}, 1.1$ to 1.3 for slope $0.5^{\circ}$, and 1.3 to 1.6 for slope $1.0^{\circ}$. Taking in consideration that the best prediction should occur when the wind is perpendicular to the road ( $60^{\circ}<$ wind-road angle $\leq 90^{\circ}$ ), slope $0.0^{\circ}$ is chosen for the best correlation for slightly-unstable conditions.

(2) for James Ruse Drive and Homebush sites ( neutral stability conditions), CALINE4 performances $(\mu)$ varies from 0.58 to 0.77 for slope $0.0^{\circ}, 0.76$ to 1.0 for slope $0.5^{\circ}$, and 0.9 to 1.6 for slope $1.2^{\circ}$. Also taking in consideration that the best prediction should be when the wind will perpendicular to the road ( $60^{\circ}<$ wind-road angle $\leq 90^{\circ}$ ), one may choose slope $0.5^{\circ}$ for the best correlation for neutral conditions .

(3) It is obvious that the ranges of prediction mentioned above are due to the different parameters affecting the model prediction, such as wind-road angle (see Figure 6.33), wind speed (see Figure 6.35), downwind distance (see Figure 6.34), and receptor height. The ranges of prediction mentioned above in both neutral and slightly -unstable conditions are narrow which means remarkably good model performance. 
Table 6.11. Summary of the performance of CALINE4 dispersion model against the eight-day experimental data for slopes $0.0^{\circ}, 0.5^{\circ}$, and $1.0^{\circ}$.

\begin{tabular}{|c|c|c|c|c|c|}
\hline Date & $\begin{array}{c}\theta \\
(\operatorname{deg} s) \\
\end{array}$ & $\mu$ & $\begin{array}{c}\text { WS } \\
(\mathrm{m} / \mathrm{s})\end{array}$ & $\begin{array}{l}\text { WRA } \\
\text { (degs) }\end{array}$ & STABUITY \\
\hline 6 April 93. Homebush & $\begin{array}{l}0.0 \\
0.5 \\
1.0 \\
\end{array}$ & $\begin{array}{l}0.4-1.0(0.60) \\
0.5-1.2(0.76) \\
0.6-1.5(0.90)\end{array}$ & $1.3-2.9(2.3)$ & $15-51(30)$ & Neutral \\
\hline 13 January 93 . Epping & $\begin{array}{l}0.0 \\
0.5 \\
1.0 \\
\end{array}$ & $\begin{array}{c}0.5-1.4(0.85) \\
0.7-1.8(1.1) \\
0.8-2.0(1.3) \\
\end{array}$ & $2.1-4.6(3.1)$ & $66-89(80)$ & S. unstable \\
\hline 22 September $92 . \mathrm{JRD}$ & $\begin{array}{l}0.0 \\
0.5 \\
1.0 \\
\end{array}$ & $\begin{array}{l}0.5-0.9(0.61) \\
0.6-1.2(0.80) \\
0.8-1.4(1.00)\end{array}$ & $1.2-1.7(1.4)$ & $15-35(22)$ & Neutral \\
\hline 16 June 92. JRD & $\begin{array}{l}0.0 \\
0.5 \\
1.0 \\
\end{array}$ & $\begin{array}{l}0.5-1.0(0.77) \\
0.7-1.3(1.00) \\
0.9-1.6(1.20) \\
\end{array}$ & $1.5-1.8(1.6)$ & $60-68(63)$ & Neutral \\
\hline 26 May 92. JRD & $\begin{array}{l}0.0 \\
0.5 \\
1.0 \\
\end{array}$ & $\begin{array}{l}0.3-1.0(0.58) \\
0.4-1.2(0.78) \\
0.5-1.5(0.90)\end{array}$ & $1.4-3.2(2.1)$ & $22-59(43)$ & Neutral \\
\hline 6 May 92. Epping & $\begin{array}{l}0.0 \\
0.5 \\
1.0 \\
\end{array}$ & $\begin{array}{l}0.7-1.1(0.93) \\
0.8-1.4(1.20) \\
1.0-1.7(1.40) \\
\end{array}$ & $1.3-1.9(1.2)$ & $38-49(45)$ & S. unstable \\
\hline 5 May 92. Epping & $\begin{array}{l}0.0 \\
0.5 \\
1.0 \\
\end{array}$ & $\begin{array}{l}0.6-1.3(0.92) \\
0.8-1.7(1.20) \\
1.0-2.0(1.40)\end{array}$ & $1.4-2.5(2.2)$ & $75-98(88)$ & S. unstable \\
\hline 5 March 92. Epping & $\begin{array}{l}0.0 \\
0.5 \\
1.0 \\
\end{array}$ & $\begin{array}{l}0.7-1.8(1.00) \\
0.9-2.3(1.30) \\
1.0-2.8(1.60)\end{array}$ & $2.0-2.5(2.3)$ & $79-84(80)$ & S. unstable \\
\hline
\end{tabular}

$\mu$ is the model performance (ratio of predicted to measured concentrations), WRA is the wind-road angle in degrees, $\mathrm{q}$ is the slope of the road in degrees, WS is the wind speed in $\mathrm{m} / \mathrm{s}$, and the values between parentheses are the average values. 


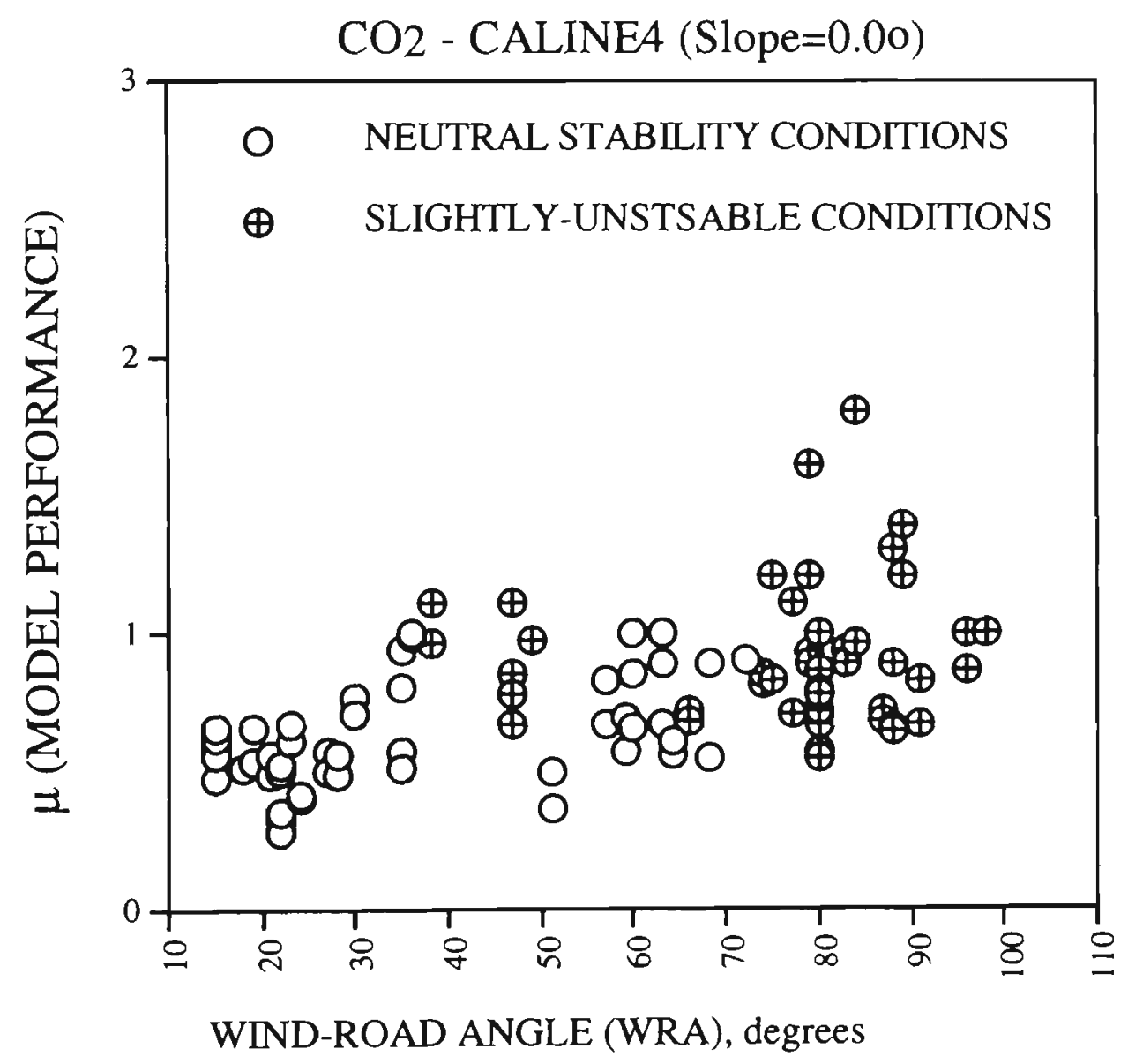

Figure 6.33 Model performance (m) versus wind-road angle for $\mathrm{CO}_{2}$ (based on calculations from CALINE4 for road slope $=0.00$ ). ( $\mu=$ predicted concentrations / measured concentrations) 


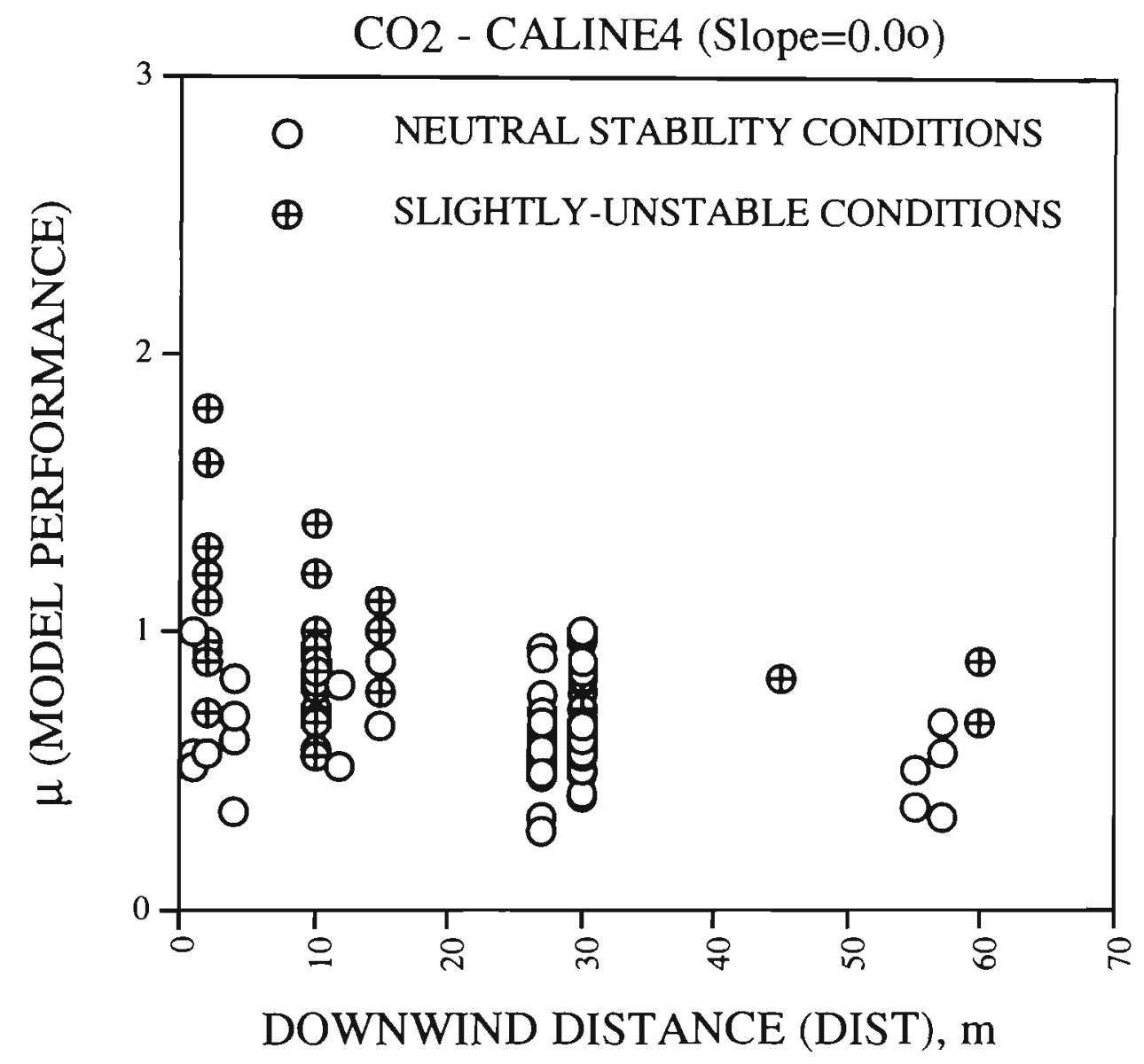

Figure 6.34 Model performance versus downwind distance for $\mathrm{CO}_{2}$ (based on calculations from CALINE4) for road slope $=0.0^{\circ}$. 


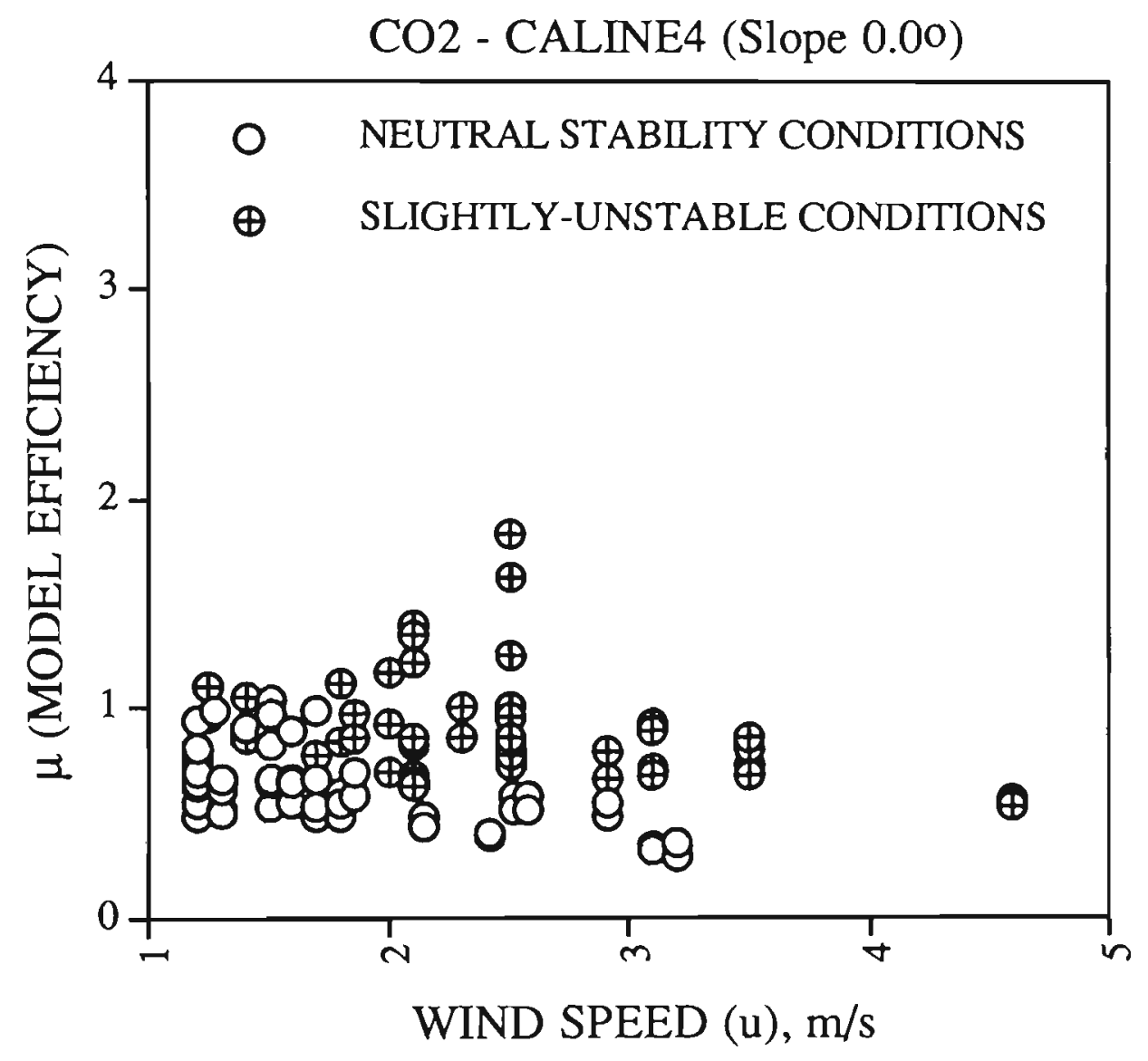

Figure 6.35 Model performance versus wind speed for $\mathrm{CO}_{2}$ for road slope $=0.0^{\circ}$. (based on calculations from CALINE4). 
It is obvious from Figure 6.33 that CALINE4 underpredicts concentrations at smaller wind-road angles $\left(<30^{\circ}\right)$. The performance improves with the increase of wind-road angles. Also, the trend shows that the model overpredicts concentrations for wind-road angles $>60^{\circ}$. Figure 6.34 shows that CALINE4 overpredicts concentrations with downwind distances close to the road because of the effect of vehicle turbulence. The model prediction improves as the downwind distance increases.

In the following part, the experimental data set for $\mathrm{CO}, \mathrm{HC}$, and $\mathrm{NO}_{\mathrm{X}}$ have been investigated. The comparison of CALINE4 predicted concentrations of $\mathrm{CO}, \mathrm{HC}$, and $\mathrm{NO}_{\mathrm{X}}$, using a slope of $1^{\mathrm{O}}$, with the experimental measurements are depicted in Figures $6.36,6.38$, and 6.40 , respectively, while the comparison of HIWAY-2 predicted concentrations of $\mathrm{CO}, \mathrm{HC}$, and $\mathrm{NO}_{\mathrm{X}}$, using a slope of $1^{\mathrm{O}}$, with the experimental measurements are depicted in Figures 6.37,6.39, and 6.41, respectively.

With regard to $\mathrm{CO}$ and $\mathrm{HC}$, the predicted difference between the slope of $0.0^{\circ}$ and $1.0^{\circ}$ is insignificant for both HIWAY-2 and CALINE4 because, as given in equations 3.11, $3.12,3.15,3.16,3.19,3.20,3.24$, and $3.25, \mathrm{CO}$ and $\mathrm{HC}$ are less dependent on the instantaneous power demands. At the same time, $\mathrm{NO}_{\mathrm{X}}$ prediction is more dependent on the instantaneous power demands as given in equations 3.13, 3.17, 3.21, and 3.26.

It is obvious from Table 6.12 and Figures 6.36 to 6.41 that for both CALINE4 and HIWAY-2, there is very good agreement for $\mathrm{CO}$ and $\mathrm{NO}_{\mathrm{X}}$ but less for $\mathrm{HC}$, which nevertheless are in the "ballpark".

Factors to be taken into account in respect of the $\mathrm{HC}$ data are that part of the $\mathrm{HC}$ emissions come from running losses, and that background levels of $\mathrm{HC}$ in the ambient air are less easy to quantify and subtract from the vehicle generated $\mathrm{HC}$. Also the data-set is less sparse.

In estimating the input exhaust emissions, the observed traffic was only divided into heavy-duty diesel vehicles and passengers/light-duty vehicles, which were lumped into the SI category, although the model could handle light-duty diesel vehicles; there was no direct estimate of what proportion of light-duty commercials were diesel. Although in practice, there is significant light-duty diesel traffic, the procedure adopted has little effect on the line emission strength. For a traffic mix of $5 \%$ heavy-duty vehicles and $5 \%$, light-duty vehicles, the $\mathrm{CO}_{2}$ and $\mathrm{NO}_{\mathrm{X}}$ emission rates varied by less than $0.5 \%$, and 
$\mathrm{CO}$ and $\mathrm{HC}$ were reduced by $3 \%$. These changes are insignificant within the normal scatter of the data.

Table 6.12 Summary of the performance of CALINEA and HIWAY-2 dispersion models against the eight-day experimental data itemised according to the stability class for slope of $\mathbf{1 . 0}^{\circ}$.

\begin{tabular}{|c|c|c|c|c|}
\hline POLLUTANT & MODEL & $\theta(\mathrm{deg})$ & $\mu$ & STABILITY \\
\hline $\mathrm{CO}$ & CALINE4 & 1.0 & $0.2-1.3(0.70)$ & Neutral \\
& CALINE4 & 1.0 & $0.3-1.6(0.90)$ & S. unstable \\
\hline \multirow{2}{*}{$\mathrm{HC}$} & CALINE4 & 1.0 & $0.4-1.9(0.90)$ & Neutral \\
& CALINE4 & 1.0 & $0.4-1.6(1.00)$ & S. unstable \\
\hline NO $_{\mathrm{X}}$ & CALINE4 & 1.0 & $0.2-2.0(0.70)$ & Neutral \\
& CALINE4 & 1.0 & $0.5-4.5(0.90)$ & S. unstable \\
\hline $\mathrm{CO}$ & HIWAY-2 & 1.0 & $0.3-1.4(0.80)$ & Neutral \\
& HIWAY-2 & 1.0 & $0.4-1.9(1.00)$ & S. unstable \\
\hline $\mathrm{HC}$ & HIWAY-2 & 1.0 & $0.6-2.2(1.20)$ & Neutral \\
& HIWAY-2 & 1.0 & $0.6-3.0(1.30)$ & S. unstable \\
\hline \multirow{2}{*}{$\mathrm{NO}_{\mathrm{x}}$} & HIWAY-2 & 1.0 & $0.4-4.5(0.90)$ & Neutral \\
& HIWAY-2 & 1.0 & $0.7-3.5(1.40)$ & S. unstable \\
\hline
\end{tabular}

$\mu$ is the model performance (ratio of predicted to measured concentrations), $\theta$ is the slope of the road in degrees, and the values between parentheses are the average values. 


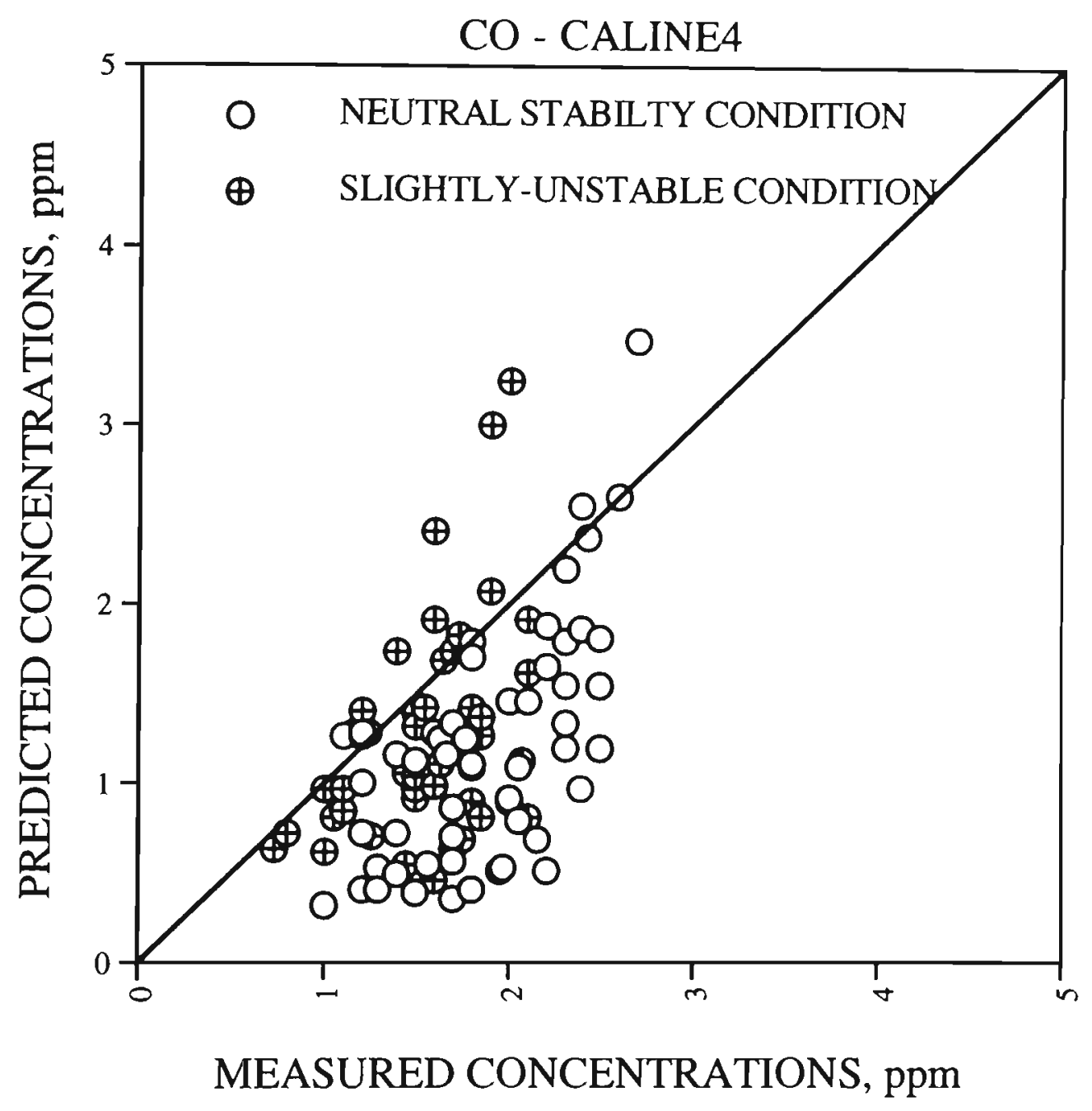

Figure 6.36 Comparison of predicted CO concentrations CALINE4 (slope = $\left.1.0^{\circ}\right)$ with measured values . 


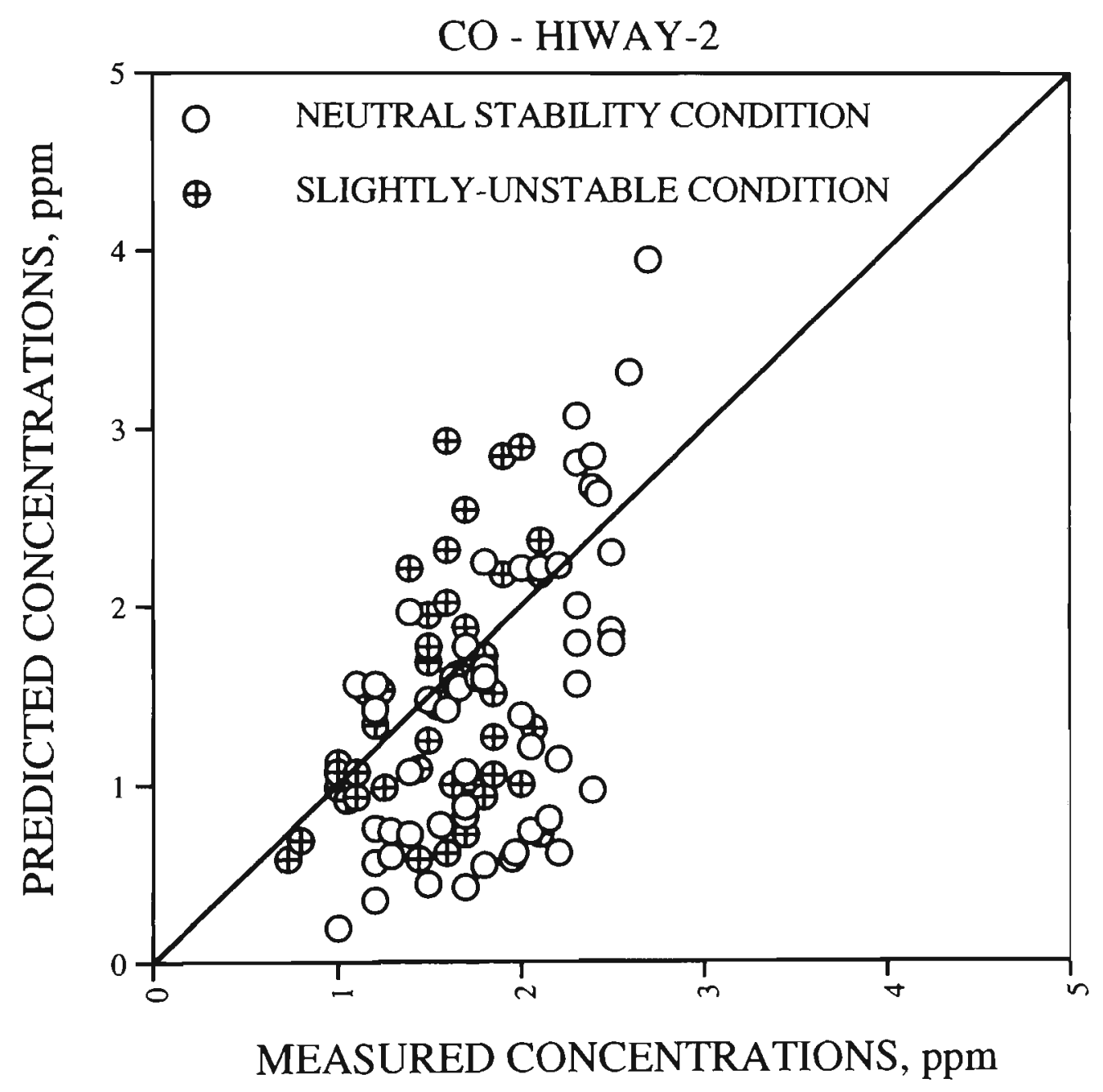

Figure 6.37 Comparison of predicted CO concentrations HWAY-2 (slope = $1.0^{\circ}$ ) with measured values (regression $r^{2}=0.238$ ). 


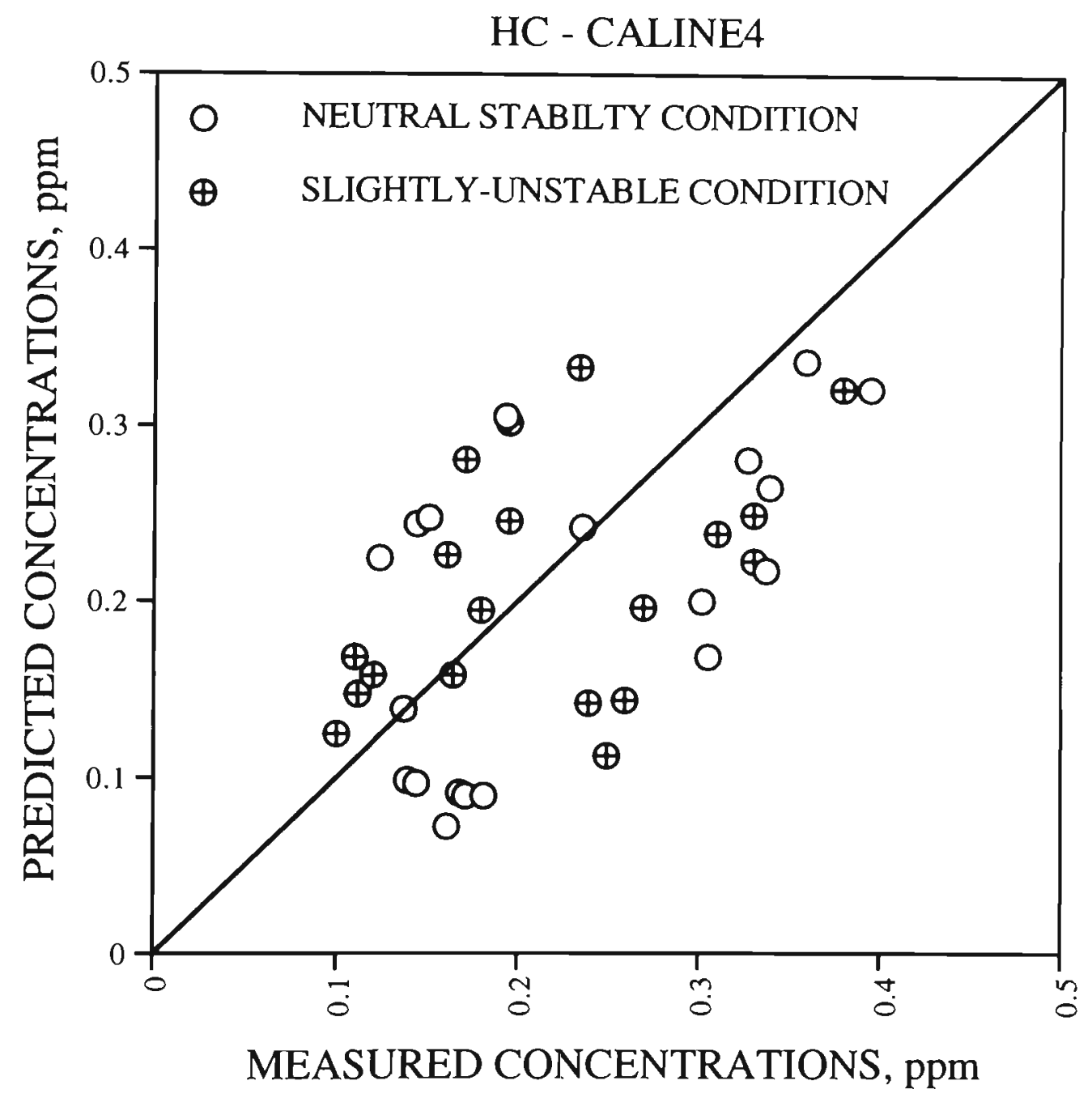

Figure 6.38 Comparison of predicted HC concentrations CALINE4 (slope = $1.0^{\circ}$ ) with measured values. 


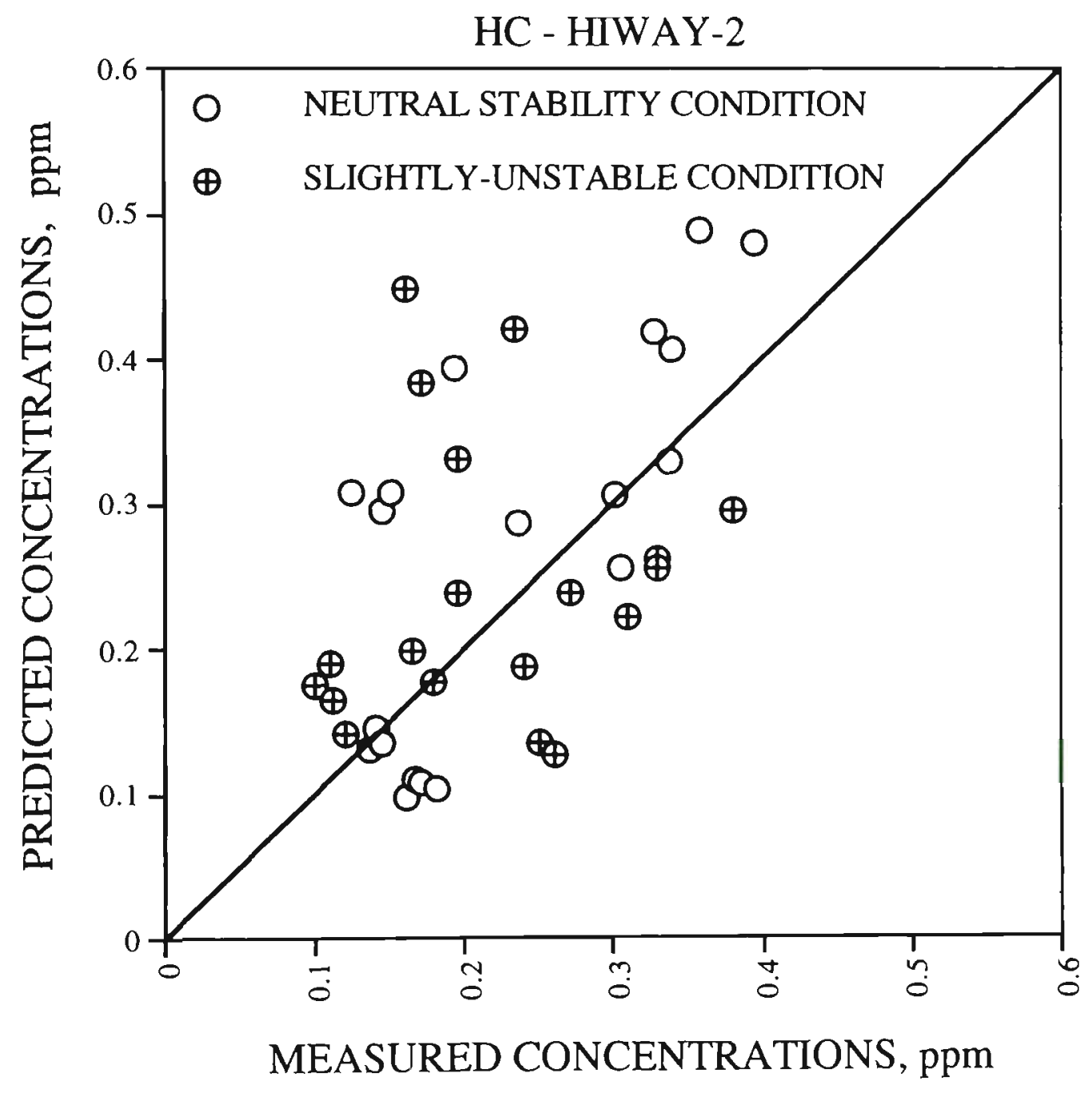

Figure 6.39 Comparison of predicted HC concentrations HIWAY-2 (slope = $\left.1.0^{0}\right)$ with measured values (regression $r^{2}=0.251$ ). 


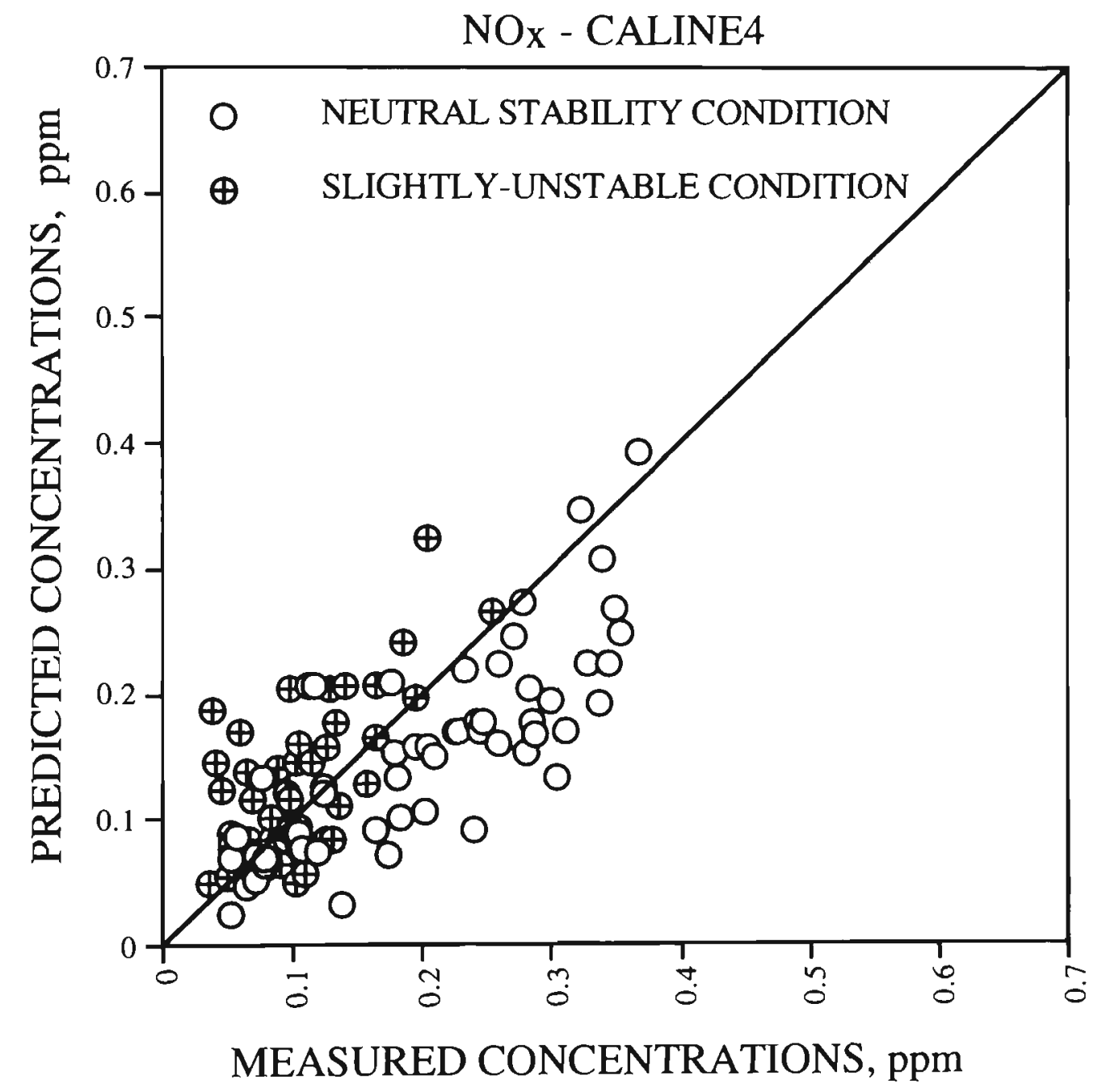

Figure 6.40 Comparison of predicted $\mathrm{NO}_{\mathbf{x}}$ concentrations from CALINE4 model (slope $=1.0^{\circ}$ ) with measured values. 


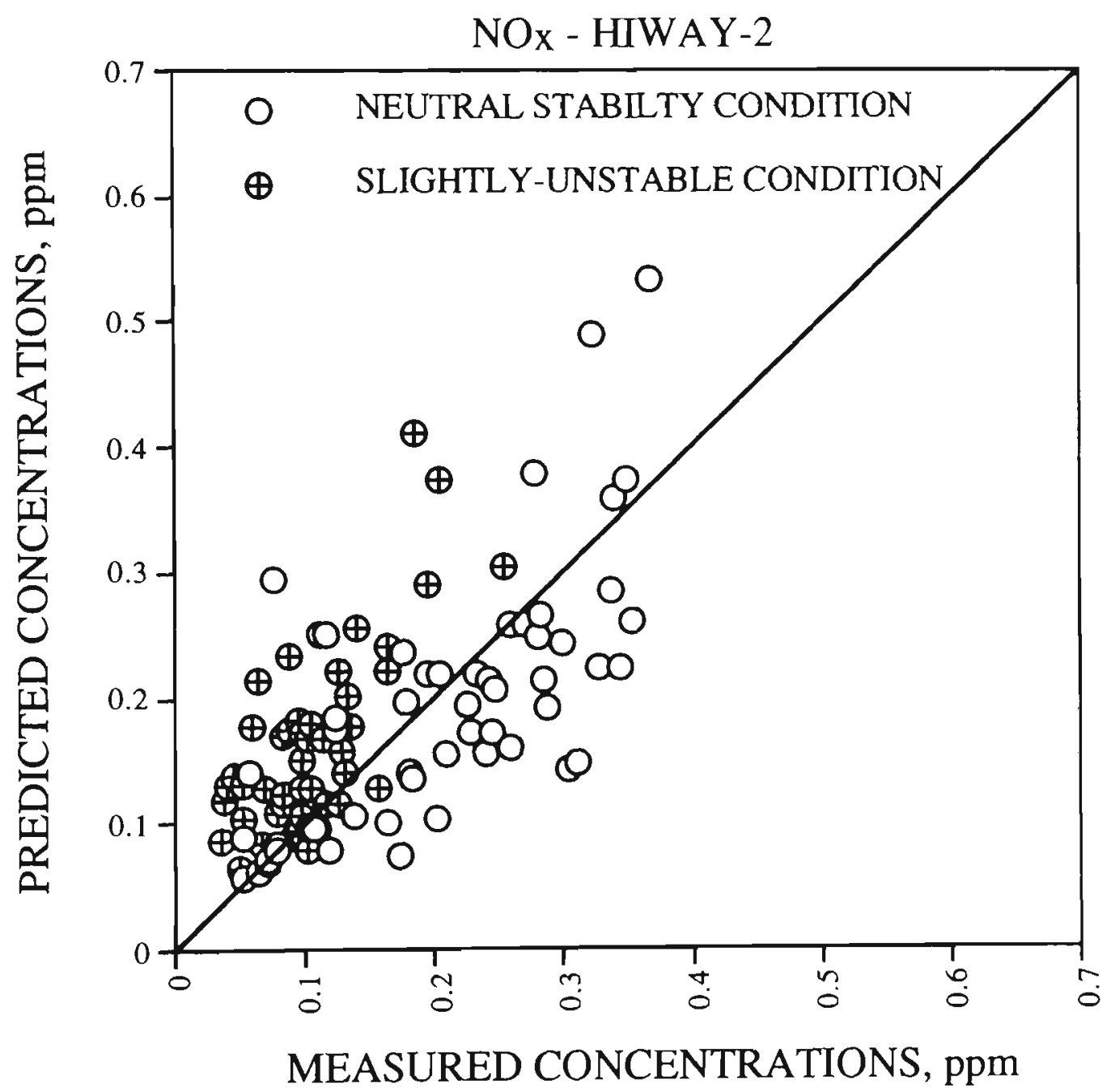

Figure 6.41 Comparison of predicted $\mathrm{NO}_{\mathrm{x}}$ concentrations from HIWAY-2 model $\left(\right.$ slope $\left.=1.0^{\circ}\right)$ with measured values (regression $r^{2}=0.493$ ). 


\section{CHAPTER 7}

\section{SUMMARY AND CONCLUSIONS}

1. A power-based exhaust emissions model has been developed (Chapter 3. section 3.2) using the approach developed by Post et al., (1981) and Kent et al., (1982). Estimates of fuel consumption and exhaust emission rates of carbon monoxide (CO), hydrocarbon $(\mathrm{HC})$, and the oxides of nitrogen $\left(\mathrm{NO}_{\mathrm{X}}\right)$ from spark ignition (both leaded and unleaded-fuelled) and diesel vehicles have been developed by considering the instantaneous power requirements .

2. The power-based emissions model has also the capability to estimate the excess carbon dioxide ( $\mathrm{CO}_{2}$ ) emissions from spark ignition (both leaded and unleaded-fuelled) and diesel vehicles (Chapter 3, section 3.2).

3. The power-based emissions model has been validated against ADR27 and ADR37 drive cycle emissions data of Williams et al., 1979 (for pre-1986 spark ignition leaded vehicles and light-duty diesel vehicles), SPCC, 1989 (for post-1986 spark ignition unleaded vehicles), and against a Victorian methodology (Camovale et al., 1991) based on high resolution analysis of ADR27 test results (for pre-1986 spark ignition leaded vehicles and for post-1986 spark ignition unleaded vehicles (see Chapter 5).

4. The power-based emissions model, in conjunction with two traffic pollution dispersion models, CALINE4 and HIWAY-2, has been tested against eight-day field measurements of concentrations of $\mathrm{CO}_{2}, \mathrm{CO}, \mathrm{HC}$, and $\mathrm{NO}_{\mathrm{X}}$ made near arterial roads covering different traffic situations, and meteorological conditions, and has been shown to provide good estimates of the concentrations of these species (see Chapter 6)". It is demonstrated that an arbitrary road slope can be used to account for the combination of non-zero slope and random vehicle acceleration manoeuvres.

5. The power-based emissions model was used to predicting fuel consumption intraffic. The predicted and measured fuel consumption of seven experimental trips carried out in Sydney using CSIRO instrumented vehicle were compared. The predicted fuel consumption were estimated over the duration of every trip taking into account the acceleration-deceleration manoeuvres, the road gradient, the effect of the aerodynamic drag over the period of the trips. The comparison of the predicted and 
measured fuel consumption of the seven experimental trips shows that the power-based emissions model provides good estimates of the fuel consumption in urban traffic situations (see Chapter 5, section 5.2.1.2).

6. The power-based emissions model produces curves for $\mathrm{CO}, \mathrm{HC}$, and $\mathrm{NO}_{\mathrm{x}}$ emission rates (at slope $0^{\circ}$ ) for spark ignition and diesel vehicles similar to those produced by the US-EPA EMFAC7F (Chapter 3, section 3.6) .

7. The advantages of the power-based emissions model, over models based on drive cycles with various adjustment factors, are the capabilities of the model to account for the road gradients, acceleration-deceleration manoeuvres, and wind-road angles which have clear effects on emissions levels ( see Appendix D).

It is demonstrated that any reasonably formulated Gaussian dispersion model such as CALINE4 or HIWAY-2 will be likely to give accurate results when used in estimating pollutant concentrations generated by arterial roads, if correct emission strengths are input into such models. In the case of the Sydney metropolitan region, which has a hilly topography, it is recommended that a more physically based-model, capable of incorporating slopes and other acceleration manoeuvres be used in such circumstances.

The performance of the power-based emissions model over a drive cycle model such as ADR27A provides good estimates of fuel consumption and exhaust emissions and also, in conjunction with dispersion models such as CALINE4 or HIWAY-2, good estimates of pollutant concentrations near arterial roads. The model also provides good estimates for the fuel consumption in urban traffic situations. There is still some fine tuning to be carried out, particularly in respect of on-road diesel emissions.

Future research work should include the extension of the model to

(1) estimation of the lead emissions from pre-1986 spark ignition vehicles which account for about $40 \%$ of the current NSW fleet.

(2) estimation of the emissions of elemental or sooty carbon particulates emitted from light and heavy-duty diesel vehicles. Such emissions need to be estimated, as light and heavy-duty diesel vehicles account for about $15 \%$ of the current NSW fleet. 
(3) development of an estimate of the emission rates of hydrocarbon evaporative emissions for the Australian fleet. 


\section{REFERENCES}

Allen R.W., Clively S.R., and Tilley J.W. 1990. Global greenhouse and energy situation and outlook. Greenhouse and coal. Greenhouse and Energy. CSIRO Publications, Melbourne, Victoria, Australia.

Benson, P. E. 1979. CALINE3 - A Versatile Dispersion Model for Predicting Air Pollution Levels Near Highways and Arterial Street. Federal Highway Administration, Washington, D.C.

Benson, P. E. 1984. CALINE4 - A Dispersion Model for Predicting Air Pollution Levels Near Roadways. Report No. FHWA/CA/TL-84/15, California Department of Transportation, Sacramento, CA.

Best P.R., Kanowski M., Stumer L., and Green D. 1986. Convection dispersion modelling utilising acoustic sounder information. Atoms. Res., 20:173.

Boden T.A., Kanciruk P., and Farrell M.P. 1990. Trends '90: A compendium of data on global change, ORNL/CDIAC-36, Carbon Dioxide Information Analysis Centre, Oak Ridge, TN, US.

BP. 1990. BP statistical review of world energy, London, UK, PB Corporate Communications Services.

Braddock N.B. and Perry K.P. 1986. Gaseous and Particulate Emissions from Gasoline- and Diesel-powered Heavy-Duty Trucks. SAE 860617. The Society of Automotive Engineers.

Briggs G.A. 1973. Diffusion Estimation for Small Emissions, ATDL Contribution File No. 79, Atmospheric Turbulence and Diffusion Laboratory.

Bureau of Transport and Communications Economics. 1993. Australian Transport Statistics In Brief.

Busch, N.E. 1973. On the mechanics of atmospheric turbulence. In: Workshop on Micro meteorology, D A. Haugen, Ed., Amer. Meteor. Soc. pp. 1-61.

Cadle S.H., Gorse R.A., and Lawson D.R. 1993. Real-world vehicle emissions - a summary of the third annual CRC-APRAC on-road vehicle emissions workshop. Air and Waste, 43, 1084-1090. 
Cafe A., Stern W., and Young B. 1993. Air Quality Assessment Southern Arterial Stage 3 Environmental Impact Statement. University of Technology, Sydney.

California Air Resources Board.1993. Methodology for estimating emissions from onroad motor vehicles (EMFAC7, Weight (E\&FWT), and BURDEN7F). Technical Support Division.

Carnovale F., Carvalho C., Summers M., and Eriksen P. 1993. MAQS CONSULTANCY - EMISSIONS INVENTORY. Progress Report. EPA (Victoria).

Carnovale F., Alviano P., Carvalho C., Deitch G., Jiang S., Macaulay D., and Summers M. 1991. Air emissions inventory Port Phillip Control Region. Report of the EPA (Victoria) SRS 91/001.

Carras J.N., and Williams D.J. 1992. Behaviour of the power station plumes in the Hunter Valley/Central Coast region. Investigation Report CET/IR 106 CSIRO, Division of Coal and Energy Technology, North Ryde Laboratory.

Carras J.N., Ross G., Sawford B., and Simpson R. 1989. Methods of source-receptor modelling for air quality applications. Air pollution from energy industries. Ed. A. Jakeman, CRES, The Australian National University.

Chock, D.P. 1977. General Motors Sulfate Dispersion Experiment: Assessment of the EPA HIWAY Model. Air Pollution Control Assoc. pp. 39-54.

Chock, D.P. 1978. A simple line-source model for dispersion near roadways. Atmos. Environment 12. pp.823-829.

Cochran L.S. and Pielke R.A. 1992. Selected International Receptor-Based Air Quality Standards. Air Waste Manage. Assoc. Vol 42, No. 12, pp. 1567-1572.

CONCAWE. 1986. The relationship between automotive diesel fuel characteristics and engine performance. The Hauge (Report No. 86/65).

DeMarrais G.A. 1978. Atmospheric stability class determination on a 481-meter tower in Oklahoma. Atmos. Environment, 12, 1957-1964.

Draxler R.R. 1976. Determination of atmospheric diffusion parameters. Atmos. Environment, 10, 99-105. 
EPA of Victoria 1979. Draft State Environment Protection Policy for the Air Environment of Victoria and Explanatory Document.

Eskridge R.E. and Catalano J.A. 1987. ROADWAY: A numerical model for predicting air pollution near highways: User's Guide. U.S. Environmental Protection Agency report No. EPA 68-024106, Research Triangle Park, NC, 125pp.

Eskridge, R.E. and J.C.R. Hunt. 1979. Highway modelling. Part 1: Prediction of velocity and turbulence fields in the wakes of vehicles. J. Appl. Meteor. 18: 387400.

Eskridge, R.E. and R.S. Thompson. 1982. Experimental and theoretical study of the wake of a block-shaped vehicle in a shear-free boundary flow. Atmos. Environment Vol 16, pp. $2821-2836$.

Eskridge, R.E. and S.T. Rao. 1983, "Measurement and prediction of traflic-induced turbulence fields near roadways," J. Appl. Meteor. 22: 1431-1443.

Eskridge, R.E. and S.T. Tao. 1988. Turbulent diffusion behind vehicles: experimentally determined turbulence mixing parameters. Atmos. Environment Vol 20, pp. 851-860.

Forrest W. 1991. Air quality trends and air pollution control initiatives. Proceeding of The New South Wales Government Summit on Air Quality.

Fox D.G. 1984. Uncertainty in air quality modelling. Bull. Amer. Met. Soc. 65 p27- 36.

Gifford F.A. 1961. Use of Routine Meteorological Observations foe Estimating Atmospheric Dispersion. Nucl. Saf., 2(4): 47-57.

Gifford F.A. 1968. An Outline of Theories of Diffusion in the Lower Layer of Atmosphere. in Meteorology and Atomic Energy - 1968, pp. 66-116.

Gifford F.A. 1976. Turbulent Diffusion Typing Scheme - A Review, Nucl. Saf., 17: 6886.

Gronskei, K. E. 1988. The influence of car speed on dispersion of exhaust gases. Atmos. Environment Vol 22, pp. 273-281.

Guensler R., Washington S., Koenig B. and Sperling D. 1993. The impact of speed correction factor uncertainty on mobile source emission inventories in the South Coast. 
Proc. Int. Speciality Conf. "The Emission Inventory - Perception and Reality", Pasadena, California, Oct. 18-20. Air and Waste Management Assoc.

Hanna S.R., Briggs G.A., and Hosker R.P. 1982. Handbook on Atmospheric Diffusion. Technical Information Centre, U. S. Department of Energy.

Irwin J.S. 1979. Estimating Plume Dispersion - A Recommended Generalised Scheme. in preprints of Fourth Symposium on Turbulence, Diffusion, and Air Pollution, Reno, Nev., Jan. 15-18. American Meteorological Society, Boston, Mass.

Irwin J.S. 1980. Dispersion estimates suggestion \#9: Processing of wind data. U.S. EPA Docket Reference No. II-B-33, Research Triangle Park, North Califomia.

Kent, J.H. and Mudford, N.R. 1978. Sydney driving patterns and automotive emission modelling. Charles Kolling Research Lab., UNSW Tech. Rep. ER-26.

Kent, J.H., K. Post, J.A. Tomlin. 1982. Second Conference on Traffic, Energy and Emissions, 19-20 May 1982 at the National Science Centre, Melbourne.

Marks R.E. and Swan P.L. 1990. Abatement: global action, Australian road transport, and macro economic costs. Greenhouse and coal. Greenhouse and Energy, CSIRO Publications, Melbourne, Victoria, Australia.

OECD/IEA. 1989. Energy policies and programs of IEA countries 1988 review. OECD, Paris.

OECD. 1993. Control of emissions from heavy-duty vehicles. Organisation for Economic Co-Operation and Development, Paris, France. OECD Environment Monographs No. 55.

Pasquill F. 1961. The Estimation of The Dispersion of Windborne Material, Meteorol. Mag., 90: 33-49

Pasquill F. 1974. Atmospheric Diffusion, Second Edition.John Wiley \& Sons, NY.

Pasquill F. 1975. The Dispersion of materials in the Atmospheric Boundary Layer. The basis for Generalisation. in Lectures on air pollution and Environmental Impact Analyses, pp. 1-34, American Meteorological Society, Boston, Mass. 
Pasquill F. 1976. Atmospheric dispersion parameters in Gaussian plume modelling. Part 2 , Possible requirements for change in the Turner Workbook values. U.S. EPA Document EPA-600/4-76-030b, Washington, D.C.

Pearman, G.I. 1990. The greenhouse effect - interfacing science and policy. Search, 21, 59-65.

Petersen, W. B. 1980. User's Guide for HIWAY-2, A Highway Air Pollution Model. EPA 600/8-80-018, U.S. Environmental Protection Agency, Research Triangle Park, NC, 1980.

Post, K., J.A. Tomlin, D. Pitt, N. Carruthers, A. Maunder, T. Gibson, J.H. Kent, and R.W. Bilger, 1981. Fuel Consumption and Emissions Research Annual Report by the University of Sydney for 1980-81 Charles Kolling Research Laboratory Technical Note ER 36.

Rao, S.T. and M.T. Keenan. 1980: Suggestions for improvement of the EPA-HIWAY model. JAPCA 30: 247-256.

Richardson A.J. 1982. Stop-start fuel consumption rates. Second Conference on Traffic, Energy and Emissions, 19-20 May 1982 at the National Science Centre, Melbourne.

Robinson N.F., Pierson W.R. and Gerler A.W. 1993. Comparison of real world CO, $\mathrm{HC}$ and $\mathrm{NO}_{\mathrm{X}}$ emission rates with motor vehicle emission models. Proc. Int. Speciality Conf. " The Emission Inventory - Perception and Reality", Pasadena, Califomia, Oct. 18-20. Air and Waste Management Assoc.

Scheepers PTJ \& Bos RP. 1992b. Combustion of diesel fuel from a toxicological perspective. I. Origin of incomplete combustion products. Int Arch Occp Environ Health, 64: $149-161$.

Seinfeld J.H., 1975. Air pollution: physical and chemical fundamentals. Mc Graw-Hill, New York.

Seinfeld J.H., 1986. Atmospheric Chemistry and Physics of Air Pollution. Willey, New York.

Sistla G., Samson P., Keenen M., and Rao S. 1978. A Study of Pollutant Dispersion Near Highways. Atrnos. Environment Vol. 13, pp. 669-685. 
Smith F.B. 1972. A Scheme for Estimating the Vertical Dispersion of a Plume from a Source near Ground Level. in Proc. of the Third Meeting of the Expert Panel on Air Pollution Modelling, Report NATO-CCMS-14, North Atlantic Treaty Organisation. Brussels.

Smith I.M. 1991. Greenhouse gases, abatement and control: the role of coal. IEACR39/1991. IEA Coal Research, United Kingdom.

Smith M.E. 1968. Recommended guide for the prediction of the dispersion of airborne effluents. 1st edition. American Society of Mechanical Engineers, NY.

SPCC 1989. Annual Report 1988/89. State Pollution Control Commission of New South Wales.

Sullivan, K.M. 1990. Greenhouse and coal. Greenhouse and Energy, CSIRO Publications, Melbourne, Victoria, Australia.

Sutton O.G. 1932. A Theory of Eddy Diffusion in the Atmosphere, Proc. R. Soc. (London), Ser. A, 135-143.

Taylor M.A.P. and Anderson M. 1982. Modelling pollution and energy use in urban road networks. Proc. 11 th ARRB Conf. 11(6), pp. 1-17

Taylor M.A.P. and Young W. 1988. Traffic Analysis : New Technology and New Solutions. Hargreen Publishing Co., Melboume.

The Australian Standard AS 2077-1982. Methods Of Test For Fuel Consumption Of Passenger Cars, Their Derivatives And Multi-purpose Passengers Cars.

Turner D.B. 1970. Workbook of atmospheric dispersion estimates. U. S. Department of Health, Education, and Welfare.

Verein Deutscher Kohlenimporteure 1990. Annual report 1989. Hamburge, Germany.

Watkins L.H. 1991. State of the art review / 1 - Air pollution from road vehicles. Transport and Road Research Laboratory - Department of Transport, London.

Watson I.D. November 1983. Line-Source Model Predictions of Carbon Monoxide Concentrations in Sydney. Clean Air 
Weil J.C., Sykes R.I. and Venkatram A. 1992. Evaluating air quality models: review and outlook. J. Appl. Met., 31, p 1121-1145.

Williams D.J., Carras J.N., Drummond M.S., Lange A.L., and Shenouda D.A. 1993. Interim Report to the Road and Traffic Authority (RTA) on air pollution near arterial roads and highways. Investigation Report CET/IR184.

Williams D.J., Carras J.N., Shenouda D.A., Drummond M.S., and Lang A.L. March 1994. Final Report to the RTA on Traffic Generated Pollution Near Roads and Highways. Investigation Report CET/ IR238 CSIRO, Division of Coal and Energy Technology, North Ryde Laboratory.

Williams, D.J., Milne, J.W., Roberts, D.B. and Kimberlee, M.C. 1989. Particle emissions from 'in-use' motor vehicles - I. Spark ignition vehicles. Atrnos. Environment 2639-2646.

Williams, D.J., Milne, J.W., Roberts, D.B. and Kimberlee, M.C. 1989. Particle emissions from 'in-use' motor vehicles - II. Diesel vehicles. Atrnos. Environment $2647-$ 2662.

World Resources Institute. 1990. World resources 1990-1991. New York, NY, USA, Oxford University Press.

Zannetti, P. 1990. Air pollution modelling: theories, computational methods, and available software. Computational Mechanics Publications, Boston. 


\section{APPENDIX A}

\section{GREENHOUSE GASES}

During the late 1970 s and 1980s a considerable developments occurred in the understanding of global atmospheric chemistry. By the mid 1980s it was clear that. in addition to the well researched gas $\mathrm{CO}_{2}$, several other gases that are active in the atmosphere, the so called greenhouse gases, were steadily increasing in concentrations. These gases are responsible for the possible future global climate change, including increases in surlace air temperature and sea level.

If global warning and associated climate changes are to occur in the future then the cause is man. During this century the world's population increased from 1.6 billion to over 5 billion people and it is estimated it will exceed 6 billion by the end of this century. The expanding population has been demanding of increased goods, scrvices, and general conditions associated with an improving lilestyle. This demand has resulted in increasing the world energy consumption by approximately $20 \%$ over the last len ycars. from 9610 Mtce in 1980 to 11440 Mtce (million tonnes of coal equivalent) in 1989. Between 1980 and 1989 coal provided 27-28\% of the energy demand, oil decreased slightly from $45 \%$ in $198(1)$ to $38 \%$ in 1989 , and gas increased liom $19 \%$, $22 \%$ over lli same period (see Figure A.1).

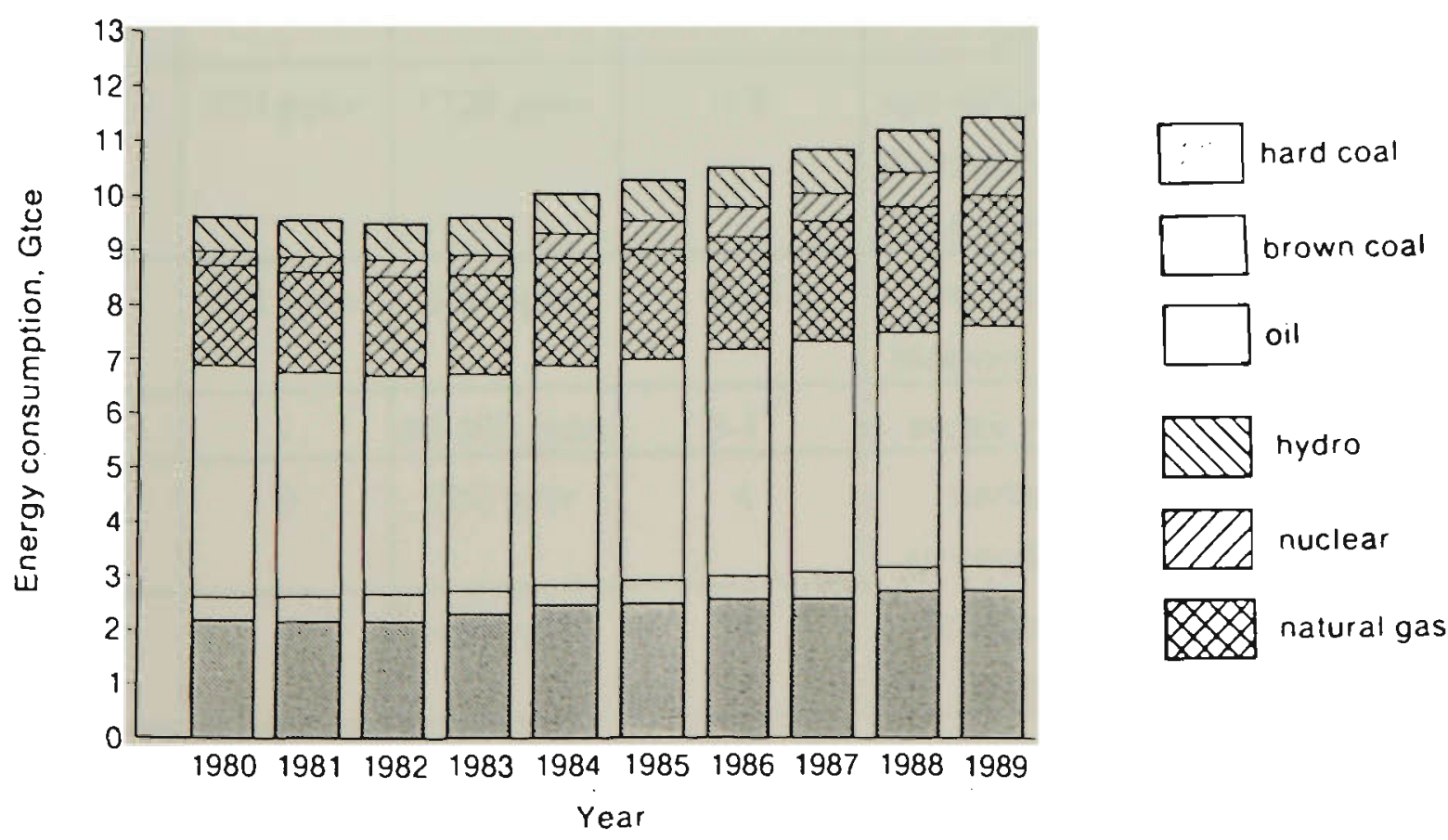

Figure A.1 World primary energy consumption (BP, 1990; Verein Deutscher Kohlenimporteure, 1990; Smith, 1991). 
Man can only survive with the aid of agriculture and energy, whilst lifestyle is considerably enhanced by the use of many other commodities, most of which give rise to various gases emissions entering the atmosphere, some are radiatively active. These greenhouse gases are principally carbon dioxide, methane, nitrous oxides, ozone, and the recently introduced chlorofluorocarbons. The pre-industrial and recent concentrations, rate of increase, and principal sources of greenhouse gases in atmosphere are summarised in Table A.1.

Table A.1 A summary of greenhouse gases including principal source and the percentage contribution based on temperature rise potential (Source: Pearman, 1990; Sullivan, 1990; Smith, 1991).

\begin{tabular}{|c|c|c|c|c|c|}
\hline \multirow{2}{*}{$\begin{array}{c}\text { greenhouse } \\
\text { gas }\end{array}$} & \multicolumn{2}{|c|}{ concentrations } & \multirow{2}{*}{$\begin{array}{c}\text { percent trend } \\
\text { (\% per } y)\end{array}$} & \multirow{2}{*}{$\begin{array}{l}\text { principal } \\
\text { source }\end{array}$} & \multirow{2}{*}{$\begin{array}{l}\text { percentage } \\
\text { contribution }\end{array}$} \\
\hline & $\begin{array}{c}\text { Pre-indust } \\
\text { (1850) }\end{array}$ & $\begin{array}{l}\text { Current } \\
\text { (1990) }\end{array}$ & & & \\
\hline $\mathrm{CO}_{2}$ & 275 ppmv & 353 ppmv & 0.4 & $\begin{array}{c}\text { deforestation and } \\
\text { land use } \\
\text { petroleum } \\
\text { coal } \\
\text { natural gas } \\
\text { other fuel } \\
\text { total }\end{array}$ & $\begin{array}{c}15 \pm 5 \% \\
14 \pm 2 \% \\
10 \pm 1 \% \\
5 \pm 1 \% \\
6 \pm 1 \% \\
50 \%\end{array}$ \\
\hline $\mathrm{CH}_{4}$ & $750 \mathrm{ppbv}$ & $1720 \mathrm{ppbv}$ & 0.8 & $\begin{array}{c}\text { agriculture, cattle, } \\
\text { biomass burning, } \\
\text { and natural gas }\end{array}$ & $15 \pm 5 \%$ \\
\hline $\mathrm{N}_{2} \mathrm{O}$ & $288 \mathrm{ppbv}$ & 310 ppbv & 0.25 & $\begin{array}{c}\text { fertilisers and } \\
\text { biomass burning }\end{array}$ & $7 \pm 3 \%$ \\
\hline $\mathrm{O} 3$ & - & 20-100 ppbv & $0-1^{*}$ & motor vehicles & $7 \pm 3 \%$ \\
\hline CFC-11 & 0 & $280 \mathrm{pptv}$ & 4 & $\begin{array}{l}\text { aerosols, } \\
\text { air conditioners, }\end{array}$ & $20 \pm 6 \%$ \\
\hline $\mathrm{CFC}-12$ & 0 & 484 pptv & 4 & $\begin{array}{c}\text { refrigeration, } \\
\text { plastics }\end{array}$ & \\
\hline
\end{tabular}

* northern hemisphere only

Measurements undertaken at a number of international baseline monitoring stations have shown over recent years that the concentrations of greenhouse gases is increasing in the troposphere, $\mathrm{CO}_{2}$ is increasing at about 0.4 percent per annum, $\mathrm{CH}_{4}$ at about 0.8 percent per annum, nitrous oxides at about 0.25 percent and the chlorofluorocarbons at about 4 
percent per annum (see Table A.1). It is obvious from Table A. 1 that $\mathrm{CO}_{2}$ is the largest contributor to greenhouse gases entering the atmosphere.

The $\mathrm{CO}_{2}$ component entering the atmosphere, apart from coming from the natural sources, which represent the vast majority of annual carbon flux, also occurs as a result of deforestation and the combustion of fossil fuels ( $\mathrm{CO}_{2}$ emissions occur as a result ni all combustion processes from both mobile and stationary sources using liquid, gaseous, and solid fuels). The trends in global emissions of CO2 from lossil fuels and other sources from 1950 t0 1990) are given in Figure A.2. The data are divided into solids, liquids, gases, gas flaring and cement. The solids category includes all hard and brown coals and their product; the liquid category includes crude petroleum and its products. the gases, coal and coke oven gas as well as natural gas. Also, the trends in global $\mathrm{CO}_{2}$ emissions, when expressed per head of population, show that the rate of increase of $\mathrm{CO}_{2}$ is growing slightly faster than the global populations (see Figure A.2).
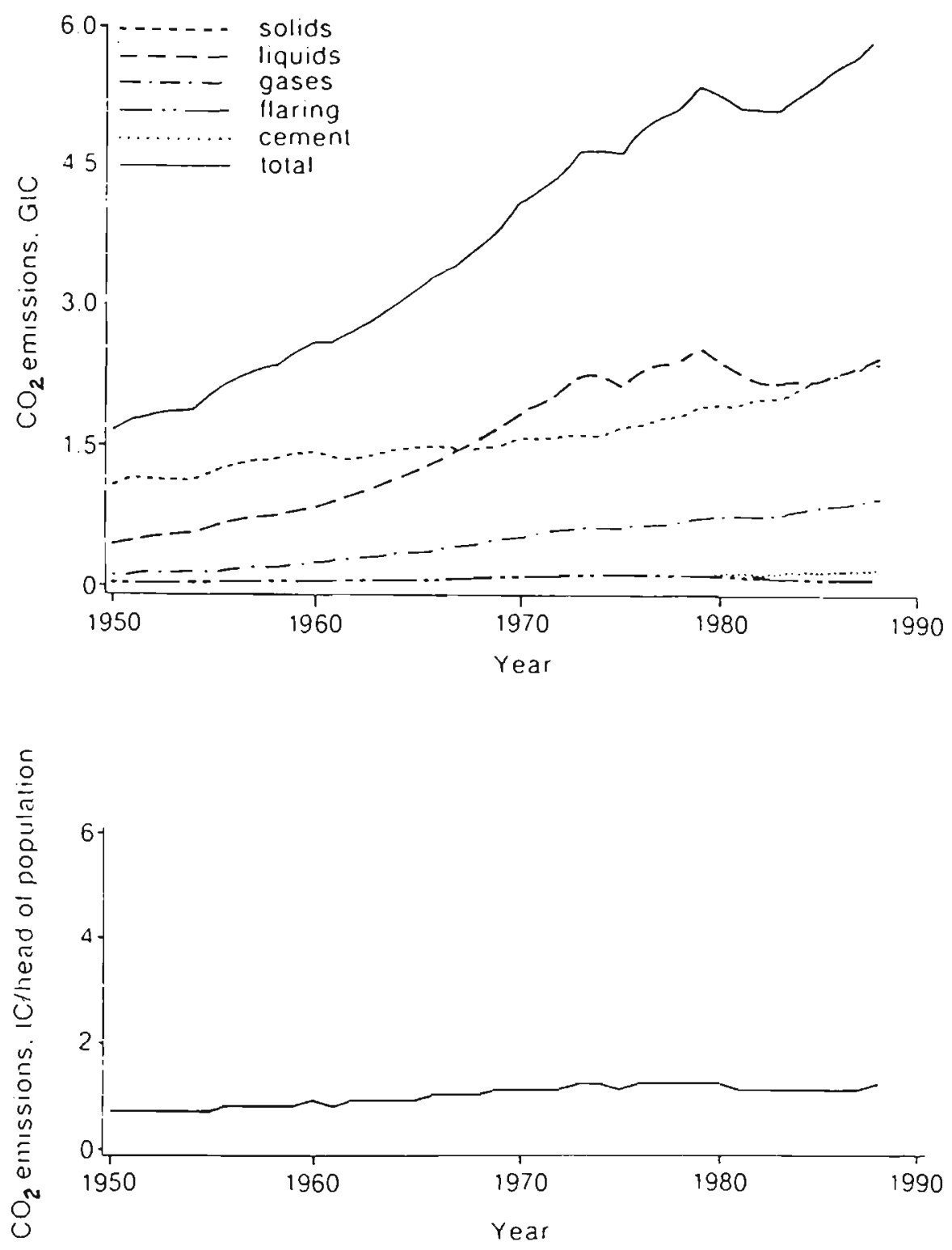

Figure A.2 Trends in global carbon dioxide emissions (Source: Boden et al., 1990; Smith, 1991). 
The World Resource Institute (WRI, 1990) estimated the annual total $\mathrm{CO}_{2}$ emissions from human activities for 1988 in the range of $6.5-8.5 \mathrm{Gtc} / \mathrm{y}$ (gigatonnes carbon/year). The estimate showed that coal, oil, and deforestaion sectors were each major contributors to global $\mathrm{CO}_{2}$ emissions (the contribution of coal, oil, and deforestaion were $27.1 \%$, $27.1 \%$, and $33 \%$, respectively, of the global $\mathrm{CO}_{2}$ emissions). Sullivan, 1990 estimated the contribution of the motor vehicles to be in the range of $12 \pm 3 \%$ of the global $\mathrm{CO}_{2}$ emissions.

In Australia, the recent energy-balance figures for 1987/88 show that the transport sector generated $74.9 \mathrm{Mt} / \mathrm{y}$ of $\mathrm{CO}_{2}$ emissions, $28.5 \%$ of total emissions from fossil fuels. ABARE (1989) figures show that road transport fuel consumption was $79.3 \%$ of total transport fuel consumption of $959.9 \mathrm{PJ} / \mathrm{y}$ (petajoule per year) in 1987/88 (see Table A.2).

Table A.2 Estimated direct and indirect emissions of Australia's $\mathrm{CO}_{2}$ (Mt/y) by end use sector and by fossil fuels - 1987/88 (Source: Marks and Swan, 1990)

\begin{tabular}{|c|c|c|c|c|c|c|c|}
\hline Sector & $\begin{array}{c}\text { Black } \\
\text { Coal }\end{array}$ & $\begin{array}{c}\text { Brown } \\
\text { Coal }\end{array}$ & $\begin{array}{c}\text { Petroleum } \\
\text { Products }\end{array}$ & $\begin{array}{c}\text { Natural } \\
\text { Gas }\end{array}$ & Electricity & $\begin{array}{c}\text { Grand } \\
\text { Total }\end{array}$ & $\begin{array}{c}\text { Share } \\
(\%)\end{array}$ \\
\hline $\begin{array}{c}\text { Agriculture and } \\
\text { Mining }\end{array}$ & 0.7 & 0.0 & 5.8 & 4.1 & 9.1 & 19.7 & 7.5 \\
\hline Industry & 21.8 & 1.3 & 11.1 & 17.2 & 47.5 & 98.9 & 37.7 \\
\hline Transport & 0.4 & 0.0 & 73.0 & 0.0 & 1.5 & 74.9 & 28.5 \\
\hline Commercial & 0.5 & 0.2 & 0.8 & 1.8 & 23.5 & 26.8 & 10.2 \\
\hline Residential & 0.1 & 0.0 & 1.3 & 4.8 & 35.9 & 42.1 & 16.0 \\
\hline Total direct & 23.5 & 1.5 & 92.0 & 27.9 & 117.4 & 262.4 & 100.0 \\
\hline Electricity & 69.2 & 38.3 & 1.7 & 8.3 & & & \\
\hline Grand total & 92.7 & 39.8 & 93.7 & 36.2 & & & \\
\hline Share (\%) & 35 & 15 & 35 & 14 & & & \\
\hline
\end{tabular}

International Energy Agency (IEA) estimated that world primary energy requirements increased 29 percent in the last 15 years from about 5923 Mtoe (megatons oil equivalent) in 1973 to 7654 Mtoe in 1987. The recent International Energy Agency (IEA) forecasts indicate that, in the absence of any major policy changes addressing the greenhouse problem, world primary energy requirements are expected to grow 54 percent in the next 15 years from about 7654 Mtoe (megatons oil equivalent) in 1987 to 118820 Mtoe in 2005 (Allen et al., 1990). 
The energy requirements for the transport sector increased 24 percent in the last 15 years from about 787 Mtoe (megatons oil equivalent) in 1973 to 787 Mtoe in 1987 (see Table A.3). According to the IEA forecasts for the next 15 years, it is expected that the energy requirements for the transport sector trends are likely to increase, resulting in increases in the transport share of global $\mathrm{CO}_{2}$ emissions.

Table A.3 Energy transformation and final consumption in IEA countries 1973 and 1987 (OECD/IEA, 1989; Allen et al.,1990).

\begin{tabular}{|l|c|c|c|}
\hline \multirow{2}{*}{$\begin{array}{c}\text { International Energy Agency (IEA) } \\
\text { Countries }\end{array}$} & \multicolumn{2}{|c|}{$\begin{array}{c}\text { Primary Energy Requirements } \\
\text { (Mtoe) }\end{array}$} & $\begin{array}{c}\text { Percent } \\
\text { increase }\end{array}$ \\
\cline { 2 - 4 } & 1973 & 1987 & \\
\hline Transformation & 838 & 1065 & 27 \\
of which electricity & 583 & 802 & 38 \\
\hline Industry & 1060 & 956 & -10 \\
\hline Transport & 635 & 787 & 24 \\
\hline Residential/commercial & 793 & 839 & 6 \\
\hline Total & 2488 & 2582 & 4 \\
\hline
\end{tabular}




\section{APPENDIX B}

\section{AIR QUALITY CRITERIA}

The emission-based air quality standards are essential for the general "health" of the Earth's atmosphere. However, for the health of the local community a receptor-based ambient air quality standard must be monitored and enforced by an independent responsible authority. An international survey for the ambient air quality standards in nineteen nations for four commonly regulated substances have shown that the majority of countries have no active air quality standards (emission or receptor-based), or ambient air quality monitoring (Cochran et al, 1992). The general lack of ambient air quality standards has resulted in some nations choosing to accept the World Health Organisation's (WHO) recommendations for air quality, as presented in Table B.1.

The significant range of ambient air quality standards between the countries reported (Table B.1) may be attributed to factors as varied as the achieveability of a nominated concentration in an industrial region, to the extent of local health and the ever present influence of politics. Also, some nations have a zoning philosophy incorporated into the standards which makes a distinction between industrial and pristine areas as to the degree to which the concentration is exceeded (Cochran et al, 1992).

Air quality standards for urban air pollutants have not been defined in New South Wales as there is insufficient Australian data on health effects of these pollutants to allow their adequate determination. In the absence of such standards, the State Pollution Control Commission ( now NSW EPA ) adopted as objectives the National Health and Medical Research Council (NHMRC) Guide-lines supplemented by World Health Organisation (WHO) Long Term Goals and the US Environmental Protection Agency (USEPA) Air Quality Standards. These air quality guidelines have been determined in the light of current international knowledge on adverse effects of air pollutants on health. Selected air quality criteria together with their agency source are listed in Table B.2

\section{B.1. Carbon monoxide}

Motor vehicles are estimated to contribute at least $87 \%$ of the carbon monoxide in the air. The 1-hour and 8-hour goals noted by the EPA provide a significant margin for safety. These goals are appropriate for such a guide-line, which is designed to protect a wide range of people in the community including the very young, the elderly and the infirm. 
Table B.1 Ambient air quality standards currently applied in nineteen nations for $\mathrm{CO}, \mathrm{SO}_{2}, \mathrm{NO}_{2}$, and $\mathrm{o3}$ (Cochran et al., 1992).

$\square$ No receptor standards --- No receptor standards (emission standards may apply)

\begin{tabular}{|c|c|c|c|c|c|c|c|c|c|c|c|c|}
\hline \multirow{3}{*}{ COUNTRY } & \multicolumn{12}{|c|}{$\begin{array}{l}\text { POLLUTANT } \\
\end{array}$} \\
\hline & \multicolumn{3}{|c|}{$\mathrm{CO}, \mathrm{mg} / \mathrm{m} 3$} & \multicolumn{3}{|c|}{$\mathrm{SO}_{2}, \mathrm{mg} / \mathrm{m} 3$} & \multicolumn{3}{|c|}{$\mathrm{NO}_{2} \mathrm{mg} / \mathrm{m} 3$} & \multicolumn{3}{|c|}{$\mathrm{O}_{3}, \mathrm{mg} / \mathrm{m} 3$} \\
\hline & $\begin{array}{l}\text { long } \\
\text { term }\end{array}$ & $\begin{array}{l}\text { med. } \\
\text { term }\end{array}$ & $\begin{array}{l}\text { short } \\
\text { term }\end{array}$ & $\begin{array}{l}\text { long } \\
\text { term }\end{array}$ & $\begin{array}{l}\text { med. } \\
\text { term }\end{array}$ & $\begin{array}{l}\text { short } \\
\text { term }\end{array}$ & $\begin{array}{l}\text { long } \\
\text { term }\end{array}$ & $\begin{array}{l}\text { med. } \\
\text { term }\end{array}$ & $\begin{array}{l}\text { short } \\
\text { term }\end{array}$ & $\begin{array}{l}\text { long } \\
\text { term }\end{array}$ & $\begin{array}{l}\text { med. } \\
\text { term }\end{array}$ & $\begin{array}{l}\text { short } \\
\text { term }\end{array}$ \\
\hline $\begin{array}{l}\text { WHO } \\
\text { (1987) }\end{array}$ & & $10.0^{\mathrm{e}}$ & $\begin{array}{c}30.0^{\mathrm{g}} \\
60.0^{\mathrm{h}} \\
100^{\mathrm{i}}\end{array}$ & & & $\begin{array}{l}350 \mathrm{~g} \\
500 \mathrm{j}\end{array}$ & & $150^{d}$ & $400 \mathrm{~g}$ & & & $150 \mathrm{~g}$ \\
\hline $\begin{array}{l}\text { Australia } \\
\text { Victoria (81) } \\
\text { Tasmania (74) }\end{array}$ & & $\mid \begin{array}{l}11.4^{\mathrm{e}} \\
12.5^{\mathrm{e}}\end{array}$ & $\begin{array}{l}34.3 \mathrm{~g} \\
37.5 \mathrm{~g}\end{array}$ & $50.0^{\mathrm{a}}$ & $\begin{array}{l}155^{d} \\
160^{d}\end{array}$ & $\begin{array}{l}445 \mathrm{~g} \\
450 \mathrm{~g}\end{array}$ & & $\begin{array}{l}120^{d} \\
120^{d}\end{array}$ & $\begin{array}{l}300 \mathrm{~g} \\
310 \mathrm{~g}\end{array}$ & & $100^{e}$ & 2409 \\
\hline Austria (87) & & $10.0^{\mathrm{d}}$ & $40.0 \mathrm{~g}$ & & $200 \mathrm{~d}$ & $200^{h}$ & & & & & $100^{e}$ & 1208 \\
\hline Canada (89) & & $6.0^{\mathrm{e}}$ & $15.0 \mathrm{~g}$ & $30.0^{\mathrm{a}}$ & $150 \mathrm{~d}$ & $450 \mathrm{~g}$ & $60^{a}$ & $200 d$ & $400 \mathrm{~g}$ & $30^{d}$ & $30^{d}$ & 1008 \\
\hline Finland (82) & & $10.0^{\mathrm{e}}$ & $30.0 \mathrm{~g}$ & $40.0^{\mathrm{a}}$ & $200 \mathrm{~d}$ & $500 \mathrm{~g}$ & & $150 \mathrm{~d}$ & $300 \mathrm{~g}$ & $\cdots$ & $\cdots$ & 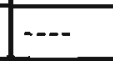 \\
\hline Germany (86) & $10.0^{\mathrm{a}}$ & 30 马 & & $140^{\mathrm{a}}$ & & & $80^{a}$ & & 2008 & -- & - & -- \\
\hline Hungary (90) & $2.0^{\mathrm{a}}$ & $5.0^{\mathrm{d}}$ & $10.0^{\mathrm{h}}$ & $70.0^{\mathrm{a}}$ & $150 \mathrm{~d}$ & $500^{h}$ & $70^{a}$ & $85^{d}$ & $100^{h}$ & & $30^{d}$ & $60^{h}$ \\
\hline Israel (92) & & $11.0^{\mathrm{e}}$ & $60.0^{\mathrm{h}}$ & $60.0^{\mathrm{a}}$ & $280 d$ & $500^{h}$ & & $560 \mathrm{~d}$ & $940 \mathrm{~h}$ & & $160^{e}$ & $230^{h}$ \\
\hline Japan (90) & & $\begin{array}{l}11.4^{\mathrm{d}} \\
22.8^{\mathrm{e}}\end{array}$ & & & $107^{d}$ & 2678 & & $80^{d}$ & & & & $118 \mathrm{~g}$ \\
\hline Kuwait (89) & & $\begin{array}{l}9.1^{\mathrm{d}} \\
11.4^{\mathrm{e}} \\
\end{array}$ & $40.0^{g}$ & $80.0^{\mathrm{a}}$ & $160 d$ & $453 g$ & & $100^{d}$ & & & & $157 g$ \\
\hline Mexico (84) & & $14.4^{\mathrm{e}}$ & & & $341^{d}$ & & & & $395 \mathrm{~g}$ & & & $216 \mathrm{~g}$ \\
\hline Netherlands (86) & & $6.0_{\delta}^{\mathrm{e}}$ & $40^{\mathrm{a}} \mathrm{d}$ & & $500 d$ & $830 \mathrm{~g}$ & & & $175 g$ & & & $120 \mathrm{~g}$ \\
\hline New Zealand (86) & & $10.0^{\mathrm{e}}$ & $40.0 \mathrm{~g}$ & $50.0^{\mathrm{b}}$ & $125^{\mathrm{d}}$ & & & $100 d$ & $200 \mathrm{~g}$ & & $60^{e}$ & $120 \mathrm{~g}$ \\
\hline Poland (90) & $0.12^{\mathrm{a}}$ & $1.0^{\mathrm{d}}$ & $5.0^{\mathrm{h}}$ & $32.0^{\mathrm{a}}$ & $300 \mathrm{~d}$ & $600^{\mathrm{h}}$ & $50.0^{\mathrm{a}}$ & $150 \mathrm{~d}$ & $500^{\mathrm{h}}$ & & $30^{d}$ & $100^{h}$ \\
\hline Saudi Arabia (91) & & $10.0^{\mathrm{e}}$ & $40.0 \mathrm{~g}$ & $80.0^{\mathrm{a}}$ & $365^{d}$ & $730 \mathrm{~g}$ & $100^{a}$ & & $660 \mathrm{~g}$ & & & $295 \mathrm{~g}$ \\
\hline S. Africa( 65) & $\cdots$ & -- & $\begin{array}{l}---- \\
\end{array}$ & $80.0^{\mathrm{a}}$ & $265^{d}$ & $780 \mathrm{~g}$ & $270^{a}$ & $540 \mathrm{~d}$ & $1080 \mathrm{~g}$ & & $100^{d}$ & $240 \mathrm{~g}$ \\
\hline Soviet Union (86) & & & 20.0 & $\ldots$ & $-\cdots$ & $-\cdots$ & 85.0 & & & & & 100 \\
\hline Switzerland (85) & & $8.0^{\mathrm{d}}$ & & $30.0^{\mathrm{a}}$ & $100 d$ & $100^{h} \mathrm{c}$ & $30.0^{\mathrm{a}}$ & $80 d$ & $100^{h} c$ & & & $\begin{array}{l}120^{d} \\
100^{h_{d}}\end{array}$ \\
\hline Taiwan (75) & & $11.4^{\mathrm{d}}$ & $22.9 \mathrm{~g}$ & $133^{a}$ & $267^{d}$ & & & $100 \mathrm{~d}$ & & -- & $-\cdots$ & $-\cdots$ \\
\hline U.S.A (90) & & $10.0^{\mathrm{e}}$ & $40.0^{\mathrm{g}}$ & $80.0^{\mathrm{a}}$ & $365^{d}$ & & $100^{\mathrm{a}}$ & & & & & 2409 \\
\hline
\end{tabular}

a: Annual mean; b: 3-month mean; c: 1-month mean; d: 24-hour mean; e: 8-hour mean; f: 3-hour mean; g: 1-hour mean; h: 30-minute mean; i: 15-minute mean; j: 10-minute mean; k: 7-day mean; $\alpha: 99.99$ percentile; $\beta$ : 99.5 percentile; $\gamma: 99$ percentile; $\delta: 98$ percentile; $\varepsilon: 95$ percentile; and $\zeta: 50$ percentile 
Table B.2 NSW selected air quality criteria with their agency .

(source: SPCC, 1989)

\begin{tabular}{|c|c|c|}
\hline Pollutant & Standard & Agency \\
\hline Carbon monoxide & $\begin{array}{l}25 \mathrm{ppm} \text { (1-hour maximum) } \\
9 \mathrm{ppm} \text { (8-hour maximum) }\end{array}$ & $\begin{array}{c}\text { WHO } \\
\text { NHMRC }\end{array}$ \\
\hline Non-methane hydrocarbons & 24 pphm (3-hour maximum) & US EPA \\
\hline Nitrogen dioxide & $\begin{array}{c}16 \text { pphm (1-hour maximum) } \\
5 \text { pphm (annual mean) }\end{array}$ & $\begin{array}{l}\text { NHMRC } \\
\text { US EPA }\end{array}$ \\
\hline Sulphur dioxide & $\begin{array}{c}50 \text { pphm (10-min maximum) } \\
25 \text { pphm (1-hour maximum) } \\
2 \text { pphm (annual mean) }\end{array}$ & $\begin{array}{l}\text { NHMRC } \\
\text { NHMRC } \\
\text { NHMRC }\end{array}$ \\
\hline Ozone & 12 pphm (1-hour maximum) & NHMRC \\
\hline Total suspended particulate matter & $90 \mathrm{mg} / \mathrm{m}^{3}$ & US EPA \\
\hline Lead in air & $1.5 \mathrm{mg} / \mathrm{m}^{3}$ ( 90 day average) & US EPA \\
\hline
\end{tabular}

The EPA notes the WHO guide-lines for carbon monoxide are $25 \mathrm{ppm}$ (1-hour maximum) and the NHMRC guide-line is 9 ppm (8-hour maximum).

Forest (1990) reported that the remarkable decrease in the number of days in which carbon monoxide exceeded the NHMRC 8-hour goal of 9 ppm over the past decade was because of the greater impact of the recent motor vehicle technology improvements, and the implementation of the emission control legislation after the introduction of the unleaded fuel in Australia in 1986 (Figure B.1).

\section{B.2 Hydrocarbons}

Hydrocarbons do play a significant role in photochemical smog formation which is characterised by the presence of excessive concentrations of ozone, and until recently the air quality standards adopted by the US EPA for non-methane hydrocarbons have been applied to NSW. It has now been recognised that this goal does not distinguish the reactive species which are involved in smog formation from the total hydrocarbon concentration, and consequently the air quality goal has been abandoned by the US EPA and the NSW EPA (Cafe et al., 1993).

Motor vehicles are estimated to contribute $45 \%$ of the hydrocarbons in the air. There is growing concern about the amount of benzene released in motor vehicle emissions. At 


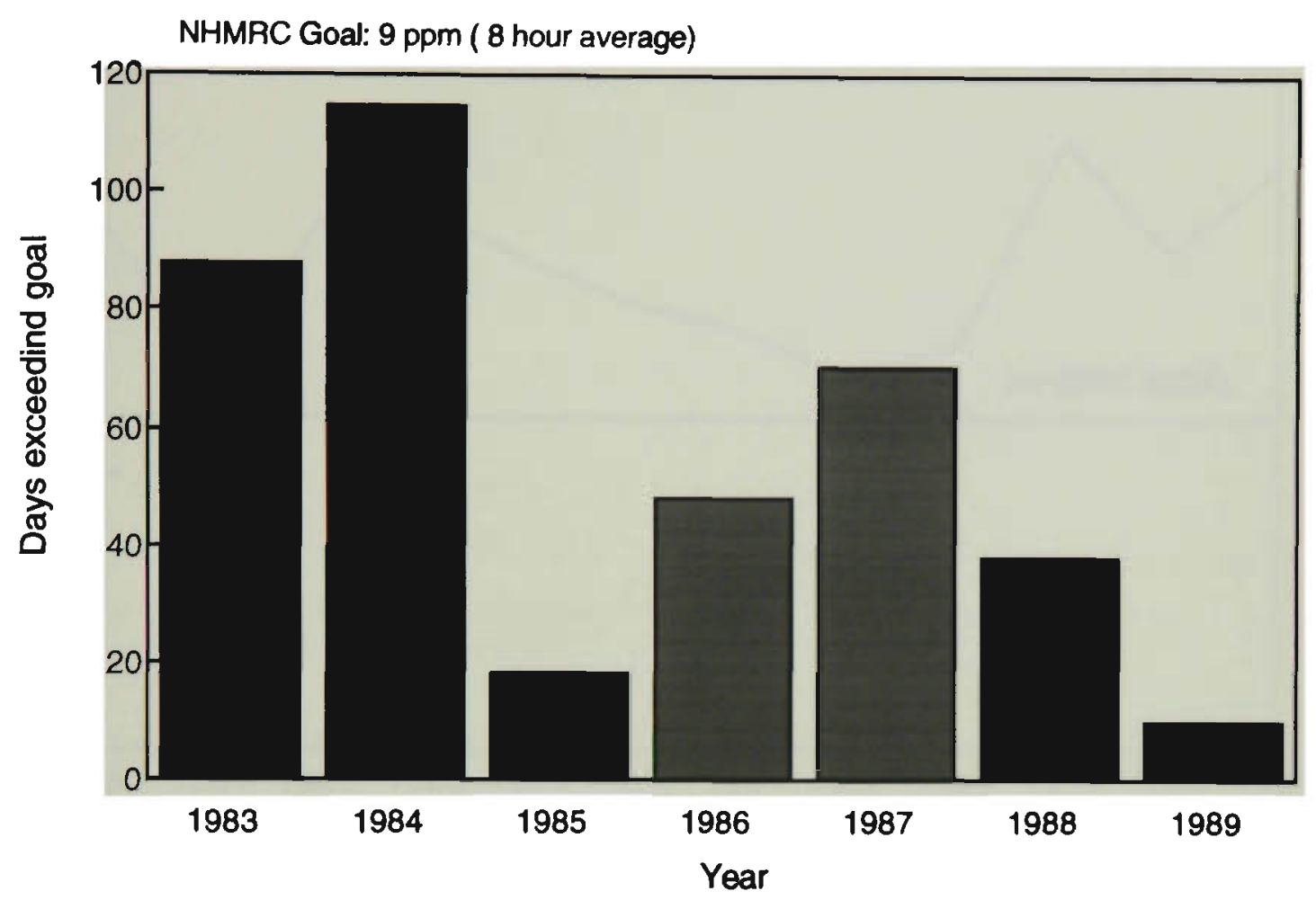

Figure B.1 Carbon monoxide levels in Sydney: Days Exceeding NHMRC Goal over the past decade for Sydney region (Forrest, 1990).

present NSW has no air quality goals for benzene. The Victorian EPA currently has a limit of $0.10 \mathrm{mg} / \mathrm{m}^{3}(0.033 \mathrm{ppm})(3-$ minute average). The WHO does not specify a level, but estimates that at a concentration of $1 \mathrm{microgram} / \mathrm{m}^{3}$ the estimated lifetime risk of leukaemia is $4 \times 10^{-6}$ (Cafe et al., 1993).

Forest (1990) reported that the ozone yearly peak levels showed considerable variability over the past decade (1980-1991), but all the yearly peak levels were above the NHMRC goal of $0.12 \mathrm{ppm}$ (Figure B.2 and Figure B.3). There appeared to be a trend downwards between 1983 and 1988 . This variation for the ozone levels came mainly as a result of the progressive introduction of legislated emission controls on passenger cars.

\section{B.3 Oxides of nitrogen}

Nitrogen oxides (NOx) emitted by motor vehicles are comprised mainly of nitric oxide, NO (approximately 95\%), and nitrogen dioxide, $\mathrm{NO}_{2}$ (approximately $5 \%$ ). Nitric oxide is the less harmful of the two, at the concentrations normally found in urban environments. 


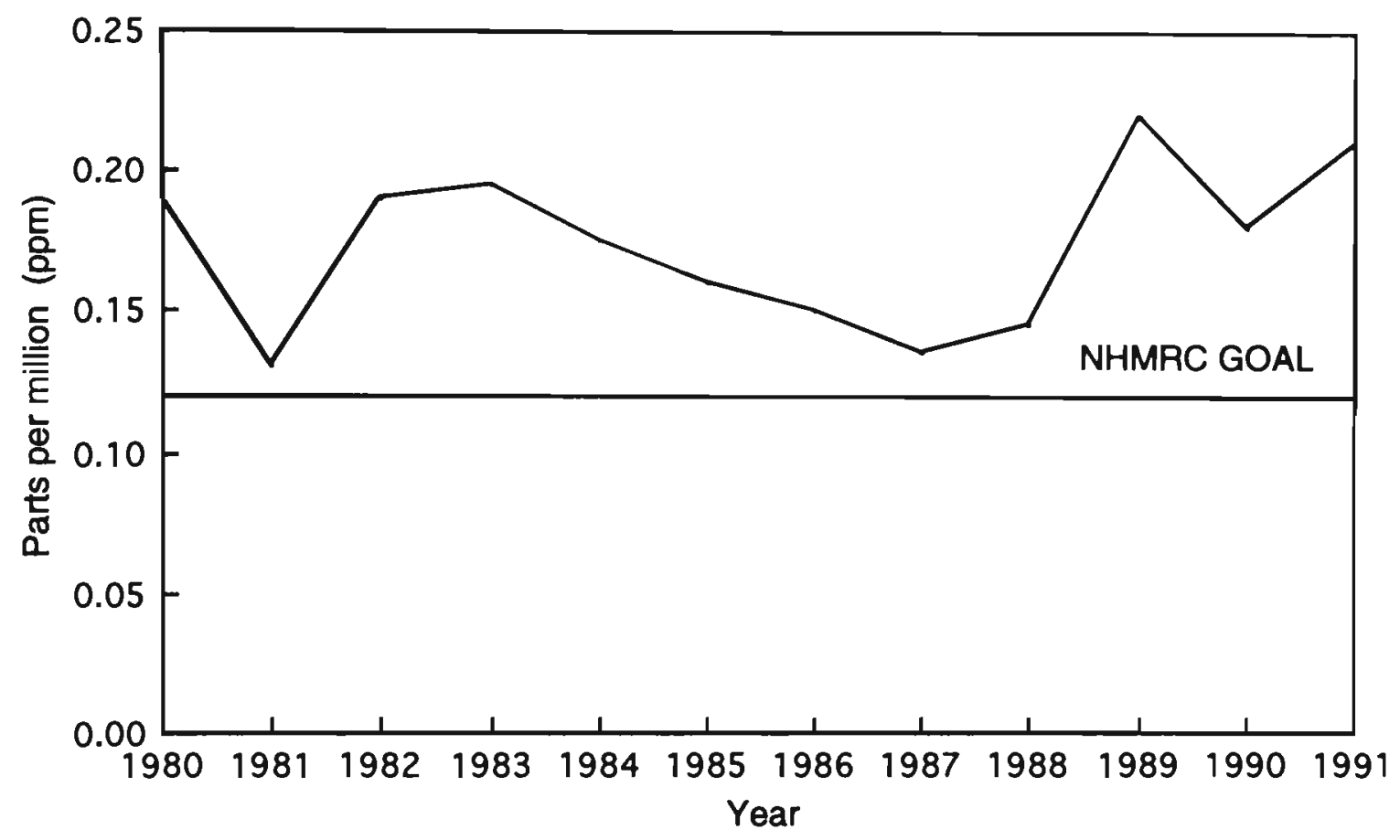

Figure B.2 Ozone yearly peak hour value for Sydney region (Forrest, 1990).

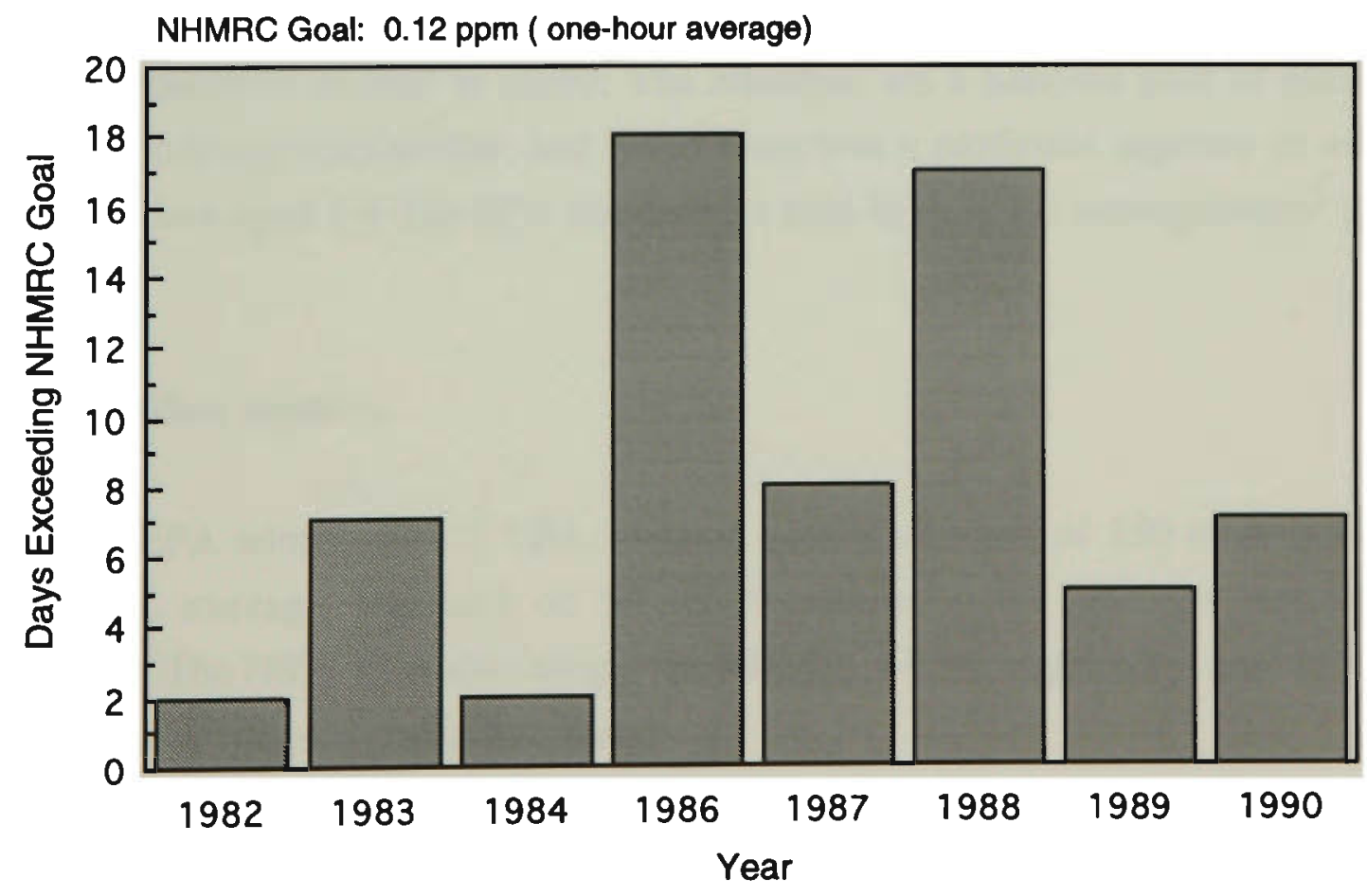

Figure B.3 Ozone: Days Exceeding NHMRC Goal over the past decade for Sydney region (Forrest, 1990). 
The EPA has not set any air quality goals for nitric oxide, but it is rapidly converted to nitrogen dioxide, for which the EPA has set goals of a 1-hour maximum of $0.16 \mathrm{ppm}$ or $328 \mathrm{microgram} / \mathrm{m}^{3}$ and annual means of $0.05 \mathrm{ppm}$ or $103 \mathrm{microgram} / \mathrm{m}^{3}$ (Cafe et al., 1993).

Also, Forest (1990) reported that the nitrogen dioxide yearly peak one-hour levels indicated that the nitrogen oxides yearly peak levels were above the NHMRC goal of $0.16 \mathrm{ppm}$ over the past decade (1980-1990), except for year 1985. Figure B.4. and Figure B.5 show that the number of days exceeding that goal went up towards twenty days in the middle of the past decade. Nitrogen dioxide is a precursor of the photochemical smog, and also has a potential for direct impact on public health and the environment .

\section{B.4 Lead in air}

The National Health and Medical Research Council (NHMRC), in June 1993, reviewed its public health guide-lines. It stated that there was new scientific evidence that suggests prolonged lead exposure can have a detrimental effect on the intellectual development of children. The present level of concern in Australia is 25 microgram/decilitre of lead in blood. The NHMRC set a national goal of blood lead level of 10 microgram/decilitre, and noted there was a particular urgency in reaching this for children aged 1-4 The EPA standard for lead in air is $1.5 \mathrm{microgram} / \mathrm{m}^{3}$ (90 day average).

\section{B.5 Particulate matters}

The NSW EPA adopts the US EPA 24-hour quality standard of $150 \mathrm{microgram} / \mathrm{m}^{3}$, and annual average standard of $50 \mathrm{microgram} / \mathrm{m}^{3}$, for particles less than 10 micrometer. The NSW EPA also adopts the NHMRC 90 microgram/ $\mathrm{m}^{3}$ annual average goal for total suspended particulate matter. 


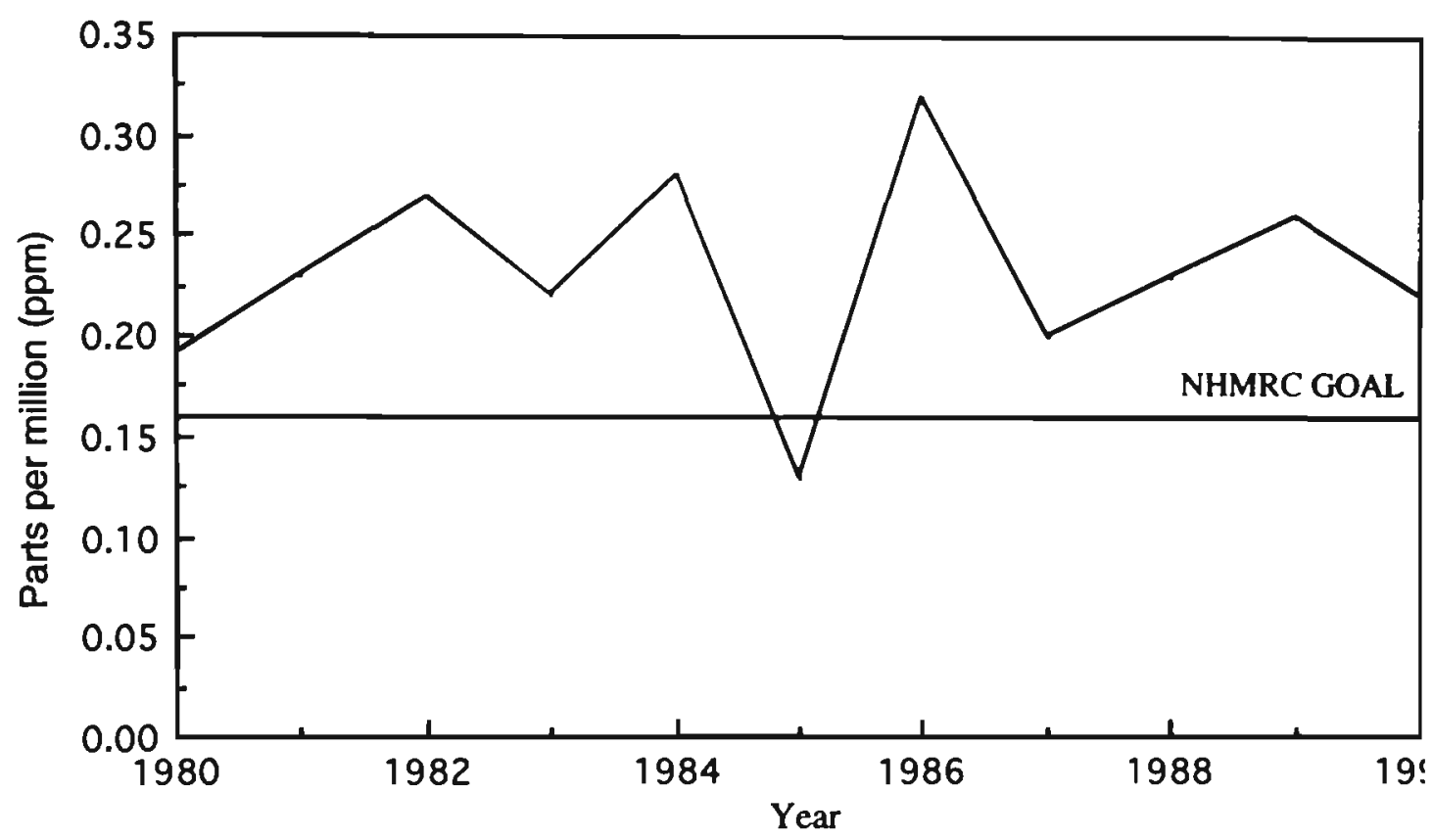

Figure B.4 $\mathrm{NO}_{2}$ yearly peak hour value for Sydney region (Forrest, 1990).

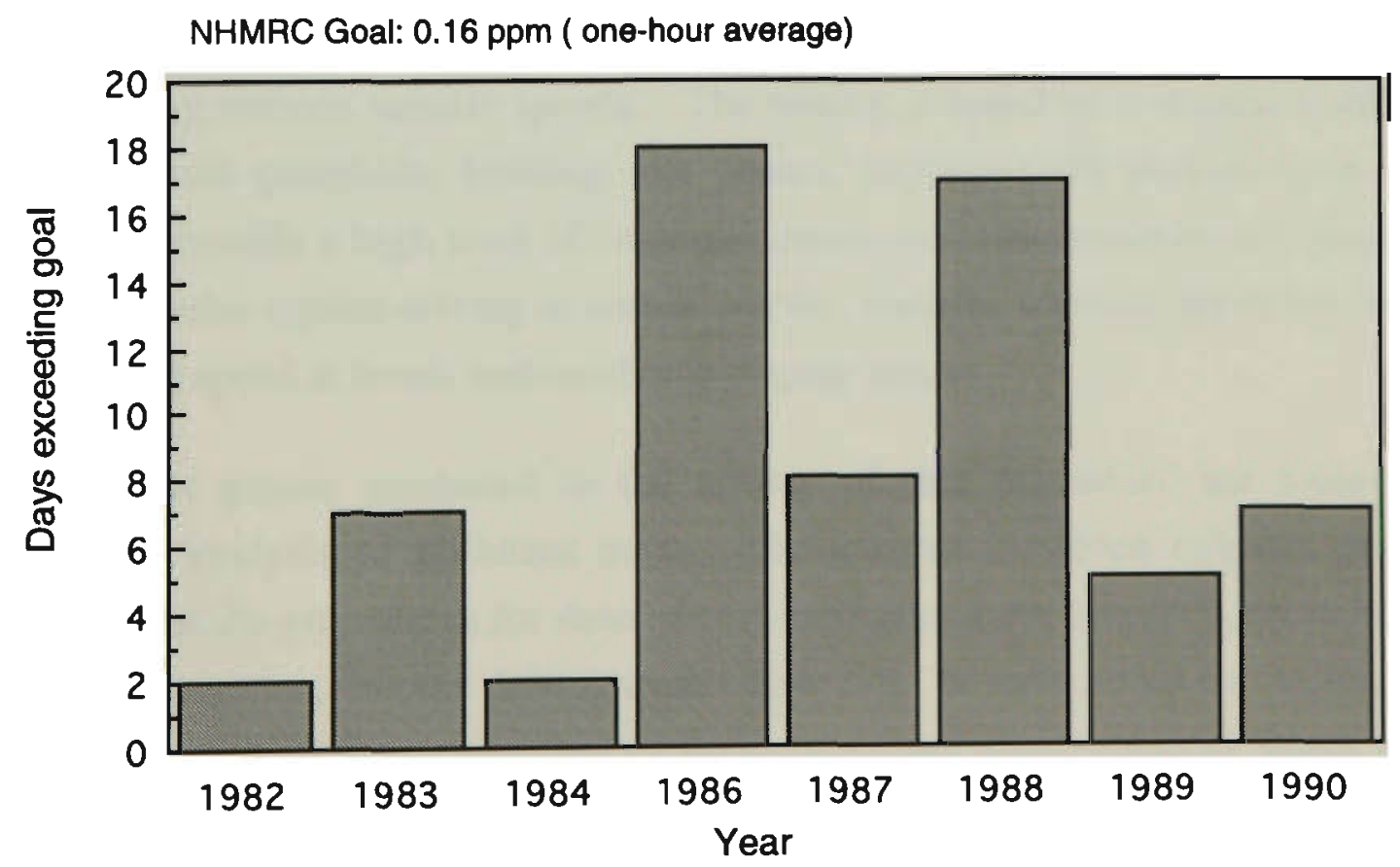

Figure B.5 NO2 : Days Exceeding NHMRC Goal over the past decade for Sydney region (Forrest, 1990). 


\section{APPENDIX C}

\section{TESTING EXHAUST AND EVAPORATIVE EMISSIONS OF THE INTERNAL COMBUSTION ENGINE}

\section{1 Testing exhaust emissions}

To determine a vehicle's emission levels precisely, then the vehicle must be tested in the emissions test cell under standardised conditions which provide an accurate reflection of actual driving conditions. These test conditions are the only means of ensuring that the individual emissions tests remain mutually comparable.

\section{C.1.1 Test Program}

The vehicle to be tested is parked with the drive wheels on special rollers with which rotating resistance can be adjusted to simulate friction losses and aerodynamic resistance using a chassis dynamometer, while inertial mass can be added to simulate the vehicle's weight. The required cooling is provided by a fan mounted a short distance from the vehicle. The measurements of emissions levels is based on a simulated driving pattern which progresses through a precise driving cycle incorporating various vehicle speeds. The testing is based on a standardised driving cycle in which gearshifts, braking, idle phases, and standstill periods have all been selected to provide a high level of correspondence with the velocities and acceleration that characterise typical driving in normal traffic. Usually, a driver sits in the vehicle to maintain the speed at levels indicated on a display screen .

The exhaust gasses produced in the course of this procedure are collected for subsequent analysis of pollutant mass. The manner in which exhaust gasses are collected and the procedures for determining emissions have largely been standardised in various countries, but the driving cycles have not. In some countries, regulations on exhaust emissions are supplemented by limits on evaporative-emissions losses from the fuel system (see Bosh Automotive Handbook, 1993).

\section{C.1.2 Chassis dynamometer}

Fluid-friction dynamometers, eddy-current brakes and DC motors simulate the inertial forces with rolling and aerodynamic resistance exert upon the vehicle by providing a corresponding, velocity-dependent braking force (resistance of the rollers to turning). 
Rapid couplings in various sizes are used to connect inertial masses to the rollers, thus simulating vehicle weight. The progression curve for braking loads must correspond to that for vehicle speed, and the required inertial masses must be maintained precisely. Ambient conditions such as atmospheric humidity, temperature, and barometric pressure also influence test results (see Bosh Automotive Handbook, 1993).

\section{C.1.3 Test samples and dilution procedures (CVS Method)}

The exhaust gases emanating from the test vehicle are diluted with fresh air at a ratio of $1: 10$ and are extracted using a special system of pumps which are arranged to maintain the respective flow volumes of exhaust gas and fresh air at a fixed ratio, i.e., the air licu is regulated according to the vehicle's momentary exhaust volume (see Figure C.1). Throughout the test a constant proportion of the diluted exhaust gas is extracted from the collection in one or several sample bags. The pollutant concentration in the sample bags at the end of the test corresponds precisely to the mean concentration in the total quantity of fresh/exhaust mixture which has been extracted. As the total volume of the fresh air/exhaust mixture can be monitored, it is possible to use the pollutant concentration as the basis for calculating the masses of the substances cmitted in the course of the test (see Bosh Automotive Handbook, 1993).

I Chassis dynamometer, 2 Inertial mass, 3 Exhaust gas, 4 Air filter. 5 Fresh (dilution) air, 6 Sampling venturi, 7 Gas remperanure, 8 Pressure, 9 Venturi, 10 Blower, Il Sample bags, 12 System ouslet.

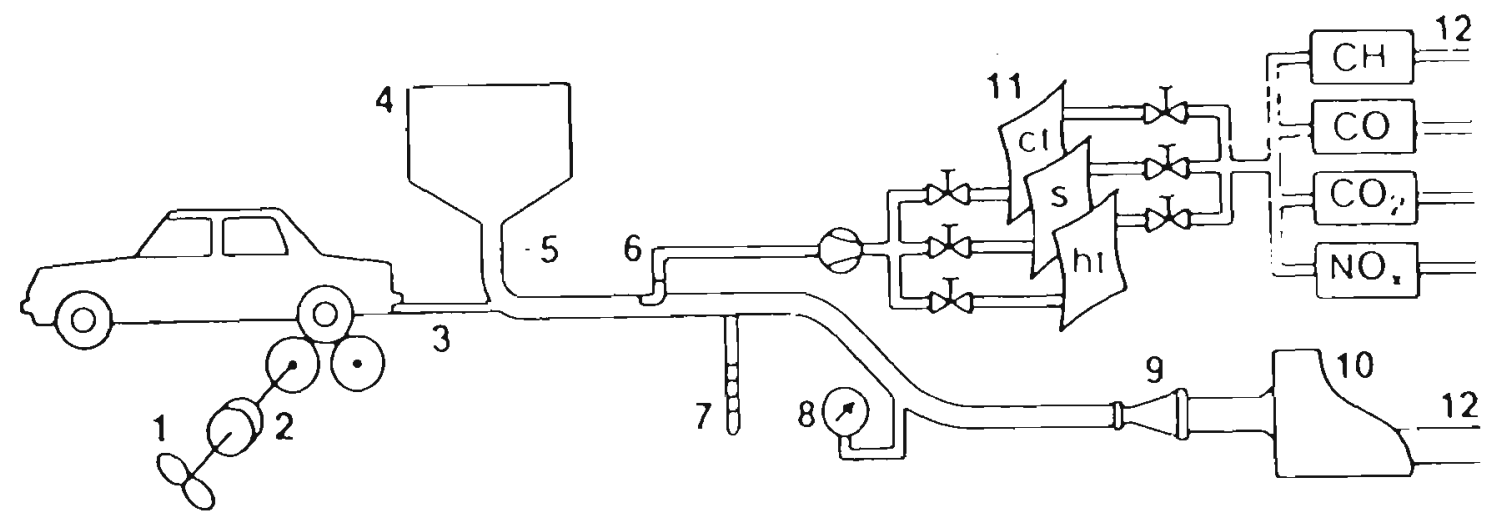

Figure C.1 Test layout for USA Federal Test Procedure (Source : Bosch AutomotiveHandbook, 1993). 
An advantage of this procedure is that condensation of the water vapour contained in the exhaust gas is avoided, which provides for a substantial reduction of the $\mathrm{NO}_{\mathrm{X}}$ losses in the bag. In addition, dilution greatly inhibits the tendency of exhaust components (especially hydrocarbons) to react with one another. However, dilution does mean that the concentration of the pollutants decreases proportionally to the mean dilution ratio, necessitating the use of more sensitive analysers.

To maintain a constant flow volume for the test, one of two different but equally acceptable pump arrangements is generally employed. In the first, a normal blower extracts the fresh-air/exhaust mixture through a venturi tube (see Figure C.1); the second layout employs a special vane pump (roots blower). Either method is capable of metering the flow volume with an acceptable degree of accuracy.

\section{C.1.3 Test cycles}

The spark ignition and light-duty diesel vehicles were tested over standard driving cycles used for the evaluation of gaseous emissions, under the Australian Design Rules ADR $27 \mathrm{C}$ and 37 which purport to replicate urban driving patterns. Two driving cycles are used in testing exhaust emissions. These cycles are CVS-C and CVS-CH driving cycles.

The driving cycle (CVS-C) is a 23-minute dynamometer-simulated city/urban driving schedule from a cold start (a cold transient segment lasting $505 \mathrm{~s}$. and the cold stabilised segment lasting $867 \mathrm{~s}$ ). The CVS-C cycle is specified in NSW Clean Air Regulations 26 (3) and is the same as that specified in Australian Design Rule ADR 27A/B/C, and the United States 1972 - Federal Test Procedure (FTP).

The CVS-CH cycle is a 23-minute dynamometer-simulated city/urban driving schedule from a cold start followed by a 10-minute hot soak, a hot start and a repetition of the first 8.5 minutes of the driving schedule. The CVS-Ch cycle is specified in NSW Clean Air Regulations 26 (4) for application to cars manufactured on or after 1st January 1986, and is the same as that specified in Australian Design Rule ADR 37, and the United States 1975 - Federal Test Procedure (FTP). Figure C.2 shows USA Test Cycle (Federal Test Procedure, FTP 75).

The USA FTP 75 test cycle consists of three test sections. These in turn, represent speeds measured in America on the streets of Los Angeles in morning commuter traffic. 
Cycle distance: 11.115 miles

Cycle duration: $1877 s+600$ pause
Average speed: $34.1 \mathrm{~km} / \mathrm{h}$

Maximum speed: $91.2 \mathrm{~km} / \mathrm{h}$

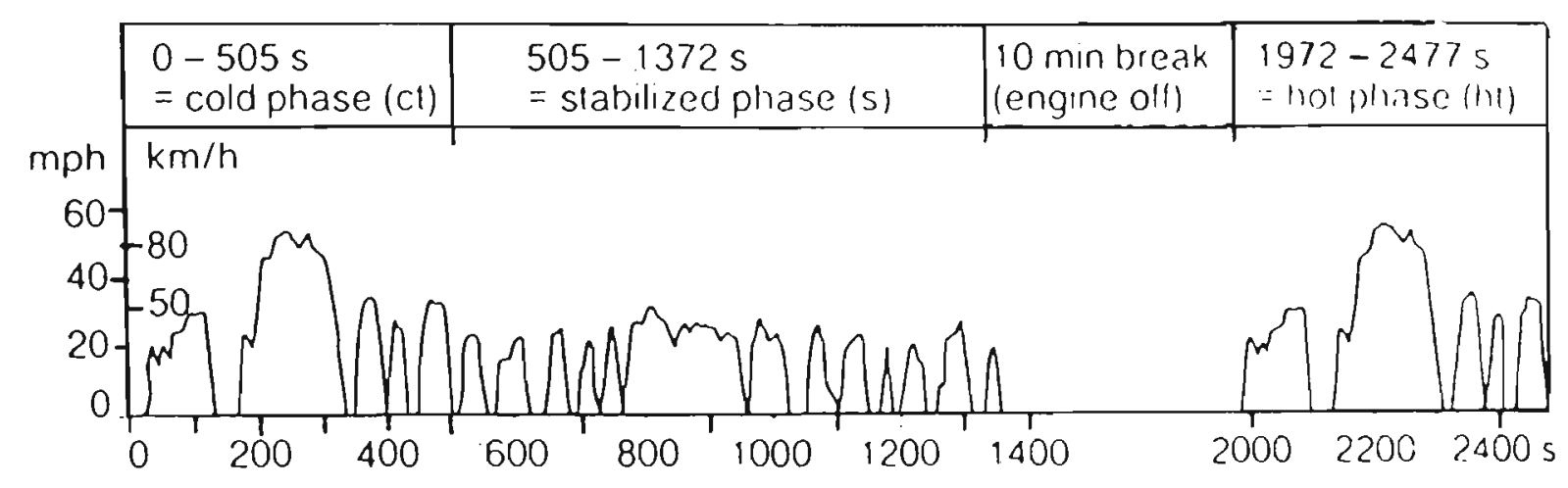

Figure C. 2 USA Test Cycle (Federal Test Procedure, ITP 75 ).

These sections 2: a transition phase (ct) for the first $505 \mathrm{~s}$, a stabilised phase (s) from $506 \mathrm{~s}$ to $1372 \mathrm{~s}$, and the hot test (ht) from $1972 \mathrm{~s}$, to $2477 \mathrm{~s}$. The vehicle to be lested is first conditioned by being left parked for 12 hours at a room temperature of $20-30)^{\circ} \mathrm{C}$ It is then started and driven through the prescribed driving cycle.

After the phase (ct), the diluted exhaust gas is collected in bag I during the cold transition phase. The exhaust samples are diverted to bag 2 at the beginning of the stabilised phase (s) without any interruption in the program sequence. The engine is switched off for a 10-minute pause immediately following the end of the stabilised phase(after $1372 \mathrm{~s}$ ). The engine is restarted for the hot test ( $505 \mathrm{~s}$ in duration). The speed sequence of this phase directly corresponds to that of the cold transition phase. Exhaust gases are collected in the third sample bag. The bag samples from the previcus phases are analyzed, as the probes should not remain in the bags for longer than 20 minutes.

The exhaust gas sample in the third sample bag is analysed once a driving sequence has been completed. The weighted sum of the pollutant emissions ( $\mathrm{HC}, \mathrm{CO}$, and $\left.\mathrm{N}()_{\mathrm{x}}\right)$ from all three bags are evaluated with reference to the distance covered, and then is expressed as emissions per mile or per kilometre.

Although the USA FTP 75 test procedure is used in the USA (including Caliormia) and in several countries (including Australia, Switzerland, Austria, Sweden, Vorway. 
Finland, Mexico, Brazil, South Korea, and Canada, the limits on pollutant emissions vary among these countries, as shown in both Table C.1 and C.2).

Table C.1 Emissions limits under USA-FED (49-states) and California FTP 75 Test cycle ( Data from Bosch Automotive Handbook, 1993).

\begin{tabular}{|c|c|c|c|c|c|}
\hline Model year & Region & $\begin{array}{c}\mathrm{CO} \\
\mathrm{g} / \mathrm{mile}\end{array}$ & $\begin{array}{c}\mathrm{HC} \\
\mathrm{g} / \mathrm{mile}\end{array}$ & $\begin{array}{c}\mathrm{NO}_{\mathrm{X}} \\
\mathrm{g} / \mathrm{mile}\end{array}$ & $\begin{array}{c}\text { Evaporation } \\
\mathrm{g} / \mathrm{test}\end{array}$ \\
\hline Since 1982 & FED & 3.41 & 0.41 & 1.0 & 2.0 \\
& CAL & 7.00 & 0.41 & 0.4 & 2.0 \\
\hline 1993 & CAL & 3.4 & 0.25 & 0.4 & 2.0 \\
\hline 1994 & FED & 3.4 & 0.25 & 0.4 & 2.0 \\
\hline
\end{tabular}

Table C.2 Emissions limits in Australia, Austria, Brazil, Canada, Finland, Mexico, Norway, South Korea, Sweden, and Switzerland for FTP 75 Test cycle (Data from Bosch Automotive Handbook, 1993).

\begin{tabular}{|c|c|c|c|c|c|}
\hline Country & $\begin{array}{c}\text { Implemen- } \\
\text { tation }\end{array}$ & $\begin{array}{c}\mathrm{CO} \\
\mathrm{g} / \mathrm{km}\end{array}$ & $\begin{array}{c}\mathrm{HC} \\
\mathrm{g} / \mathrm{km}\end{array}$ & $\begin{array}{l}\mathrm{NO}_{\mathrm{X}} \\
\mathrm{g} / \mathrm{km}\end{array}$ & $\begin{array}{c}\text { Evaporation } \\
\text { g/test }\end{array}$ \\
\hline Switzerland & 1987 & 2.1 & 0.25 & 0.62 & 2.0 \\
\hline Austria & $1987 / 88$ & 2.1 & 0.25 & 0.4 & 2.0 \\
\hline Sweden & 1989 & 2.1 & 0.25 & 0.4 & 2.0 \\
\hline Norway & 1989 & 2.1 & 0.25 & 0.4 & 2.0 \\
\hline Finland & 1990 & 2.1 & 0.25 & 0.4 & 2.0 \\
\hline Mexico & 1991 & 7.0 & 0.7 & 1.4 & 2.0 \\
\hline \multirow[t]{3}{*}{ Brazil } & 1990 & 24.0 & 2.1 & 2.0 & - \\
\hline & 1992 & 12.0 & 1.2 & 1.4 & - \\
\hline & 1997 & 2.0 & 0.3 & 0.6 & - \\
\hline \multirow[t]{2}{*}{ Australia } & 1986 & 9.3 & 0.9 & 1.9 & 2.0 \\
\hline & & $\begin{array}{c}\mathrm{CO} \\
\mathrm{g} / \mathrm{mile} \\
\end{array}$ & $\begin{array}{c}\mathrm{HC} \\
\mathrm{g} / \mathrm{mile}\end{array}$ & $\begin{array}{c}\mathrm{NO}_{\mathbf{X}} \\
\mathrm{g} / \mathrm{mile} \\
\end{array}$ & $\begin{array}{c}\text { Evaporation } \\
\text { g/test }\end{array}$ \\
\hline Canada & 1987 & 3.4 & 0.41 & 1.0 & 2.0 \\
\hline South Korea & 1988 & 3.4 & 0.41 & 1.0 & 2.0 \\
\hline
\end{tabular}




\section{2 DETERMINATION EVAPORATIVE EMISSIONS FROM FUEL SYSTEM}

Apart from the emissions stemming from the engine's combustion process, motor vehicles also emit hydrocarbons $(\mathrm{HC})$ in the form of evaporative emissions resulting from fuel vaporisation in the tank and supply lines. Some countries (e.g., USA) already have laws limiting the allowable evaporative losses ( see Table C.1 and Table C.2).

The SHED (Sealed Housing for Evaporative Determination) test is the most common procedure for determining evaporative emissions. It comprises two test phases - with varying conditioning procedures - which are conducted in a gas-tight chamber. The first part of the test is carried out with the fuel tank approximately $40 \%$ full. The test fuel is warmed from its initial temperature of $10-14.5^{\circ} \mathrm{C}$, with actual testing of the $\mathrm{HC}$ concentration in the chamber starting once it reaches $15.5^{\circ} \mathrm{C}$. After one hour the temperature of the fuel has risen by $14^{\circ} \mathrm{C}$; at this point testing is concluded with a final sampling of the $\mathrm{HC}$ concentrations. Evaporative emissions are determined by comparing the initial and the final measurements.

For the second part of the test, the vehicle is first warmed up by being run through the FTP 75 test cycle. It is then parked in the chamber. The increase in HC concentration as the vehicle cools during the hour it remains parked is then measured. The sum of the results from both tests must be less than the present limit value of $2 \mathrm{~g}$ hydrocarbon vapour. 


\section{APPENDIX D}

\section{THE EFFECTS OF ROAD GRADIENT, ACCELERATION-DECELERATION MANOEUVRES, AND THE AERODYNAMIC DRAG ON THE POWER REQUIREMENTS AND EMISSIONS LEVELS}

One of the characteristics of the Power-Based Emissions Model is the capability of the model to account for the effect of both road slope and acceleration manoeuvres on the emissions estimates.

The effects of the vehicle speed and the influence of road slope on the instantaneous power demands and fuel consumption are illustrated in Tables D.1-D.4 and Figures D.1-D.4. These Tables and Figures show how the power demands and fuel consumption varies with vehicle speed and road gradient for a spark-ignition vehicle of all-up mass of $1430 \mathrm{~kg}$, and for a heavy-duty diesel truck of all-up mass of $10000 \mathrm{~kg}$. It can be seen from these Tables that the extra power required to overcome a slope (or to carry out an acceleration manoeuvre) can easily double the fuel consumption. At the same time, Tables D.1-D.4 and Figures D.1-D.4 show also the effect of negative slope (down hill) on the power demands and fuel consumption.

It should be noted that in the calculations leading to Tables D.1-D.4 that the instantaneous power required, $Z_{t}$, is set to zero if it is less than zero due to the effect of negative slope, and the corresponding fuel consumption will be the idle fuel consumption.

Also, in the following part, the impact of the road slope on $\mathrm{CO}, \mathrm{HC}$, and $\mathrm{NO}_{\mathrm{X}}$ emission levels has been investigated in detail. This effect is shown in Tables D.5-D.10 and Figures D.5-D.10, for a pre-1986 spark ignition vehicle with all-up mass of $1430 \mathrm{~kg}$, and for a heavy-duty diesel vehicle with all-up mass of $10000 \mathrm{~kg}$. It can be seen from these tables and figures that the road gradient has a substantial effect on NOx emission levels, while it has less effect on both $\mathrm{CO}$ and $\mathrm{HC}$ emissions levels.

With regard to the capability of the Power -Based Emissions Model to account for acceleration-deceleration manoeuvres, it is demonstrated that the impact of acceleration-deceleration manoeuvres of $\pm 0.615 \mathrm{~km} / \mathrm{h} / \mathrm{s}$ on the power demands, fuel consumption, and pollutant emissions is equal to the effect the road slope with $\pm 1^{\circ}$ as discussed in detail earlier. 
Table D.1 The instantaneous power demands for a spark ignition vehicle with allup mass of $1430 \mathrm{~kg}$ as a function of road slope and vehicle speed.

\begin{tabular}{|c|c|c|c|c|c|c|c|}
\hline \multirow{2}{*}{$\begin{array}{c}\text { SPEED } \\
(\mathrm{km} / \mathrm{h})\end{array}$} & \multicolumn{7}{|c|}{$\mathrm{Z}_{\mathrm{t}}(\mathrm{Kw})$} \\
\cline { 2 - 8 } & $\theta=-50$ & $\theta=-30$ & $\theta=-10$ & $\theta=00$ & $\theta=10$ & $\theta=30$ & $\theta=5^{\circ}$ \\
\hline 10 & 0 & 0 & 0 & 0.58 & 1.26 & 2.61 & 3.97 \\
\hline 20 & 0 & 0 & 0 & 1.29 & 2.64 & 5.36 & 8.07 \\
\hline 30 & 0 & 0 & 0 & 1.94 & 3.97 & 8.05 & 12.11 \\
\hline 40 & 0 & 0 & 0.64 & 3.32 & 6.03 & 11.46 & 16.89 \\
\hline 50 & 0 & 0 & 1.39 & 4.74 & 8.13 & 14.92 & 21.70 \\
\hline 60 & 0 & 0 & 2.49 & 6.51 & 10.98 & 18.73 & 26.86 \\
\hline 70 & 0 & 0 & 4.00 & 8.69 & 13.43 & 22.94 & 32.34 \\
\hline 80 & 0 & 0 & 6.00 & 11.32 & 16.75 & 27.62 & 38.45 \\
\hline 90 & 0 & 0 & 8.42 & 14.45 & 20.56 & 32.78 & 44.98 \\
\hline 100 & 0 & 0 & 11.46 & 18.16 & 24.94 & 38.53 & 52.08 \\
\hline 110 & 0 & 0 & 15.08 & 22.48 & 29.94 & 44.88 & 59.79 \\
\hline
\end{tabular}

Table D.2 The fuel consumption for a spark ignition vehicle with all-up mass of $1430 \mathrm{~kg}$ as a function of road slope and vehicle speed.

\begin{tabular}{|c|c|c|c|c|c|c|c|}
\hline \multirow{2}{*}{$\begin{array}{c}\text { SPEED } \\
(\mathrm{km} / \mathrm{h})\end{array}$} & \multicolumn{7}{|c|}{$F_{\mathrm{c}}(\mathrm{mL} / \mathrm{min})$} \\
\cline { 2 - 8 } & $\theta=-50$ & $\theta=-3^{\circ}$ & $\theta=-1^{\circ}$ & $\theta=0^{\circ}$ & $\theta=1^{\circ}$ & $\theta=3^{\circ}$ & $\theta=5^{\circ}$ \\
\hline 10 & 24.75 & 24.75 & 24.75 & 29.97 & 36.07 & 48.24 & 60.48 \\
\hline 20 & 24.75 & 24.75 & 24.75 & 36.36 & 48.56 & 72.99 & 97.38 \\
\hline 30 & 24.75 & 24.75 & 24.75 & 42.21 & 60.55 & 97.2 & 133.74 \\
\hline 40 & 24.75 & 24.75 & 30.51 & 54.63 & 79.06 & 127.89 & 176.76 \\
\hline 50 & 24.75 & 24.75 & 37.26 & 67.42 & 97.05 & 159.03 & 220.05 \\
\hline 60 & 24.75 & 24.75 & 47.16 & 83.34 & 120.06 & 193.32 & 266.49 \\
\hline 70 & 24.75 & 24.75 & 60.75 & 102.96 & 145.53 & 223.11 & 315.81 \\
\hline 80 & 24.75 & 24.75 & 78.75 & 126.63 & 175.5 & 273.33 & 370.8 \\
\hline 90 & 24.75 & 24.75 & 100.53 & 154.80 & 209.07 & 319.77 & 429.57 \\
\hline 100 & 24.75 & 24.75 & 127.89 & 188.19 & 249.25 & 371.52 & 493.47 \\
\hline 110 & 24.75 & 24.75 & 160.47 & 227.07 & 294.27 & 428.67 & 562.86 \\
\hline
\end{tabular}

$\mathrm{ml} / \mathrm{min}$ : millilitre per minute 
Table D.3 The instantaneous power demands for a heavy-duty diesel vehicle with all-up mass of $10000 \mathrm{~kg}$ as a function of road slope and vehicle speed.

\begin{tabular}{|c|c|c|c|c|c|c|c|}
\hline \multirow{2}{*}{$\begin{array}{c}\text { SPEED } \\
(\mathrm{km} / \mathrm{h})\end{array}$} & \multicolumn{7}{|c|}{$\mathrm{Z}_{\mathrm{t}}(\mathrm{Kw})$} \\
\cline { 2 - 8 } & $\theta=-5^{\circ}$ & $\theta=-3^{\circ}$ & $\theta=-1^{\circ}$ & $\theta=0^{\circ}$ & $\theta=1^{\circ}$ & $\theta=3^{\circ}$ & $\theta=5^{\circ}$ \\
\hline 10 & 0 & 0 & 0 & 4.03 & 8.78 & 18.29 & 27.75 \\
\hline 20 & 0 & 0 & 0 & 8.88 & 18.54 & 37.38 & 56.32 \\
\hline 30 & 0 & 0 & 0.59 & 14.85 & 29.10 & 57.60 & 86.01 \\
\hline 40 & 0 & 0 & 3.15 & 22.15 & 41.12 & 79.15 & 117.03 \\
\hline 50 & 0 & 0 & 7.38 & 31.14 & 54.89 & 102.39 & 149.74 \\
\hline 60 & 0 & 0 & 13.57 & 42.07 & 70.57 & 127.57 & 184.39 \\
\hline 70 & 0 & 0 & 21.97 & 55.23 & 88.52 & 154.98 & 221.27 \\
\hline 80 & 0 & 0 & 32.89 & 70.90 & 108.85 & 184.90 & 260.66 \\
\hline 90 & 0 & 0 & 46.60 & 89.35 & 132.00 & 217.60 & 302.83 \\
\hline 100 & 0 & 0 & 63.38 & 110.88 & 158.30 & 253.38 & 348.08 \\
\hline 110 & 0 & 0 & 83.53 & 135.78 & 188.00 & 292.13 & 396.7 \\
\hline
\end{tabular}

Table D.4 The fuel consumption for a heavy-duty diesel vehicle with all-up mass of $10000 \mathrm{~kg}$ as a function of road slope and vehicle speed.

\begin{tabular}{|c|c|c|c|c|c|c|c|}
\hline \multirow{2}{*}{$\begin{array}{c}\text { SPEED } \\
(\mathrm{km} / \mathrm{h})\end{array}$} & $\theta=-5^{\circ}$ & $\theta=-3^{\circ}$ & $\theta=-1^{\circ}$ & $\theta=0^{\circ}$ & $\theta=10$ & $\theta=30$ & $\theta=50$ \\
\cline { 2 - 8 } & 49.5 & 49.5 & 49.5 & 73.69 & 102.20 & 159.24 & 216.00 \\
\hline 10 & 49.5 & 49.5 & 49.5 & 102.78 & 159.78 & 273.78 & 387.42 \\
\hline 20 & 49.5 & 49.5 & 53.04 & 138.60 & 224.1 & 395.10 & 565.56 \\
\hline 30 & 49.5 & 49.5 & 68.40 & 182.40 & 296.40 & 524.40 & 751.68 \\
\hline 40 & 49.5 & 49.5 & 93.78 & 236.34 & 378.84 & 663.84 & 947.94 \\
\hline 50 & 49.5 & 49.5 & 130.92 & 301.92 & 472.70 & 814.92 & 1155.84 \\
\hline 60 & 49.5 & 49.5 & 181.32 & 380.88 & 580.45 & 979.38 & 1377.12 \\
\hline 70 & 49.5 & 49.5 & 246.84 & 474.90 & 702.96 & 1158.90 & 1613.46 \\
\hline 80 & 49.5 & 49.5 & 329.10 & 585.60 & 842.10 & 1355.10 & 1866.48 \\
\hline 90 & 49.5 & 49.5 & 429.78 & 714.78 & 999.78 & 1569.78 & 2137.98 \\
\hline 100 & 49.5 & 49.5 & 550.68 & 864.18 & 1177.68 & 1802.28 & 2429.7 \\
\hline 110 & & & & &
\end{tabular}




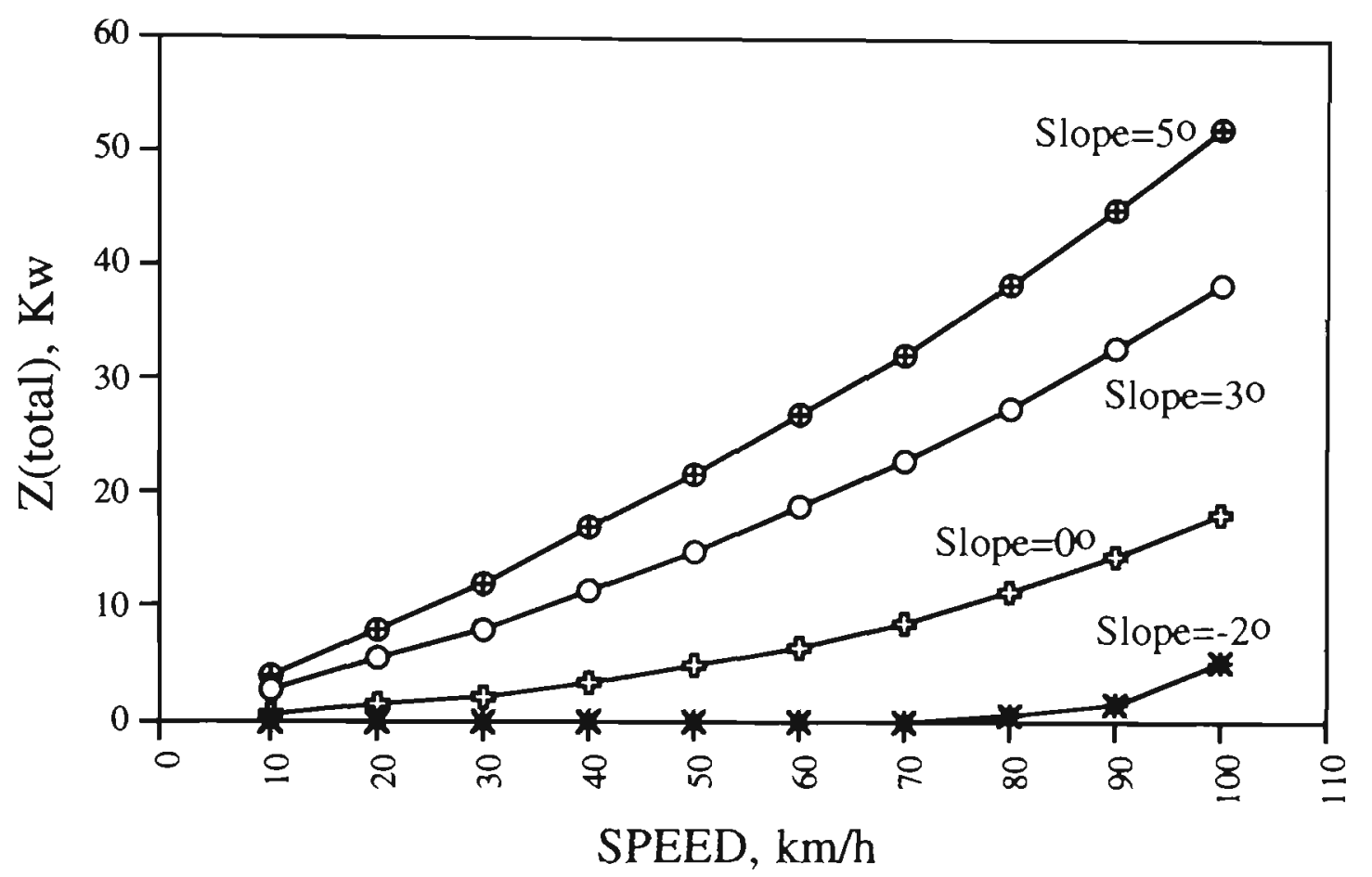

Figure D.1 The instantaneous power demands for a spark ignition vehicle with all-up mass of $1430 \mathrm{~kg}$ as a function of road slope and vehicle speed.

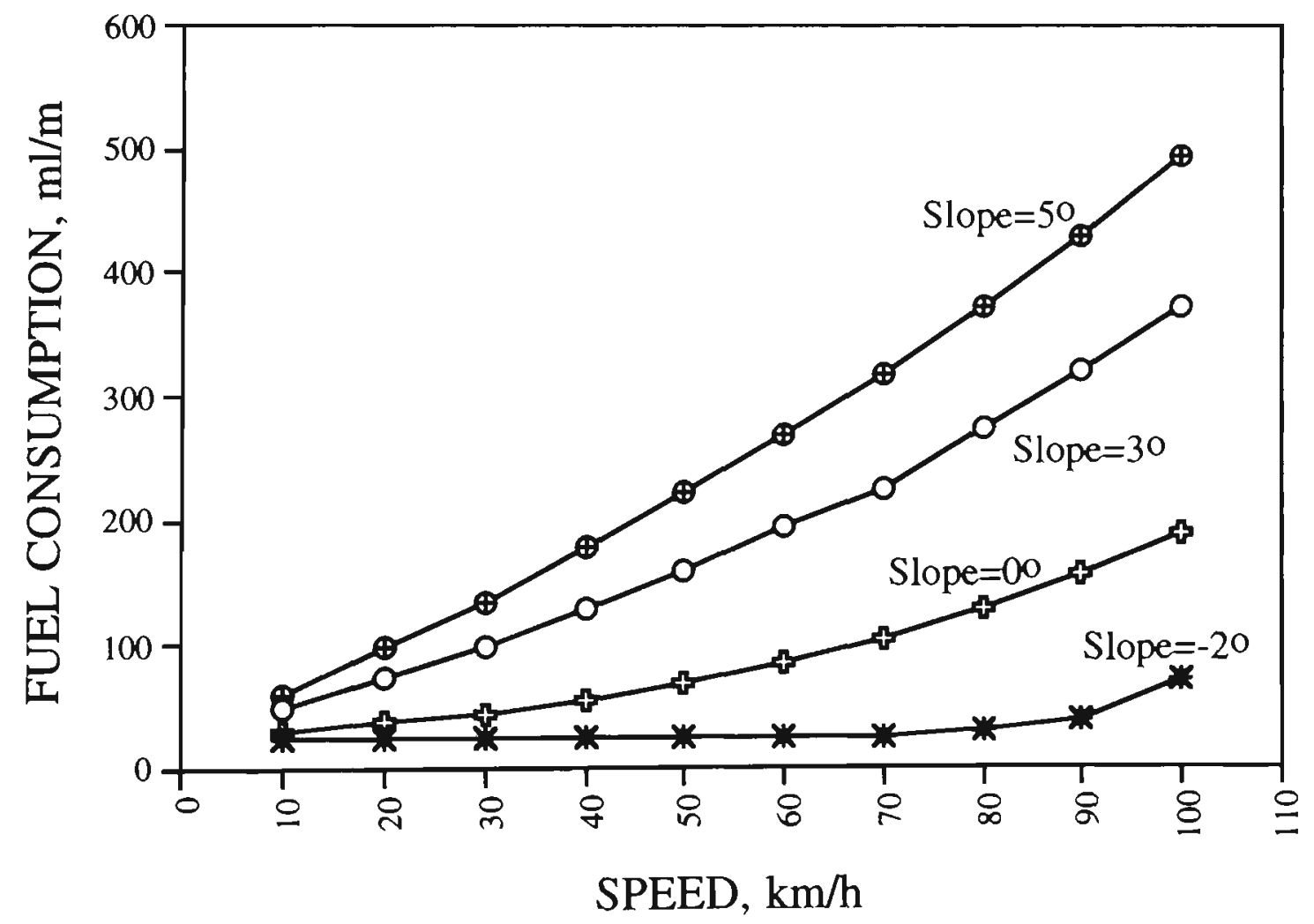

Figure D.2 The fuel consumption for a spark ignition vehicle with all-up mass of $1430 \mathrm{~kg}$ as a function of road slope and vehicle speed. 


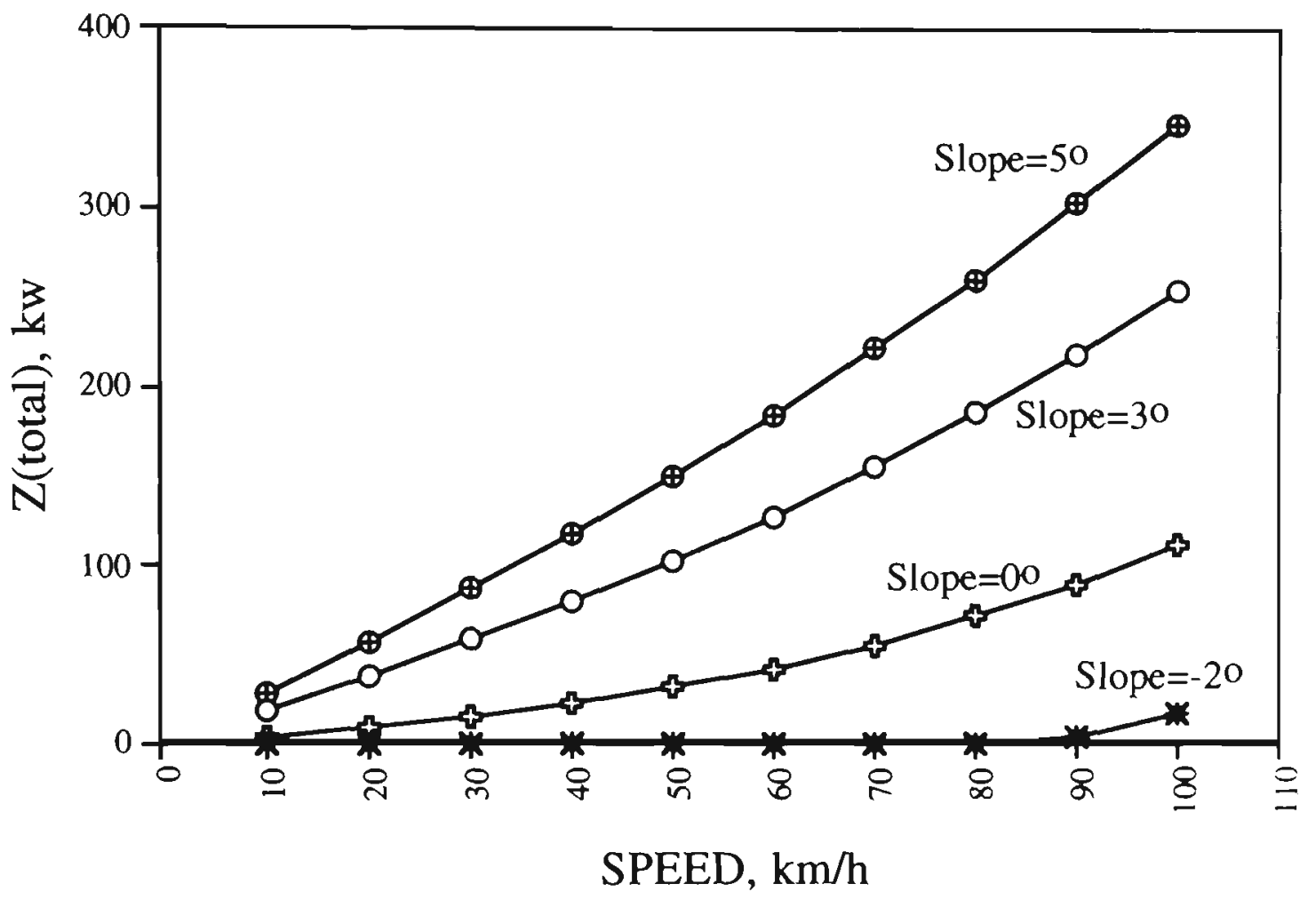

Figure D.3 The instantaneous power demands for a a heavy-duty diesel truck with all-up mass of $10000 \mathrm{~kg}$ as a function of road slope and speed.

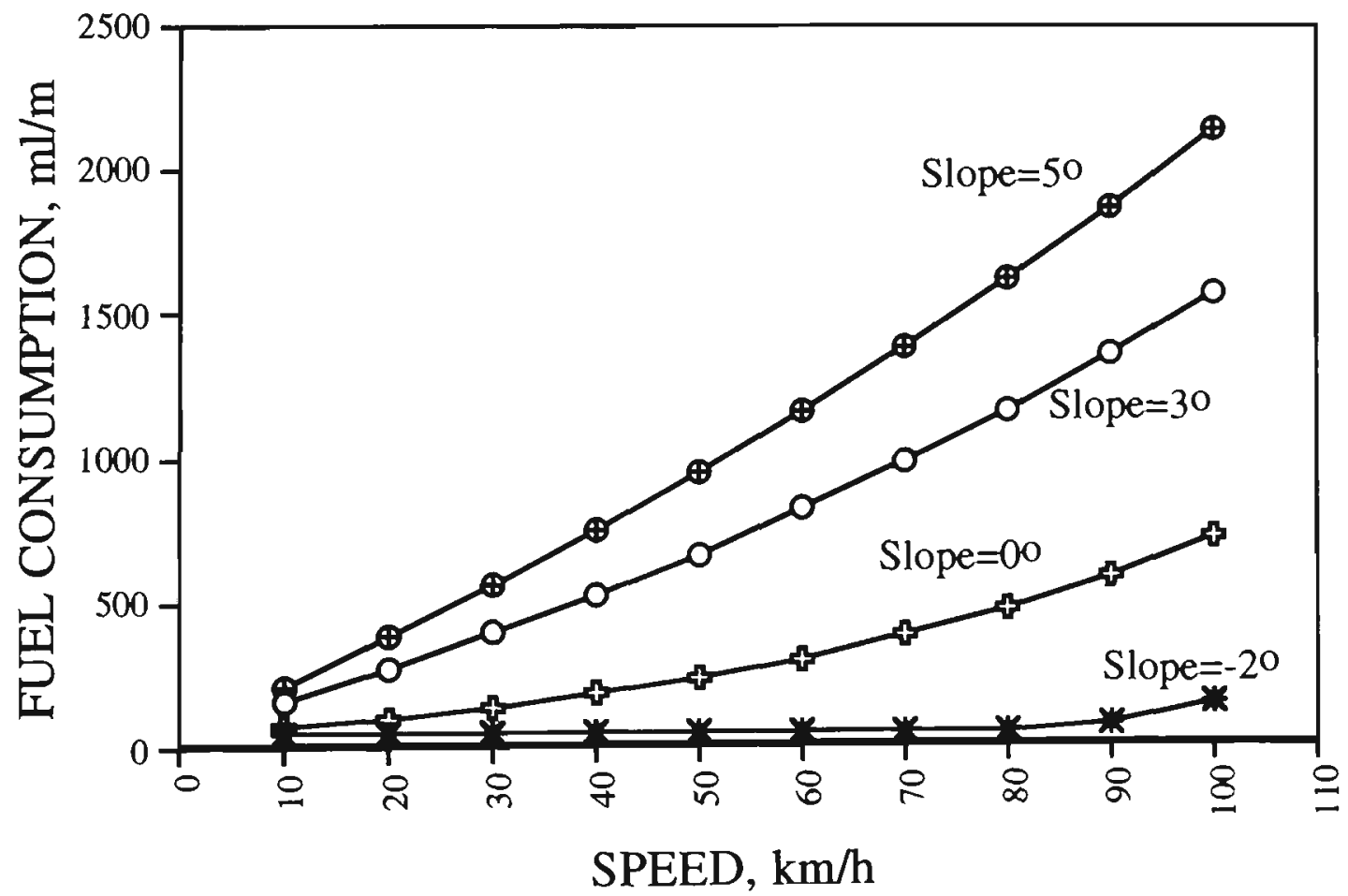

Figure D.4 The fuel consumption for a a heavy-duty diesel truck with all-up mass of $10000 \mathrm{~kg}$ as a function of road slope and vehicle speed. 
Table D.5 Carbon monoxide emission levels (CO) for a pre-1986 spark ignition vehicle with all-up mass of $1430 \mathrm{~kg}$ as a function of road slope and vehicle speed.

a. CO emissions in $\mathrm{g} / \mathrm{min}$

\begin{tabular}{|c|c|c|c|c|c|c|c|}
\hline \multirow{2}{*}{$\begin{array}{c}\text { SPEED } \\
(\mathrm{km} / \mathrm{h})\end{array}$} & \multicolumn{7}{|c|}{ CO (g/min) } \\
\cline { 2 - 8 } & $\theta=-50$ & $\theta=-30$ & $\theta=-1^{\circ}$ & $\theta=0^{\circ}$ & $\theta=10$ & $\theta=30$ & $\theta=50$ \\
\hline 10 & 4.13 & 4.13 & 4.13 & 4.17 & 4.21 & 4.33 & 4.44 \\
\hline 20 & 4.13 & 4.13 & 4.13 & 4.22 & 4.31 & 4.55 & 4.77 \\
\hline 30 & 4.13 & 4.13 & 4.13 & 4.28 & 4.42 & 4.77 & 5.09 \\
\hline 40 & 4.13 & 4.13 & 4.18 & 4.37 & 4.56 & 5.05 & 5.48 \\
\hline 50 & 4.13 & 4.13 & 4.24 & 4.50 & 4.76 & 5.32 & 5.86 \\
\hline 60 & 4.13 & 4.13 & 4.32 & 4.64 & 4.96 & 5.62 & 6.28 \\
\hline 70 & 4.13 & 4.13 & 4.45 & 4.82 & 5.19 & 5.96 & 6.71 \\
\hline 80 & 4.13 & 4.13 & 4.61 & 5.03 & 5.45 & 6.33 & 7.21 \\
\hline 90 & 4.13 & 4.13 & 4.80 & 5.26 & 5.66 & 6.75 & 7.73 \\
\hline 100 & 4.13 & 4.13 & 5.04 & 5.58 & 6.12 & 7.21 & 8.29 \\
\hline 110 & 4.13 & 4.13 & 5.33 & 5.93 & 6.53 & 7.72 & 8.91 \\
\hline
\end{tabular}

b. CO emissions in $\mathbf{g} / \mathbf{k m}$

\begin{tabular}{|c|c|c|c|c|c|c|c|}
\hline \multirow{2}{*}{$\begin{array}{c}\text { SPEED } \\
(\mathrm{km} / \mathrm{h})\end{array}$} & \multicolumn{7}{|c|}{ CO $(\mathrm{g} / \mathrm{km})$} \\
\cline { 2 - 8 } & $\theta=-5^{\circ}$ & $\theta=-3^{\circ}$ & $\theta=-1^{\circ}$ & $\theta=0^{\circ}$ & $\theta=1^{\circ}$ & $\theta=30$ & $\theta=5^{\circ}$ \\
\hline 10 & 24.78 & 24.78 & 24.78 & 25.02 & 25.26 & 25.98 & 26.64 \\
\hline 20 & 12.39 & 12.39 & 12.39 & 12.66 & 12.93 & 13.56 & 14.31 \\
\hline 30 & 8.26 & 8.26 & 8.26 & 8.56 & 8.84 & 9.54 & 10.18 \\
\hline 40 & 6.20 & 6.20 & 6.27 & 6.56 & 6.84 & 7.58 & 8.22 \\
\hline 50 & 4.96 & 4.96 & 5.09 & 5.40 & 5.71 & 6.38 & 7.03 \\
\hline 60 & 4.13 & 4.13 & 4.32 & 4.64 & 4.96 & 5.62 & 6.28 \\
\hline 70 & 3.54 & 3.54 & 3.81 & 4.13 & 4.45 & 5.11 & 5.75 \\
\hline 80 & 3.10 & 3.10 & 3.46 & 3.77 & 4.09 & 4.75 & 5.41 \\
\hline 90 & 2.75 & 2.75 & 3.20 & 3.51 & 3.77 & 4.50 & 5.15 \\
\hline 100 & 2.48 & 2.48 & 3.02 & 3.35 & 3.67 & 4.33 & 4.97 \\
\hline 110 & 2.25 & 2.25 & 2.91 & 3.23 & 3.56 & 4.21 & 4.86 \\
\hline
\end{tabular}


Table D.6 Hydrocarbon emission levels (HC) for a pre-1986 spark ignition vehicle with all-up mass of $1430 \mathrm{~kg}$ as a function of road slope and vehicle speed.

a. $\mathrm{HC}$ emissions in $\mathrm{g} / \mathrm{min}$

\begin{tabular}{|c|c|c|c|c|c|c|c|}
\hline \multirow{2}{*}{$\begin{array}{c}\text { SPEED } \\
(\mathrm{km} / \mathrm{h})\end{array}$} & \multicolumn{7}{|c|}{$\mathrm{HC}(\mathrm{g} / \mathrm{min})$} \\
\cline { 2 - 8 } & $\theta=-5^{\circ}$ & $\theta=-3^{\circ}$ & $\theta=-1^{\circ}$ & $\theta=0^{\circ}$ & $\theta=10$ & $\theta=3^{\circ}$ & $\theta=50$ \\
\hline 10 & 0.413 & 0.413 & 0.413 & 0.417 & 0.421 & 0.433 & 0.444 \\
\hline 20 & 0.413 & 0.413 & 0.413 & 0.422 & 0.431 & 0.455 & 0.477 \\
\hline 30 & 0.413 & 0.413 & 0.413 & 0.428 & 0.442 & 0.477 & 0.509 \\
\hline 40 & 0.413 & 0.413 & 0.418 & 0.437 & 0.456 & 0.505 & 0.548 \\
\hline 50 & 0.413 & 0.413 & 0.424 & 0.450 & 0.476 & 0.532 & 0.586 \\
\hline 60 & 0.413 & 0.413 & 0.432 & 0.464 & 0.496 & 0.562 & 0.628 \\
\hline 70 & 0.413 & 0.413 & 0.445 & 0.482 & 0.519 & 0.596 & 0.671 \\
\hline 80 & 0.413 & 0.413 & 0.461 & 0.503 & 0.545 & 0.633 & 0.721 \\
\hline 90 & 0.413 & 0.413 & 0.480 & 0.526 & 0.566 & 0.675 & 0.773 \\
\hline 100 & 0.413 & 0.413 & 0.504 & 0.558 & 0.612 & 0.721 & 0.829 \\
\hline 110 & 0.413 & 0.413 & 0.533 & 0.593 & 0.653 & 0.772 & 0.891 \\
\hline
\end{tabular}

b. HC emissions in $\mathbf{g} / \mathbf{k m}$

\begin{tabular}{|c|c|c|c|c|c|c|c|}
\hline \multirow{2}{*}{$\begin{array}{c}\text { SPEED } \\
(\mathrm{km} / \mathrm{h})\end{array}$} & \multicolumn{7}{|c|}{$\mathrm{HC}(\mathrm{g} / \mathrm{km})$} \\
\cline { 2 - 8 } & $\theta=-5^{\circ}$ & $\theta=-30$ & $\theta=-1^{\circ}$ & $\theta=0^{\circ}$ & $\theta=1^{\circ}$ & $\theta=30$ & $\theta=5^{\circ}$ \\
\hline 10 & 2.478 & 2.478 & 2.478 & 2.502 & 2.526 & 2.598 & 2.664 \\
\hline 20 & 1.239 & 1.239 & 1.239 & 1.266 & 1.293 & 1.356 & 1.431 \\
\hline 30 & 0.826 & 0.826 & 0.826 & 0.856 & 0.884 & 0.954 & 1.018 \\
\hline 40 & 0.620 & 0.620 & 0.627 & 0.656 & 0.684 & 0.758 & 0.822 \\
\hline 50 & 0.496 & 0.496 & 0.509 & 0.540 & 0.571 & 0.638 & 0.703 \\
\hline 60 & 0.413 & 0.413 & 0.432 & 0.464 & 0.496 & 0.562 & 0.628 \\
\hline 70 & 0.354 & 0.354 & 0.381 & 0.413 & 0.445 & 0.511 & 0.575 \\
\hline 80 & 0.310 & 0.310 & 0.346 & 0.377 & 0.409 & 0.475 & 0.541 \\
\hline 90 & 0.275 & 0.275 & 0.320 & 0.351 & 0.377 & 0.450 & 0.515 \\
\hline 100 & 0.248 & 0.248 & 0.302 & 0.335 & 0.367 & 0.433 & 0.497 \\
\hline 110 & 0.225 & 0.225 & 0.291 & 0.323 & 0.356 & 0.421 & 0.486 \\
\hline
\end{tabular}


Table D.7 Oxides of nitrogen emission levels $\left(\mathrm{NO}_{\mathbf{X}}\right)$ for a pre-1986 spark ignition vehicle with all-up mass of $1430 \mathrm{~kg}$ as a function of road slope and vehicle speed.

a. $\mathrm{NO}_{\mathbf{X}}$ emissions in $\mathrm{g} / \mathrm{min}$

\begin{tabular}{|c|c|c|c|c|c|c|c|}
\hline \multirow{2}{*}{$\begin{array}{c}\text { SPEED } \\
(\mathrm{km} / \mathrm{h})\end{array}$} & \multicolumn{7}{|c|}{$\mathrm{NO}_{\mathrm{X}}(\mathrm{g} / \mathrm{min})$} \\
\cline { 2 - 8 } & $\theta=-50$ & $\theta=-30$ & $\theta=-10$ & $\theta=00$ & $\theta=10$ & $\theta=30$ & $\theta=50$ \\
\hline 10 & 0.113 & 0.113 & 0.113 & 0.183 & 0.264 & 0.425 & 0.592 \\
\hline 20 & 0.113 & 0.113 & 0.113 & 0.267 & 0.430 & 0.756 & 1.081 \\
\hline 30 & 0.113 & 0.113 & 0.113 & 0.346 & 0.590 & 1.079 & 1.566 \\
\hline 40 & 0.113 & 0.113 & 0.188 & 0.511 & 0.837 & 1.488 & 2.140 \\
\hline 50 & 0.113 & 0.113 & 0.280 & 0.681 & 1.088 & 1.903 & 2.717 \\
\hline 60 & 0.113 & 0.113 & 0.494 & 0.960 & 1.426 & 2.359 & 3.336 \\
\hline 70 & 0.113 & 0.113 & 0.593 & 1.156 & 1.719 & 2.866 & 3.993 \\
\hline 80 & 0.113 & 0.113 & 0.833 & 1.471 & 2.109 & 3.427 & 4.727 \\
\hline 90 & 0.113 & 0.113 & 1.123 & 1.847 & 2.571 & 4.047 & 5.513 \\
\hline 100 & 0.113 & 0.113 & 1.488 & 2.292 & 3.096 & 4.737 & 6.363 \\
\hline 110 & 0.113 & 0.113 & 1.913 & 2.810 & 3.706 & 5.499 & 7.287 \\
\hline
\end{tabular}

b. $\mathrm{NO}_{\mathrm{X}}$ emissions in $\mathrm{g} / \mathrm{km}$

\begin{tabular}{|c|c|c|c|c|c|c|c|}
\hline \multirow{2}{*}{$\begin{array}{c}\text { SPEED } \\
(\mathrm{km} / \mathrm{h})\end{array}$} & \multicolumn{7}{|c|}{$\mathrm{OO}_{\mathrm{X}}(\mathrm{g} / \mathrm{km})$} \\
\cline { 2 - 8 } & $\theta=-5^{\circ}$ & $\theta=-3^{\circ}$ & $\theta=-1^{\circ}$ & $\theta=0 \mathrm{O}$ & $\theta=10$ & $\theta=3^{\circ}$ & $\theta=50$ \\
\hline 10 & 0.678 & 0.678 & 0.678 & 1.098 & 1.584 & 2.550 & 3.552 \\
\hline 20 & 0.339 & 0.339 & 0.339 & 0.801 & 1.290 & 2.268 & 3.243 \\
\hline 30 & 0.226 & 0.226 & 0.226 & 0.692 & 1.180 & 2.158 & 3.132 \\
\hline 40 & 0.170 & 0.170 & 0.282 & 0.767 & 1.256 & 2.232 & 3.210 \\
\hline 50 & 0.136 & 0.136 & 0.336 & 0.817 & 1.306 & 2.284 & 3.260 \\
\hline 60 & 0.113 & 0.113 & 0.494 & 0.960 & 1.426 & 2.359 & 3.336 \\
\hline 70 & 0.097 & 0.097 & 0.508 & 0.991 & 1.473 & 2.457 & 3.423 \\
\hline 80 & 0.085 & 0.085 & 0.624 & 1.103 & 1.582 & 2.570 & 3.545 \\
\hline 90 & 0.075 & 0.075 & 0.749 & 1.231 & 1.714 & 2.698 & 3.675 \\
\hline 100 & 0.068 & 0.068 & 0.893 & 1.375 & 1.858 & 2.842 & 3.812 \\
\hline 110 & 0.062 & 0.062 & 1.043 & 1.533 & 2.021 & 2.999 & 3.975 \\
\hline
\end{tabular}


Table D.8 Carbon monoxide emission levels (CO) for a heavy-duty diesel vehicle with all-up mass of $10000 \mathrm{~kg}$ as a function of road slope and vehicle speed.

\section{a. CO emissions in $\mathrm{g} / \mathrm{min}$}

\begin{tabular}{|c|c|c|c|c|c|c|c|}
\hline \multirow{2}{*}{$\begin{array}{c}\text { SPEED } \\
(\mathrm{km} / \mathrm{h})\end{array}$} & \multicolumn{7}{|c|}{$\mathrm{CO}(\mathrm{g} / \mathrm{min})$} \\
\hline & $\theta=5^{\mathrm{O}}$ & $\theta=-30$ & $\theta=-1^{\mathrm{O}}$ & $\theta=0^{\circ}$ & $\theta=1^{\circ}$ & $\theta=3^{\circ}$ & $\theta=5^{\circ}$ \\
\hline 10 & 0.825 & 0.825 & 0.825 & 0.865 & 0.915 & 1.005 & 1.105 \\
\hline 20 & 0.825 & 0.825 & 0.825 & 0.915 & 1.015 & 1.195 & 1.385 \\
\hline 30 & 0.825 & 0.825 & 0.835 & 0.975 & 1.125 & 1.395 & 1.685 \\
\hline 40 & 0.825 & 0.825 & 0.855 & 1.045 & 1.145 & 1.615 & 1.905 \\
\hline 50 & 0.825 & 0.825 & 0.895 & 1.135 & 1.375 & 1.845 & 2.335 \\
\hline 60 & 0.825 & 0.825 & 0.965 & 1.245 & 1.525 & 2.105 & 2.665 \\
\hline 70 & 0.825 & 0.825 & 1.045 & 1.375 & 1.705 & 2.365 & 3.025 \\
\hline 80 & 0.825 & 0.825 & 1.155 & 1.535 & 1.915 & 2.675 & 3.435 \\
\hline 90 & 0.825 & 0.825 & 1.295 & 1.715 & 2.135 & 3.005 & 3.845 \\
\hline 100 & 0.825 & 0.825 & 1.455 & 1.935 & 2.415 & 3.355 & 4.305 \\
\hline 110 & 0.825 & 0.825 & 1.665 & 2.185 & 2.705 & 3.745 & 4.795 \\
\hline
\end{tabular}

b. CO emissions in $\mathrm{g} / \mathrm{km}$

\begin{tabular}{|c|c|c|c|c|c|c|c|}
\hline \multirow{2}{*}{$\begin{array}{c}\text { SPEED } \\
(\mathrm{km} / \mathrm{h})\end{array}$} & \multicolumn{7}{|c|}{$\mathrm{CO}(\mathrm{g} / \mathrm{km})$} \\
\cline { 2 - 8 } & $\theta=-5^{\circ}$ & $\theta=-3^{\circ}$ & $\theta=-1^{\mathrm{O}}$ & $\theta=0^{\mathrm{O}}$ & $\theta=1^{\mathrm{O}}$ & $\theta=3^{\circ}$ & $\theta=5^{\circ}$ \\
\hline 10 & 4.950 & 4.950 & 4.950 & 5.190 & 5.490 & 6.036 & 6.630 \\
\hline 20 & 2.475 & 2.475 & 2.475 & 2.745 & 3.045 & 3.585 & 4.155 \\
\hline 30 & 1.650 & 1.650 & 1.670 & 1.950 & 2.250 & 2.790 & 3.370 \\
\hline 40 & 1.238 & 1.238 & 1.283 & 1.568 & 1.718 & 2.423 & 2.858 \\
\hline 50 & 0.990 & 0.990 & 1.074 & 1.362 & 1.650 & 2.214 & 2.802 \\
\hline 60 & 0.825 & 0.825 & 0.965 & 1.245 & 1.525 & 2.105 & 2.665 \\
\hline 70 & 0.707 & 0.707 & 0.896 & 1.178 & 1.461 & 2.202 & 2.593 \\
\hline 80 & 0.619 & 0.619 & 0.866 & 1.151 & 1.436 & 2.006 & 2.576 \\
\hline 90 & 0.550 & 0.550 & 0.863 & 1.143 & 1.423 & 2.003 & 2.563 \\
\hline 100 & 0.495 & 0.495 & 0.873 & 1.161 & 1.449 & 2.013 & 2.583 \\
\hline 110 & 0.450 & 0.450 & 0.908 & 1.192 & 1.475 & 2.043 & 2.615 \\
\hline
\end{tabular}


Table D.9 Hydrocarbon emission levels (HC) for a heavy-duty diesel vehicle with all-up mass of $10000 \mathrm{~kg}$ as a function of road slope and vehicle speed.

a. HC emissions in $\mathrm{g} / \mathrm{min}$

\begin{tabular}{|c|c|c|c|c|c|c|c|}
\hline \multirow{2}{*}{$\begin{array}{c}\text { SPEED } \\
(\mathrm{km} / \mathrm{h})\end{array}$} & \multicolumn{7}{|c|}{$\mathrm{HC}(\mathrm{g} / \mathrm{min})$} \\
\cline { 2 - 8 } & $\theta=-50$ & $\theta=-3^{\circ}$ & $\theta=-10$ & $\theta=00$ & $\theta=10$ & $\theta=3^{\circ}$ & $\theta=50$ \\
\hline 10 & 0.425 & 0.425 & 0.425 & 0.429 & 0.434 & 0.444 & 0.452 \\
\hline 20 & 0.425 & 0.425 & 0.425 & 0.434 & 0.444 & 0.463 & 0.481 \\
\hline 30 & 0.425 & 0.425 & 0.426 & 0.440 & 0.454 & 0.483 & 0.511 \\
\hline 40 & 0.425 & 0.425 & 0.428 & 0.447 & 0.466 & 0.504 & 0.542 \\
\hline 50 & 0.425 & 0.425 & 0.432 & 0.456 & 0.480 & 0.527 & 0.575 \\
\hline 60 & 0.425 & 0.425 & 0.439 & 0.467 & 0.496 & 0.553 & 0.609 \\
\hline 70 & 0.425 & 0.425 & 0.447 & 0.480 & 0.514 & 0.580 & 0.649 \\
\hline 80 & 0.425 & 0.425 & 0.458 & 0.496 & 0.534 & 0.610 & 0.686 \\
\hline 90 & 0.425 & 0.425 & 0.472 & 0.514 & 0.557 & 0.643 & 0.728 \\
\hline 100 & 0.425 & 0.425 & 0.488 & 0.535 & 0.583 & 0.678 & 0.773 \\
\hline 110 & 0.425 & 0.425 & 0.508 & 0.561 & 0.613 & 0.717 & 0.822 \\
\hline
\end{tabular}

b. $\mathrm{HC}$ emissions in $\mathrm{g} / \mathrm{km}$

\begin{tabular}{|c|c|c|c|c|c|c|c|}
\hline \multirow{2}{*}{$\begin{array}{c}\text { SPEED } \\
(\mathrm{km} / \mathrm{h})\end{array}$} & \multicolumn{7}{|c|}{$\mathrm{HC}(\mathrm{g} / \mathrm{km})$} \\
\cline { 2 - 8 } & $\theta=-5^{\circ}$ & $\theta=-30$ & $\theta=-1^{\circ}$ & $\theta=0^{\circ}$ & $\theta=10$ & $\theta=30$ & $\theta=5^{\circ}$ \\
\hline 10 & 2.550 & 2.550 & 2.550 & 2.574 & 2.604 & 2.664 & 2.712 \\
\hline 20 & 1.275 & 1.275 & 1.275 & 1.302 & 1.332 & 1.389 & 1.443 \\
\hline 30 & 0.850 & 0.850 & 0.852 & 0.880 & 0.908 & 0.966 & 1.022 \\
\hline 40 & 0.638 & 0.638 & 0.642 & 0.671 & 0.699 & 0.756 & 0.813 \\
\hline 50 & 0.510 & 0.510 & 0.518 & 0.547 & 0.576 & 0.632 & 0.690 \\
\hline 60 & 0.425 & 0.425 & 0.439 & 0.467 & 0.496 & 0.553 & 0.609 \\
\hline 70 & 0.364 & 0.364 & 0.383 & 0.411 & 0.441 & 0.497 & 0.556 \\
\hline 80 & 0.319 & 0.319 & 0.344 & 0.372 & 0.401 & 0.458 & 0.515 \\
\hline 90 & 0.283 & 0.283 & 0.315 & 0.343 & 0.371 & 0.429 & 0.485 \\
\hline 100 & 0.255 & 0.255 & 0.293 & 0.321 & 0.349 & 0.407 & 0.464 \\
\hline 110 & 0.232 & 0.232 & 0.277 & 0.306 & 0.334 & 0.391 & 0.448 \\
\hline
\end{tabular}


Table D.10 Oxides of nitrogen emission levels $\left(\mathrm{NO}_{\mathrm{X}}\right)$ for a heavy-duty diesel vehicle with all-up mass of $10000 \mathrm{~kg}$ as a function of road slope and vehicle speed.

a. $\mathrm{NO}_{\mathrm{X}}$ emissions in $\mathrm{g} / \mathrm{min}$

\begin{tabular}{|c|c|c|c|c|c|c|c|}
\hline \multirow{2}{*}{$\begin{array}{c}\text { SPEED } \\
(\mathrm{km} / \mathrm{h})\end{array}$} & \multicolumn{7}{|c|}{$\mathrm{NO}_{\mathrm{X}}(\mathrm{g} / \mathrm{min})$} \\
\cline { 2 - 9 } & $\theta=-50$ & $\theta=-30$ & $\theta=-10$ & $\theta=0^{\circ}$ & $\theta=10$ & $\theta=30$ & $\theta=5^{\circ}$ \\
\hline 10 & 0.225 & 0.225 & 0.225 & 0.950 & 1.805 & 3.517 & 5.220 \\
\hline 20 & 0.225 & 0.225 & 0.225 & 1.823 & 3.562 & 6.953 & 10.363 \\
\hline 30 & 0.225 & 0.225 & 0.331 & 2.898 & 5.463 & 10.593 & 15.706 \\
\hline 40 & 0.225 & 0.225 & 0.792 & 4.212 & 7.626 & 14.472 & 21.285 \\
\hline 50 & 0.225 & 0.225 & 1.553 & 5.830 & 10.107 & 18.657 & 27.178 \\
\hline 60 & 0.225 & 0.225 & 2.673 & 7.785 & 12.933 & 23.187 & 33.417 \\
\hline 70 & 0.225 & 0.225 & 4.185 & 10.166 & 16.159 & 28.125 & 40.005 \\
\hline 80 & 0.225 & 0.225 & 6.147 & 12.987 & 19.818 & 33.507 & 47.151 \\
\hline 90 & 0.225 & 0.225 & 8.613 & 16.317 & 23.985 & 39.393 & 54.585 \\
\hline 100 & 0.225 & 0.225 & 11.637 & 20.187 & 28.719 & 45.837 & 62.865 \\
\hline 110 & 0.225 & 0.225 & 15.255 & 24.665 & 34.065 & 52.785 & 71.631 \\
\hline
\end{tabular}

b. $\mathrm{NO}_{\mathrm{X}}$ emissions in $\mathrm{g} / \mathrm{km}$

\begin{tabular}{|c|c|c|c|c|c|c|c|}
\hline \multirow{2}{*}{$\begin{array}{c}\text { SPEED } \\
(\mathrm{km} / \mathrm{h})\end{array}$} & \multicolumn{7}{|c|}{$\mathrm{NO}(\mathrm{g} / \mathrm{km})$} \\
\cline { 2 - 8 } & $\theta=-5^{\circ}$ & $\theta=-3^{\circ}$ & $\theta=-1^{\circ}$ & $\theta=0^{\circ}$ & $\theta=1^{\circ}$ & $\theta=3^{\circ}$ & $\theta=50$ \\
\hline 10 & 1.350 & 1.350 & 1.350 & 5.700 & 10.830 & 21.102 & 31.320 \\
\hline 20 & 0.675 & 0.675 & 0.675 & 5.469 & 10.686 & 20.859 & 31.089 \\
\hline 30 & 0.450 & 0.450 & 0.662 & 5.796 & 10.926 & 21.186 & 31.412 \\
\hline 40 & 0.338 & 0.338 & 1.188 & 6.310 & 11.439 & 21.713 & 31.927 \\
\hline 50 & 0.270 & 0.270 & 1.864 & 6.996 & 12.128 & 22.388 & 32.614 \\
\hline 60 & 0.225 & 0.225 & 2.673 & 7.785 & 12.933 & 23.187 & 33.417 \\
\hline 70 & 0.193 & 0.193 & 3.587 & 8.714 & 13.851 & 24.107 & 34.290 \\
\hline 80 & 0.169 & 0.169 & 4.610 & 9.740 & 14.864 & 25.130 & 35.363 \\
\hline 90 & 0.150 & 0.150 & 5.742 & 10.878 & 15.990 & 26.262 & 36.390 \\
\hline 100 & 0.135 & 0.135 & 6.982 & 12.112 & 17.231 & 27.502 & 37.719 \\
\hline 110 & 0.123 & 0.123 & 8.321 & 13.454 & 18.581 & 28.792 & 39.071 \\
\hline
\end{tabular}




\section{CARBON MONOXIDE (CO)}

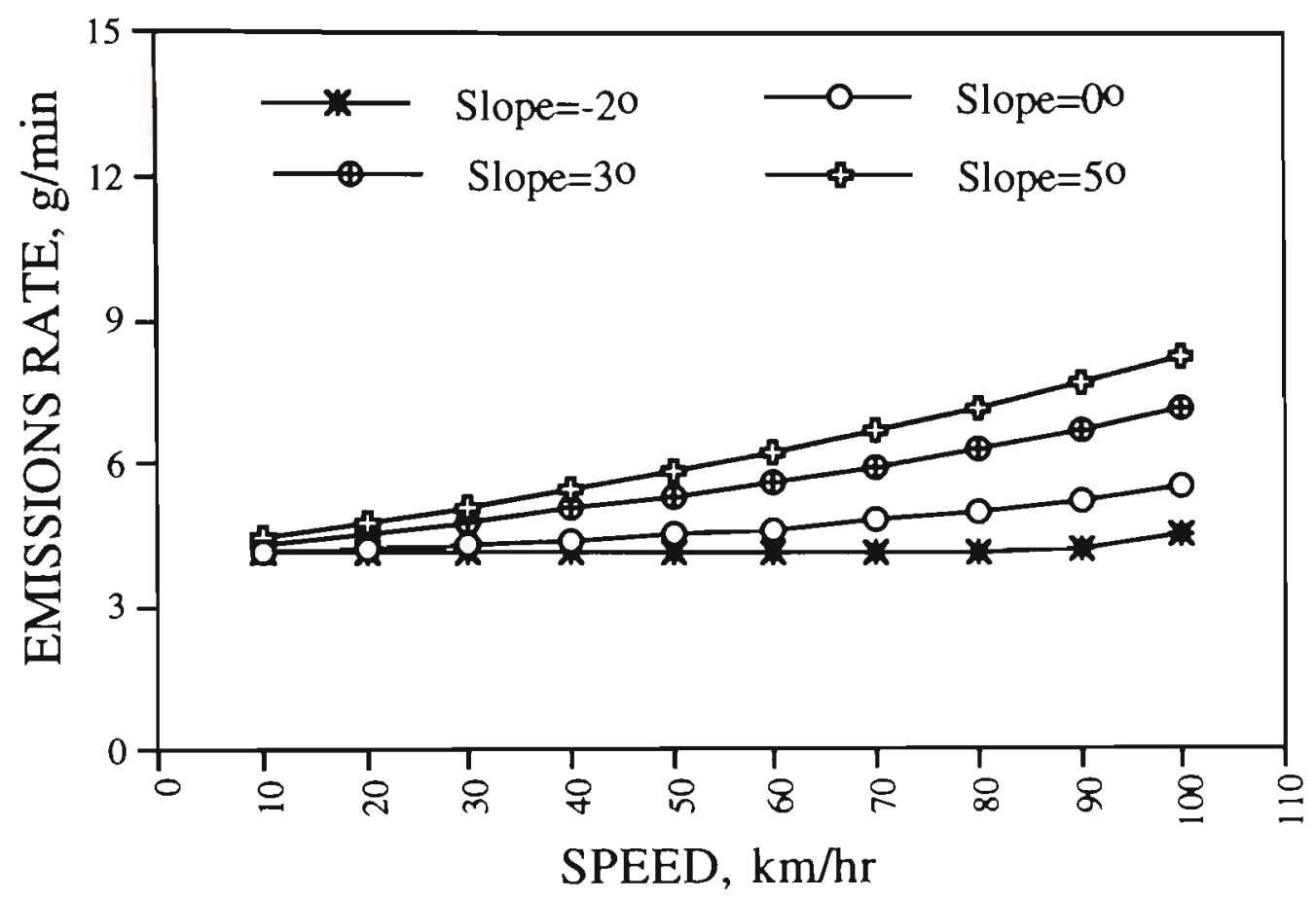

Figure D.5 CO emission levels versus vehicle speed for a pre-1986 spark ignition vehicle with all-up mass of $1430 \mathrm{~kg}$ and as a function of road slope.

CARBON MONOXIDE (CO)

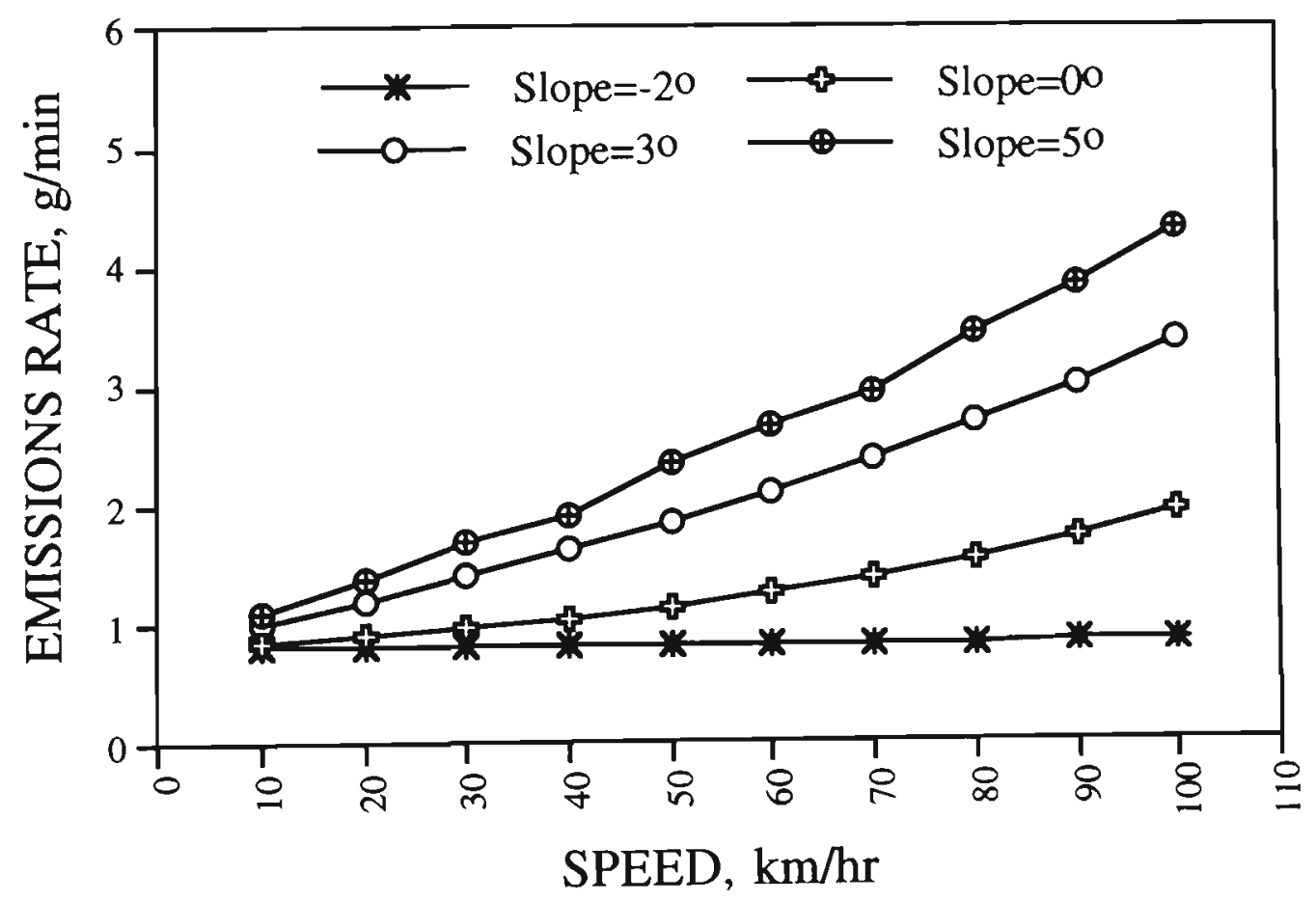

Figure D.6 CO emission levels versus vehicle speed for a heavy-duty diesel vehicle with all-up mass of $10000 \mathrm{~kg}$ and as a function of road slope. 


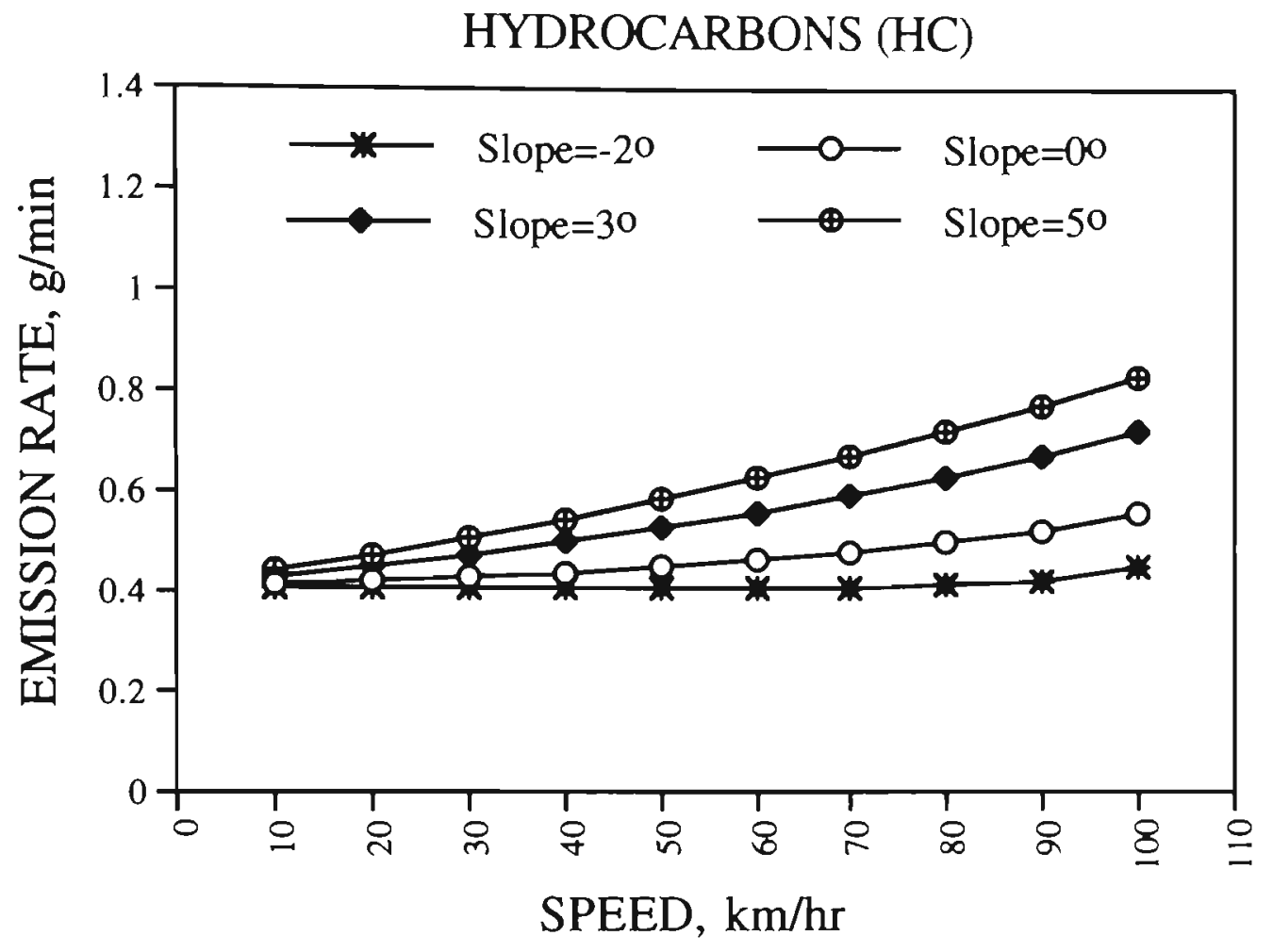

Figure D.7 HC emission levels versus vehicle speed for a pre-1986 spark ignition vehicle with all-up mass of $1430 \mathrm{~kg}$ and as a function of road slope.

HYDROCARBONS (HC)

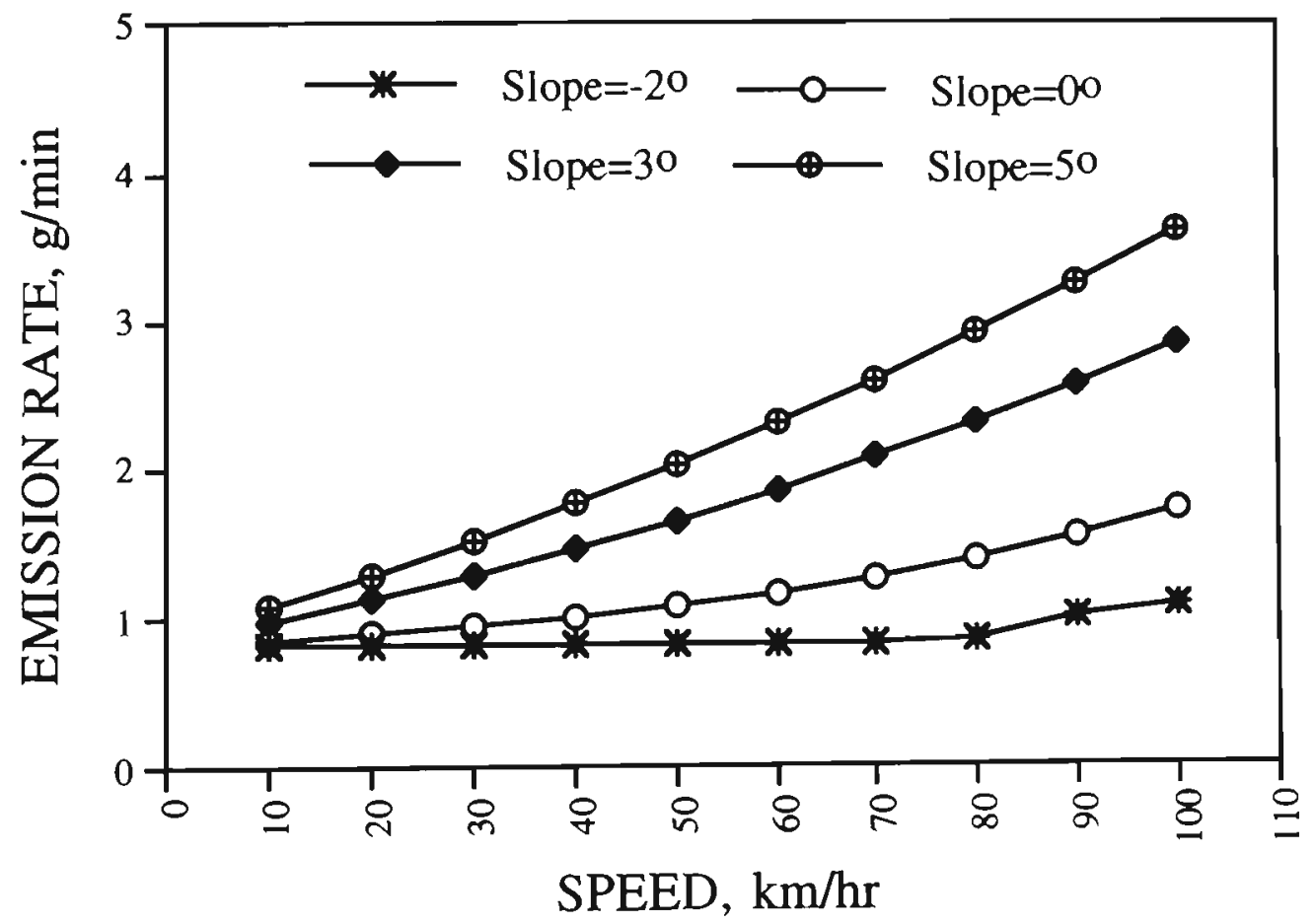

Figure D.8 HC emission levels versus vehicle speed for a heavy-duty diesel vehicle with all-up mass of $10000 \mathrm{~kg}$ and as a function of road slope. 


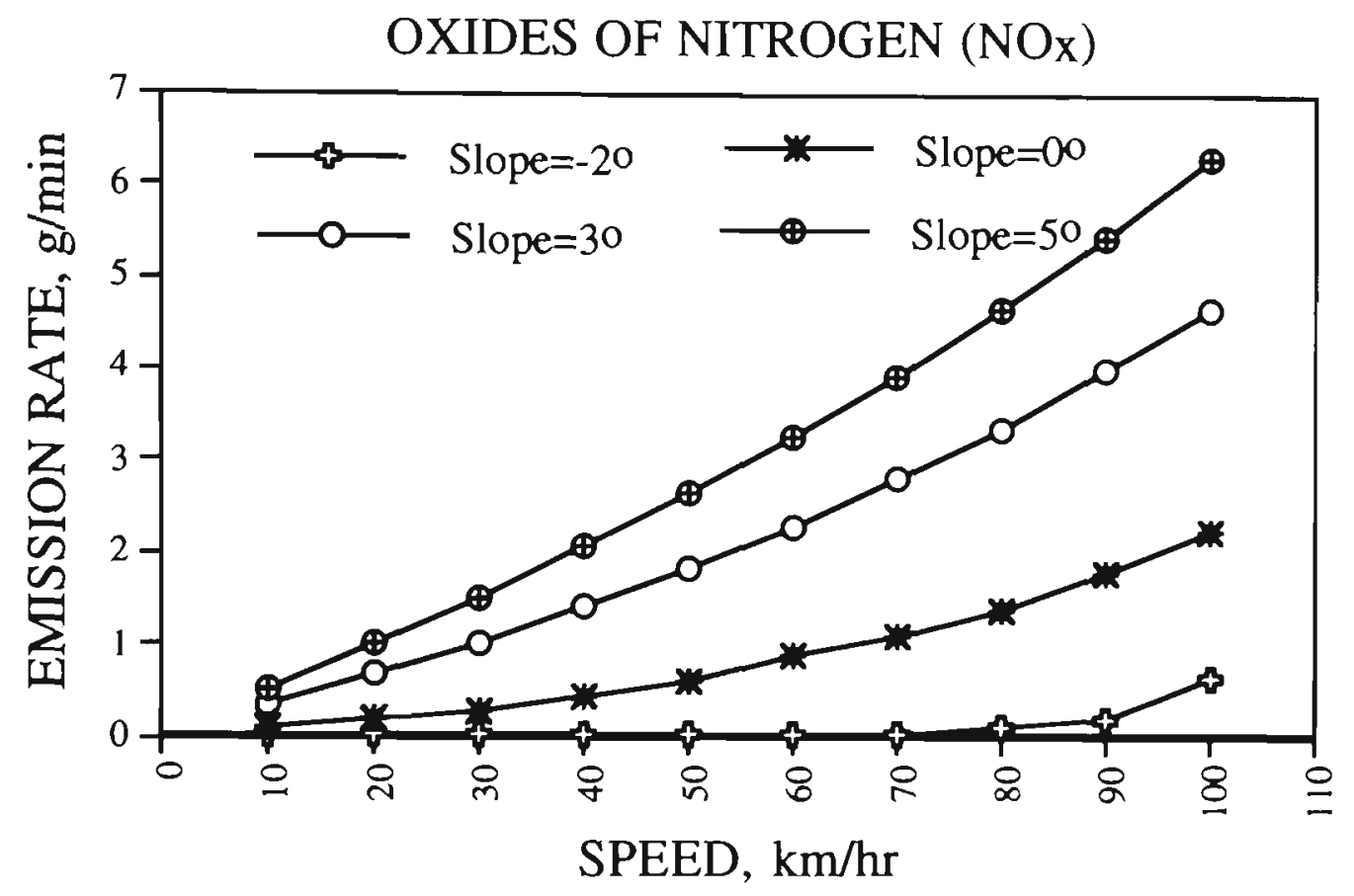

Figure D.9 NOx emission levels versus vehicle speed for a pre-1986 spark ignition vehicle with all-up mass of $1430 \mathrm{~kg}$ and as a function of road slope.

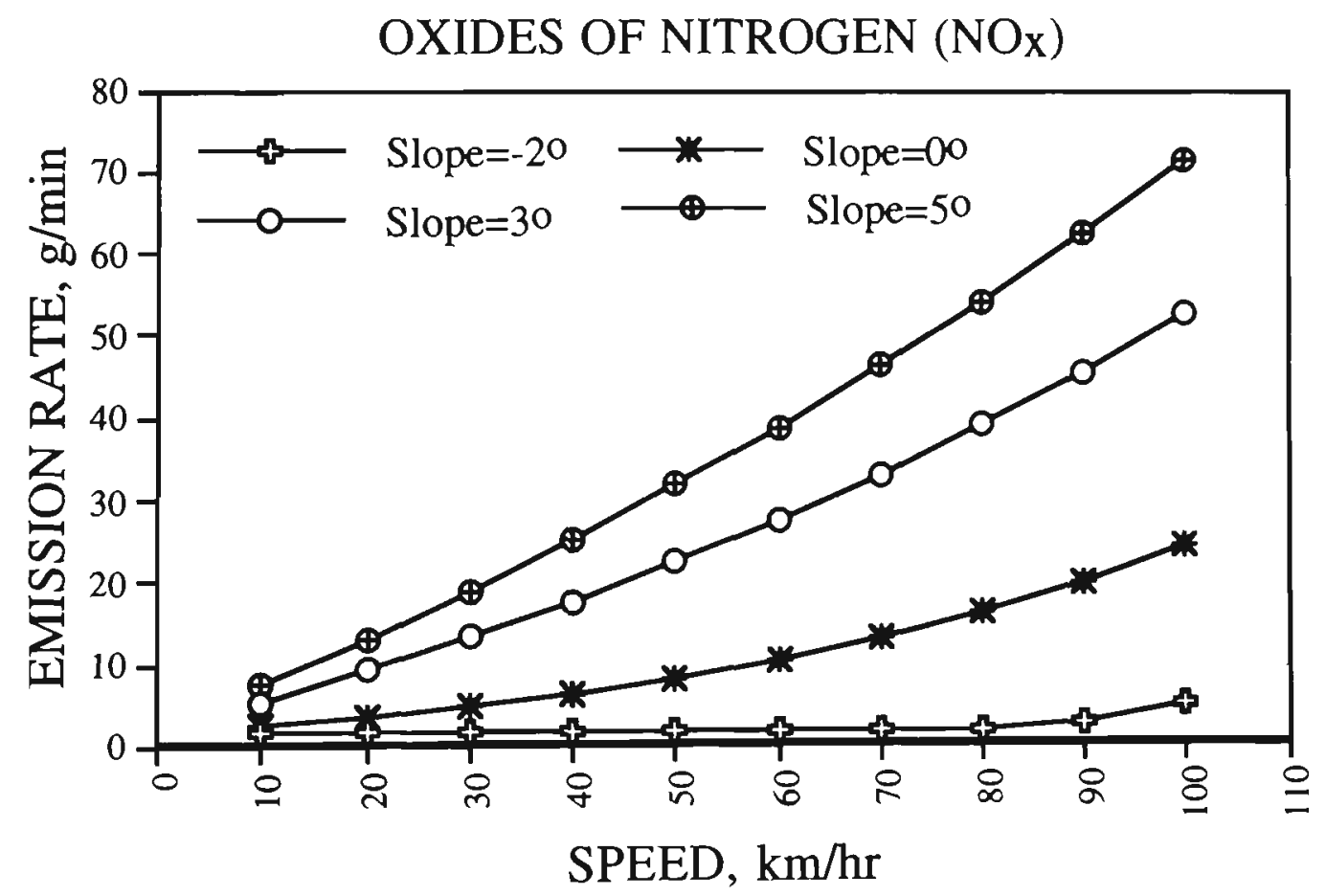

Figure D.10 NO $\mathrm{NO}_{\mathrm{x}}$ emission levels versus vehicle speed for a heavy-duty diesel vehicle with all-up mass of $10000 \mathrm{~kg}$ and as a function of road slope. 
The capability of the model to account for the acceleration and deceleration manoeuvres is essential when dealing with estimating traffic pollution in urban areas. because the driving pattern in these areas includes significant parts of acceleration and deceleration manoeuvres. This conclusion agrees with Lyons et al., 1990 who reported that the integration of driving characteristics and vehicle emissions based on speed and acceleration illustrated a marked variation in emission factor from the city business district to the outer suburbs.

Another interesting characteristic of the power-based exhaust emissions model is that the model accounts for the effects of wind speed and wind-road angle on power demands, fuel consumption and the gaseous emissions of $\mathrm{CO}_{2}, \mathrm{CO}, \mathrm{HC}$, and $\mathrm{NOx}$.

Close et al., 1981, reported that the aerodynamically inefficient shapes of trucks and buses require a great deal of power to push the truck or bus through the air. The power required to overcome air drag increases directly in proportion with the frontal area of the vehicle. Weights or mass of the vehicle have nothing to do with air drag but vehicle speed through the air is extremely important. The faster the vehicle travels through the air, or the greater the relative speed of air resistance, the greater will be the air drag on the vehicle. The increase in power demands will result in increasing both the fuel consumption and gaseous emissions.

Figures D.11 and D.12 show the effect of high drag. The power demands and fuel consumption increase as a function of the wind-road angle for a typical interstate articulated truck with over-all mass of 30 tons, height of $4.3 \mathrm{~m}$, width of $2.5 \mathrm{~m}$, length of $7 \mathrm{~m}$, and travelling at $80 \mathrm{~km} / \mathrm{h}$.

It is clear from Figures 107 and 108 that if the wind is a cross-wind (blowing across the road) such that the wind-road angle is $<90 \mathrm{o}$, the drag factor can increase, while if a cross-wind is such that $90^{\circ}<$ the wind-road angle is $\leq 180^{\circ}$, the drag factor can decrease because the wind will assist by blowing from the rear of the vehicle, and though will give the vehicle a boost of wind power.

It is demonstrated that the effect of wind-road on both $\mathrm{CO}_{2}$ and $\mathrm{NO}_{\mathrm{x}}$ emissions are higher than $\mathrm{CO}$ and $\mathrm{HC}$ emissions because $\mathrm{CO}_{2}$ and $\mathrm{NOx}$ are power-dependent pollutants. 


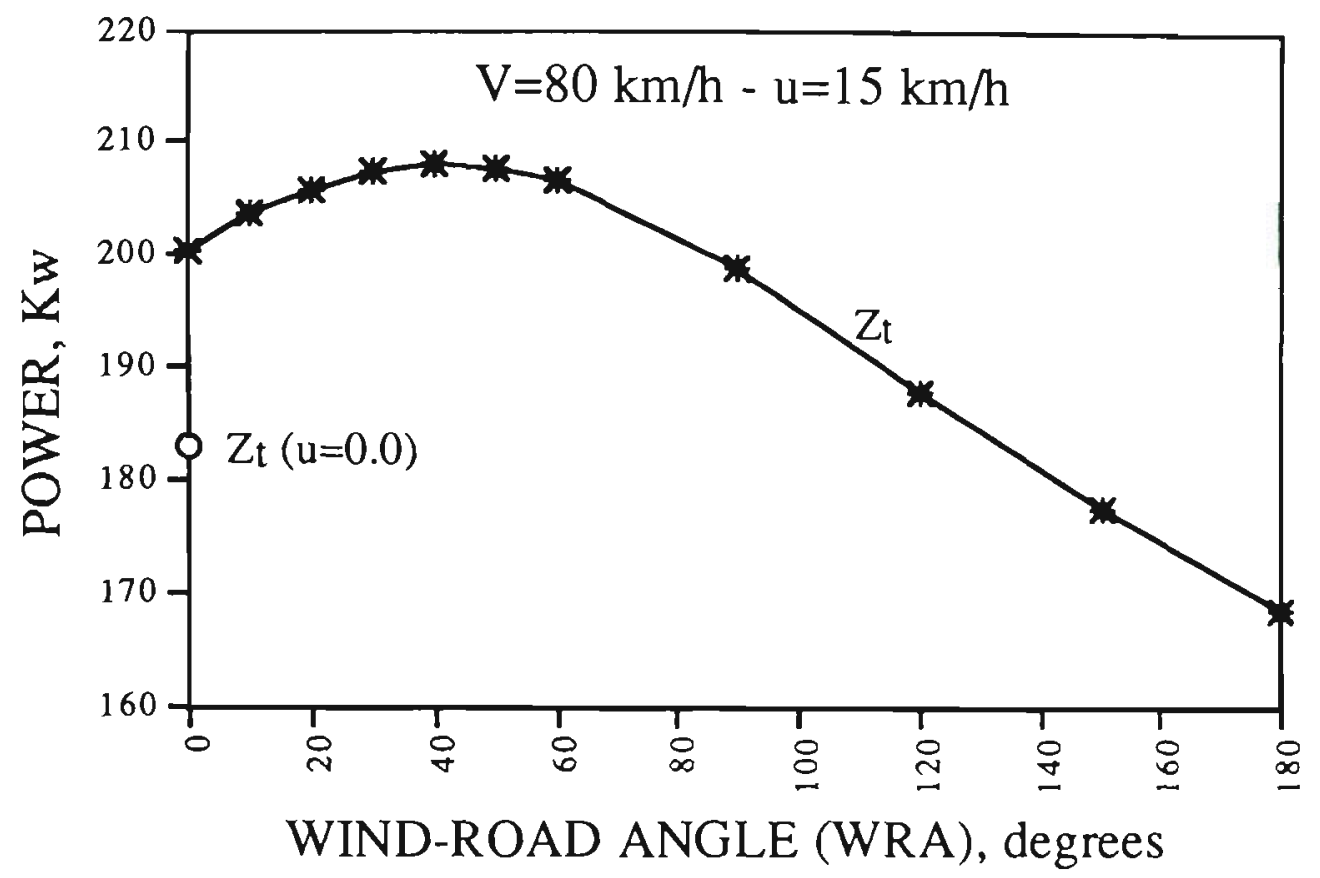

Figure D.11 The power demands versus wind-road angle for an articulated truck with mass of 30 tons travelling at $80 \mathrm{~km} / \mathrm{h}$ through wind of $15 \mathrm{~km} / \mathrm{h}$. (Calculations based on the power-based emissions model fo a car with dimensions of $2.5 \mathrm{~m}$ width, $4.3 \mathrm{~m}$ height, and $7 \mathrm{~m}$ length.)

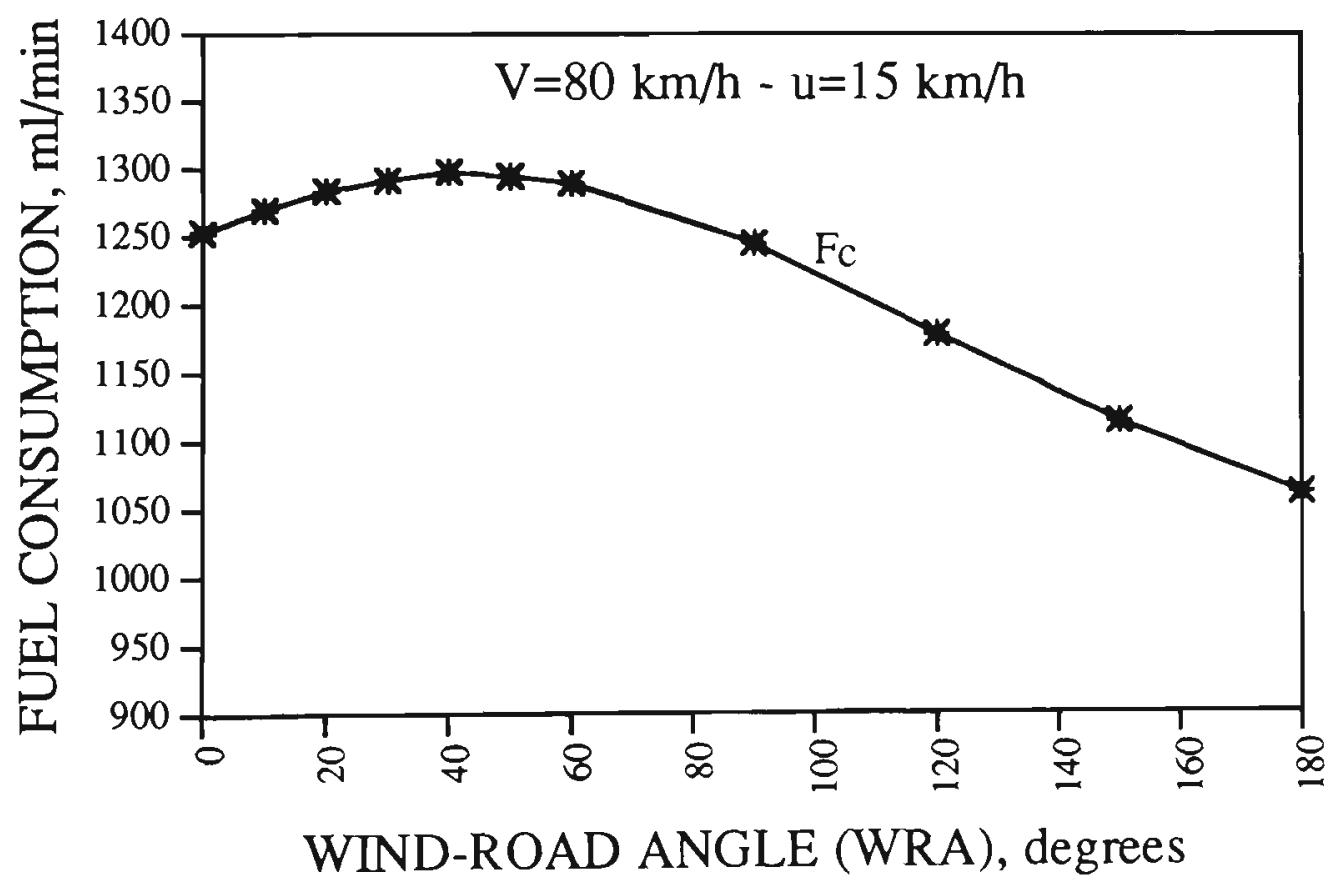

Figure D.12 The fuel consumption versus wind-road angle for an articulated truck with mass of 30 tons travelling at $80 \mathrm{~km} / \mathrm{h}$ through wind of 15 $\mathrm{km} / \mathrm{h}$. (Calculations based on the power-based emissions model for a car with dimensions of $2.5 \mathrm{~m}$ width, $4.3 \mathrm{~m}$ height, and $7 \mathrm{~m}$ length.) 